HUMANIORA: GERMANISTICA 5

\title{
Nationalepen zwischen Fakten und Fiktionen
}

\author{
herausgegeben von \\ Heinrich Detering, Torsten Hoffmann, \\ Silke Pasewalck, Eve Pormeister
}

Konferenzbeiträge 
HUMANIORA: GERMANISTICA 5 



\title{
HUMANIORA: GERMANISTICA 5
}

\section{Nationalepen zwischen Fakten und Fiktionen}

\author{
Beiträge \\ zum komparatistischen Symposium \\ 6. bis 8. Mai 2010 Tartu \\ herausgegeben von \\ Heinrich Detering \\ Torsten Hoffmann \\ Silke Pasewalck \\ Eve Pormeister
}

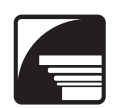

TARTU UNIVERSITY PRESS 
Reihe HUMANIORA: GERMANISTICA der Universität Tartu

\section{Wissenschaftlicher Beirat:}

Anne Arold (Universität Tartu), Dieter Cherubim (Georg-AugustUniversität Göttingen), Heinrich Detering (Georg-August-Universität Göttingen), Hans Graubner (Georg-August-Universität Göttingen), Reet Liimets (Universität Tartu), Klaus-Dieter Ludwig (HumboldtUniversität zu Berlin), Albert Meier (Christian-Albrechts-Universität zu Kiel), Dagmar Neuendorff (Ábo Akademie Finnland), Henrik Nikula (Universität Turku), Eve Pormeister (Universität Tartu), Mari Tarvas (Universität Tallinn), Winfried Ulrich (Christian-Albrechts-Universität zu Kiel), Carl Wege (Universität Bremen).

\section{Umschlaggestaltung:}

Kalle Paalits

unter Verwendung des Fotos „Kalevipoegs Stein am Saadjärv“ von Dieter Neidlinger

\section{Layout:}

Aive Maasalu

ISSN 1736-4345

ISBN 978-9949-19-911-2

Urheberrecht: Alle Rechte an den Beiträgen verbleiben bei den Autoren, 2011

Tartu University Press www.tyk.ee 
Für die Unterstützung danken die HerausgeberInnen dem Deutschen Akademischen Austauschdienst 



\section{INHALTSVERZEICHNIS}

Heinrich Detering, Torsten Hoffmann, Silke Pasewalck, Eve Pormeister.

Nationalepen zwischen Fakten und Fiktionen. Zur Einführung ...

Thomas Taterka (Riga). Die Nation erzählt sich selbst.

Zum europäischen Nationalepos des 19. Jahrhunderts

Hans Graubner (Göttingen). Epos, Volksepos, Menschheitsepos zum Epos-Konzept bei Herder

Barbara Schaff (Göttingen). Vom vielgelesenen zum ungelesenen

Text: Ossians Vermächtnis in der schottischen Kultur

Heinrich Detering (Göttingen). Das Nationalepos im

Kinderzimmer: Die „Kinder- und Hausmärchen“ der Brüder

Grimm

Silke Pasewalck (Tartu). Schillers „Wilhelm Tell“ - ein Schweizer

Nationalepos?

Karin Hoff (Göttingen). Erzählung als Erinnerung:

Die Bedeutung der Isländersagas für das nation building (nicht nur) in Island

Esbjörn Nyström (Tartu/Stockholm). „Frit(h)iofs saga“ ein schwedisches Nationalepos zwischen Esaias Tegnér und Selma Lagerlöf. 169

Zuzana Stolz-Hladká (Göttingen/Konstanz). Identitätskonstruktionen in der tschechischen Literatur des 19. Jahrhunderts. Der Entwurf einer nationalen Identität durch Sprache und Literatur 
Christian Niedling (Helsinki). Helden wie wir? Die Rezeption von „Kalevala“ und „Nibelungenlied“ als Nationalepen im 19. Jahrhundert

Torsten Hoffmann (Frankfurt a. M.). Letzte Tage der Männlichkeit. Die Nibelungen in Heiner Müllers „GERMANIA“-Dramen 232

Eve Pormeister (Tartu). Das estnische Epos „Kalevipoeg“ in der Spannung zwischen Nationalepos und Menschheitsepos. Eine Interpretation der Höllenfahrtszenen 256

Mari-Ann Palm (Tartu). Fr. R. Kreutzwald als zeitkritischer Beobachter. Anhand seiner Beiträge in der Wochenschrift „Das Inland“ 280

Marin Laak und Piret Viires (Tartu/Tallinn). Das estnische Epos „Kalevipoeg“ und seine Rezeption in Kultur und Literatur 295 Angaben zur Person 319 


\section{Nationalepen zwischen Fakten und Fiktionen. Zur Einführung}

Das 18. und 19. Jahrhundert bringen im Zuge der proto-nationalen und nationalen Bewegungen in Europa ein neuartiges Interesse an tatsächlich oder vermeintlich autochthonen literarischen Überlieferungen des „Volkes“ hervor. In der Folge der entsprechenden Sammlungen (von Percys „Reliques of Ancient Poetry“ bis zu Herders „Stimmen der Völker in Liedern“) und jeweils im Kontext eines spezifischen $n a$ tion building entstehen im Zusammenhang damit oft umfangreiche epische Dichtungen, die als Rekonstruktion teils oder ganz verlorener „nationaler“ Epen aufgefasst werden. Dabei kann es sich um der Heldenepik nahestehende Texte handeln wie im Fall von Macphersons „Ossian“, aber auch um Corpora vorgeblich „nationaler“ Volksdichtung wie Arnims und Brentanos „Des Knaben Wunderhorn“ oder die „Kinder- und Hausmärchen“ der Brüder Grimm. Die spätesten und in vieler Hinsicht interessanten dieser zugleich neuen und vorgeblich uralten nationalen Epen sind das finnische „Kalevala“ des Elias Lönnrot und das in seiner Folge und nach seinem Vorbild entstandene estnische „Kalevipoeg“ von Friedrich Reinhold Kreutzwald. Anders als die meisten ihrer Vorgänger geben diese beiden nationalromantischen Epen sich offen als philologisch-poetische Konstruktionen zu erkennen, in denen sich Dokumentation und Fiktion mischen - freilich mit dem Ziel, aus Dokumenten und Imagination ein Verlorenes zu rekonstruieren, das als Ursprung der gegenwärtigen (oder in naher Zukunft wiederherzustellenden) Nation geltend gemacht und damit, einer romantischen Analogie folgend, zugleich als Ausdruck ihres eigentlichen Wesens, ihrer kollektiven Identität erscheinen soll.

Solche Beobachtungen gaben den Anlass zu einem komparatistischen Symposion, das aus der vom DAAD geförderten „Germanistischen Institutspartnerschaft“ zwischen der Tartuer und der Göttinger Germanistik hervorging, das vom 6. bis zum 8. Mai 2010 an der Universität Tartu stattfand und an dem Wissenschaftler aus Estland, Lettland, Finnland und Deutschland teilnahmen. Ziel war es, die explizite und 
implizite Poetik einiger dieser Texte exemplarisch herauszuarbeiten. Dabei sollten historische und systematische Analogien und Differenzen sichtbar gemacht und ebenso langlebige wie unangemessene Klischees („Authentizität“ vs. „Fälschung“) wenn nicht überwunden, so doch wenigstens kritisch reflektiert werden.

Rasch erwies es sich als notwendig, einen weiten Eposbegriff zugrunde zu legen. Die leitende Frage nach Formen der Funktionalisierung vorgeblich oder tatsächlich alter und anonymer epischer Überlieferungen im Kontext eines nation building und der Konstruktion eines dafür konstitutiven kulturellen Gedächtnisses erforderte es, neben Epen im engeren Sinne auch solche Texte in den Blick zu nehmen, die im strengen Sinne nicht in die literarische Gattung des Epos fallen, aber in signifikant ähnlicher Weise instrumentalisiert, konzipiert und kanonisiert wurden, etwa die „Kinder- und Hausmärchen“ der Brüder Grimm oder die „Wilhelm Tell“-Überlieferungen einschließlich ihrer Transformation in Schillers Geschichtsdrama. Schon Jacob Grimm legt diesen weiten Begriff nahe: „ich behaupte folgende sätze und ihre identität: die älteste geschichte jedweden volks ist volkssage, jede volkssage ist episch. das epos ist alte geschichte. alte geschichte und alte poesie fallen nothwendig zusammen."

Im Vergleich der unter dieser Voraussetzung erörterten Texte und ihrer Rezeptionsformen zeichneten sich wiederkehrende Merkmale und Spannungsverhältnisse ab, die in aller Vorläufigkeit und Unvollständigkeit festgehalten zu werden verdienen:

1. Alter und künstliche Alterung: Wo ein Text nicht wie das „Nibelungenlied" nachweislich alter Überlieferung entstammt, muss er (in der Stilisierung durch den Autor oder in der Rezeption) älter gemacht werden, als er tatsächlich ist. Deshalb muss beispielsweise das - überwiegend doch von Kreutzwald selbst neu geschriebene - „Kalevipoeg“ in Figurenkonstellation, Handlungsverläufen und metrischen Merkmalen dieselbe Dichte an archaischer Überlieferung suggerieren wie das von Lönnrot u.a. aus wenn auch heterogenem - altem Material zusammengesetzte „Kalevala“; deshalb müssen auch die Grimm’schen Märchen, ihrer Vorrede zufolge, von einer alten Bäuerin erzählt worden sein und nicht von einer jungen, französisch gebildeten Stadt- 
bürgerin. Ist aber die Behauptung hohen Alters wesentlich für die Wirkungsmöglichkeit des Textes, so wird doch seine vorgebliche oder tatsächliche Wiederentdeckung in der Gegenwart als Zeichen eines hier und jetzt neu erwachenden Nationalgeistes gelesen. Der neu entdeckte oder jedenfalls neu gelesene Text muss uralt sein; der uralte Text aber muss neu vergegenwärtigt werden.

2. Anonymisierung und Autorschaft: Der Autor tritt einerseits hinter das Nationalepos zurück; er erscheint nur im Gestus des Sammlers, Redaktors, Übersetzers. Andererseits kann er auf diesem Umweg in der Wirkungsgeschichte der Texte doch wieder einen überaus starken Autorstatus gewinnen, der ihn etwa zum Wiedererwecker der Nation stilisiert. Für den Fall etwa, dass der Fälschungsvorwurf gegenüber dem „Ossian“ sich bestätigen und Macpherson also doch nicht bloß der bescheidene Herausgeber dieser Dichtungen gewesen sein sollte, zieht der erste deutsche Übersetzer Michael Denis (alias „Barde Sined“) vorsorglich Macpherson als potentielles Genie in Betracht: „Er [der Übersetzer] glaubt noch Ossians Aechtheit, obwohl er sich, als ein Zeitgenoß des 18. Jahrhundertes, freuen müsste, wenn dieses Jahrhundert einen solchen Genius hervorgebracht hätte.“ Kreutzwalds Wohnhaus wird zum nationalen Wallfahrtsort der Esten (und darum natürlich auch der Symposionsteilnehmer, die dorthin eine Exkursion unternahmen). Und die Deutsche Märchenstraße verbindet, als sei das ganz selbstverständlich, vermeintliche Märchenschauplätze mit Wohnorten Jacob und Wilhelm Grimms.

3. Dem entspricht die immer wieder zu beobachtende Spannung von Authentizitätsbehauptung und Fiktionalitätsvorbehalt. Wo der Nachweis einer uralten Volksüberlieferung oder eines historischen fundamentum in re nicht geführt werden kann, da tritt ersatzweise der Rekurs auf (etwa geniepoetisch oder frühromantisch begründete) Wahrheitspostulate für die Fiktion ein. Dann kann etwa die historisch nicht nachweisbare Wilhelm-Tell-Figur als kollektive und von Schiller kongenial erfühlte Emanation eines schweizerischen Volksgeistes oder der Ossian als Ausdruck einer seelischen Verbundenheit Macphersons mit der schottischen Volksseele gedeutet werden. 
4. Nationalität und Gender: Viele auf der Tagung diskutierte Beobachtungen legen es nahe, zwischen weiblichen und männlichen Nationalepen und dementsprechend zwischen weiblichen und männlichen, matriarchalen und patriarchalen Nationalitätskonzepten zu unterscheiden. Liegt dem Roman „Babička“ der tschechischen Autorin Božena Němcová die Vorstellung einer nationalen Wiedergebärerin zugrunde und stehen die Grimm'schen Märchen - im scharfen Gegensatz, ja geradezu komplementär zum gleichzeitig durch Zeune und andere als Heroisierung deutschen Mannestums gelesenen und übersetzten „Nibelungenlied“ - unter dem Leitbild einer (groß-)mütterlichen Erzählerinnenfigur, so setzen etwa „Kalevipoeg“ oder „Kalevala" ganz auf männliche Helden als Repräsentanten einer mannhaften Nation. Gerade in so hoch literarischen Rezeptionen von Nationalepen wie etwa im Fall der NibelungenRezeption bei Heiner Müller können solche Genderaspekte neu produktiv werden.

5. Menschheitsdichtung und Nationalliteratur: Für die nationale Funktionalisierung einer epischen Überlieferung ist die Originalitätsbehauptung konstitutiv; sie erfordert eine Relativierung, $\mathrm{Zu}$ rückdrängung oder Leugnung über- und internationaler Genealogien gerade dort, wo diese philologisch besonders evident wird. Das gilt für das lettische Epos „Lāčplēsis“ ebenso wie für die Märchen. „Wenn aber ein Gelehrter meint, daß unser Dornröschen-Märchen aus Frankreich sei, [...] so soll man ihn auslachen“, höhnt der völkische Schriftsteller Philipp Stauff mit einer Empörung, die von heimlicher Verzweiflung nicht ganz weit entfernt ist. Herders Vorstellung des ,wandernden Ursprungs“ ist letztlich auf ein Menschheitsepos ausgerichtet - gerade vor dieser Kontrastfolie zeigt sich die Nationalisierung der Epen in ihrer ganzen Problematik (ein besonders deutlicher Anschauungsfall wäre das Nibelungenlied und seine Rezeption bis in den Faschismus). Dabei stehen Nationalepen immer auch in Abhängigkeit von- und Konkurrenz zueinander (Ossian als „schottischer Homer"), beeinflussen sich gegenseitig und adaptieren Merkmale, Figurenkonstellationen und Rezeptionsweisen. Diese Spannung von Nationalem und Menschheitlich- 
Universellem zeigte sich während der Tagung vom „Kalevipoeg“ bis zu Schillers „Tell“. Oft gehen die Texte gerade dort, wo ihre Rezeptionsgeschichte eine nationale Vereindeutigung und Verengung erzwingen will, nicht darin auf - eine Einsicht, die noch immer neue Lektüreperspektiven eröffnen kann.

6. Schaufensterfunktion und Spiegeleffekt: Das nationale Epos „stellt dar, dass wir eine Nation sind“, und zwar in markanter Profilierung nach außen; und es zeigt zugleich nach innen, ,wer wir uns sind. Im Nationalepos soll ein Volk sein eigenes Bild erkennen können" (so Thomas Taterka in diesem Band). Die große Zeit der europäischen Nationalepen im 18. und 19. Jahrhundert ähnelt damit dem, was Lacan für die individuelle Identitätsbildung das „Spiegelstadium“ genannt hat.

7. Text und Territorialisierung: Auffallend häufig beziehen sich nationalepische Texte nicht nur wie die Sage auf bestimmte Orte, sondern werden auch - durch volkstümliche, gelehrte oder kommerzielle Zuschreibungen - physisch in die Landschaft eingetragen, die auf diese Weise ihrerseits im Sinne des Epos semantisiert wird. Wie das Territorium Islands als Palimpsest von Saga-Schauplätzen gelesen und entsprechend kartographiert werden kann, so kann eine Reise durch Estland über weite Strecken als Reise durch das nationale Epos, ja manchmal geradezu durch Kalevipoegs Körper erlebt werden: Auffallende Landschaftselemente wie Steinsetzungen oder Seen werden ätiologisch als Kampfspuren aus den Abenteuern des Helden, als Teile seines Körpers oder als die von seiner Mutter über den Tod des Vaters vergossenen Tränen gedeutet. Hier zeigt sich eine Schnittstelle des Tagungsthemas zur Literaturgeographie. Selbst die ihrer Genrezugehörigkeit entsprechend topographisch ortlosen Volksmärchen sind in touristischen Unternehmungen wie der Deutschen Märchenstraße resolut lokalisiert worden.

Während der Tagung hat Thomas Taterka konstatiert, dass die für das nation building wichtigste Eigenschaft von Nationalepen ihre bloße Existenz ist: Sie sind vor allem dazu da, da zu sein. Eine Nation bedarf ihrer nicht, um sie zu lesen, sondern um sie zu haben - so wie die Grie- 
chen den Homer, die Römer den Vergil, die Deutschen das Nibelungenlied haben. Ohne Epos keine Nation, ohne Leser aber beides. Dass es dieser Beobachtung zum Trotz, die von den Tagungsteilnehmern „Taterkas Gesetz“ genannt wurde, dennoch lohnen könnte, die nationalen Epen neu zu lesen, ja dass die Neulektüre nicht nur lehrreich, sondern auch überaus unterhaltsam sein kann - davon hat der Verlauf der Tartuer Tagung jedenfalls die Teilnehmer überzeugt. Es bleibt zu wünschen, dass etwas von dieser Erkenntnisfreude sich auch den Lesern dieses Bandes mitteilt.

In seinem für die Geschichte und die Systematik der europäischen Nationalepen grundlegenden Artikel geht Thomas Taterka (Riga) davon aus, dass Nationalepen spätestens im 19. Jahrhundert eine elementare Funktionsstelle im kulturellen Haushalt jeder Nation zugewiesen wird (die noch dort zu erkennen ist, wo ein Nationalepos bis heute fehlt, z.B. in England). Taterka deutet Nationalepen als quasi-religiöse Texte, in denen die Totalität einer Nation symbolisch gefasst, ihr selbst sichtbar gemacht (Spiegeleffekt) und anderen Nationen präsentiert werden soll (Schaufenstereffekt) - nicht zuletzt auch zur Modellierung von Kulturkonkurrenzen. Im 19. Jahrhundert entstehen Nationalepen als Nationalepen, sie realisieren ein vorgängiges Programm, dessen Kernpunkte die deutschen Romantiker und insbesondere Jacob und Wilhelm Grimm formuliert haben: Danach müssen Nationalepen u.a. als „natürlich“ gewachsen präsentiert, als „Naturpoesie“ in Opposition zur „Kunstpoesie“ der Gebildeten in Stellung gebracht werden und Nationalgeschichte insofern produzieren, als sie ein vermeintliches Beweisstück für die historische Existenz eines Volkes liefern.

Herders Auffassung vom Volksepos hat den semifiktionalen Nationalepen des 19. Jahrhunderts als Anregung und Legitimation gedient. Der Aufsatz von Hans Graubner (Göttingen) zeigt an der Entstehung und Fortbildung des Epos-Konzepts bei Herder selbst, wo diese Inanspruchnahme berechtigt ist und wo sie hinter seinen Intentionen zurückbleibt. Herders Vorstellung von dem durch festigende Traditionen hindurch wandernden Ursprung lässt neue Volksepen durchaus zu, seine Zielvorstellung vom humanen Menschheitsepos dagegen entfernt sich weit von jeder Fixierung auf Nationalepen. 
Die wechselvolle Geschichte der „Poems of Ossian“, die in der zweiten Hälfte des 18. Jahrhunderts zum schottischen Nationalepos (v)erklärt wurden, zeichnet Barbara Schaff (Göttingen) in drei Schritten nach: Zunächst führt sie vor, wie im Kontext sich verändernder nationalpolitischer Diskurse die „Poems of Ossian“ immer wieder ästhetisch und moralisch neu bewertet wurden. Zweitens geht sie den Bemühungen nach, die Gedichte in die Topographie Schottlands einzutragen (nicht zuletzt als spirituelle Fluchträume vor der Industrialisierung) - wobei sich die topographische Unbestimmtheit der Texte durchaus als Vorteil erweist. Abgeschlossen werden Schaffs Überlegungen von einem Blick auf die gegenwärtige „Ossian“-Rezeption, die den Schluss nahe legt, dass die Texte zwar ihr ästhetisches Verfallsdatum überschritten haben und kaum noch gelesen werden, sich aber trotzdem weiterhin identitätspolitisch instrumentalisieren lassen.

Auch wenn die „Kinder- und Hausmärchen“ der Brüder Grimm kein Nationalepos im engeren Sinn darstellen, führt Heinrich Detering (Göttingen) vor, wie die Textbearbeitungen der Herausgeber darauf angelegt sind, eine gerade im Kontrast zum wiederentdeckten Nibelungenlied besonders wirkungsmächtige, weil unpathetische Variante nationaler Epik zu konstruieren - nicht zuletzt dort, wo Märchen internationaler Herkunft möglichst unauffällig nationalisiert werden. Als Naturpoesie, so die Leitidee der Grimms, komme in den Märchen das Denken und Erzählen des Volks zum authentischen Ausdruck. Vor dem Hintergrund der antinapoleonischen Befreiungskriege und einer insofern „national entfremdeten“ Gegenwart eignen sich die „Kinderund Hausmärchen" wie wenige andere Texte dazu, in kindlich-unschuldigem Gestus nationale Mythologie zu produzieren.

Ebenso ist Schillers „Wilhelm Tell“ im engeren Sinne kein Nationalepos, jedoch war das Geschichtsdrama in seiner Rezeptionsgeschichte wirkungsmächtig für die Nationsbildung (in Deutschland und insbesondere in der Schweiz), wie Silke Pasewalck (Tartu) ausführt. So stehen die Ambivalenz und Polysemantik des Schiller'schen Dramas einer funktionalen Rezeption als Nationalstück entgegen. Gleichwohl wurde (und wird) der literarische Text zum Ausgangs- und Bezugspunkt historischer Fiktionen, was an zentralen Erinnerungsorten wie etwa Tellsplatte und Hohler Gasse dargelegt wird. Mit Max Frischs „Wilhelm Tell für die Schule“ aus dem Jahr 1970 führt Silke Pasewalck schließlich 
ein Beispiel für eine Reliterarisierung des Tellstoffes an, das gegen nationalmythologisierende Tendenzen gerichtet ist.

Mit dem Artikel von Karin Hoff (Göttingen) wendet sich der Band den skandinavischen Literaturen und Kulturen zu, für deren Geschichte und Selbstverständnis die isländische Literatur des Mittelalters von elementarer Bedeutung ist. Die Verfasserin geht der Frage nach, welche Spuren die isländischen Sagas im kollektiven Gedächtnis der Isländer und der Skandinavier im Allgemeinen hinterlassen haben. Die Sagas übernehmen die Funktion von Nationalepen dergestalt, dass sie als anonym tradierte Texte in die Gegenwart hineinwirken und die Geschichte Islands und seiner Familien retrospektiv legitimieren.

Wie die altisländischen Stoffe in den skandinavischen Literaturen der nationalromantischen Epoche weitergewirkt und rezipiert wurden, zeigt Esbjörn Nyström (Tartu/Stockholm) am Beispiel Schwedens auf. Esaias Tegnérs 1825 erschienenes Versepos „Frit(h)iofs saga“, das die altisländische Saga „Friðpjófs saga ins frækna“ zur Vorlage nahm, entfaltete im 19. Jahrhundert für die nationale Identität (Rest-)Schwedens kompensatorische Wirkung und wurde bis ins frühe 20. Jahrhundert als schwedisches Nationalepos rezipiert. Der zweite Teil des Beitrags ist der literarischen Rezeption in Selma Lagerlöfs gleichnamigem Opernlibretto gewidmet, bei der es zu signifikanten Verschiebungen kommt: etwa zu einer Loslösung vom nationalen Pathos und einer Akzentverlagerung vom männlichen Heldentypus hin zu den Frauenfiguren. Damit zeichnet der Beitrag eine rezeptionsgeschichtliche Entwicklungslinie nach, die auch für andere Weiterschreibungen von Nationalepen exemplarisch ist.

Dass im Zuge des nation building gerade auch solche Texte die exemplarische Rolle eines Nationalepos übernehmen, die nicht in die literarische Gattung des Epos fallen, stellt in ihrem Beitrag über die Erweckung der tschechischen Identität Zuzana Stolz-Hladká (Göttingen/Konstanz) dar. Vor allem der tschechischen Sprache, und damit zugleich der Literatur, soll dabei eine identitäts- und sinnstiftende sowie kulturkonstituierende Funktion und Wirkung zukommen, was Stolz-Hladká am Beispiel des Gedichtes „Slovo české“ von František Šír veranschaulicht. Vor dieser Folie betrachtet die Verfasserin zwei gefälschte Handschriftenfunde aus den Jahren 1817 und 1818, „Rukopis 
Královédvorský“ und „Rukopis Zelenohorský“, von denen namentlich das letztgenannte Manuskript mit der Darstellung der legendären Stammesfürstin Libuše als einer Recht sprechenden Herrscherin sich nachhaltig auf die grundlegenden Texte der tschechischen Literatur ausgewirkt hat. So greifen spätere epossubstituierende Basistexte der tschechischen Literatur immer wieder auf diese „Urmutter“ zurück.

Die Entstehung des finnischen Nationalepos „Kalevala“ wird von Christian Niedling (Helsinki) aus der historischen Identitätskrise abgeleitet, in die Finnland am Anfang des 19. Jahrhunderts dadurch geriet, dass es nach fünfhundertjähriger Zugehörigkeit zu Schweden an Russland fiel. Vor dem Hintergrund von Herders Überlegungen zur Nationalpoesie und angeregt vom Kreis der Turkuer Romantiker sammelt, kompiliert und bearbeitet Elias Lönnrot Volksdichtungen und gibt sie ab 1835 in mehreren Bearbeitungsstufen als „Kalevala“ heraus. So differenziert wie an wenigen anderen Beispielen lässt sich hier die Genese und die zeitgenössische Diskussion eines Nationalepos verfolgen, die Niedling im zweiten Teil seines Aufsatzes mit der parallelen (und ebenso politisch motivierten) Rezeption des „Nibelungenlieds“ als Nationalepos in Deutschland vergleicht.

Bis ins späte 20. Jahrhundert hinein sieht Heiner Müller die deutsche Geschichte von einem im "Nibelungenlied“ angelegten Grundraster geprägt, in dessen Zentrum die Saal- bzw. Kesselschlacht steht. Torsten Hoffmann (Frankfurt a. M.) deutet vor diesem Hintergrund die markanten Veränderungen in den Nibelungenszenen der beiden „GERMANIA“-Stücke Müllers als einen Versuch, die Nibelungen durch eine doppelte Umpolung zukunftsfähig zu halten: Während sie im ersten Drama den Zusammenhalt von Nationalismus und Männlichkeit beschwören, stellt das zweite Stück mit Kriemhild eine dezidiert antimännliche Protagonistin ins Zentrum, die - im Kontext von Müllers Beschäftigung mit anderen mythologischen Frauenfiguren - das vormalige Nationalepos internationalisieren und in die europäische Literaturgeschichte einschreiben soll.

Dass (National-)Epen über die nationale bzw. ideologische und die historische Verengung hinaus sich auch anderen Rezeptionsweisen und Lesarten zu öffnen und zumindest unter manchen Aspekten überzeitliche Gültigkeit zu erlangen vermögen, führt in ihrem Aufsatz zum 
„Kalevipoeg“" Eve Pormeister (Tartu) vor. Diese mögliche Hinwendung vom Nationalen zur allgemeinen Gültigkeit sollen vornehmlich die interpretatorischen Darlegungen über die Höllenfahrt-Szenen erhellen, zum Teil aber auch die Textgenese, der Entstehungskontext und die Rezeptionsbedingungen. Die Verfasserin entwickelt die These, dass das estnische Epos nicht allein aus nationaler Warte zu rezipieren und zu bewerten sei, sondern dass es - um mit Herders Worten zu sprechen zugleich auch Züge eines Menschheitsepos in sich trage.

Mari-Ann Palm (Tartu) geht in ihrem Beitrag den publizistischen Schriften nach, die F. R. Kreutzwald von 1837 bis 1859 für die in Dorpat (estn. Tartu) erscheinende Wochenschrift „Das Inland“ verfasst hat. Kreutzwalds Beiträge und Korrespondenznachrichten sind zeitkritische und aufklärerische Kommentare, die durch Themenwahl und Darstellungsweise auf die Situation der livländischen Landbevölkerung aufmerksam gemacht und damit eine wichtige Rolle für die entstehende nationale Bewegung in den Ostseeprovinzen Livland, Estland und Kurland gespielt haben. Kreutzwalds deutschsprachige Publizistik, die als Vorgeschichte des „Kalevipoeg“ gelesen werden kann, stellt noch immer, wie Palm verdeutlicht, ein Desiderat der germanistischen und kulturhistorischen Forschung dar.

Marin Laak und Piret Viires (Tartu/Tallinn) nähern sich dem estnischen Nationalepos „Kalevipoeg“ als einem nuancenreichen und mehrschichtigen sowie neue Texte generierenden literarischen Grundtext. Nach einem Einblick in die Rezeptionsgeschichte führen die Verfasserinnen in Grundzügen die sich durch intra-textuelle Bezüge bildenden textstrukturierenden Eigenheiten, wie z.B. das als mehrdimensionales Zeichen verwendete Bild des Steins, vor, um sich anschließend der kulturell-kontextuellen Bedeutung, den soziokulturellen Deutungen und den literarischen Interpretationen des Epos in der estnischen Gegenwartskultur zuzuwenden. Ihr besonderes Augenmerk gilt den intertextuellen Bezügen der postmodernen (auch auf neuen Medien und dem Internet basierenden) Literatur des ausgehenden 20. und des beginnenden 21. Jahrhunderts zum „Kalevipoeg“. 
Die Tagung „Nationalepen zwischen Fakten und Fiktionen“, auf der die hier abgedruckten Beiträge vorgestellt und diskutiert worden sind, wurde ebenso wie der Druck dieses Bandes ermöglicht durch die großzügige Unterstützung des DAAD. Die Herausgeber danken außerdem herzlich Christina Grübel (Tartu) für die umsichtige Organisation der Tagung sowie Nina Kullrich und Adrian Bruhns (Göttingen) für ihre Hilfe bei der Einrichtung der Texte. Nicht zuletzt danken wir den Beiträgerinnen und Beiträgern für die unkomplizierte Kooperation. 


\section{Die Nation erzählt sich selbst. Zum europäischen Nationalepos des 19. Jahrhunderts*}

Erstaunlich ist das Geschick der Gattung Epos im Europa des 19. Jahrhunderts. Einerseits wird sie um 1800 versargt, als hoffnungslos obsolet. Die Argumente sind vielfältiger Natur, geschichtsphilosophischer, mediengeschichtlicher, auch ästhetischer. Andererseits setzt um die gleiche Zeit eine Neubelebung der heroischen Großform ein. Diese Revitalisierung ist der Germanistik sehr viel weniger geläufig als die Grabreden. Am allerwenigsten bekannt ist sie ihr als gesamteuropäisches Phänomen. Der sich zu einem „Europa der Nationen“ auseinander legende Kontinent erscheint in dieser Dimension als ein literarisches Feld. Überall tritt die archaische Form in moderner Funktion auf: als Nationalepos. Stichwortgeber für die intime Verbindung von Epos und Nation ist in ganz Europa der vielzügige deutsche Epos-Diskurs, von Herder und Humboldt und Hegel, Friedrich August Wolf und den Grimm und Karl Lachmann bis zu Heyman Steinthal und Wilhelm Jordan. Im kulturellen Haushalt einer jeden Nation ist nun für das Epos eine Systemstelle vorgesehen. Diese Stelle muss besetzt werden, sei es durch Nationalisierung eines vorhandenen Textes zum Nationalepos, sei es durch die Verfertigung eines Textes als Nationalepos. Epenbesitz ist für die europäische Nation des 19. Jahrhunderts nicht weniger elementar als Wir-Bewusstsein und Geschichte-Haben und mit beidem symbiotisch verknüpft. Der ganz Europa durchziehende Vorgang der Etablierung von Nationalepen, in denen sich der Charakter des eigenen Volkes in unverwechselbarer Weise aussprechen sollte, erweist sich so als Beleg für den unhintergehbar transnationalen und internationalen Charakter der europäischen Literaturen und Kulturen gerade dort, wo sie sich unterstrichen national gebärden.

\footnotetext{
* Eine kürzere Fassung dieses Aufsatzes ist in diesem Jahr bereits an anderer Stelle erschienen (vgl. Taterka 2011). Ich danke den Herausgebern beider Bände für die freundliche Erlaubnis, von diesem Text hier Gebrauch machen zu dürfen.
} 
Das Europa von heute mag leicht eine der Weltgegenden sein, die zur Beschäftigung mit dem Heldenepos am allerwenigsten einladen. Beide Glieder des Kompositums sind hier problematisch geworden. Auf allem „Heldischen“ lastet seit dem Ausgang des Zweiten Weltkrieges zumindest in Westeuropa schwerer Verdacht. Es in hoher Literatur zu besingen und zu preisen ist gänzlich aus der Mode gekommen. Wer dies dennoch versucht, läuft Gefahr, sich der Lächerlichkeit preiszugeben. Im Ganzen entspricht das Verhältnis des Alten Kontinents zum Heroischen recht genau dem lakonischen Spruch aus dem „Leben des Galilei“: „Unglücklich das Land, das Helden nötig hat.“ (Brecht 1939: 116).

Aber auch das zweite Element des Binoms hat in Europa zuletzt wenig Glück gemacht. Noch im ausgehenden 18. Jahrhundert an der Spitze der Gattungshierarchie stehend, hat die Gattung Epos im 19. Jahrhundert, wenn man den Handbüchern Glauben schenkt, an Status eingebüßt, um im 20. Jahrhundert als aussterbende Gattung ein kümmerliches Dasein zu fristen und schließlich gänzlich aus der Übung zu kommen (vgl. zuletzt Labarthe 2007). Mit Blick auf die zeitgenössische Literatur wird man die große heldenepische Narration in gebundener Rede, lange Zeit Gipfel- und Sehnsuchtspunkt der Literaturen Alteuropas, als historisches Phänomen ansprechen müssen. Für den herrschenden literarischen Geschmack nimmt sie sich obsolet und fossil aus, als eine „ästhetische Sackgasse“ (Berelis 1999: 25). Es scheint schlechterdings kein Bedürfnis mehr empfunden zu werden nach einer hochgewerteten literarischen Gattung, die darin ihr Wesen hat, dass sie in endlosen Versketten „männliche Aggression im Dienste einer großen Unternehmung in Szene setzt" (Zumthor 1990: 95).

Hebt man allerdings die Augen über den europäischen Tellerrand, so bietet sich ein zum Erstaunen anderes Bild. Es gibt weite Himmelsstriche, in denen das Epos unverändert in Geltung steht oder Geltung neu erlangt. In vielen Weltgegenden werden Traditionen und Riten und Feste um das Epos als ihr performatives Zentrum herum lebendig gehalten, ist das Gattungsmodell produktiv und besetzt das Epos als Ort der Begegnung zwischen oraler Volkskultur und Schriftkultur eine kulturtypologisch prominente Stelle (vgl. etwa Honko 1990a; Beissinger/Tylus/Wofford 1999; Jansen/Maier 2004). Zu studieren ist dies in Zentralasien, wo der aus der Konkursmasse der Sowjetunion hervorgegangene Staat Kirgistan das gegen Ende des 19. Jahrhunderts 
von dem St. Petersburger Gelehrten Wilhelm Radloff konstituierte und sich seitdem uferlos fortspinnende Manas-Epos von unterdessen mehr als zwei Millionen Versen systematisch zum nation building einsetzt, die Sängerkaste der Manaschi blühen und gedeihen lässt und das prekäre Nationalgefühl seiner Bürger von diesem Text herschreiben und auf ihn allerdings auch verpflichten will (vgl. Başgöz 1978; van der Heide 2004). Die Mongolei ließe sich nennen, wo bei Feldforschungen in den 1980er Jahren „about 350 epics have been recorded, of which roughly one third have been published“ (Honko 1993: 3). Tibet wäre anzuführen, wo seit Jahrzehnten die Verschriftlichung der Khan Ghesar-Epen und ihre Fügung zu Zyklen im Gange ist, mit ordnungsgemäßer Verankerung in den Fünfjahrplänen der Volksrepublik China (vgl. Zhi 1990: 503). Westafrika mit dem Soundjata der Mandinge gehörte ebenso hierher wie Indien mit dem Siri oder an das Mahābhārata und das Rāmāyana anschließende Prozesse in der indonesischen und thailändischen Literatur. Eine eigene Diskussion wert wäre der anders gelagerte, dann aber doch wieder einschlägige Fall von Derek Walcotts Westindienepos „Omeros“ aus dem Jahre 1990, eines mit dem Nobelpreis gewürdigten Schlüsseltextes in den Debatten um postkoloniale Identität und postkoloniales Schreiben. Es ist eine schneidende Erinnerung Europas daran, was das Epos ihm einst gewesen, dass Walcotts an die Wurzel gehende Auseinandersetzung mit der europäischen Kultur im Prozess des writing back sich just des Epos bedient, als der literarischen Metasprache, in der Gründungsurkunden abendländischer Identität verfasst sind, die Epen unter dem Namen Homers.

Eine Erinnerung sei dies, sagten wir. Denn auch auf dem Alten Kontinent, um den Bogen zurückzuschlagen, standen die Dinge einmal sehr anders. Die Zeiten, in denen dies so war, liegen näher, als man vielleicht meinen möchte. Nicht allein die Antike, das Hochmittelalter und die Renaissance sahen Blütezeiten des Epos. Seine wahre Hochzeit fällt vielmehr, wird man mit Blick auf das bloße Aufkommen notieren müssen, in das lange 19. Jahrhundert. Zwischen den in ganz Europa Epoche machenden und die romantische Bewegung mächtig anregenden Pseudo-Ossianischen „Mini-Epen“ (Hatto 1980) des James Macpherson in den 1760er Jahren und dem nach handfesten Anregungen eines finnischen Folkloristen abgesungenen „Peko“-Epos der Setu im Südosten Estlands aus dem Jahre 1927 (vgl. Vabarna 1995; Arukask 2002) 
scheinen quer über den Kontinent, von den Hebriden bis in den Ural und den Altai, von Lappland und Finnland und Skandinavien bis in die Provence, von Irland bis auf den Balkan und die Peloponnes Epen regelrecht aus dem Boden zu schießen. Für mehr als ein Jahrhundert ist die Sehnsucht nach dem Epos eine gesamteuropäische idée fixe, und eher unmöglich als schwierig wäre es, ein Volk oder eine größere Völkerschaft zu nennen, die von diesem Verlangen gänzlich unberührt geblieben wären.

Diese späte Blüte bedarf der Erklärung. Sie steht quer zu allem, was der Germanist oder Anglist oder Romanist über die Evolution der altehrwürdigen Gattung gelernt haben mag. Ihr Einsatz fällt in eben den Moment, da das Heldenepos von der avancierten Ästhetik in aller Form zu Grabe getragen wird. Pünktlich zum Ausgang des aufgeklärten Jahrhunderts, im Jahre 1799, deduziert Wilhelm von Humboldt sein Ableben: „Bis also das epische Genie durch die That das Gegentheil beweist, kann man [...] die heroische Epopee in unsern Tagen mit vollkommenem Recht unter die Zahl der Unmöglichkeiten rechnen." (von Humboldt 1799: 343) Humboldt entwickelt den Gedanken, dass das Heldenepos, als Standeskunst einer bevorrechteten Kriegerkaste mit ihrem elitären Wertekosmos, notwendig ein Opfer der mit der Französischen Revolution eingeleiteten Zeitenwende werden müsse. In sich modernisierenden Zuständen stünde seine Ablösung durch neue Formen an, wie sie Goethe in „Hermann und Dorothea“ entwickle, seiner „bürgerlichen Epopee“.

In die gleiche Richtung läuft ein anderes Argument, das in einer durchmedialisierten, technomorphen Welt wie der unsrigen noch überzeugender anmuten mag. Das Heldenepos erscheint hier weniger als geschichtsphilosophischer Anachronismus denn als technikgeschichtliche und medienhistorische Unmöglichkeit:

Von einer andren Seite: Ist Achilles möglich mit Pulver und Blei? Oder überhaupt die „Iliade“ mit der Druckerpresse und gar Druckmaschine? Hört das Singen und Sagen und die Muse mit dem Preßbengel nicht notwendig auf, also verschwinden nicht notwendige Bedingungen der epischen Poesie? (Marx 1857/58: 45)

Man muss Karl Marx nicht sehr mögen, wo er vom „Überbau“ handelt. Hier aber berührt er einen wichtigen Punkt. In den sich zu historischen 
Medien- und Kulturwissenschaften wandelnden Philologien wird er intensiv verhandelt, unter Stichworten wie „orale und litterale Kulturen“ oder „Folgen der Schriftkultur“ oder "Stimme und Schrift" oder auch „Aufstieg und Niedergang der Gutenberg-Galaxie“. Lange vor Marx hatte ihn der auch hierin durch Vico und Hamann belehrte Johann Gottfried Herder in einen Satz gezogen: „Bücher waren das Grab des Epos.“ (Herder 1795a: 425f., Anm. $\dagger$ ). Die lapidare Äußerung fällt in einer in die „Horen“ eingerückten Polemik gegen Friedrich August Wolf, dessen „Prolegomena ad Homerum“ dem 19. Jahrhundert mit der Liedertheorie eine Legitimation für das Verfertigen von Epen durch das „Zusammensingen“ von Volksliedern stifteten. Diese durch Lachmanns Nibelungen-Studien weiter befestigte Doktrin sollte gerade im nordöstlichen Ostseeraum Wirkung entfalten, wobei das ragende Muster des Lönnrot'schen „Kalevala“ überall Pate stand (vgl. Niedling 2007: 29-36, Lāms 2008: 49-56).

$\mathrm{Zu}$ den Zweiflern zu gesellen wäre auch der bedeutende livländische Essayist Carl Gustav Jochmann mit seiner faszinierenden Schrift „Die Rückschritte der Poesie“ (1828), die durch ihren Herausgeber Walter Benjamin spät zu einem kleinen Ruhm gefunden hat. Jochmann bringt ein Argument für die Unzeitgemäßheit des Heldenepos, das weder aus der Geschichtsphilosophie bezogen ist noch aus der Ästhetik oder der Mediengeschichte. Es ist ein typisch aufklärerisches: ein bildungsgeschichtliches also. Das Problem des Epos sei nicht dessen Verfertigung. Die könne wohl noch gelingen. Doch sei keine angemessene Aufnahme mehr zu erwarten. Vielleicht nicht der Kunstgeschmack, ganz gewiss aber der Bildungsstand des aufgeklärten Publikums sei über diese unzeitgemäß gewordene Form lange hinaus:

Kein Heldenlied macht ferner Glück. Wir überreden uns wohl noch es zu bewundern, und wir bringen es zu Zeiten wirklich dahin, aber desto seltener d a h i n es zu lesen. Das macht, wir bedürfen seiner nicht mehr, wir sind nicht länger einfältig und roh genug, um seiner zu bedürfen. [...] Wo [...] beide, Vernunft und sittliches Gefühl, schon zum vollen Bewußtseyn erwachten, oder wenigstens erwachen dürfen, wo der Wunderglaube von jeher nur eine Thatsache war, und nicht einmal ein Lehrsatz geblieben ist, im Gebiete der wirklichen Welt und ihren Veränderungen, giebt es schlechterdings keinen Stoff, der sich zu etwas mehr als höchstens einer Erzählung in Versen, der sich zum Epos eignete. [...] [E]in gebildeteres Volk durch Heldengedichte in Bewegung setzen zu 
wollen, dürfte völlig so unstatthaft seyn, als es unmöglich ist, Erwachsene durch die Mährchen zu täuschen, die einen so überwiegenden Einfluß auf alle Gefühle und Überzeugungen ihrer Kindheit ausübten. [...] Was die Ilias dem ihrigen, ist einem späteren Zeitalter die Geschichte. (Jochmann 1828: 165, 183, 166)

Freilich beherrschen die fortschrittsfrohen Stimmen, die das Heldenepos als aus der Zeit gefallen abtun und ihm sein Ende ansagen, den Diskurs keineswegs allein. Neben ihnen werden Stimmen laut, die dem Heldenepos auch unter veränderten Weltzuständen - nennen wir sie der Prägnanz halber: in der Moderne - ein Daseinsrecht einräumen. So meldet sich kaum 15 Jahre nach Humboldt eine nicht weniger gewichtige Stimme, die entschieden dafür hält, dass mit dem heraufziehenden Zeitalter auch eine neue Ära der heroischen Poesie angebrochen sei:

Jede Nationaldichtung muß schal seyn oder schal werden, die nicht auf dem Menschlichsten ruht, auf den Ereignissen der Völker und ihrer Hirten, wenn beide für Einen Mann stehn. Könige sind darzustellen in Krieg und Gefahr, wo sie eben dadurch als die Ersten erscheinen, weil sie das Schicksal des Allerletzten bestimmen und theilen, und dadurch viel interessanter werden als die Götter selbst, die, wenn sie Schicksale bestimmt haben, sich der Theilnahme derselben entziehen. In diesem Sinne muß jede Nation, wenn sie für irgend etwas gelten will, eine Epopöe besitzen [...]. (Goethe 1829: 103f.)

Der so meint, ist allerdings Goethe. In „Dichtung und Wahrheit“ fällt er seinem Interpreten Humboldt gewissermaßen ins Wort. Freilich ist er von dessen Urteil getrennt durch einen epochalen Umbruch, durch das Umschaffen Europas im Gefolge der napoleonischen Kriege. Goethe setzt voraus, was Humboldt 1799 noch ganz unbekannt gewesen war und was dem Spätaufklärer Jochmann auch 1828 noch immer nicht der Rede wert ist: den Vorgang der Nationalisierung Alteuropas, das Sich-Auseinanderlegen des Kontinents zu einem Europa der Nationen. Die politischen Kollektivsubjekte, mit denen fortan zu rechnen ist, das sind nicht mehr die Länder und Staaten und Reiche allein. Es sind zunehmend auch die Völker. Freilich in einem von der Großen Revolution heraufgeführten anderen Aggregatzustand: als Nationen. In dem ganz Europa ergreifenden Vorgang des Konstituierens von Nationen wird die zum Verdämmern bestimmte Großgattung zum Leben zurückerweckt. Das nationalistische Jahrhun- 
dert wird auch, und in einem damit, das nationalepische. Prägnant formuliert findet sich der solidarische Zusammenhang von Epos und Nation bei dem Tallinner Literaturwissenschaftler Jaan Undusk:

In und mit dem Epos tritt ein Volk von seinem ursprünglichen-göttlichen, großenteils unbewußten Dasein in das selbstbewußte menschlich-nationale Dasein hinüber [...]. [V]on einem Objekt des mythischen Schicksals wird es ein Subjekt der Weltgeschichte, mit einem Wort: das Volk wird eine Nation. Für die Kulturologie des 19. Jahrhunderts war das Epos nicht selten wie eine schriftlich niedergelegte Spur, die die Nation auf ihrem Wege aus der vorhistorischen Dämmerung in die Weltarena der Geschichte hinterläßt, ein Nachweis post factum für ihre Nationwerdung. (Undusk 2000: 10)

Dies bezeichnet eine der elementaren Dimensionen des Epos, seine Funktion im Außenverhältnis, im Verhältnis der Nationen untereinander. In dieser Dimension wird erzeugt, was man der Eingängigkeit halber Schaufenstereffekt nennen könnte: Das Epos stellt dar, dass wir eine Nation sind. Dieser Effekt neigt freilich in einer Art Übersprungshandlung zur Ingression: von der Behauptung der Existenz der eigenen Nation zu ihrer Überhebung über andere, zumal über benachbarte Nationen oder über jene, von denen man sich dominiert fühlt. Das Nationalepos schickt sich trefflich zur Modellierung von Kulturkonkurrenzen. Ein Schulbeispiel dafür liefert das lettische Epos. Hatten die national inspirierten Letten eben noch verzweifelt darunter gelitten, noch immer kein Nationalepos vorweisen zu können, mit unangenehmer Verspätung gegenüber den Finnen mit dem „Kalevala“ (zuerst 1835/36) und gegenüber den estnischen Nachbarn mit dem „Kalevipoeg“ (1857/61), da werden sie von Andrejs Pumpurs in der Vorrede zu seinem „lettischen Volksepos“ „Lāčplēsis“ (1888) schon von Nachzüglern zu Vorreitern erhoben. Pumpurs reiht sein Volk umstandslos unter die „epischen Völker“ ein (vgl. Krastin,a 2004: 39-45). Damit geraten die Letten unversehens auf Augenhöhe mit den Indern, Persern, Griechen und Germanen. Dies sind die Völkerschaften, die Wilhelm Jordan, ein leicht obskurer deutscher Literat und als in Europa und Nordamerika praktizierender Rhapsode ein selbsternannter Nachfolger Homers, in seiner von Pumpurs enthusiastisch aufgegriffenen Ependoktrin als die vier „epischen Völker“ angesetzt hatte (Jordan 1876; v. a. im 2. Brief). Die Aufnahme der lange als „Bauernvolk“ verachteten Letten als fünftes Glied dieser edlen Kette ist überdeutlich 
ein Akt kompensatorischer Selbstnobilitierung einer bis tief in das 19 . Jahrhundert hinein kolonial fremdbestimmten ethnischen Gemeinschaft, die sich eben als Nation konstituierte. Diese Erhöhung der eigenen Nation impliziert freilich die Herabsetzung anderer. Die heikle Beziehung zu den Epen der benachbarten Finnen und Esten Pumpurs' Text kommt nicht nur zwei Generationen später als jener Lönnrots und immer noch eine als jener Kreutzwalds, er wäre auch ohne das Vorbild des „Kalevala“ wie des „Kalevipoeg“ ein gänzlich anderer geworden, um es sehr behutsam auszudrücken - lässt sich damit wenden. Denn nach der von Pumpurs fortgeschriebenen Epenlehre Jordans, die man ungescheut rassistisch nennen darf, sind nur ,arische Völker“ zum „wahren Epos“ (Jordan 1876: 41). befähigt. Vorweg ausgeschlossen sind damit die Nachbarn der Letten im Nordosten, die als Finnougrier „nichtarischen“ Finnen und Esten. Deren „Kalevala“ und „Kalevipoeg“ finden sich bei Pumpurs' Stichwortgeber denn auch obenhin abgetan, als bloße „Ansätze zum Epos“ (ebd., 43). Ganz anders das „litauisch-lettische Volk“. Dieses sei, wie Pumpurs herausstreicht, nicht nur zweifelsfrei arisch. Es stehe auch näher am „arischen Urvolk“ (Pumpurs 1888: 141) als selbst die Germanen. Nach der biologistischen Kulturlogik des 19. Jahrhunderts ist es damit in höherem Maße zum Epos begabt als die „germanischen“ Deutschen mit ihren Nibelungen, auf deren Entbindung zum wahren Nationalepos der Deutschen in seinen vier starke Bände hindurch erbarmungslos stabenden „Nibelunge“ (1867/74) Pumpurs' Lehrmeister Wilhelm Jordan sich viel zugute tat.

Damit aber nicht genug. Die kompensatorische Überhebung des lettischen Epos gegenüber seinem estnischen Gegenstück wird auch in den Text des „Lāčplēsis“ selbst aufgenommen. Sie wird in Szene gesetzt. In einem Zweikampf zwischen dem lettischen Bärentöter (Lāčplēsis, wörtlich: „Bärenreißer“) und dem estnischen Riesen Kalapuisis (eine lettonisierte Version von Kalevipoeg, „Sohn des Kalev“) treffen nicht nur ein lettischer und ein estnischer Recke aufeinander. Es ringen hier in ihren Titelhelden auch das lettische und das estnische Epos. Im Treffen der beiden wird nicht nur (auf der Ebene des plot) der stärkere Held gesucht, sondern auch (auf der Ebene der Nationalkulturen) der überlegene Text. Da dieser Kampf im lettischen Epos ausgetragen wird, kann der Ausgang des Rangstreites keinen Augenblick zweifelhaft 
sein. Der Sieg des lettischen Bärentöters über den estnischen Riesen ist eine Triumphgeste des lettischen Epos über das estnische. Durch die im Text imaginierte und ausagierte Überlegenheit wird der prekäre Status des Textes selbst gegenüber seinem estnischen Vorläufer übertüncht, der nicht nur um einiges früher in der Welt war, sondern von Pumpurs auch weidlich ausgeschrieben wurde - was beides mit der im Text selbst entfalteten Überlegenheits- und einer nachgeschobenen Verbrüderungsgeste vom Tisch gewischt wird.

Beiseite geschafft wird mit der gleichen Szene ein weiterer Umstand, der dem lettischen Nationalepiker schwer hätte zu schaffen machen können. Im „Lāčplēsis“ werden nicht allein Kulturkonkurrenzen ausgetragen, vorzugsweise solche, die einen zuvor stattgehabten Kulturtransfer verschleiern. Verhandelt wird hier auch und vor allem Geschichte, in welch besonderem Aggregatzustand auch immer. Der ungeschlachte estnische Riese ist nicht von ungefähr in das Lettenland eingefallen. Er kommt über die friedfertigen Nachbarn als Vorbote der deutschen Eroberer. Nun lehrt ein Blick in die Quellen, zumal in das „Chronicon Heinrici“ als den Muttertext aller Geschichtserinnerung der baltischen Region, dass diese Rollenzuweisung die historische Überlieferung um 180 Grad verkehrt. Die mittelalterliche Chronistik die Pumpurs sehr wohl kannte - erzählt die Geschichte eben umgekehrt: Jene Völkerschaften und Stämme des Hochmittelalters, in denen sich im 19. Jahrhundert die Letten erkennen wollen, allen voran die Ahnenethnie der Lettgaller, hatten nicht nur als erste in der Region und ohne größeren Widerstand die Taufe genommen. Die Frischbekehrten zogen auch sogleich mit den deutschen Kreuzfahrern gegen die beharrlich am Heidentum festhaltenden Esten. Will sagen: Sie taten in der Geschichte eben das, was im lettischen Epos den Esten zugeschrieben wird. In diesem Rollentausch ist der Wunsch nach einer anderen, nach einer kontrafaktischen Geschichte zu fassen. Es ist der gleiche Wunsch, der auch die sich gegen Ende des 19. Jahrhunderts ausbildende lettische Nationalgeschichtsschreibung bestimmt, die die Beteiligung an den Kriegszügen gegen die Esten übergeht und in der ersten lettischen Übersetzung der Heinrichschronik (1883) die entsprechenden Passagen tilgt oder schönt (für den Zusammenhang und die Belege im Einzelnen vgl. Cīrulis 2007). 
Die Nobilitierung des eigenen Volkes und des eigenen Epos geht wie jedwede Privilegierung notwendig zu Lasten anderer. Bei Pumpurs ereilt die für die Letten mustersetzenden Finnen und Esten eben das Geschick, das sein Lehrmeister Wilhelm Jordan über die von den Deutschen lange kräftig nachgeahmten und nun rüde verpönten Vorbildkulturen der Romanen verhängt hatte: „Italienern, Spaniern, Franzosen z.B. wird, wie bisher, das wahre Epos immerdar versagt bleiben“ (Jordan 1876: 27). Dieser Befund gilt jedoch keineswegs für Andrejs Pumpurs und seinen „Lāčplēsis“ oder für den Wilhelm Jordan der „Epischen Briefe“ und der „Nibelunge“ allein. Ganz im Gegenteil haben wir hier gewöhnliche Fälle einer vielleicht universellen Praxis vor uns. Denn das Epos ist in der Tat, in den auf arabische epische Erzählungen gemünzten Worten Bridget Connellys, ,a saga of identity and, as such, a saga of alterity" (Connelly 1986: 225). Auch bei den im lettischen Nationalepos so ungut bedienten Esten findet sich die nämliche Praxis. Auch hier erscheint sie in einem ambivalenten Nahverhältnis, in diesem Falle im Verhältnis zu den nächsten „Stammverwandten“, zu dem „finnougrischen Brudervolk“ der Finnen. Dessen „Kalevala“ verdankt der „Kalevipoeg“ Entscheidendes: „The Kalevala was the chief stimulus behind the birth oft the Kalevipoeg." (Laugaste 1990: 275f.; grundlegend auch hierzu Annist 2005) Für seine „Esthnischen Sagen“, seine „Sagen“ und den Aufsatz „Über den heidnischen Glauben der alten Esten“, die später einen der Grundsteine für Kreutzwalds „Kalevipoeg“ abgeben sollten, hatte Friedrich Robert Faehlmann zunächst Lönnrots „Altes Kalevala“ nach Kräften ausgeschrieben, um die solcherart von ihm selbst verfertigten Texte dann nicht allein „als Beweis für die hohe Kulturstufe der Esten“ anzuführen, sondern auch als schlagenden Beleg dafür, dass „die Esten den Finnen viel in der Kultur voraushaben“ (zit. n. Jansen 2000: 40; vgl. Hasselblatt 2006: 213f.) Der von Faehlmann ausgeschriebene Elias Lönnrot wiederum

was at least partly prompted by a desire to find a Finnish equivalent to the Scandinavian heritage of sagas and epic poetry from mediaeval Iceland. [...] In his dissertation he had [...] defended the theory that Väinämöinen belonged to the race of trolls and giants mentioned in the Icelandic texts, once the aborigines of the North but driven away by Odin and his followers. [...] If he really seriously believed in this theory, it must have been tempting for him to let the Finnish giants take their revenge on the Scandinavian 
gods by creating a new Edda, a sort of Anti-Edda, seen from a Finnish perspective. (Lönnroth 1990: 73, 88)

Den nordosteuropäischen Nationalepikern vorangegangen war auch in diesem Punkt der wahre Ältervater der europäischen nationalepischen Bewegung, James Macpherson, der für seine „ossianischen“ Epen auch die irische Überlieferung ausschlachtete, um dann unter Berufung auf die so verfertigten Texte eine historische und kulturelle Überlegenheit der Schotten über die Iren zu behaupten (vgl. Thomson 1952; Mac Craith 2004). Was bei den so Behandelten zu geharnischten Reaktionen führte, wie Macphersons skeptischer Unterstützer David Hume im Gespräch mit Edmund Burke erfahren musste: „I was told by Burke, a very ingenious Irish gentleman, the author of a tract on the Sublime and Beautiful, that on the first publication of Macpherson's book, all the Irish cried out, we know all these poems, we have always heard them from our infancy" (Brief an Hugh Blair vom 19.09.1763; Hume 1932: 400, Nr. 215). Das Nationalepos und seine Ausdeutung gehören zu den Orten, an denen Kulturkonkurrenzen und Kulturkonflikte mit besonderer Vorliebe und Vehemenz modelliert und ausgetragen werden. Nicht anders geschah es mit der Auslegung des Nibelungenepos durch eine sich als vaterländische Philologie verstehende Germanistik, die sich nach der Reichseinigung weiter und weiter ins Xenophobe verschob: „Was zunächst so etwas wie eine Kompensation für das Fehlen nationalstaatlicher Einheit gewesen sein mag, verstärkte sich jetzt als Ausdruck des neugewonnenen Selbstbewußtseins.“ (von See 1994: 107) Wobei sich fragen ließe, welche Verstärkung Äußerungen nötig hätten wie die folgende von Gervinus aus dem Jahre 1835, die gelegentlich der „Nibelungen“ und der „Gudrun“ „nationale Identität“ und „Alterität“ im Medium der Literaturgeschichte teilt wie Licht und Schatten:

Beide Gedichte dürfen für die Nation ein ewiger Ruhm heißen. [...] Wenn wir diese Dichtungen voll gesunder Kraft, voll biederer wenn auch rauher Sinnesart, voll derber aber auch reiner Sitte betrachten neben dem schamlosen, eklen und windigen Inhalt der britischen und neben den schalen, läppischen und zuchtlosen Stoffen der französischen Romane [der jeweiligen mittelalterlichen höfischen Literatur, Th. T.], ja neben dem bigotten fränkischen Volksepos, so werden wir ganz andere Stimmen für die angestammte Vortrefflichkeit unseres Volkes reden hören als die dürren Aussagen der Chronisten, und im Keime werden wir bei unsern Vätern schon die Ehrbarkeit, die Besonnenheit, die Innigkeit, und alle 
ehrenden Eigenschaften finden, die uns noch heute im Kreise der europäischen Völker auszeichnen. Diese herrlichen Stoffe uralter Dichtung lassen, wenn sie auch nicht geistige Routine zur Schau tragen, wie das die fremden Poesien jener Zeit besser können, auf eine Fülle des Gemüthes und auf eine gesunde Beurtheilung aller menschlichen und göttlichen Dinge schließen, die seitdem ein Erbtheil der Nation geblieben sind, das mit jedem neuen Umsatz wuchernd zu einem weiteren Vermögen heranwächst. (Gervinus 1835: 283)

Diese agonal angelegten Inszenierungen deutscher Identität, vor denen Jahrhunderte und Jahrtausende wie nichts sind, treibt Jacob Grimm in seiner Rezension des Buches auf die Spitze (vgl. Jacob Grimm 1835b). Dies führt auf eine andere, eine seinem Referenzsubjekt entschiedener zugewandte Dimension des Nationalepos. Das Nationalepos spielt eine Rolle nicht allein bei der Begegnung unter Nationen. Es leistet auch vortreffliche Dienste als Ort der (vermeintlichen) Begegnung eines Volkes mit sich selbst. Diesen Effekt könnte man den Spiegeleffekt nennen: Das Epos stellt nicht allein dar, dass wir sind, sondern auch, wer wir uns sind. Im Nationalepos soll ein Volk sein eigenes Bild erkennen können. Das Epos soll der Ort sein, da es seiner (vermeintlichen) Essenz - seines „Nationalcharakters“ - ansichtig werden könne: „Die Welt eines Volkes wird im Epos dargestellt. So ist das Epos das Buch, die Bibel eines Volkes. Eine ganze Anzahl von Völkern hat solche Bibeln, worin: was ihr Geist ist, wie eine bestimmte Stufe der Bildung ausgesprochen ist.“ (Zit. n. Christians 2004: 72) So Hegel vom Katheder der Berliner Universität. Nicht anders meinte es Wilhelm Grimm in seiner Vorlesung über die „Gudrun“: „Das Gedicht von Gudrun ist unmittelbar aus dem Wesen eines ganzen deutschen Volkes hervorgegangen, dessen lebensvolles Bild es uns in reinem Spiegel zeigt." (Wilhelm Grimm 1843/49: 526) „Bibel“ und „Wesensspiegel“ eines Volkes: Damit sind Epen festgelegt als „monumenta nationum“, wie es in Hegels „Vorlesungen zur Ästhetik“ heißt (zit. n. Clairmont 1994: 242). Sie werden bestimmt als Denkmäler, die für ihr Referenzsubjekt von definierender Kraft seien. Diese ihnen zugeschriebene Potenz erhebt sie zu formativen Texten: „Insofern sind diese Denkmäler nichts Geringeres als die eigentliche Grundlage für das Bewußtsein eines Volkes“ (Hegel 1823-1829/1835: 331). Ihre Prägekraft als „nationale Grundbücher“ (ebd., 286) entfalten Epen freilich nur für die jeweilige Gemeinde: für die besondere Nation also, die sich 
in ihnen als in ihrem Epos gemeint erkennen will. Zugrunde liegt diesem identitätsstiftenden Effekt die Vorstellung von der Nation als textzentrierter Gemeinschaft - in genauer Analogie zu den Buchreligionen, denen die Nationalbewegungen ja in der Tat entscheidende Impulse verdanken und die sie in mehr als einer Hinsicht auch beerbt haben. Ein schönes Beispiel für die geradezu osmotischen Übergänge zwischen Religiosität und Nationalität liefert Adam Mickiewicz, der Verfasser des polnischen Nationalepos „Pan Tadeusz“: „Die Institution der Nation ist nichts anderes als die Gesamtheit der dem Menschen gegebenen Hilfe, die Wahrheit zur Anwendung zu bringen, die er zuvor im Gotteshaus empfing." (Zit. n. Zadencka 2000: 112) Ein weniger schönes findet sich unter den volkstümlich verballhornten Worten des unseligen Arndt: „Ein einiges Volk zu sein, sei die Religion unserer Zeit, die höchste Religion sei das Vaterland lieber zu haben als Herren, Weiber und Kinder“ (1809 im 2. Tl. von „Geist der Zeit“, zit. n. Freytag 1875: 543; für den tatsächlichen Text vgl. Arndt 1809: 85). Eine dritte Variante steht zu lesen auf dem Epitaph des provenzalischen Nationalepikers Frédéric Mistral in Maillane: „Non nobis, Domine, / non nobis, sed nomini tuo / et Provinciae nostrae da gloriam.“ (Zit. n. von Jan 1959: 43) Wie der Nationalismus als säkularisierte Religion, so ließen sich Nationaldichtungen ohne Forcierung als quasi-religiöse Texte bestimmen. Nichts anderes tut Wilhelm Grimm, wenn er den ungläubig staunenden Brentano brieflich bescheidet über den Unterschied zwischen „niemals absolut vollkommen[er]“ „moderne[r] Kunst“ einerseits und als „Volksdichtung“ oder „Naturpoesie“ auftretender Nationaldichtung andererseits: „Nur die Nationaldichtung ist vollkommen, weil sie ebenso wohl, wie die Gesetze auf dem Sinai, von Gott selber geschrieben ist, sie hat keine Stücke, wie ein Menschenwerk." (Brief vom 15.12.1810, zit. n. Steig 1914: 143) An den Geist, der sich in so verstandener Nationaldichtung rein und ganz aussprechen soll, wird die nationale Gemeinschaft zurückgebunden in immer aufs neue wiederholten Akten der Lektüre und der Auslegung, durch die intime Teilhabe des Einzelnen an einer auf das Äußerste emotionalisierten und zugleich in zeremonielle Formen gebundenen Kommunikation, in deren beständigem Vollzug die moderne Nation sich bildet und erhält, wenn wir der konstruktivistisch inspirierten Nationalismustheorie Glauben schenken wollen (vgl. Anderson 1998 und 
Smith 1996; abwägend Hroch 2005). Dass eine so verstandene Nation als kommunikativ gestiftete und kommunikativ auch $\mathrm{zu}$ erhaltende Einheit zu fassen wäre - und nicht etwa als primordiale Gegebenheit aus „Blut“ oder „Geschichte“ - erhellt von selbst. Wäre dem anders, die Nation wäre des Buches nicht bedürftig. Vielleicht muss man die Nation nicht zwingend als Gemeinschaft von säkularisierten Gläubigen verstehen. Ganz gewiss aber muss man sie verstehen als imaginierte Gemeinschaft von Mit-Lesern, wie sie sich vorgebildet findet im Judentum und im Protestantismus mit ihren Lektüregeboten:

Menschen, die die verschiedensten Idiome gebrauchten und davor nur schwer oder gar nicht miteinander reden konnten, vermochten sich nun mit Hilfe von Buchdruck und Papier zu verständigen. In diesem Prozeß wurden sie allmählich der Hunderttausende, ja Millionen Menschen in ihrem eigenen Sprachbereich gewahr - und gleichzeitig der Tatsache, daß ausschließlich jene Hunderttausende oder Millionen dazu gehörten. Diese Mit-Leser, mit denen sie über den Buchdruck verbunden waren, bildeten in ihrer besonderen, diesseitigen und „ersichtlichen“ Unsichtbarkeit den Begriff der national geteilten Gemeinschaft. (Anderson 1998: 45)

Gewiß ist die Etablierung der Nation als textbedürftiger Vorgang zu denken, als textgestützt und textgeschützt, und möglicherweise ist die Nation - um diesen Punkt tobt ein Schulstreit - tatsächlich textgeboren. Eine empirische Stütze fände diese These an dem Projekt zu einer lettischen Nation, das Anfang des 19. Jahrhunderts aus bestimmten Formen des Textumgangs erwachsen ist, die sich bis in Einzelheiten hinein nachzeichnen lassen (vgl. Boguna/Cīrulis/Rutka/Taterka 2011). Gerade im Hinblick auf die komplexen Lagen in Mittel- und Osteuropa - die in Rücksicht auf den Kontinent insgesamt ungleich gewöhnlicher sind, als es die unausrottbare Fixierung auf die happy few glauben macht, auf die staatsgezeugten und scheinbar selbstverständlichen Nationen wie die französische oder die englische - tut auch der Historiker gewiss nichts Falsches, wenn er Winke ernsthaft bedenkt wie jenen von Czesław Miłosz zu den „,aus der Literatur geborenen Nationen“ des Ostseeraums (zit. n. Varpio/Zadencka 2000: 2). Mit Blick auf Gründerfiguren wie Gervinus oder De Sanctis mag auch der Germanist oder der Romanist den Gedanken zulassen, dass die Literatur als geistiger Raum der Nation, mit Hofmannsthal zu sprechen, vor der Errichtung von Nationalstaaten die Nation als politisches Gebilde eben nicht allein vertreten 
musste, sondern sie in gewissen Grenzen auch tatsächlich vertreten konnte.

Doch zurück zum Epos. Wir sehen ihm bei Hegel und Goethe sein Daseinsrecht in der modernen Welt nicht bestritten, es vielmehr aus deren Bedingungen kräftig neu legitimiert. Freilich wird die Berechtigung des Epos nicht unter ästhetischen Gesichtspunkten zugestanden. Hier wie dort erscheint das Epos als funktional gebundene Textform, die von einem sich als Nation verstehenden Kollektiv und dessen Geschicken nicht abzulösen ist. Es wird verstanden als Spielform einer „poetry of community" (vgl. Beissinger/Tylus/Wofford 1999). Deren Referenzgemeinschaft ist unter den Augen der Zeitgenossen der Großen Revolution und der napoleonischen Kriege eine andere geworden. Es ist nicht mehr die elitäre Kriegerkaste der Aristokratie, deren Identität als aus dem Gesellschaftsganzen herausgehobener Herrenschicht das Epos bestimmt und bebildert und pflegt und schützt. Der Adel hat im Ergebnis von Aufklärung und Revolution nicht allein an Macht eingebüßt. Er hat auch verloren an Legitimität und Status, an kulturellem Kapital. Dieses ging über an die Nation. Die Nation beerbt den Adel auch darin, dass sie dessen archaische Standeskultur, das Heldenepos voran, für ihre sehr gegenwärtigen Zwecke in Dienst nimmt und so am Leben erhält (dies gegen Köhler 1982: 17). In besonderer Weise greifbar wird diese doppelte translatio bei den Polen. Hier war „Nation“ ursprünglich eine Standesbezeichnung für die exklusive Gemeinschaft des reichstagsfähigen Adels. In einem Atem mit der Ausweitung des Begriffs öffnet sich nun auch die vormalige Standesliteratur für das nunmehr als Nation begriffene Gesamtvolk, bis hin an dessen Ränder: „Beide Werke [„Maria“ von Malczewski und „Das Schloss von Kaniow“ von Goszyński, Th. T.] [...] reproduzierten wie viele andere Epen aus der damaligen Zeit die ethnische Idee. [...] Anstelle des Adelsstandes wurden jetzt das Volk oder sogar die ethnischen Minderheiten eingeführt." (Ruszczyńska 2000: 96f.)

Diese demotisierende Öffnung der Gattung ist bei Herder geistig vorweggenommen. In seiner Umdeutung der Welt als eines geschichtlichen Raumes, in dem wir nicht die Potentaten und die von ihnen beherrschten Staaten und Reiche handeln sehen, sondern die Völker, räumt er dem Epos eine Schlüsselposition ein: 
Das Feld der Epoee, wenn es dieses Namens werth seyn soll, fodert gleichsam die Mitwirkung der ganzen Natur, die ganze Ansicht der Welt zwischen Himmel und Erde [...]. Im Herzen und Geist der Nation soll es ein Schauplatz des Weltalls, ein lebendiges Wort für Alle, in Allem werden: so ward es Homer, weil sein Gesang von Allem, was im Gesichtskreise seiner Nation lag, gleichsam die Krone erfaßte. (Herder 1803: 281)

Das Epos soll der Nation alles umfassen, oder doch von allem das Höchste. Solch ein Richtpunkt auf „alles“ hat einen Namen: Totalität. Die der Gattung angesonnene totalisierende Funktion ließe sich in die Mundarten verschiedener Wissenschaften verschieden übersetzen. Im Dialekt der zeitgenössischen Geschichtswissenschaft könnte dies so klingen: Das Epos besorgt das Stiften eines Meta-Narrativs, einer Über-Erzählung nationaler Identität: „ein lebendiges Wort für Alles, in Allem“. Damit wird dem Epos im kulturellen Haushalt der Nation eine elementare Funktionsstelle eröffnet: jene, in der die Totalität der Nation symbolisch gefasst und ihr selbst sichtbar gemacht werden kann. In der Eigensprache einer von Niklas Luhmann inspirierten Literaturwissenschaft: „Anstatt eine periodisch begehbare Sonderrealität zu schaffen, konzentriert sich das Epos-Programm darauf, die unkommunizierbaren Gesamtgesellschaften als ,Gemeinschaft' aus dem heterogenen Bereich des Literatursystems heraus zu stimulieren." (Christians 2004: 82) Nennen wir die hier abgesteckte Funktionsstelle der Eingängigkeit halber die Eposstelle. Für alles, in allem, von allem die Krone: Das beschreibt auch im Verein noch nicht unbedingt einen sakralen Text. Ganz gewiss jedoch beschreibt es einen absoluten Text. Solch einen absoluten Text zu schaffen: Dies ist der Anspruch, unter dem die neoepischen Unternehmungen antreten. Als absoluten Text hatte Mistral seine 1904 mit einem (geteilten) Nobelpreis gekrönte „Mirèio“ entworfen, als „a Provençal encyclopedia, a Provençal Bible, the universal Provençal text“ (Schenda 1990: 366). Als absoluter Text ist sie aufgenommen worden: „Un pays est devenue un livre.“ (Lamartine, Zit. n. von Jan 1959: 90, Anm. 1) Dem Enthusiasten der Nation kann ein derart bedeuteter Text dann durchaus eine ganze Welt vertreten: „Die in einer Studentenschaft wirkenden Studierenden J. A. von Essen und J. A. Wegelius wollten 1839 die akademische Ausbildung in Finnland auf dem Epos gegründet sehen." (Niedling 2007: 68) Das Nationalepos ist ein Text allerhöchster Bedeutsamkeit. Dieser Grad an Bedeutsamkeit muss im Jahrhundert des Historismus genetisch und temporal ko- 
diert werden, übersetzt also in „anfänglich“ und „uralt“. Der absolute Text muss als Anfangstext gedacht werden, als Gruppenidentität begründender Urtext (vgl. Undusk 2000: 8; Christians 2004: 12).

Gruppenidentität wiederum wird im 19. Jahrhundert regelmäßig aus einem genetisch-organologischen Argument hergeleitet. Sie soll sich aus Herkunft und Geschichte zwingend ergeben, anders aber auch nicht zu haben sein:

Mindestens seit der ersten Hälfte des 19. Jahrhunderts bestand unter den Eliten und den Gebildeten allgemeiner Konsens darüber, dass alle existierenden Subjekte, Institutionen und sogar Visionen, die allgemeine Anerkennung beanspruchten, ihr Existenzrecht mit Hilfe der Geschichte formulieren und begründen müssten. Diese Verabsolutierung der aus der Vergangenheit überlieferten „Rechte“ war nichts Neues, sondern ein modifiziertes Erbe der alten Feudalgesellschaft und ihrer Normen. (Hroch 2005: 150)

Geschichte-Haben ist eines der wichtigsten Beweismittel, die zugelassen sind im Streit der Nationen um a) die Berechtigung ihrer Existenz und b) ihre Rangordnung untereinander. Dieses Beweismittel ist obligatorisch. Es muss vorgewiesen werden können. Gerade für die vielen Nationen, die man die nicht-selbstverständlichen nennen könnte - nichtdominante ethnische Gruppen ohne kontinuierliche Tradition eigener Staatlichkeit und mit einer „leeren Geschichte“ (Anthony D. Smith), wie sie sich in Europa konzentrieren in den kolonial verfassten Vielvölkerreichen der Habsburger, der Romanows, der Hohen Pforte der Ottomanen und, nicht zu vergessen, auf den Britischen Inseln mit dem keltischen Gürtel -, gerade für nicht-selbstverständliche Nationen hat sein Fehlen im 19. Jahrhundert fatale Folgen. Günstigstenfalls führt dieser Ausfall zu Rangminderung. Schlimmstenfalls werden der Nation Dasein und Daseinsrecht überhaupt bestritten. In beiden Fällen sitzt sie am Katzentisch, unter den prekären Nationen: den „geschichtslosen“. Geschichtslos aber, das ist im Europa des 19. Jahrhunderts keine Feststellung. Es ist ein Urteil, ein Richtspruch: die Verurteilung zum Leben mit dem Trauma, mit dem Trauma der Inferiorität.

Das aus „Geschichtslosigkeit“ rührende Trauma kann freilich geheilt werden nach eben der Logik, die es zufügt. Nach der Logik der Romantik also. Das Epos, und nur das Epos, hat diese sanierende Macht. Seine erlösende Kraft wird verfügt in durch ganz Europa hin mächtig 
nachhallenden Schlüsselsätzen eines späteren Hohepriesters der romantischen Bewegung und des Ältervaters aller Nationalphilologien, Jacob Grimm. Dieser verfügt im Duktus des Gesetzgebers: „ich behaupte folgende sätze und ihre identität: die älteste geschichte jedweden volks ist volkssage. jede volkssage ist episch. das epos ist alte geschichte. alte geschichte und alte poesie fallen nothwendig zusammen." (Jacob Grimm 1807b: 10, Anm. 4) Das Epos also ist alte Geschichte, und wo ein Epos ist, dort muss alte Geschichte gewesen sein: Mit diesem Syllogismus wird das Vorhandensein eines Epos zum Beweisstück für die historische Existenz eines Volkes erhoben. Historische Existenz aber bedeutet im Zeitalter von Romantik und Historismus nicht allein die Ausstattung mit besonderer Würde. Historische Existenz bedeutet Daseinsberechtigung überhaupt. Diese Verschränkung ist so wichtig, dass sich zu Grimms Diktum in den nationalen Epos-Diskursen quer über den Kontinent zuverlässig ein adaptierendes Gegenstück findet. In jede besondere Umgebung muss es eigens übersetzt werden. Auf den lettischen Fall bezogen klingt diese Übersetzung im Jahre 1877, sieben Jahrzehnte nach Grimms Diktum und ein Jahrzehnt vor Erscheinen des „Lāčplēsis“, bei dem deutschbaltischen Geistlichen und Sprachforscher Karl Ulmann so:

So bildet sich auch der Charakter eines Volkes in seiner Geschichte und darum kann von den epischen Liedern eines Volkes allerdings gesagt werden, daß sie den Charakter desselben am treusten und unmittelbarsten widerspiegeln. - Ein Volk aber, das keine epischen Volkslieder hat? Warum hat es keine? Einfach, weil es bis jetzt noch keine Geschichte des Singens und Sagens werth, weil es nur ein Leben mit der Natur, aber kein irgendwie gleichberechtigtes Leben im Zusammenstoß mit andren Völkern gehabt hat. (Ulmann 1877: 713)

Ulmann demonstriert hier eine der Möglichkeiten der Auslegung des „Grimmschen Gesetzes“ der Äquivalenz von Epos und Geschichte. Es kann zur Deutung eines Mangels herangezogen werden, rückwärtsgewandt also und erklärend: Die Letten haben keine epischen Lieder, weil ... . Das gleiche Gesetz lässt sich aber auch in die Gegenrichtung auslegen, als Stimulans für auf die Herstellung von Zukunft gerichtetes Handeln. Geschichte kann im Text des Epos nicht nur abgebildet, sie kann dort auch nachgeholt werden. Das Grimmsche Gesetz der gemeinsamen Wurzel von alter Geschichte und Epos eröffnet „ge- 
schichtslosen“ Nationen die Möglichkeit, den Raum der Geschichte durch eine Seitentür zu betreten: durch „alte Poesie“. Wem keine des Singens und Sagens werte Geschichte zuteilwurde, der kann sich diese Geschichte nun im Nachhinein verschaffen: Er kann sie sich im Epos erschreiben. Epos und Geschichte können füreinander eintreten. Sie können dies in solchem Grade, dass sie leicht miteinander verwechselt werden können. So geschah es Elias Lönnrot, dem die eigene Schöpfung, sein „Kalevala“, unversehens als finnische Urgeschichte entgegentrat:

Lönnrot went so far that the ancient Kalevala era appeared to him as one stage in history of which the Kalevala was evidence. This perhaps explains the astonishing fact that Lönnrot from time to time speaks of the Kalevala as a source of academic scholarship providing an insight into the social life of the past. He clearly played down his own contribution and played up the historical and ethnographic source value of the Kalevala more than was justified. (Honko 1990c: 560)

Die von Jacob Grimm gewiesene Möglichkeit, über das Epos zu alter Geschichte zu gelangen, wird quer durch Europa ein kräftiges Inzentiv für die nationalepischen Bewegungen. Die jeweiligen ethnopatriotischen Aktivisten, eine eingeschworene „priesthood of nationalism“ (Pearson 1999: 66), bilden ein in aller Regel anfangs sehr überschaubares Grüppchen von Schriftstellern und Publizisten und Gelehrten und Geistlichen und Ärzten: Von Studierten also, die als „Männer des Wortes" an dessen Macht glauben oder doch glauben wollen. Die Verheißung von „alter Geschichte“ im Medium des epischen Wortes wirkt ungleich kräftiger auf die nationalepischen Prozesse als jeder eigentlich literarische Impuls. Durch die von Jacob Grimm dekretierte solidarische Bindung an Geschichte wird das Nationalepos vollends zu wichtig, um es dem Selbstlauf und den Unwägbarkeiten des literarischen Betriebes zu überlassen: „The creation of a national epic is not a poetic but a political act." (Honko 1996: 29) Das Nationalepos ist so wenig ästhetisches Spielwerk, wie es Selbstzweck wäre. Es ist ein Vehikel, zum Höchsten zu gelangen - zur Geschichte, wo diese fehlt, zur richtigen, wo man die falsche hat. Sehr zugespitzt: Das Nationalepos ist eine der wenigen Währungen, in denen Geschichte erworben werden kann. Epenbesitz wird damit zumal unter den nicht staatenbildenden, den "geschichtslosen“ und zu Zeiten des Historismus damit auch gesichtslo- 
sen Völkern tatsächlich zu der Geltungsfrage, von der Goethe noch in halb prophetischem Gestus sprach. Entsprechend wird das Nationalepos im 19. Jahrhundert überall behandelt: nicht als literarische, sondern als Existenzfrage. Dies gilt für die wenigen staatlich gesicherten Nationen wie für die immerhin historisch und kulturell befestigten um keinen Deut weniger, als für die vielen Nationen in posse oder in statu nascendi: „[I]t seemed as if no self-respecting or aspirant nation could be complete without its own national epic“ (Dentith 2006: 66). Diese Überzeugung von der Notwendigkeit des Nationalepos ist Grimmsches Erbteil:

Der theoretische Gehalt von Jacob Grimms Eposinterpretation ist die Auffassung, daß die großen Epen als Nationalgedichte die poetische Identität zwischen dem idealen und realen Dasein eines Volkes bilden: sie sind notwendige Glieder im Ganzen eines Volkes. (Jendreiek 1975: 165)

Bei Nationalepos und nationalepischem Diskurs geht es nicht um Literatur, und selbst um Geschichte, wie der Historiker sie verstehen würde, geht es nur scheinbar. Beides sind nur Mittel zum Zweck auf dem Weg zum eigentlichen Ziel. Dieses Ziel hat zwei Dimensionen. Sie heißen Legitimität und Identität. Zu ihrer Herstellung gelten „Epos“ und „Geschichte“ - die der livländische Aufklärer Jochmann als Vertreter zweier einander ablösender kultureller Formationen sehen wollte - nach dem Grimmschen Gesetz als Äquivalente. Dieser außerordentliche Status wird unterstützt durch einen altüberkommenen „Wahrheitsanspruch der Gattung“ (Schöning 1983: 89). Das Epos - und unter allen Formen kultureller Manifestation das Epos allein mit seinem vorab zu kreditierenden „respect for truth“ (Skafte Jensen 1990: 34) - ist bei Jacob Grimm der Geschichte ebenbürtig: „Das Epos ist die Bestimmung der Geschichte - in der doppelten Bedeutung des Begriffs: es wirkt auf sie ein und hat sie in sich." (Ehrismann 1991: 17*). Das Epos kann Geschichte beglaubigen, es kann sie vertreten, und es soll sie, so hoffen die nationalepischen Aktivisten, einmal neu und anders heraufführen können.

Diese Annahme wird quer über den Kontinent geteilt. Beispielhaft beredten Ausdruck findet sie in der estnischen Spielform der nationalepischen Bewegung. Man öffne die Programmrede, die der bekennende Revaler Estophile Georg Schultz („Dr. Bertram“) im Jahre 1839 in Dorpat/Tartu vor der Gelehrten Estnischen Gesellschaft hielt, die sich 
im Jahr zuvor nach dem Vorbild der Finnischen Literaturgesellschaft begründet hatte, wie diese die Verfertigung eines Nationalepos zu ihren vornehmsten Aufgaben zählte und in den 1840er Jahren in nicht weniger als zehn Sitzungen das „Kalelava“ behandelte (vgl. Laugaste 1990: 269):

Denken Sie sich, welch erhebenden Einfluß auf ein niedergetretenes Volk das erwachte Bewußtsein geschichtlicher Existenz und Größe haben muß! Ginge es ihm nicht wie jenem Bettler, dem man plötzlich sagt: Du bist ein Königssohn! - Denn beweist wohl irgend etwas unwidersprechlicher die geschichtliche Bedeutung eines Volkes als der Besitz einer Epopöe. Uns aber, als den Beförderern der geistigen Wiedergeburt dieses Volkes, uns, den Philestonen, gebührt es, diesen Torso, der verstümmelt und mit späteren Zusätzen verunstaltet in den entlegendsten Winkeln der Provinz seiner Anerkennung entgegenharrt - diesen in abgelegenen Thälern und tiefen Wäldern verhallenden Gesang - auf eine seiner würdige Art in die Reihen der glänzendsten Erzeugnisse des menschlichen Geistes einzuführen. Dadurch könnte es vielleicht gelingen, das Volk zum Bewußtsein zu bringen, ihm Selbstgefühl einzuflößen und indem man ihm die Erbschaft einer großen Vergangenheit übergiebt, es von der erbärmlichen Tendenz zurückzubringen, in ein copirtes Zwittergeschlecht auszuarten. Hierdurch würde die Hauptaufgabe des Vereins gelöst werden, denn ich glaube, meine Herren, daß Sie dieses bezwecken. Oder was ist unsere Absicht, unsere Tendenz? Glauben wir an eine Zukunft des Volkes oder nicht? Ist es wahrscheinlicher, daß es allmählig in eins von den beiden mächtigen Nachbarvölkern sich verlieren sollte? Aber wozu diente denn das Bestreben, ein Gebäude stützen zu wollen, das den Keim des Verfalls schon in sich trägt? Nein - ich glaube an die originelle Kraft des Volkes. Ich glaube, daß es in der langen Völkerreihe gleichsam ein Element darstellt. [...] Wie soll nun unsere Gesellschaft die Aufklärung und geistige Wiedergeburt eines mündig erklärten, von Leibeigenschaft losgesprochenen und doch unter der Last seiner Unwürdigkeit und Verzagtheit fortseufzenden Volkes am kräftigsten fördern?

Ich glaube durch zwei Dinge. Geben wir dem Volk ein Epos und eine Geschichte, und alles ist gewonnen! $\mathrm{Zu}$ dem zweiten ist Material genug vorhanden, zu dem ersten lassen Sie uns noch sammeln. (Zit. n. Reimann 1900: XIf.)

Schultz-Bertram steht deutlich unter dem Eindruck des Kalevala-Prozesses (vgl. Honko 1986; Honko 1990b), der 1835/36 mit dem Druck des „Alten Kalevala“ durch die Finnische Literaturgesellschaft zu einer 
ersten Kristallisation gefunden hatte. Aber das ist es nicht allein. Nachgerade schulmäßig koordiniert Schultz-Bertrams Rede Epos und Geschichte nach dem Grimmschen Gesetz. Beides sind ihm funktionale Äquivalente bei der Arbeit an dem, woran der „Philestone“ glaubt und worum es ihm in Wahrheit zu tun ist: an der "Zukunft des Volkes“. Geschichte und Zukunft sind in der gleichen Richtung zu suchen. Diese Doppelrichtung des Zeitpfeiles ist erzromantisch: Ursprung ist das Ziel. An der besonderen Form von Nationalgeschichte, die das Epos weniger erzählt als vielmehr verkörpert - man erinnere sich an Hegels Diktum: Epen seien monumenta nationum -, soll Zukunft gewonnen werden. Roman Woerner, ein Aktivist der finnischen Nationalbewegung, bringt dies 1886 mit Rücksicht auf das „Kalevala“ auf den Punkt: „[A]n unseren alten, ureigenen Dichtungen müssen wir uns erheben, sie sind als Zeugnisse einer selbständigen Vergangenheit das werthvollste Unterpfand einer entwicklungsreichen Zukunft“ (zit. n. Voßschmidt 1989: 76).

Vergangenheit aber ist nicht Geschichte. Geschichte ist der Bezug, den eine Gegenwart auf Vergangenheit nimmt. Geschichte ist nicht gewesen, Geschichte entsteht, und sie entsteht einer jeden Gegenwart neu. Eine Funktion der Gegenwart ist es, wie sich Vergangenheit und Geschichte zueinander verhalten. Im Epos, das Geschichte in literarischen Formen beschwört und das als literarisches Denkmal selbst Geschichte ist, wechselt Vergangenheit den Aggregatzustand. Sie gerinnt zu Memoria (vgl. Assmann 2004; Assmann 1996). Was sich im Nationalepos darstellt oder ihm über seine Deutung angeschafft wird, das ist ein Kultus der Erinnerung. Er steht im Modus einer "affective history“ (Dentith 2006: 47). Der an ihm haftende Einsatz ist der allerhöchste: „Erinnerung erlöst die Vergangenheit vom Fluch der Sinnlosigkeit.“ (Assmann 2005: 19f.) Aus einer als sinnvoll erinnerten Vergangenheit soll Zukunft gewonnen werden. Im finnischen Kontext kann dies so klingen, in einer Rede des Direktors der Finnischen Literaturgesellschaft unmittelbar nach Erscheinen des zweiten Teils des „Alten Kalevala“ im Jahre 1836: „Im Besitz dieser epischen Gedichte kann Finnland mutig und selbstbewusst seine Urgeschichte richtig verstehen und dadurch auch seine künftige Geistesentwicklung. Es kann zu sich selbst sagen: ,Auch ich habe eine Geschichte!“” (J. G. Linsén, Zit. n. Niedling 2007: 66) Den Vorgang einer erstrebten Wiedergewinnung 
der eigenen Urgeschichte als eines Goldenen Zeitalters übersetzen viele Nationaldichtungen in ihre Hauptfiguren. Die Verklammerung von Vergangenheit und Zukunft wird personalisiert. Sie wird Wiedergängerfiguren weit hinter den Meeren oder tief im Berg aufgetragen, den Väinämöinen und Ymanta, den Vanemuine und Manas, den Marko und Barbarossa und Arthur, den Lāčplēsis und Holger Danske und Piast und wie sie heißen mögen. Dies alles sind Erlöserfiguren. Die Logik, nach der sie sich bewegen, ist gerade nicht die Logik der Geschichte. Es ist die Logik des Rituals. Die tatsächlich stattgehabte, die wirkliche Geschichte wird suspendiert in der Umarmung von phantomatischer Vorgeschichte und erträumter Zukunft. Deren Vereinigung geschieht über die Geschichte hinweg, von der ein Historiker erzählen könnte. Diese Geschichte muss überwunden werden zugunsten der ursprünglichen kollektiven Identität in ihrer ewig reinen, naturhaften Wesenheit. Sie muss überwunden werden, weil sie die mythischen Räume, in denen diese reine Wesenheit zu herrschen berufen ist, voneinander trennt. Die Geschichte ist ein Fremdkörper in der mythischen Zeit, wie dem frommen Christen die Zeit ein Fremdkörper zwischen den beiden Polen der Ewigkeit ist. Die mythische Zeit ist die Zeit eines durch das Zwischentreten der Geschichte geteilten Paradieses, zu deren Vereinigung jene Wiedergänger berufen sind:

Wie vergangenheit und zukunft, das verlorne paradis und das erwartete, in der vorstellung des volks sich verschmelzen; so glaubt es an ein erwachen seiner geliebten könige und helden aus dem bergschlaf: Fridrichs und Carls, Siegfrieds wohl auch Dietrichs. das ist des epos rechtes zeichen, dass es seinen gestalten ewige, unvergängliche dauer sichert. (Jacob Grimm 1835a: 540)

Was sich in der Rückkehr der nationalen Wiedergänger erfüllt, das ist nicht die Nationalgeschichte. Was sich erfüllt, das ist der nationale Mythos. Die Wiederkehr des Heros hat Heilsbedeutung (vgl. Assmann 1996: 240). Der Nationalheros entrückt die Nationalgeschichte in den Rahmen der Heilsgeschichte. Er soll als ein anderer Messias aus der lichten Vergangenheit der Vorzeit in die trübe Gegenwart zurückkehren und für alle Zukunft Ordnung und Gerechtigkeit in das Chaos der Welt stiften, indem er seine Nation in den gebührenden Rang zurück erhebt. Er gibt die Nation ihrer wahren Bestimmung zurück, indem er ihre falsche Geschichte aufhebt. Umgekehrt kann die Tätigkeit an der 
Heraufführung der Nation gedeutet werden als Zuarbeit zu der im Epos verheißenen Wiederkehr des Heros:

Väinämöinen's parting promise to return once again appeared in the eyes of the Lönnrot working on the abridged edition of the Kalevala on the brink of the 1860s to be coming true: "The national and linguistic events of present-day Finland are carrying out 'Väinämöinen's prophecy" [...]. The poetic message from the past was at one with the nation's living history. (Honko 1990c: 564)

Die Figur der Gewinnung des für die Zukunft erwünschten Status als Wiederherstellung, die Inszenierung der Konstituierung einer Nation als deren Renaissance, wird quer durch Europa nicht von ungefähr bezeichnet als „Wiedergeburt“ oder „Wiedererwachen“ oder „Wiederauferstehung“. Der Grund dafür liegt auf der Hand:

It has always been a central tenet of nationalist faith that no nation can be "new", only "renewed". Typically, all self-respecting nations undergo a three-phase career: an initial cultural flowering or "Golden Age"; a suppression of identity and promise at foreign hands; and an "Awakening" to ultimate fulfillment as a modern nation-state. (Pearson 1999: 69)

Diese Vorstellung findet ein genaues Analogon in der Instruktion für die Gewinnung des Nationalepos. Bereits dem nationalepischen Pionier James Macpherson mag sie vor Augen gestanden haben: „It is perhaps not impossible that Macpherson was, in fact, under the impression that he was collecting the ,disjecta membra" of an old Gaelic epic." (Thomson 1952: 12) Dies hielt ihm die Hochland-Kommission zugute, als sie meinte, sein Ziel sei die Retablierung eines „work of merit to its original purity“ (Mackenzie 1805: 44) gewesen. Aus den kostbaren Relikten der eigenen Vorzeit muss das Epos zurückgewonnen werden. Es muss ins Leben zurückgerufen werden - „wiedergeboren“ - aus den ureigenen Beständen, aus den ureigenen Sagen und den ureigenen Liedern als den im äußersten Fall „einzigen selbsterzeugten redenden Denkmäler[n] dieses Volkes“ (so für die Esten Kreutzwald 1861: III). Damit schlägt die Stunde der Folklore, ganz gleich, ob sie für die Suche nach dem rechten Rohstoff auf die Volkssage verweist (nach dem Grimmschen Gesetz) oder auf das Volkslied (nach der Liedertheorie) oder auch auf beides zugleich. Im Hintergrund der im nationalepischen Diskurs entfalteten „Ökonomie des Eigenen“ (Wyss 1979: 223), die überall alles Fremde fernhalten möchte, „den wahn an entlehnung und über- 
tragung“ (Jacob Grimm 1835a: VIII), steht regelmäßig das Programm einer sezessionistischen Geschichtsschreibung, einer regelrechten counter-history (vgl. Funkenstein 1993: 32-49) aus dem Geist der Folkloristik und einer als Hort des guten Alten gedachten widerständigen Mündlichkeit: „[W]enn die herrschende Klasse die Schrifttechniken in ihrer Hand vereint, wird alles Mündliche virtuell zum Gegenstand von Unterdrückung, und die mündlichen Dichter gelten zu Recht oder zu Unrecht als Sprachrohre der Unterdrückten“ (Zumthor 1990: 195). „Das Volk“, schriftlose Nicht-Gebildete und schriftlose Subalterne rücken auf zu berufenen Bewahrern einer Identität, die als nationale verstanden wird. So sahen es Görres und die Grimm. So sah es auch der „Vater der lettischen Geschichtsschreibung“, Jānis Krodznieks, der Ende des 19. Jahrhunderts die Folklore zum Gegengewicht zu der über sieben Jahrhunderte hin von Deutschen allein bestrittenen Geschichtsschreibung des Baltikums ausrief:

Wir können aber all diesen [deutschen] Schriftstellern nicht vertrauen, die zwar viel geschrieben haben, aber Völker vermischt haben wie Brei mit Kohl; wir müssen auf all die Zeichen alter Zeiten achten, die in der Sprache, in den Sitten, im alltäglichen Leben, in den Liedern, Sagen, im Volksglauben und in den Märchen erhalten geblieben sind. (übers. n. Cīrulis 2007: 44)

In beiden Fällen, für das Nationalepos wie für die Nationalgeschichtsschreibung, wird der programmatisch beschworene Anschluss an eine ureigene Traditionsspur - der oft genug, von den ossianisierenden Gesängen Macphersons über Faehlmanns estnische Sagen bis zu den alttschechischen Handschriften des Václav Hanka auf deren Verfertigung hinausläuft - geleitet von dem Wunsch, hinter einen als auferlegt, als uneigentlich und entfremdet empfundenen Zustand als Kolonialisierter zurückgelangen und zu selbstbestimmten Zuständen in ihrer unvermischt reinen Ursprünglichkeit zurückfinden zu können. Die Aufgabe, die in den formativen Texten der nationalen Bewegungen den Erlöserfiguren auferlegt wird, das Herstellen einer entkolonialisierten Zukunft als Wiedergewinnung eines eigenen Altertums vor der jeweiligen „überfremdenden“ Kolonialisierung, diese Aufgabe befördern in der wirklichen Welt die Aktivisten der nationalepischen Bewegungen. Sie wissen, Schultz-Bertram spricht es deutlich genug aus, ein probates Mittel zur Heraufführung der „Zukunft des Volkes“. Es besteht in ei- 
nem Integral von Epos und Geschichte. Das Herbeiführen beider durch die Aktivisten der Bewegung - in Schultz-Bertrams Worten: „das Geben“ - soll Hand in Hand erfolgen. Die hier ungeschützt ausgesprochene Funktionalisierung des Epos im nationalen Diskurs ist es, der sich die Wiederbelebung des totgesagten Genres im sich rapide nationalisierenden Europa des 19. Jahrhunderts verdankt. Die neuen Epen entstehen als Nationalepen, in Realisierung eines vorgängigen Programms. Regelmäßig ist die Idee zum Nationalepos und ist auch die Debatte darüber lange vor dem besonderen Text da, in dem beides, wenn es gut geht, kanonisierten Niederschlag findet: „Die Entstehung des estnischen Epos wurde gleichsam von außen veranlasst, zunächst war es in Form einer Idee vorhanden." (Veidemann 2004: 264) Beim finnischen Vorbild war es nicht anders: „When it was published in 1835, the Kalevala was the materialization of hopes that had already been held out for several generations." (Alboniemi 1990: 231) Prägnanten Niederschlag hatte diese Hoffnung im Jahre 1817 bei dem Fennomanen Carl Axel Gottlund gefunden:

If someone were to collect the old folksongs and to make of them an organical entity, be it an epic, a drama or whatever, he could make of them a new Homer, Ossian or Nibelungenlied; and Finnish Nationalism would be aroused, conscious of itself, adorned by the splendour and honour of its high nature and the halo of its own development, for the admiration of both the present-day world and posterity. (übers. n. Honko 1990b: 192)

Wie aber materialisiert sich die Idee zu einer Nationaldichtung? Wie baut sie sich ihren Körper, wie wird sie Text? Auf sehr verschiedenen Wegen, die hier nicht dargestellt werden können. Stets aber sind Nationaldichtungen „Auftragsarbeiten der Nation“ (Behschnitt 2001). Die Idee zum Nationalepos einmal gefasst, muss die Nation dieses gleichsam bei sich selbst in Auftrag geben. Dabei bildet sich um das nationalepische Projekt ein System geschlossener Kommunikation aus. Kulturtypologisch wäre das Nationalepos der Ort, da die Nation sich selbst erzählt, indem sie von sich selbst zu sich selbst spricht, um sich selbst in diesem Sprechakt zu konstituieren. Im Vollzug selbstbestätigender Kommunikation soll sich bilden, was seit unvordenklichen Zeiten zu bestehen unterstellt werden musste: die Nation. Die Kommunikationssituation um das Nationalepos, wie der nationalepische Diskurs sie zwingend vorschreibt, ist durch und durch paradox. Ins Extrem getriebene 
Kreiskausalität, mit Luhmann zu sprechen, bildet ihren Grundzug. Das Nationalepos ist gültig - oder, Jacob Grimms Wort zu benutzen: es ist wahr - dann und nur dann, wenn die Nation alle um das Epos zu vergebenden Rollen in einem ausfüllt: Inspirator, Initiator, Auftraggeber, Mäzen, Autor, Kunstrichter, Publikum, Gegenstand. Gelingt es, alles dies wie selbstverständlich ins Gleiche zu bringen, dann kann tatsächlich der Eindruck einer unio mystica der Nation mit sich selbst in ihrem Epos entstehen: „Das Publikum, für das es bestimmt ist (das es sich bestimmt), empfindet es als Autobiographie, als sein eigenes kollektives Leben, das es sich erzählt im Grenzbereich zum Schlaf und zur Neurose." (Zumthor 1990: 98) Eben dies ist der Zustand, den das Nationalepos oder seine Auslegung herzustellen suchen. Es ist der Zustand, in dem es begriffen werden kann als sprachliche Inkarnation seiner Nation (vgl. Harvilahti 1996), als ihre geoffenbarte Manifestierung im Medium des Wortes. Das Nationalepos ist der Ort, wo die Nation in ungekränkter Sichselbstgleichheit bei sich ist. Es ist ein symbolischer Ort vollkommener Identität.

Freilich kann dieser erzromantisch konstruierten Kommunikationssituation in der wirklichen Welt des europäischen 19. Jahrhunderts nirgendwo Genüge getan werden. Es war nicht die finnische Nation, die sich das „Kalevala“ als ihre Autobiographie erzählte, „im Grenzbereich zum Schlaf und zur Neurose“. Es war Elias Lönnrot, „who, in the words of Eino Leino, dreamed up the Kalevala" (Oksala 1990: 68). Diese schizoid anmutende Kommunikationssituation führt zu den veitstanzähnlichen Verrenkungen, die die „tyrannisierende Epostheorie“ (Honko 1985) der deutschen Romantik den nationalepischen Akteuren auferlegt. Sie führt zu der heiligen Scheu der Verfasser „traditionsorientierter Epen“ (Lauri Honko) wie Lönnrot oder Kreutzwald oder Pumpurs, sich auf dem Titelblatt zu ihrer Autorschaft zu bekennen, weil dies mit den romantischen Axiomen von dem „im Volke lebenden Gesammt-Epos“ (Radloff 1885: XII) und von der Nation als „Gesammtsänger“ (Steinthal 1862) ebenso streiten würde wie mit der Auflage zur autopoetischen Produktion des wahren Epos, wie sie ein anderer Artikel des Grimmschen Gesetzes verfügt hatte:

so wie es aber unmöglich ist, die alte sage auf dieselbe art zu behandeln, wie mit der neueren geschichte verfahren werden musz [...], so ungereimt ist es, ein epos erfinden zu wollen, denn jedes epos musz sich selbst dichten, 
von keinem dichter geschrieben werden. beweis sind die menge miszlungener arbeiten in allen nationen. (Jacob Grimm 1807b: 10, Anm. 4)

Grimm macht keinen Hehl daraus, wen er an der Spitze der Bewegung sieht, die notwendig zu „miszlungenen Arbeiten“ führe: „in seiner Aeneis hat Virgil selbst geglaubt ein epos zu liefern, und die ganze zeit hat es den critikern und dichtern für ein solches gegolten. heutzutage wird gleichwohl keiner anstehen, ihm alle wesentlichen grundzüge wahrer epischer poesie abzuerkennen." (Jacob Grimm 1835b: 180) Diese Umwertung der europäischen Kultur von Jahrhunderten richtet sich bei Grimm weniger gegen Vergil selbst. Sie richtet sich gegen die Herrschaft einer vom Volk wie den Völkern getrennten Eigenkultur der Gebildeten, die sich für Grimm in den romanischen Literaturen verkörpert. Deren Erfolg im Norden hält Grimm für nicht weniger verderblich als Herder dies getan hatte. Gegen diese Kultur wird unter Berufung auf Homer das Epos in Stellung gebracht, als Verkörperung einer Volkspoesie, wie sie Jacob Grimm brieflich gegenüber Savigny festlegt: „nicht von eines Menschen Mund ausgegangen“, sondern „Resultat eines ganzen Volkes“ (Grimm/Grimm 1953: 101; Brief v. 20.05.1811). Das „wahre Epos“ ist nach Grimm definiert genau durch den schneidenden Gegensatz, in dem es zur Poesie der Gebildeten steht: „also epos und kunstpoesie stehen einander entgegen, wer diese übt, schätzt jenes gering, das epos hat sich mitten im volk durch langsamen wachsthum gefördert und gezeitigt" (Jacob Grimm 1835b: 181). Für alles, was in dieser Weise entstanden gedacht werden soll - im Volke naturwüchsig von selbst sich dichtend -, prägen die Grimm ein Wort um, das sie bei Herder borgen: Naturpoesie (vgl. Lichtenstein 1928). In diesem Umprägen ,entsteht die Gleichung Volkspoesie = Naturpoesie $=$ Nationalpoesie; die Begriffe werden vielfach promiscue verwendet. Den Begriff der Nationalpoesie rechtfertigt und charakterisiert der Gedanke, daß das Ganze des Volkes an der Naturpoesie beteiligt ist“ (Bausinger 2000: 22). Nationalpoesie muss von selbst entstehen, wie es bei den Grimm wieder und wieder heißt. Sie muss sich, so bestimmt es Jacob, „von selber an und fortgesungen haben“ (Jacob Grimm 1811b: 6), während Wilhelm weiß, dass ein „echtes Volksgedicht von selbst entstanden und überall bekannt ist" und dass „ein Volkslied sich selbst dichtet und anpaßt“ (Wilhelm Grimm 1808: 112, 141, Anm. 2). Wie das vonstatten gegangen sein soll allerdings, 
und was der kritische Philologe nun zu denken habe bei „Grimms freilich sehr wunderliche[m] Ausdrucke“ (Lachmann 1816: 87) - das wissen die Grimm nicht bündig zu erklären, auch in dem sich über viele Jahre erstreckenden Briefwechsel mit dem Freund Lachmann nicht (vgl. Grimm/Grimm/ Lachmann 1927). Das Sich-selbst-Dichten muss aber auch nicht erklärt werden, ja es darf nicht erklärt werden: „Über der Art, wie das zugegangen, liegt der Schleier eines Geheimnisses gedeckt, an das man Glauben haben soll." (Jacob Grimm 1811b: 6) In anderen Worten: Das Axiom von der autopoietischen Erzeugung der Nationalpoesie ist ein Glaubensartikel. Das Epos untersteht ihm in besonderer Weise. Sich dichten muss das Epos, nicht etwa geschrieben werden, und auch gedichtet werden kann es nicht. Mit Hegel gesprochen: „Es singt sich selbst“, es „tritt [...] selbständig, ohne einen Autor an der Spitze zu haben, auf" (zit. n. Clairmont 1994: 244; Hegel 1823-1829/1835: 336). Die harte Verpflichtung des Epos auf das „Sichvonselbstmachen“ (ebd., 118), auf kollektiv-organisches Werden, macht deutlich, in welchem Horizonte sich die Grimm die Geschichte der wahren Nationalliteratur denken: unter dem Bild einer Naturgeschichte der Literatur. Diese Leitvorstellung erzwingt im Gegenzug die aufs äußerste gesteigerte Zurücknahme der vortragenden individuellen Stimme mit ihrer an die Wunde der Kulturspaltung erinnernden Subjektivität: „Das Epos [...] läßt dem vortragenden Rhapsoden nichts übrig, als mit seiner individuellen Subjektivität ganz gegen die Taten und Begebenheiten, von denen er Bericht erstattet, zurückzutreten. Je weniger er sich vordrängt, desto besser; ja, er kann ohne Schaden eintönig und seelenlos sein“, so Hegel (Hegel 1823-1829/1835: 219). Im gleichen Sinne der junge Jacob Grimm zu den Nibelungen: „Demnach wäre der verfasser des N. 1. unbekannt, wie es gewöhnlich bei allen national-gedichten ist und sein musz, weil sie dem ganzen volke angehören, und alles subjective zurücksteht." (Jacob Grimm 1807a: 4)

Diese Auflagen verfehlen ihre Wirkung nicht. „Ohne Schaden eintönig und seelenlos“, „zurücktreten alles Subjektiven“: Eben dies ist es, was Julius Krohn, der an Hegel und Grimm und Heyman Steinthal geschulte finnische Begründer der evolutionären Epostheorie, an Elias Lönnrot loben kann. Lönnrot sei vor anderen zum Rhapsoden des finnischen Volkes begabt gewesen gerade durch einen erfreulich deutli- 
chen Mangel an jedweder dichterischen Kreativität, der seiner Subjektivität Zügel angelegt habe:

Ein Glück können wir es auch nennen, dass Lönnrot selbst nicht die geringste praktische poetische Begabung hatte. Die wenigen Gedichte, welche er geschrieben hat, sind ganz erbärmlich. Dadurch wurde ein gar zu grosser persönlicher Einfluss auf die Ausbildung des Kalevala-Epos verhindert. (Krohn 1888: 67f.)

In der auf „starke Autorschaft“ eingeschworenen literarischen Welt des europäischen 19. Jahrhunderts sind dies harte Auflagen. Ihnen antwortet das Bestreben der nationalepischen Dichter, sich entweder gänzlich unsichtbar zu machen oder sich als bloßes Medium auszugeben - als „Mund des Volkes“, wie die immer wieder angezogene Wendung lautet. Bei Joseph Görres etwa ist der Mund des Volkes der Ort, an dem James Macpherson die Ossianschen Gesänge antraf: „[N]ur der Zweifel, ob die Nachforschung nicht Jahrhunderte zu spät gekommen sey, konnte die Gewißheit des historischen Calculs problematisch machen. Die Besorgniß erwies sich als nichtig, da Macpherson die Denkmäler wirklich im Munde des Volkes fand, sie wurden mit Liebe und Freude aufgenommen." (Görres 1810: 46) Auch bei Hegel liegt die Wendung bereit, mit leicht verschobenem Akzent, aber darum nicht weniger brauchbar: „Die Sache, die objektive Anschauungsweise des Volkes stellt sich dar. Doch selbst der Volksgesang bedarf eines Mundes, der ihn aus dem vom Nationalgefühl erfüllten Innern heraus singt" (Hegel 1823-1829/1835: 338). Das bezeichnet genau die Rolle, in der sich Elias Lönnrot sah: „Nicht nur die Späteren haben Lönnrot als lebenden Mund der Sage, als Sprecher des Kollektivs verstanden, er verstand sich auch selbst so.“ (Fromm 2005: 65) Das „Heraussingen aus einem vom Nationalgefühl erfüllten Inneren“ möchte sich auch der arisch-germanische Rhapsode Wilhelm Jordan zurechnen, der nicht nur beim lettischen Epos Gevatter stand, sondern auch vermeinte, mit seinen „Nibelunge“ (1867/74) den mittelalterlichen bloßen Stoff zum „wahren Nibelungenepos“ der Deutschen erst entbunden zu haben: „Es bleibt wenig, ja, genau betrachtet, nichts übrig, was vom Zustandekommen des Epos der einzelne Poet sein Verdienst nennen darf", steht bei Jordan zu lesen, und ein namenloses Glück für den Dichter sei es,

durch die sog. Zufälligkeiten des Lebenslaufes hinein gedrängt, in Wahrheit durch heilige Führung hinein befohlen zu sein in den Beruf, in welchem er 
lernen mußte, der Mund zu werden, durch den diese Sage aufs Neue reden will in der Sprache der Zeitgenossen, um die Ahnungen der Vorfahren erfüllt zu zeigen in einer glorreichen Gegenwart. (Jordan 1876: 31,36; Hervorh. Th. T.)

Alles dies sind Varianten ein und derselben Stilgeste, des Sprechens „,through a greater mouth““ (Honko 1990c: 562). Sie erheischt das Sich-Auslöschen des persönlichen Sprechers, seine Inszenierung als bloßes Medium des heiligen Wortes: als reiner Spiegel. Die ausgefeilte Schriftkultur des 19. Jahrhunderts muss einschlägige Beglaubigungsund Beteuerungsgesten mit den armen Mitteln des gedruckten Wortes arrangieren. Im mündlichen Vortrag hingegen kann die Beglaubigung im performativen Dreieck zwischen Körper und Stimme und Dingobjekt sehr viel bezwingender vorgeführt werden, ad oculos et aures. Etwa bei tibetischen Sängern des Khan Ghesar, die sich so in Szene setzen:

Before starting to sing, some artists would place a bronze mirror on the incense-burner table. They would first recite from the scriptures and then begin to sing while looking into the mirror. Those who sang the epic in that way would claim that they did not know the epic at all, but only acted as narrators, telling the people what they saw in the mirror. Without the mirror, they could tell nothing. Of course, ordinary people could see nothing in the mirror but their own reflections; this would be explained by the fact, that they are not related to the Gods. Only those who were fortunate enough to have been related to the Gods in some way could see the image and acts of King Gesar in the mirror. [...] There were also performers who would hold a pièce of blank paper in their hands and narrate while reading this "heavenly book". ('Jam-dpal-rgyal-mtsho 1990: 479)

Nicht von ungefähr werden hier gerade Buch und Spiegel in der Rolle der dinglichen Zeugen vorgewiesen. Sie sind keine Requisiten. Sie sind Richtpunkte auf das Kollektive und auf das Göttliche, an denen die allzu subjektive Stimme des Sängers Peilung nimmt. Es sind eben die Richtpunkte, die uns oben bei Hegel und Wilhelm Grimm begegneten.

Ein Seitenstück zur Stilgeste erzwungener Selbstauslöschung bildet die heilige Scheu der als „Mund ihrer Nation“ auftretenden europäischen Neoepiker, die glücklich verfertigten Texte nach ihrer Herstellung beim Namen zu nennen und sie freiheraus als das zu bezeichnen, als was sie doch erträumt und verfertigt wurden: nämlich als Epen, und als 
Nationalepen. Darauf verzichtet Elias Lönnrot in der Erstausgabe seines „Kalevala“ (vgl. Niedling 2007: 66, Anm. 152) ebenso wie Andrejs Pumpurs in seinem „Lāčplēsis“ (vgl. Pumpurs 1888: 142). Gelegentlich begegnen beide Verzichtsgesten in steigernder Verschränkung. So auch in der zwischen 1857 und 1861 synoptisch deutsch und estnisch gedruckten Erstausgabe des „Kalevipoeg“:

Die für die doppelsprachige Ausgabe vorgesehene Überschrift „Estnisches Nationalepos" hat Kreutzwald in seiner übergroßen Bescheidenheit gestrichen. Ja, diese ging soweit, dass er an Reinthal den 17. März 1857 schreibt: „Meinen Namen weiter als Herausgeber auf dem Titel anzugeben, halte ich für eitle Prahlerei, er steht ja schon zu allem Überfluß unter der Vorrede." So enthält denn das modificirte Titelblatt bloß die eigenthümliche Angabe: „Kalewipoeg, eine Estnische Sage, verdeutscht von Carl Reinthal.“ (Reimann 1900: XXIV)

Das ist eben die „übergroße Bescheidenheit“, an der ein Jahrhundert vor Kreutzwald schon James Macpherson heftig laboriert hatte. Bei Macpherson hatte sie sich ergeben als „interplay of patriotic motives and personal vanity and ambition that is so characteristic of his early work" (Thomson 1990: 123f.). Im Vorrücken des 19. Jahrhunderts sollte sich diese „übergroße Bescheidenheit“ zu einer regelrechten déformation professionelle der europäischen Nationalepiker auswachsen. Der Schöpfer des „Kalevipoeg“ teilt sie mit vielen seinesgleichen. Die gedruckte Bescheidenheit ist ihnen ebenso gemeinsam wie das sich privatim aussprechende Verlangen nach Anerkennung als Homer ihres Volkes. Nennt sich der Autor jedoch auf dem Titelblatt, und nennt er sich hier als Autor und nicht etwa unter der Maske eines Herausgebers oder Sammlers oder Redakteurs, so ist er vollauf berechtigt, den Kredit des „Homeric factor“ (Sher 1991: 236) der eigenen Person zuzuleiten in aller Bescheidenheit, versteht sich. So hält es Frédéric Mistral, wenn er sich in der Eingangsstrophe seiner „Mirèio“ als „[u]mble escoulan dóu grand Oumèro“" (Mistral 1978: I, 3) einführt, als bescheidener Schüler des großen Homer. Der mit allen Wassern des Pariser Betriebes gewaschene Großschriftsteller Lamartine freilich versteht im Fluge, wie diese Demutsgeste auszulegen ist. Er streicht das „Schüler“, streicht auch das „bescheiden“, reiht Mistral in seinem „Cours familier de Littérature" unter die Großen der Weltliteratur ein und verleiht ihm den ersehnten Titel, „l' Homere de Provence“ (zit. n. ebd., 473). Anders 
als bei Mistral - „halb Homer, halb Berthold Auerbach“ (von Hofmannsthal 1892: 80), so erscheint der neuprovenzalische Schriftsteller dem wenig pietätvollen Wiener Abiturienten Hofmannsthal kann sich dieses Verlangen bei den Verfassern traditionsorientierter Epen nur privatim aussprechen. Aus dieser Zwickmühle war kein Entkommen. Schon der wahre Stammvater der europäischen nationalepischen Bewegung hatte nicht aus ihr herausgefunden. Nicht genug, dass James Macpherson durch den Mund des mythischen Sängers Ossian sprechen musste. Er hatte dem gälischen Barden auch den Ehrentitel eines „Homer of the Highlands“ (Blair 1765: 138) zu gönnen. Nicht der Zeitgenosse Macpherson konnte der Rhapsode und der Barde und der schottische Homer sein, der allein seinen Epen jene Würde zu verleihen vermochte, um die es ihm und seinen ethnopatriotisch gestimmten Entdeckern und Förderern um Hugh Blair zu tun war. Hier war nicht zu helfen mit einer Würde, die aus der Beschaffenheit eines Textes rührt. Hier ging es um eine Würde, die einem Text allein aus der rechten Autorschaft zukommen konnte. Herder verkannte dies gründlich, als er in den Fehden um die Echtheit des Ossian und um die einander ausschließenden irischen und schottischen Ansprüche mit einem Vorschlag zur Güte auftrat (vgl. Herder 1795b). Er drang ebenso wenig durch wie ein Jahrzehnt darauf Macphersons genauer Landsmann Walter Scott, als er schottischen Nationalstolz und schottische Nationaleitelkeit in Bezug auf den Ossian auf eine weniger gefährliche Bahn zu lenken suchte:

But, while we are compelled to renounce the pleasing idea, "that Fingal lived, and that Ossian sung", our national vanity may be equally flattered by the fact, that a remote, and almost barbarous corner of Scotland, produced, in the eighteenth century, a bard, capable not only of making a enthusiastic impression on every mind susceptible of poetic beauty, but of giving a new tone to the poetry throughout all Europe. (Scott 1805: 462)

Dieses Argument, mit dem Scott versöhnlich schließen möchte, war schon ein halbes Jahrhundert zuvor ohne Kraft. Wo es nach 1800 begegnet, bezeichnet es nur mehr ein Missverständnis. Die romantische Doktrin von der naturwüchsig-volkhaften Entstehung hatte die Auflagen an die Mystifikationen um die Autorschaft des Nationalepos unterdessen noch einmal verschärft, bevor sie schließlich vollends ins Transzendente verrückt wurden. Das Übereignen der Autorschaft an einen 
persönlichen Autor, wie alt und ehrwürdig dieser auch immer sein mochte, war mit Jacob Grimms „Glaubensbekenntnis“ (Gass 1940: 17) ganz unzulässig geworden: „nichts ist verkehrter geblieben, als die anmaszung epische gedichte dichten oder gar erdichten $\mathrm{zu}$ wollen; als welche sich nur selbst zu dichten vermögen“"(Jacob Grimm 1808: 401). Verlangt war nun das Abtreten der Autorschaft an die Nation selbst als den einzig berechtigten Nationalepiker, als den „Gesammtsänger“, der allein jetzt noch einem Text die rechten Weihen $\mathrm{zu}$ verleihen vermochte. Elias Lönnrot sah dies ebenso klar und deutlich, wie die Creuzer und Görres und Kanne und Hegel es befohlen und die Grimm es wieder und wieder eingeschärft hatten:

Speaking of the origin of folk poetry in the foreword to the Kanteletaar he says: "Folk poems cannot [...] be said to have been made. They are not made, they make themselves, they are born, they grow and take shape without any special care on the part of a maker. [...] The moment they are said to be made by some particular person, they lose their value as folk poetry." Not even an anonymous maker is required; folk poems are born again and again, collectivly and naturally out of the basic feelings and thoughts of man and become the property of all. This is a highly orthodox, though not original, concept of the Romantic era. It prevailed Lönnrot from emphasizing his own part in the begetting of the Kalevala: "authorship" would have destroyed its value as folk poetry. (Honko 1990b: 213)

Der Erfolg dieser Mystifikation ist besiegelt in dem Moment, in dem sie den Verfasser des Nationalepos selbst überwältigt und ihm die Erinnerung an die eigene Autorschaft austreibt. Von Elias Lönnrot - seit 1853 Professor der finnischen Sprache an der Universität Helsinki, wo er Semester für Semester über das „Kalevala“ las - ist überliefert, dass er diesen Punkt erreichte:

One cannot help being astonished at the concrete vision of the world of the Kalevala Lönnrot had created in his mind in the 1840s. He could envisage the geographical relations between the two focal points of his epic, Pohjola and Kalevala, the nature of his characters and the "belonging" of some of the poems to the Kalevala poems just as if he had forgotten his own role in creating that ancient world. (Outi Lehtipuoro, zit. n. Honko 1990c: 560)

So entsteht das Nationalepos im Schnittpunkt ganzer Ketten medialer und kommunikativer Simulationen. Im Falle glücklichen Gelingens fallen sie zusammen in einem Text, dessen Merkzeichen darin besteht, 
dass er sich ausnimmt als „absolutely archaic“ (Newton). Der kunstvoll erzeugte Effekt des Uralten wird zum untrüglichen „Stempel der Aechtheit" (Jacob Grimm 1811a: 169), wie es bei Jacob Grimm im Aufruf zum „Altdeutschen Sammler“ heißt. Es ist der Stempel, dessen Gepräge schon Hugh Blair am Ossian hatte ausmachen wollen:

The manner of composition bears all the marks of the greatest antiquity. [...] The compositions of Ossian are so strongly marked with characters of antiquity, that although there were no external proof to support that antiquity, hardly any reader of judgement and taste, could hesitate in referring them to a very remote aere. (Blair 1765: 33, 29f.)

Die gleiche Überzeugung, die Blair an der Anlage des Ossian gewann, bildete sich Hegel an dessen Gegenständen:

Obschon berühmte englische Kritiker wie z.B. Johnson und Shaw blind genug gewesen sind, sie für ein eigenes Machwerk Macphersons auszugeben, so ist es doch ganz unmöglich, daß irgendein heutiger Dichter dergleichen alte Volkszustände und Begebenheiten aus sich selber schöpfen könnte. (Hegel 1823-1829/1835: 403)

Mit großer Verspätung noch einmal bemüht wird das Argument von dem greisen Jacob Grimm, nach der Mitte des 19. Jahrhunderts einer der allerletzten unbeirrbaren Verteidiger des Ossian und stets aufgelegt, „das ihm angethane leid zu rächen“:

je mehr man in ihn eindringt, desto schlagender wird seine wahrheit auf allen seiten und selbst da, wo sie dem ersten herausgeber noch unerkannnt bleiben muste, vorrücken. er ist echt und ungefälscht, eine menge äuszerer und innerer zeugnisse treffen für ihn zusammen, nichts ist an ihm was hätte können erdichtet werden (Jacob Grimm 1863: 542; vgl. Jacob Grimm 1845: 79 und die spätere Note * ebd.).

Alle drei, Blair wie Hegel wie Jacob Grimm, der sich lange mit dem Plan zu einem Buch zur Rettung des Ossian getragen hatte und in seinem Todesjahr wirklich die ersten Stücke zu Papier brachte (vgl. Hübner 1935: 34), alle drei sind einem Phänomen aufgesessen, das man den Ton, prägnanter vielleicht noch den Sound des Archaischen nennen könnte. Erlegen ist diesem Sound auch Wilhelm Grimm, der sich besser als jeder andere selbst auf das Erzeugen eines nicht weniger überzeugenden Sounds verstand: „Wer könnte den Ossian übergehen und das Wesen des Epos erforschen wollen?" (Wilhelm Grimm 1818: 
221). Nur der, mag man versucht sein zu antworten, der die Brüder Grimm übergehen wollte bei der Erforschung des Wesens des deutschen Volksmärchens, dessen wahrer Name vielleicht doch „Gattung Grimm" lautet (Jolles 1974: 219; vgl. dazu auch den Artikel von Heinrich Detering in diesem Band). Über einen solchen Effekt, über einen solchen Sound des absolut Archaischen allein kann dem Epos die Aura des Sakralen zuwachsen, in dem die Romantik es ansiedelt. Und auf diese Aura kommt allerdings alles an, soll das Nationalepos dazu taugen, die ihm angesonnene Funktion als kommunikatives Quellereignis der Nation zu versehen.

Gezählt sind die in den hier angedeuteten Horizonten entstandenen oder in ihnen zu Nationalepen erhobenen Texte noch nicht. Die sonst so geschäftige vergleichende Epenforschung hat sie bislang nicht zu einem Objekt eigenen Studiums gemacht. Selbst als besondere Familie innerhalb der uferlos wuchernden Sippe der Epen sind sie noch kaum erkannt. Einstweilen darf man für Europa von einigen Dutzend Texten ausgehen, die sich in dieser Rolle durchgesetzt haben, die Eposstelle besetzen und nach der Approbation durch „ihre“ Nation dieser tatsächlich ein Nationalepos sind. Das Anregen und Projektieren, das Wägen und Wählen, das Aussuchen und Ablehnen und Annehmen der als Freier um die Gunst der Nation antretenden Werke gehört zu der Rollenvielfalt, in der die Nation als ideelles Gesamtsubjekt des nationalepischen Prozesses auftritt. Hinter den im Rampenlicht stehenden Siegern dürfen wir eine ungleich größere Anzahl gestrandeter Kandidaten vermuten, die den rettenden Hafen der Akklamation nicht erreichten. Hekatomben solcher Texte liegen versargt in den unauslotbaren Tiefen der nationalen Literaturgeschichten. So kann der Rigenser Lettonist und Altphilologe Ojārs Lāms für das Lettische ein knappes Dutzend gescheiterter Brautwerber um die Gunst der Nation namhaft machen. Der späte Triumph von Pumpurs „Lāčplēsis“, entschieden durch die Parteinahme des nachmaligen Nationaldichters Rainis im Revolutionsjahr 1905/06, fast zwei Jahrzehnte nach dem ersten Erscheinen, ließ sie geschlagen auf der Schädelstätte des literarischen Feldes zurück (vgl. Lāms 2008: 83-163). Wie bei jedem kommunikativen Akt hängt auch das Gelingen nationalepischer Kommunikation an der rechten Rezeption. In diesem Fall: an der Aufnahme als Nationalepos. Erst der Akt der Anerkennung durch „die Nation“ - der durchaus mit einer Pha- 
senverschiebung von Jahrzehnten oder auch von Jahrhunderten eintreten kann - schließt den kommunikativen Zirkel, in dem die nationale Energie kreisen kann. Erst die Akklamation durch die Nation macht aus einem dieser angedienten Text tatsächlich das Nationalepos, weil es erst dann als Nationalepos fungieren kann:

It is the reception, that marks the birth of a national epic. Without the approval and enthusiasm of the receiving community, the process of creating a national epic comes to an abrupt end and passes into oblivion. Only when the society hails the epic as the carrier of its cultural identity, accepts its "song of truth" about its own origins, communal history and mythology, and the ultimate set of values and aspirations, seen as coming from the past but in fact reaching to the future, only then does its status as a national epic become established. (Honko 1996: 31)

Die durch nichts zu mindernde Intensität des Ringens um das Nationalepos, die oft lange schwebende Entscheidung über den zu kürenden Text, die harte Unbedingtheit der Auslese und schließlich die Gnadenlosigkeit, mit der die unterlegenen Bewerber im Augenblick der Kanonisierung des Siegers in die Acht getan werden: alles dies bestätigt Goethes Ahnung. Es geht hier tatsächlich um etwas Elementares, um etwas Unabdingbares, um ein must-have und keinesfalls um Redeluxus. Wobei sich die Härte der Auswahl auch daraus ergibt, dass die Systemstelle "Nationalepos“ genau eine ist. Sie duldet nur einen Text, nicht zwei oder fünf oder sieben. Wie auch sonst die Zahl, in der die Nation sich erkennt, die Eins ist. All ihre Symbole werden nur in der Einzahl gelitten. Es kann nur ein Nationalepos geben - wie es nur eine Nationalflagge gibt, nur einen Präsidenten (oder nur eine Präsidentin), nur eine Fußballnationalmannschaft, nur eine Verfassung, auch nur eine Nationalhymne - aber durchaus, wie derzeit in Spanien, Zehntausende von Kandidaten dazu, die allesamt sein werden wie nie gewesen im Moment der Schilderhebung des einen Siegreichen. Doch werden die unterlegenen Kandidaten nicht etwa vergessen. Sie unterliegen einer regelrechten damnatio memoriae, einer die Erinnerung an sie weniger verdrängenden als ausmerzenden Tätigkeit. Ihnen geschieht wie dem Prätendenten auf den Zarenthron, dessen Illegitimität sich erwiesen hat. Dass der Sieger der rechte Text ist, das zeigt sich auch daran, dass er sich als (vermeintlich) einzige Möglichkeit naturalisiert und das Moment der Kontingenz vergessen macht, das über seiner Bestallung 
waltete. Der Eins aber, als der Zahl der Nation, kommt das Epos entgegen wie keine literarische Gattung sonst. Stets wird es begleitet von dem Wunsch, dass „von einem jeden Zeitalter immer nur ein Epos geboren [wird] und immer wie ein Geschenk der Gnade" (Steckner 1927: 51). Oder, in den Worten André Jolles':

Auch als dichterische Tat hat das Epos etwas zeitlich Abgeschlossenes und Endgültiges. Das Lied lockt andre Lieder hervor, der Roman tritt gewöhnlich in der Mehrzahl auf [...]. Aber auch im Volke treten sie auf wie die Wölfe im Winter - vielleicht erst einer, aber dann in ganzen Rudeln. Dagegen ist ein gutgelungenes Epos wie das Junge eines Löwen - nur eines, aber ein Löwe. [...] Sind die Wege der Literatur mit Liedgeröll gepflastert die Epen stehen wie Meilensteine. (Jolles 1918: 80)

Weil das Nationalepos im 19. Jahrhundert eine Systemstelle im kulturellen Haushalt einer jeden auf sich haltenden Nation auszufüllen hat und in den Begriff der Nation selbst eingeht, wird das Leerbleiben dieser Position schmerzhaft verspürt. Zuweilen noch heute: „In Hungary, scholars as well as the public miss, even now, the so called ,naive epic', and the bitterness over its loss [...] is still felt" (Domokos 1990: 344). Dies ist kein Phantomschmerz. Ein starker Beleg für die Erklärungsnot, die auf den Unglücklichen lastet, denen kein Nationalepos zuteilwurde, kommt aus unverhoffter Richtung. Er kommt von Seiten der scheinbar Nicht-Bedürftigen, weil der Nicht-Kolonialisierten und der Nicht-Subalternen schlechthin: der Engländer mit ihrer selbstgewiss in sich ruhenden Identität einer staatsgezeugten inselbewohnenden Nation, einer ebenso „vollen“ wie glorreichen Geschichte, dem kulturellen Superioritätsgefühl eines ganz Europa zu seinen Schülern zählenden Volkes und dem unerschütterlichen Selbstbewusstsein eines in einem weltumspannenden Kolonialreich frei waltenden und sich seines zivilisatorischen Weltberufs allezeit gewissen Hegemons. Gleichwohl verspürte man auch in England unter dem Druck des vorrückenden europäischen Diskurses um die Mitte des 19. Jahrhunderts zunehmend den Mangel an einem Nationalepos. Am deutlichsten artikuliert findet sich dieser Mangel bei Thomas Carlyle, dem Botschafter Goethes und des deutschen Geistes in der angelsächsischen Welt. In dessen Essay „The English“, einer großen Apostrophe an England, steht zu lesen:

Thy epic unsung in words, is written in huge characters on the face of this Planet, - sea moles, cottontrades, railways, fleets and cities; Indian Empires, 
Americas, New Hollands; legible throughout the Solar System! [...] Great honour to him whose epic is a melodious hexameter Iliad [...]. But still greater honour, if his Epic be a mighty Empire slowly built together, a mighty Series of Heroic Deeds, - a mighty Conquest over chaos. (Carlyle 1843: 160)

Das ist deutlich genug ironisch gefärbt, um es mit einem Körnchen Salz zu nehmen. Nichtsdestotrotz macht es die Stelle kenntlich, die wir oben die Epenstelle genannt haben. Bei ihr handelt es sich tatsächlich um eine Systemposition: Sie ist sichtbar auch dann, wenn sie unbesetzt ist. Zeigt sie sich leer, dann wird auch dem sonst in jeder Hinsicht ungekränkten Hegemon eine Erklärung abgezwungen. Nichts beweist schlagender den Triumph des nationalepischen Paradigmas als der Sphärenwechsel vom Metrum des heroischen Verses zur Kulturgestalt der Erdoberfläche, zu welcher der gebürtige Schotte (Ossian!) Carlyle sich genötigt sieht, um das Skandalon aus der Welt zu schaffen, dass die Herren der Welt nicht über ein Nationalepos verfügen. Und wirklich tat sich kaum ein anderes europäisches Volk schwerer mit der Herrichtung oder der Verfertigung eines Nationalepos als das stolze Albion, dem doch alle Mittel überreichlich zu Gebote standen. Nur war dem Problem damit nicht beizukommen. Es bestand in der nationalepischen Formulierung weniger einer englischen als vielmehr einer britischen Identität. Diese hätte England als den Hegemon ebenso einschließen müssen wie die Subalternen im celtic fringe - die nun wiederum ihre jeweils besondere nationale Identität agonal gegen die englische entwickelten, diesen Antagonismus hingebungsvoll kultivierten und aus ihm ihr nationales Argument gewannen. Schon der Ossian, die pia fraus des James Macpherson, die im Gefolge des endgültigen Verlustes der schottischen Unabhängigkeit in der Schlacht von Culloden (1746) auf den Weg gebracht worden war, schon der Ossian verdankte auf den Inseln selbst seine Wirkung bei Freund und Feind nicht zuletzt einem spezifisch anti-englischen Affekt, der seinerseits durch einen anti-schottischen Affekt befeuert wurde, hinter dem sich ein weiterer anti-englischer Affekt verbarg:

National prejudice towards Scottland was rampant in England during the second half of the eighteenth century. [...] Among English men of letters the sentiment was particularly understandable, for since the 1750 s the Scottish literati had been rigorously challenging the English assumption of supremacy. (Sher 1991: 213) 
In diesen heillos vertrackten Gemengelagen schieden die auf der Insel in Fülle vorhandenen ,primary epics“ (Arthur T. Hatto) allesamt aus. Der Beowulf zeigte sich zu nordisch, das Mabinogion und der Zyklus um King Arthur zu keltisch. Letzterer war überdies unheilbar angelsachsenfeindlich. Von diesen Kandidaten ließ sich keiner überzeugend ins Britische nationalisieren (vgl. Dentith 2006: 69ff.). Damit blieb nur der Weg offen, das Nationalepos zu einer erwünschten britischen Nation entweder als traditionsorientiertes Epos aus folkloristischem Material zu verfertigen oder es $a b$ ovo zu schaffen. $\mathrm{Zu}$ beidem folgten die Anläufe einander in dichten Reihen. Doch blieben sie allesamt stecken, ohne auf die Epenstelle zu gelangen. Die Akklamation blieb ihnen versagt. Das Publikum, auf das sie es abgesehen hatten, mochte der Einladung zur Identifizierung mit einer britischen Identität im Medium des Epos nicht folgen. Als kleinster gemeinsamer Nenner blieben am Ende für das Historische die Balladen um Robin Hood, die nicht zu einer akzeptierten versepischen Form fanden, während für das Bedürfnis an „britischer“ Gegenwärtigkeit die Integrationsfigur der Queen Victoria eintrat (vgl. Dentith 2006; auch Barczewski 2000 und Tucker 2009).

Wenn aber ein Nationalepos selbst in der am festesten gegründeten, am wenigsten gekränkten und am glorreichsten waltenden aller europäischen Mächte peinlich vermisst wird, wenn allüberall ebenso inständige wie beharrliche Bemühungen um das Nationalepos anzutreffen sind, die vor keiner Verirrung zurückschrecken, wenn die Anlage der als Nationalepos entstehenden Texte einander ebenso gleicht wie die Wege, auf denen sie zustande kommen, wenn die Deutungen der im 19. Jahrhundert zu Nationalepen erhobenen Texte einander ähneln wie ein Ei dem anderen, wenn sich Nationalepen untereinander in lebhaftem Gespräch begriffen zeigen - wenn dies alles so ist, dann ist es vermutlich wenig ergiebig, sich die europäischen Nationalepen geordnet zu denken wie Perlen auf der Schnur und sich zu ihrer Untersuchung ein Stück nach dem anderen durch die Finger gleiten zu lassen. Dann setzt man vielleicht besser an anderer Stelle an: Nicht bei den einzelnen Epen und ihrer jeweiligen Referenznation, sondern bei dem ganz Europa beherrschenden Willen zum Nationalepos, der sie überall zuverlässig hervortrieb. Auch sind die von Land zu Land verschiedenen Ausprägungen des nationalepischen Diskurses bei allen Unterschieden doch auf eine gemeinsame Mitte bezogen, auf den Leitdiskurs der 
deutschen Romantik, mit dem Grimmschen Gesetz als dem einen und der Liedertheorie als dem anderen Hauptstück. Ohne den Bezug auf diesen Leitdiskurs bliebe der innere Zusammenhang der einzelnen nationalepischen Bewegungen unverständlich. Umgekehrt weisen die an der Oberfläche so vielgestaltigen Vorgänge im Typologischen Grundzüge auf, die im Baltikum oder in Mitteleuropa oder auf dem Balkan ebenso Geltung haben wie in der Romania oder auf den Britischen Inseln oder im Altai. Der Nestor der vergleichenden Epenforschung beklagt zu Recht, dass der Phänotyp der Gattung Epos so verzweifelt vielgestaltig ausfalle (Arthur Waley, zit. n. Hatto 1980: 2). Bei den europäischen Nationalepen des 19. Jahrhunderts aber liegt der Fall anders. Hier spricht alles für ein gesamteuropäisches Narrativ und für eine gesamteuropäische Poetologie, die einer umfassenden Untersuchung wert wären, diese aber auch verlangten. Vermutlich würde sie einen ähnlichen Befund ergeben wie die Untersuchung der im 19. Jahrhundert entstandenen Nationalgeschichten ganz verschiedener europäischer Nationen, die ,auffällig übereinstimmende Grundstrukturen einer gemeinsamen narrativen Grammatik“ (Winkler 2005: 68) aufweisen.

Untereinander in Verbindung stehen die europäischen Nationalepen aber nicht nur über die geteilte Mitte, die sie im deutschen Epos-Diskurs haben. Sie sind auch netzartig miteinander verbunden durch eine geradezu überbordende Intertextualität, durch Übernahmen und Entlehnungen und Reflexe und sonstiges responses, die über eine Vielzahl von Vermittlungsgliedern laufen und dabei wie in einem Spiegelkabinett die bizarrsten Rückkopplungs- und Verzerrungseffekte hervortreiben können. In dieser Perspektive gerät just die Verfertigung und Deutung der als unverwechselbarer Ausdruck eines besonderen Nationalcharakters aufgefassten Nationalepen zu einem Lehrstück für die schlechterdings unhintergehbare Transnationalität der europäischen Nationalliteraturen (vgl. Lauterbach 2004). Was sich als chthonischer Monolog eines solchen „Nationalcharakters“ aus dem (vermeintlich) uralten Geist der jeweiligen Nationalkultur, der jeweiligen Nationalgeschichte und der jeweiligen Nationalliteratur inszeniert, das bildet sich unter dem strengen Diktat eines paneuropäischen Leitdiskurses in dem buntesten Gewirr von Stimmen und Zungen, das sich denken lässt. Suchte man ein Modell, um diesen Phänomenen einen systematischen Ort anzuweisen, so drängt sich die 
Vorstellung eines gesamteuropäischen diskursiven Feldes auf. Formiert wird es durch eine auf ihm zirkulierende „soziale Energie“ (Stephen Greenblatt), die entlang der von der deutschen Eposdoktrin abgesteckten Feldlinien Möglichkeiten zu nationalepischer Manifestierung aufspürt und ergreift. Das Nationalepos ist einer der prominentesten unter den Orten, an denen „nationale Energie“ in literarische Formen gebunden werden kann. Hier kristallisiert „das Nationale“ in Gebilden, die ungeachtet der unentwegten Beteuerungen ihrer Einzigartigkeit, auf eine gemeinsame Wurzel zurückzuführen sind. Das überrascht nur solange, wie man sich von den Sirenenklängen des Nationalen - und „des Nationalliterarischen“ - täuschen lässt und verkennt, dass all diese Texte und Deutungen auf ein und demselben Feld, in ein und denselben Horizonten und unter ein und demselben Paradigma entstehen, zu dem Romantik, Historismus und Nationalismus in schöner Dreieinigkeit quer über den Kontinent zusammentreten. Wobei an dem sich dabei ergebenden besonderen Text oft genug am allerwenigsten hängt: „Die Narrative der Epen waren bloße Oberflächenvariationen, Quelle folkloristischer Begleitproduktion und Namens- und Stichwortgeber für die Semiosphärenmacher. Austauschbar und unwichtig." (Joachimsthaler 2007/2009: 63) Kaum je geht es um die besondere Gestalt des Textes, immer aber um seine Eignung zum Identifikationsangebot seiner Nation. Daran hat er sich zu bewähren. Oft genug wird dies eigens festgehalten. Für den eben abgeschlossenen „Kalevipoeg“ tun dies im Jahre 1861 die St. Petersburger Akademiemitglieder Schiefner und Wiedemann in ihrer Begründung für die Vergabe des Demidow-Preises: „Keine Ilias hat Dr. Kreutzwald geschaffen, wohl aber der estnischen Literatur ein Capitalwerk geschenkt, das für alle Zeiten den Esten das sein wird, was den Griechen ihre Ilias ist" (zit. n. Reimann 1900: XXVII). Für die Litauer tut es Jurgis Mikšas', als er 1883 Kraszewskis auf Polnisch verfasste „Witolorauda“ (1846) in der „Auszra“ würdigt, in der Zeitschrift der aufkommenden litauischen Nationalbewegung: „Was für die Griechen ,Odyssee“ und ,Ilias' sind, für die Römer die ,Aeneis', für die Juden das Alte Testament - das ist für uns Litauer dieses Lied der ,Witolorauda', der erste Teil des großen Epos ,Anafielas‘“" (Zit. n. Stalīunas 2000: 207; zu den Hintergründen vgl. Kessler 2007/2009 und Kessler 2010) Allesamt sind die europäischen Nationalepen Literatur gewordener Ausdruck eines political 
will, und überall des nämlichen. Er mag sich in die verschiedenartigsten Manifestationen auseinander legen, bleibt aber dabei doch ein und derselbe: der Wille zur Nation und zu ihrer Manifestierung im Medium des gebundenen Wortes und der heldenepischen Erzählung. Wer die Nation als das von jenem political will gesteuerte rhetorisch-diskursive Unternehmen zu fassen sucht, von dem uns die Forschung der letzten Jahrzehnte so überzeugend erzählt, der findet hier ein dicht besetztes Feld vor, auf dem diesem folgenreichen europäischen Projekt bei seiner Verfertigung zuzuschauen ist.

\section{Literatur}

Alboniemi, Pirkki (1990): The Reception of the Kalevala and its Impact on the Arts. In: Honko (Hrsg.) (1990a), S. 231-244.

AlmQvist, Bo/Séamas Ó Catháin/Pádraig Ó Héalaí (Hrsg.) (1987): The Heroic Process: Form, Function and Fantasy in Folk Epic. Dun Laoghaire [Dublin].

Anderson, Benedict (1998): Die Erfindung der Nation. Zur Karriere eines folgenreichen Konzepts. Erw. Ausg. Berlin (= Ullstein-Buch 26529).

ANNIST, August (2005): Friedrich Reinhold Kreutzwaldi „Kalevipoeg”. Hrsg. v. Ülo Tedre. Tallinn.

ARndT, Ernst Moritz (1809): Geist der Zeit. 2. Teil. In: Arndts Werke. Auswahl in 12 Teilen. Hrsg., mit Einleitungen und Anmerkungen versehen v. August Leffson und Wilhelm Steffens. 7. Tl. Hrsg. v. Wilhelm Steffens. Berlin et al. [1912].

ARUKASK, Madis (2002): Runo songs, "Kalevipoeg", and "Peko" in the Question of National Identity. In: Lauri Honko (Hrsg.) (2002): The Kalevala and the World's Traditional Epics. Helsinki (= Studia Fennica. Folkloristica 12), S. 420-432.

Assmann, Jan (2004): Das kulturelle Gedächtnis. Schrift, Erinnerung und politische Identität in frühen Hochkulturen. 4. Aufl. München (= Becksche Reihe 1307).

Assmann, Jan (1996): Ägypten. Eine Sinngeschichte. Darmstadt.

Assmann, Jan (2005): Die Lebenden und die Toten. In: Jan Assmann/Franz Maciejewski/Axel Michaels (Hrsg.) (2005): Die Lebenden und die Toten. Trauerrituale im Kulturvergleich. Göttingen, S. 16-36.

BARCZEWSkI, Stephanie L. (2000): Myth and National Identity in Nineteenth-Century Britain: The Legends of King Arthur and Robin Hood. Oxford.

BAŞGÖZ, Ilhan (1978): The Epic Tradition among Turkish People. In: Felix J[ohannes] Oinas (Hrsg.) (1978): Heroic Epic and Saga. An Introduction to the World's Great Folk Epics. Bloomington/London, S. 310-335. 
BAusinger, Hermann (1980): Formen der „Volkspoesie“. 2., verb. u. verm. Aufl. Berlin (= Grundlagen der Germanistik 6).

BEHSCHNITT, Wolfgang (2001): Zur Funktion von Literatur in Identitätsdiskursen der bürgerlichen Gesellschaft. In: ders.: (Hrsg.) (2001): Aneignung Abgrenzung - Auflösung. Zur Funktion von Literatur in den skandinavischen Identitätsdiskursen. Würzburg (= Identitäten und Alteritäten 8), S. 14-33.

BEISSINGER, Margaret/Jane Tylus/Susan Wofford (Hrsg.) (1999): Epic Traditions in the Contemporary World: The Poetics of Community. Berkeley et al.

Berelis, Guntis (1999): Latviešu literatūras vēsture. No pirmajiem rakstiem lìdz 1999. gadam. Riga.

BlaIr, Hugh (1765): A Critical Dissertation on the Poems of Ossian, the Son of Fingal. The second edition. To which is added, An Appendix, containing a variety of undoubted Testimonies establishing their Authenticity. London.

BogunA, Julija/Imants CīRulis/Līva RutKA/Thomas TATERKA (2011): Von der Schrift der Gemeine zur Stimme der Nation. Zur Konstruktion lettischer Identität um 1800 in J. Pulans „Stahftś tahś Lattweefchu Tautaś“. In: Heinrich Bosse/Otto-Heinrich Elias/Thomas Taterka (Hrsg.) (2011): Baltische Literaturen in der Goethezeit. Würzburg, S. 15-64.

BRECHT, Bertolt (1939): Leben des Galilei. Berlin 1998.

Carlyle, Thomas (1843): The English. In: ders.: Past and Present. London 1897, S. 157-166.

Christians, Heiko (2004): Der Traum vom Epos. Romankritik und politische Poetik in Deutschland (1750-2000). Freiburg (= Rombach-Wissenschaften. Litterae 118).

CĪRulis, Imants (2007): „Die Geschichte der Letten“. Zum identitätsstiftenden historischen Konzept bei den Jungletten. B.A.-Arbeit, Universität Lettlands, Riga, Germanistische Abteilung.

Clairmont, Heinrich (1994): „Man kann von Homer's Gedichten weiß Gott was sprechen und zusammenbringen...". Hegel, Herder und das Epos. In: Hans-Jürgen Gawoll/Christoph Jamme (Hrsg.) (1994): Idealismus mit Folgen. Die Epochenschwelle um 1800 in Kunst und Geisteswissenschaften. Festschrift Pöggeler. München, S. 235-250.

Connelly, Bridget (1986): Arab Folk Epic and Identity. Berkeley et al.

Dentith, Simon (2006): Epic and Empire in Nineteenth-Century Britain. Cambridge (= Cambridge Studies in Nineteenth-Century Literature and Culture).

Domokos, Péter (1990): Epics of the Eastern Uralic Peoples. In: Honko (Hrsg.) (1990a), S. 343-358.

Dundes, Alan (1985): Nationalistic Inferiority Complexes and the Fabrication of Fakelore: A Reconsideration of Ossian, the "Kinder-und Hausmärchen”, 
the "Kalevala", and Paul Bunyan. In: Journal of Folklore Research 22 (1985), S. 5-18.

EHRISMANN, Otfrid (1991): Vorwort. In: Jacob Grimm und Wilhelm Grimm: Forschungsausgabe. Hrsg. v. Ludwig Erich Schmitt. Abt. 1: Die Werke Jacob Grimms. Bd. 1: Kleinere Schriften 1. Reden und Abhandlungen. Nachdr. der Ausg. Gütersloh 1879. Neu hrsg. v. Otfrid Ehrismann. Hildesheim et al. 1991, S. $1 *-34 *$.

Faehlmann, Friedrich Robert (1839): Sagen. In: ders.: Teosed. Bd. 1. Hrsg. v. Mart Leppik et al. Tartu 1999, S. 55-68.

Freytag, Gustav (1875): Arndt, Ernst Moritz. In: Allgemeine Deutsche Biographie. Bd. 1. München/Leipzig, S. 541-548.

Fromm, Hans (2005): Nachwort. In: Kalevala. Das finnische Epos des Elias Lönnrot. Aus d. finnischen Urtext übertragen v. Lore Fromm u. Hans Fromm. 1. Tl. Wiesbaden, S. 341-386.

Funkenstein, Amos (1993): Perceptions of Jewish History. Berkeley et al.

GASKILL, Howard (Hrsg.) (1991): Ossian Revisited. Edinburgh.

GASKILl, Howard (2003): Ossian, Herder, and the Idea of Folk Song. In: David Hill (Hrsg) (2003): Literature of the Sturm und Drang. Rochester, N. Y. et al. (= Camden House History of German Literature 6), S. 95-116.

Gass, Karl-Eugen (1940): Die Idee der Volksdichtung und die Geschichtsphilosophie der Romantik. (Zur Interpretation des Briefwechsels zwischen den Brüdern Grimm und Achim von Arnim). Wien (= Abteilung für Kulturwissenschaft des Kaiser Wilhelm-Instituts im Palazzo Zuccari, Rom. Reihe 1: Vorträge. H. 19/20).

GERVINUS, G[eorg] G[ottfried] (1835): Geschichte der poetischen National-Literatur der Deutschen. 1. Tl. Von den ersten Spuren der deutschen Dichtung bis gegen das Ende des 13ten Jahrhunderts. Leipzig.

Gibbons, Luke (1996): This Sympathetic Bond: Ossian, Celticism and Colonialism. In: Terence Brown (Hrsg.) (1996): Celticism. Amsterdam/Atlanta, S. 273-291.

GÖRRES, Joseph (1810): [Rez. zu:] Probe einer neuen Übersetzung der Gedichte Ossians aus dem gaelischen Original, v. C[hristian] W[ilhelm] Ahlwardt [...] 1807. In: Joseph Görres: Gesammelte Schriften. Hrsg. v. Wilhelm Schellberg [...] fortgeführt v. Leo Just. Bd. 4. Geistesgeschichtliche und literarische Schriften 2 [1808-1817]. Köln 1955, S. 46-50.

GoeTHE, Johann Wolfgang (1829): Dichtung und Wahrheit. Goethe's Werke. Vollständige Ausgabe letzter Hand. Bd. 25. Stuttgart/Tübingen.

GreenblatT, Stephen Jay (1988): Shakespearean Negotiations: The Circulation of Social Energy in Renaissance England. Berkeley.

GrImM, Jacob (1807a): Über das Nibelungen Liet. In: Jacob Grimm und Wilhelm Grimm: Forschungsausgabe. Hrsg. v. Ludwig Erich Schmitt. Abt. 1: Die 
Werke Jacob Grimms. Bd. 4: Kleinere Schriften 4. Nachdr. der Ausg. Gütersloh 1869. Neu hrsg. v. Otfrid Ehrismann. Hildesheim et al. 1991, S. 1-7. GRIMM, Jacob (1807b): Von Übereinstimmung der alten Sagen. In: Jacob Grimm und Wilhelm Grimm: Forschungsausgabe. Hrsg. v. Ludwig Erich Schmitt. Abt. 1: Die Werke Jacob Grimms. Bd. 4: Kleinere Schriften 4. Nachdr. der Ausg. Gütersloh 1869. Neu hrsg. v. Otfrid Ehrismann. Hildesheim et al. 1991, S. 9-12.

GRIMM, Jacob (1808): Gedanken wie sich die Sagen zur Poesie und Geschichte verhalten. In: Jacob Grimm und Wilhelm Grimm: Forschungsausgabe. Hrsg. v. Ludwig Erich Schmitt. Abt. 1: Die Werke Jacob Grimms. Bd. 1: Kleinere Schriften 1. Nachdr. der Ausg. Gütersloh 1879. Neu hrsg. v. Otfrid Ehrismann. Hildesheim et al. 1991, S. 400-404.

GRIMM, Jacob (1811a): Aufforderung an die gesammten Freunde deutscher Poesie und Geschichte erlassen. In: Steig (Bearb.) (1914), S. 164-171.

GRIMM, Jacob (1811b): Über den altdeutschen Meistergesang. Mit e. Vorw. v. Ofrid Ehrismann. In: Jacob Grimm und Wilhelm Grimm: Forschungsausgabe. Hrsg. v. Ludwig Erich Schmitt. Abt. 1: Die Werke Jacob Grimms. Bd. 29. Neu hrsg. v. Otfrid Ehrismann. Hildesheim et al. 1993.

Grimm, Jacob (1813): Gedanken über Mythos, Epos und Geschichte. In: Jacob Grimm und Wilhelm Grimm: Forschungsausgabe. Hrsg. v. Ludwig Erich Schmitt. Abt. 1: Die Werke Jacob Grimms. Bd. 4: Kleinere Schriften 4. Nachdr. der Ausg. Gütersloh 1869. Neu hrsg. v. Otfrid Ehrismann. Hildesheim et al. 1991, S. 74-85.

GRIMM, Jacob (1835a): Deutsche Mythologie. Göttingen.

GRIMM, Jacob (1835b): [Rez. zu:] Geschichte der poetischen nationalliteratur der Deutschen von dr. G. G. Gervinus. erster theil [Leipzig 1835]. In: Jacob Grimm und Wilhelm Grimm: Forschungsausgabe. Hrsg. v. Ludwig Erich Schmitt. Abt. 1: Die Werke Jacob Grimms. Bd. 5: Kleinere Schriften 5. Nachdr. der Ausg. Gütersloh 1871. Neu hrsg. v. Otfrid Ehrismann. Hildesheim et al. 1991, S. 176-187.

GRIMM, Jacob (1845): Über das finnische Epos. Gelesen in der Akademie der Wissenschaften am 13. Merz 1845. In: Jacob Grimm und Wilhelm Grimm: Forschungsausgabe. Hrsg. v. Ludwig Erich Schmitt. Abt. 1: Die Werke Jacob Grimms. Bd. 2: Kleinere Schriften 2. Nachdr. der Ausg. Gütersloh 1865. Neu hrsg. v. Otfrid Ehrismann. Hildesheim et al. 1991, S. 75-113.

GRIMM, Jacob (1863): Über Ossian. In: Jacob Grimm und Wilhelm Grimm: Forschungsausgabe. Hrsg. v. Ludwig Erich Schmitt. Abt. 1: Die Werke Jacob Grimms. Bd. 7: Kleinere Schriften 7. Nachdr. der Ausg. Gütersloh 1884. Neu hrsg. v. Otfrid Ehrismann. Hildesheim et al. 1991, S. 537-543.

GRIMM, Wilhelm (1808): Über die Entstehung der altdeutschen Poesie und ihr Verhältnis zu der nordischen. In: Jacob Grimm und Wilhelm Grimm: For- 
schungsausgabe. Hrsg. v. Ludwig Erich Schmitt. Abt. 2: Die Werke Wilhelm Grimms. Bd. 1: Kleinere Schriften 1. Nachdr. der Ausg. Gütersloh 1881. Neu hrsg. v. Otfrid Ehrismann. Hildesheim et al. 1992, S. 92-170.

[GRIMm, Wilhelm] (1818): [Rezension zu:] Ossians Gedichte. Rhythmisch übersetzt von J. G. Rhode. Zweyte verbesserte Ausgabe. In: Jacob Grimm und Wilhelm Grimm. Forschungsausgabe. Hrsg. v. Ludwig Erich Schmitt. Abt. 2: Die Werke Wilhelm Grimms. Bd. 2: Kleinere Schriften 2. Nachdr. der Ausg. Gütersloh 1882. Neu hrsg. v. Otfried Ehrismann. Hildesheim et al. 1992, S. 220.

GRIMM, Wilhelm (1843/49): Einleitung zur Vorlesung über Gudrun. In: Jacob Grimm und Wilhelm Grimm. Forschungsausgabe. Begr. v. Ludwig Erich Schmitt. Abt. 2: Die Werke Wilhelm Grimms. Bd. 4: Kleinere Schriften 4. Nachdr. der Ausg. Gütersloh 1887. Neu hrsg. von Otfried Ehrismann. Hildesheim et al. 1992, S. 524-576.

GRIMM, Jacob/Wilhelm Grimm (1953): Briefe der Brüder Grimm an Savigny. Aus dem Savignyschen Nachlaß. Hrsg. v. Wilhelm Schoof. Berlin (= Hessische Briefe des 19. Jahrhunderts 1).

GRIMM, Jacob/Wilhelm Grimm/Karl Lachmann (1927): Briefwechsel der Brüder Jacob und Wilhelm Grimm mit Karl Lachmann. Hrsg. v. Albert Leitzmann. Mit einer Einl. v. Konrad Burdach. Tl 2. Jena.

HARVIlaHTI, Lauri (1996): Epos and National Identity: Transformations and Incarnations. In: Oral Tradition 11, S. 37-49.

HasselblatT, Cornelius (2006): Geschichte der estnischen Literatur. Von den Anfängen bis zur Gegenwart. Berlin/New York.

Hatto, Arthur T. (Hrsg.) (1980): Tradition of Heroic and Epic Poetry. Bd. 1. The Traditions. London (= Modern Humanities Research Association).

HegEL, Georg Wilhelm Friedrich (1823-1829/1835): Vorlesungen über die Ästhetik. Tl. III. Werke in 20 Bänden. Bd. 15. Frankfurt a. M. (= Suhrkamp-Taschenbuch 615).

VAN DER HEIDE, Nienke (2004): Epic as Arena - Models of Statehood and the Kyrgyz Manas Epic. In: Jansen/Maier (Hrsg.) (2004), S. 65-70.

Heinrich VON LetTland (1228): Heinrici Chronicon Livoniae. Editionis quam paraverant L[eonid] Arbusow et A[lbert] Bauer textum denuo imprimendum curavit Albertus Bauer. Würzburg 1959.

Herder, Johann Gottfried (1795a): Homer, ein Günstling der Zeit. In: ders.: Sämmtliche Werke. Hrsg. v. Bernhard Suphan. Bd. 18. Berlin 1883, S. 420446.

HERDER, Johann Gottfried (1795b): Homer und Ossian. In: ders.: Sämmtliche Werke. Hrsg. v. Bernhard Suphan. Bd. 18. Berlin 1883, 446-462. 
Herder, Johann Gottfried (1803): Theoxonien. I. Vom Heiligen der Epischen Dichtkunst. In: ders.: Sämmtliche Werke. Hrsg. v. Bernhard Suphan. Bd. 24. Berlin 1886, S. 278-284.

VON HOFMAnNSTHAL, Hugo (1892): Südfranzösische Eindrücke. In: ders.: Gesammelte Werke in Einzelausgaben. Hrsg. v. Herbert Steiner. Prosa 1. 6. bis 10. Tsd. Frankfurt a. M. 1956, S. 77-82.

Honko, Lauri (1985): Tyrannisoiva eeposteoria. In: Suomalaisen Kirjallisuuden Seura, 1985, S. 4-9.

Honko, Lauri (1987): The Kalevala Process. In: Folklife Annual 1986. Hrsg. v. Alan Jabbou u. James Hardin (Hrsg.) (1987): Washington, S. 66-79.

Honko, Lauri (Hrsg.) (1990a): Religion, Myth and Folklore in the World's Epics. The Kalevala and its Predecessors. Berlin/New York (= Religion and Society $30)$.

Honko, Lauri (1990b): The Kalevala: The Processual View. In: Honko (Hrsg.) (1990a), S. 181-229.

Honko, Lauri (1990c): The Kalevala: Problems of Interpretation and Identity. In: Honko (Hrsg.) (1990a), S. 555-575.

Honko, Lauri (1993): Teachings of the Silk-Road Epics: A Workshop in Turku. In: Folklore Fellow's Network, 1993, H. 7, S. 2-4.

Honko, Lauri (1996): Epic and Identity: National, Regional, Communal, Individual. In: Oral Tradition 11 (1996), S. 18-36.

Hroch, Miroslav (2005): Das Europa der Nationen. Die moderne Nationsbildung im europäischen Vergleich. Göttingen (= Synthesen. Probleme europäischer Geschichte 2).

HÜBneR, Arthur (1935): Jacob Grimm. Festvortrag in der Preussischen Akademie am 4. Januar 1935. In: ders.: Kleine Schriften zur deutschen Philologie. Hrsg. v. Hermann Kunisch und Ulrich Pretzel. Berlin 1940, S. 26-36.

vON HumboldT, Wilhelm (1799): Über Goethes Hermann und Dorothea. In: ders.: Werke in fünf Bänden. Hrsg. v. Andreas Flitner und Klaus Giel. Bd. 2. Berlin 1961, S. 125-356.

Hume, David (1932): The Letters of David Hume. Hrsg. v. J[ohn] Y[oung] T[homson] Greig. Bd. 1. Oxford.

'JAM-DPAL-RGYAL-MTSHO (1990): The Singers of the King Gesar Epic. In: Honko (Hrsg.) (1990a), S. 471-484.

VON JAN, Eduard (1959): Neuprovenzalische Literaturgeschichte. 1850-1950. Heidelberg (= Hochschulwissen in Einzeldarstellungen).

Jansen, Jan/Henk M. J. Maier (Hrsg.) (2004): Epic Adventures: Heroic Narrative in the Oral Performance Traditions of Four Continents. Münster (= Literatur. Forschung und Wissenschaft 3).

Jansen, Ea (2000): Das estnische Pantheon. In: Varpio/Zadencka (Hrsg.) (2000a), S. 31-48. 
JendReieK, Helmut (1975): Hegel und Jacob Grimm. Ein Beitrag zur Geschichte der Wissenschaftstheorie. Berlin (= Philologische Studien und Quellen 76).

JOACHIMSTHALER, Jürgen (2007/2009): Mythos „Volk”. Zu Vorgeschichte und Entstehung der National-Texturen Mittel-, Ostmittel- und Nordosteuropas. In: Nordost-Archiv N. F. XVI (2007/2009), S. 19-77.

Jochmann, Carl Gustav (1828): Die Rückschritte der Poesie. In: ders.: Über die Sprache. Hrsg. v. Peter König. Mit einem Vorwort zu dieser Ausgabe v. Hans-Peter Schütt und einem einführenden Essay v. Ulrich Kronauer. Gesammelte Schriften 1. Heidelberg 1998, S. 151-195.

Jolles, André (1918): Wege zu Phidias. Briefe über antike Kunst. Berlin.

Jolles, André (1974): Einfache Formen. Legende, Sage, Mythe, Rätsel, Spruch, Kasus, Memorabile, Märchen, Witz. Studienausg. der 5., unv. Aufl. Tübingen (= Konzepte der Sprach- und Literaturwissenschaft 15).

JORDAN, Wilhelm (1867/74): Nibelunge. 4 Tle. Frankfurt a. M./Leipzig.

JORDAN, Wilhelm (1876): Epische Briefe. Frankfurt a. M.

KESSLER, Stephan (2007/2009): Literatur und werdende Nation in Lettland und Litauen. Die Versepen „Lāčplēsis“ (1888) und „Witolorauda“ (1846). In: Nordost-Archiv N. F. XVI (2007/2009), S. 127-180.

KeSSLER, Stephan (2010): Die Zeitschrift „Auszra“ - ein echter Grenzfall. In: Regina Hartmann (Hrsg.) (2010): Grenzen auf der Landkarte - Grenzen im Kopf? Kulturräume der östlichen Ostsee in der Literatur vom 19. Jahrhundert bis zur Gegenwart. Bielefeld, S. 241-263.

KÖHLER, Erich (1982): Gattungssystem und Gesellschaftssystem. In: ders.: Literatursoziologische Perspektiven. Gesammelte Aufsätze. Hrsg. v. Henning Krauss. Heidelberg (= Studia Romanica 46), S. 11-25.

Krastiña, Elīna (2004): Das erfundene Epos. Germanistische Untersuchungen zu Andrejs Pumpurs’ Epos „Lä̌̌cplēsis“. B.A.-Arbeit, Universität Lettlands, Riga, Germanistische Abteilung.

KreutzWALD, Friedrich Reinhold (1861): Vorrede. In: Kalewipoeg, eine Estnische Sage. Zusammengestellt v. F. R. Kreutzwald, verdeutscht v. C[arl] Reinthal und Dr. [Georg Schulz-]Bertram. Hrsg. v. der gelehrten Estnischen Gesellschaft. Dorpat, S. III-XVI.

KroHn, J[ulius] (1888): Die Entstehung der einheitlichen Epen im allgemeinen. In: Zeitschrift für Völkerpsychologie und Sprachwissenschaft. Bd. 18. Leipzig, S. 59-68.

LABARTHE, Judith (2007): L'epopee. Paris (= Collection U. Séries Lettres).

LaChmann, Karl (1816): Über die ursprüngliche Gestalt des Gedichts von der Nibelungen Noth. Berlin.

LĀMS, Ojārs (2008): Lāčplēša zvaigznājs. Latviešu eposa ǵenēze un funkcionalitāte Eiropas klasisko un jaunlaiku eposa tradīciju kontekstā. Riga. 
Laugaste, Eduard (1990): The Kalevala and Kalevipoeg. In: Honko (Hrsg.) (1990a), S. 265-285.

LAUTERBACH, Frank (2004): Einleitung. Nationalkulturelle Identitätskonstruktionen im Spannungsfeld dialektischer Differenzierung. In: ders. et al. (Hrsg.) (2004): Abgrenzung - Eingrenzung. Komparatistische Studien zur Dialektik kultureller Identitätsbildung. Göttingen (= Abhandlungen der Akademie der Wissenschaften zu Göttingen. Philologisch-Historische Klasse. Dritte Folge, 264), S. 1-13.

Lichtenstein, Ernst (1928): Die Idee der Naturpoesie bei den Brüdern Grimm und ihr Verhältnis zu Herder. In: Deutsche Vierteljahrsschrift für Literaturwissenschaft und Geistesgeschichte 6 (1928), S. 513-547.

LÖNnRot, Lars (1990): The Old Norse Analogue: Eddic Poetry and Fornaldarsaga. In: Honko (Hrsg.) (1990a), S. 73-92.

Lundmark, Bo: (1979): Anders Fjellner - Samernas Homeros - och diktningen om solsönerna. Umeå (= Acta Bothniensia occidentalis 4).

MackenzIE, Henry (Hrsg.) (1805): Report of the Committee of the Highland Society of Scotland, appointed to inquire into the Nature and Authenticity of the Poems of Ossian, with a Copious Appendix, containing some of the principal Documents on which the Report is founded. Edinburgh.

MaC Craith, Mícheál (2004): 'We know all these poems': The Irish Response to "Ossian". In: Howard Gaskill (Hrsg.) (2004): The Reception of Ossian in Europe. London/New York, S. 91-108.

MARX, Karl (1857/58): Einleitung [zu den „Grundrissen der Kritik der politischen Ökonomie“]. In: Karl Marx/Friedrich Engels: Werke. Hrsg. vom Institut für Marxismus-Leninismus beim ZK der SED. Bd. 42. Berlin 1983, S. $15-45$.

McDiarmand, Matthew P. (1973): Ossian as Scottish Epic. In: Scottish Literary News 3, 1973, H. 3, S. 4-9.

Mistral, Frederi [Frédéric] (1859): Mireille / Mireìo. Éd. bilingue. Chronologie introd. et archives de l'oeuvre par Charles Rostaing. Paris 1978 (= Texte intégral 304).

Niedling, Christian (2007): Zur Bedeutung von Nationalepen im 19. Jahrhundert. Das Beispiel von Kalevala und Nibelungenlied. Köln (= Universitätsschriften 2).

OKsala, Teiras (1990): Virgil's Aeneid as Homeric, National and European Epic. In: Honko (Hrsg.) (1990a), S. 49-71.

PEARSON, Raymond (1999): History and historians in the service of nationbuilding. In: Michael Branch (Hrsg.) (1999): National History and Identity: Approaches to the Writing of National History in the North-East Baltic Region Nineteenth and Twentieth Centuries. Helsinki (= Studia Fennica. Ethnologica 6), S. 63-77. 
Pumpurs, Andrejs (1888): Läčplēsis, latvju tautas varonis. Tautas eposs. Ar Jāzepa Rudzīša ievadapcerējumu un komentāru. Riga 1988.

RADLOFF, Wilhelm (1885): Die Sprachen der nördlichen türkischen Stämme. Abt. 1: Proben der Volksliteratur. Tl. V: Der Dialekt der Kara-Kirgisen. St. Petersburg.

ReImann, W[ilhelm] 1900: Einleitung. In: Kalewipoeg. Aus dem Estnischen übertragen v. F[riedrich] Löwe. Reval, S. V-XXVIII.

RuszCZYŃSKA, Marta (2000): Probleme der nationalen Wiedergeburt in der polnischen Literatur der Romantik bis 1831, besonders im Warschauer Milieu. In: Varpio/Zadencka (Hrsg.) (2000a), S. 87-99.

Schenda, Rudolf (1990): Frédéric Mistral's Poem „Mireille“ and Provençal Identity. In: Honko (Hrsg.) (1990a), S. 359-378.

SCHMIDT, Wolf Gerhard (Hrsg.) (2003/04) „Homer des Nordens“ und „Mutter der Romantik“. James Macphersons Ossian und seine Rezeption in der deutschsprachigen Literatur. 4 Bde. Berlin/New York.

SCHÖNING, Udo (1983): Nationales Epos oder epische Nation? Zu einem Problem der Chanson de geste. In: Romanisches Jahrbuch 34 (1983), S. 87100.

[ScOTT, Walter] (1805): [Doppelrezension zu:] Report of the Committee of the Highland Society of Scotland appointed to inquire into the Nature and Authenticity of the Poems of Ossian [...] 1805. / The Poems of Ossian \&c. containing the Poetical works of James Macpherson [...] by Malcolm Laing [...] 1805. In: Edinburgh Review, or Critical Journal, July 1805, No. XII, S. 429-462.

VON SEE, Klaus (1994): Das Nibelungenlied - ein Nationalepos? In: ders. (1994): Barbar, Germane, Arier. Die Suche nach der Identität der Deutschen. Heidelberg, S. 83-134.

SHER, Richard B. (1991): Percy, Shaw and the Ferguson 'cheat': National Prejudice in the Ossian Wars. In: Gaskill (Hrsg.) (1991), S. 207-245.

Skafte Jensen, Minna (1990): The Homeric Epics and Greek Cultural Identity. In: Honko (Hrsg.) (1990a), S. 29-48.

Smith, Anthony D. (1996): Nations and their Past. In: Nations and Nationalism 2 (1996), S. 358-365.

STAliūnas, Darius (1999): Die litauische Nationalidentität und die polnischsprachige Literatur. In: Yrjö Varpio/Maria Zadencka (Hrsg.) (1999): Themen des literarischen Nationalismus und der nationalen Literatur im Ostseeraum. Tampere (= Literatur und nationale Identität 2), S. 201-216.

STEckner, Hans (1927): Der epische Stil von Hermann und Dorothea. Halle a. S. (= Sächsische Forschungsinstitute in Leipzig. Forschungsinstitut für neuere Philologie. Altgermanische Abt. H. IV). 
STEIG, Reinhold (Bearb.) (1914): Clemens Brentano und die Brüder Grimm. Mit Brentanos Bildnis. Stuttgart/Berlin.

Steinthal, Heyman (1868): Das Epos. In: Zeitschrift für Völkerpsychologie und Sprachwissenschaft. Bd. 5. Berlin, S. 1-57.

TATERKA, Thomas (2011): „Epische Völker‘. Nationalepen des 19. Jahrhunderts in Europa und im Ostseeraum. In: Withold Bonner und Ewald Reuter (Hrsg.) (2011): Umbrüche in der Germanistik. Ausgewählte Beiträge der Finnischen Germanistentagung 2009. Frankfurt a. M. (= Finnische Beiträge zur Germanistik 26), S. 191-227.

Thomson, Derick S. (1952): The Gaelic Sources of Macpherson's “Ossian”. Edinburgh/London (= Aberdeen University Studies 130).

Thomson, Derick [S.] (1990): Macpherson's Ossian: Ballad Origins and Epic Ambitions. In: Honko (Hrsg.) (1990a), S. 115-130.

TuCker, Herbert F. (2009): Britain's Heroic Muse 1790-1910. Oxford et al.

Ulmann, K[arl] (1877): Volkslied und Volkscharakter. In: Baltische Monatsschrift XXV, 1877, S. S. 705-714.

Undusk, Jaan (2000): Nationsbildung als Textgestaltung. Die Rhetorik der Synekdoche im Diskurs des Nationalen Erwachens. In: Varpio/Zadencka (Hrsg.) (2000a), S. 9-30.

Vabarna, Anna (1995): The Setu Epic “Peko" Sung by Anna Vabarna. Hrsg. v. Paul Hagu/Seppo Suhonen. Kuopio.

VARPIO, Yrjö/Maria Zadencka (2000): Vorwort. In: Varpio/Zadencka (Hrsg.) (2000a), S. 1-5.

VARPIO, Yrjö/Maria Zadencka (Hrsg.) (2000a): Zur Literatur und Geschichte des 19. Jahrhunderts im Ostseeraum. Finnland, Estland, Lettland, Litauen und Polen. Stockholm (= Literatur und nationale Identität 3).

Veidemann, Rein (2004): Fr. R. Kreutzwalds „Kalevipoeg“ als ein heiliger Text in der estnischen literarischen Kultur. In: [KREUTzWALD, Friedrich Reinhold] (2004): Kalevipoeg. Das estnische Nationalepos. In der Übersetzung v. Ferdinand Löwe. Hrsg. v. Peter Petersen. Stuttgart, S. 263-268.

Vossschmidt, Liisa (1989): Das Kalevala und seine Rezeption im 19. Jahrhundert. Eine Analyse von Rezeptionsdokumenten aus dem deutschen Sprachraum. Frankfurt a. M. et al. (= Bochumer Schriften zur deutschen Literatur 9).

Winkler, Martina (2005): Clios Art zu dichten. Erzählkonventionen in Nationalhistorien. In: Alfrun Kliems/Martina Winkler (Hrsg.) (2005): Sinnstiftung durch Narration in Ost-Mitteleuropa. Geschichte - Literatur - Film. [Stuttgart] (= Geschichtswissenschaft und Geschichtskultur im 20. Jahrhundert 7), S. 5587.

Wolf, Friedrich August (1795): Prolegomena ad Homerum sive de operum Homericorum prisca et genuina forma variisque mutationibus et probabili ratione emendandi. Halis Saxonum. 
Wyss, Ulrich (1979): Die wilde Philologie. Jacob Grimm und der Historismus. München.

ZADENCKA, Maria (2000): Stanisław Wyspianski und der romantische Mythos des Opfers und der Tat. In: Varpio/Zadencka (Hrsg.) (2000a), S. 100-123. ZHI, Jia (1990): Epics in China. In: Honko (Hrsg.) (1990a), S. 503-518.

ZumThor, Paul (1990): Einführung in die mündliche Dichtung. Berlin. 


\section{Epos, Volksepos, Menschheitsepos - zum Epos-Konzept bei Herder}

Wer sich mit dem Nationalen in der Literatur und mit den im 19. Jahrhundert aus dem Boden schießenden Nationalepen im Zuge des so genannten „nationalen Erwachens“ vieler europäischer Völker beschäftigt, wird überall auf Herder verwiesen, gilt er doch als der Initiator jener Bewegung, welche die nationale Identität der Völker aus ihren frühen Überlieferungen abzuleiten bestrebt ist.

Schaut man aber genauer zu, wie konkret sich die Initiatoren jener Nationalbewegungen auf Herder beziehen, welche seiner Schriften sie rezipiert haben, so wird man oft enttäuscht. Es bleibt auch in der Forschung meist bei allgemeinen Hinweisen. In den Aufsätzen zum estnischen „Kalevipoeg“ etwa, die in Peter Petersens Ausgabe des Epos aufgenommen wurden, findet sich Herders Anregung nur sehr allgemein als Topos behandelt. Da heißt es z.B. zur Entstehung der Nationalepen: „Bahnbrechend waren [...] die Ideen und Publikationen Johann Gottfried Herders“ (Hasselblatt 2004: 299), oder, speziell zum „Kalevipoeg“":

In diesem Epos vereinen sich der von dem Aufklärungsgedanken getragene Rationalismus und der herdersche Romantizismus, der sich an die Vergangenheit und an das mündliche Erbe der Völker wandte und die von der Zivilisation unberührte Natur bewunderte und idealisierte. (Valk 2004: 315)

Keine Hinweise finden sich darauf, was die Förderer des estnischen Nationalepos, was etwa Friedrich Reinhold Kreutzwald, der Verfasser des Epos, was Friedrich Robert Faehlmann, Friedrich Georg von Bunge oder auch Georg Schultz-Bertram von Herder gelesen haben, so dass sich die Berufung auf ihn konkretisieren ließe. ${ }^{1}$ Es gilt aber wohl auch hier, was sich für die Rezeption Herders im 19. Jahrhundert überhaupt abzeichnet. Er wurde gelesen, aber nicht zitiert. Einige

\footnotetext{
${ }^{1}$ Vielleicht könnte sich die estnische Germanistik dieser Frage annehmen.
} 
seiner Grundideen waren gleichsam per Osmose bald in aller Munde, ohne dass erörtert wurde, wie sie bei Herder selbst entstanden und begründet worden waren. Der späte Herder hatte das bereits wahrgenommen und versucht, aus dieser Not eine Tugend zu destillieren:

Dein Name ist längst vergessen; dein Eigenthumsrecht war vielleicht schon mit dem ersten Viertheiljahre dahin, indem behende, rüstige Sprecher es sogleich zu dem Ihrigen machten; aber was ist Eigenthumsrecht und Name bei einem Gut, das der Menschheit zugehört? Je reiner du denkest, desto mehr wirst du dich selbst des Unrechts der Vergessenheit freuen, und dich in ihm geehrt finden. (SWS 16: 47)

Unabhängig davon, welche Ideen Herders für die Entstehung der Nationalepen im 19. Jahrhundert tatsächlich rezipiert worden sind, ist aber auch Herders Position selbst umstritten. Seit Längerem steht in Frage, ob und in welchem Maße er überhaupt als Ahnherr der Nationalbewegungen gelten, ob er gar als Initiator des so genannten nation building in Anspruch genommen werden kann. Man unterscheidet für die Entstehung von Nationen den objektivistischen vom subjektivistischen Ansatz. Im ersten Fall nimmt man an, dass Nationen aus ihren Ursprüngen organisch gewachsen sind, im zweiten, heute favorisierten Fall des nation building, betont man, dass Nationen durch die Initiative einzelner konzipiert und politisch durchgesetzt werden. ${ }^{3}$ Herders Zugehörigkeit zu einer der beiden Auffassungen ist umstritten. Es lassen sich aber in seiner anthropologischen Geschichtskonzeption durchaus Ansätze für beide Auffassungen finden. Auch sein Nachdenken über das Epos kann dazu beitragen, diese Ansätze zu erhellen. Im Folgenden sollen die Entstehung, der gedankliche Kontext und die Zielsetzung von Herders Epos-Konzept in drei Abschnitten dargelegt werden: 1. Lied und Epos, 2. Volksepos, 3. Menschheitsepos.

\section{Lied und Epos}

Als der junge Herder 1764 nach Königsberg kam, wurde er bekannt und bald eng befreundet mit Johann Georg Hamann, dem anregen-

\footnotetext{
${ }^{2}$ Herderzitate werden im Text nach der Werk-Ausgabe von Bernhard Suphan unter der Sigle SWS mit Band- und Seitenangabe nachgewiesen.

${ }^{3}$ Vgl. dazu den instruktiven Aufsatz von Endre Hárs (2008: 5).
} 
den, aber rätselhaften „Magus in Norden“4. Herder war der erste, der die Anregungen des Magus aufnahm, entwickelte und abwandelte. Das gilt auch für sein Epos-Konzept. In Hamanns „Aesthetica in nuce“ fand er zwei Bemerkungen, die er zur Blüte entfaltete.

Die erste Bemerkung war der berühmte Satz: „Poesie ist die Muttersprache des menschlichen Geschlechts." (Hamann 1968: 81) Herder verstand diesen Satz so: Am Beginn der Bewusstseins- und Zivilisationsgeschichte der Menschen waren ihre sprachlichen Äußerungen nicht abstrakte Begriffe, sondern ganzheitliche Empfindungsausdrücke mit allen Sinnen, sie waren emotionale Lieder, also Poesie.

Die zweite Bemerkung Hamanns, die Herder aufgriff, führt direkt zum Epos, denn sie bezieht sich auf den Leittext der europäischen epischen Tradition, auf das Epos Homers. Hamann schrieb:

Meine Bewunderung oder Unwissenheit von der Ursache eines durchgängigen Sylbenmaaßes in dem griechischen Dichter ist bey einer Reise durch Curland und Liefland gemäßigt worden. Es giebt in angeführten Gegenden gewisse Striche, wo man das lettische oder undeutsche Volk bey aller ihrer Arbeit singen hört, aber nichts als eine Cadenz von wenig Tönen, die mit einem Metro viel Ähnlichkeit hat. Sollte ein Dichter unter ihnen aufstehen: so wäre es ganz natürlich, daß alle seine Verse nach diesem eingeführten Maasstab ihrer Stimmen zugeschnitten seyn würden. (Hamann 1968: 143f.)

Alle Aspekte in diesem Text Hamanns sind für Herders Epos-Konzept von grundlegender Bedeutung. Da ist zunächst die Hervorhebung eines einheitlichen Metrums, wie etwa des Hexameters, für ein Epos. Dieses Metrum liegt nicht einem Sprechen, sondern einem Gesang zugrunde. Dadurch schließt sich diese Stelle für Herder mit der anderen von der Poesie, vom Lied als der „Muttersprache des menschlichen Geschlechts“ zusammen. Das Metrum ist nach Hamann auf die „Stimmen“ des Volks „zugeschnitten“. Das heißt, es ist auf die sinnlichste Bedingung der menschlichen Äußerung, auf die hörbare Stimme, bezogen. Dadurch wird das Metrum für Herders Epos-Theorie zentral:

\footnotetext{
${ }^{4}$ Diesen Beinamen erhielt Hamann von Friedrich Carl von Moser, der 1762 auf einen Angriff Hamanns mit einer Einzelschrift geantwortet hatte, die den Titel führte: „Treuherzigen Schreiben eines Layen-Bruders im Reich, an den Magum in Norden oder doch in Europa“.
} 
Es ist der innerste Ursprung aller anfänglichen Äußerungen und deshalb ursprünglicher als alle begrifflichen Inhalte solcher Gesänge; das Metrum ist gleichsam die kondensierte Vorgeschichte des Volks. Im Metrum haben sich die Eigentümlichkeiten der Weltsicht und der Weltbehandlung eines Volkes abgelagert und zu einer Form gehärtet, in die alles Spätere gefasst werden muss, wenn es dem Volk eigen sein soll. Wichtig ist deshalb für Herders Ursprungstheorie Hamanns Ableitung des Metrums aus kollektiven Lebenszusammenhängen, wodurch das Metrum eine Art anonymen Ursprungs aus dem Charakter eines Volkes erhält. Aber eine direkte Herleitung aus Arbeitsrhythmen, wie Hamann nahelegt, scheint Herder nicht betont zu haben, vermutlich, weil sie bereits Arbeitsteilung voraussetzt. Herder nimmt eher einen religiösen Ursprung an und führt die Entstehung von Metren auf anfängliche kollektive Gebete zurück, die „Könige“ oder „Priester“ (SWS 32: 106) dem Volk in einer ihm gemäßen Wiederholungsstruktur vorsangen, die durch „gleichmäßige Füße, die wieder kommen“, das „erste rohe Sylbenmaaß" (ebd., 107) bot. An anderer Stelle hört er aus dem Stabreim skaldischer Gesänge Anklänge „zum Gange des Kriegsheers“ (SWS 5: 165) heraus.

Der nächste wichtige Gedanke Hamanns liegt darin, dass ein Dichter, der in diesem Volke „aufsteht“, sich „ganz natürlich“, gleichsam unbewusst, an diese sinnlichste Ursprungsbedingung seines Volkes hält. Er muss „seine Verse nach diesem eingeführten Maasstab ihrer Stimmen“ zuschneiden. Diese Vorstellung, dass eine metrische Disposition in einem Volk immer schon vorliegt, wenn Einzeldichtung beginnt, ist auch Herders Überzeugung, weil darin Kreativität und Tradition, die beiden Hauptaspekte seiner Geschichtsauffassung, ${ }^{5}$ zusammengeführt werden: Für ihn

bildet sich Geschichte im Spannungsfeld zweier Pole, zwischen Tradition und Ursprünglichkeit. Tradition sichert die Kontinuität eines Gegenstandes, so daß er derselbe bleibt - Ursprünglichkeit greift schöpferisch ein,

\footnotetext{
${ }^{5}$ Herder nennt in den „Ideen zur Philosophie der Geschichte der Menschheit“ diese „Principien“ seiner „Philosophie [...]: sie heißen Tradition und organische Kräfte.“ Durch sie wird die „Naturgeschichte des Menschen“ (SWS 13: 347), also „die Erziehung unsres Geschlechts in zwiefachem Sinn genetisch und organisch: genetisch durch die Mittheilung, organisch durch die Aufnahme und Anwendung des Mitgetheilten" (SWS 13: 348).
} 
wandelt ab, sorgt diskontinuierlich für die Diversität des Identischen. (Bosse 1979: 81$)^{6}$

Der ursprüngliche Einfall eines Genies ist immer Schöpfung; sie liegt auch dem anonymen Genie des Volkes als Ursprung des Metrums zugrunde. Aber aus dem schöpferischen Ursprung bildet sich eine Traditionslinie historischer Identität heraus, auf die alle weiteren Schöpfungen nachahmend und abwandelnd bezogen bleiben.

Die erstaunlichste und für Herders geschichtliches Denken wichtigste Anregung Hamanns liegt aber im Bezug dieser Stelle auf die Querelle des Anciens et Modernes, auf den Streit um die Vorbildlichkeit der griechischen Kultur für die Gegenwart. Hamann schreibt, dass ihm beim Hören der lettischen Arbeitsgesänge in Livland und Kurland die „Bewunderung“ für Homers Hexameter „gemäßigt worden“ sei. Gemeint ist, Homer könne sie nicht erfunden haben, die Bewunderung für sein Originalgenie werde übertrieben; denn auch Homer nehme nur eine Tradition auf, innerhalb derer er erst seine poetische Kraft entfalten konnte. Herder formuliert diese Einsicht später lapidar: „Bekanntlich erfand Homer den Hexameter nicht“ (SWS 24: 234). Und er zieht aus der Bemerkung Hamanns die gewichtige Folgerung, dass die Entstehung von Lied und Epos nicht nur an ein Volk, etwa die Griechen, und nicht nur an eine vergangene Zeit, etwa die Antike, gebunden sind. Der Ursprung ist gleichsam auf historischer Wanderschaft durch die Zeit. Er kann zu jeder Zeit, an jeder Stelle der Welt von einem Individuum oder einem Volk erschaffen werden und dann die alten Traditionen in neue fortbilden. Hier liegt eine der Quellen für Herders Historismus, für die geschichtliche Gleichursprünglichkeit jedes Genies und jedes Volks: „Sehr leer war daher der Streit über den Vorzug der Alten oder der Neuern, bei welchem man sich wenig Bestimmtes dachte." (SWS 18: 135) Denn von den Völkern gilt: „[J]edes blühet an seiner Stelle in Gottes Ordnung." (Ebd., 138) Herders Interesse an der Geschichte ist nicht antiquarisch, sondern anthropologisch. So gilt, dass zu jeder Zeit geniale Schöpfungen entstehen können. Deshalb enthalten seine Volksliedsammlungen nicht nur Lieder aus der Frühzeit der Völker, sondern ebenso Lieder von Matthias Claudius, von Goethe und von Herder selbst. Ebenso gilt die Ebenbürtigkeit der Völker im Laufe der

\footnotetext{
${ }^{6}$ Bosses Artikel ist noch immer eine der besten Einführungen in Herders Denkwelt.
} 
Geschichte: Die Metren der „Undeutschen“ in Kurland und Livland, also des lettischen und estnischen Volks, können neben Homer bestehen, und „das Lied des litauischen Mädchens kann sich ungescheut neben der Ode Sapphos sehen lassen" (Gaier 1990: 960). In Hamanns Aufwertung der Letten und Esten werden die kleinen baltischen Völker erstmals als kulturell produktiv dem klassischen Kulturvolk der Griechen an die Seite gestellt. Und in Herders Ausarbeitung dieses Ansatzes zu einer umfassenden Geschichts- und Kulturtheorie stehen seither alle Völker als gleichursprünglich auf der Menschheitsliste.

Wie verbindet nun Herder die beiden Anregungen Hamanns von der Poesie als Muttersprache, die Herder als ursprüngliches Lied versteht, und von der Bedeutsamkeit des Metrums im Epos, wie verbindet er also Lied und Epos miteinander? Er verbindet sie geschichtsphilosophisch, indem er ihnen in seinem anthropologischen Geschichtsverständnis eine genetische Abfolge zuweist. $\mathrm{Zu}$ diesem Geschichtsverständnis zunächst ein orientierendes Wort: In Herders Geschichtskonzept kreuzen sich die beiden gegensätzlichen Geschichtsauffassungen des 18. Jahrhunderts: die Vorstellung der Hochaufklärung vom Fortschritt der Geschichte und die Rousseau'sche Konzeption von ihrem Abstieg. Einerseits wird der Mensch im Verlauf der Geschichte immer vollkommener und hat im 18. Jahrhundert einen strahlenden Höhepunkt erreicht, andererseits wird er im Gang der Zivilisationsgeschichte aus seinem natürlichen Ursprung gerissen, immer stärker seinem Wesen entfremdet und ist im 18. Jahrhundert auf einem Tiefpunkt der Trennung von seiner wahren Natur angelangt. Herder ist nun der Überzeugung, dass in der Geschichte immer beide Tendenzen zum Austrag kommen. Deshalb erdenkt er Modelle, die sie vereinigen. Dazu gehören seine organologischen Vergleiche der Geschichte mit dem pflanzlichen Wachstum vom Keim über Blüte und Frucht der Völker bis zu ihrem Verwelken (z.B. SWS 14: 144); oder die Parallelisierung von Menschheitsgeschichte und Individualgeschichte, indem er von Kindheit und Jugend, vom Mannes- und Greisenalter der Völker spricht (z.B. SWS 1: 151-155). Natürlich sind das nur Hilfsvorstellungen, um das Nebeneinander geschichtlicher Aufstiegs- und Abstiegsphasen begreiflich zu machen. Aber da es Herder immer um die Rettung und Erneuerung der Gegenwart geht, hält er sich dort mit diesen Hilfsvorstellungen zurück, denn deren Bilderlogik ließe für die Ge- 
genwart nur das Greisenalter des Verwelkens übrig. Dagegen setzt er die Vorstellung vom wandernden schöpferischen Ursprung, der jederzeit in einem Genie oder einem Volk erwachen und auf der Basis des Vergangenen eine neue Blütezeit eröffnen kann. ${ }^{7}$

Auf dieser geschichtsphilosophischen Skala Herders gehört das Lied zur Anfangsstufe der Entwicklung, gehört zu Keim und Kindheit der Völker, das Epos hingegen zu ihrer Blüte und Jugend. Herder denkt Keim und Kindheit der Völker mit Rousseau als ganzheitlich, sinnlich, roh und unzivilisiert. Die Sprache besteht noch in Klängen und Rhythmen, in Ausrufen, Inversionen, ist voller „Sprünge und Würfe“ (SWS 5: 197), wie Herder sagt. Sie ist, ganz auf das Hören bezogen, ausschließlich mündliche Klangrede in einfachen, emotionalen Gesängen aus der ursprünglichen Natur des Menschen. Zu ihrer Weitergabe bildet sich mit der Zeit eine besondere Spezies von Volkssängern heraus.

In der anthropologischen Geschichtsvorstellung Herders schließt sich das Epos an das Lied an und steht an der entscheidenden Schnittstelle zwischen Kindheit und Jugendblüte der Völker, zwischen dem Strom der Rede des Naturmenschen und der redenden Aufbewahrung des Vergangenen. Es dokumentiert den Übergang von der Mündlichkeit zur Schriftlichkeit, ${ }^{8}$ von der Natur zur Kunst, vom Kollektiv zum Individuum. Das Epos hat die große Aufgabe, die ursprüngliche Natur des Menschen aus der mündlichen Kundgabe in die Schriftform zu retten und zu erhalten. Es muss die Verluste der Unmittelbarkeit durch ästhetische Mittel, also künstlich, auffangen. Der Epiker tritt damit zwar als schöpferisches Individuum hervor, bleibt aber zugleich auf die Tradition des Kollektivs bezogen. Denn seine Aufgabe besteht darin, die ursprünglichen Lieder des Volks zu sammeln, zusammenzufügen und öffentlich vorzutragen. In dieser Praxis des Vortrags langer Gesänge bleibt die mündliche Tradierung nach Herder noch für eine längere

\footnotetext{
${ }^{7}$ Nach Ulrich Gaier versteht Herder seine „Konzeption des Ursprungs als das immer Wirksame, das sich nicht in göttlich glänzenden, sondern primitiven Anfängen manifestiert und sich in einer Metempsychose (Seelenwanderung) immer neue Gestalten gibt" (Gaier 1985: 818).

8 „Ein Dichter wie Homer lebte im Jünglingsalter der Sprache, wo die Seele der Dichter ,nicht schrieb, sondern sprach, und auch schreibend lebendige Sprache tönete‘." (Bosse 1979: 86 mit SWS 1: 395).
} 
Zeit erhalten. „Selbst Homer schrieb noch nicht, sondern er sang [...]“ (SWS 32: 88).

Der Übergang vom ursprünglichen Lied zum epischen Gesang, der Herder als Schaltstelle für die weitere Ausdifferenzierung der Gattungen gilt, wird von ihm in immer neuen Ansätzen umschrieben. Je nach Argumentationsziel wird dabei mal mehr die ursprüngliche Naturnähe des Epos, mal sein neuer Kunstcharakter betont. Im Lied liegt der Schwerpunkt auf dem „melodischen Gange der Leidenschaft oder Empfindung“, auf der „Weise“, wie Herder sagt. Ihr gegenüber ist „der Inhalt selbst $[\ldots]$ nicht von Belange“" (SWS 25: 332). Im epischen Gesang hingegen verlagert sich der Schwerpunkt auf den Inhalt, denn das Epos vermittelt mythische Geschichtserzählung. Im ursprünglichen Lied wird durch Metrum und Weise die Basis gelegt für "Sicherheit und Vestigkeit des Ausdrucks“ (SWS 5: 182), die heute nur noch „unverdorbne Kinder, Frauenzimmer, Leute von gutem Naturverstande“ (ebd.) zeigen. Diese Basis wussten dann die epischen Sänger wie Homer und Ossian „mit Würde, mit Wohlklang, mit Schönheit zu paaren“, wodurch sie „Seele und Mund in den festen Bund gebracht hatten" (SWS 5: 182), den sie in ihren epischen Kunstwerken erschufen. Das heißt aber auch, dass „endlich die Kunst kam und die Natur auslöschte“ (ebd.).

\section{Volksepos}

Der Bezug des Epos auf voraufgehende Volks-Lieder ist der wichtigste Aspekt, der für Herder das Epos zur ursprünglichsten, naturnahen Kunst, zur Dichtung des Menschen macht. Er drückt das durch den Terminus „Volksepos“ aus. Herder spricht zwar auch vom Epos einer Nation, aber damit meint er nicht das Epos einer Staatsnation im Sinne des 19. Jahrhunderts. Der Staat ist für ihn vielmehr eine Erscheinung des zivilisatorischen Niedergangs, verantwortlich für viele Aspekte der Entfremdung des Menschen von seiner Natur. Herder lässt zwar die Menschheit sich von „Stammvätern zu Familien, von Familien zu Stämmen, Völkern und Nationen, jedoch nicht weiter, nicht zwingend zu Staaten und anderen politischen Gemeinschaften“ (Hárs 2008: 8) fortbilden. Hárs (ebd.) macht mit den folgenden Herderzitaten deutlich, dass Herder entsprechend der objektivistischen Tendenz seiner 
Ursprungsvorstellung nicht glaubt, dass der Mensch „für den Staat gemacht seyn soll, daß aus dessen Einrichtung nothwendig seine erste wahre Glückseligkeit keime“ (SWS 13: 340). Auf „Regenten und Staaten hat die Natur nicht gerechnet; sondern auf das Wohlseyn der Menschen in ihren Reichen“ (SWS 14: 248). Die natürliche Erfüllung des Menschseins geschieht daher in der gewachsenen Kultur einer Nation, d.h. im Volk, nicht im Staat. ${ }^{9}$

Was aber ist Herders „Volk“? Es ist in erster Linie ein anthropologisches Konstrukt, eine theoretische Fiktion, ein Arbeitsbegriff, geboren aus Herders Lebensziel, den Menschen der Gegenwart über die Erneuerung seiner Dichtung neu zu erschaffen. Sein „Volk“ ist eine „Ganzheit [, die] nicht mehr oder noch nicht existiert" (Bosse 1979: 87f.). Daher hat sein Volksbegriff zugleich eine Vergangenheits- und eine Zukunftsbedeutung. Einerseits ist das Volk der ursprünglich ganzheitliche Zustand des Menschen, in dem die Trennung der Vermögen mit der Entfremdung von der Sinnlichkeit noch nicht eingetreten ist. Das Volk sind jene „Geschöpfe, die noch näher an der Natur sind, als Gelehrte“ (SWS 32: 41). Andererseits kann und muss diese Ganzheit durch geniale Volkserzieher wiederhergestellt werden. Ein ganzheitlicher Philosoph und Menschenbildner, wie Herder selbst, kann die Entfremdung rückgängig machen. Denn

die hierarchisierende Auftrennung der menschlichen Erkenntniskräfte ist für Herder [...] kein anthropologisches Datum, sondern eine kulturgeschichtlich hervorgebrachte Konvention des Denkens, die es zu überwinden gilt. (Deiters 2002: 186)

\footnotetext{
${ }^{9}$ Der späte Herder sieht den Staat freilich positiver, wenn er als „Kunst aller Künste, die Gesetzgebung und Staatskunst" (SWS 16: 47f.) hervorhebt oder konstatiert, dass die „wohl unzweifelhaft [...] höchste, schwerste und nützlichste Kunst der Menschen, die Einrichtung einer Nation zur allgemeinen Wohlfahrt" (SWS 16: 600) sei. Diese Kunst ziele auf den „Einen großen Endzweck, der National-Wohlfart“ (SWS 16: 601). Hárs (2008: 11-13) scheint in dieser subjektivistischen Annahme eines genialen Staatslenkers für die Nationenbildung einen Widerspruch zu Herders vorherrschender objektivistischer Auffassung zu sehen, aber Herders anthropologische Geschichtsauffassung vom wandernden (genialen) Ursprung lässt das Zugleichsein beider Tendenzen durchaus zu.
} 
In Herders Volksbegriff ist der eigentliche

Referenzpunkt [...] nicht, wie er vorgibt, eine wie auch immer auf ihn gekommene mündliche Tradition, sondern eine Idee: Der Begriff des Volks in seiner anthropologischen Bedeutung als Totalität des menschlichen Gattungswesens. (Deiters 2002: 196)

Diese ideale Konstruktion „Volk“ wird daher zum Kernbegriff in Herders Geschichtsanthropologie und verkörpert darin zunächst das Schöpferische, Ganzheitliche, Sinnliche des anfänglichen Menschen, seine wahre Natur, die im Laufe der Zivilisationsgeschichte zertrennt, zerstückelt und aufgelöst worden ist. Im Niedergangshorizont der Gegenwart des 18. Jahrhunderts stehen sich daher für Herder zwei verdorbene Menschentypen als Ergebnis dieser Trennungsgeschichte gegenüber: der trockene, seinen Sinnen entfremdete Gelehrte und der triebhafte, seiner Vernunft entfremdete Pöbel. ${ }^{10}$ In dieser Entfremdungssituation wird dann jene Idealvorstellung des Volks zu Herders anthropologischer Richtgröße für die Zukunft. Aus dem „Volk“ als historischem Ursprung entstanden die ersten Lieder und Gesänge und aus ihm als durch die Geschichte wanderndem Ursprung können im Rahmen der durch den historischen Ursprung gesetzten Tradition neue geschichtliche Möglichkeiten des ganzheitlichen Menschen durch geniale Einzelne erschaffen werden. Das Volk ist nichts als „die gesellschaftliche Entsprechung des individuellen Seelengrundes und Ursprungs“" (Gaier 1985: 818). Was auf der Individualebene das Originalgenie, das ist auf der Kollektivebene das Volk. Die ursprünglichen Lieder waren "Stimme des Volks“ (SWS 25: 645). Jeder originale Poet schöpft aus dieser Quelle und spricht mit dieser Stimme.

Deshalb ist für Herder nicht nur Homer, sondern auch Shakespeare, der in seinen Augen große Erneuerer der Antike, ein „Volksdichter“ (ebd., 314), ${ }^{11}$ und deshalb auch nimmt er Lieder von Goethe - und seine eigenen - in seine Volkslied-Sammlungen auf. Als Originalgenie Volksdichter zu sein, garantiert dem Poeten des Sturm und Drang anthropologische Ursprünglichkeit und gibt ihm in den Auflösungswirren der Ständegesellschaft eine neue Legitimation, nachdem der an

\footnotetext{
${ }^{10}$ Vgl. zu dieser Unterscheidung den schon zitierten, vorzüglichen Aufsatz von Franz Josef Deiters (2002: 186).

${ }^{11}$ Vgl. dazu ebd., 183.
} 
diese Gesellschaft gebundene poeta doctus seine Autorität als Lehrer des Volks eingebüßt hatte. ${ }^{12}$ Der neue Poet dichtet nicht mehr aus der Gelehrsamkeit für seinesgleichen und für die Ungelehrten, sondern aus dem Ursprung des Volks für das Volk. Dadurch gewinnt er ein neues Verhältnis zu seinem Publikum und eine neue Rechtfertigung seines Tuns.

Betrachten wir genauer, wie Herder das Volksepos aus den Volksgesängen ableitet. Sein Vorzugsbeispiel ist Homer, dem später als nordisches Beispiel Ossian an die Seite tritt. Noch innerhalb der mündlichen Kulturen haben sich aus einzelnen Liedern Gesänge gebildet, die sich um einzelne Führungsgestalten und historische Ereignisse eines Volkes ranken. Herder nennt sie „Volkssagen“ (SWS 24: 230), in denen die geschichtlichen Erfahrungen eines Volks aufbewahrt wurden. Von Volkssängern, den griechischen Rhapsoden oder den nordischen Barden wurden sie öffentlich vorgetragen und dienten dazu, die Identität eines Stammes oder Volks aufzubauen und zu erhalten. Homer und Ossian sind solche Sänger, die zwar am Ende einer Entwicklung stehen, aber die Sangestradition eines Volks noch in lebendigster Nähe zum natürlichen Ursprung aufnehmen und weitergeben. Für diese entscheidende geschichtliche Instanz am Übergang von der „Volkssage“ zum Epos, die nach Herder die Namen „Homer“ oder „Ossian“ trägt, findet er ein ganzes Spektrum von Bezeichnungen, die nur aus seiner Vorstellung vom Zugleichsein von Tradition und Ursprung, von Bewahrung und Schöpfung verständlich sind. Er nennt sie sowohl „Sammler" (SWS 24: 228) und „Chronikschreiber“ (ebd., 230) als auch kunstvolle Poeten und Dichter. Sie sind Sammler, weil sie die Fülle der umlaufenden Volksgesänge zusammenfassen, also die Tradition bewahren, und sie sind Poeten, weil sie das Heterogene des Vorgefundenen zu einem ästhetischen Ganzen verdichten. Das können sie, weil sie als Naturgenies denselben schöpferischen Ursprung in sich tragen, der in der Natur des Volks lebt und der als Neuerungsimpuls durch die Geschichte der Traditionen geht. Hieraus ist auch verständlich, dass bei Herder keine eindeutige Position zur Frage der historischen Authentizität der alten epischen Texte auszumachen ist. Schon früh vertritt er die Auffassung, dass an Homers Epen eine Vielzahl von

${ }^{12}$ Vgl. dazu ebd., 182. 
Vorsängern beteiligt war. Homer ist ihm eine Instanz, nicht eine Person. Deshalb ist er auch der Meinung, dass ihm Friedrich August Wolf, der bedeutende Erneuerer der Altertumswissenschaft, nichts Neues sagen konnte. ${ }^{13}$ Und selbst Macpherson gesteht er zu, dass er für den Ossian vielleicht „nur rohen Stof“ (SWS 18: 452) empfing, den er „mit Schöpferhand zusammen [setzte]“ (ebd.).

Die Echtheit Ossians war für Herder nicht problematisch, solange seine Ursprünglichkeit feststand. Ossian bleibt ihm geradezu das große Beispiel dafür, daß Poesie mehrfach entsprang, also immer wieder entspringen kann. (Bosse 1979: 87)

Im Blick auf Herders Ziel einer Erneuerung der Dichtung steht nicht die historische Authentizität eines Epos im Vordergrund, sondern vielmehr die Frage, ob es „Volksartig“ (SWS 25: 313) ist, also die ganzheitlich sinnliche Ursprungsnatur des Menschen verkörpert und in die zu erneuernde Gegenwart vermitteln kann. So hätte Herder wohl auch Lönnrots Arbeit am „Kalevala“, vielleicht sogar Kreutzwalds Arbeit am „Kalevipoeg“ zustimmend in seinen anthropologisch-historischen Kategorien unterbringen können.

Da das Epos schon in mündlicher Zeit durch den poetischen Zugriff des Dichters auf die Volkstradition entsteht, will ich vier von Herder besonders hervorgehobene Aspekte der Poetik des Volksepos anführen. Erstens: In die vielen unendlich fortsetzbaren Gesänge der Volkssagen bringt der Eposdichter einen großen Erzählzusammenhang mit Anfang, Ende und durchlaufenden Verknüpfungen der Ereignisse. Dadurch verdichtet er dem Volk erstmals seinen Werdegang zu einer eigenen, in sich schlüssigen Geschichte. Zweitens: Da das Epos als erstes Kollektivmedium die gesamte Weltsicht eines Volkes versammelt, stellt es zugleich eine Art Enzyklopädie des damaligen Wissens dar, wodurch der Eposdichter zugleich zur universalen Wissensinstanz wird. Drittens: Unter den vielen überlieferten Sagenfiguren wählt der Dichter einen überragenden Helden aus, etwa Achill oder Odysseus, und komponiert die Geschehnisse um dessen Person herum. Der epische Held gehört für Herder notwendig zum Epos, weil er in seinem Konzept eine bedeutsame anthropologische Position einnimmt. Er bringt das charakte-

\footnotetext{
${ }^{13}$ Vgl. die spärliche Anmerkung zu Wolfs epochalem Werk in Herders „Homer, ein Günstling der Zeit“ (SWS 18: 428).
} 
ristische innere Wesen des gesamten Volks zum Ausdruck und verkörpert dessen ursprüngliche Natur. Deshalb muss er eine herausragende und überlegene Figur sein. Viertens - und das ist wohl der für Herder wichtigste Punkt -: Das Epos kommt nicht ohne Götter aus, nicht ohne das Wunderbare im Hintergrund, das mit dem Helden im Bunde ist.

[D]as Anständigste, Würdigste aber, was dieser Dichtung ziemte, blieb dennoch das Göttliche, ( $(\theta \varepsilon\llcorner\mathrm{ov})$ das Leben der Götter mit Menschen, die Einwirkung des Himmels auf die Erde; dies ist die Seele des epischen Gedichtes. (SWS 24: 278f.)

Da Herder auch für das Wunderbare eine anthropologische Begründung gibt, ist dessen Präsenz nicht nur für die antiken Epen notwendig, sondern es muss auch im zu erneuernden Epos der Gegenwart zentral sein. Jede wirksame Theologie, nicht nur der Mythos, ist Anthropologie. Die Götter und das Wunderbare stehen für die Bewältigung der Endlichkeit des Menschen, der auch als überragender Held Zufälligkeiten ausgesetzt ist, dessen Pläne immer wieder durchkreuzt werden, der Phasen der Ohnmacht durchlebt. Deshalb kann er nur vollkommen und vorbildlich werden, wenn Götter ihm zur Seite stehen. Diese Nähe zum Göttlichen gehört zur innersten Ursprungsnatur eines Volks, von der sich die zivilisierte Gegenwart weit entfernt hat. Herder kritisiert, dass die zeitgenössische Poesie das Wunderbare zum bloß Zauberischen erniedrigt hat oder es ganz verschwinden lässt. Das sei historisch gefährlich, weil anthropologisch falsch.

Ich hebe die Anthropologie als Zentrum des Herder'schen Geschichtsdenkens deswegen so hervor, weil nur dieser Ansatz es ihm erlaubt, die Hochschätzung des historischen Ursprungs mit dem Ziel einer Erneuerung der Gegenwart zu verbinden. Dass die ganze „Philosophie [...] auf Anthropologie zurückgezogen" (SWS 32: 37, 59) werden müsse, ist seine Grundeinsicht. Spätestens hier muss aber ein Blick auf Herders Humanitätspathos geworfen werden. Weil er überzeugt ist, dass die Menschlichkeit des Menschen nur erhalten und gefördert werden kann, wenn seine ursprüngliche Ganzheit auch in der Moderne mit künstlerischen Mitteln wiederhergestellt wird, sollen die Volksepen, welche diese Ganzheit lebendig repräsentieren, gesammelt, rekonstruiert, ergänzt, ja letztlich auch neu geschrieben werden. Daraus ergibt sich aber ein Argument Herders gegen die politische Funktion des Nationalepos, das im 19. Jahrhundert entstand. Die Wiederherstellung 
der Volksepen ist für ihn kein Selbstzweck, sondern eine Durchgangsstation auf dem Wege zur Humanität, die ihren Kern ausmacht. Die verschiedenen Volksepen sollen miteinander verglichen werden, um zu erweisen, dass sie alle diesen humanen Kern lebendig enthalten. Ihn herauszuarbeiten und für die Erneuerung der Menschheit zu nutzen, ist Herders Fernziel, wenn er seine Zeitgenossen ermuntert, Volkslieder, Volkssagen und Volksepen zu sammeln und - wenn sie denn Originalgenies sind - auch zu schreiben. Wenn dagegen die Volksepen als Nationalepen verstanden werden, wenn sie dazu dienen, die Überlegenheit der eigenen gegenüber anderen Nationen auszuspielen, wenn sie schließlich zur Legitimation von Nationalstaaten herhalten müssen, dann ist diese Entwicklung nicht im Sinne Herders. Er zielt über die Nation und ihren Selbstruhm hinaus auf eine humane Anthropologie als Zentrum eines zukünftigen Menschheitsepos.

\section{Menschheitsepos}

Der Übergang vom Volks- oder Nationalepos zum Menschheitsepos hängt aufs Engste mit Herders Gegenwartsanalyse zusammen. Aufgrund der Zerstückelung der ursprünglichen Ganzheit des Volks, die sich in der Isolierung der Individuen und im Antagonismus der Nationen spiegelt, wirkt Poesie nicht mehr auf das Kollektiv, sondern nur noch auf den Einzelnen. Sprach die ursprüngliche Dichtung das Volk als Ganzes an und umfasste seine gesamte Lebensführung, seine Geschichte und politische Existenz, so muss sie jetzt die Humanität in jedem einzelnen Individuum wecken, um auf diese Weise „die Menschheit in ihrem ganzen Umfange auszubilden“ (Bosse 1979: 89). Durch die „Beförderung der Humanität“ (SWS 17: 1) als Herders Universalziel „verliert“ die Dichtung ihren ursprünglichen „durch und durch politischen Sinn an einen Bildungsauftrag, kraft dessen sie sich aus den Machtkämpfen der Gegenwart heraushält" (Bosse 1979: 89). Der humane Bildungsauftrag fordert ein Überspringen der politischen Staatsnation, wie sie sich im 19. Jahrhundert herausbildet.

Herder zieht sich bei seinem Entwurf für die „Beförderung der Humanität“ und bei der Forderung nach einem Menschheitsepos auf das humane Zentrum seiner Anthropologie zurück, in dem Politik, Machtkämpfe, Unmoral und wohl generell das Böse nicht ursprünglich vor- 
kommen. Epische Erhebungen historischen Unrechts wie die Darstellungen der frevelhaften Kreuzzüge oder der grausamen Eroberungen Amerikas werden deshalb verworfen. Als besonders abstoßend verurteilt Herder, dass sogar im heutigen Europa „die habsüchtig-mordende, stolze Christen-Epopee noch gefeiert" (SWS 24: 292) werde.

Zum Verständnis dieser Ausklammerung des Bösen aus dem Epos muss auf den theologischen Kern der Auffassung Herders vom wandernden Ursprung eingegangen werden, der die wahre Menschlichkeit am Beginn der Volks- und Menschheitsgeschichte und ihre historisch immer mögliche geniale Erneuerung verbürgt. Herder entwirft seine Anthropologie aus der theologischen Vorstellung, dass der Mensch nach dem Ebenbild Gottes geschaffen sei. In der Geschichte des Individuums und der Menschheit gehe es deshalb darum, „wie das wahre Ebenbild Gottes im Menschen zu seiner ursprünglichen Bestimmung gebildet werden kann" (Zippert 1994: 864). Es ist also die historische Aufgabe des Menschen, dieses an seinem Ursprung in ihn gelegte Ebenbild in seinem geschichtlichen Dasein als Individuum und als Volk immer perfekter herauszuarbeiten. „[I]ch werde, was ich bin!“ (Herder, Briefe 1: 139), so formulierte Herder diesen aus seiner Theologie abgeleiteten historisch-anthropologischen Grundsatz in einem frühen Brief an Mendelssohn. An dieser Stelle gewinnt bei Herder das Fortschrittsdenken der Aufklärung über Rousseau die Oberhand. Doch wird der „Fortschritt“ der Aufklärung durch Herders Vorstellung von der Ausarbeitung des Ebenbildes religiös aufgeladen und wandelt sich in einen „Fortgang“, der "die echte, ganze, moralische Natur des Menschen“ (SWS 18: 140) zum Vorschein bringen wird. Geschichte und Herders Verständnis von Heilsgeschichte als menschlicher Ausbildung des göttlichen Ebenbildes fallen im Fortschreiten der Menschheit zusammen. Aus dieser Verknüpfung der aufgeklärten Auffassung von der Perfektibilität des Menschen mit der Ebenbildlichkeit entsteht Herders Bildungsbegriff: Bildung ist Herausbildung der Ebenbildlichkeit. Seither besitzt Bildung, jedenfalls in Deutschland, eine religiös getönte Aura. Es geht Herder also darum, dass durch den Rückgang in den historischen und in den seelischen Ursprung des Menschen das göttliche Ebenbild in ihm „aufgeweckt“ (SWS 32: 39) wird und er dann „sich an sich selbst zum Gotte schafft" (Herder 1985: 34). Er verbindet nun dieses Ebenbild durchaus mit der Hamann'schen Vorstellung vom „Christus in 
uns"; allerdings versteht er diesen nicht als leidenden, sondern als eine Art triumphierenden Christus, als den Inbegriff der menschlichen Schöpferkraft, der als schaffender Ursprung im Menschen durch die Geschichte zieht und jederzeit Neues hervorbringen kann. Das WieGott-sein-Wollen und -Werden aus der Sündenfallerzählung ist für Herder nicht Verhängnis, sondern Ziel der Menschengeschichte.

Wie verbindet er nun diese Auffassung mit seinem Epos-Konzept? Das Epos hat die Aufgabe, die Herausbildung der Heilsgeschichte in der menschlichen Historie darzustellen, „denn die höchstphilosophische Geschichte des menschlichen Geistes und Herzens, in lebendigen Charakteren auf die wirksamste Weise durch erzählende Rede dargestellt, ist ja das Epos“ (SWS 24: 240). Es „schafft die wahre, die vollkommene, die ewigdaurende Geschichte“ (ebd., 241).

Herder spricht in seinen späten Äußerungen besonders häufig vom „lebendigen Wort“ des Epos. Darin verknüpft er den Gedanken vom lebendigen Ursprung im Naturgesang mit dem „lebendigen Wort“, das Christus im Neuen Testament bedeutet. Entsprechend stellt er seine Ausführungen unter den Titel „Vom Heiligen der Epischen Dichtkunst“ (ebd., 278). Herders Auffassung davon, dass Götter und Helden für jedes Epos, für das vergangene wie das zukünftige, unabdingbar sind, wird aus seiner theologischen Anthropologie begründet. Sie fließt aus einer spinozistisch gewendeten Vorstellung von der Inkarnation, die Gott und Mensch von gleicher Art sein lässt: „[W]o im lebendigen Wort der Nationen eine Stimme der Musen episch erschallet, ists in dieser Verbindung des Himmels und der Erde" (ebd., 279). Das Religiöse schadet dem Epos nicht, sondern ist seine Voraussetzung, „solange das Menschliche [...] des Helden“ (ebd., 282) dadurch hervorgehoben wird. Nur eine Religion, deren Kern das Humanum ist, macht das Epos "göttlich" (ebd.). Unter dieser Voraussetzung verlässt Herder die Bindung des Epos an ein jeweils geschichtliches Volk. Der Held des Epos wandelt sich vom Volksrepräsentanten zum Menschheitsrepräsentanten.

Gern vergäßen wir an ihm Nationen, Sprachen, Secten, geschweige Lehrbegriffe und Vorurtheile, sobald und solange er in uns das lebendige Wort, d. i. den Begriff und die That Eines einzig möglichen Weltheilandes sprechen machte. (Ebd.) 
Herders Eposkonzept zielt auf eine Werk-Utopie ab, die Völker und Sprachen, an die das bisherige Epos gebunden war und an die Herder auch bisher den Ursprung des Epos gebunden hatte, übersteigt. Es ist gleichsam ein pfingstliches Menschheitsepos, das ihm vorschwebt. Es wird kein Epos der Nationen und Sprachen mehr sein, sondern ein Menschheitsepos.

Dieser „hohen Anfoderung“ (SWS 24: 281) kann aber keiner der groBen Volksheroen der Vergangenheit mehr genügen. Auf der Suche nach dem Menschheitshelden wird das Volksepos überschritten, und das Religiöse im Menschheitsepos muss vom Range einer Weltreligion sein, die alle Nationen übergreift. Eine solche Weltreligion stellt für Herder aber nur die christliche Religion dar, und als zentraler Held seines künftigen Menschheitsepos kommt nur Christus selbst infrage: „Welch großes, ewiges, lebendiges Wort (єпоऽ) in aller Menschen Herzen ist, recht verstanden, der Christus! eine reine Gestalt, die Gottheit im Menschen, sichtbar, gegenwärtig, verkläret.“ (Ebd., 282) Herders Christus ist der Inbegriff des Menschlichen im Sinne des Ursprungs von allem Schöpferischen und Guten. „Die Religion Christi, die Er selbst hatte, lehrte und übte, war die Humanität selbst." (SWS 17: 121) Herder fordert also ein Christus-Epos als Menschheitsepos. Die unter dieser Auffassung konkurrierenden Epen Miltons und besonders Klopstocks Messias hält er für unzureichend, und zwar deswegen, weil sie nicht seine erhabene Vorstellung von der göttlichen Ebenbildlichkeit des Menschen treffen. Milton zeichne die Menschennatur als zu „schwach“ und Klopstock hänge zu sehr an den biblischen Bildern und sei „einer helleren Führung seines Gedichtes" (SWS 24: 292), also der göttlichen Erhöhung des Menschen, ausgewichen. Wer aber soll dann dieses Christus-Epos schreiben?

In seinen Überlegungen zu den Volksliedern kennt Herder zwei Wege des Zugangs zum Ursprungskern der Völker. Der eine Weg ist der „blos von außen, durch Fratzenkupferstiche und Nachrichten, die den Kupferstichen gleichen," der andere, entscheidende Weg aber ist der "von innen“, von Menschen zu Menschen, welche „Sprache, Seele, Empfindungen haben“, also „unsre Brüder“ (SWS 25: 81) sind. Dieser Herder'sche Weg, von innen heraus das Menschheitsepos zu entwerfen, ist nicht weit entfernt von dem Satz „Nach Innen geht der geheimnißvolle Weg“ (Novalis, Schriften 2: 418) aus dem „Blüthen- 
staub“ des Novalis, der Herders Werk gut gekannt hat. ${ }^{14}$ Für Herder ist es also das gemeinsame Menschliche, das den Zugang zum Ursprung der Humanität, zum inneren Christus verbürgt. Und nur, weil der Eposschreiber diesen Ursprung in sich selber trägt, vermag er sich in dasjenige „[hin]ein zu setzen“ (SWS 25: 83), „was [...] am tiefsten sitzt, gleichsam Geburts-Stamina des Volks enthält und am innigsten charakterisieret" (ebd., 82f.). Die innere Christus-Förmigkeit aller Völker und Zeiten, die er selbst in sich trägt, befähigt also den Schreiber eines Christus-Epos zu seinem Werk.

Weil Herder die Möglichkeit dieses Weltepos aus seiner Ebenbildlichkeits-Anthropologie entwirft, glaubt er auch an dessen Verwirklichung: „[W]irkt Göttliches in der Menschheit [...], so laßet uns an einem [...] Epos der Gottheit im Fortgange der Menschheit nicht zweifeln." Denn es wird „Zu seiner Zeit [...] an einem solchen Sänger nicht fehlen“ (SWS 24: 283). Beispielhafte Verse aus Herders eigener Feder an der zitierten Stelle bezeugen, dass er sich durchaus auch selbst als „solchen Sänger“ verstand, und er hat sich tatsächlich an einem derartigen Menschheitsepos versucht. Von diesem existiert allerdings nur der erste Gesang, der mit den für ein Epos standesgemäßen Worten beginnt: „O Muse singe mir den hohen Rath / des Menschengottes mit der Menschenschaar [...]" (SWS 29: 556). Dieses Epos war auf 10 Gesänge geplant, und es gibt eine detaillierte Inhaltsangabe für die Gesänge 1 bis $9,{ }^{15}$ für den 10. Gesang aber fehlt sie. Spätestens dieser hätte wohl den heiklen Christus-Ausklang bieten müssen. Der Inhalt der ersten neun Gesänge hat aber erstaunliche Ähnlichkeit mit den „Ideen zu einer Philosophie der Geschichte der Menschheit“. So kann das Hauptwerk Herders auch als eine Art Prosafassung seines geplanten Menschheitsepos gelten. Dieses Menschheitsepos aber, als Fernziel seines Volksepos-Konzepts, hat mit den Nationalepen des 19. Jahrhunderts kaum noch etwas gemein. Sie wären für Herder nur Durchgangsstationen zum fernen Weltepos, in dessen Mittelpunkt der vergöttlichte Mensch stehen wird. Ihre politische Intention jedoch, die gerade in der Betonung der Selbstständig-

\footnotetext{
${ }^{14}$ Vgl. den Index zur Novalisausgabe, Schriften, Bd. 5. Gewiss hat Novalis auch die Vorreden zu Herders Volksliedern gekannt, aus denen das obige Herderzitat stammt. Eine Büchernotiz des Novalis geht in diese Richtung: „Herder [...], Volkslied“ (Novalis, Schriften, Bd. 4, S. 690).

${ }^{15}$ Abgedruckt bei Ulrich Gaier (1990: 1477-1479).
} 
keit einzelner Staatsnationen, in ihrer Differenzierung von anderen oder ihrer Überlegenheit über andere Nationen besteht, läuft der christologischen Humanität, also der innersten Motivation der Herder'schen Epos-Konzeption zuwider.

\section{Literaturverzeichnis}

\section{Primärliteratur}

Hamann, Johann Georg (1968): Aesthetica in nuce. Hrsg. v. Sven Aage Jørgensen. Stuttgart.

Herder, Johann Gottfried (o. J.): Sämtliche Werke. Bd. 1-33. Hrsg. v. Bernhard Suphan, ab Bd. 25 hrsg. v. Carl Redlich. Reprograph. Nachdruck der Ausgabe Berlin 1877-1913. Hildesheim/New York.

Herder, Johann Gottfried (1977-2005): Briefe. Bd. 1-12. Hrsg. v. Wilhelm Dobbek und Günter Arnold, ab Bd. 9 hrsg. v. Günter Arnold. Weimar.

HERDER, Johann Gottfried (1985): Dithyrambische Rhapsodie über die Rhapsodie kabbalistischer Prose. In: ders. (1985): Frühe Schriften (1764-1772). Hrsg. v. Ulrich Gaier (= Johann Gottfried Herder: Werke in zehn Bänden, Bd. 1). Frankfurt a. M., S. 30-39.

Novalis (1977-1988): Schriften. (Bd. 1-5). Hrsg. v. Paul Kluckhohn und Richard Samuel, ab Bd. 2 hrsg. v. Richard Samuel; Bd. 5 hrsg. v. HansJoachim Mähl und Richard Samuel. Darmstadt.

\section{Sekundärliteratur}

Bosse, Heinrich (1979): Herder (1744-1803). In: Horst Turk (Hrsg.) (1979): Klassiker der Literaturtheorie, München, S. 78-91.

DeITERS, Franz Josef (2002): Das Volk als Autor? Der Ursprung einer kulturgeschichtlichen Fiktion im Werk Johann Gottfried Herders. In: Heinrich Detering (Hrsg.) (2002): Autorschaft: Positionen und Revisionen. Stuttgart, S. 181-201.

GAIER, Ulrich (1985): Der frühe Herder. In: Johann Gottfried Herder: Frühe Schriften (1764-1772). Hrsg. v. Ulrich Gaier (= Johann Gottfried Herder: Werke in zehn Bänden, Bd. 1). Frankfurt a. M., S. 813-832.

GAIER, Ulrich (1990): Stellenkommentar. In: Johann Gottfried Herder: Volkslieder Übertragungen Dichtungen. Hrsg. v. Ulrich Gaier (= Johann Gottfried Herder: Werke in zehn Bänden, Bd. 3). Frankfurt a. M., S. 928-1486.

HÁRS, Endre (2008): Herder und die Erfindung des Nationalen. In: Kakanien revisited 12, S. 1-13. Verfügbar unter:

http://www.kakanien.ac.at/beitr/theorie/EHars3.pdf (24.10.2011). 
Hasselblatt, Cornelius (2004): Kalevs Sohn im estnischen und europäischen Kontext. Zur Entstehungsgeschichte des Kalevipoeg. In: Kalevipoeg. Das estnische Nationalepos. (2004). In der Übersetzung von Ferdinand Löwe. Hrsg. v. Peter Petersen. Stuttgart/Berlin, S. 297-306.

VALK, Ülo (2004): Tendenzen und Anhaltspunkte in der Forschungsgeschichte des „Kalevipoeg“. In: Kalevipoeg. Das estnische Nationalepos (2004). Hrsg. v. Peter Petersen. Stuttgart/Berlin, S. 315-321.

ZIPPERT, Thomas (1994): Herder als Theologe. In: Johann Gottfried Herder: Theologische Schriften. Hrsg. v. Christoph Bultmann und Thomas Zippert (= Johann Gottfried Herder: Werke in zehn Bänden, Bd. 9/1). Frankfurt a. M., S. 861-875. 


\section{Vom vielgelesenen zum ungelesenen Text: Ossians Vermächtnis in der schottischen Kultur}

Als Nationalepen werden gemeinhin Texte bezeichnet, die einer Nation zur Selbstvergewisserung dienen. Symbolhafte Handlungen, Bilder, Praktiken und prototypische Heldenfiguren stellen ein Bedeutungsreservoir dar, mit Hilfe dessen Nationen ihre historische Fundierung ästhetisch und nicht zuletzt auch linguistisch absichern können. Im Kontext der Rezeption europäischer Nationalepen im 18. und 19. Jahrhundert nimmt James Macphersons Gedichtsammlung „Poems of Ossian“ jedoch aus drei Gründen eine Sonderstellung ein. Zum einen sprengte sie bereits kurz nach ihrer Veröffentlichung im Jahr 1762 die Grenzen einer nationalen Semantik und wirkte bis weit in das 19. Jahrhundert hinein in einem globalen Kontext. Die melancholische Leitvorstellung einer freiheitsliebenden Heldengemeinschaft, die ruhmvoll untergeht, erschien im Europa nationalstaatlicher Konkurrenzen als attraktive Formel zur Rahmung von Nationalepen v. a. kleiner Völker. Zum Zweiten entfalteten die „Poems of Ossian“ ein ästhetisches Potential, das sich, abgekoppelt vom politisch-identifikatorischen Gehalt der Texte, nicht nur literarisch, sondern auch in den Medien Musik, Malerei und Architektur über Schottland hinaus weiter entfaltete. Die Transformation des klassischen homerischen Epos in den empfindsamromantischen Gestus des neuen literarischen Paradigmas der „Naturpoesie“ (Herder), ${ }^{1}$ die Inszenierung des Nationalepos als Sammlung loser Fragmente, als hybrides Konvolut archaischer Mythen, trafen und gestalteten den Zeitgeist wie kein anderer Text. Auch als Paradigma erhabener Naturästhetik und moderner Empfindsamkeit bewiesen die „Poems of Ossian“ europäische Strahlkraft. Und mehr noch: Die reproduktive Rezeption Ossians in unzähligen Übersetzungen, die produktive Rezeption in Nachdichtungen und Bearbeitungen, die analytischkritische Rezeption in ossian-informierten Texten zu Ästhetik sowie zu Moral- und Geschichtstheorie, die nationalpolitische Rezeption, die

\footnotetext{
${ }^{1}$ Den Begriff der Naturpoesie entwickelte Herder am Beispiel des Ossian im Aufsatz „Über Ossian und die Lieder alter Völker“.
} 
Ossian in der Pan-Keltizismus-Bewegung der 1890er Jahren fruchtbar machte, die philologische Rezeption, die um die Authentizitätsfrage kreiste: All diese Rezeptionsstränge ${ }^{2}$ wirkten europaweit von der Vorromantik bis in das 20. Jahrhundert weiter.

Und drittens schließlich wurde bei kaum einem anderen Nationalepos eine solch erbitterte und langwierige Debatte über die Echtheit der Texte geführt; eine Debatte, die sich im Zuge irischer oder schottischer nationalpolitischer Bewegungen immer neu entzündete.

Drei Leitfragen konturieren im Folgenden den Versuch, Bedeutung und Resonanz von Macphersons Werk in der schottischen Kultur umreißen zu können: (1) Wie verschieben sich die ästhetischen und moralischen Werturteile über Macphersons Texte im Kontext sich ändernder nationalpolitischer und literarischer Diskurse? (2) Welche materiellen Zeugnisse resultieren aus der Ossian-Rezeption in Schottland, wie beeinflusst sie die Landschaftserfahrung der Romantik und des 19. Jahrhunderts; und werden die „Poems of Ossian“ auch als materielle Zeugnisse der Nation verstanden und topographisch verankert? Und schließlich: (3) Welche kulturelle Rolle spielt „Ossian“ - als Gedichtsammlung, als Begriff, als nationaler Erinnerungsort - heute noch in der schottischen Gegenwartskultur?

\section{Die „Poems of Ossian“" im Kontext nationalpolitischer Diskurse}

Macpherson und Hugh Blair, Rhetorikprofessor in Edinburgh und sein spiritus rector, hatten die „Poems of Ossian“ als genuine Übersetzung verschiedener gälischer Quellen aus dem dritten Jahrhundert deklariert. Das waren sie sicherlich nicht, aber sie waren auch nicht lediglich die Ergüsse eines skrupellosen schottischen Hochstaplers. Die Debatte um die Echtheit der Texte dauerte bis weit in das 19. Jahrhundert an und flammte immer wieder - etwa im Zuge von Neuausgaben - auf. Vor allem die Tatsache, dass Macpherson nie mit den gälischen Originalen aufwarten konnte, nährte den Fälschungsverdacht. Erst 1807

\footnotetext{
${ }^{2} \mathrm{Zu}$ dieser Kategorisierung s. Howard Gaskill und Wolf Gerhard Schmidt (Bd. 4, 2003/2004).
} 
publizierte die Highland Society in London eine gälische Ausgabe mit Teilen der „Fragments of Ossian“.

Die Echtheitsfrage ist nicht nur ein literarästhetischer Disput, sondern steht mit dem Anspruch der Texte, ein nationales Epos zu sein, in direktem Zusammenhang. Sie wurde vor allem in Großbritannien erbittert geführt. Zu einer Zeit, da Schottland die politische Eigenständigkeit verloren hatte, wurde mit den Ossian-Texten der Anspruch erhoben, einen Gründungsmythos der gälischen Kultur zu dokumentieren, der ca. 500 Jahre älter als das entsprechende englische Dokument war. Resteuropa dagegen sah in Macpherson eher einen genialen Kulturvermittler, der es verstanden hatte, den Geist der frühen Epoche einzufangen. Achim von Arnim schrieb 1808 an Clemens von Brentano: „Aber unter all diesem nachgemachten Altherthum ist nie etwas erschienen, was den Geist der Zeit so lebendig berührt hat wie Macpherson mit seiner Neumachung der alten Gedichte.“ (Zit. n. Gaskill/Schmidt 2004: 550) In der englischen Kritik ging es des Weiteren nicht nur darum, Macpherson als Fälscher zu entlarven, sondern ihn auch als Dichter zu desavouieren. Er hatte sich eines doppelten Vergehens schuldig gemacht: eines moralischen, da er Texte als fremde ausgegeben hatte, die seine eigenen waren, und eines ästhetischen, da seine eigenen Kompositionen einfach schlecht waren. Diese Anklagen erwiesen sich als kulturell zählebig. Noch 1871 griff in einer „Ossian or no Ossian“ betitelten Rezension einer Neuausgabe des Ossian in Charles Dickens' Magazin „All the Year Round" der Rezensent eine Authentizitätsdebatte auf, die in der Mitte des viktorianischen Zeitalters längst ein Anachronismus war. Er stellt die hinlänglich bekannten Fragen: Hatte es Ossian wirklich gegeben? Falls nicht, waren die ihm zugeschriebenen Gedichte alt oder modern? Wer war ihr Autor? Und er resümiert: „Whenever Macpherson meddled he muddled" (Dickens 1871: 42); wann immer er in die gälischen Texte eingriff, verpfuschte er sie. Die Debatte ist damit jedoch noch lange nicht zu Ende: Die untoten Geister der gälischen Kultur werden schließlich in den 1890er Jahren noch einmal in Schottland im Zuge des Pan-Keltizismus und der "Scottish Twilight"-Bewegung reaktiviert, die parallel zur Irish Renaissance das gälische Erbe als politischen Akt der Selbstbestimmung verstand. 1896 gab Patrick Geddes, der Initiator der „Scottish Twilight“-Bewegung, die „Poems of Ossian“ in einer Prachtausgabe anlässlich des 100. Todestages von 
Macpherson zusammen mit William Sharp neu heraus. William Sharp, der auch durch sein Pseudonym Fiona MacLeod bekannt wurde, unter dem er post-ossianische Highlandromanzen, Geschichten und Gedichte schrieb, verfasste ein Vorwort zu dieser Ausgabe. Das Vorwort ersetzte die bislang immer mit abgedruckte „Critical Dissertation“ von Hugh Blair, die ja streng philologisch für die Authentizität der Texte argumentierte. Nun ging es nicht mehr lediglich um den Fiktionsvorwurf. Sharp positionierte sich im Zuge des Pan-Keltizismus im größeren Rahmen der irisch-schottisch-gälischen Kultur und setzte sich mit der Frage auseinander, ob der Fingal-Mythos nun irisch oder schottisch sei. In Bezug auf die Echtheitsfrage wählt er einen Mittelweg: Zwar seien die Texte nicht, wie der „Engländer“ Samuel Johnson behauptete, von Macpherson verfasste englische Texte, aber sie seien auch keine reinen Übersetzungen, sondern vielmehr hybride Mischformen: basierend auf gälischen Quellen und vom Geist des 18. Jahrhunderts durchdrungen.

Die Rehabilitierung Macphersons wurde schließlich von dem gälischen Muttersprachler Derek Thomson in den 1950er Jahren eingeleitet, der in einer philologisch orientierten Studie nachwies, dass Macpherson sich doch auf gälische Balladen und Handschriften (v. a. die Handschrift „Book of the Dean of Lismore“ aus dem 16. Jahrhundert) bezogen hatte (vgl. Thomson 1952). Damit wurde weitgehend der Bericht der Highland Commission von 1805 bestätigt. Seit den 80er Jahren des 20. Jahrhunderts und damit dem Zeitgeist der postmodernen Geschichtsauffassung hat sich eine Neubewertung der Texte als kongeniale Dichtung durchgesetzt. Benedict Andersons „Imagined Communities“ (1983) oder Eric Hobsbawm und Terence Rangers Sammelband „The Invention of Tradition“ (1983) waren beides wegweisende Werke, die konstruktivistische Sichtweisen von Geschichte stützen und die Bedeutung von Literatur bzw. von Printmedien für die Herstellung von nationaler Identität hervorhoben. Andersons Konzept der „vorgestellten Gemeinschaft“, die durch Printmedien soziale Kohäsion erlangt, scheint mit dem Beispiel des „Ossian“ paradigmatisch belegbar zu sein. Nicht nur verweist der Text selbst auf eine mythische Gemeinschaft der Fianna, auf die nur noch im kulturellen Gedächtnis zurückgegriffen werden kann, sondern die Rezeption des „Ossian“ beweist vielmehr, wie erst durch die Übersetzung in eine 
gemeinsame Sprache und die Verbreitung in Printmedien die Texte die Wirkungsmacht nationaler Selbstvergewisserung erlangten.

Auch im Zuge der sich im Poststrukturalismus durchsetzenden Aufwertung der literarischen Fälschung oder Mystifikation als kreativer Akt, der die kulturell zementierte Vorstellung vom Autor als Originalgenie dekonstruierte, und der damit verbundenen Interessensverlagerung der Kritik vom Original auf die Kopie oder das Simulacrum erlebte Ossian eine Renaissance. Macpherson wurde nicht mehr als Fälscher verteufelt, sondern als ein Autor gesehen, der mit seismographischer Sensibilität die heterogenen ästhetischen, politischen und emotionalen Bedürfnisse seiner Epoche literarisch beantworten konnte. „Macpherson's achievement is to create ,the Mouth of Ossian' at work: the making of history by the bard of oral culture“ (Haywood 1983: 146): Mit dieser Wertung nobilitierte Ian Haywood 1983 Macphersons Leistung als schöpferisch. Seine Inszenierung von Performanz, die Erfindung der bardischen Stimme, die ja Teil einer oralen Kultur ist, auf die der Zugriff nicht möglich ist, wird nun als bedeutender Teil der Konstruktion einer mythischen keltischen Vorgeschichte aufgewertet. Zwei weitere Werke, Howard Gaskills 1991 veröffentlichter Sammelband „Ossian Revisited“ und Fiona Staffords Monographie „The Sublime Savage: A Study of Macpherson and the Poems of Ossian“ von 1998, verstärkten diese Tendenz. Stafford weist Macpherson eine Brückenfunktion zwischen dem Edinburgh der Aufklärung und der gälischen Hochlandkultur zu und zeigt, wie Macpherson die Polaritäten seiner Zeit zu einem universalen romantischen Epos amalgamieren konnte. In der britischen Gesellschaft des 18. Jahrhunderts brachten die Gegensätze von bürgerlicher ziviler Stadtkultur und Industrialisierung, aristokratischem Konservativismus, militärischer Stärke und beginnendem Imperialismus Friktionen hervor. Stafford stellt dar, dass Ossian einen Weg bot, um die martialischen Traditionen mit den zivilen Tugenden des bürgerlichen Zeitalters zu harmonisieren. ${ }^{3}$ Howard Gaskills und Wolf Gerhard Schmidts vierbändige Ausgabe der Gedichte und ihrer diversen Übersetzungen und Rezeptionsstränge (2004) widmen sich der Bedeutung Ossians im europäischen Kontext und legen dar, wie sich in kurzer Zeit ein wirkungsmächtiger ossianischer Diskurs etablierte, der die Veranke-

\footnotetext{
${ }^{3}$ Diesem Ansatz widerspricht Dafydd Moore (2000).
} 
rung der Gesänge, entkoppelt von der Person des Autors, im europäischen kulturellen Gedächtnis garantierte. Interessant in der Diskussion der nationalpolitischen Aspekte des Ossian ist nicht zuletzt auch die Tatsache, dass die revisionistische literaturwissenschaftliche Debatte (Pittock, Gaskill, MacLeod und Duncan) in den 1990er Jahren und damit gerade zu dem Zeitpunkt einsetzt, als die Scottish National Party wieder erstarkte und Schottland sich im Zuge der Dezentralisierung auf dem Weg zu einem eigenen Parlament befand.

Bezeichnend für diesen revisionistischen Lektüreansatz ist nun nicht mehr die Betonung des Ursprungs der Nation, sondern die Sicht des Nationalepos als Dokument ihres Untergangs. Betont wird damit das Moment der Melancholie, denn prominent in die Gedichte eingeschrieben ist der Topos des Verlustes. Es ist dies der Verlust von Text der Titel weist ja auf den fragmentarischen Zustand der Sammlung hin ${ }^{4}-$ wie aber auch Verlust und Vergängnis auf der inhaltlichen Ebene: Ossian ist ein alter blinder Barde, der als letzter seines Geschlechts die Kämpfe, Heldentaten und den Heldentod seines Vaters Fingal und dessen legendärer Schar, der Fianna, besingt und damit den Verlust eines entschwundenen heroischen Zeitalters. Der Gründungsmythos einer Nation ist hier gleichzeitig als ihr Verschwinden markiert, der nationalistische Ton des Ossian wird durch die elegischen Noten politisch entschärft. Die Entstehung der Gedichte steht im zeitlichen Zusammenhang mit dem endgültigen Verlust der politischen Macht der Stuarts und damit der gälischen Kultur der Highlands nach der Niederschlagung des letzten Highlander Aufstandes 1745. Neuere Ansätze der Macpherson-Forschung sehen deshalb die Gedichte weniger als Ursprungsmythen denn als elegischen Abgesang, der das Auslöschen der gälischen Kultur im Zuge der Union der Parlamente betont. Murray Pittock kontextualisiert Ossian im politischen Verlust der schottischen Unabhängigkeit in der zweiten Hälfte des 18. Jahrhunderts. Nachdem die beiden jakobitischen Rebellionen von 1715 und 1745 gescheitert waren, war Schottland endgültig in der Union aufgegangen. Dies

\footnotetext{
${ }^{4}$ Mit dem Titel „Fragments“ steht Macpherson am Anfang einer sich in der Literatur der Romantik vollends durchsetzenden Vorliebe für das Fragment und damit einen ambivalenten Begriff, der das Werdende, Unfertige genauso bezeichnen kann wie Ruinen und Vergangenes. Bezogen auf den Begriff der Nation können Fragmente sowohl Anfang als auch Ende markieren.
} 
bedeutete wirtschaftliche Vorteile, aber eben auch den Verlust nationaler Identität. Ossian, so Pittock, erzählt den Untergang der Highland-Kultur nach Culloden, die Kargheit und Kahlheit der Highlands werden zu einem Symbol des neuen Britanniens: Die ehemalige Blüte Schottlands unter den Stuarts ist vorbei (vgl. Pittock 1991). Damit sind die Texte nostalgischer Ausdruck einer Vergangenheit, die von vornherein bereits als Fiktion konstruiert war. Dieser Gedanke klingt auch in dem Ansatz Ian Duncans nach, der Macpherson als Ursprung der Tradition der Scottish Gothic Fiction ausmacht und argumentiert, in der elegischen Geisterbeschwörung der ossianischen Texte, der Konstruktion der Helden als Schattenwesen, würde die gälische Kultur als Untote erscheinen, die sich dem Zugriff entzöge. Macphersons Akt der Übersetzung ins Englische, so Duncan, radierte die gälischen Texte aus, um sie als eine tote poetische Sprache, einbalsamiert in englischer Prosa heraufzubeschwören, die in der schottischen Gegenwart der Aufklärung und des politischen und wirtschaftlichen Zusammenwachsens mit England nach der Union eine unheimliche Präsenz behält (vgl. Duncan 2000: 72).

\section{Ossianische Topographien}

Gerade in den ersten Jahrzehnten nach der Publikation der „Poems of Ossian“, in denen die Authentizitäts- und Provenienzdebatte besonders scharf geführt wurde, spielte die Suche nach manifesten topographischen Beweisen eine große Rolle. In Schottland wurde „Fingal's Cave“, eine 1772 von dem Naturforscher Sir Joseph Banks auf der Hebrideninsel Staffa wiederentdeckte Basaltsteinhöhle, zum ossianischen locus classicus, der auch musikalisch in Werken von Mendelssohn-Bartholdy bis Pink Floyd Resonanz fand. Neben den Verfechtern der schottischen Provenienz gab es genauso eine Fraktion, die Irland als Schauplatz requirierte: Hugh Campbell, der 1819 die Schrift „Ossiana, or, Fingal ascertained and traced in Ulster: by the Analogy of Names and Places mentioned in Ossian's Poems“ (zit. n. Schmidt 2003: 243) veröffentlichte, glaubte Ossian in Irland verorten zu können. Im Allgemeinen waren jedoch diese Versuche topographischer Festschreibungen selten, ${ }^{5}$ denn das bestimmende Merkmal

\footnotetext{
${ }^{5}$ Damit unterscheiden sich topographische Bezüge zu Ossian in Schottland wesentlich von anderen topographischen Referenzen in Nationalepen, wie beispielsweise den
} 
der Gedichte ist gerade deren mangelnde topographische Konkretisierung, die nebelhafte Verschleierung von Orten und die monochrome Zeichnung von Bächen, Mooren, Inseln, Bergen und dem Meer mit einem begrenzten lexikalischen Inventar, das es erschwert, einzelne kulturelle Gedächtnisorte zu lokalisieren. Vielmehr wurden die schottischen Highlands insgesamt zum Inbegriff ossianischer Landschaften. In Macphersons Verbindung der ästhetischen Traditionen einer alten mündlichen Kultur mit den neuen ästhetischen Rezeptionsnormen des Sublimen und Pittoresken, wie sie von William Gilpin entwickelt worden waren, erhielten sie eine neue, mythopoetische Qualität.

Die topographische Unbestimmtheit der Gedichte erwies sich jedoch weniger als Defizit denn als Vorteil. Denn die typische Kargheit der schottischen Highlands entsprach dem textuellen Primat des NichtSichtbaren in Macphersons Gedichten und lud Lesende und Reisende dazu ein, in ihrer Imagination die leeren Landschaften mit den mythischen Schatten der Literatur aufzufüllen. Dies setzte sich als dominantes Rezeptionsmuster eines ossian-befeuerten Highland-Tourismus aus: Es sind nicht einzelne Stätten, die besucht werden, sondern es ist generell die ossian-typische Landschaft, die dazu anregt, die Texterfahrung auf unterschiedliche Orte zu projizieren. Wichtig war vor allem das Lektüreerlebnis in situ, dass den affektiven Genuss der Texte zu steigern verhieß: Herder, einer der glühendsten Ossian-Verehrer, gibt diese Rezeptionsempfehlung für den „Lustgesang des Volkes“:

Ossian $[\ldots]$ habe ich in Situationen gelesen, wo ihn die meisten, immer in bürgerlichen Geschäften, und Sitten und Vergnügen zerstreute Leser, als blos amusante, abgebrochene Lecture, kaum lesen können. Sie wissen das Abentheuer meiner Schiffahrt; aber nie können Sie sich die Würkung einer solchen, etwas langen Schiffahrt so denken, wie man sie fühlt. Auf Einmal aus Geschäften, Tumult und Rangespossen der bürgerlichen Welt, aus dem Lehnstuhl des Gelehrten und vom weichen Sopha der Gesellschaften auf Einmal weggeworfen, ohne Zerstreuungen, Büchersäle, gelehrten und ungelehrten Zeitungen, über Einem Brette, auf offnem allweiten Meere, [...] mitten im Schauspiel einer ganz andern, lebenden und webenden Natur, zwischen Abgrund und Himmel schwebend, täglich mit denselben

konkreten Orten, die in Estland mit dem Kalevipoeg in Verbindung gebracht werden. Vgl. hierzu u. a. den Beitrag von Eve Pormeister in diesem Band. 
endlosen Elementen umgeben, und dann und wann nur auf eine neue ferne Küste, auf eine neue Wolke, auf eine ideale Weltgegend merkend nun die Lieder und Thaten der alten Skalden in der Hand, ganz die Seele damit erfüllet, an den Orten, da sie geschahen [...] jetzt von fern die Küsten vorbey, da Fingals Thaten geschahen, und Ossians Lieder Wehmut sangen, [...] glauben Sie, da lassen sich Skalden und Barden anders lesen, als neben dem Katheder des Professors. (Herder, zit. n. Schmidt 2003: 657)

Eingefordert wird hier die Lektüre, ja sogar das laute Lesen des Ossian in einer sublimen Landschaft. Denn auch die Klangwelt der Texte, die Norman Shaw als sonor beschrieben hat, kommt einer imaginativen Auffüllung entgegen:

Macpherson strives to reproduce what I will call a sonorous landscape which runs parallel to the narrative; maintaining a vagueness that permeates the text. The sonorous, I suggest, is a device that references the sonic, yet which strives to realize what is beyond the audible or visible. (Shaw o. J.)

Die Gedichte schaffen einen mnemonischen Klangraum, der realisiert, was jenseits des Hörbaren oder Sichtbaren liegt und mehr im Echo repräsentiert wird denn im primären Ton. Die Echoqualität der Texte metaphorisch als Nachklang des Vergangenen, Verwehten zu verstehen und strukturell auf der Ebene der vielen Wiederholungen realisiert - wird visuell durch die Schatten oder Geister repräsentiert, die die Highlands bevölkern. Nur so ist die authentische, weil emotional aufgeladene und die Seele erfüllende Erfahrung des Ursprünglichen garantiert. Und damit erweisen sich die „Poems of Ossian“ für Reisende des 19. Jahrhunderts als idealer Projektionsraum für die sich im Zeichen zunehmender Industrialisierung, Verstädterung und des damit einhergehenden Landschaftsverlustes verstärkende Sehnsucht nach unberührter Natur. Ossianisch aufgeladene schottische Landschaften werden dementsprechend in vielen Reisebeschreibungen des 19. Jahrhunderts als Gegenraum für von der Industrialisierung und der Großstadt erschöpfte Touristen angepriesen. Der kruden Materialität des Alltags wird ein ossianischer Fluchtraum der vagen Ursprünglichkeit entgegengesetzt, in dem die mit Sagen und Mythen aufgeladene Landschaft eine spirituelle Erfahrung verspricht. Alexander Smith konzipiert 1865 in dem höchst erfolgreichen Reisebericht „A Summer in Skye“ die Topographie der Insel ganz im Sinne der 
Ossian-Rezeption als primär nicht visuell erfahrbar. Die „schweigenden Armeen aus Nebeln und Dämpfen“, der peitschende Regen verhüllen ständig die Sicht und verfremden die Landschaft in einem archaischen Sinn:

In Skye the Londoner is visited with a stranger sense of foreignness than in Holland or in Italy. The island has not yet, to any considerable extent, been overrun by the tourist. To visit Skye is to make a progress into "the dark backward and abysm of time." You turn your back on the present, and walk into antiquity. You see everything in the light of Ossian as in the light of a mournful sunset. With a Norse murmur the blue Lochs come running in. You hear a foreign language; you are surrounded by Macleods, Macdonalds, and Nicolsons; you come on gray stones standing upright on the moor, marking the site of a battle or the burial-place of a chief. You listen to traditions of ancient skirmishes; you sit on ruins of ancient date, in which Ossian might have sung. [...] The sound of the sea is continually in your ears, the silent armies of mists and vapours perpetually deploy, the wind is gusty on the moor, and ever and anon the jags of the hills are obscured by swirls of fiercely-blown rain. And, more than all, the island is pervaded by a subtle spiritual atmosphere. It is as strange to the mind as it is to the eye. Old songs and traditions are the spiritual analogues of old castles and burying-places; and old songs and traditions you have in abundance. There is a smell of the sea in the material air, and there is a ghostly something in the air of the imagination. There are prophesying voices amongst the hills of an evening. The raven that flits across your path is a weird thing, mayhap by the spell of some strong enchanter a human soul is balefully imprisoned in the hearse-like carcass. You hear the stream and the voice of the kelpie in it. You breathe again the air of old story-books; but they are northern, not eastern ones. To what better place, then, can the tired man go? There he will find refreshment and repose. There the wind blows out on him from another century. The Sahara itself is not a greater contrast from the London street than is the Skye wilderness. (Smith 1865: 125f.)

Die vernebelte Sicht birgt den Reiz einer anti-aufklärerischen Unbestimmtheit, die in der synästhetischen Erfahrung von Landschaft als Ton und Geruch eine neue, emotional ungleich bewegendere, sublime Landschaftserfahrung garantiert. Paradoxerweise ruft jedoch gerade diese immaterielle Landschaftserfahrung die Erinnerung an eine kollektive Vergangenheit hervor und garantiert deren Bestand.

Diese Form der ossianischen Landschaftserfahrungen wurde performativ in einem bestimmten, zeittypischen touristischen Modus realisiert, brachte 
jedoch in einem zweiten Schritt auch eine Kette neuer Texte hervor: Reiseführer, Reiseberichte, Tagebücher aus den schottischen Highlands, aber auch Gedichte von der Romantik bis zum späten 19. Jahrhundert zeugen von der Persistenz ossianisch geprägter Landschaftswahrnehmung. Gerade die fehlenden topographischen Referenzen schaffen einen Freiraum, in dem neue textuelle Visionen realisiert werden. Dadurch wird der Originaltext der „Poems of Ossian“ zunehmend mit einer Reihe intertextueller Bezugnahmen überlagert, die von Walter Scott zu Beginn bis William Sharp alias Fiona McLeod am Ende des 19. Jahrhunderts ossianische Rhetorik und Natursymbolik fortschreiben. ${ }^{6}$ Für die nationalliterarische Bedeutung von Macphersons Gedichten im schottischen literarischen Kanon ist dies von entscheidender Bedeutung: Der Status eines Nationalepos, den die „Poems of Ossian“ vielleicht im 18. Jahrhundert in der besonderen politischen Situation residualer schottischer Unabhängigkeitsgefühle gehabt haben mögen, verliert sich allmählich im 19. Jahrhundert und wird durch eine politisch entschärfte melancholische Landschaftslyrik von Ossian-Epigonen überschrieben.

Neben diesen performativen und literarischen Einschreibungen in einen ossianisch interpretierten Raum finden sich in Schottland jedoch auch noch andere, materielle Rezeptionszeugnisse der „Poems of Ossian“, die in einem identitätspolitischen Kontext zu sehen sind. Kurz nach der Publikation der Gedichte dokumentieren einige Landbesitzer ihr schottisches Nationalbewusstsein mit ossianisch markierten Bauten. Die Ausgestaltung der Ossian Hall in Pennicuik House (1773), eines palladianischen Herrenhauses südlich von Edinburgh, dokumentiert nicht nur einen Wandel ästhetischer Vorlieben - bevor der Bauherr Sir James Clerk den Architekten Alexander Runciman mit einem ossianischen Deckengemälde beauftragte, waren die römischen Titus-Thermen als Motiv geplant gewesen -, sondern enthält auch eine identitätspolitische Aussage: Ein geplantes klassisch-europäisches Deckengemälde, das den Bauherrn als klassisch gebildeten Grand Tourist ausgewiesen hätte, wird durch das "modernere“ mythologische Gemälde ersetzt. Dies bedeutet jedoch im Zeichen der seit 1707 bestehenden Union der Parlamente keine separatistische Aussage mehr, sondern eher eine politisch entschärfte, nostalgisch-ästhetische nationale Bezugnahme.

\footnotetext{
${ }^{6}$ Vgl. z. B. die Gedichte „The Lord of the Isles“ von Walter Scott und „The Caves of Staffa" von William Sharp.
} 


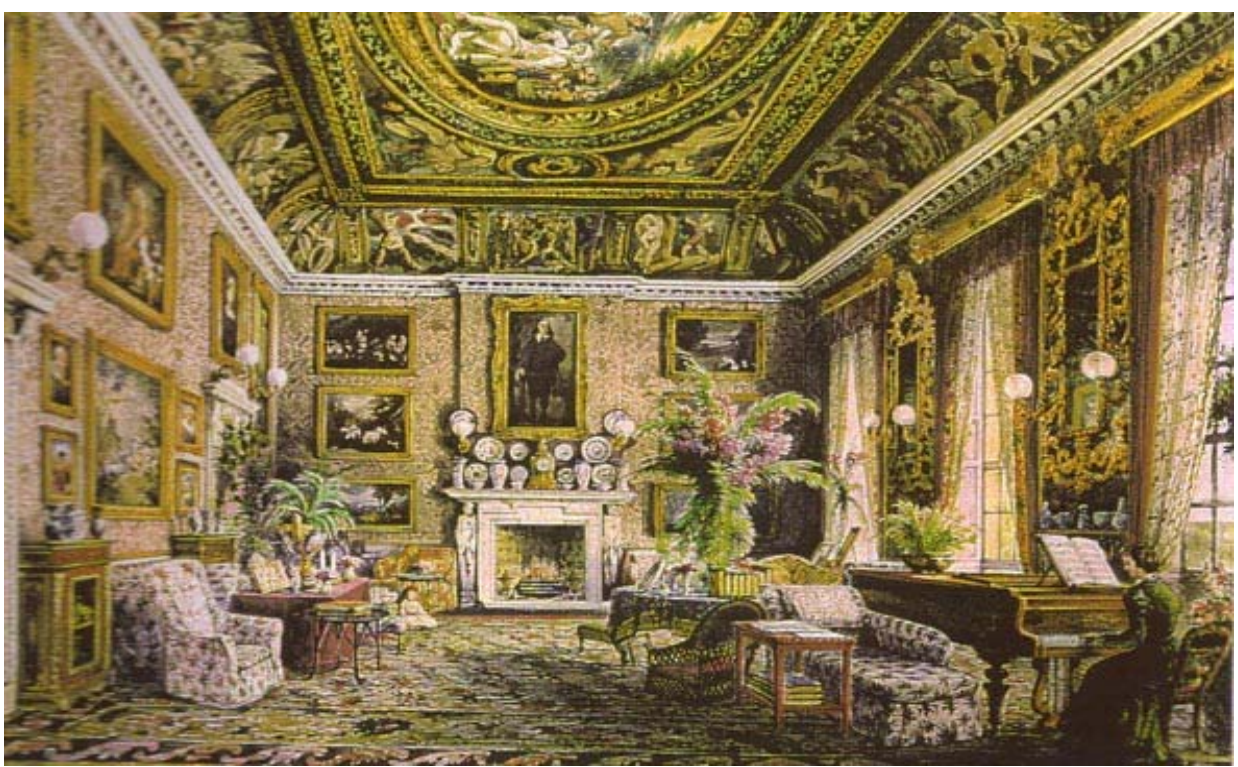

Abb. 1: Alexander Runciman, "Ossian Hall”, Pennicuik House, Scotland. Quelle http://www.penicuikhouse.co.uk/history-penicuikhouse.aspx (03.11.2011)

Ähnlich zu verstehen sind auch zwei architektonische Follies des 2. Duke of Atholl, „Ossian's Cave“ und „Ossian's Hall“ - Letzeres ein kleiner Rundbau direkt über einem Wasserfall, den der Duke of Atholl 1783 in der Nähe von Dunkeld erbauen ließ. Die Stelle über dem Wasserfall ist hier nicht im Sinne einer konkreten topographischen Referenz gemeint, sondern generell als eine im Kontext der Natursymbolik der Gedichte typische Stelle. Denn Wasser - Meeresrauschen, Wasserfälle, Flüsse und Tränen - ist ein dominantes semantisches Feld der Gedichte, das mit Emotionen der Erhabenheit, Melancholie und Vergänglichkeit korrespondiert. Besonders markiert ist meist auch die Klangqualität des Wassers, die dem blinden Sänger Farben und Formen ersetzt. Eine beliebige Stelle aus den „Poems of Ossian“, der Anfang der „Battle of Lora“, sei hierfür als Beispiel zitiert:

Son of the distant land, who dwellest in the secret cell! do I hear the sounds of thy grove? or is it the voice of thy songs? The torrent was loud in my ear, but I heard a tuneful voice; dost thou praise the chiefs of thy land; or the spirits * of the wind? But, lonely dweller of the rocks! look over that heathy plain: thou seest green tombs, with their rank, whistling grass; with their 
stones of mossy heads: thou seest them, son of the rock; but Ossian's eyes have failed.

A mountain stream comes roaring down and sends its waters round a green hill: four mossy stones, in the midst of withered grass, rear their heads on the top: two trees which the storms have bent, spread their whistling branches around. This is thy dwelling, Erragon: this thy narrow house: the sound of thy shells has been long forgot in Sora: and thy shield is become dark in thy hall. (Macpherson 1762: 92)

Mit „Ossian’s Hall“ errichtete der Duke of Atholl einen Gedächtnisort, der Besuchern die Lektüre im Naturerlebnis vergegenwärtigen konnte und gleichzeitig auch schottische Landschaft zur Authentifizierung der Texte heranzog.

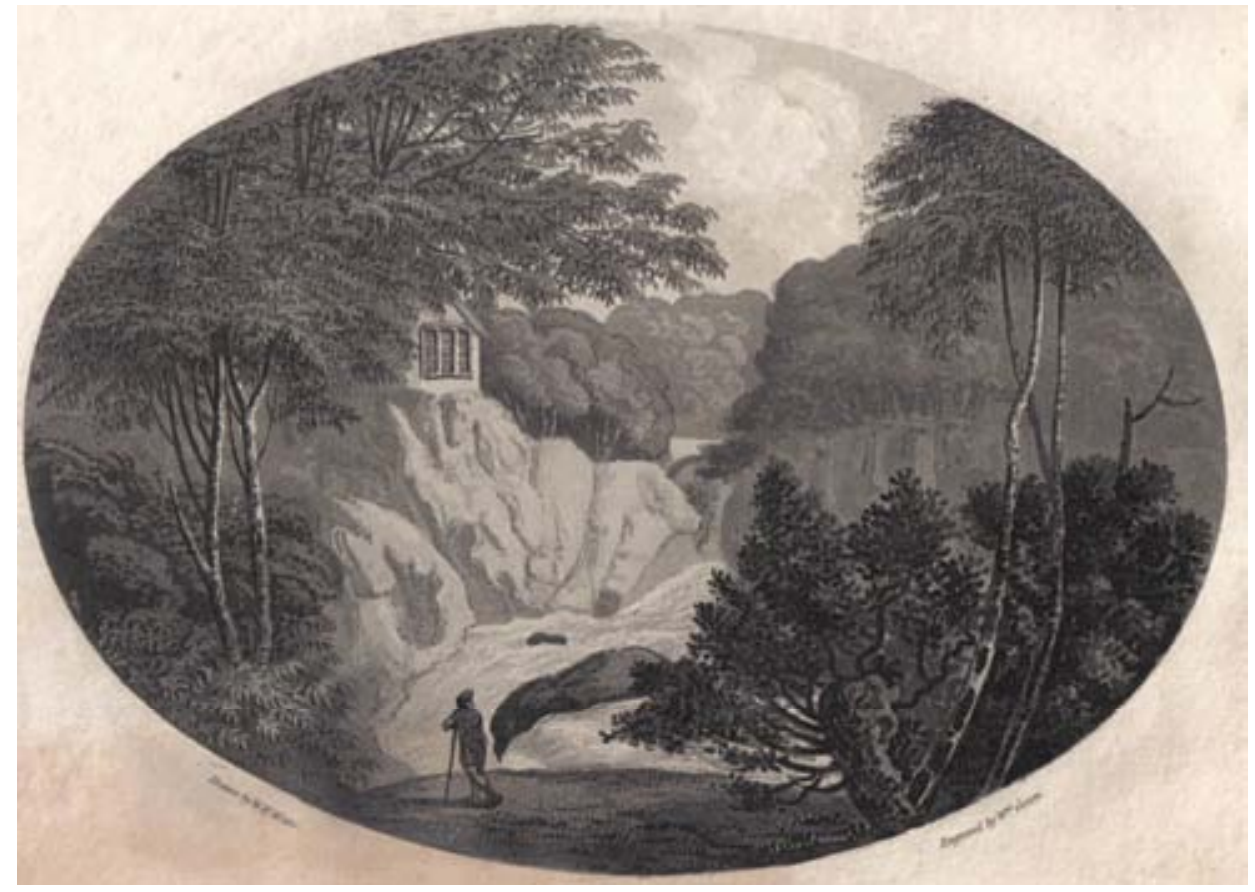

Abb. 2: „Ossian's Hall“

Quelle: GARneTT, Thomas (1811): Observations on a Tour through the Highlands and part of the Western Isles of Scotland, particularly Staff and Icolmkill. Bd. 2. London, S. 71.

Beim Betreten erblickten die Besucher zunächst ein Wandgemälde, das Ossian im Kreis von Jungfrauen darstellte. Sobald der Führer einen 
bestimmten Mechanismus betätigte, teilte sich das Gemälde und verschwand hinter der Wandvertäfelung. Nun sah man in einen zweiten Raum, der völlig mit Spiegeln verkleidet war, die den Blick auf den Wasserfall reflektierten - das Wasser schien von allen Seiten herunterzuströmen. Auch hier war der Effekt als synästhetisches, sich gegenseitig verstärkendes Erlebnis von Bild und Ton konzipiert: Das Wasserrauschen wurde mit den in den Spiegeln multiplizierten Bildern kombiniert. Als eine besonders bemerkenswerte Reaktion von Zeitgenossen ist ein Gedicht von William Wordworth zu erwähnen, in dem er sich mit dieser materiellen Repräsentation von Ossian auseinandersetzt. Schockiert über die Künstlichkeit des kleinen Baus kritisiert er ihn als unangemessen, ja als Ausgeburt einer krankhaften Phantasie:

What! Ossian here - a painted Thrall, Mute fixture on a stuccoed wall;

To serve - an unsuspected screen

For show that must not yet be seen;

And, when the moment comes, to part

And vanish by mysterious art;

Head, harp, and body, split asunder,

For ingress to a world of wonder;

A gay saloon, with waters dancing

Upon the sight wherever glancing;

One loud cascade in front, and lo!

A thousand like it, white as snow--

Streams on the walls, and torrent-foam

As active round the hollow dome,

Illusive cataracts! of their terrors

Not stripped, nor voiceless in the mirrors,

That catch the pageant from the flood

Thundering adown a rocky wood.

What pains to dazzle and confound!

What strife of colour, shape and sound

In this quaint medley, that might seem

Devised out of a sick man's dream! [...] (Wordsworth 1827: 68f.)

Der im Wandgemälde gefangene Ossian widerspricht der romantischen Sehnsucht nach Vagheit, die Rezeptionsnorm der imaginativen Auffüllung "leerer“ Landschaft wird durch die konkrete Realisierung der „Ossian's Hall“ verletzt: Wordsworth beschreibt dies mit einem körperlichen Bild, in dem Kopf, Harfe und Körper des Barden zerteilt wer- 
den, wenn die Mechanik den Blick auf den Spiegelraum freigibt. Die Perfektion der komplizierten Mechanik widerspricht dem Tenor der Gedichte, der ja gerade durch seine ungeschliffene Archaik eine der Industrialisierung vorgängige Natürlichkeit inszenierte. Gegenüber der technischen, artifiziellen (und damit schlechten) Kunst, für die das Folly steht, imaginiert Wordsworth eine aus Stein gehauene Repräsentation des Ossian, die seinem Ideal einer naturnahen, natürlichen Kunst und damit dem Urtext kongenial entspricht. Er verkennt jedoch dabei, wie die meisten seiner Zeitgenossen, wie hochgradig literarisch und artifiziell Macphersons naturpoetische Kompositionen gewesen waren:

But, nursed in mountain solitude,

Might some aspiring artist dare

To seize whate'er, through misty air,

A ghost, by glimpses, may present

Of imitable lineament,

And give the phantom an array

That less should scorn the abandoned clay;

Then let him hew with patient stroke

An Ossian out of mural rock, [...] (Wordsworth 1827: 71f.)

\section{Die „Poems of Ossian“" als ungelesener Text}

Sucht man auf dem zeitgenössischen Buchmarkt nach Macphersons Gedichten, stößt man neben der für ein akademisches Publikum konzipierten Ausgabe von Howard Gaskill bezeichnenderweise lediglich auf eine Neuausgabe des „Forgotten Books“ Verlages. Dies zeigt deutlich, wie sehr die Ästhetik der Gedichte ihr Verfallsdatum überschritten hat. Die „Poems of Ossian“ haben ihren Stellenwert als Zeitdokument, als ein kurioses Hybrid archaischer Bildwelt und empfindsamer Rhetorik, dessen nationalpolitische und ästhetische Wirkungsmacht ihm einen Platz in der Literaturwissenschaft garantiert. Wirklich gelesen werden sie heute nicht mehr. Was bleibt also von Ossian in der schottischen Gegenwartskultur außer der bereits erwähnten nationalpolitischen Komponente, die in den 1990er Jahren im Zuge der schottischen Parlamentsgründung wissenschaftlich aufgearbeitet wurde? Im literarischen Kanon schottischer Literatur wurden ossianische Naturbeschreibungen von späteren Autoren aufgenommen und überschrieben, in der Populärkultur wurde Ossian von den Gedichten Macphersons entkop- 
pelt. Der Name Ossian steht nicht mehr für den Protagonisten der Gesänge, also den blinden alten Sänger, sondern für eine imagined community keltischer Helden, die sich durch ein starkes Zusammengehörigkeitsgefühl und Kämpfe auszeichnet. Schottische Identität ist hier auf einen Signifikanten in Form eines archaischen Keltentums reduziert.

Dies geht zuweilen auch über Schottland hinaus: Die ungarische Heavy Metal Band „Ossian“ hat sich einen Namen gewählt, der mit dem Klangrepertoire des Heavy Metal vielleicht noch besser kompatibel ist als mit dem von Schubert oder Mendelssohn-Bartholdy, wie folgendes, beliebig gewähltes Zitat aus Fingal zeigt: „Man met with man, and steel with steel. Shields sound, and warriors fall. As a hundred hammers on the red sons of furnace, so rose, so rung their swords." (Macpherson 1762: 48) In Schottland selbst wird man auf der Suche nach Ossian bei einer Biermarke fündig. Das preisgekrönte Bier der Inveralmond Brauerei wird in Schottland als „Oschn“, also gälisch ausgesprochen, und ist schon dadurch von englischen Ales oder kontinentalen Bieren abgegrenzt. Auf dem Label verweist ein keltisches Ornament auf den symbolischen Ursprung, und laut Werbetext der Brauerei liegt der Produktionsort des Biers unweit des Grabes von Ossian, der aus dem Reich der Fiktion unversehens in die Geschichte gehoben wird: „Ossian, Son of Fingal, was a legendary warrior from the 3rd century. His grave stone can be seen north west of Perth in the ,Sma Glen', of which Sir Walter Scott wrote... ,In this still glen, remote from men, Sleeps Ossian, in the narrow glen “" ${ }^{\text {i. }}$. Macpherson und sein literarisches Werk bleiben unerwähnt, stattdessen tritt der viel bekanntere Nationaldichter Scott zur Beglaubigung an und verweist auf das Grab Ossians als materielles Zeichen der historischen Echtheit.

Abschließend sei ein Beispiel angeführt, das jedoch zeigt, wie Ossian auch heute noch im Sinne eines identitätsstiftenden Bedeutungsträgers mobilisiert werden kann. Es ist die Photoinstallation „Ossian, Fragments of Ancient Poetry" des schottischen Künstlers Calum Colvin, die dieser im Oktober 2002 in der Scottish National Portrait Gallery in Edinburgh ausstellte und anlässlich der Wahl Edinburghs als erster Unesco City of Literature in Paris im Unesco Gebäude im Jahre 2005 wiederholte. ${ }^{8}$

\footnotetext{
${ }^{7}$ http://www.inveralmond-brewery.co.uk/classic-collection.html; 4.1.2011.

${ }^{8} \mathrm{Vgl}$. http://www.calumcolvin.com; 4.1.2011.
} 


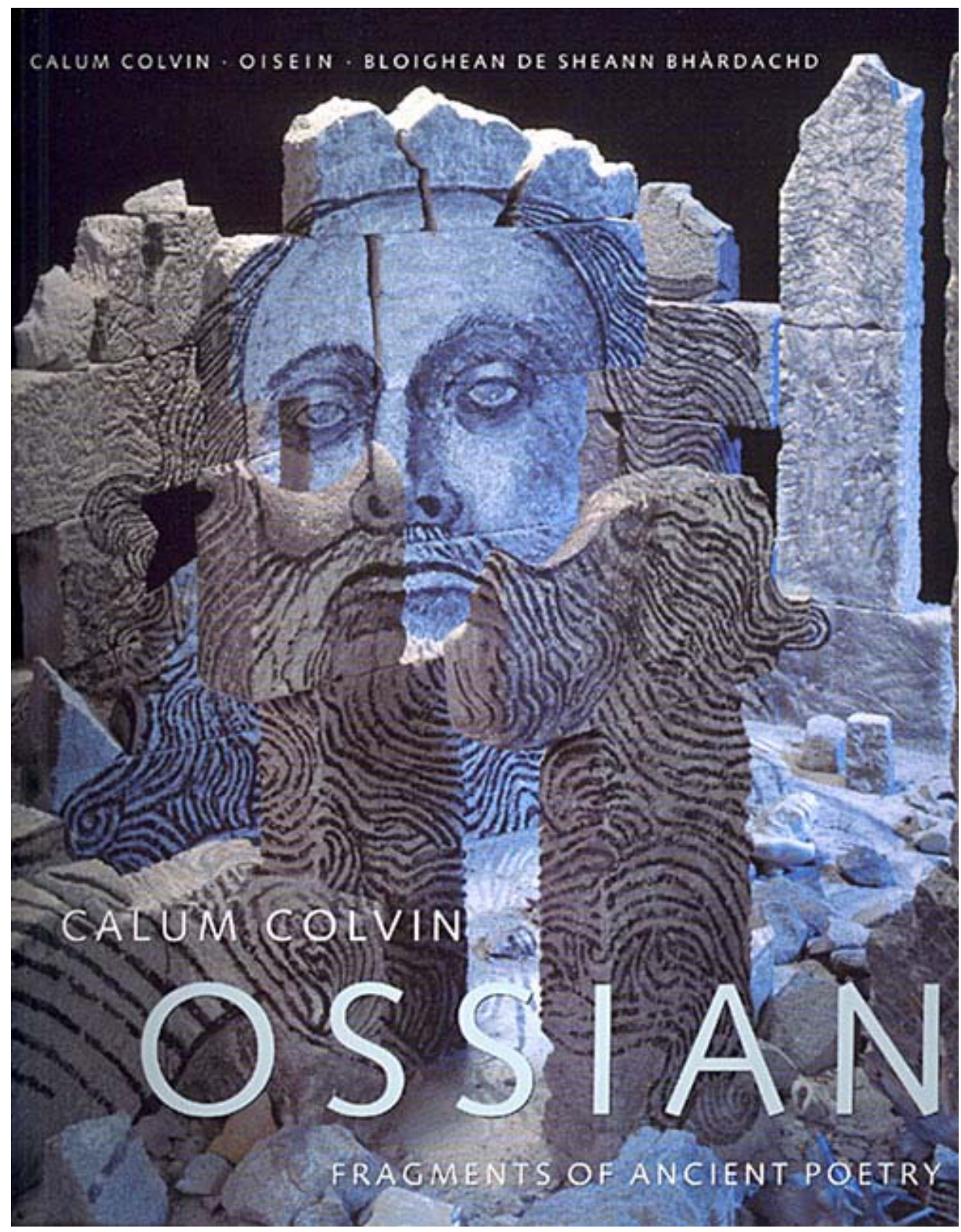

Abb. 3: Calum Colvin: Ossian (Installation)

Quelle: Colvin, Calum (2002): Ossian. Fragments of Ancient Poetry. Hrsg. v. Tom Normand. Edinburgh. 
Colvin nähert sich dem Verhältnis von nationaler Identität und Geschichte, Erinnerung und Mythos auf der Basis von Macphersons Gedichten. Bezeichnenderweise ist jedoch in der fotografischen Inszenierung der Text absent, auch hier wird er als kultureller Gedächtnisort aufgerufen, ohne konkretisiert zu werden. In der Installation ist vielmehr das Porträt Ossians prominent, dessen Darstellung als blinder alter Sänger auf einen Stich des schottischen Malers Alexander Runciman aus dem 18. Jahrhundert zurückgeht. Damit knüpft Colvin an die die Gedichte bestimmende zeitgenössische Rezeptionsnorm des 18. Jahrhunderts an: die nostalgische und melancholische Vorstellung des Verlustes einer heroischen Vergangenheit. In der Videoinstallation überblendet Colvin das Porträt mit Fragmenten behauener Steine. Dies mögen Trümmer zerstörter Bauten sein, die nationaldistinktive ornamentale Merkmale zeigen: Man erkennt ein keltisches Kreuz, und auch die Haare und der Bart Ossians erinnern an keltische Skulpturen. Stein als das dauerhafteste Material eines Landes und das Antlitz eines Sängers als eines der ephemersten Phänomene werden so zu einem Zeichen zusammengefügt, in dem sowohl Natürliches wie Gemachtes, Destruktion und Verlust, Bedeutungswandel wie auch Kontinuität aufscheinen - die Komponenten, die das Ossianverständnis bis heute prägen. Die Fragmente verweisen in einem konkreten schottischen geschichtlichen Kontext auf die Zerstörung der gälischen Kultur der Highlands, die Entvölkerung im 18. Jahrhundert durch die Highland Clearances und den Verlust von Identität. Ambivalent als Zeichen sind sie allemal: Die Technik der Collage kann als ironischer postmoderner Verweis auf die Absenz von Ganzheit und Geschlossenheit in Geschichtsentwürfen verstanden werden, genauso wie sie auch als Versuch gesehen werden kann, die Form des Fragments als kollektives Narrativ der Nation zu verstehen, das eine sinn- und identitätsstiftende Funktion besitzt. Denn die Geschichte der schottischen Nation und damit auch ihr kollektives Gedächtnis sind von Brüchen und Spaltungen gekennzeichnet: die linguistische Trennung in die drei Sprachkulturen Gälisch, Scots und Englisch; die religiöse Spaltung in Katholiken und Presbyterianer, und die politischen Konflikte zwischen Unionisten und Jakobitern. Colvins Technik der Überblendung der Fragmente ist beides: die Ausstellung von Unterschieden und Gebrochenheit genauso 
wie die Strategie, Teile zu einem Ganzen zu verbinden, ohne die Bruchstellen und damit distinktiven Merkmale unkenntlich zu machen.

Und schließlich ist auch der Kontext der Ausstellung in Paris, die Wahl Edinburghs zur ersten Unesco City of Literature, ein nicht unerhebliches Zeichen dafür, das auch der ungelesene Text die Symbolkraft eines Nationalepos behalten kann: Macpherson's Gedichte werden in Colvins Installation zur Projektionsfläche und zentralen Achse, an der nationale Geschichte, kollektive Erinnerung und Identität gespiegelt werden. Colvins Projekt mag als Zeugnis dafür gelten, dass auch ein Text, der in den Anfängen seiner Rezeption als Nationalepos verstanden wurde und als solches über die nationalen Grenzen hin einflussreich war, der später im Sinne einer bestimmten Landschaftsästhetik umsemantisiert wurde und im Latenzgedächtnis der Nation versank, dennoch reaktualisiert und identitätspolitisch funktionalisiert werden kann, solange seine Fragmente in irgendeiner Weise noch Bedeutung haben. Gelesen werden müssen die „Poems of Ossian“ dafür nicht unbedingt.

\section{Literaturverzeichnis}

\section{Primärliteratur}

HERDER, Johann Gottfried (1984): Auszug aus einem Briefwechsel über Ossian und die Lieder der alten Völker. In: ders. (1984): Werke. Hrsg. v. Wolfgang Pross. Werkausgabe Band I: Herder und der Sturm und Drang: 17641774. München, S. 477-525.

MacPherson, James (1762): Fingal. An Ancient Epic Poem. In Six Books: Together with several other Poems, composed by Ossian the Son of Fingal. London.

MacPherson, James (2003): The Poems of Ossian and Related Works [1996]. Hrsg. v. Howard Gaskill. Edinburgh.

ScOTT, Walter (1815): The Lord of the Isles: A Poem. Edinburgh.

SHARP, William (1884): Earth's Voices. Transcripts from Nature, Sospitra, and Other Poems. London.

SMITH, Alexander (1865): A Summer in Skye. London.

WORDSWORTH, William (1827): Effusion in the Pleasure-ground on the banks of the Bran, near Dunkeld. In: ders. (1827): The Poetical Works of William Wordsworth. Werkausgabe. Band III: Memorials of a Tour in Scotland. London, S. 68-74. 


\section{Sekundärliteratur}

Allen, Paul Marshall/Joan Allen (1999): DeRis Fingal's Cave, The Poems of Ossian, and Celtic Christianity. New York.

ARNDT, Astrid/et al. (Hrsg.) (2004): Imagologie des Nordens: kulturelle Konstruktionen von Nördlichkeit in interdisziplinärer Perspektive. Frankfurt a. M./New York.

Blunt, Alison/Gillian Rose (Hrsg.) (1994): Writing Women and Space. Colonial and Postcolonial Geographies. New York/London.

Dickens, Charles (Hrsg.) (1871): Ossian or no Ossian. In: All the Year Round v. 10.06.1871, S. 37-42.

Duncan, Ian (2000): Walter Scott, James Hogg and Scottish Gothic. In: David Punter (Hrsg.) (2000): A Companion to the Gothic. Oxford, S. 70-80.

FERGuson, William (1998): The Identity of the Scottish Nation. An Historic Quest. Edinburgh.

Fulford, Tim (1996): Landscape, Liberty and Authority: Poetry, Criticism and Politics from Thomson to Wordsworth. Cambridge.

GaSkILL, Howard (Hrsg.) (2004): The Reception of Ossian in Europe. London/New York.

GASKILL, Howard/Wolf Gerhard ScHmidT (Hrsg.) (2004): „Homer des Nordens“ und „Mutter der Romantik“. James Macphersons Ossian und seine Rezeption in der deutschsprachigen Literatur. Bd. 4: Kommentierte Neuausgabe wichtiger Texte zur deutschen Rezeption. Berlin/New York.

Grenier, Katherine Haldane (2005): Tourism and Identity in Scotland, 17701914. Creating Caledonia. Aldershot.

HAYWOOD, Ian (1983): The Making of History: Historiography and Literary Forgery in the Eighteenth Century. In: Literature and History 9, H. 2, S. 139151.

http://www.inveralmond-brewery.co.uk/classic-collection.html (4.1.2011).

http://www.calumcolvin.com (4.1.2011).

LeERSEN, Joep (1998): Ossianic Liminality: Between Native Tradition and Preromantic Taste. In: Fiona Stafford/Howard Gaskill (Hrsg.) (1998): From Gaelic to Romantic. Ossianic Translations. Amsterdam, S. 1-16.

MCNEIL, Kenneth (2007): Scotland, Britain, Empire. Writing the Highlands, 1760 1860. Columbus.

Moore, Dafydd (2000): Heroic Incoherence in James Macpherson's “The Poems of Ossian”. In: Eighteenth-Century Studies 34, H. 1, S. 43-59.

MOORE, Dafydd (2003): Enlightenment and romance in James Macpherson's ,The poems of Ossian': Myth, Genre and Cultural Change. Aldershot.

MOORE, Dafydd (Hrsg.) (2004): Ossian and Ossianism. London.

Normand, Tom (2008): Memory, Myth and Melancholy: Calum Colvin's Ossian project and the tropes of Scottish photography. In: Interfaces: Image, Texte, Language 27, S. 99-108. 
Ossian und die Kunst um 1800. Hamburger Kunsthalle, 9. Mai bis 23. JUNi 1974 (1974). Ausstellungskatalog.

PiTtock, Murray (1991): The Invention of Scotland: The Stuart Myth and the Scottish Identity, 1638 to the Present. London.

PORTER, James (2001): "Bring me the Head of James Macpherson": The Execution of Ossian and the Wellsprings of Folkloristic Discourse. In: The Journal of American Folklore 114, H. 454, S. 396-435.

ScHmidT, Wolf G. (Hrsg.) (2003/04): ,Homer des Nordens“ und ,Mutter der Romantik'. James Macphersons Ossian und seine Rezeption in der deutschsprachigen Literatur. Berlin/New York.

SCHMIDT, Wolf G. (2007): Des „heiligen“ Ossian „geweihtes Andenken“: Kulturpoetische Refiguration als Movens der Moderne. In: Bernd Engler (Hrsg.) (2007): Kulturelle Leitfiguren - Figurationen und Refigurationen. Berlin, S. 133-147.

SHAw, Norman (o. J.): Ossian, Sonority and the Celtic Twilight in Geddes' Circle. Verfügbar unter:

http://patrickgeddes.co.uk/feature_twentyone_ossian.html (3.1.2011).

Simpson, Kenneth (1988): The Protean Scot. The Crisis of Identity in Eighteenth Century and Scottish Literature. Aberdeen.

STAFFORD, Fiona (1988): The Sublime Savage: A Study of James Macpherson and the Poems of Ossian. Edinburgh.

Stafford, Fiona/Howard Gaskill (Hrsg.) (1998): From Gaelic to Romantic. Ossianic Translations. Amsterdam.

Thomson, Derek (1952): The Gaelic Sources of Macpherson's Ossian. Aberdeen.

WAtson, G. J. (1998): Yeats, Macpherson and the Cult of Defeat. In: Fiona Stafford/Howard Gaskill (Hrsg.) (1998): From Gaelic to Romantic. Ossianic Translations. Amsterdam, S. 216-225. 


\section{Das Nationalepos im Kinderzimmer: Die ,Kinder- und Hausmärchen“" der Brüder Grimm}

Die Subsumierung der Grimm'schen „Kinder- und Hausmärchen“ unter ein Tagungsthema, das sich auf nationale Epen bezieht, setzt in der Tat jenen sehr weiten Eposbegriff voraus, von dem im Vorwort die Rede war. Denn hier geht es ja um nicht mehr als eine Sammlung kurzer narrativer Texte mündlichen und anonymen Ursprungs, für die allerdings der Tatbestand des Gesammeltseins und der Präsentation als einer Sammlung wesentlich ist, die Repräsentativität und (schon durch Präsentationsformen wie Einleitung, Kommentierung, Nummerierung) eine gewisse Vollständigkeit und Geschlossenheit suggeriert. In den „Kinder- und Hausmärchen“ soll das Ganze programmatisch mehr sein als die Summe seiner Teile. Und der kulturhistorische Bereich, zu dem es lange verschüttete Zugänge wieder freilegen soll, ist mit Wilhelm Grimms bekannter Formel aus der Einleitung eben das, was auch das große Epos, philologisch rekonstruiert und durch den Buchdruck neu zugänglich gemacht, wieder eröffnen soll. „In diesen Volksmärchen liegt“, Wilhelm Grimms berühmtem Diktum zufolge, „lauter urdeutscher Mythus“. ${ }^{\prime}$

Gewiss, hier gibt es keine Helden, nur Märchenfiguren; keine topographisch identifizierbaren Schauplätze und keine auch nur annähernd geschichtlichen Zeiten, sondern nur das Irgendwann und Irgendwo des Volksmärchens; keine Götter, sondern nur Geister und Dämonen, von der bösen Hexe bis zur guten Frau Holle. Aber was heute und seit langer Zeit in den Spinnstuben und an den Kinderbettchen erzählt worden ist: Nach Art und Umfang „kleine“ Literatur zeigt doch - das sollen die kommentierten Texte uns durch die kindgemäße Gestalt hindurch

\footnotetext{
${ }^{1}$ „Kinder- und Hausmärchen“, Vorrede 1812; vgl. hierzu Rötzer 1995: 23. Zu den biographischen und werkpolitischen Entstehungszusammenhängen, den wissenschaftlichen und ideologischen Voraussetzungen und Implikationen der Grimm'schen Märchen jetzt grundlegend Martus (2009) sowie Uther (2010).
} 
zu erkennen geben - Bruchstücke großer, erwachsener, nationaler Mythologie. Nie ist das Märchen so entschieden als die gleichsam verkindlichte Spielform des Mythos präsentiert worden wie in dieser Sammlung von „Kinder- und Hausmärchen“.

Deshalb soll hier, im Rahmen unserer Tagung und wirklich nur innerhalb des durch sie gesetzten Rahmens, ein kurzer Blick auch auf diesen eigentümlichen Sonderfall eines nationalen Epos (oder epusculum) geworfen werden. Zu diesem Zweck werde ich zunächst lediglich einige Forschungsergebnisse zusammenfassen, die in der Fachliteratur allgemein bekannt und akzeptiert sind, und mich dabei vor allem auf die Arbeiten von Heinz Rölleke beziehen (unter denen die Einführung „Die Märchen der Brüder Grimm“ den besten Überblick gibt). Ich werde also in der Sache gar nichts Neues und Eigenes sagen, sondern lediglich einige für uns relevante Bereiche des Forschungsstandes resümieren und dann im Blick auf unser Thema zu perspektivieren versuchen.

Es war einmal ein Märchen, das handelte von der Herkunft der Grimm'schen Märchen. Die beiden Brüder, von denen dieses Märchen erzählt, sind ausgezogen, um die ursprüngliche Poesie wiederzufinden. Nach langen Wanderungen in den Wäldern zwischen Main und Weser begegnen sie alten, weisen Frauen, und von denen hören sie fast vergessene Geschichten vom Rotkäppchen und vom Froschkönig, von Rumpelstilzchen und von den alten Zeiten, in denen das Wünschen noch geholfen hat, uralte Überlieferungen, im Volkston erzählt. Was die Brüder aber unter der alten Linde und auf der Ofenbank aufmerksam mitgeschrieben haben, das geben sie alsbald in den Druck, und so werden die Geschichten von neuem Eigentum des Volkes, dessen Geist sie hervorgebracht hat; und da sie nach all den Jahren immer noch nicht gestorben sind, leben sie noch heute. - Eine schöne Geschichte, und ein gefundenes Fressen für die, deren Beruf die Erforschung von Geschichten ist. Denen aber ist nichts heilig, und so haben Märchenforscher wie Heinz Rölleke (Rölleke 2004a, 2004b, 2000, 1984), Lothar Bluhm (Bluhm 1995) und Hans-Jörg Uther (Uther 2008) die schöne Geschichte dahin verwiesen, wohin sie gehört: ins Reich der Märchen.

Die wirkliche Geschichte beginnt wie so viele Wissenschaftsgeschichten der Romantik im aufgeklärten Göttingen. Dort, wo eine Generation 
später Jacob und Wilhelm Grimm als Professoren lehren und von wo sie dann wegen politischer Unbotmäßigkeit wieder vertrieben werden, lernen sich im Göttinger Sommer 1801 Achim von Arnim und Clemens Brentano kennen, bei einer Feier für den besuchsweise hier weilenden Goethe. Das literarisch bedeutungsvollste Ergebnis ihrer Freundschaft wird die Sammlung „Des Knaben Wunderhorn. Alte deutsche Lieder“ (Heidelberg 1805 und 1808, 1819), die bekanntlich in romantischer Freiheit anonyme Überlieferungen, anonymisierte literarische Vorlagen und eigene Neudichtungen sammelt, bearbeitet und zum Idealbild einer (wie das Heidelberger Schloss auf dem Titelkupfer) wunderbar wiederhergestellten deutschen Vergangenheit kombiniert. Mit der Publikation des ersten Bandes geht 1805 der Plan einher, „alte mündlich überlieferte Sagen und Mährchen [...] mit der Fortsetzung dieser Sammlung“ (Brentano 1977: 348) zu verbinden; 1806-1808 veröffentlichen die Freunde Mustertexte in Zeitschriften. Seit 1806 arbeiten Jacob und Wilhelm Grimm an der Lied-, der Märchen- und Sagensammlung mit, und bereits 1808 schickt Jacob Grimm sieben Texte an Brentanos Freund und Mitstreiter Friedrich Carl von Savigny. Am 17. Oktober 1810 schicken die Brüder dann vierundfünfzig Märchen an Brentano, der sie nicht zurückgibt und so in dieser ursprünglichunredigierten Form der Nachwelt erhält (vgl. [Brüder Grimm] 1975).

Philip Otto Runge, der romantische Maler und Freund Tiecks, Brentanos und anderer frühromantischer Dichter, schreibt 1805, nach dem Erscheinen des ersten „Wunderhorn“-Bandes, zwei Märchen: „Von dem Fischer un siner Fru“ (der Grundlage auch für Günter Grass' monumentales Roman-Märchen „Der Butt“, 1977) und „Von den Machandelboom" (1812 erstmals selbständig gedruckt). 1808 schickt er sie, als Dank für „Des Knaben Wunderhorn“, an dessen Heidelberger Verleger. Arnim und Brentano wiederum leiten diese meisterhaften Verschriftlichungen niederdeutscher Volksüberlieferung an die Brüder Grimm weiter - die entscheidende Anregung für die „Kinder- und Hausmärchen“ (in denen beide Texte dann unter den Nummern 19 und $27 \mathrm{zu}$ finden sein werden). „Sowohl in Rücksicht der Treue, als der trefflichen Ausführung wüßten wir“, so Jacob rückblickend 1811, „kein besseres Beispiel zu nennen, als die von dem seligen Runge [...] gelieferte Erzählung vom Wacholderbaum, plattdeutsch, welche wir unbedingt zum Muster aufstellen“ ([Brüder Grimm] 1994: 264). Dabei hat 
Runge abgesehen von den medienbedingten Vereindeutigungen, die mit der Verschriftlichung selbst einhergingen, die mündlichen Überlieferungen aus Pommern mindestens stilistisch überformt und den Text im übrigen auch selber in unterschiedlichen Varianten mündlich erzählt; schon hier also lässt sich ein erster Übergang vom „Volks-“ zum Kunstmärchen beobachten.

Auf Runges Spuren treiben die Brüder ihre systematische Suche nach Überlieferungen weiter. Anfang 1811 ergeht ihre „Aufforderung an die gesammten Freunde deutscher Poesie und Geschichte" mit breiter Wirkung unter den Gebildeten. 1812 drängt dann Achim von Arnim sie in Kassel zur Herausgabe der ersten Sammlung:

Er war es, der uns, als er in jener Zeit einige Wochen bei uns in Cassel zubrachte, zur Herausgabe angetrieben hatte [...] Er meinte wir sollten uns nicht zu lange damit zurückhalten, weil bei dem Streben nach Vollständigkeit die Sache am Ende liegen bliebe. (,Kinder- und Hausmärchen“, Vorrede 1837)

So erscheinen zu Weihnachten 1812 in einer Auflage von 900 Exemplaren die „Kinder- und Haus-Märchen. Gesammelt durch die Brüder Grimm“ mit sechsundachtzig Märchen, philologisch kommentiert eine, wie Rölleke bemerkt, „Zwittergestalt zwischen Kinderbuch und wissenschaftlicher Dokumentation“ (Rölleke 2004a: 82). Vom zweiten Band an, der 1815 folgt (es sind jetzt bereits 156 Märchen), redigiert Wilhelm die weiteren Auflagen. Dem Wunsch und Bedenken vieler Kritiker, die mehr Volkstümlichkeit verlangen, folgt er bereitwillig und mit großem literarischen Geschick. So entsteht die Ausgabe von 1819, aus deren Vorrede ich zitiert habe. 1822 folgt als dritter ein Anmerkungs-Band. ${ }^{2}$ Mit der dritten Auflage haben die Märchen 1837 die Textauswahl, die Form und den Ton erreicht, die wir bis heute mit ihnen verbinden. ${ }^{3}$ Zehn Jahre später, also 1825, werden fünfzig Märchen für die illustrierte „Kleine Ausgabe“ zusammengestellt. Sie erst ist es, die zum eigentlichen Bestseller wird. Die zweite Auflage erscheint 1833, dann geht es Schlag auf Schlag; weitere Auflagen erscheinen 1836, 1839, 1841, 1843, 1844, 1850, 1853 und 1858. Alles in allem

\footnotetext{
${ }^{2}$ Die zweite Auflage von 1819 ist zusammen mit dem Anmerkungsband von 1822 neu herausgegeben und kommentiert von Hans-Jörg Uther ([Brüder Grimm] 2004).

${ }^{3}$ Vgl. Röllekes Ausgabe ([Brüder Grimm] 1985) auf Grundlage der Version von 1837.
} 
werden von den Brüdern etwa 240 Märchen gesammelt; zweihundert davon sowie zehn „Kinderlegenden“ stehen in der Ausgabe letzter Hand (der „Großen Ausgabe“), der siebten Auflage von 1857.

Die germanistische Märchenforschung hat - die philologische und volkskundliche Arbeit der Brüder Grimm nicht nur fortsetzend, sondern oft genug auch korrigierend - umfassend nachgewiesen, aus welcher Vielzahl von Quellen diese Texte sich speisen und durch welche Vermittlungsschritte sie hindurchgegangen sind. Sie hat dabei, allen voran Heinz Rölleke, auch gezeigt, mit welchen eklatanten Wissenschaftsfiktionen die Grimms ihre Präsentation der Arbeitsergebnisse verbunden haben - dass es sich also etwa bei der „alten Marie“ der Vorreden und Briefe durchaus nicht um eine „ächt hessische“ Frau, sondern um eine junge Hugenottin aus einer französischsprachigen Familie handelte, dass auch die alte „Viehmännin“, also die auf dem Titel des zweiten Bandes eindrucksvoll abgebildete Dorothea Viehmann aus Niederzwehren bei Kassel, keineswegs eine alte hessische Bäuerin war, sondern eine Schneidersgattin mit kleiner Landwirtschaft aus einer ebenfalls hugenottischen Familie namens Pierson, dass auch andere der von den Grimms befragten hessischen Märchenerzählerinnen unter mehr oder weniger dominierendem französischem Kultureinfluss sozialisiert worden waren - und dass insgesamt nicht weniger als etwa vierzig mündliche Beiträger und etwa dreißig schriftliche Quellen herangezogen worden sind: von Giovan Francesco Straparolas „Piacevoli notti“ (1550-1553) und Giambattista Basiles „Lo cunto de li cunti“ (1634-1636), besser bekannt unter dem seit 1674 gebräuchlichen Titel „Il Pentamerone“ (und 1846 in einer deutschen Gesamtübertragung mit einer Vorrede von Jacob Grimm erschienen), über Charles Perraults ebenfalls von den Grimms ausdrücklich bewunderte und empfohlene galant-ironische „Histoires ou Contes du Temps passé avec des Moralitez“ (1697) und Marie-Cathérine d'Aulnoys „Les illustres fées, contes galans“ (1698) bis zu Musäus' „Volksmährchen der Deutschen“ (1782-1786) mitsamt deren Folgesammlungen.

So nachhaltig sind diese Forschungsergebnisse mittlerweile ins Bewusstsein der Gebildeten eingegangen, dass Heinz Rölleke sich veran-

\footnotetext{
${ }^{4}$ Zwei Neuausgaben liegen vor. Die erste stammt von Heinz Rölleke ([Brüder Grimm] 1994), die zweite von Hans-Jörg Uther ([Brüder Grimm] 1996).
} 
lasst sah, vor neuen und wiederum falschen Extremen zu warnen: als entsprängen alle Märchen nur einer auf dem Umweg über sekundäre Oralisierung zu den Grimms gelangten schriftlichen Kunstpoesie, und als seien die deutschen Märchen im wesentlichen Importe gebildeter hugenottischer Familien. Es ist, so hält er fest, am Ende doch wieder mehr Deutsches, mehr Mündliches, mehr Anonymes und Altes in den Texten enthalten, als heutige wissenschaftlich aufgeklärte Leser manchmal glauben wollen.

Dennoch sind die Bearbeitungen des Überlieferten durch die Grimms zu dem, was André Jolles die „Gattung Grimm“5 genannt hat, kaum weniger einschneidend als etwa diejenigen, die James Macpherson an der ihm wie auch immer vorliegenden Überlieferung vorgenommen hat. Dazu gehört zunächst und vor allem natürlich der Medienwechsel von der Mündlichkeit zur Schriftlichkeit mit seinen weitreichenden Folgen; dazu gehören Kombinationen, Streichungen und Dehnungen und überhaupt inhaltliche wie sprachliche Bearbeitungen größten, im Laufe der Editionsgeschichte fortschreitenden Ausmaßes. Diese wichtigen, aber andernorts umfangreich dokumentierten Eingriffe sind hier nur mit diesen knappen Stichworten zu resümieren. Denn worauf es hier ankommt, ist die Funktionalisierung all dieser Veränderungen für die Konstruktion der „Kinder- und Hausmärchen“ als einer so eigenartigen wie wirkungsmächtigen Variante eines nationalen Epos - oder doch jedenfalls einer nationalen Epik.

Denn soviel sie auch eingreifen, so ausdauernd beharren die Grimms darauf, dass sie mit ihrem Werk nicht Kunst präsentierten, sondern Natur. Schon in einem Brief an Arnim hat Jacob Grimm das „Volksmährchen“ als „Naturpoesie“ dem „Kunstmährchen“ als „Kunstpoesie" gegenübergestellt und es damit im Sinne romantischen Denkens aufgewertet. Auch die Publikations- und Rezeptionsgeschichte der Märchen wird zunehmend bestimmt von der Identifikation einer in den Märchen zum authentischen Ausdruck kommenden, ursprünglichkunstlosen "Natur" - verstanden als ein vor- und außergeschichtliches mythisches Erzählen - mit der Kategorie des „Volkes“. Dieser letztere Begriff wird sich bald auf folgenreiche Weise als ambivalent erweisen.

\footnotetext{
${ }^{5}$ In seiner zuerst 1930 in Halle (Saale) erschienenen Studie „Einfache Formen“. S. dazu auch den Beitrag von Thomas Taterka in diesem Band.
} 
Und diese Verbindung ist nun in hohem Maße anschlussfähig an einen dritten Leitbegriff der Epoche: die Kindheit. Eben erst, im 18. Jahrhundert, als sozialer und psychischer Erfahrungsraum entdeckt, wird sie in Deutschland mit der Frühromantik zum Traumbild und, eben als Traumbild, zur geschichts- und kulturphilosophischen Leitmetapher. Ihre klassische und unüberbietbar knappe Formulierung hat sie bei Novalis gefunden. In dessen berühmtem 97. „Blüthenstaub“-Fragment von 1798 ist so lakonisch wie rätselhaft zu lesen: „Wo Kinder sind, da ist ein goldenes Zeitalter.“ (Novalis 1965: 457) Ausführlicher und anschaulicher lautet derselbe Gedanke in der Vorrede zu den „Kinder- und Hausmärchen“ 1819 so:

Darum geht innerlich durch diese Dichtungen jene Reinheit, um derentwillen uns Kinder so wunderbar und selig erscheinen: sie haben gleichsam dieselben blaulichweißen makellosen glänzenden Augen, die nicht mehr wachsen können, während die andern Glieder noch zart, schwach und zum Dienste der Erde ungeschickt sind. ([Brüder Grimm] 1980: 16)

Diese beiden programmatischen Äußerungen umspannen zwei Jahrzehnte einer geschichtsphilosophischen Ideologisierung der Kindheit, für die sich eine Fülle weiterer Belege anführen ließe und die alle Wandlungen von Früh-, Hoch- und Spätromantik bemerkenswert überdauert. Das Kind ist danach der wahre, nämlich ursprünglich-unschuldige Mensch. Es repräsentiert eben deshalb das erste, ursprünglich-unschuldige Zeitalter der Menschheitsgeschichte; in der Lebensgeschichte jedes einzelnen Menschen wiederholt sich die große Geschichte der Menschheit, samt Paradies und Sündenfall. Was immer der Prozess der gesellschaftlichen Modernisierung an Dezentrierungs- und Fragmentierungserfahrungen mit sich bringt, von der arbeitsteiligen Gesellschaft über das Auseinandertreten von Mythos und Geschichte, Glaube und Wissenschaft bis zu den technischen, ökologischen, industriellen Umwälzungen der kapitalistischen Globalisierung: dem zum Idealbild erhobenen „Kind“ wird die Vereinigung des Entzweiten zugetraut, zugemutet.

Was immer an Heils- und Erlösungsbedürftigkeit in der Welt der Erwachsenen erwacht, das Kind soll es heilen - wobei oft in der Schwebe bleibt, wie weit dabei von den jetzt lebenden Kindern und wie weit von jenem Kind die Rede ist, das die Erwachsenen einmal waren, wie weit von einem Idealbild und wie weit von kleinen Menschen aus Fleisch 
und Blut und mit „blaulichweißen Augen“. Gegen die Triebwelt der Geschlechtlichkeit soll das Kind eine unverdorbene Unschuld und Reinheit repräsentieren. Gegen die politischen Machtansprüche und Gewalten soll es die Flötentöne anstimmen, mit denen in Goethes „Novelle“ der kindliche Knabe die ausgebrochenen Löwen und Tiger bezwingt. Gegen die sich immer weiter in Fachdisziplinen ausdifferenzierende Bildungskultur soll die Naivität der Volkskunst nicht aus irgendeinem wunderbaren Instrument ertönen, sondern aus dem kindlichen, also aus „Des Knaben Wunderhorn“.

Weil für die Phantasie des Kindes noch „alles in der Natur belebt und beseelt“ ist, wie es Friedrich Schlegel in der „Lucinde“ als „ein Ideal“ (Schlegel 1962: 14) wahrer Kindlichkeit darstellt, weil es in die Welt der Erwachsenen folglich „so neugierig und doch so bange“ (ebd., 68) hineinblickt, deshalb soll das Kind gegen die Entzauberung der Welt die Geltung einer mythischen Weltsicht garantieren, die im Märchen ihre Spielform gefunden hat. So heißen denn auch die Geschichten, die gegen die napoleonische Besatzung eine vorgeblich unverfälschte deutsche Volkstradition mobilisieren sollen, mit einem zu diesem Zweck neu erfundenen Doppelbegriff „Kinder- und Hausmärchen“.

Der für die romantische Suche nach „echter“ Kleinepik aus mündlicher Volksüberlieferung konstitutive Gegensatz von Erwachsensein und Kindheit - er wird nun in der Zeit der antinapoleonischen Befreiungskriege und im weiteren Prozess eines nation building mit zunehmender Intensität und Leuchtkraft projiziert auf den zeitgemäßen Gegensatz von national entfremdeter Gegenwart und einer uralten nationalen Mythologie, die mit den Märchen in nicht etwa kindlich depravierter Entstellung, sondern im Gegenteil in kindlich-unschuldiger Reinheit auf uns gekommen sei. So problematisch derartige Vergleiche immer sind, so statthaft mag der europäische Seitenblick hier doch sein: Wie mitten in der Zeit einer vermeintlichen englischen Überfremdung im schottischen Hochland die uralten Gesänge Ossians wunderbar wieder hörbar werden - fragmentarisch zunächst, aber erstaunlich rasch immer vollständiger und präziser -, wie mitten in der Zeit einer vermeintlich deutschen Dominanz die altnordischen Sagas durch Grundtvigs Übersetzung ins Dänemark des 19. Jahrhunderts katapultiert werden, so folgen in Deutschland, im Kampf um eine nationale Identitätskonstruktion in der Abwehr der französischen Kultur, auf das ebenfalls in 
den Befreiungskriegen triumphal neu gelesene und übersetzte „Nibelungenlied“ und auf die Volkspoesie aus „Des Knaben Wunderhorn“ die „Kinder- und Hausmärchen“. Jetzt, gerade zur rechten Zeit, wird in ihnen wiederentdeckt, was der Bildungskultur in den armen Spinnstuben und an den Kinderbettchen beinahe abhanden gekommen wäre: der Nationalmythos in der Kinderstube. Im „ächten deutschen Mythos“ der Märchen entdeckt sich ein mythisches Deutschland selbst.

Dieser politischen Instrumentalisierung und Ideologisierung entspricht ein Wandel des „Volks“-Begriffs von einer sozialen zur nationalen Kategorie. Indem „das Volk“ nicht mehr die Schriftunkundigen im Gegensatz zur herrschenden Bildungskultur bedeutet, sondern das deutsche Volk in Opposition zum französischen, englischen, polnischen, verengt sich die vormals weltliterarische Perspektive, aus der die VolksMärchen gewissermaßen als eine prosaische Variante der „Stimmen der Völker in Liedern" gelesen wurden, auf eine nationalliterarische $\mathrm{Zu}$ ordnung. Dieser Wandel eines Begriffs und Konzepts aber bringt die philologischen Sammler und Editoren Grimm in einen Konflikt mit den politisch-kulturellen Zeitgenossen gleichen Namens. Was die Philologen Grimm als deutsche Varianten international durch die Jahrhunderte nachweisbarer Erzählstoffe genealogisch rekonstruieren, von Basile über Perrault bis zu den skandinavischen Märchensammlern, das müssen die Dichter Grimm durch ihre Kommentierung und mehr noch durch die fortlaufende Überarbeitung der Texte gleichsam nachträglich nationalisieren.

Dass das zunächst noch keineswegs programmatisch durchdacht war, deutet eine auffallende Differenz des Titels gegenüber den Titeln der folgenden und in vieler Hinsicht vergleichbaren Sammelarbeiten der Grimms an. Die heißen „Deutsche Sagen“ (1816, 1818), „Deutsche Rechtsalterthümer“ (1828) und „Deutsche Mythologie“ (1835, 1844), ganz zu schweigen von der „Deutschen Grammatik“ (1819-37) oder der "Geschichte der deutschen Sprache“ (1848). Nur ein Werk fällt auffallend aus dieser Reihe: die „Kinder- und Hausmärchen“, eben weil sie aus dem „Volk“ in einer sozialen, nicht nationalen Bedeutung des Wortes kommen, weil sie anders als Sagen oder Rechtstexte europäisches, weltliterarisches Gemeingut sind. 
Wilhelm Grimms seit den sozialkritischen siebziger Jahren oft gescholtene, aber poetisch wunderbare Überarbeitungen, die eigentlich erst den unvergesslichen Grimm'schen Märchenton erzeugen: sie erzeugen mit ihrer Tendenz zur pädagogischen Entschärfung und Verniedlichung, wie Rölleke und andere sie detailliert nachgewiesen haben, nicht nur eine zeitgemäße Verbürgerlichung der Texte. Insofern diese Bürgertugenden der Frömmigkeit, Rechtschaffenheit, Geradheit, Keuschheit usf. als spezifisch deutsche reklamiert und den komplementären Untugenden der Nachbarvölker, zuerst der Franzosen, gegenübergestellt werden, passen sie die Texte darüber hinaus auch einem spezifischen und komplexen nationalen Autostereotyp an.

Aus dieser Ambivalenz speisen sich weite Teile der „Kinder- und Hausmärchen"-Rezeption, fortschreitend mit der Gründung des Bismarckreichs und in der neuromantischen Zuspitzung deutscher Autound antifranzösischer Heterostereotypien in der wilhelminischen Epoche. Ein Beispiel für viele gibt Alfred Bieses vielgelesene „Deutsche Literaturgeschichte" von 1907-11, die es bis 1931 auf nicht weniger als fünfundzwanzig Auflagen brachte (vgl. Biese 1907, 1909, 1911). Für Biese sind die Grimm'schen „Kinder- und Hausmärchen“ eine

Sammlung der unsterblichen, wundervollen, ernsten und lustigen Mären unseres Volkes, die an Schönheit, Tiefe und Reichtum in den Literaturen anderer Völker kaum ihresgleichen haben, in denen der Charakter des deutschen Volkes sich vielleicht unmittelbarer darstellt als in irgend einem anderen Werke. [...] Aus dem Volke sind sie gesammelt, der Geist des Volkes träumt und plaudert, lacht und weint in ihnen. (Biese 1911: 441)

Der Geist des Volkes träumt und plaudert - das heißt hier unmissverständlich: der Geist des deutschen Volkes. Da ist der Weg von der romantischen Wiederentdeckung der Kindermärchen zur Erfindung eines deutschen Nationalepos aus kindgemäßer Kurzprosa auf einem ersten Höhepunkt angelangt.

Aber es fehlt doch noch etwas. Der vorerst letzte Schritt, der die „Kinder- und Hausmärchen“ weiter an die dem Genre eigentlich wesensfremde Welt der Sagen heranführen sollte, war ihre Topographisierung. Schon die vielen Ortsangaben, die von den Grimms selbst den Textaufzeichnungen von Beginn an hinzugefügt worden sind (,,aus dem Hessischen"), wurden sehr rasch - und vielleicht mit ihrem stillschweigenden Einverständnis - nicht nur als Hinweis auf die Herkunft dieser Version 
verstanden, sondern als Hinweis auf eine enge Zusammengehörigkeit gerade dieses Stoffes mit dieser besonderen Landschaft. Von dieser Verkürzung aus, dieser Verwechslung von Überlieferungsort (in einer langen Reihe vieler anderer) und Handlungsort, war es nur noch ein kleiner Schritt zu volkstümlichen Identifikationen von topographischen Elementen beliebter Märchen mit der realen Topographie einer Region, zur Identifikation etwa der Sababurg im Reinhardswald mit dem Schloss Dornröschens.

Mit der Entdeckung, dass sich solche Zuordnungen auch für den Tourismus kommerziell nutzen lassen, wurde aus solchen kasuellen Gleichsetzungen ein System. In seiner bekanntesten Erscheinungsform trägt es seit 1975 den Namen Deutsche Märchenstraße und beruht auf einer Verkettung vorgeblicher, nach dem Modell der Sage konkretisierter Märchenschauplätze (ineins mit wesentlichen Lebensstationen der Brüder Grimm von Hanau, das den Anfang der Straße markiert, über Kassel bis nach Göttingen) durch die touristische Route, die auf Landkarten vermerkt und durch entsprechende Wegweiser und Hinweisschilder überdies auch buchstäblich in die Landschaft eingetragen wird. ${ }^{6}$ Wo sich vor der Konstruktion dieser "Märchenstraße“ keine Zuschreibungen finden ließen, da werden sie in freier Erfindung neu hergestellt, etwa durch die Errichtung von Brunnen oder die Aufstellung von Skulpturen, die das Rotkäppchen oder Frau Holle gewissermaßen am Originalschauplatz wieder sichtbar zu machen vorgeben. (Der einzige Ort, an dem das tatsächlich aus dem Märchentext heraus nahegelegt wird, ist ausgerechnet ein Ort, an dem die Märchenhandlung sich gerade nicht ereignet: In Bremen, dem Zielort der Route, sind die Bremer Stadtmusikanten selbst ja, Gerhard Marcks' schöner Skulptur zum Trotz, niemals angekommen.)

Allein der betont kindlich-spielerische Charakter erlaubt es, diese Topographisierung ohne allzu auffallende Konflikte mit der Märchenforschung selbst vorzunehmen. Und doch wird in ihrer simplen Drastik eine Dynamik anschaubar, die von Beginn der Aufzeichnungen an die Rezeption der „Kinder- und Hausmärchen“ mitbestimmt hat: Nationale Epen brauchen Schauplätze, an den die Nation ihren Spuren nachgehen kann, in denen Text und Territorium endlich eins werden.

\footnotetext{
${ }^{6}$ Eine affirmative Darstellung gibt Eberhard Michael Iba (2011). Eine kritische Analyse unternimmt Dorothee Hemmes Göttinger Dissertation (2009).
} 


\section{Literatur}

\section{Primärliteratur}

Brentano, Clemens (1977): Sämtliche Lieder und Briefe. Bd. 8: Des Knaben Wunderhorn. Alte deutsche Lieder. Teil III. Hrsg. v. Heinz Rölleke. Stuttgart.

([BRÜDER GRIMM] (1975): Die älteste Märchensammlung der Brüder Grimm. Synopse der handschriftlichen Urfassung von 1810 und der Erstdrucke von 1812. Herausgegeben und erläutert von Heinz Rölleke. Cologny-Genève.

[Brüder Grimm] (1980): Kinder- und Hausmärchen. Ausgabe letzter Hand mit den Originalanmerkungen der Brüder Grimm. Hrsg. v. Heinz Rölleke. Bd. 1, Stuttgart.

[BRÜDER GRIMM] (1985): Kinder- und Hausmärchen gesammelt durch die Brüder Grimm. Vollständige Ausgabe auf der Grundlage der dritten Auflage (1837). Hrsg. v. Heinz Rölleke. Frankfurt a. M.

[BRÜDER GRIMm] (1994): Brüder Grimm: Kinder- und Hausmärchen. Ausgabe letzter Hand mit den Originalanmerkungen der Brüder Grimm. Mit einem Anhang sämtlicher, nicht in allen Auflagen veröffentlichter Märchen und Herkunftsnachweisen. Band 3: Originalanmerkungen, Herkunftsnachweise, Nachwort. Hrsg. v. Heinz Rölleke. Durchgesehene und bibliographisch ergänzte Ausgabe. Stuttgart.

[BRÜDER GRIMm] (1996): Brüder Grimm: Kinder- und Hausmärchen. 4 Bände. Hrsg. v. Hans-Jörg Uther. München.

[BRÜDER GRIMM] (2004): Brüder Grimm: Kinder- und Hausmärchen. Faksimile der 2. Auflage der KHM von 1819 sowie des Anmerkungsbandes von 1822. Hrsg. v. Hans-Jörg Uther. Hildesheim.

Novalis (1965): Schriften. Bd. 2: Das philosophische Werk I. Hrsg. v. Richard Samuel. Stuttgart.

SchleGel, Friedrich (1962): Dichtungen. Werkausgabe. Bd. 4. Hrsg. v. Hans Eichner. Paderborn.

\section{Sekundärlitertaur}

BIESE, Alfred (1907): Deutsche Literaturgeschichte. Band 1: Von den Anfängen bis Herder. München.

BIESE, Alfred (1909): Deutsche Literaturgeschichte. Band 2: Von Goethe bis Möricke. München.

BIESE, Alfred (1911): Deutsche Literaturgeschichte. Band 3: Von Hebbel bis zur Gegenwart. München.

Bluhm, Lothar (1995): Grimm-Philologie. Beiträge zur Märchenforschung und Wissenschaftsgeschichte. Hildesheim.

Hemmes, Dorothee (2009): Märchenstraßen - Lebenswelten. Zur kulturellen Konstruktion einer touristischen Themenstraße. Berlin. 
IBA, Eberhard Michael (2011): Die Deutsche Märchenstraße. Eine sagenhafte Reise vom Main zum Meer. Hameln.

Martus, Steffen (2009): Die Brüder Grimm. Eine Biographie. Berlin.

RÖLlEKE, Heinz (1984): „Wo das Wünschen noch geholfen hat“: Gesammelte Aufsätze zu den „Kinder- und Hausmärchen“ der Brüder Grimm (Wuppertaler Schriftenreihe Literatur, Bd. 23). Bonn.

Rölleke, Heinz (2000): Die Märchen der Brüder Grimm: Quellen und Studien. Gesammelte Aufsätze. 2. Auflage. Trier.

Rölleke, Heinz (2004a): Die Märchen der Brüder Grimm. Eine Einführung. Stuttgart.

RöLlEke, Heinz (2004b): Grimms Märchen und ihre Quellen. Die literarischen Vorlagen der Grimmschen Märchen synoptisch vorgestellt und kommentiert. 2. Auflage. Trier.

RÖTZER, Hans Gerd (1995): Märchen. Bamberg.

UTHER, Hans-Jörg (2008): Handbuch zu den Kinder- und Hausmärchen der Brüder Grimm. Berlin.

UTHER, Hans-Jörg (2010): Handbuch zu den „Kinder- und Hausmärchen“ der Brüder Grimm. Entstehung - Wirkung - Interpretation. Berlin/New York. 


\section{Schillers ,Wilhelm Tell'6 - ein Schweizer Nationalepos?}

\section{Schillers ,Wilhelm Tell“" zwischen nationalem Mythos und Geschichtsdrama}

Im Webportal myswitzerland.com von Schweiz Tourismus, der größten Tourismus-Organisation der Schweiz, wird für eine Dampferfahrt auf dem Vierwaldstättersee geworben. Im ersten Abschnitt, unter dem Motto: „Mit Volldampf durch die Geschichte“, heißt es:

Gleich an der Ecke erinnert der Schillerstein an den Schöpfer des Nationalepos Wilhelm Tell, in der Ferne liegt die sagenumwobene Tellsplatte, und einige Radschläge weiter legt der Dampfer beim Rütli an. Hier, am Geburtsort der alten Eidgenossenschaft, beginnt der „Weg der Schweiz“.

Der Schillerstein, „Wilhelm Tell“ als Nationalepos, die Tellsplatte, das Rütli als Geburtsort der Schweiz - was sind hier Fakten und was sind Fiktionen? Was gehört ins Reich der Sage oder in die fiktive Welt von Schillers Drama, was kann als historisches Faktum gelten und was könnte man - mit Eric Hobsbawm - als historische Fiktion begreifen? ${ }^{2}$ Bis heute herrscht unter den Historikern keine Einigkeit über die genauen geschichtlichen Ereignisse um 1300 in der Schweiz. Als sicheres historisches Zeugnis gilt lediglich der sogenannte Bundesbrief, eine Urkunde, die im Jahr 1291 von den drei Waldstätten Uri, Schwyz und Unterwalden unterzeichnet wurde. Der Rütlischwur selbst hat sich historisch nie beweisen lassen. ${ }^{3}$ Die Tellfigur gehört, wie man inzwischen weiß, gewiss ins Reich der Fiktion, sie entstammt einem internationalen Sagenstoff und ist damit weder historisch verbürgt noch in der Schweiz zu Hause. ${ }^{4}$ Und mehr noch: Es gibt historisch gesehen auch „keine An-

\footnotetext{
${ }^{1}$ http://www.myswitzerland.com/de/erlebnisse/ausfluege-sommer/bergsommertipps/mit-volldampf-durch-die-geschichte.html (13.01.2011).

${ }^{2}$ S. insbesondere Hobsbawm ${ }^{3} 2005$ sowie Hobsbawm/Ranger 1992.

${ }^{3}$ S. dazu Piatti 2004: 421f. Barbara Piattis Publikation stellt dem Leser eine Vielzahl an Material zur Verfügung.

${ }^{4}$ S. dazu Suppanz 2005: 58: „Was die Tell-Sage betrifft, so enthält die historische Überlieferung keine Nachrichten von einem Schützen Tell und von der Ermordung Geßlers durch ihn.“ Die Wandersage „kursierte in mündlicher wie schriftlicher
} 
haltspunkte für den legendären Burgenbruch, das gleichzeitige Schleifen der verhassten Sitze der habsburgischen Reichsvögte im Zuge eines Volksaufstandes“ (Piatti 2004: 42). Es war Schiller, der die Tell-Figur in seinem gleichnamigen Geschichtsdrama zum Angelpunkt der Schweizer Befreiungsbewegung gemacht, den Rütlischwur bildkräftig ausgestaltet und symbolisch aufgeladen hat - die Schweiz sollte es ihm danken und sein Drama in den Rang ihres Nationalepos erheben. Gleichwohl hat Schiller nie die Faktizität behauptet, sondern ein Geschichtsdrama mit Allgemeinheitsanspruch intendiert. Erst die Wirkungsgeschichte sollte die Tell-Figur und die fiktive Welt von Schillers Drama historisieren.

So will denn auch der Werbetext auf der Webseite von MySwitzerland.com allem Anschein nach gar nicht so genau zwischen Fakten und Fiktionen unterscheiden; im Gegenteil, in Formulierungen wie „sagenumwobene Tellsplatte“ werden Fiktionen und Reales geradezu amalgamiert. Und es ist ja auch nicht allein von Tell und Schiller die Rede, sondern von dem Schillerstein und der Tellsplatte - zwei realen Objekten also, die das Faktische der Fiktion gewissermaßen verbürgen. Felsen werden zu semantisch aufgeladenen Naturphänomenen. ${ }^{5}$ Bei dieser semantisierten Landschaft haben wir es mit historischen Fiktionen in einem speziellen Sinne zu tun: Der Weg der heutigen Schweiz beginnt weniger am vermeintlich faktischen Geburtsort der Rütliwiese als vielmehr in der fiktiven Welt von Schillers Drama, das - als Nationalepos rezipiert - der eigentliche Geburtshelfer war. Das bedeutet, die historische Fiktion geht nicht auf ein Faktum zurück, das in die Vergangenheit verlängert wird, sondern der historischen Fiktion liegt ein fiktionaler Text zugrunde. Und die Sache stellt sich noch

Überlieferung in Europa, wurde auch in der Schweiz situiert und verband sich dort mit den historischen Fakten zum nationalen Mythos" (Suppanz 2005: 64). Verwiesen wird auf den dänischen Geschichtsschreiber Saxo Grammaticus, in dessen Chronik von einem Apfelschuss im Zusammenhang mit der Figur des Königs Blauzahn und dessen Gefolgsmann Toko berichtet wird. Vgl. auch Barbara Piatti: „Es gibt innerhalb dieser Gründungsgeschichte keine Zeugnisse, die auf einen Helden und Meisterschützen Tell hinweisen würden." (Piatti 2004: 42)

${ }^{5}$ Eine hochaufragende Felspyramide, der sogenannte Mythenstein, wurde 1860 in „Schillerstein“ umbenannt. Als „Tellsplatte“ wird eine Felsplatte bezeichnet, auf der sich Tell mit einem gewagten Sprung aus dem Schiff vor Gessler gerettet haben soll - die fiktive Welt aus Schillers Stück hinterlässt also ihren Abdruck in der realen Schweizer Berglandschaft. 
komplizierter dar, wenn man sich zudem klar macht, dass Schillers „Tell“-Drama nur durch seine Rezeption als Nationalepos diese Wirkung entfaltet hat.

Dieser besondere Fall soll Gegenstand der vorliegenden Untersuchung sein. Betrachtet man Schillers Drama „Wilhelm Tell“, das 1804 unter Goethes Leitung im Weimarer Hoftheater Premiere hatte, in Hinblick auf seine Zugehörigkeit zum Genre der Nationalepen, so fällt ein eigentümlicher Umstand ins Auge: Auf der Entstehungsebene ist Schillers „Tell“ überhaupt kein Nationalepos, sondern ein Drama, mithin ein fiktionaler Text; auf der Rezeptionsebene ist er sowohl Drama als auch Nationalepos. Voraussetzung dieser Argumentation ist ein weiter Eposbegriff, wonach das Genre nicht notwendigerweise an die epische Gattung gebunden ist. Entscheidend ist die kanonische Wirkung eines literarischen Textes für die Nationsbildung und speziell für das kulturelle Gedächtnis eines „Volkes“ bzw. einer „Nation“. ${ }^{6}$ Unter dieser Voraussetzung ist auch Schillers „Wilhelm Tell“ zu den Nationalepen zu rechnen. Trotz seiner Sonderstellung lässt sich, so die These, etwas Allgemeines aus der Untersuchung dieses Falles für das Genre ableiten. Am Fall des „Tell“ kann gezeigt werden, klarer womöglich als bei Texten, die schon auf der Entstehungsebene als Nationalepen angelegt sind, dass dieses Genre seinem spezifischen ontologischen Status nach zwischen Fakten und Fiktionen steht. Im Vergleich mit einem fiktionalen Text - Schillers Geschichtsdrama - wird das besonders manifest.

Meinen Überlegungen liegt die folgende Argumentationsbewegung zugrunde: In einem ersten Schritt möchte ich aufzeigen, inwiefern Schillers letztes Drama sich nicht zum Nationalepos eignet bzw. einer solchen Rezeption eigentlich entgegensteht. Zentral sind hierbei die Deutungsoffenheit und Widersprüchlichkeit des Stückes als fiktionaler Text. In einem zweiten Schritt soll die Rezeption als Nationalstück der Schweiz in wichtigen Etappen und mit einigen ihrer zentralen Merkmale nachgezeichnet werden. Der literarische Text wird im Zuge dieser Rezeption, so die Argumentation, vereindeutigt, auf Lesarten hinsichtlich eines nationalen Mythos reduziert und mithin zum Ausgangspunkt einer historischen Fiktionsbildung. Die Rezeption als Nationalepos ver-

\footnotetext{
${ }^{6}$ Vgl. hierzu auch die Beiträge von Heinrich Detering und Zuzana Stolz-Hladká in diesem Band.
} 
ändert also zwei spezifische Charakteristika der Literarizität des Textes: Erstens verändert sich das Verhältnis zwischen Fiktionalität und Faktizität und zweitens reduziert diese Rezeption seine Polysemantik und Widersprüchlichkeit. Schließlich führe ich als letzten Schritt mit Max Frischs „Wilhelm Tell für die Schule“ aus dem Jahr 1970 ein Beispiel für die Reliterarisierung des Tellstoffes an. Zwei Grundzüge sind gleichermaßen für diese Tendenz verantwortlich: die Demontage des nationalen Mythos und eine Öffnung des Deutungshorizontes, eine $\mathrm{Zu}-$ rücknahme der Bedeutungsreduktion. Reliterarisiert wird dabei nicht Schillers Text, denn als Text bleibt dieser stets das, was er ist; reliterarisiert wird vielmehr der Tellstoff. Der Stoff wird zu einem weiteren literarischen Text, allerdings zu einem, der sich zum Nationalepos oder für einen nationalen Mythos als gänzlich ungeeignet erweist.

\section{Inwiefern Schillers ,Wilhelm Tell“" einer Rezeption als Nationalepos entgegensteht}

Schon der Gattung und den Produktionsbedingungen nach ist Schillers Geschichtsdrama „Wilhelm Tell“ nicht recht als Nationalepos geeignet: Weder haben wir es im strengen Sinne mit einem epischen Text zu tun noch kann Schiller unterstellt werden, dass er den Schweizern ein Nationalstück schreiben wollte. Schiller ist weder Schweizerischer Herkunft noch hat er länger in der Schweiz gelebt oder andere persönliche Bindungen an das Land. Mehr noch: Schiller hat das „Land des Tell“ nur medial erfahren, es nicht einmal während seiner Arbeit am „Tell“ besucht. ${ }^{7}$ Die bei zahlreichen Nationalepen zu bemerkende Anonymisierungstendenz, wonach der Autor rhetorisch hinter seinem Text zurücktritt oder nurmehr als Sammler und Redaktor firmiert, trifft auf Schillers „Wilhelm Tell“ ebenfalls nicht zu. Das gilt sowohl für die Entstehungsbedingungen als auch für die Wirkungsgeschichte. Denn neben dem Stück ehrt die Schweiz zugleich dessen Autor, den sie in den Rang ihres Nationaldichters erhoben und dem sie mit dem eingangs

\footnotetext{
${ }^{7}$ Schiller hat sich während seiner Arbeit am „Wilhelm Tell“ die Schweiz in Form von Bildern, Karten und Berichten in sein Arbeitszimmer geholt. Darauf geht ausführlich Barbara Piatti ein (vgl. Piatti 2004: 73-128, Piatti 2008: 156f.).
} 
erwähnten Schillerstein denn auch ein signifikantes Denkmal gesetzt hat. $^{8}$

Wirkungsästhetisch und textintern lassen sich weitere Aspekte finden, die dem „Tell“ als Nationalepos entgegenstehen. Zunächst sei die Rezeption untersucht, danach die Textebene.

Kein anderes Stück Schillers hat eine solch intensive und lang anhaltende Wirkungsgeschichte erfahren wie sein letztes Drama, eine Rezeptionsgeschichte, die sich über zwei Jahrhunderte erstrecken und sich gleichermaßen in der Schule, im Theater, auf Festen, auf der politischen Bühne und nicht zuletzt in der Landschaft abspielen sollte: „Als fester Bestandteil der gymnasialen Lehrpläne, als Referenz von Festspielen, Festgedichten, Reiseführern, Plakaten, Denkmälern, Gemälden und literarischen Werken wurde das Stück kanonisiert und folklorisiert“ (Kurz 2007: 283f.), resümiert Gerhard Kurz. Der „Tell“ wurde gelesen, aufgeführt, zitiert, kommentiert, interpretiert, weitergeschrieben, persifliert und aus unterschiedlichsten Motiven (und in zahlreichen Ländern wie in Deutschland, der Schweiz, aber auch in Frankreich) politisch in Dienst genommen. ${ }^{9}$

Neben seiner publikumswirksamen Resonanz in Schule, Theater und politischer Rede hat das Drama zudem eine Vielzahl und Vielfalt an Interpretationen in Literaturgeschichte und Literaturwissenschaft erfahren. Frank Suppanz spricht in seinem kursorischen Überblick über die Interpretationen nach 1945 folgerichtig von einem „Spektrum an Möglichkeiten, den ,Tell‘ zu deuten“ (vgl. Suppanz 2005: 178-187, hier 178). Dieses Spektrum kann man nach Frank Suppanz kursorisch über Gegensatzpaare strukturieren: Zwei besonders markante Dichotomien wären gesellschaftliche versus individualistische Interpretation sowie die Deutung als Nationalstück (vor allem der Schweiz, aber auch Deutschlands) versus die Deutung als Geschichtsdrama. Hat die DDRLiteraturwissenschaft die Tell-Figur zum „Fürsprecher revolutionärer Bewegung“ gemacht und das Stück als „Zustimmung zu den Zielen der Französischen Revolution“ (Thalheim 1956, zit. n. Suppanz 2005: 178)

\footnotetext{
${ }^{8}$ Der „Schillerstein“ trägt die Inschrift: „Dem Sänger Tells / F. Schiller / Die Urkantone 1859“. Zu beachten ist das Wort „Sänger“, das den Schreibakt mit einer Pathosformel belegt und wohl nicht zufällig an epische Dichter wie Homer oder Vergil denken lässt. ${ }^{9}$ S. ausführlich zur Wirkungsgeschichte des „Wilhelm Tell“ Peter Utz (1984).
} 
gelesen, so haben Interpretationen aus Westdeutschland und der Schweiz dagegen Schillers Kritik am Verlauf der Französischen Revolution betont und in ihren Deutungen explizit Privates auf Gesellschaftliches bezogen. So führt etwa Benno von Wiese in seiner Interpretation private und politische Aspekte im Motiv der Familie und dem Ziel der „Wiederherstellung der natürlichen Familienordnung“ zusammen und deutet Tell auf dieser Folie nicht als Tyrannenmörder, sondern als jemanden, der zwar „in eigener Sache handelt, [...] doch zugleich für alle" (von Wiese 1959: 773f., zit. n. Suppanz 2005, 180). Während Schillers „Tell“ in der Schweiz - wie im folgenden Abschnitt noch ausführlich gezeigt werden soll - als Nationalstück, ja Nationalepos gelesen und rezipiert wurde, betonen Interpretationen, die an Schillers Geschichtsauffassung ausgerichtet sind, dass der lokale Stoff „als Fall der allgemeinen Menschengeschichte“ gestaltet wird und zugleich „zum Paradigma der zukünftigen Geschichte“ (Ueding 1992: 391, zit. n. Suppanz 2005: 182) erhoben wird.

Auch wenn den literaturwissenschaftlichen Deutungen ihrerseits zum Teil ideologische Vorgaben zugrundeliegen, ist für die Argumentation allein der Umstand bemerkenswert, dass Schillers „Tell“ - ähnlich wie andere große Texte der Weltliteratur - eine solche Vielzahl unterschiedlichster Interpretationen und Deutungen hervorrufen konnte. Die Deutungsvielfalt resultiert nicht allein aus der wechselvollen Geschichte, sondern ist im Text selbst, seiner Deutungsoffenheit, seinen Spannungen und Gegensätzen angelegt. ${ }^{10}$

\footnotetext{
${ }^{10}$ Hier sei auf mein Verständnis von Literatur verwiesen, das als Prämisse dem Aufsatz zugrunde liegt, aber innerhalb der Literarizitätsdebatte keineswegs unumstritten ist. Die Forschungsdiskussion wurde unlängst von Simone Winko zusammengefasst und gebündelt (Winko 2009). Ich unterscheide literarische und nicht-literarische Texte durch das Merkmal der Literarizität. Dieses Merkmal gründet nicht nur in der Rezeption, wie oft behauptet wird (vgl. etwa die Empirische Literaturwissenschaft), sondern zeichnet den Text selbst aus. In vorliegendem Aufsatz sind zwei Kriterien der Literarizität virulent, die Fiktionalität und die Polysemantik bzw. Widersprüchlichkeit. Selbstverständlich ist kein literarischer Text davor gefeit, nicht in seiner Widersprüchlichkeit und nicht als fiktionaler Text rezipiert zu werden, wie kein nichtliterarischer Text davor bewahrt werden kann, literarisch rezipiert zu werden. So willkürlich daher die Rezeption sein kann, so unveränderlich bleibt dennoch der Text.
} 
Zumal in der jüngeren Literaturwissenschaft werden denn auch stärker die Ambivalenz, Widersprüchlichkeit und Deutungsoffenheit des Stücks betont, Aspekte mithin, die seiner Funktionalisierung eigentlich entgegenstehen und damit auch einer Rezeption als Nationalepos zuwiderlaufen. So stellt Karl Guthke die Ambivalenz der Tell-Figur heraus, „einerseits den Heroismus des Selbsthelfers, andererseits den von Schuldgefühlen und Selbstzweifeln Geplagten“ (vgl. Suppanz 2005: 184). Gerhard Kurz betont die „problematische Seite dieses Helden“, ihm zufolge führt das Stück sogar ,in kritischer Befragung die Entstehung des Mythos eines Helden vor, der als Gründungsfigur einer freiheitlichen Republik eigentlich nicht taugt" (Kurz 2007: 285). Peter André-Alt hat in seiner Schiller-Monographie die „Widersprüchlichkeit des Stücks als angemessenen Ausdruck einer adäquaten Zeitanalyse“ (zit. n. Suppanz 2005: 185) hervorgehoben. Und der Schweizer Literaturwissenschaftler Peter von Matt betont an Schillers Stück die „Vielschichtigkeit in der Komposition“. ${ }^{11}$

Die dem Stück immanenten Spannungen und Widersprüche möchte ich schließlich noch am Dramentext selbst herausstellen. Von der Fülle an Aspekten, die zu nennen wären, sollen lediglich zwei Momente herausgegriffen werden, da diese einer Rezeption als Nationalepos besonders deutlich entgegenstehen: erstens die Ausformung des Tell-Charakters sowie ihre Stellung innerhalb der dramatischen Handlung und zweitens das Verhältnis von Stoff und Idee. Die Figur des Tell nimmt, wie bereits gesagt, eine wichtige Stellung innerhalb der dramatischen Handlung ein. Im Unterschied zum „Chronicon Helveticum“ von Ägidius Tschudi (1734) und der „Geschichte Schweizerischer Eidgenossenschaft" (1786/87) des Schweizer Historikers Johannes Müller Quellen, die Schiller beide studiert hat und in denen Tell nur eine von vielen Figuren war - wird Tell in Schillers Drama zum Protagonisten und Titelgeber aufgewertet. ${ }^{12}$ Doch andererseits ist Tell nur scheinbar die Hauptfigur des Stücks, gibt es doch nicht nur eine zentrale Handlung, sondern drei Handlungsstränge, die Tell-Handlung, die

\footnotetext{
${ }^{11}$ Katharina Mommsen und Peter von Matt unterhalten sich im Weimarer Pausengespräch über Friedrich Schillers Wilhelm Tell. In: Piatti 2004: 111-125, hier 114.

12 Schiller knüpft damit an das Bundeslied und die Tellspiele an, in denen die sagenhafte Gestalt Befreier und Gründer der Eidgenossenschaft war (vgl. dazu Schmidt 2003: 54).
} 
Handlung der Eidgenossen und die Rudenz-Handlung, die mittels einer Technik der dreifachen Handlungsführung zum einen voneinander getrennt und zum anderen auf komplexe Weise ineinander verzahnt sind. Und obwohl Tell im Unterschied zu den Quellen eine Aufwertung erfährt, wird er doch andererseits deutlich den Eidgenossen gegenübergestellt, und auch dies im Unterschied zu den Quellen: Bezeichnenderweise schwört Tell in Schillers Drama beim Rütli-Schwur nicht mit. Es war deshalb kein Zufall, dass Schillers Stück in der Schweiz zunächst nur verhaltene Aufnahme gefunden hat; zu groß war die Diskrepanz zwischen dem damals schon lebendigen Mythos vom Freiheitshelden Tell und der Tell-Figur bei Schiller, die sich nicht recht zur Mythisierung eignen wollte. Peter von Matt kommentiert die Erstrezeption in der Schweiz:

Man fühlte sich zwar geschmeichelt, aber man hatte erwartet, Tell würde ganz und gar in der Mitte stehen, auch was den Rütlischwur und die Staatsgründung anging, und nun bewegte er sich bloß in einem einzigen von drei Handlungsbereichen und schwor auf dem Rütli nicht einmal mit. (Matt 1988: 24)

Tell wird in Schillers Stück als Einzelgänger, geradezu als vorgesellschaftlicher Mensch, gestaltet, sein Handeln steht damit im Gegensatz zu der gemeinsamen Handlung der Eidgenossen. Auch die Rechtsauffassungen Tells einerseits und der Akteure des Rütli-Schwures andererseits könnten nicht gegensätzlicher sein: Das Gesetz, das sich der Einzelne gibt, bringt Tell nach der Provokation mit dem Apfelschuss dazu, den Tyrannen Gessler zu erschießen. Dieser Rechtsauffassung steht als Gegenentwurf die gegenseitige Verpflichtung der Eidgenossen gegenüber, sich als Einzelne dem Gesetz, das sich die Gemeinschaft gibt, zu fügen (,-- Wir wollen sein ein einzig Volk von Brüdern / In keiner Not uns trennen und Gefahr.“ Z. 1448f.). Diese Verpflichtung zur Gemeinschaft schließt das Handeln aus privater Rache ausdrücklich aus. Der Ausspruch „Bezähme jeder die gerecht Wut / Und spare für das Ganze seine Rache, / Denn Raub begeht am allgemeinen Gut, / Wer selbst sich hilft in seiner eigenen Sache“ (Z. 1462-1465) steht denn auch zu Tells späterer Tat in offenkundigem Widerspruch. Denn dieser erschießt Gessler nicht, weil er damit die Schweizer von ihrem Tyrannen befreien will, sondern aus privater Rache. Seine Tat ist eine radikale Einzeltat, die er mit niemandem bespricht, für die er sich keine Hilfe holt und die 
er auch durch keine gemeinsame Sache zu rechtfertigen versucht. In seinem Monolog, der der Tat unmittelbar vorausgeht und die Handlung absichtsvoll retardiert, kommen seine Motive zum Ausdruck:

Ich lebte still und harmlos - das Geschoß

War auf des Waldes Tiere nur gerichtet,

Meine Gedanken waren rein von Mord -

$D u$ hast aus meinem Frieden mich heraus

Geschreckt, in gärend Drachengift hast Du

Die Milch der frommen Denkart mir verwandelt,

Zum Ungeheuren hast Du mich gewöhnt -

Wer sich des Kindes Haupt zum Ziele setzte,

Der kann auch treffen in das Herz des Feinds.

Die armen Kindlein, die unschuldigen,

Das treue Weib muß ich vor deiner Wut

Beschützen, Landvogt. - da, als ich den Bogenstrang

Anzog - als mir die Hand erzitterte -

Als du mit grausam teufelischer Lust

Mich zwangst, aufs Haupt des Kindes anzulegen -

Als ich ohnmächtig flehend rang vor dir,

Damals gelobt ich mir in meinem Innern

Mit furchtbarm Eidschwur, den nur Gott gehört,

Daß meines nächsten Schusses erstes Ziel

Dein Herz sein sollte - Was ich mir gelobt

In jenes Augenblickes Höllenqualen,

Ist eine heilge Schuld - ich will sie zahlen. (Z. 2569-2590)

Tell rechtfertigt vor sich selbst die unmittelbar bevorstehende Tat. Danach handelt er aus Notwehr, aus Rache, zum Schutz seiner Familie und aus Treue zu sich selbst, dem Gelöbnis ,in [s]einem Innern mit fruchtbarm Eidschwur". Die Tat stellt sich aus Tells Sicht gleichermaBen als notwendig wie als fatal („Drachengift", das „Ungeheure“, „heilge Schuld“) heraus. Den Zwiespalt, in dem sich die Tell-Figur befindet, und die Widersprüchlichkeit der Motive, die zu seiner Tat führten, betont noch die unmittelbar angeschlossene Parricida-Handlung: Zum einen werden durch die Einführung der Parricida-Figur die Unterschiede $\mathrm{zu}$ einem politisch motivierten Mord, einem Attentat, deutlich, wie es Parricida verübt hat, zum anderen aber sind beide Figuren durch ihre Taten und ihre Isoliertheit von der Gesellschaft aufeinander bezogen, der eine vogelfrei, der andere distanziert von einer ihn in der Schlussszene bejubelnden Gemeinschaft. 
Ein weiterer Gegensatz ist zwischen Tatmotiv und Tatwirkung auszumachen: Denn obwohl Tell als Einzelner und nicht für die Gemeinschaft handelt, wird er dennoch zum Helden der Befreiung gekürt: „Es lebe Tell! der Schütz und der Erretter" (Z. 3282), heißt es in der letzten Szene.

Auch wenn man nicht so weit gehen wollte, Schillers Tell als Anti-Helden zu lesen, so wäre doch zu konstatieren, dass die Figur sich in dem Geschichtsdrama aus dem Jahr 1804 nicht eben als Nationalheld empfiehlt. Mit guten Gründen hat Karl Guthke denn auch, argumentierend mit der Sonderstellung Tells, „die Sinnstruktur des gesamten Dramas“ (Guthke 2005: 303) von einem Verständnis des Stücks als politisches Festspiel abgerückt:

Der Sinn des Nebeneinanders von Tell-Handlung und Volksaufstand, der Sinn der Sonderstellung Tells, die Schiller im Gegensatz zu den Quellen so stark betont, wäre dann nicht ein politischer [...], sondern ein dramaturgischer, der Schillers menschengestalterischem Impetus Entfaltungsraum gibt und zugleich die Sinnstruktur des gesamten Dramas konstituiert. Diese wäre nicht mehr die eines im Festtagsjubel kulminierenden „Schauspiels“. (Ebd.)

Betrachtet man als zweiten Aspekt das Verhältnis von Stoff und Idee, das die Anlage des Stückes bildet, so bestätigt sich einmal mehr die Behauptung, dass wir es bei Schillers „Tell“ mit einem fiktionalen Text zu tun haben. Hierfür lassen sich viele Kronzeugen in der Literaturwissenschaft anführen. Deutliche Worte, die sich nicht zuletzt als Seitenhieb gegen die alljährlich stattfindenden „Tell“-Freilichtaufführungen in Interlaken ${ }^{13}$ lesen lassen, findet der Schweizer Autor und Literaturwissenschaftler Adolf Muschg:

Käme ich in den Fall, Schillers Tell heute zu inszenieren, [...] so würde ich die erste Lektüre mit einer Provokation beginnen: Vergessen Sie die Schweiz, würde ich den Schauspielern sagen, sie hat mit Schillers Tell nichts zu tun. Und „nichts“ heißt bei Schiller: Sie gibt nichts weiter als den Stoff dazu her. (Muschg 2007: 79)

\footnotetext{
${ }^{13}$ Vgl. hierzu S. 142f. des vorliegenden Aufsatzes.
} 
Am Stoff der Schweizer Befreiungsgeschichte war Schiller nicht primär interessiert - und das gilt ebenso für die historischen Stoffe, die seinen anderen Geschichtsdramen zugrundeliegen. Schillers Verständnis von Geschichtsdrama und Herders Eposkonzept stehen sich diesbezüglich diametral gegenüber. Denn was Schiller interessierte, war weder die historische Herkunft noch der Realitätsgehalt des Stoffes, sondern vielmehr dessen Eignung „für die poetische Behandlung“ (Muschg 2007: 79). Herders Eposkonzept stärkte hingegen die Vorstellung von historisch und lokal verwurzelten Erzählungen - auch wenn die folgenreiche Herder-Rezeption häufig übersehen hat, dass Herders Konzept gemäß seiner Vorstellung des „wandernden Ursprungs“ letztlich an einem Menschheitsepos ausgerichtet war und damit, ähnlich wie Schiller, allgemein anthropologisch fundiert ist. ${ }^{14}$

Und so ist der „Wilhelm Tell“ zwar ins Gewand des späten 13. Jahrhunderts gekleidet und in der Landschaft rund um den Vierwaldstättersee angesiedelt, stellt deshalb jedoch mitnichten ein Schweizer Historiendrama dar. Schillers ästhetischem Verständnis nach, wie er es in seinen ästhetischen Schriften, insbesondere in den Briefen „Über die ästhetische Erziehung des Menschen“ oder in dem Traktat „Über naive und sentimentalische Dichtung“, entworfen hat, bietet das Drama die Möglichkeit, ein Modell auf die Bühne zu projizieren, das sich der Kausalität und Faktizität der historischen Ereignisfolge enthebt. Im Falle des „Wilhelm Tell“ ist dies der Versuch, der realen Französischen Revolution in der Fiktion eine ideale Revolution entgegenzustellen, und zwar bewusst im Modus der Utopie, nicht der historischen Realität. Schillers Schauspiel zeigt dabei, wie Bernhard Auge betont, ein „bewusst idealisiertes Volk“ (Auge 2003: 167), ${ }^{15}$ das nicht mit den realen Schweizern verwechselt werden dürfe.

\footnotetext{
${ }^{14}$ Vgl. hierzu ausführlicher Hans Graubners Beitrag zu diesem Band.

${ }^{15}$ Bernhard Auge zitiert Friedrich Dürrenmatt, der den Finger in die gleiche Wunde legt: „So ist er [ = Schiller $]$ auch im Tell groß darin, dass er hier die Geschichte eines Volkes gibt, aber eben auch nur so, wie Schiller das Volk sieht: als Idee [...] Die Größe des Tell [...] liegt in seiner Abstraktheit. Das Schicksal, das er auf einer schweizerischen Bühne erleiden muss, liegt darin, dass, notgedrungen, diese Abstraktheit aufgehoben wird.“ (Dürrenmatt, zit. n. Auge 2003: 169).
} 
Auf der Textebene wurde also an zwei Aspekten gezeigt, inwiefern Schillers Geschichtsdrama „Wilhelm Tell“ seiner Rezeption als Nationalepos entgegensteht. Der erste Aspekt ist die Anlage der Tell-Figur: Tell ist bei Schiller gerade nicht als nationaler Freiheitsheld determiniert, sondern zum einen im bewussten Gegensatz zur Handlung der Eidgenossen konzipiert und zum anderen als ambivalente Figur angelegt. ${ }^{16}$ Der zweite Aspekt ist der ideelle Gehalt des Stoffes und damit der enthistorisierende Zug von Schillers dramatischer Bearbeitung. Daran wird der Grundcharakter des Dramas als fiktionalem Text, nämlich Literatur zu sein, manifest: Es ging Schiller nicht darum, historische Realität abzuspiegeln, sondern im Modus der Fiktionalität eine ideale Revolution durchzuspielen. Diese ideale Revolution fand nicht in der Schweiz statt, sondern nur in der Literatur.

Weshalb Schillers „Tell“ als Nationalstück der Schweiz im Laufe des 19. und 20. Jahrhunderts dennoch einen wahren Siegeszug in Schulen, auf Festbühnen und durch die Schweizer Landschaft rund um den Vierwaldstättersee antreten konnte und in welcher Weise dies den Literarizitätscharakter des Textes betrifft, soll Gegenstand des folgenden Abschnitts sein.

\section{Schillers „Wilhelm Tell“" als Schweizer Nationalepos}

Es ist ein Phänomen für sich, dass deutungsoffene Texte im Laufe ihrer Wirkungsgeschichte immer wieder vereindeutigend interpretiert und funktionalisiert wurden. Dieses Phänomen lässt sich bei Schillers „Wilhelm Tell“ lehrreich beobachten. Eine markante Linie dieser Lektüre ist die Aufnahme und Verbreitung als Nationalstück. Dabei sind weniger die Gründe relevant, weshalb sich Schillers Stück dafür offenbar doch geeignet haben muss (die Sprachgewalt der Rütlischwur-Szene, die dramatischen Effekte bis hin zur auf die Bühne geholten Landschaft einschließlich einer symbolträchtigen Naturszenerie). Wichtiger ist vielmehr die Art und Weise, wie diese Rezeption vonstatten ging und

\footnotetext{
${ }^{16}$ Die Spannung zwischen Befreiung und Tragik liegt ebenso der Tell-Figur zugrunde wie die Spannung von Drama und Idylle dem gesamten Stück.
} 
geht. Ich möchte mich auf die Rezeption des Stückes in der Schweiz begrenzen, obwohl sich sehr wohl zeigen ließe, dass Schillers Drama auch in Deutschland als Nationalstück gelesen wurde und es diesbezüglich lange Zeit eine Konkurrenz zwischen Deutschland und der Schweiz gegeben hat. ${ }^{17}$

Die Landschaft um den Vierwaldstättersee hat als Effekt dieser Rezeption gewissermaßen das Gepräge des Schiller'schen Stücks erhalten; sie wurde, um es mit Peter Utz zu sagen, ,auratisch aufgeladen vom Siegeszug des Schauspiels" (Utz 1984: 51). ${ }^{18}$ Was wir heute noch, wie eingangs geschehen, an einem touristischen Werbetext beobachten können, nahm im Literaturtourismus des 19. Jahrhunderts seinen Anfang. Scharenweise schickten sich etwa Künstler aus dem In- und Ausland an, die Schweiz auf den Spuren von Schillers Stück zu bereisen. Die Imagination des Stückes präfigurierte die Wahrnehmung der Wirklichkeit, was einige Beispiele illustrieren sollen: Die Einleitung zum „Tell“ „las man mit Vorliebe auf einer Bootsfahrt. ,Jetzt sind wir endlich auf dem See, der Himmel hell und klar, da wird Schiller hervorgeholt, und sein ,Tell' mit Andacht gelesen, denn hier ist der Ort dafür“" (zit. n. Hentschel 2002: 286). ${ }^{19}$ Ziel jeder literarisch inspirierten Schweizreise war denn auch das Rütli, auf dem man sich mit Vorliebe bei Mondschein niederließ und das John Ruskin als „the most sacred spot in Swiss history" (zit. n. Piatti 2004: 143) bezeichnet. Folgerichtig machen im Jahr 1835 Franz Liszt, Richard Wagner und Georg Herwegh zu dritt einen Ausflug auf die Rütli-Wiese, wo sie mit Quellwasser Büderschaft

17 Zwei markante Unterschiede zwischen der Aufnahme in Deutschland und in der Schweiz wären auszumachen. Während in der Schweiz eindeutig der „Wilhelm Tell“ und nur dieser Text als Nationalstück in Frage kam, konkurrierte der "Tell“ in Deutschland mit anderen Schiller-Texten. Und überdies verlief die Rezeption in der Schweiz im Unterschied zu der in Deutschland naht- und bruchloser. Der „Wilhelm Tell“" wurde ebenso wie andere Schiller-Texte in Deutschland von verschiedenen sich widerstreitenden politischen Kräften funktionalisiert, weshalb Ute Frevert den Autor auch als „Dichter für viele deutsche Nationen“ (vgl. Frevert 2007 und Piatti 2004: 181240) bezeichnet.

${ }^{18}$ Neben Peter Utz stütze ich mich vor allem auf Barbara Piattis kulturgeschichtliche Darstellung „Tells Theater“, die eine Fülle von Zeugnissen zur Wirkungsgeschichte des „Tell“ zusammengetragen hat (vgl. Piatti 2004).

${ }^{19}$ Unbekanntes Brieftagebuch. 
trinken und den Schwur der Eidgenossen reinszenieren. ${ }^{20}$ Legendär ist die Beschreibung von Mark Twain, dem zufolge das Rütli zwar nur ein „abgelegener Flecken, eine kleine Wiese“ sei, das er aber dennoch pathetisch wie folgt kommentiert: „,[] $]$ ch wüsste kein anderes Stück Erde, das heiliger wäre oder mehr wert, Ozeane und Kontinente zu durchqueren, um es zu sehen“ (zit. n. Piatti 2004: 141).

Der Auratisierung und Semantisierung der Landschaft folgte deren Umgestaltung auf dem Fuße: Nach und nach wurden die „Tell“-Orte (Rütli, Altdorf, Tellsplatte, Hohle Gasse, Bürglen) durch architektonische Eingriffe nach den Regieanweisungen Schillers gestaltet, um den semantisch aufgeladenen Erwartungen als Kulisse zu entsprechen. Im Laufe des 19. Jahrhunderts sollte sich immer stärker eine patriotischnationale Note in die Semantisierung und Auratisierung der TellSchauplätze mischen: Im Rahmen der Schillerfeier des Jahres 1859 wurde das Rütli in einem feierlichen Festakt der Eidgenossenschaft geschenkt und der Mythenstein zum Schillerstein umgestaltet; auf der Tellsplatte, wo sich Tell frei nach Schiller mit einem tollkühnen Sprung aus dem Schiff und aus den Händen Gesslers befreit haben soll, richtete man die so genannte Tellskapelle ein, die mit vier Fresken zu Szenen des Schiller'schen Stücks ausgemalt wurde. ${ }^{21} 1895$ wurde das TellDenkmal in Altdorf eingeweiht, das mit Versen aus Schillers „Wilhelm Tell" beschriftet worden war. Kurz darauf fand die Eröffnung des Tellspielhauses, ebenfalls in Altdorf, statt. ${ }^{22}$ Und schließlich wurde - als wohl deutlichstes Beispiel - im Jahr 1937 die Hohle Gasse nach Schillers Bühnenanweisungen restauriert.

\footnotetext{
${ }^{20}$ S. Piatti 2004: 142f. Man könnte noch Elias Canettis Mutter hinzunehmen, die ihre reale Geruchswahrnehmung in die Imagination integriert. Canetti schildert in seiner Autobiographie Die gerettete Zunge eine Schweizreise im Sommer 1918 und erinnert sich dabei an einen Ausspruch seiner Mutter: „Kein Wunder, dass die Schweiz hier entstanden ist! Unter diesem Zyklamengeruch hätte ich alles geschworen." (Zit. n. Piatti 2004: 179).

${ }^{21}$ Der Historienmaler Ernst Stückelberg hielt sich bei der Ausmalung „sehr genau an Schillers Regieanweisungen - selbst der ,Mondregenbogen“ der Rütli-Szene ist zu sehen." (Piatti 2004: 166f.) Die vier Fresken zeigen den Rütlischwur, den Apfelschuss, den Tellsprung und Gesslers Tod in der Hohlen Gasse.

${ }^{22}$ Bis heute finden in Altdorf Tell-Aufführungen, in der Regel alle vier Jahre, statt (vgl. www.altdorf.ch).
} 

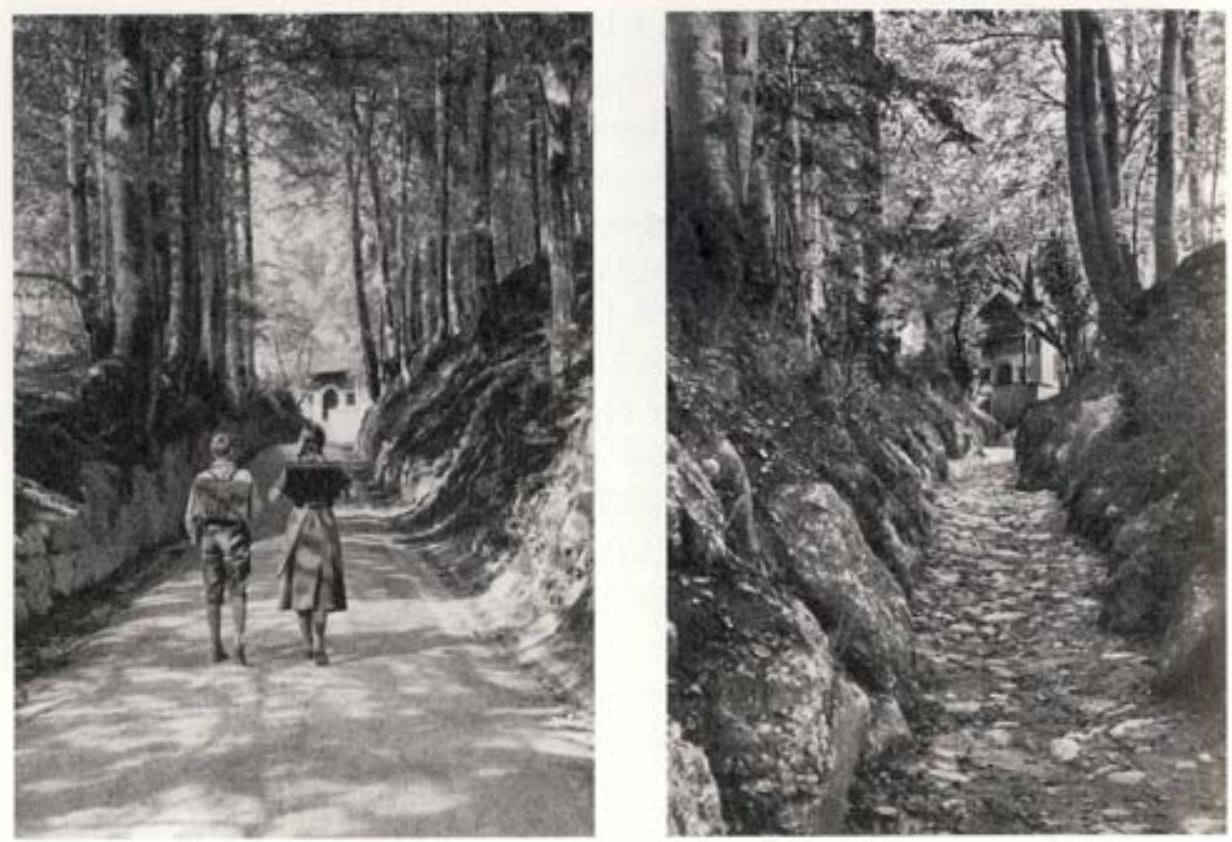

Abb. 1 und 2: Die Hohle Gasse bei Küssnacht am Rigi - um 1930, vor der Restaurierung/1937, und nach der Restaurierung (rechts).

Quelle: Piatti 2004: 218, Abb. 64: Ansichtskarten, Graphische Sammlung, Schweizerische Landesbibliothek, Bern.

Hatte Schiller die Schweizer Landschaft im Jahr 1804 auf die Weimarer Bühne gebracht und mit ihr eine symbolisch aufgeladene Natur in Kunst überführt - einen Nachtregenbogen und einen Sonnenaufgang in der Rütlischwur-Szene, ein Gewitter in der Auftaktszene und zu Beginn des vierten Aufzuges - so imprägniert Schillers fiktive Welt nun umgekehrt die Schweizer Landschaft. Seien es Tellsplatte, Schillerstein, Tell-Denkmal, Tellspielhaus oder schließlich die Restaurierung der Hohlen Gasse: „Unter dem Eindruck von Schillers dramatischer Schöpfung wurde“, mit Barbara Piattis Worten, „die Gegend [..] zur Denkmal- und Erinnerungslandschaft umgestaltet“ (Piatti 2004: 217). ${ }^{23}$

23 S. dazu ausführlicher Piatti 2004: 217f. Barbara Piatti hat in ihrer Studie zur „Geographie der Literatur“ überdies zeigen können, dass Schillers Wilhelm Tell die Literaturregion Vierwaldstättersee geprägt hat wie kein anderer Autor, und das in einem Maße, dass die Schauplätze des Tell von der nachfolgenden Literatur auffällig ausgespart worden sind: „Diese Tell-Topographie ist [...] eine exclusive. [...] Eine 
Während wir gemeinhin davon ausgehen, dass ein Autor bzw. eine Autorin Fakten (Quellen) benutzt, um Fiktion (in diesem Fall ein Schauspiel) zu erzeugen, verhält es sich bei diesem Rezeptionsvorgang umgekehrt: Die fiktive Welt wird ihrerseits zur Quelle, die „Fakten“ herstellt. Pointiert könnte man deshalb geradezu sagen, dass Schiller die Schweiz „erfunden“ und sein Stück die nationale Erinnerungslandschaft am Vierwaldstädter See „vorentworfen“ hat. Denn auf der Bühne der Landschaft wird sichtbar, was gleichermaßen für das Selbstverständnis als Nation gilt. Die Schweizer konnten dank Schiller ein Nationalbewusstsein aufbauen. Das Stück bot den nötigen Kitt für dieses zu Beginn des 19. Jahrhunderts völlig zerfallene und durch Napoelon fremdbestimmte Land. Das heißt, der Prozess des nation building ist in diesem Fall durch einen fiktionalen Text entscheidend befördert, wenn nicht erst ermöglicht worden.

Eine wichtige Funktion für diese „Nationalschule“ hatten Freilichtaufführungen des „Tell“:

Wie aber müsste Wilhelm Tell im freien Schweizerlande, auf freier Höhe unter Gottes Hinmmel von und vor Schweizern aufgeführt wirken! [Es wäre] eine Nationalschule, eine lebendig gewordene Geschichte voll Lehre und Mahnung für alle Geschlechter. (Zit. n. Piatti 2004: 189)

Gottfried Keller schildert in seinem „Grünen Heinrich“ eine solche Aufführung, bei der Laienschauspieler mitwirken (Keller 2003: 408f.). Keller hat diese Aufführungspraxis keineswegs erfunden, sondern der Wirklichkeit nachgebildet. Die fiktive Welt des Schiller'schen Stückes ist so vollständig in das kollektive Gedächtnis der Schweizer eingegangen, dass bald nicht mehr zwischen Dichtung und Wirklichkeit, Geschichte und Gegenwart unterschieden wurde. Einer der Belege für die Langlebigkeit und Aktualität dieser historischen Fiktionsbildung sind die TellSpiele in Interlaken, die sich bis heute einer ungebrochenen Beliebtheit erfreuen. ${ }^{24}$

mögliche Erklärung für diesen Sachverhalt wäre, dass der Ort dermaßen stark semantisiert ist, dass jede Handlung (denken wir an eine Liebesszene oder einen Mord) sofort überlagert würde von den bereits historischen und mythologischen Bedeutungsschichten." (Piatti 2008: 222f.)

${ }^{24}$ Seit 1912, nur unterbrochen durch die beiden Weltkriege, finden jeden Sommer in Interlaken die sogenannten Tellspiele statt, die den Zuschauerzahlen nach zu urteilen bis heute ausgesprochen beliebt sind. Siehe zu Geschichte, Selbstverständnis und 
Bis zum Zweiten Weltkrieg wurde Schillers „Tell“ relativ bruchlos für die nationale Sache der Schweizer in Dienst genommen. Neben der Inszenierung als Nationalstück ist das Drama dabei auch gerne als wirksames politisches Instrument gegen Deutschland in Szene gesetzt worden, vor allem während der Zeit des Nationalsozialismus. Nachdem Hitler den „Tell“ 1938 als Folge des Attentatsversuchs durch den Schweizer Maurice Bavaud verboten hatte, entfaltete es im Nachbarland eine umso stärkere und ungebrochenere Wirkung. Das gipfelte in der so genannten Geistigen Landesverteidigung, bei der mit Schillers Freiheitsdrama gegen Hitler und den Faschismus mobil gemacht wurde und die Schweiz sich als widerständige und wehrhafte Nation inszenierte. ${ }^{25}$ Die Schattenseiten dieser Rezeption wurden nach 1945 vollends sichtbar: Schweizer Schriftsteller kritisierten sie als Instrumentalisierung und Flucht vor der eigenen historischen Verantwortung. Der wirkungsmächtigste Text im Kontext dieser Mythendemontage ist sicherlich Max Frischs Parodie „Wilhelm Tell für die Schule“ aus dem Jahr 1970, auf die ich abschließend näher eingehen möchte.

Als vorläufiges Resümee möchte ich aber zunächst die beiden dargestellten Lesarten des „Wilhelm Tell“ miteinander vergleichen: Idealisiert Schiller den historischen Stoff in seinem Geschichtsdrama kraft Fiktionalisierung - das heißt, wird der Stoff Schweizer Freiheitskampf in der dramatischen Gestaltung in eine ideale Revolution überführt -, so findet in der Rezeption als Nationalepos geradezu der umgekehrte Vorgang statt: Die fiktive Welt des Stückes projiziert sich referentiell auf die vermeintliche Geschichte der Schweiz. Damit wird die Idealität der fiktiven Geschichte historisiert - und der fiktionale Text deutungsdeterminiert rezipiert. Ein Nationalepos, oder besser: ein Text, der als Nationalepos rezipiert wird, generiert in aller Regel ein besonderes Spannungsverhältnis von Fiktion und Faktum, ${ }^{26}$ das eine Tendenz zur

\footnotetext{
Hintergründen der Tellspiele: www.tellspiele.ch/ (23.01.2011).

${ }^{25}$ Legendär geworden ist die Aufführung im Züricher Schauspielhaus mit Heinrich Gretler als Tell und Wolfgang Langhoff als Gessler, die 1939 Premiere hatte.

${ }^{26}$ Ich spreche hier von einem besonderen Spannungsverhältnis, weil das Verhältnis zwischen Fiktion und Faktum auch anderen Textsorten zugrundeliegt, etwa der Camouflage oder dem Schlüsselroman, bei denen Fakten verschlüsselt in der fiktiven Welt des Textes auftauchen, um entschlüsselt rezipiert wieder auf diese zu verweisen. Konstitutiv ist die Spannung zwischen Fakten und Fiktionen ebenfalls für die engagierte Literatur, die als fiktionaler Text Ursache für etwas sein will, die etwas
} 
Vereindeutigung und Bedeutungsreduktion impliziert. Dies lässt sich am Beispiel von Schillers „Wilhelm Tell“ aufgrund des Doppelcharakters des Textes - einmal Geschichtsdrama, einmal Nationalepos - besonders gut zeigen. Die Rezeption als Nationalepos hat demnach Auswirkungen auf den Literarizitätscharakter des Textes: Die Fiktion wird historisiert und die Doppel- bzw. Mehrdeutigkeit nivelliert.

\section{Reliterarisierung des Tellstoffes am Beispiel von Max Frisch: „Wilhelm Tell für die Schule“}

Mit Max Frischs „Wilhelm Tell für die Schule“ aus dem Jahr 1970 liegt ein bemerkenswerter Versuch vor, diese Entwicklung wieder rückgängig zu machen. ${ }^{27}$ Dabei geht es Frisch nicht darum, erneut im Geiste Schillers zu schreiben und Schillers „Wilhelm Tell“ von einer reduzierten Lesart zu befreien; im Gegenteil liest sich Frischs Textexperiment zu einem Gutteil als Persiflage eben dieser Referenzfolie. Wichtig für unsere Zusammenhänge ist Frischs Text aber nicht aufgrund seiner kritischen Auseinandersetzung mit Schiller - das wäre eine eigene Fragestellung -, auch nicht wegen seines aufklärerisch-mythendemontierenden Impetus (vgl. hierzu ausführlich Jeziorkowski 1982), sondern vornehmlich als Versuch, den Tellstoff wieder zu dem zu machen, was er ist: (eine) Geschichte im Als-ob-Modus. Und das geschieht nun mit literarischen Mitteln, die denkbar andere sind, als wir sie von Schillers Geschichtsdrama kennen.

Strukturell gesehen besteht „Wilhelm Tell für die Schule“ aus zwei alternierend angeordneten Textelementen, die formal und stilistisch deutlich unterschieden sind: Ein Erzähltext im Präteritum ist mit Fußnoten versehen, die jedem Abschnitt nachgestellt sind. Selbst wer die

\footnotetext{
bewirken und Fakten schaffen will. Die hierbei jeweils beleuchtete Referentialität ist jedoch von dem Spannungsverhältnis von Fiktion und Faktum zu unterscheiden, das ein Text als Nationalepos generiert; die Fiktion des Nationalepos behauptet, Zeugnis seiner geschichtsträchtigen Referenz zu sein. Als solche kann sie stets auch als historische Fiktion begriffen werden.

${ }^{27}$ Neben Max Frisch wären zahlreiche weitere Schweizer Autoren und Autorinnen zu nennen, die gleichfalls kritisch und demontierend auf den Nationalmythos „Wilhelm Tell“ reagiert haben, und das nicht erst seit 1945, etwa Robert Walser, Peter Bichsel, Friedrich Dürrenmatt und andere mehr (vgl. dazu Matt 1991: 13-31).
} 
hochgestellten Ziffern ignoriert, stößt nach wenigen Seiten auf einen Anmerkungsapparat, der den Erzähltext unterbricht. Die Anmerkungen zitieren zum einen aus historischen Quellen und Arbeiten, angefangen vom „Weißen Buch von Sarnen“ über Aigidius Tschudi bis zu jüngeren historischen Darstellungen, und selbst die Schweizer Tagespresse wird aufgerufen; zum anderen enthalten die Anmerkungen Kommentare in wissenschaftlichem Gestus, entweder zu den angeführten Zitaten oder zum Erzähltext.

Beide formal getrennten Teile funktionieren zusammen als Kontrafaktur der Legendenbildung um Wilhelm Tell sowie deren Historisierung: Während die Erzählpassagen die Tell-Legende konterkarieren gleichwohl ohne den reichlich dürftigen Quellen widersprechen zu müssen -, legen die historisch-kritischen Anmerkungen den Vorgang der Historisierung und historischen Fiktionsbildung offen. Protagonist der Erzählpassagen ist nicht, wie dem Titel nach zu erwarten wäre, Wilhelm Tell, sondern „ein dicklicher Ritter“ (Frisch 1971: 7), der unschwer als Tells Widersacher Gessler zu erkennen ist, dem Typus des Tyrannen aus Schillers Stück aber ganz und gar nicht entspricht. Denn weder haben wir es hier mit einem Helden noch mit einem Anti-Helden zu tun; der „dickliche Ritter“ wäre eher der Kategorie des mittleren Helden zuzuordnen, die weder zur Identifikation noch zur Projektion einlädt. „Ritter Konrad oder Grisler“ (ebd., 16) - auf die Bedeutung des oder im Namen gehe ich später ein - kommt nicht als Herrscher in die Gegend um den Vierwaldstättersee, sondern um einen ihm selbst unliebsamen Auftrag so schnell wie möglich hinter sich zu bringen. Auch ist er nicht Movens der Geschichte, sondern in diese verstrickt und von dieser getrieben. Als solcher steht er im doppelten Gegensatz zum typischen Helden eines Epos, beeinflusst er doch weder die Geschichte noch können seine Handlungen als „große Taten“ bezeichnet werden. Vielmehr sind es die kleinen Leiden des Alltags, die die Erzählung prägen: „Der dickliche Ritter“ leidet an Langeweile, die ihm die Gegenwart des Fräulein von Bruneck verursacht, an Kopfweh und Unwohlsein als Auswirkung des ungewohnten Föhns, und überhaupt kann er als Ortsfremder mit der unwegsamen Hochgebirgsgegend und der schroffen Art der Gebirgsbewohner nicht recht warm werden. Diese Affektionen des Protagonisten stehen allesamt in deutlichem Gegensatz zu dem Bild, das der Leser von der Figur im Kopf hat, 
ein Bild, das selbstverständlich bei der Lektüre vorausgesetzt wird und den komisierenden und ent-emphatisierenden Effekt bewirkt. Keine neue heroische Sage wird hier erzählt, vielmehr haben wir es mit einem Anti-Epos zu tun, wofür neben der Figurenzeichnung und der Handlungsführung überdies die ständigen Unterbrechungen der Erzählung durch die Anmerkungen sprechen: Dies verhindert ebenso eine einfühlende Lektüre wie einen geschlossenen Erzählzusammenhang.

Im Kern ist Frischs „Wilhelm Tell für die Schule“ damit eine Demontage des Mythos vom Tyrannen Gessler - und im Gegenzug vom Freiheitshelden Tell: Frischs Text ist am Leitfaden der wichtigsten Stationen von Schillers „Tell“-Stück strukturiert: Gessler-Hut, ApfelschussSzene, Tellsprung, Ermordung Gesslers. Dabei sind die Episoden aber jeweils so erzählt, dass das Verhältnis von Täter und Opfer in die Schwebe gerät, sich zuweilen sogar umkehrt, etwa wenn es nicht „der dickliche Ritter" ist, der Tell zum Apfelschuss auf seinen Sohn provoziert, sondern Tell selbst bzw. sein Sohn (vgl. ebd., 87-96). Der Sprung vom Schiff auf die Tellsplatte findet bei Frisch erst gar nicht statt, da „der dickliche Ritter“ Tell vor der Überfahrt zurücklässt. Diese effektvoll umgesetzte Demontage eines nationalen Mythos wäre jedoch noch keine Literatur, wenn sie nicht zugleich eine Kategorie zurückgewänne, die seit Aristoteles für die Definition von Dichtung zentral ist: die Kategorie der Möglichkeit. Es ist, als wollte der Erzähltext aussagen: Es hätte auch so gewesen sein können, die Quellen sind nicht eindeutig, sondern sie eröffnen einen Möglichkeitsraum. Es ist eine Version des Tell-Stoffes, die geradezu dazu anregt, weitere Tell-Versionen zu erfinden - nicht zuletzt als Anregung für Schüler, kreativ mit dem Stoff umzugehen. Indem Frisch die Quellen nutzt, um eine alternative Legende zu erzählen, macht er die Funktionsweise von Legenden deutlich, nämlich Geschichte(n) im Als-Ob-Modus zu sein, weitere Geschichten zu bewirken, erzählt und neu erzählt zu werden. Der erste Satz macht sogleich den unsicheren epistemischen Status deutlich und etabliert den besonderen ontologischen Status der Fiktion: „Wahrscheinlich Konrad von Tillendorf [...], vielleicht auch ein anderer, der Grisler hieß [...], jedenfalls aber ein Ritter ohne Sinn für Landschaft ritt an einem sommerlichen Tag des Jahres 1291 durch die Gegend, die heute als Urschweiz bezeichnet wird.“ (Ebd., 7) Die überlieferten (möglichen) Namen relativieren sich, und dagegen wird im Gestus der 
Gewissheit das „jedenfalls aber“ gesetzt, was so aussagekräftig ist wie der typische Märchenanfang „Es war einmal ...“. Es ist nicht weniger als die Eröffnung des fiktionalen Raumes.

Welche Funktion haben aber nun die historischen-kritischen Anmerkungen? Die Fußnoten untermauern das Erzählte nur der Form nach historisch; inhaltlich legen sich auch die Anmerkungen nicht fest. Sie unterstreichen die dürftige und sogar widersprüchliche Quellenlage. Zwar sind sie formal gebaut, als würden sie das Erzählte historisch-kritisch absichern, aber die Ironie und Satire, die den Erzähltext prägen, dienen dazu, die scheinbar sachlichen Aussagen im selben Atemzug der Lächerlichkeit zu überantworten. Selbst die ausgewählten Zitate bekommen dabei einen kabarettistischen Unterton. Die Demontage des nationalen Mythos geht mit einer Öffnung des Deutungshorizontes und einer Zurücknahme der Bedeutungsreduktion einher.

\section{Schlussfolgerungen}

Schillers „Wilhelm Tell“ hat innerhalb der Texte, die im 19. und 20. Jahrhundert als Nationalepen rezipiert wurden, einen Sonderstellung inne. Weder von der Textintention noch in der Textanlage als Nationalepos konzipiert, wurde und wird Schillers „Wilhelm Tell“ dennoch als solches rezipiert. Lässt sich aus diesem Befund auch etwas Allgemeines für das Genre ableiten? Aus dem spezifischen Fall können, wie ich meine, allgemeine Schlussfolgerungen für eine auf Nationsbildung ausgerichtete Textrezeption gezogen werden. Allgemein kennzeichnend könnte sein, was für den Schiller-Fall im Vergleich zwischen Geschichtsdrama und Nationalepos konstatiert wurde, dass nämlich die Fiktion historisiert wird, Mehrdeutigkeiten und Widersprüche zugunsten der nationalen Identifikationsfolie verschwinden. Damit ist jedoch keine Aussage über die Texte selbst getroffen, lediglich über deren Rezeption. Ein Vergleich zu anderen Nationalepen in dieser Hinsicht und eine Erörterung der Gründe für diese bestimmte Art der Rezeption wäre noch zu leisten. Aber selbst wenn diese These sich anhand weiterer Untersuchungen bestätigen würde, gingen die Texte unter ihrer Rezeptionsgeschichte als Nationalepos nicht verloren. 


\section{Literatur}

\section{Primärliteratur}

FrISCH, Max (1971): Wilhelm Tell für die Schule. Frankfurt a. M.

KELLER, Gottfried (2003): Der grüne Heinrich. Hrsg. v. Jörg Drews. Stuttgart.

SCHILleR, Friedrich (2004): Wilhelm Tell. Durchgesehene Ausgabe; mit einem Jubiläumsanhang von Barbara Piatti. Stuttgart.

\section{Sekundärliteratur}

André-Alt, Peter (2000): Schiller. Leben - Werk - Zeit. Eine Biographie. Bd. 2. München.

AugE, Bernhard (2003): Der Schweizer Nationalmythos und seine Demontage. Schillers Wilhelm Tell in Dürrenmatts Roman Durcheinandertal. In: Peter Ensberg/Jürgen Kost (Hrsg.) (2003): Klassik-Rezeption. Würzburg, S. 167178.

Butler, Michael (2000): The Politics of Myth. The Case of William Tell. In: William Collins Donahue/Scott Denham (Hrsg.) (2000): History and Literature. Essay in Honor of Karl S. Guthke. Tübingen, S. 73-90.

FreVERT, Ute (2007): Ein Dichter für viele deutsche Nationen. In: Jan Bürger (Hrsg.) (2007): Friedrich Schiller. Dichter, Denker, Vor- und Gegenbild. Göttingen, S. 57-75.

GuTHKE, Karl (2005): Schillers Dramen. Tübingen.

Hentschel, Uwe (2002): Mythos Schweiz. Tübingen.

Hobsbawm, Eric (2005): Nationen und Nationalismus: Mythos und Realität seit 1780. Mit einem aktuellen Vorwort des Autors und einem Nachwort von Dieter Langewiesche. Aus dem Engl. von Udo Rennert. Bonn ${ }^{3}$.

Hobsbawm, Eric/Terence RANGeR (1992): The Invention of Tradition. Cambridge 1992.

JezIORKowski, Klaus (1982): Wilhelm Tell as Peter Jenny: on Frisch's Wilhelm Tell für die Schule. In: Gerhard Probst/Jay Bodine (Hrsg.) (1982): Perspectives on Frisch. Lexington, S. 93-108.

KuRZ, Gerhard (2007): Drachengift. Zu Schillers Wilhelm Tell. In: Sascha Feuchert/Joanna Jablkowska/Jörg Riecke (Hrsg.) (2007): Literatur und Geschichte. Festschrift für Erwin Leibfried. Frankfurt a. M., S. 283-289.

MARX, Frank Rainer (1991): Das Epos. In: Otto Knörrich (Hrsg.) (1991): Formen der Literatur in Einzeldarstellungen. Stuttgart ${ }^{2}$, S. 75-87.

MATT, Peter von (1988): Die ästhetische Identität des Festspiels. In: Balz Engler/Georg Kreis (Hrsg.) (1988): Das Festspiel. Formen, Funktionen, Perspektiven. S. 12-28.

MATT, Peter von (1991): Kritischer Patriotismus. In: ders (1991): Der Zwiespalt der Wortmächtigen. Essays zur Literatur. Zürich, S. 7-31. 
Muschg, Adolf (2007): Schillers Schweiz. In: Friedrich Schiller. Dichter, Denker, Vor- und Gegenbild. Hrsg. v. Jan Bürger. Göttingen 2007, S. 76-93.

Nazareth, Timo (2006): Schiller und die Schweiz. Ein deutscher Patriot für die Eidgenossenschaft. In: Klaus Manger (Hrsg.) (2006): Der ganze Schiller Programm ästhetischer Erziehung. Heidelberg, S. 561-569.

PABIS, Ester (2003): Wilhelm Tell für die Schule: die Entdeckung der Rhetorik der nationalen Sinnkonstruktion. In: Kálmán Kovács (Hrsg.) (2003): Textualität und Rhetorizität. Frankfurt a. M., S. 161-179.

PiATTI, Barbara (2004): Tells Theater. Eine Kulturgeschichte in fünf Akten zu Friedrich Schillers „Wilhelm Tell“. Basel.

PiATti, Barbara (2008): Die Geographie der Literatur. Schauplätze, Handlungsräume, Raumphantasien. Göttingen.

ScHmidT, Joseph (2003): Friedrich Schiller: Wilhelm Tell. Erläuterungen und Dokumente. Stuttgart.

SuPPANZ, Frank (2005): Friedrich Schiller: Wilhelm Tell. Erläuterungen und Dokumente. Stuttgart.

ThalHeIM, Hans-Günther (1969): Notwendigkeit und Rechtlichkeit der Selbsthilfe in Schillers Wilhelm Tell. In: ders (1969): Zur Literatur der Goethezeit. Berlin, S. 146-193.

UEDING, Gert (1992): Wilhelm Tell. In: Walter Hinderer (Hg.) (1992): Interpretationen. Schillers Dramen. Stuttgart, S. 385-425.

UTZ, Peter (1984): Die ausgehöhlte Gasse. Stationen der Wirkungsgeschichte von Schillers ,Wilhelm Tell“. Königstein/Taunus.

WiESE, Benno von (1959): Friedrich Schiller. Stuttgart.

Winko, Simone (2009): Auf der Suche nach der Weltformel. Literarizität und Poetizität in der neueren literaturtheoretischen Diskussion. In: Simone Winko/Fotis Jannidis/Gerhard Lauer (Hrsg.) (2009): Grenzen der Literatur. Zu Begriff und Phänomen des Literarischen (Revisionen. Grundbegriffe der Literaturtheorie 2) Berlin, S. 374-398. 


\section{Erzählung als Erinnerung: Die Bedeutung der Isländersagas für das nation building (nicht nur) in Island}

Wenn Island in jüngster Zeit auch in aller Munde ist - erst die Wirtschaftskrise, dann der Ausbruch des Eyjafjallajökull und der Themenschwerpunkt auf der Frankfurter Buchmesse 2011 -, so ist diese plötzliche und teilweise ungewollte Popularität doch eine Ausnahme. Gemeinhin wird Island als klein und an der Peripherie Europas wahrgenommen und gerade aufgrund seiner rigiden Sprachpolitik, die eine fast ungebrochene Tradition vom Mittelalter bis heute aufweist, auch ein wenig belächelt. Welches andere Land in Europa hat sich sonst bemüht, eigene Wörter für das Telefon oder den Computer zu finden, um sich ebenso besorgt wie selbstbewusst gegenüber möglichen sprachlichen Übergriffen aus dem Englischen und Amerikanischen zur Wehr zu setzen? Und das mit einer Sprache, die den Amerikanern so unaussprechlich vorkommt, dass man sich im Frühjahr 2010 gar nicht erst bemühte, den ausgebrochenen Vulkan beim Namen zu nennen und ihn nur als „E 15“ bezeichnete: was meinte, dass der Unaussprechliche mit einem $\mathrm{E}$ beginnt, dem weitere fünfzehn Buchstaben in nicht nachzuvollziehender Weise folgen.

Für das Verständnis dieses Beharrens auf möglichst ungebrochene Traditionen, auf Unabhängigkeit und Eigenständigkeit des modernen Islands ist ein Blick auf die Bedeutung der mittelalterlichen Literatur wesentlich. Denn diese zeichnet sich dadurch aus, dass sie in Europa einzigartig ist: So wird die nordische Mythologie in den Eddischen Liedern besungen, und die skaldische Dichtung hat mit ihrer eigenwilligen und enigmatischen Metaphorik, den kenningar, weit über die Grenzen Islands hinaus Nachahmer gefunden. Jorge Luis Borges gehörte zu ihren größten Bewunderern. Die Geschichte Islands wird in den Sagas in der Landessprache erzählt, lakonische Prosaerzählungen, die in dieser Form ebenfalls keine Entsprechungen in anderen Kulturen haben. Ungeachtet der von der Forschung immer wieder unternommenen 
Versuche, die kontinentaleuropäischen Einflüsse auf die altisländische Dichtung nachweisen zu wollen, ist das Verhältnis eher umgekehrt und bestätigt die isländische Perspektive: Es sind nämlich vielmehr die anderen Nord- und Mitteleuropäer, die um 1800 ihre kulturelle Legitimation unter anderem auf diese „gemeinnordische“ Tradition zurückführen wollen. ${ }^{1}$ Für die Geschichte und das Selbstverständnis der skandinavischen Literaturen und Kulturen wird dann die isländische Literatur des Mittelalters von elementarer Bedeutung. Sie liefert den Fundus an Stoffen und Mythen, auf den sich alle skandinavischen und zeitweise auch die deutsche Literatur spätestens seit dem 18. Jahrhundert berufen, um ein Eigenes, der klassischen Antike und deren europäischen klassizistischen Ausformungen und Traditionen Entgegengesetztes, herauszubilden. Die Spezifika dieser Dichtung werden also im Zuge des nation building in Europa von diversen Nationen erkannt und als Eigenes adaptiert. Warum insbesondere der Sagaliteratur eine solche Wirkungsmacht zukommt, möchte ich im Folgenden nachzeichnen und daran drei Dinge festmachen: 1. Island rekurriert in seiner Selbstwahrnehmung und Selbstdarstellung als eigenständiges Land immer wieder und vor allem in politischen Krisensituationen wesentlich auf eine reiche, im europäischen Kontext einzigartige Kultur und Literatur. Diese Traditionen sind ungeachtet der Modernisierungsschübe der isländischen Gesellschaft nach wie vor aktuell und weiterhin unhinterfragter Bestandteil des Selbstverständnisses der isländischen Nation. 2. Die isländische Literatur und insbesondere die Sagas haben wesentlich am mapping, also der Topographie und Kartierung eines im Mittelalter besiedelten Landes, beigetragen, das bis heute an Gültigkeit und Glaubwürdigkeit nicht verloren hat. Die Helden der mittelalterlichen isländischen, norrönen Dichtung haben den Orten ihre Namen gegeben und sind es gerade deshalb wert, erinnert zu werden und im kollektiven Bewusstsein weiter präsent zu sein. ${ }^{2}$ 3. Island, das bis ins 20. Jahrhundert hinein unter Vorherrschaft der großen skandinavischen Nachbarstaaten, Norwegen und Dänemark, stand, definiert sich über jene literarischen Quellen, die für das norwegische und dänische nation building Anfang des 19. Jahrhunderts ebenfalls herangezogen wurden. Die nordische Mythologie und die Sagenstoffe

\footnotetext{
${ }^{1}$ Vgl. dazu u. a. Hafner 1996 sowie Gerecke 2002.

${ }^{2}$ S. dazu Ólason 1998.
} 
werden Mitte des 18. Jahrhunderts nicht nur in Island, sondern auch in den skandinavischen Ländern und in Deutschland wieder entdeckt und für das sich etablierende Nationalbewusstsein funktionalisiert.

Es geht mir im Folgenden also vor allem um die Prosagattung der Isländersaga und die Frage danach, welche Spuren die Sagas im kollektiven Gedächtnis der Isländer und der Skandinavier im Allgemeinen hinterlassen haben. Sie sind keine Epen im engen Wortsinne, übernehmen aber durchaus die Funktion von Nationalepen dergestalt, dass sie als anonym tradierte Texte in die Gegenwart hineinwirken und die Geschichte Islands und seiner Familien retrospektiv legitimieren. Insofern erfüllen sie auch eine Abgrenzungsfunktion von anderen nationalen Epen und Mythen. ${ }^{3}$

Die Íslendingasögur behandeln in der Regel die Geschichte einer isländischen Familie oder eines einzelnen Helden in der so genannten söguöld, der Sagazeit, die von der Besiedelung Islands um 870 bis etwa 1030/1050 reicht. Diese Besiedelung erfolgte in der Regel durch gesellschaftlich angesehene, vergleichsweise gebildete und wohlhabende norwegische Bauern und Seefahrer, die mit dem norwegischen König in Konflikt geraten waren. Die zunächst mündlich tradierten Geschichten, die von der erfolgreichen Landnahme durch die emigrierte norwegische Oberschicht handeln, wurden hauptsächlich im 13. Jahrhundert und später aufgezeichnet. Die „Grettis saga“, die ich hier beispielhaft herausgreifen möchte, ist sehr spät entstanden, verfügt jedoch über die genretypischen Merkmale: offene Komposition, Formelhaftigkeit der Rede und einen streng chronologischen Handlungsablauf. Sie vermittelt darüber hinaus ein für die Íslendingasögur charakteristisches Geschichtsbild und Traditionsbewusstsein, das sich an der Vorzeit orientiert und damit Kontinuität anstrebt. Inwieweit eine solche dauerhafte Erinnerung durch die schriftliche Fixierung mündlicher Erzähl-

\footnotetext{
${ }^{3}$ Zum Verhältnis von Abgrenzung und nation building beziehe ich mich im Folgenden auf Frank Lauterbach (2004: 1-16, hier bes. 10): „Diese (doppelte) Dialektik von Abgrenzung und Eingrenzung zu untersuchen, heißt folglich auch, den Versuchen der Sublimierung der Präsenz inner- wie interkultureller Alteritäten durch Gesten textueller Autorität innerhalb der diskursiven Setzungen bzw. rhetorischen Konstruktionen des Nationalen ebenso nachzuspüren wie den damit verbundenen sozialen, politischen oder ideologischen Interessen, die zum Ausgangspunkt von gesellschaftlichen Inklusions- und Exklusionsakten werden.“
} 
traditionen sichergestellt werden und damit den Charakter eines „Nationalepos" gewinnen kann, machen die charakteristischen Erzählverfahren und -strategien der Saga deutlich. Sie tragen zur Konstitution und Etablierung eines gruppenspezifischen kulturellen Gedächtnisses bei und dienen damit der kulturellen Sinnproduktion und der Nationenbildung. Doch zunächst ein kurzer Überblick über den Inhalt und die Erzählweise der „Grettis saga“, um die Besonderheit dieser für das kollektive Selbstverständnis so bedeutsamen Textsorte vorzustellen:

Ein Mann heißt Grettir. Er ist der zweite Sohn des Ásmundr Hærulangr und der Ásdís. Sie haben einen großen Hof auf Island und sind beliebt und einflussreich. Grettir ist in seiner Jugend schwierig und streitsüchtig, ein kolbitr, ein Taugenichts, der Spottgedichte verfasst. Er ist jedoch außerordentlich mutig und stark. Er trägt einen ganzen Ochsen allein, er kämpft gegen Trolle und Berserker. Schließlich besiegt er im Kampf sogar den Wiedergänger Glámr. Der sterbende Glámr verheißt ihm ógefa, Unglück. Grettirs Tapferkeit wird ihm nicht Ruhm und Ehre, sondern Schaden und Unheil bringen. Die Vorhersage des Wiedergängers tritt ein: Grettirs Heldentaten werden von nun an gegen ihn ausgelegt, und er wird mit der Acht belegt, der härtesten Strafe, die das isländische Recht kennt. Mehr als 18 Jahre, länger als jeder andere Isländer, lebt er im Zustand der Rechtlosigkeit. Lange weiß sich der tapfere Grettir zu wehren, bis er schließlich, kurz vor Aufhebung der Acht, von seinen Feinden mit Hilfe von Zauberei überwunden und getötet wird. Mit dem Schwert fest in der Hand stirbt er. Viele Orte sind nach ihm benannt und erinnern an seine außerordentlichen Heldentaten. Damit endet die Lebensgeschichte des Grettir Ásmundarsonar.

Ein anderer Mann heißt porsteinn drómundr. Er ist der Halbbruder des Grettir. Er reist bis nach Miklagarðr (Byzanz), um Grettirs Tod zu rächen, was ihm auch gelingt. porsteinn ist nicht so stark wie Grettir, aber er ist ein gœfumaðr, ein vom Schicksal begünstigter, glücklicher Mann. In Byzanz verliebt er sich in die verheiratete Spes, und mit Hilfe einer List gelingt es den Liebenden zu fliehen. porsteinn kehrt mit Spes zurück nach Island. Als die Kinder erwachsen sind, unternimmt das Paar einen Bußgang nach Rom. Beide beenden ihr Leben im Kloster.

Dieses letzte Kapitel, eine Art Epilog, der „Spesar páttr“, Erzählung von Spes, genannt wird, erinnert noch einmal an die Einzigartigkeit 
Grettirs: Niemand lebte länger in der Acht als er, er war zu seiner Zeit der stärkste und tapferste Isländer, er ist der einzige, der in Byzanz gerächt wurde. Die Helden, die der Saga ihren Namen geben, sind immer einzigartig und damit Identifikationsfiguren - trotz oder gerade wegen ihres ungebändigten Charakters. Sie sind Einzelgänger und dennoch für die Gemeinschaft Vorbild.

Die Aneinanderreihung der hier skizzierten Episoden der Saga folgt nicht immer kausalen Zusammenhängen, vielmehr sind die Ereignisse additiv chronologisch angeordnet. Charakteristisch für eine derartige chronologische Erzählweise ist das Fehlen von Rückblicken und zeitlichen Einschüben. Auf die Zukunft wird nur in Form von Prophezeiungen, wie etwa denen des Wiedergängers Glámr, verwiesen. Diese lakonische Anordnung der Ereignisse entspricht dem Anspruch auf Objektivität der Sagas, die allesamt anonym, ohne Autorsignatur verfasst sind und die damit - vielen anderen Nationalepen vergleichbar - durch Anonymisierung eine kollektive Autorschaft repräsentieren. Die Íslendingasögur und damit auch die „Grettis Saga“ sind bewusst nicht als die geschlossene Komposition eines einzelnen Verfassers zu verstehen, sondern als die verschriftlichte Version einer langen Erzähltradition. Auf diese mündliche Erzähltradition wird unter anderem durch die stereotype Einführung von Personen, nach dem Muster Grettir hét maðr („Ein Mann heißt Grettir“) oder durch die formelhaften Authentizitätsnachweise svá er sagt, svá segja menn, sumir segja (alle im Sinne von: „so wird gesagt“, „die Leute sagen“) verwiesen. Diese Formeln funktionieren unabhängig davon, ob sie tatsächlich Reminiszenzen einer oralen Erzähltradition sind. Sie erzeugen den Eindruck, es handele sich um die schriftliche Fixierung einer schon seit Generationen erzählten Geschichte. Die mündliche Vergangenheit und der Verzicht auf eine individuelle Autorschaft (auch des Kompilators, der an keiner Stelle bewusst in Erscheinung tritt) sind damit fester Bestandteil des SagaDiskurses.

Unterstrichen wird die weitgehend ungebrochene und als bekannt vorausgesetzte Erzähltradition durch das Fehlen eines Prologs oder einer einleitenden Rede: In den Íslendingasögur werden weder die Intention der erzählten Geschichte noch eine Selbstbeschreibung des Autors vorangestellt. Sie geben sich damit als die schriftliche Fixierung einer bekannten Erzähltradition zu erkennen und konstituieren ein kollektives 
kulturelles Wissen der Isländer. ${ }^{4}$ Dieses reicht weit zurück in die heidnische Vergangenheit, die jedoch auch für die Gegenwart der Saga-Aufzeichnung von Bedeutung ist. Heidentum und Christentum, Oralität und Literalität stehen hier nicht in Opposition zueinander, sondern nahezu gleichberechtigt nebeneinander.

Mit dem spezifischen Verhältnis von Mündlichkeit und Schriftlichkeit korrespondiert die Verflechtung von Erzählung und Geschichtsschreibung. In der „Grettis saga“ sind - wie in den Íslendingasögur überhaupt - fiktive Geschichten und Historie untrennbar miteinander verbunden. So sind Grettirs Existenz und die seiner Vor- und Nachfahren mehrfach in anderen Quellen bezeugt, seine Acht wird dort ebenso erwähnt wie das ihm zugeschriebene kulturelle und soziale Umfeld. Diesen Bezügen stehen die vielen übernatürlichen Elemente der Saga zur Seite, die als Teil der Lebenswelt wahrgenommen werden, wie beispielsweise die Kämpfe mit Trollen und Wiedergängern. ${ }^{5}$

Für das mittelalterliche Textverständnis stellt ein solches Miteinander von Fakten und Fiktion kein Problem dar. Es geht um die Erzählung der Historie: die Besiedelung Islands, die Etablierung der bedeutenden isländischen Familien, die Christianisierung und die Einrichtung eines eigenen Rechtssystems. Die sagenhaften Taten des starken Helden Grettir sind ebenso selbstverständlicher Bestandteil der Geschichte. Orale Erzähltradition und Historiographie sind in diesem Geschichtsverständnis gleichberechtigt präsent. Diese Narrativität und Konstruktion der Historia ist für die Íslendingasögur charakteristisch, die sich ausnahmslos auf die Ereignisse der sogenannten söguöld, der Sagazeit, beziehen, also auf den Zeitraum vom Ende des 9. bis zur Mitte des 11. Jahrhunderts.

\footnotetext{
${ }^{4}$ Preben Meulengracht Sørensen macht auf das Fehlen des Prologs aufmerksam und deutet diese Tatsache als Ausdruck einer dezidiert mündlichen Tradition, die sich von den Konventionen der kontinentalen Literaturen entschieden absetzt (Meulengracht Sørensen 1995: 57).

5 „Mittelalterliche Geschichtsschreibung diente grundsätzlich der Traditionsbildung, nämlich dem Zweck der dauerhaften Erinnerung (memoria) und der genauen chronologischen Zuordnung, wie sie nur eine schriftliche Fassung zu verleihen vermochte. Schriftlichkeit allein machte es möglich, sich verbindlich auf den Geschichtsbericht (als Quelle) zu berufen und die Vorlagen auszuschreiben“ (Goetz 1993: 249f.).
} 
Innerhalb dieser Zeitspanne bewegt sich auch das Geschehen in der "Grettis Saga“. Die Saga selbst ist vermutlich nicht vor den ersten beiden Jahrzehnten des 14. Jahrhunderts, wahrscheinlich noch später, entstanden. Die ältesten erhaltenen Handschriften stammen aus dem 15. Jahrhundert. Damit sind sowohl das erzählte Geschehen als auch die Aufzeichnung des Stoffes sehr spät anzusetzen. Gerade aufgrund der späten Aufzeichnung der „Grettis saga“ stellt sich die Frage, inwieweit die schriftliche Fixierung der mündlich tradierten Geschichten zur Etablierung eines kollektiven kulturellen Gedächtnisses beiträgt und inwiefern dieser Medienwechsel auch an spezifisch literarischen Verfahren greifbar wird.

Zur Bedeutung ihres Stoffes gibt die Saga selbst Hinweise: „[...] pví at frá peim er jafnan flest sagt, er sagan er helzt frá gör" (Grettis saga, 5) „[...] denn immer wird von denen am meisten erzählt, von denen die Geschichte vor allem gemacht wird“ -, heißt es bereits ganz am Anfang. Die Helden, die den Stoff für die Erzählung liefern, sind auch diejenigen, die in die Geschichte eingehen. Erzählung und Geschichte werden damit als identisch aufgefasst: Die Saga konzentriert sich auf die außergewöhnlichen Heldentaten und verankert sie im kulturellen Gedächtnis.

Diejenigen, von denen „immer am meisten erzählt“ wird, werden in der aktuellen Gegenwart der Aufzeichnung bewusst. Sie sollen nicht vergessen werden, vielmehr gilt es, die Vergangenheit für die Gegenwart nutzbar zu machen. ${ }^{6}$ Und diese Geschichte Islands setzt nicht erst mit der Christianisierung (999/1000) an, sondern sie reicht weit, bis in die heidnische Vorzeit, zurück. Die langen Genealogien, mit denen die bedeutenden Personen in den Sagas stets eingeführt werden, tragen diesem Bemühen nach einer Integration der Vorzeit ins eigene Geschichtsbild Rechnung und legitimieren zugleich die Gegenwart aus

\footnotetext{
${ }^{6}$ Zur - auch moralischen - Bedeutung der Vergangenheit für die Gegenwart, das heißt dem Vorbildcharakter des Epos für die gegenwärtige Generation vgl.: „Das Gedächtnis kann eine moralische Haltung sein, wenn es dazu verwendet wird, vergangene Dinge im Hinblick auf kluge Lebensführung in der Gegenwart zu erinnern und klug in die Zukunft vorauszuschauen. [...] Das Gedächtnis als Wiedererinnerung und als dasjenige, mit dessen Hilfe nützliche Lehren aus der Vergangenheit gezogen werden, ist Teil der Prudentia.“ (Yates 1990: 63)
} 
dem Geist der glorreichen Vergangenheit des eigenen Geschlechts. ${ }^{7}$ Solche genealogischen Verbindungen sind in jeder Phase der Reaktivierung der mittelalterlichen Geschichte Islands (und in Norwegen) immer wieder aufgegriffen worden: zuerst in der ersten Aufschreibephase der Isländersagas im 13. Jh., die nicht zufällig mit dem Verlust der Autonomie der Isländer zusammenfällt und ein letztes Aufbäumen gegen die Abhängigkeit von den Norwegern zu sein scheint, schließlich in den folgenden Jahrhunderten, in denen es unter unterschiedlichen Vorherrschaften - der Dänen, der Norweger - stand und sich von diesen als eigenständige Nation emanzipieren wollte, bis hin zur Abwehr einer „Amerikanisierung“ von Sprache und Kultur nach dem Zweiten Weltkrieg, als die Amerikaner ihre Atomstation auf Island errichteten. Bis heute haben sich die Bedeutung der Genealogien und der Verweis auf die literarische Produktion auf Island gehalten.

Die Gedächtnisforschung hat zu Recht darauf hingewiesen, dass das Erinnern des Vergangenen immer in der Gegenwart ansetzt. Es geht um die lückenlose Herleitung der Gegenwart aus dem Geist der Vergangenheit. Das kommunikative, d.h. mündlich tradierte Gedächtnis, soll möglichst lange und unverändert lebendig erhalten werden. ${ }^{8}$ Die Verschriftlichung bewahrt es schließlich vor dem Vergessen und überführt es so ins kulturelle Gedächtnis. Damit strebt die Aufzeichnung eine „dauerhafte Erinnerung“ an, die jederzeit reaktiviert werden kann und die „Zurückführung“ des Gegenwärtigen auf das Vergangene intendiert: Die vergangene Periode der isländischen Unabhängigkeit hat Vorbildcharakter und wird im kulturellen Gedächtnis „rekonstruktiv“ festgeschrieben (J. Assmann 1992: 30).

„Gedächtnis will [...] Gegenwart, Gemeinschaft und Teilhabe [schaffen]“ (Wenzel 1991: 69), betont Horst Wenzel und fokussiert damit entschieden den Bezug zum aktuellen Geschehen als Movens für die

\footnotetext{
7 Zur Bedeutung des Konzepts „Genealogie“ und der „Zurückführung“ der Vergangenheit in die Gegenwart vgl. Gumbrecht 1983: 165.

${ }^{8}$ J. Assmann 1992. Vgl. auch A. Assmann: „Die Kommunikation zwischen den Epochen und Generationen bricht ab, wenn ein bestimmter Fundus an gemeinsamem Wissen abhanden gekommen ist. [...] Es besteht also eine Parallele zwischen dem kulturellen, epochenübergreifenden Gedächtnis, das durch normative Texte gestützt ist, und dem kommunikativen, in der Regel drei Generationen verbindenden Gedächtnis der mündlich weitergegebenen Erinnerungen.“ (A. Assmann 1999: 13)
} 
Gedächtniskultur. Heinrich Becks Beschreibung des spezifischen Erinnerungsverfahrens in den Íslendingasögur weist in eine ähnliche Richtung: Die Saga „verwendet zwar historischen Stoff, geht aber in einer Weise mit ihm um, wie das in Oralkulturen wohl bekannt ist. Dort wird die geschichtliche Erinnerung auch gepflegt, die Pflege aber aus der Perspektive der Gegenwart betrieben. Die Saga-Tradition verfährt in ähnlicher Weise: Die Erinnerung wählt aus, aktualisiert und orientiert an Fragen und Problemen der Gegenwart" (Beck 1997: 10). Und Otto Gerhard Oexle sieht das Erinnern als bewusste Bewältigung der gegenwärtigen Lage, in der sich das Individuum (oder das Kollektiv) gegen Leiden, Vernichtung und Krise behauptet (vgl. Oexle 1995: 10).

Auch die Aufzeichnungen der Íslendingasögur setzen in einer krisenhaften Situation ein, nämlich mit dem Ende des isländischen Freistaates und mit der erneuten Abhängigkeit vom norwegischen Königshof (1262 bzw. 1264). Zu einem Zeitpunkt, der von Verlust und Resignation gezeichnet ist, thematisieren die Íslendingasögur die Vergangenheit des Freistaates. Zugleich werden die in der so genannten Sturlungenzeit, also den letzten Jahren vor dem Verlust der Unabhängigkeit, ausgetragenen Zwistigkeiten und Bürgerkriege auf Island ebenfalls erinnert: Sie sind auch ein Grund für den Verlust der Autonomie der Isländer. Die Isländersagas versuchen nun explizit die Tugenden der Vergangenheit, wie Tapferkeit, Heldenmut und den Kampf um die Freiheit ihres Landes, zu mobilisieren und an die friedvolle Periode des isländischen Freistaates zu erinnern. Diese Erzählungen über die verlorene Zeit sind in den 200 Jahren, die zwischen der söguöld und der beginnenden schriftlichen Fixierung liegen, zunächst weiterhin im kommunikativen Gedächtnis präsent.

Mit ihrer Verschriftlichung erhält ihre Rolle, das kollektive kulturelle, d.h. über mehr als drei Generationen reichende, Gedächtnis zu vermitteln, eine neue Dimension. Sie beugt dem Vergessen der - im eigentlichen Wortsinne - sagenhaften Vergangenheit vor, indem sie die mündlich wiedergegebenen Erzählungen schriftlich festhält und ein Archiv der isländischen Geschichte anlegt. ${ }^{9}$ Das kulturelle Gedächtnis

\footnotetext{
${ }^{9}$ So grenzt Jan Assmann das kulturelle Gedächtnis ab von der „Wissenschaft“ und dem „kommunikativen Gedächtnis“, das nur einen beschränkten Zeithorizont umfasse (in der Regel drei bis vier Generationen, also 80 bis 100 Jahre). In den Íslendingasögur ist
} 
wird damit in den Dienst einer umfassenden kulturellen Sinnproduktion gestellt: Diese erfolgt über die explizite Auswahl aus dem Fundus vorgegebenen Materials.

Denn die Saga nimmt sich die Freiheit auszuwählen, was weitergegeben und als vorbildlich gelesen werden soll. So bedient sich der Text deutlich früher entstandener Íslendingasögur und der „Landnámabók“, eines der ersten historiographischen Texte über die Besiedelung Islands, als Quellen. Mehrfach erfolgen in der „Grettis saga“ auch Hinweise darauf, dass bewusst aus einer großen Stoffülle selektiert wurde, dass noch sehr viel mehr Erzählungen über den unglücklichen Helden existieren, dass diese für die hier vorgelegte schriftliche Fassung jedoch nicht weiter von Interesse sind: „Viele Jugendstreiche verübte Grettir, die nicht in die Saga aufgenommen sind." 10 Wichtige Hinweise zur Chronologie werden zwar aus historiographischen Gründen gemacht, ihre weitere Ausführung jedoch explizit abgelehnt: „Im Frühjahr starb der Gode Snorri, und in dem Jahr trug sich vieles zu, was diese Geschichte nicht berührt." (76. Kap., 191) ${ }^{11}$ Auch die Christianisierung wird nur beiläufig erwähnt und für die „Grettis saga“ als nicht weiter relevant erklärt: „Das war nach der Ankunft von Bischof Friðrek und porvald Koðránssonar und ihren Leuten in Island; [...] Sie verkündeten als erste das Christentum im Nordland; [...] Zwischen dem Bischof und seinen Leuten und den Nordländern trug sich viel Erzählenswertes zu, was aber nichts mit dieser Geschichte zu tun hat."12

Diese Handlungen, die gewissermaßen auf Nebenschauplätzen stattfinden und Stoff anderer Íslendingasögur - etwa der „Njáls saga“ und der „Laxdæla saga“ - , sind, werden in der „Grettis saga“ explizit vernachlässigt und nicht aufgezeichnet. Das Moment der Schriftlichkeit, das

der Zeithorizont zwischen erzählter Geschichte und Zeit der Aufzeichnung jedoch nicht so groß, so dass hier kulturelles und kommunikatives Gedächtnis relativ eng verbunden sind. Auf den kommunikativen Aspekt wird gerade durch die fingierte Mündlichkeit immer wieder eingegangen.

${ }^{10}$ „Mọrg bernskubrọgð gerði Grettir, pau sem eigi eru í sọgu sett.“ (ÍF, 42)

11 „Um várit andaðisk Snorri goði, ok mart bar til tíðenda á pessum misserum, pat sem ekki kemr við pessa sögu.“ (ÍF, 243)

12 „petta var eptir útkvámu Friðreks byskups ok peira porvalds Koðránssonar; [peir bjuggu pá at Lokjamóti, er petta var.] peir boðuðu kristni fyrist fyrir norðan land; [lét porkell prímsignask ok margir menn með honom.] Mart bar til tíðenda um sameign peira byskups ok Norðlendinga, pat er ekki kemr við pessa sögu." (ÍF, 35) 
eine konsequente Entscheidung für die „Dauerpräsenz“ einer Version der Erzählung voraussetzt, wird hier dominant. Auf der einen Seite beugt die Aufzeichnung der Saga dem Vergessen der Geschichte Grettirs vor und stellt sich mit dieser Erinnerungsarbeit in den Dienst eines dezidiert politischen Interesses, indem sie den isländischen Freistaat der Abhängigkeit von Norwegen als vorbildlich entgegenhält. Auf der anderen Seite bricht sie, indem sie ihre spezifische Lesart der Tradition fixiert, mit der "Struktur der [mündlichen] Erinnerung“ (A. Assmann 2009: 153). Diese zeichnet sich gerade durch Diskontinuität und Variabilität aus. Und auf diesen immanenten Konflikt zwischen den unterschiedlichen Überlieferungstraditionen machen die Verweise auf das, was ausdrücklich nicht gesagt wird, aufmerksam. ${ }^{13}$

Besonders deutlich wird das ambivalente Verhältnis zwischen der Memoria als Kunst, Erinnerung durch mündliche Tradierung lebendig zu halten, und deren Manifestation im schriftlichen Kontext am Beispiel der eingefügten Skaldenstrophen. Auch sie verweisen unter anderem auf Ereignisse, über die der Prosakontext keine weitere Auskunft gibt. Mehr als 70 Skaldenstrophen sind in die „Grettis saga“ aufgenommen, von denen 47 Grettir zugeschrieben werden. Die Datierung der Strophen ist schwierig, einige stammen aus der söguöld. Sie werden als authentische Dichtung Grettirs gelesen und finden sich auch in älteren literarischen Kontexten, etwa der „Snorra Edda“ und der „Landnámabók". Die meisten stammen jedoch aus der unmittelbaren Gegenwart der Saga-Aufzeichnung. ${ }^{14}$ Die Skaldendichtung, als den Isländern eigene Kunstform, verbindet die spezifische Memorialfunktion gebun-

\footnotetext{
13 „So unentbehrlich und suggestiv die Schrift als Metapher des Gedächtnisses ist, so unvollkommen und irrführend ist sie auch. Widerspricht doch die Dauerpräsenz des Niedergeschriebenen eklatant der Struktur der Erinnerung, die stets diskontinuierlich ist und Intervalle der Nichtpräsenz notwendig einschließt.“ (A. Assmann 2009: 153). Aleida Assmann macht jedoch auch auf die spezifische Gedächtnisfunktion der Schrift als „Gedächtnisstütze“ aufmerksam: „Aber die Schrift ist nicht nur Verewigungsmedium, sondern auch Gedächtnisstütze. Schrift ist zugleich Medium und Metapher des Gedächtnisses. Der Vorgang des Aufschreibens und Einschreibens ist die älteste und durch die lange Mediengeschichte hindurch immer noch aktuellste Metapher des Gedächtnisses." (Ebd., 184f.)

${ }^{14}$ Bereits Tacitus erkennt in der Erinnerung und der Geschichtsüberlieferung die Besonderheit der germanischen Dichtkunst: „Celebrant carminibus antiquis quod unum apud illos memoriae et annalium genus est." (Tacitus, hier Zit. n. Goetz 1993: 242)
} 
dener Sprache mit dem Interesse, Historie zu tradieren. Die Tatsache, dass die eingefügten Strophen teilweise auf Handlungen anspielen, die in der Saga selbst gar nicht ausgeführt werden, unterstützt den Eindruck einer Stofffülle, die außerhalb und neben der literarischen Fassung existiert. Sie sind ebenso Ausdruck einer eigenständigen oralen Gedächtniskultur wie auch fester Bestandteil einer Schriftkultur, die sich als Fortführung einer mündlichen Gedächtnispraxis begreift. Die in der europäischen mittelalterlichen Literatur einzigartige Kombination aus Prosaerzählung und Skaldik wird denn auch immer wieder als Spezifikum isländischer Dichtung hervorgehoben.

Im Anschluss an diese verschiedenen Reaktionen des Textes auf die orale Erzähltradition stellt sich nun die Frage nach der Funktion solcher Vorgehensweisen: Welche Ziele verfolgt die Erinnerungsgemeinschaft mit der Festschreibung der Saga?

Die Saga als bewusst geformter Text wählt aus, was sie erinnert, und konstituiert damit das kulturelle Gedächtnis einer bestimmten Gruppe, schafft eine „Erinnerungsgemeinschaft“ (Burke 1991: 298), die sich über die Tugenden der Sagazeit definiert. ${ }^{15}$ Und darüber geben die Varianten der verschiedenen Saga-Handschriften Auskunft: Sie stellen das Konzept einer rekonstruktiven Erinnerung nicht in Frage, lassen jedoch Akzentverschiebungen und Interessensverlagerungen erkennen. Die deutlichsten Abweichungen zwischen den ältesten Handschriftengruppen A und B finden sich in der Beschreibung der Bestattung Grettirs. In den Handschriften der Gruppe A werden Grettirs Gebeine von der Insel Drangey geholt, wo er sich zuletzt aufhielt und getötet wurde, und an der Kirche von Reykir beerdigt. Später wird „Grettirs Kopf [...] daheim in Bjarg an der Kirche begraben “. ${ }^{16}$ Durch die

\footnotetext{
${ }^{15}$ Der Begriff der „Erinnerungsgemeinschaft“ findet sich auch bereits in Aby Warburgs Programm der kollektiven Erinnerung: Vgl. dazu Kany 1987: 176. Vgl. dazu auch Oexle (1995: 40): „Geschichtsschreibung wie andere Formen schriftlicher Überlieferung sind im Mittelalter nicht immer nur das Ergebnis einer intellektuellen Tätigkeit gelehrter Individuen an ihren Schreibtischen. Historiographische Einzelwerke können von sozialer Memoria konstituiert sein, Einzelwerke wie auch ganze Gattungen der Historiographie können auf das Zusammenleben von Gruppen und ihrer Praxis der Memoria verweisen, insofern sie zum Beispiel ihre Gründer und deren historisches Wirken kommemorierten, so daß sich die liturgische, die soziale und die historiographische Memoria wechselseitig bedingten."

${ }^{16}$ „en höfuð Grettis var grafit heima at Bjargi at kirkju.“ (ÍF, 269f.)
} 
Bestattung wird der rechtlose und aus der Gesellschaft ausgestoßene Grettir, der kurz vor der Aufhebung der Acht starb, postum in die christliche Gemeinschaft zurückgeführt. Diese Lesart lässt gegen Ende der Saga das Selbstverständnis der Isländer als Christen erkennen, ungeachtet der vielen heidnischen Elemente, die fester Bestandteil der Erzählung sind. Darüber hinaus wird mit dem Grab ein Erinnerungsort für die Nachwelt geschaffen.

In den B-Gruppen-Handschriften bleiben Grettirs Gebeine auf der Insel Drangey. Seine Feinde nehmen nur seinen Kopf als Todesbeweis mit. Der christliche Kontext ist an dieser Stelle offensichtlich irrelevant. Das kulturelle und soziale Gedächtnis, das diese Erinnerung pflegt, präferiert also den heroischen Charakter der Saga. Der tapfere, wenn auch aussichtslose Kampf bis in den Tod wird hier zum Vorbild für die gegenwärtige Situation der Isländer präsentiert. Auffallend ist, dass gerade die jüngeren B-Gruppen-Handschriften eine solche heroische Lesart vorlegen, und die älteren, also früh verfassten, die versöhnliche, christliche Komponente betonen. Auffallend ist auch, dass sich dieses Nebeneinander von heidnischem Kult und christlicher Tradition ebenfalls bis in die Gegenwart gehalten hat.

Auch im „Spesar páttr“, der Erzählung im Anhang der „Grettis saga“, wird das Verhältnis von Christlichem und Heidnischem diskutiert. Der „páttr" fügt sich lückenlos an die Lebensgeschichte Grettirs, weicht jedoch in seiner Kürze und Textgestalt von diesem ersten Teil ab. Zunächst erfolgt die Anbindung des „páttr“ über die Genealogie, die familiäre Verbundenheit der Nachkommen. Grettirs Halbbruder porsteinn zieht aus, um Grettirs Tod zu rächen. Auch das Ende des „Spesar páttr“ weist noch einmal auf die Taten des geächteten Helden hin und würdigt ihn als außerordentlichen Menschen. Während die Geschichte von Grettir sehr stark von heidnischen Elementen bestimmt wird, favorisiert der „Spesar páttr“ vor allem mit dem Ende in Rom eine eindeutig christliche Perspektive. Verbunden sind die beiden Teile durch die Opposition von Glück und Unglück, gæfa und ógæfa.

Diejenigen Forschungspositionen, die von einer geschlossenen Komposition von „Grettis Saga“ „Ásmundarsonar“ einschließlich dem „Spesar páttr" sprechen und eine solche Geschlossenheit auch als Kennzeichen dieser spezifisch isländischen Literatur verstanden wissen wollen, be- 
ziehen sich insbesondere auf diese Verbindung zwischen dem tapferen, aber unglücklich handelnden Grettir und seinem weniger starken, jedoch vom Glück begünstigten Halbbruder porsteinn. Und diese Wendung zum Glück wird nicht selten mit porsteinns christlicher Demut am Ende begründet: Seine Frau Spes, mit deren Namen zugleich die christliche Hoffnung bezeichnet ist, und er selbst beschließen ihr Leben im Kloster.

Auch wenn der "páttr“ noch andere Lesarten nahelegt, ergeben sich aus der Zusammenführung von Grettirs Lebensgeschichte und dem „páttr“ zwei Deutungsmodelle: ein heidnisches, für das Grettirs Taten stehen, und ein christliches. Für eine christliche Deutung spricht die in den A-Gruppen-Handschriften genannte Beerdigung Grettirs an der Kirche in Bjarg: Das Interesse der Erinnerungsgemeinschaft, die diese Variante weitergibt, ist deutlich von christlichen Tugenden wie Demut, Verzeihung und Reue bestimmt.

Dennoch lassen sich die Brüche zwischen der Lebensgeschichte Grettirs und dem „Spesar páttr“ nicht übersehen. Und nicht umsonst hat die Frage danach, wie diese Teile zusammenhängen, die Sagaforschung stark beschäftigt. porsteinns Aufbruch nach Byzanz, der ja zunächst in unmittelbarer Beziehung zu Grettirs Tod steht, gestaltet sich zunehmend als Abenteuerreise, die in vielen Punkten kontinentalen Vorlagen entspricht: Die List, durch welche die untreue Spes und ihr Liebhaber porsteinn der Strafe entkommen, weist deutliche Parallelen zur TristanDichtung auf. Das Heldenideal, das Grettirs Leben dominierte, tritt hier in den Hintergrund und wird nur am Ende noch einmal aufgegriffen. Der „páttr“ eröffnet damit eine Nebenhandlung, die für eine Erinnerungsgemeinschaft, die vor allem den starken Helden würdigen möchte, keine weiteren Bezugspunkte aufweist, außer dem Hinweis, dass niemand so weit reiste, um ein Familienmitglied zu rächen.

Die Bedeutung des „Spesar páttr“ hängt also entschieden davon ab, welches Selbstbild das kulturelle Gedächtnis einer bestimmten Rezeptions- und Erinnerungsgemeinschaft darin wiederfinden will. Da der Akzent der Saga deutlich auf der Figur des zwiespältigen Helden Grettir liegt, der seine Umgebung von den bösen Mächten befreien möchte, ihr und sich selbst aber zunehmend Unglück bringt, scheint seine Rolle als unbeirrbarer Kämpfer gegen alle Widerstände für seine 
Popularität und seinen Vorbildcharakter maßgeblich zu sein. Die Episoden in Byzanz und Rom hingegen tragen zu diesem Bezugsrahmen nur insofern bei, als Grettirs Tod dem Aufbruch aus Island vorausgeht. Von dem Ausgang des „páttr“ jedoch auf das Wertesystem der gesamten Saga zu schließen, führt zu weit und vernachlässigt die Bedeutung des dezidiert isländischen Ehrbegriffs und der selbstverständlichen Einbindung der heidnischen Gegenwelt in einen christlichen Kontext.

Vor diesem Hintergrund erklärt sich, warum der ambivalente Held Grettir nicht vergessen, sondern die von ihm vertretenen Tugenden in Erinnerung gerufen werden sollen: Der Held, der gleichermaßen AuBenseiter, Geächteter und Identifikationsgestalt ist, wird von Beginn an in seiner Vielschichtigkeit vorgestellt. Er ist ein Taugenichts und unbeherrscht, er ist aber auch ein kunstvoller Skalde und mutiger Kämpfer. Dass seine Taten schließlich von seiner Umwelt genau gegenteilig gedeutet werden, ist das Schicksal des ógœefumaðr. Es ist also kein strahlender Held, der mit der isländischen Geschichte der söguöld erinnert wird, sondern einer, der trotz widriger Umstände Außergewöhnliches schafft.

Die Repräsentation und Vergegenwärtigung der Vergangenheit folgt den Interessen der isländischen Bauern und deren Etablierung im Freistaat: Die Geschichte der isländischen Familien wird als identisch mit der Islands gesetzt. Und diese in den Sagas festgeschriebene Perspektive hat bis heute Bestand. Die Interessen einer bestimmten Gruppe, die darüber entscheidet, was im Gedächtnis bewahrt werden soll, können sich unter wechselnden gesellschaftlichen, politischen und kulturellen Bedingungen und Bezugsrahmen zwar verschieben: Die Bedeutung der Saga als Erinnerungsträger und Fundament einer sich durchaus wandelnden - nationalen Identität wird jedoch nirgends in Frage gestellt (vgl. Bhabha 2000: 237-240).

Und es sind - anders als in vielen anderen Mythen - die schwierigen, keineswegs nur strahlenden, aber sich in jeder noch so aussichtslosen Situation immer wieder bewährenden, ambivalenten Helden, die Stoff für die Geschichte sind, die erinnert werden und als Identifikationsmuster bis in die Gegenwart fungieren. Die harten klimatischen Bedingungen auf dem Inselstaat bedingen keine glatten Helden, sondern 
bringen widerborstige Einzelgänger hervor, die sich den Widrigkeiten von Natur und Herrschern selbstbewusst stellen. ${ }^{17}$

Aus diesem Grund ist seine Geschichte es wert, immer wieder erzählt zu werden, und aus diesem Grund wird auch explizit auf die vielen Orte verwiesen, die an die Kämpfe gegen seine Widersacher erinnern: Der Landschaft und den in ihr lokalisierten Ereignissen kommt nämlich eine entscheidende Rolle als Garant der Erinnerung zu. „Grettis saga“ ist untrennbar mit der isländischen Topographie verbunden und nimmt eine literarische Kartierung weiter Teile des Landes vor (vgl. Glauser 2006: 40f.). So sind Steine nach Grettir benannt, Grettishaf, die Schlucht, in der er die Trollhexe besiegt, Grettisgeil, eine Landzunge, Grettisoddi, sowie ein kleiner Hügel, Grettispúfa. Alle diese Gedächtnisorte verewigen ebenso wie sein Geburtsort Bragi und die Zufluchtsinsel Drangey den Helden: Sie sind Teil einer rekonstruktiven, an der Vergangenheit orientierten, und einer prospektiven, für die Nachwelt angelegten, Gedächtniskultur. Der starke und geächtete Grettir lebt denn auch wie kaum eine andere epische Figur in der Erinnerung und Imagination der Isländer durch die Jahrhunderte weiter. Immer wieder ist die Saga auf- und abgeschrieben worden, sie ist fester Bestandteil der Schulcurricula, und der Literaturnobelpreisträger Halldór Laxness, der mit seiner modernistischen Prosa zunächst bewusst gegen die Übermacht der Sagaprosa noch im 20. Jahrhundert anschrieb, huldigte mit seinem Roman „Gerpla“ (1964) unter anderem auch dem beliebten Unglücksmenschen Grettir.

"Grettis Saga Ásmundarsonar" führt die Bedeutung vor, die den Íslendingasögur als gruppenidentitätsstiftendem Medium zukommt. Sie dient der Rückeroberung und produktiven Aneignung der vergangenen Freiheit und Größe und übernimmt die Funktion eines Nationalepos ebenso wie die anderen Sagas auch. ${ }^{18}$ Mit der schriftlichen Fixie-

\footnotetext{
${ }_{17}$ Ähnlich findet sich diese Ambivalenz von Einzelgängertum und Identifikationsgestalt für die Gemeinschaft auch bei der Schiller'schen Wilhelm Tell-Figur. Vgl. hierzu den Aufsatz von Silke Pasewalck im vorliegenden Band.

${ }^{18}$ Vgl. dazu auch Preben Meulengracht Sørensen (1995: 81): „Sagalitteraturen er en tilbageerobring og omskabelse af det svundne til meningsfuld historie. En selvbevidst overklasse af bønder skabte billeder af en fortid, som de betragtede som deres egne slægters.[...] Islændingesagaerne blev det vigtigste medium for denne manifestation af historisk betinget status." [Die Sageliteratur ist ein Rückeroberung und Umschöpfung
} 
rung der zunächst in der mündlichen Erzählung präsenten Stoffe schreibt die Sagaliteratur die isländische Geschichte fest. Damit wird nicht nur das Verhältnis von oraler Tradition und Verschriftlichung vorgeführt, es wird auch der historiographische Anspruch der Íslendingasögur hervorgehoben. Heidnisches und Christliches stehen hier ebenso nebeneinander wie imaginäre Geschichten und Historie.

Die Saga ist im Kontext nicht nur einer, sondern wiederholter politischer und kultureller Umbruchszeiten zu verstehen und rekurriert auf den Wandel, indem sie unterschiedliche Werte und den Medienwechsel von der Oralität zur Literalität Seite an Seite präsentiert. Im kulturellen Gedächtnis der isländischen Bauern des 13. bis 15. Jahrhunderts wird damit ein Gruppenbewusstsein geschaffen, das sich gerade über den in der „Grettis saga“ vorgeführten ambivalenten Ehr- und Tapferkeitsbegriff konstituiert und weit darüber hinaus Bestand hat. Die kulturelle Sinnproduktion erfolgt über die Thematisierung der Umbrüche: Der legitimatorische und identifikatorische Charakter der Sagaliteratur findet darin seinen Ursprung. Dass gerade diese isländische Geschichte auch im Zuge des nation building insbesondere in Norwegen 1814 bemüht wird, lässt sich aus der jeweiligen Perspektive auf die Geschichte und deren Geschichte erklären: Schließlich waren es Norweger, die einst auszogen, Island zu besiedeln. Wenn man den Anfang hier sucht, dann ergibt sich daraus auch der Stoff, aus dem nicht nur die isländische Geschichte gemacht wurde.

des Verschwundenen zu einer bedeutungsvollen Geschichte. Eine selbstbewusste bäuerliche Oberklasse schuf Bilder einer Vorzeit, die als die ihrer Vorväter gedeutet wurde. [...] Die Isländersagas waren das wichtigste Medium zur Manifestation eines historisch bedingten Status'.] Übersetzt von K. H. 


\section{Literaturverzeichnis}

\section{Primärliteratur}

Grettis saga Ásmundarsonar (1936). Hrsg. v. Guðni Jónsson. (=Íslenzk Fornrit, ÍF VII). Reykjavík.

Grettis saga. Die Saga von Grettir dem Starken (1998). Hrsg. und aus dem Isländischen übersetzt v. Hubert Seelow. München.

\section{Sekundärliteratur}

Albertus Magnus: De bono. In: Heinrich Kühle et al. (Hrsg.) (1951): Opera omnia. Münster, S. 82-113.

Assmann, Aleida (1999): Erinnerungsräume, Formen und Wandlungen des kulturellen Gedächtnisses. München.

Assmann, Jan (1992): Das kulturelle Gedächtnis. Schrift, Erinnerung und politische Identität in frühen Hochkulturen. München.

Bнавна, Homi K. (2000): DissemiNation: Zeit, narrative Geschichte und die Ränder der modernen Nation. In: ders. (2000): Die Verortung der Kultur. Tübingen, S. 207-253.

BECK, Heinrich (1997): Vorwort. In: (Hrsg.) (1997): Laxdoela Saga. Aus d. Altisl. übersetzt v. Heinrich Beck. München, S. 214-222.

BURke, Peter (1991): Geschichte als soziales Gedächtnis. In: Aleida Assmann/ Dietrich Harth (Hrsg.) (1991): Mnemosyne. Frankfurt a. M., S. 289-304.

GERECKE, Anne-Bitt (2002): Transkulturalität als literarisches Programm. H. W. v. Gerstenbergs Poetik und Poesie. Göttingen.

GLAusER, Jürg (2006): Mittelalter. In: ders. (Hrsg.) (2006): Skandinavische Literaturgeschichte. Stuttgart, 1-50.

Goetz, Hans-Werner (1993): Verschriftlichung von Geschichtskenntnissen. Die Historiographie der Karolingerzeit. In: Ursula Schäfer (Hrsg.) (1993): Schriftlichkeit und Mündlichkeit. Tübingen, S. 229-248.

GuMBRECHT, Hans Ulrich (1983): Schriftlichkeit in mündlicher Kultur. In: Aleida und Jan Assmann/Christof Hardmeier (Hrsg.) (1983): Schrift und Gedächtnis. München, S. 1581-74.

HAFNER, Ulrike (1996): „Norden“ und „Nation“ um 1800. Der Einfluß skandinavischer Geschichtsmythen und Volksmentalitäten auf deutschsprachige Schriftsteller zwischen Aufklärung und Romantik (1740-1820). Triest.

KAny, Roland (1987): Mnemosyne als Programm. Geschichte, Erinnerung und die Andacht zum Unbedeutenden im Werk von Usener, Warburg und Benjamin. Tübingen.

LAUTERBACH, Frank (2004): Einleitung: Nationalkulturelle Identitätskonstruktionen im Spannungsfeld dialektischer Differenzierungen. In: Frank 
Lauterbach/Fritz Paul/Ulrike-Christine Sander (Hrsg.) (2004): Abgrenzung Eingrenzung. Komparatistische Studien zur Dialektik kultureller Identitätsbildung. Göttingen, S. 1-16.

Meulengracht Sørensen, Preben (1995): Fortalling og are, studier $i$ islandingesagaerne. Oslo.

Ólason, Vésteinn (1998): Dialogues with the Viking Age. Narration and Representation in the Sagas of the Icelanders. Reykjavík.

Oexle, Otto Gerhard (1995): Memoria als Kultur. In: ders. (Hrsg.) (1995): Memoria als Kultur. Göttingen, S. 9-78.

Wenzel, Horst (1991): Imaginatio und Memoria. Medien der Erinnerung im höfischen Mittelalter. In: Aleida Assmann/Dietrich Harth (Hrsg.) (1991): Mnemosyne. Formen und Funktionen der kulturellen Erinnerung. Frankfurt a. M., S. $57-82$.

YATES, Frances A. (1990): Gedächtnis und Erinnern: Mnemonik von Aristoteles bis Shakespeare. Oldenburg. 


\section{„Frit(h)iofs saga“6 - ein schwedisches National- epos zwischen Esaias Tegnér und Selma Lagerlöf}

In „Mårbacka“, einer Schilderung ihrer eigenen Kindheit, erzählt die Nobelpreisträgerin Selma Lagerlöf (1858-1940) von ihrem Vater, dem Leutnant Erik Gustav Lagerlöf, und dessen literarischen Vorlieben:

Eller också, ifall han [=S. L.:s far] inte var hågad för att prata, lät han fru Lagerlöf eller mamsell Lovisa läsa högt ur Tegnér. Något mer härligt än Fritiofs saga trodde han inte fanns i denna värld. Hellre än att vara kejsare av Frankrike eller tsar av Ryssland ville han vara den Lundaprofessorn, som hade besjungit Fritiofs och Ingeborgs kärleksöden. Han tyckte också mycket om Runeberg och hörde gärna både Fänrik Ståls sägner och hans episka dikter föreläsas. Men han tyckte just inte om, när någon sade, att den finska skalden var större än Tegnér. (Lagerlöf 1922: 263)

Aber auch, wenn er selbst [=S. L.:s Vater] nicht zum Plaudern aufgelegt war, ließ er Frau Lagerlöf oder Mamsell Lovisa aus Tegnér vorlesen. [Etwas Herrlicheres als Die Fritjofs-Sage, glaubte er, gebe es in dieser Welt nicht.] Viel lieber als Kaiser von Frankreich oder Zar von Rußland wäre er dieser Professor in Lund gewesen, der die Liebe von Fritjof und Ingeborg besungen hatte. Er liebte und verehrte auch Runeberg und hatte es sehr gerne, wenn Fähnrich Ståls Erzählungen sowie dessen [=Runebergs] epische Gedichte vorgelesen wurden. Aber er hörte es nicht gerne, wenn jemand sagte, der finnische Skalde sei größer als Tegnér. (Lagerlöf 1923: $261)^{1}$

Obwohl Esaias Tegnér in der Tat ein Vetter von Selma Lagerlöfs Großvater war (vgl. Wägner 1958: 19), stellt die in „Mårbacka“ zum Ausdruck gebrachte Faszination für die „Frithiofs saga“ innerhalb der Familie Lagerlöf bei weitem keinen verwandtschaftsbedingten Einzelfall dar: Gleich nach seinem Erscheinen und noch lange Zeit danach genoss dieser 1819-1825 entstandene epische Gedichtzyklus bzw. dieses Vers-

\footnotetext{
${ }^{1}$ Der Satz „Något mer härligt...“ im Original hat keine Entsprechung in der zitierten deutschsprachigen Fassung. Seine Übersetzung habe ich deshalb in eckigen Klammern nachgetragen. Im Folgenden stammen die Übersetzungen ins Deutsche, sofern nicht anders vermerkt, ebenfalls von meiner Person.
} 
epos in Schweden und bedingt auch im schwedischsprachigen Teil von Finnland sowie später unter den schwedischsprachigen Emigranten in den Vereinigten Staaten den Rang eines Nationalepos.

\section{„Frithiofs saga“" von Esaias Tegnér}

Als die romantischen Strömungen vor allem durch deutsch- und dänischsprachige Einflüsse auch die schwedischsprachige ${ }^{2}$ Dichtung im ersten Jahrzehnt des 19. Jahrhunderts erreichten, fiel das Ganze zeitlich zufällig mit einem historischen Ereignis zusammen, das die schwedischsprachige Romantik in sehr hohem Maße prägen sollte: mit dem schwedisch-russischen Krieg von 1808-1809, in dem Schweden ein Drittel seines Territoriums verlor und Finnland als Großfürstentum innerhalb Russlands zum ersten Mal staatsrechtliches Subjekt wurde.

Die daraus resultierende notgedrungene Veränderung in der nationalen Identität bildet zusammen mit dem romantischen Interesse an der Vergangenheit sowie an alter, volkstümlicher Dichtung als Ausdruck des „Volksgeistes“ den Hintergrund zur häufigen Beschäftigung mit altnordischen Stoffen in der romantischen Literatur aus „Rest-Schweden“. In der nationalen Krise nach der Teilung des Landes musste eine neue „schwedische“ Identität gefunden bzw. erfunden werden, was sich

\footnotetext{
2 Die in etlichen Einzelphilologien und entsprechenden Literaturgeschichten zu beobachtende Abwesenheit einer Distinktion zwischen den Kriterien Sprache einerseits und „Kultur“, „Nation“ bzw. „Raum“ andererseits findet sich auch bezogen auf den „schwedischen“ Fall. Am auffallendsten ist der Titel „Litteraturens historia i Sverige“ (dt. wortwörtlich: „Geschichte der Literatur in Schweden“) beim einbändigen Standardwerk von Bernt Olsson und Ingemar Algulin (1. Auflage 1987). Trotz seines Titels umfasst es, wie alle anderen entsprechenden Literaturgeschichten, auch die schwedischsprachige Literatur aus Finnland und gleichzeitig ebenfalls die auf schwedischem Boden entstandene mittel- und neulateinische Dichtung. Im Gegensatz dazu steht eine weitere Literaturgeschichte von Göran Hägg, in dessen Vorwort die Sprache als „eine kulturelle Einheit jenseits der des oberflächlichen Nationalismus“ beschrieben wird und „schwedische Literatur“ als „Literatur geschrieben in der schwedischen Sprache“ gedeutet wird (Hägg 1996: 14, im Orig.: „en kulturell enhet bortom den ytliga nationalismens“ bzw. „,svensk litteratur" [...] litteratur skriven på svenska språket“). Hägg verzichtet daher auch ausdrücklich auf die mittel- und neulateinische Literatur aus Schweden. Im vorliegenden Artikel wird in den dafür geeigneten Fällen, um den immer wieder möglichen Missverständnissen vorzubeugen, von schwedischsprachiger Literatur gesprochen.
} 
pointiert in Esaias Tegnérs Gedicht „Svea“ (1811) zeigt. Allgemein spielten jetzt die altnordischen (altisländischen) literarischen Werke, deren Stoffe bzw. eine altnordische Atmosphäre (so wie in Erik Gustaf Geijers Gedicht „Vikingen“) eine wesentliche Rolle. Die identitätsstiftende Funktion der altnordischen Literatur für eine neu zu konzipierende Nation sollte sich dann sowohl in Norwegen als auch in Island wiederholen. ${ }^{3}$

In Stockholm - neben Uppsala, Lund und Åbo (Turku) einer der Hauptorte der schwedischsprachigen romantischen Bewegung - wurde im Februar 1811 Götiska förbundet (dt. „Götischer Bund“) gegründet. Die Gesellschaft entsprang einer nationalen Gesinnung und einem historisch-mythologischen Interesse. Sie stellte keine rein literarische Gesellschaft dar, obwohl Schriftsteller zum Mitgliederkreis zählten und bald sehr wesentliche Beiträge leisteten. Der Dichter Erik Gustaf Geijer gab die „Iduna“, die Zeitschrift dieser Gesellschaft, heraus und veröffentlichte dort von Beginn an eigene Gedichte mit altnordischem Bezug sowie eigene Übersetzungen aus dem Altisländischen.

In Götiska förbundet, einer Wiederbelebung des so genannten Götizismus, war die Beschäftigung mit dem Altnordischen, verstanden als kulturelle Wurzeln der schwedischen Nation, ein Weg zur Neufindung einer schwedischen nationalen Identität. Die Beschäftigung mit dem Altnordischen ist jedoch nicht nur auf den engeren Kreis des Götiska förbundet begrenzt, sondern kehrt in den ersten Jahrzehnten nach Einbruch der Romantik auch bei fast jedem bedeutenden schwedischsprachigen Lyriker wieder.

Diesem Enthusiasmus für die nordische Vergangenheit und deren Potenzial als (einzige oder hauptsächliche) Stoff- und Ideenquelle der zeitgenössischen Dichtung in größeren Formen stand Esaias Tegnér, Dichter und Gräzist an der Universität Lund, zuerst sehr skeptisch gegenüber. Gleichwohl zählte auch er ab November 1811 zu den Mitgliedern des Götiska förbundet (vgl. Lönnroth 2001: 13) und bearbeitete altnordische Stoffe und Milieus dann auch in Gedichten wie „Skidbladner“ (1812) und „Bifrost“ (1813; späterer Titel: „Asatiden“).

\footnotetext{
${ }^{3}$ Vgl. hierzu auch den Beitrag von Karin Hoff in vorliegendem Band.
} 
Der dänische Dichter Adam Oehlenschläger sollte durch seinen epischen Gedichtzyklus „Helge“ (1814) Tegnér vom Potenzial der altnordischen Stoffe in der zeitgenössischen Versepik überzeugen und den Ansporn zu eigenen Umsetzungen geben. Tegnér nahm als Vorlage für seinen Versuch in dieser Gattung die altisländische Saga „Friðpjófs saga ins frækna" (im 13. oder 14. Jahrhundert entstanden oder niedergeschrieben), die er laut eigener Angabe seit seiner frühen Kindheit kannte und in einer dreisprachigen Ausgabe (Altisländisch, Schwedisch, Latein) von 1737 benutzte (vgl. Lundquist 1986: 156).

Wie Lönnroth darlegt, bleibt die „ambivalente“ Einstellung Tegnérs zum Altnordischen auch noch in „Frithiofs saga“ erhalten - ja, gerade „die Widersprüche und nicht zuletzt das Schwanken, was die Haltbarkeit des götischen Programms betrifft, machen das hervorragendste götische Gedicht, ,Frithiofs saga', zu einem poetischen Meisterwerk“ (Lönnroth 2001:26). ${ }^{4}$ Es sei Tegnér, so Lönnroth, nur deshalb möglich gewesen, das „götische Programm“ zu erneuern, weil er es nie vollends akzeptiert habe, sondern es „im Licht klassischer Dichtung und seiner eigenen sehr besonderen Variante klassischer Ästhetik umgedeutet hat" (ebd., 5). ${ }^{5}$ Bemerkenswert ist vor allem der seelische Ausgleich, den das klassische Gedankenerbe mit sich bringt: zwischen den wilden Urkräften des Nordens und dem beherrschten, harmonischen, schönen Süden.

Das klassische Erbe blieb dem Gräzisten Tegnér von entscheidender Bedeutung, was in „Frithiofs saga“ wiederholt durchschimmert, vor allem in der Verehrung von Griechenland. Darüber hinaus hat Tegnér durch Verschiebungen in der Handlung der Intrige und durch Hinzufügung eines neuen philosophischen Inhalts einen gegenüber der Saga neuen Motivkomplex geschaffen, der für seinen epischen Gedichtzyklus zentral ist: das Motiv von Schuld und Versöhnung (vgl. Schück/Warburg 1929: 585). Bemerkenswert an „Frithiofs saga“ ist auch, wie Tegnér die Ausdrucksmittel und Versmaße von Gedicht zu

\footnotetext{
${ }^{4}$ Im Orig.: „motsägelserna och inte minst tveksamheten om det götiska programmets hållbarhet [...] gör Tegnérs främsta götiska dikt ,Frithiofs saga, till ett poetiskt mästerverk“.

${ }^{5}$ Im Orig.: „omtolkade den i ljuset av klassisk diktning och sin egen mycket speciella variant av klassisk estetik“.
} 
Gedicht verändert, sowie die große stilistische Vielfalt in der sprachlichen Gestaltung.

Der Ausgangspunkt von Tegnérs „Frithiofs saga“ ist das gemeinsame Aufwachsen von Frithiof, dem Sohn eines Bauern, und Ingeborg, Tochter von König Bele, beim gemeinsamen Ziehvater Hilding. Zwischen den beiden Kindern entwickelt sich bis ins Erwachsenenalter ein sehr enges Verhältnis. Nach dem Tod von Bele übernehmen seine beiden Söhne, Helge und Halfdan, gemeinsam den Thron. Den Antrag Frithiofs um die Hand ihrer Schwester Ingeborg lehnen die beiden Könige hochmütig ab. Auch der alte König Ring vom Nachbarreich stellt einen Heiratsantrag, der ebenfalls abgelehnt wird. Hieraus resultiert ein Krieg, an dem teilzunehmen sich Frithiof stur weigert. Im Anschluss daran trifft er sich mit Ingeborg in einem Hain, der dem milden Gott Balder geweiht ist. Er zieht dadurch noch mehr die Wut der Königsbrüder auf sich und wird mit einem schwierigen Auftrag außer Landes gesandt. Ingeborg klagt in einem Monolog ihr Schicksal. Nach einem für ihn erfolgreichen Jahr kehrt Frithiof nach Hause zurück und erfährt, dass König Ring den Krieg gewonnen und Ingeborg als Kriegsbeute geheiratet hat; zudem hat König Helge Frithiofs Hof Framnäs niedergebrannt. Frithiof will sich rächen und findet Helge im Tempel von Balder. Nach einem Streit um das Armband, das Frithiof einst Ingeborg geschenkt hat und das jetzt das Standbild Balders schmückt, steckt Frithiof durch Unachtsamkeit das Standbild und mit diesem den gesamten Tempel in Brand. Des Landes verwiesen ziehen Frithiof und sein Waffenbruder Björn in südlichere Gegenden, doch obwohl von Griechenland begeistert, sehnt sich Frithiof nach drei Jahren zurück nach Ingeborg und seinem Vaterland. Als alter Mann verkleidet besucht er nach seiner Rückkehr den Hof König Rings und gewinnt das Vertrauen des Königs. Nach einigen Monaten stirbt Ring und sein minderjähriger Sohn wird unter Frithiofs Vormundschaft König. Der Balderstempel wird wieder aufgebaut. Ein Balderspriester spricht zu Frithiof von einem Balder des Südens, ,jungfruns son“ (Tegnér 1986: 143; dt: „Sohn der Magd“, Tegnér 1826: 188) und erzählt ihm auch, dass Helge während eines Feldzuges bei den Finnen gestorben sei, zerquetscht durch das Standbild des finnischen Gottes Jumala. Durch den Balderspriester angeregt, versöhnt sich Frithiof mit Halfdan und kann danach Ingeborg heiraten. 


\section{„Frithiofs saga“ - das schwedische Nationalepos?}

Bereits nach dem Vorabdruck einiger Lieder (Gedichte) in „Iduna“ im Jahr 1820 lobte Per Daniel Amadeus Atterbom, als Dichter und Theoretiker gewissermaßen der Protagonist der schwedischsprachigen Romantik, die dabei noch nicht vollendete „Frithiofs saga“ als ein Epos, das als Vertreter seiner Nation unter den Epen anderer europäischer Nationen eine selbstverständliche Stellung einnehmen würde.

In Atterboms Bewertung spiegelt sich der internationale Diskurs der Zeit seit Herder und verstärkt durch die Heidelberger Romantik wieder. Atterbom und Etliche nach ihm meinten nun, das schwedische Nationalepos identifiziert zu haben.

Nach dem Hof des Protagonisten Frithiof, der bei Tegnér Framnäs heißt, wurden im 19. und frühen 20. Jahrhundert zahlreiche Höfe und größere Gebäude, sowohl in Schweden als auch in den schwedischsprachigen Teilen Finnlands, benannt. Einige durch den Komponisten Bernhard Crusell vertonte Lieder aus „Frithiofs saga“ verbreiteten sich im 19. Jahrhundert auch mündlich und auffallend schnell in verschiedenen, oft veralternden Varianten, quasi als Volkslieder (vgl. Gustafsson 1991: 212f. und Nordenfors 2008: 198-203, 206). In den Schulen war „Frithiofs saga“ häufig Pflichtlektüre. Dieser nationalistisch geprägte Enthusiasmus war möglich, obwohl die altnordische Vorlage von „Frithiofs saga“ tatsächlich in Norwegen spielt und auch der Gedichtzyklus nicht von Schweden spricht. In einer Zeit erneuerten Interesses am Götizismus und später in der Atmosphäre des Skandinavismus (bzw. Pan-Skandinavismus) stellte die norwegische Anknüpfung eher einen Vorteil dar. Außerdem waren Schweden und Norwegen seit 1814 (bis 1905) in einer Union vereinigt, deren nationalideologische Implikationen Tegnér bereits im Gedicht „Nore“ von 1814 gefeiert hatte.

Die schwedischsprachige Literatur des 19. Jahrhunderts weist jedoch gleich zwei potentielle Kandidaten für den Rang eines Nationalepos auf, die im Lagerlöf-Zitat am Anfang dieses Beitrages beide erwähnt werden und deren Autoren dort auch noch nicht ganz zufällig in einer Art Konkurrenzverhältnis einander gegenübergestellt werden. Johan Ludvig Runebergs „Fänrik Ståls sägner“ (1848-1860) handelt von dem für die schwedische wie für die finnische nationale Identität entschei- 
denden Krieg 1808-1809. Das Werk fand große Resonanz sowohl in der Heimat Runebergs, Finnland, als auch in Schweden. Henrik Schück spricht 1930 aus eigener Erfahrung den Status von „Fänrik Ståls sägner“ als Nationalepos an: „[D]ieser Gedichtzyklus war es, der für uns [Schulkinder in den 1860er Jahren] Frithiofs saga als Nationalepos verdrängt hat“ (Schück/Warburg 1930: 438). ${ }^{6}$ „Fänrik Ståls sägner" haben auch im allgemeinen Bewusstsein vor allem unter der Schwedisch sprechenden Bevölkerung in Finnland ihre Position bis in die Gegenwart einigermaßen verteidigen können, während dies in der zweiten Hälfte des 20. Jahrhunderts für die Stellung von „Frithiofs saga" in Schweden nicht mehr zutrifft.

Im 19. und im frühen 20. Jahrhundert war diese Position jedoch immer noch im Großen und Ganzen unangetastet. Im Laufe der 1890er Jahre wurden zwei Opern bzw. Opernlibretti auf Basis der „Frithiofs saga“ verfasst; neben der unten zu behandelnden auch eine, die interessanterweise unter den schwedischen Emigranten in den Vereinigten Staaten sehr stark zur Markierung einer eigenen ethnischen Identität beitrug: „Fridthjof and Ingeborg“ (1898) vom schwedischamerikanischen Komponisten Charles F. Hanson mit einem zweisprachigen (schwedisch-englischen) Libretto von Anna Cronjelm Wallberg (vgl. Harvey 1995: 82-85 und Beijbom 1996: 163-165).

Seit Mitte des 20. Jahrhunderts hat eine deutliche Verschiebung in der Wahrnehmung sowohl von „Frithiofs saga“ als auch von Tegnér stattgefunden. Das häufig abschätzige Tegnér-Bild unter den Schriftstellern der 1980er Jahre wird in einem Aufsatz von Detlef Brennecke beleuchtet (vgl. Brennecke 1983). Über die Tatsache, dass „Frithiofs saga“ kaum noch gelesen wird und keine Pflichtlektüre im muttersprachlichen Unterricht mehr darstellt, schreiben auch Lönnroth und Wingborg (vgl. Lönnroth 2001: 29, Wingborg 1996: passim; allgemein zu Tegnér auch Elam 1999: 573). Gewiss ist „Frithiofs saga“ heutzutage nicht mehr als lebendiges Nationalepos, sondern als ein gewesenes zu bezeichnen.

Mit dieser allgemeinen Auffassung geht das Urteil in der Literaturgeschichtsschreibung der letzten Jahrzehnte einher; dort ist der Ruhm

\footnotetext{
${ }^{6}$ Im Orig.: „det var denna diktcykel, som för oss [skolbarn på 1860-talet] trängde ut Frithiofs saga såsom nationalepos“.
} 
von „Frithiofs saga“ erheblich verblasst. Der Text stellt immer noch ohne Zweifel ein bedeutendes Werk der schwedischen Romantik dar, wird aber insgesamt anders und negativer als früher bewertet. Wingborg erwähnt diesbezüglich den Unterschied zwischen den Einträgen zu Tegnér in einer allgemeinen Enzyklopädie aus den 1950er und aus den 1990er Jahren (vgl. Wingborg 1996: 233). Hägg fällt in seiner Literaturgeschichte von 1996 ein hartes Urteil über „Frithiofs saga“: So sei „das einst so geliebte Werk unrettbar den Klassikertod gestorben“, „das meiste hat nur noch mentalitätshistorisches Interesse“ und „was Frithiof getötet hat, ist gerade das Streben nach Zeitlosigkeit“ (Hägg 1996: 223). ${ }^{7}$

\section{Selma Lagerlöfs „,Fritiofs saga“" - Librettisierung eines Nationalepos}

Selma Lagerlöfs Opernlibretto „Fritiofs saga“ mag ein unbekanntes, und gemessen an der übrigen Produktion der Autorin auch nicht sehr gelungenes Werk sein; von grundsätzlichem Interesse ist es dennoch, nicht zuletzt als Ausdruck der bereits beschriebenen Bedeutung, die Tegnérs „Frithiofs saga“ im 19. Jahrhundert innerhalb der schwedischen Sprachgemeinschaft ausübte.

Was die Forschungslage zum Libretto und zur Oper betrifft, ist zunächst anzumerken, dass die Lagerlöf-Literatur die Zusammenarbeit der Autorin mit der Komponistin Elfrida Andrée (1841-1929) und insbesondere deren dichterisches Ergebnis, das Libretto „Fritiofs saga“, weitgehend schweigend übergeht. Obwohl Teile des Librettos - in einem besonderen Textauszug - veröffentlicht wurden, ist „Fritiofs saga“ nur selten in Werkverzeichnissen Lagerlöfs zu finden. In der in den 1960er Jahren erschienenen Auswahl von Lagerlöfs Briefen fehlt die Korrespondenz mit Andrée. Die Biographien von Elin Wägner und Vivi Edström gehen beide sehr schnell an der Zusammenarbeit mit Andrée vorbei (vgl. Wägner 1958: 126 und Edström 2002: 175f.).

\footnotetext{
${ }^{7}$ Im Orig.: „det en gång så älskade verket [har] ohjälpligt dött klassikerdöden“, „det mesta har bara mentalitetshistoriskt intresse“, „Det som dödat Frithiof är just strävan till tidlöshet“.
} 
Die einzige ausführlichere Hintergrunddarstellung findet sich bezeichnenderweise in einer Biographie von Eva Öhrström über Elfrida Andrée, für die die Oper wohl das anspruchsvollste kompositorische Projekt war. Die folgende Darstellung der Entstehung basiert zum Teil auf Öhrströms Untersuchung. Eine genauere Analyse des Textes, seines Verhältnisses zur Tegnér'schen Vorlage und die literaturhistorische Kontextualisierung stehen jedoch auch nach Öhrström aus. ${ }^{8}$

Wie bereits das einleitende Zitat in diesem Artikel ausdrücklich zeigt, gehörte „Frithiofs saga“ zu den wichtigen frühen und bis ins Erwachsenenalter nachhaltigen literarischen Eindrücken Selma Lagerlöfs. ${ }^{9}$ Im Übrigen nahm Lagerlöf Tegnér insgesamt zum Vorbild für die eigenen literarischen Versuche. Birgitta Holm zeichnet etwa Tegnérs Einfluss auf Selma Lagerlöfs langes, unveröffentlichtes Gedicht „Madame de Castro“ aus den 1880er Jahren nach, das auch als Verserzählung bezeichnet werden kann (vgl. Holm 1984: 139-143). Noch in Lagerlöfs erstem Roman „Gösta Berlings saga“ trägt neben dem Titel auch der episodische Aufbau Spuren formaler Einflüsse von „Frithiofs saga“ (vgl. Elam 1999: 573).

In der schwedischsprachigen Literaturgeschichte wird zwischen „Åttitalet“ (den 80er) und "Nittitalet" (den 90er) unterschieden, d.h. zwischen der vorwiegend naturalistischen, engagierten und radikalen Literatur der 1880er Jahre einerseits (u.a. der frühe August Strindberg, Ola Hansson und nicht zuletzt eine Autorinnengruppe mit Anne Charlotte Leffler, Alfhild Agrell und Victoria Benedictsson als den drei wichtigsten Namen) und der Literatur der 1890er Jahre andererseits (u.a. Verner von Heidenstam, Selma Lagerlöf, Gustaf Fröding, Erik Axel Karlfeldt), die Werte wie Phantasie, Natur, Vergangenheit und Nation wieder ins Zentrum stellte und sich gewissermaßen als eine Art Neo-Romantik beschreiben ließe.

\footnotetext{
${ }^{8}$ Ein Aufsatz von Louise Vinge, in dem das Opernlibretto behandelt wird, ist kurz vor Drucklegung des vorliegenden Bandes erschienen; er konnte daher leider nicht mehr berücksichtigt werden. Vgl. VINGE, Louise (2011): Selma Lagerlöf och Esaias Tegnér. In: Maria Karlsson/Louise Vinge (Hrsg.) (2011): Spår och speglingar. Lagerlöfstudier 2011. Möklinta, S. 34-51.

${ }^{9}$ Auch im Zitat kehrt übrigens die Schreibweise „Fritiof“ wieder, die im Titel und Text des Librettos durchgängig vorkommt.
} 
Lagerlöfs Debüt „Gösta Berlings saga“ (1891) entsprach zeitlich und inhaltlich den Bemühungen ihres Kollegen Verner von Heidenstam. In "Gösta Berlings saga“ hatten die oben genannten Werte der neuen bzw. erneuerten Ästhetik auch Eingang in die Erzählprosa gefunden. Vom auffälligen romantischen „Code“ in Lagerlöfs Erstling, nicht zuletzt in der Erzählweise, spricht unter anderen Birgitta Holm (1984: 21).

Vor dem Hintergrund des literarischen Milieus der 1890er Jahre erscheint der Rückgriff auf „Frithiofs saga“ recht naheliegend. Die Zusammenarbeit mit der älteren Komponistin Elfrida Andrée ging allerdings auf deren Initiative zurück und hat einige weitere interessante zeitgeschichtliche Konnotationen.

Im Opernschaffen schwedischer Komponisten und mit ihnen kooperierender Librettisten hatte die Nationalromantik parallel dazu ihre Blütezeit. Es wurde vielfach auf schwedische Volksmärchen, volkstümliche Traditionen und Stoffe zurückgegriffen (wie in Ivar Hallströms und Frans Hedbergs „Hertig Magnus och sjöjungfrun“ sowie „Den bergtagna"), und auch auf das Altnordische und die Wikinger-Zeit (in Andreas Halléns und Hans Herrigs deutschsprachigem „Harald der Wiking“ sowie in Hallströms und Hedbergs „Vikingarne“).

Andrée hatte Selma Lagerlöf im Kontext eines Preiswettbewerbs, der im Januar 1894 angekündigt wurde, eine Zusammenarbeit vorgeschlagen; die Auswahl des Werks zur Einweihung des neuen Opernhauses der Königlichen Oper Stockholm (Kungliga Teatern) vier Jahre später sollte durch einen anonymen Wettbewerb entschieden werden. Trotz der grundsätzlich freien Stoffwahl fügte die Operndirektion der Ausschreibung hinzu: „Dock framhåller direktionen önskvärdheten af att de fosterländska ämnena komma i åtanke“ (K. Operans direktion 1894; dt.: „Die Direktion betont jedoch die Erwünschtheit dessen, dass die vaterländischen Themen in Betracht gezogen werden“) - für die Stimmungen im damaligen schwedischen Musik- und Kulturleben war dies sehr charakteristisch.

Die Zusammenarbeit zwischen Andrée und Lagerlöf weist auch eine politisch radikale Seite auf, die zumindest die Entstehung des Librettos und der Oper (aber, wie sich zeigen wird, auch den Operntext selbst) vom romantischen Gedankengut und von „Frithiofs saga“ zu entfernen scheint, geht es dabei doch auch um die Frauenfrage. Elfrida Andrée ist 
eine herausragende Person nicht nur, was die schwedische Musikgeschichte betrifft, sondern auch in der schwedischen Geschichte allgemein: Sie absolvierte Ausbildungen sowohl zur Organistin als auch zur Telegrafistin, und sie gab damit Anlass zu zwei Gesetzesänderungen in den 1860er Jahren. Andrée war die erste fest angestellte Organistin in einer europäischen Domkirche (1867, in Göteborg). Als Komponistin hatte sich Andrée zunächst an frühromantischen Stilidealen (Schubert, Schumann, Mendelssohn) orientiert, die inzwischen aber als altmodisch galten. In ihrer Oper „Fritiofs saga“ sollte sie zum ersten Mal eine neue, eher spätromantisch geprägte Tonsprache verwenden (vgl. Öhrström 1999: 390f.).

Lagerlöf rückte nach einigen Monaten von den anfänglichen Vorschlägen Andrées ab. Problematisch an diesen Vorschlägen sei unter anderem die Tatsache, dass die Helden „utländingar“ („Ausländer“) seien der Wunsch der Operndirektion nach „vaterländischen Themen“ klingt insofern deutlich mit. Stattdessen schlägt Lagerlöf „Frithiofs saga" als Vorlage vor (offensichtlich auch als Gegenvorschlag in der Frage des „Vaterländischen“). Schon von Beginn an unterstreicht die Librettistin, dass „mycket stora afvikelser“ („sehr große Abweichungen“) von Tegnérs Vorlage vonnöten seien, dass dieser Stoff aber den Vorteil eines Vorwissens beim Publikum hätte (Brief von Lagerlöf an Andrée, 11.7.1894). Das Libretto war im Oktober 1894 im Großen und Ganzen abgeschlossen, wenn Andrée auch danach noch Textänderungen von ihrer Librettistin verlangte; die Atmosphäre im Briefwechsel ist häufig gespannt.

Die sehr umfassende Oper (berechnete Spielzeit: fünfeinhalb Stunden, vgl. Öhrström 1999: 269) lag im Dezember 1895 in Partitur fertig vor und wurde rechtzeitig als anonymer Beitrag zum Wettbewerb eingereicht. Der Wettbewerb erwies sich, als vierzehn Monate später das Ergebnis verkündet wurde, als ein großer Misserfolg für Andrée und Lagerlöf; übrigens wurde am Ende keiner der eingereichten Beiträge für die Einweihung des Opernhauses ausgewählt. 1899 erfolgte eine Aufführung in privatem Rahmen (vgl. Öhrström 1999: 263-265). Im selben Jahr erschien ein Textauszug, in dem Teile des Dialoges wiedergegeben werden, die von epischen Abschnitten unterbrochen waren, in denen die Handlung summarisch nacherzählt wurde. Sieben Jahre später hegte Andrée immer noch die Hoffnung, ihre Oper einmal 
szenisch aufgeführt zu sehen, und hatte sich in diesem Zusammenhang dafür entschieden, den dritten Akt in seiner Gänze zu tilgen, wie aus einem ihrer letzten Briefe an Lagerlöf hervorgeht (Brief von Andrée an Lagerlöf, 27.12.1906); danach bricht der Kontakt vollständig ab.

\section{Tegnér und Lagerlöf - von Frithiof zu Fritiof ${ }^{10}$}

Die folgende Analyse bezieht sich auf die Reinschrift (fremde Handschrift, ${ }^{11}$ Lagerlöf o. J.) im Selma Lagerlöf-Archiv der Königlichen Bibliothek Stockholm. Auf den gedruckten Textauszug, der zwischen einer rein epischen und einer dramatischen Darstellungsweise wechselt, soll wegen seiner vom eigentlichen Libretto abweichenden textuellen Eigenschaften in diesem Zusammenhang nur sporadisch eingegangen werden. Dasselbe betrifft auch die Partitur Elfrida Andrées.

Im Folgenden stehen das Libretto Selma Lagerlöfs und dessen Verhältnis zur Tegnér'schen Vorlage im Zentrum. Motivisch ist ein Grundzug in Lagerlöfs CEuvre erkennbar, der sich mit Tegnérs Text trifft, und zwar der Motivkomplex Schuld-Strafe-Versöhnung, auch wenn sich hier teilweise andere Akzente als bei Tegnér finden. Auf der Ebene der sprachlichen Gestaltung versucht Lagerlöf auf verschiedenen Wegen, den Bekanntheitsgrad und die Beliebtheit ihrer Vorlage auszunutzen. Mehrmals kommen in den Repliken direkte Zitate aus Tegnérs Text vor, obwohl jene Zitate zuweilen in etwas andere Kontexte eingebunden sind. Wegen seines hohen Anteils an Figurenrede in Form von Monologen und Dialogen ist Tegnérs „Frithiofs saga“ ein recht dankbarer Gegenstand für eine Dramatisierung. Gelegentlich kommen Tegnér-Zitate sogar in den Bühnen- und Spielanweisungen vor, wo Lagerlöf die entsprechenden Stellen auch durch Anführungszeichen markiert. Neben diesen wörtlichen Übernahmen hat Lagerlöf jedoch auch, was den Handlungsverlauf und die dramatis personae betrifft, recht große Verschiebungen vorgenommen.

\footnotetext{
${ }^{10}$ Für einige wichtige Hinweise und Anregungen zu diesem Teil des Aufsatzes danke ich den Teilnehmern des skandinavistischen Oberseminars an der Universität Tartu.

${ }^{11}$ In Briefen an Andrée spricht Lagerlöf von der Reinschrift eines Freundes bzw. einer Freundin, erwähnt aber keinen Namen (Briefe von Lagerlöf an Andrée, 15.3.1895 und 5.10.1895). Es findet sich im Lagerlöf-Archiv auch eine Handschrift des ersten Aktes von Selma Lagerlöf selbst.
} 
So wird der Anfang der Geschichte ausgeklammert, ${ }^{12}$ und mit Ausnahme der wörtlichen Übernahme von einem Teil des IX. Gedichts „Ingeborgs Klagan“ („Ingeborg’s Klage“"13) besteht der größte Teil des ersten Aktes aus Handlungsmomenten, die, wenn sie bei Tegnér überhaupt vorkommen, bei ihm lediglich wiedererzählt werden (im XII. Gedicht, „Frithiofs Återkomst“, „Frithiofs Rückkehr“). Im zweiten Akt ist das Gerüst der Handlung aus dem XIII. Gedicht, „Balders Bål“ („Baldurs Tempelbrand“), und dem XIV. Gedicht, „Frithiof går i landsflykt“ („Frithiof landflüchtig“), zusammengesetzt, jedoch mit weiteren Elementen angereichert. Der dritte, in Griechenland spielende, Akt stellt einen sehr kräftigen Ausbau von wenigen Strophen aus Tegnérs XV. Gedicht, „Vikingabalk“ („Wikinger Recht“), dar. Der vierte Akt schließlich verkürzt den Zeitverlauf zwischen Fritiofs Rückkehr (im XVII. Gedicht) und Rings Tod (im XX. Gedicht) radikal und baut zudem einen bei Tegnér zumindest in dieser Weise nicht vorhandenen Mordanschlag ein.

Die Ausgangssituation der eigentlichen Bühnenhandlung in der ersten Szene des ersten Aktes ist ein Zustand der Abwesenheit: Fritiof ist weggereist und hat Ingeborg zurückgelassen. Erst im zweiten Akt tritt der Titelheld in eigener Person auf. Das Motiv der Abwesenheit vom eigentlichen Wohn- oder Bestimmungsort und/oder der Sehnsucht bei den Zurückgelassenen findet sich häufig in Lagerlöfs Werk: Im größten Teil der Handlung von „Gösta Berlings saga“ ist die Majorin, die frühere Leiterin des Hofes Ekeby und Schutzpatronin der „Kavaliere“, von eben diesem Hof vertrieben. „En herrgårdssägen“ (dt. Titel: „Eine Gutsgeschichte“) verbindet die Geschichte vom unsteten und unglücklichen Leben des wahnsinnigen Gunnar Hede mit der Geschichte einer sich seit vielen Jahren nach ihm sehnenden Ingrid. Der Roman „Kejsarn av Portugallien“ (dt.: „Der Kaiser von Portugallien“) schildert, wie die Sehnsucht des zurückgelassenen Vaters nach der geliebten Tochter zu schweren Wahnvorstellungen führt.

\footnotetext{
${ }^{12}$ Einige prägnante Szenen daraus sollen jedoch - so die ursprüngliche Handschrift Lagerlöfs, ein handschriftlicher Zusatz zum Typoskript und die Partitur - in jeweils kurzen Tableaus während der Ouvertüre gezeigt werden.

13 Die deutschsprachigen Titel der einzelnen Gedichte sind der ersten deutschen Übersetzung (Tegnér 1826) entnommen.
} 
Auffällig ist auch der umfangreiche Ausbau eines bei Tegnér quantitativ unbedeutenden Handlungsmoments: Im XXIV. und letzten Gedicht, „Försoningen“ („Die Versöhnung“), wird König Helges Tod im Tempel des Finnengottes Jumala bei Tegnér kurz geschildert. Es handelt sich um eine vereinzelte und zudem feindselige Begegnung Helges mit Jumala, und ein Glaubenskonflikt zwischen dem Asa-Glauben und der finnischen Volksreligion ist hiermit lediglich angedeutet. Durch die Einführung der Figur der Gautemi, ${ }^{14}$ Tochter der „Finnenkönige“ und Gattin Helges, hat Lagerlöf den Glaubenskonflikt und den damit verbundenen nationalen Konflikt in den Mittelpunkt ihres Textes gestellt. Gautemis nationale Identität ist nicht eindeutig: Auf das Samische weisen einige Elemente hin, wie etwa „fjällen“ (hohe Berge im heutigen Grenzgebiet zwischen Schweden und Norwegen), ihre Kleidung „brokigt klädd och rikt smyckad“ (Lagerlöf o. J.: I/4, dt.: „bunt gekleidet und reich geschmückt“); „lapp-pels [...], silfverbälte och näfverskor“ (Lagerlöf o. J.: IV/6, dt.: ,lappländischer Pelzmantel, Silbergürtel und Schuhe aus Birkenrinde“, IV/6) - und auch das an sie gerichtete Schimpfwort „finnmarkshäxa“ (dt.: „Finnmarkshexe“), das an das norwegische, nach der Ursprungsbevölkerung der Samen genannte „Finnmark“ anknüpft. Im älteren norwegischen Sprachgebrauch heißt „finne“ nicht wie heutzutage „Finne“, sondern „Same“. Gleichzeitig ist "Jumala" bei Lagerlöf wie auch bei Tegnér ein Hinweis auf den finnischen Volksglauben, sodass Gautemi sowohl samische als auch finnische Züge aufweist.

Der erste Akt wird durch die berühmteste weibliche Figurenrede aus „Frithiofs saga“, „Ingeborgs Klagan“ (das IX. Gedicht bei Tegnér, hier in verkürzter Form) eingeleitet. Damit zeichnet sich eine Tendenz ab, die das ganze Libretto prägt. Im ganzen ersten Akt ist der Titelheld abwesend. Stattdessen nimmt die bei Tegnér recht blass gezeichnete Ingeborg eine wichtige Rolle ein: Ingeborg handelt aktiv, sowohl wenn sie ihre Schwägerin Gautemi in der zweiten Szene des ersten Aktes befreit, als auch wenn sie dieselbe Gautemi in der letzten Szene des ersten

\footnotetext{
${ }^{14}$ Diese Schreibweise kommt in der im Lagerlöf-Archiv aufbewahrten Reinschrift sowie im gedruckten Textauszug (bis auf zwei dortige Satz- bzw. Druckfehler) sowie in den Briefen Lagerlöfs vor. Im Typoskript aus dem Andrée-Archiv findet sich jedoch durchgängig der Name „Gantemi“, in Partitur und in Briefen Andrées auch die Schreibweise „Guatemi“, die auch Öhrström in ihrer Andrée-Biographie übernimmt.
} 
Aktes verbal angreift und damit ihrer eigenen Ehrlosigkeit entkommt. Von großem Gewicht ist die Einführung der von Lagerlöf erfundenen Gestalt der Gautemi. Auch ein weibliches Kollektiv tritt in diesem Akt auf: die Frauen, die in der zweiten Szene Gautemi (ihre Königin!) gefangen genommen und gefesselt haben.

Gautemi erweist sich bereits im ersten Akt als eine der zentralen Figuren im Libretto. An mehreren entscheidenden Stellen ist sie es, die die Handlung durch ihre Taten vorantreibt. Sie versucht anfangs aus Sympathie für ihre Schwägerin Ingeborg, diese vor der Heirat mit König Ring zu retten, was ihr allerdings schändlich misslingt: Sie provoziert damit eine Auseinandersetzung, die den anwesenden künftigen Gatten Ingeborgs, Ring, sehr verwundert. Gautemi entblößt dann auch noch die ganze Geschichte von Fritiof und Ingeborg, was Ingeborg sofort als verheerend auffasst:

Så var det du mig hjälpte, o Gautemi!

$\mathrm{Nu}$ är jag fri, Nu jublar du, fjällens dotter.

Förstår du ej, du mörka, att du mig lämnar

Förkastad och utan heder?

(Lagerlöf o. J.: I/12; dt.: „So hast du mir geholfen, o Gautemi! / Nun bin ich frei, nun jubelst du, Tochter der Berge, / Verstehst du nicht, du Dunkle, dass du mich lässt / Verworfen und ohne Ehre?“)

Angesichts des Risikos, die „oskuldshvita“ (Lagerlöf o. J.: I/12; „unschuldsweiße“) Ingeborg als eine Ehrlose zu verwerfen, sieht sich Ring verpflichtet, sie zu heiraten. Das tut er aber mit dem ausdrücklichen Hinweis auf „en listig kvinna“, die „snärjt oss båda“ (Lagerlöf o. J.: I/12; dt.: „eine verschlagene Frau“; „uns beide umgarnt“).

Im zweiten Akt gibt es noch weitere weibliche Kollektive, etwa die Hexen im Jumala-Kult sowie eine Gruppe von Frauen, die das Baldersfest feiern. Von den auftretenden Männern erscheint König Helge auch noch als ein schwacher Charakter, indem er durchweg dem Willen seiner Frau Gautemi folgt.

In jenem zweiten Akt hat Fritiof dann seinen ersten Auftritt, und zwar im Balderstempel, wo sich die Auseinandersetzung mit Helge ähnlich wie bei Tegnér abspielt. Allerdings geht dem Auftritt Fritiofs eine neu erfundene Szene zuvor, die den Kontext verschiebt. Unterstützt durch die Balderspriester (!) und Hexen ersetzen Helge und Gautemi das 
Standbild von Balder durch ein neues, das von Gautemis Gott Jumala. Allerdings geschieht alles im Geheimen. Danach, in einer Art Arie, stellt Gautemi die Gründe ihrer Bosheit dar. Sie sagt, sie dürfe, obwohl sie jung sei, nicht dabei sein, wenn gefeiert und getanzt wird, und selbst ihr gut gemeinter Versuch, Ingeborg vor der Heirat mit Ring zu retten, sei schlecht aufgenommen worden:

Så snart jag mig närmar, tages jag mot

Med hån och hot

Därför sitter jag här bland häxor och troll

Och närer mitt groll.

(Lagerlöf o. J.: II/4; dt.: „Sobald ich mich nähere, werde ich empfangen / Mit Hohn und Drohungen, / Deshalb sitze ich hier unter Hexen und Ungeheuern / Und nähre meinen Groll.“)

Das darauffolgende Handlungsmoment, als Fritiof in den Tempel eindringt und Helge angreift, sowie auch (wortgetreu) Fritiofs Repliken, hat Lagerlöf von Tegnér übernommen. Es ist jedoch nicht wie bei Tegnér das Balder-Standbild, sondern das Standbild des fremden Gottes Jumala, das Fritiof am Ende zerstört. Relevant für die Schuldfrage wird somit, dass Fritiof durch Unachtsamkeit nicht den geweihten Ort des ureigenen nationalen Glaubens vernichtet hat, sondern unbewusst den eines fremden Glaubens.

In der Szene selbst wird mehrfach daran erinnert. Zwischen den von Tegnér wörtlich entlehnten Strophen Fritiofs sagt Helge: „En svag, föraktlig gud är Asa Balder“ (Lagerlöf o. J.: II/5; dt.: „Ein schwacher, verachtenswerter Gott ist Asa Balder“) oder rufen die Hexen Jumala an.

Im dritten, im christlichen Griechenland spielenden, Akt ist die griechische Prinzessin Agnes von erheblicher Bedeutung, auch für das Gesamtgeschehen. Schon bei Tegnér führt der Besuch in Griechenland einen Gesinnungswechsel bei Frithiof herbei; die spezifische Ursache, dass eine ihn liebende Frau wegen seiner Verwüstungen ums Leben kommt, stammt jedoch von Lagerlöf.

Wie häufig in Lagerlöfs Euvre findet sich in der Gestalt der Agnes eine Frau, deren Opfer (in diesem Fall durch den Tod) und Liebe zu einem männlichen Protagonisten dessen Lebenseinstellung verändert; Parallelen ließen sich unter anderem zu Edit in „Körkarlen“ (dt. Titel: „Der 
Fuhrmann des Todes“) oder Ingrid in „En herrgårdssägen“ (dt. Titel: „Eine Gutsgeschichte“) ziehen.

Im vierten Akt hat Lagerlöf das Geschehen um die Rückkehr Fritiofs und den Tod Rings zeitlich konzentriert, aber durch den von der anwesenden Gautemi veranstalteten Mordanschlag gegen Ring, den Fritiof im Streit gegen seinen eigenen Waffenbruder Björn abwehrt, dramatisch zugespitzt.

Insgesamt ist dem Libretto somit eine deutliche Konzentration auf weibliche Schicksale und Taten eigen, was es von der männlich dominierten Handlung bei Tegnér deutlich abhebt. ${ }^{15}$ Diese Akzentverschiebung ist in den zeit- und literarhistorischen Kontext einzugliedern, in die zunehmende Diskussion um die gesellschaftliche Rolle der Frau seit Mill und Ibsen sowie den Autorinnen der schwedischsprachigen 1880er Jahre, einer Entwicklung, an der auch Lagerlöf und Andrée teilhatten.

Am bemerkenswertesten unter den Zusätzen Lagerlöfs ist die Gestalt der Gautemi. Erstens ist sie eine tatkräftige Frau, und ihre Rolle im Libretto unterstreicht deutlich die Akzentverschiebung gegenüber Tegnér, namentlich dass bei Lagerlöf die Frauen im Mittelpunkt stehen. Zweitens verkörpert sie den Glaubenskonflikt, der als neues zentrales Element im Libretto gegenüber Tegnérs Vorlage hinzukommt. Durch diesen Glaubenskonflikt verändert sich auch die Schuldfrage in Bezug auf das Verbrechen Fritiofs gegen Balder. Fritiof erfährt im vierten Akt - gerade durch die durchgängig etwas vorlaute Gautemi das dem Rezipienten bereits Bekannte: Er hat bei der Auseinandersetzung mit Helge im zweiten Akt gar nicht das Balder-Standbild, sondern ein Jumala-Standbild zerstört und ist deswegen schuldfrei. Der mit Gautemi verbundene Glaubenskonflikt vereinfacht die bei Tegnér recht verwickelte Schuldfrage und die Einteilung in Gut und Böse. Durch die Hinzufügung eines neuen, sichtbaren Hintergrunds wird die Intrige in diesem Teil also paradoxerweise vereinfacht; eine Konzentration auf

15 Lagerlöfs Libretto könnte man in dieser Hinsicht mit anderen „Nationalepen“ vergleichen, in denen weibliche Figuren einen hervorragenden Platz einnehmen. Beispiele wären etwa die Figur der Babička in Božena Němcovás gleichnamigem Roman oder die Nibelungen-Rezeption bei Heiner Müller, bei der die Kriemhild-Figur gegenüber den männlichen Heldentypen des mittelalterlichen Epos deutlich aufgewertet wird. S. zum Aspekt des Gendering von Nationalepen die Beiträge von Zuzana Stolz-Hladka, Torsten Hoffmann und Eve Pormeister in diesem Band. 
das Sichtbare erscheint auch als ein Gattungsmerkmal des Opernlibrettos.

Mit der Einführung eines Glaubenskonflikts hängt auch Gautemis Funktion als Vertreterin der Fremde zusammen. Durch die bereits erwähnten exotischen Merkmale wird sie als ein fremdes, bedrohliches Element gezeichnet und ist als solches ein wichtiger Gegenpol, um den gewünschten „vaterländischen“ Geist des Werkes zu untermauern.

Gautemi erscheint als Vertreterin zweier Kulturen, der samischen und der finnischen. Am deutlichsten ist die samische Identität. Hier wird auf das alte Bild von den Samen als fremdartigen, bösen Zauberern Bezug genommen, welches bereits in der altnordischen Literatur verankert ist.

Die finnische Seite von Gautemi könnte noch auf eine andere Weise erklärt werden. In den 1880er und 1890er Jahren wurden in Stockholm das verstärkt russisch geprägte Finnland, die tatsächlich aggressive fennomanische Agitation auf schwedischem Boden und selbst die finnischsprachige Bevölkerung in Nordostschweden als sicherheitspolitische Bedrohungen aufgefasst, Bedrohungen, die neue militärische Strategien Schwedens zur Folge hatten (vgl. Elenius 2001: 131-134). Möglicherweise lässt sich die finnische Konnotation von Gautemi, die im größten Teil des Librettos tatsächlich als eine Bedrohung des Vaterlandes erscheint, auch durch diesen zeitgeschichtlichen Kontext erklären. Auf jeden Fall ist die Diskussion um die Darstellung von Samen und Finnen bei Lagerlöf (vgl. zu dieser Problematik Elenius 2005) zu ergänzen und zu differenzieren.

Bei der Einreichung des Werkes zum Wettbewerb wählte Lagerlöf als Motto ein Zitat aus einem weiteren Gedicht Tegnérs, "Jätten“ (1813; dt. „Der Riese“). Das Motto lautet: „Det onda är odödligt liksom det goda“ (Brief von Lagerlöf an Andrée, 5.10.1895; dt.: „Das Böse ist unsterblich so wie das Gute“; vgl. die entsprechende Stelle in Tegnér 1968: 98 und auch eine ähnliche Passage im Libretto, Lagerlöf o. J.: II/13). Dieses Motto weist sehr stark in die Richtung von Gautemi als einer zentralen Gestalt im Libretto, als einer Projektionsgestalt des Bösen. Interessant ist die Wahl gerade von "Jätten“ in diesem Zusammenhang, da dieses Rollengedicht ebenfalls im Kontext des Asa-Glaubens spielt; das lyrische 
Ich ist ein Riese, ein Feind der Asa-Götter, der Skalden und der Menschen, der in bösen Taten Befriedigung findet.

Gautemis Bosheit ähnelt der des Riesen, ist von Lagerlöf jedoch auch psychologisch erklärt worden; sie fühlt sich ausgestoßen, und es handelt sich daher auch um eine Außenseiterproblematik, die ebenfalls bei Lagerlöf, aber vor allem bei ihrem Dichterkollegen Gustaf Fröding zu einem häufigen und bedeutsamen Motiv der schwedischsprachigen 1890er Jahre wurde.

Am allerwichtigsten ist Gautemis dramaturgische Funktion als Katalysator für die verschiedenen zum Teil neu hinzugekommenen dramatischen Handlungsabläufe und Verwicklungen, die gerade in einer Dramatisierung und insbesondere bei einer Bearbeitung für die Opernbühne mit einbezogen und sichtbar gemacht werden müssen. Gautemi ist somit eine Figur, die im Libretto Lagerlöfs gleich mehrere essentielle Funktionen erfüllt.

In der Zeit nach der intensiven Arbeit am Libretto, im Jahr 1895, erwähnt Lagerlöf in einem Brief an ihre Freundin Sophie Elkan ganz nebenbei, sie sei (unter anderen Dichtern auch) Tegnér „entwachsen“ (Lagerlöf 1993: 52). ${ }^{16}$ Zeichen dafür finden sich zwar schon davor, doch möglicherweise war auch die Librettisierung von „Frithiofs saga“ an diesem Prozess beteiligt. In diesem Fall war das Libretto gewiss nicht ohne Bedeutung für Lagerlöfs weiteres Schaffen, und in der Entwicklung von der Vergötterung in ihrer Kindheit über die intensive Auseinandersetzung bis hin zur Verwerfung scheint Lagerlöf nicht allein zu sein; ebenso lässt sich auch die spätere Entwicklung der Tegnér-Rezeption im Allgemeinen, insbesondere die seines Nationalepos, beschreiben.

\footnotetext{
${ }^{16}$ Im Orig.: ,vuxit ifrån“.
} 


\section{Literaturverzeichnis}

\section{Primärliteratur}

\section{Ungedruckte Primärliteratur}

ANDREE [sic], Elfrida (o. J.): Fritiofs saga. Opera i fyra akter. Musik af - . Text. På grundval av Tegnérs dikt och med delvis bibehållande af hans ord utarbetad af Selma Lagerlöf [Frithiofs Saga. Oper in vier Akten. Musik von - Text. Auf der Grundlage des Tegnér'schen Gedichts und unter teilweiser Beibehaltung seiner Worte ausgearbeitet von Selma Lagerlöf]. [Typoskript; AndréeStenhammar-arkivet, Statens musiksamlingar, Stockholm, Kp. 12:1].

ANDRÉE, Elfrida (1894-1906): [Briefe an Selma Lagerlöf. Kungliga Biblioteket, Stockholm, Ep L 45].

ANDRÉE, Elfrida (o. J.): Fritiofs saga. Opera i fyra akter af Elfrida Andrée [Fritiofs Saga. Oper in vier Akten von Elfrida Andrée]. [Handschriftliche Partitur in drei Bänden; Andrée-Stenhammar-arkivet, Statens musiksamlingar, Stockholm, Kp. 12:1].

LAGERLÖF, Selma (o. J.): Fritiofs saga [Handschriftliche Reinschrift mit Änderungen und Korrekturen; Selma Lagerlöfs samling, Kungliga Biblioteket, Stockholm, L 1:10].

LAGERLÖF, Selma (1894-1906): [Briefe an Elfrida Andrée. Originale in AndréeStenhammar-arkivet, Statens musiksamlingar, Stockholm; durchgesehen in Fotokopie in Kungliga Biblioteket, Stockholm, Ep L 45].

\section{Gedruckte Primärliteratur}

ANDrÉE, E. /Selma LAGERLÖF (1899): Textutdrag till Operan Fritiofs Saga. Utarbetad på grundval af Tegnérs dikt och med delvis bibehållande af hans ord [Textauszug zur Oper Fritiofs Saga. Ausgearbeitet auf der Grundlage des Tegnér'schen Gedichts und unter teilweiser Beibehaltung seiner Worte]. Göteborg.

K. OPERANS DIREKTION (1894): En täflingsinbjudan [Eine Einladung zu einem Wettbewerb]. In: Svensk musiktidning 14, H. 2, S. $14 \mathrm{f}$.

LAGERLÖF, Selma (1922): Mårbacka. Stockholm.

LAGERLÖF, Selma (1923): Mårbacka. Jugend-Erinnerungen. Einzige berechtigte Übersetzung aus dem Schwedischen von Pauline Klaiber-Gottschau. München.

LAGERLÖF, Selma (1993): Du lär mig att bli fri: Selma Lagerlöf skriver till Sophie Elkan. Urval och kommentarer av Ying Toijer-Nilsson [Du lehrst mich, frei zu werden: Selma Lagerlöf schreibt an Sophie Elkan. Auswahl und Kommentare von Ying Toijer-Nilsson]. Stockholm [1992].

Tegnér, Esaias (1826): Die Frithiofs-Sage. Aus dem Schwedischen übersetzt von Amalie von Helvig, geborner Freiin von Imhoff. Stuttgart/Tübingen. 
Tegnér, Esaias (1968): Samlade dikter. Utgivna av Tegnérsamfundet. II. 18091816. Redigerad av Fredrik Böök och Åke K. G. Lundquist [Gesammelte Gedichte. Herausgegeben von der Tegnér-Gesellschaft. II. 1809 -1816. Ediert von Fredrik Böök und Åke K. G. Lundquist]. Lund.

TEGnér, Esaias (1986): Samlade dikter. Utgivna av Tegnérsamfundet. IV. Frithiofs saga. 1825. Redigerad av Åke K. G. Lundquist [Gesammelte Gedichte. Herausgegeben von der Tegnér-Gesellschaft. IV. Frithiofs Saga. 1825. Ediert von Åke K. G. Lundquist]. Lund.

\section{Sekundärliteratur}

Beıjвом, Ulf (1996): Tegnér och Amerika. [Tegnér und Amerika.] In: Marian Ullén (Hrsg.) (1996): Under det höga valvet. En Tegnérbok sammanställd av Smålands Akademi [Unter dem hohen Gewölbe. Ein Tegnér-Buch zusammengestellt durch die Småländische Akademie]. Stockholm, S. 156-184.

BRennecke, Detlef (1983): Är Tegnér en humbug? Den svenske klassikern i nutida författaropinion [Ist Tegnér ein Humbug? Der schwedische Klassiker in der Meinung gegenwärtiger Autoren]. In: Tegnérsamfundet (Hrsg.) (1983): Tegnérbildens förvandlingar: Föreläsningar hållna vid Tegnérsymposiet $i$ Lund 11-13 november 1982 [Verwandlungen des Tegnér-Bildes: Vorlesungen gehalten am Tegnér-Symposion in Lund 11.-13. November 1982]. Lund, S. 116-144.

EDSTRÖM, Vivi (2002): Selma Lagerlöf: Livets vågspel [Selma Lagerlöf. Das Wagnis des Lebens]. Stockholm.

ELAM, Ingrid (1999): Esaias Tegnér - klassicist och nationalskald [Esaias Tegnér - Klassizist und Nationalskalde]. In: Lönnroth, Lars/Sven Delblanc (Hrsg.) (1999) [1987/1988]: Den svenska litteraturen 1: Från runor till romantik. 800-1830 [Die schwedische Literatur 1: Von Runen zur Romantik. 8001830]. Stockholm, S. 549-573.

Elenius, Lars (2001): Både finsk och svensk. Modernisering, nationalism och språkförändring $i$ Tornedalen 1850-1939 [Finnisch und schwedisch zugleich. Modernisierung, Nationalismus und Sprachveränderung in Tornedalen 1850-1939]. Umeå [Diss. Universität Umeå].

ELENIUS, Lars (2005): Selma Lagerlöf och Norrland [Selma Lagerlöf und Norrland]. In: Maria Karlsson / Louise Vinge (Hrsg.) (2005): I Selma Lagerlöfs värld. Fjorton uppsatser [In Selma Lagerlöfs Welt. Vierzehn Aufsätze]. Stockholm/Stehag, S. 182-209.

Gustafsson, Magnus (1991): Esaias Tegnér: Fritiofs [sic] saga. Musik i omvandling... [Esaias Tegnér: Fritiofs [sic] Saga. Musik in Umwandlung...]. In: Musikrevy 46, H. 4, S. 211-213. 
HÄGG, Göran (1996): Den svenska litteraturhistorien [Die schwedische Literaturgeschichte]. Stockholm.

Harvey, Anne-Charlotte (1995): The First Swede in Worcester. In: The Swedish American Historical Quarterly 46, H. 1, S. 75-92.

HoLm, Birgitta (1984): Selma Lagerlöf och ursprungets roman. Romanens mödrar 2 [Selma Lagerlöf und der Roman des Ursprungs. Die Mütter des Romans 2]. Stockholm.

LÖNnRoth, Lars/Sven Delblanc (Hrsg.) (1999) [1987/1988]: Den svenska litteraturen 1: Från runor till romantik. 800-1830 [Die schwedische Literatur 1: Von Runen zur Romantik. 800-1830]. Stockholm.

LÖNNROTH, Lars (2001): Tegnér och det nordiskt sublima [Tegnér und das Nordisch-Sublime]. Lund.

LuNDQUisT, Åke K. G. (1986): Vägen till Frithiofs saga [Der Weg zu Frithiofs Saga]. In: Esaias Tegnér (1986): Samlade dikter. Utgivna av Tegnérsamfundet. IV. Frithiofs saga. 1825. Redigerad av Åke K. G. Lundquist [Gesammelte Gedichte. Herausgegeben von der Tegnér-Gesellschaft. IV. Frithiofs Saga. 1825. Ediert von Åke K. G. Lundquist]. Lund, S. 153-186.

NORDENFORS, Ola (2008): Adaptationer av Esaias Tegnérs Frithiofs saga [Adaptionen von Esaias Tegnérs Frithiofs Saga]. In: Clas Zilliacus (Hrsg.) (2008): Gränser i nordisk litteratur. Borders in Nordic Literature. IASS XXVI 2006. Vol. 1. Åbo, S. 197-208.

ÖHrström, Eva (1999): Elfrida Andrée: Ett levnadsöde [Elfrida Andrée: Ein Lebensschicksal]. Stockholm.

Olsson, Berndt/Ingemar Algulin (1987): Litteraturens historia $i$ Sverige [Geschichte der Literatur in Schweden]. Stockholm.

SCHÜCK, Henrik/Karl WARBURG (1929): Illustrerad svensk litteraturhistoria. Tredje, fullständigt omarbetade upplagan utgiven av Henrik Schück. Femte delen: Romantiken [Illustrierte schwedische Literaturgeschichte. Dritte, völlig überarbeitete Auflage, hrsg. v. Henrik Schück. Fünfter Teil: Die Romantik]. Stockholm.

SCHÜCK, Henrik/Karl WARBURG (1930): Illustrerad svensk litteraturhistoria. Tredje, fullständigt omarbetade upplagan utgiven av Henrik Schück. Sjätte delen: Efterromantiken [Illustrierte schwedische Literaturgeschichte. Dritte, völlig überarbeitete Auflage, hrsg. v. Henrik Schück. Sechster Teil: Die Nachromantik]. Stockholm.

WÄGNER, Elin (1958) [1942/1943]: Selma Lagerlöf. Stockholm.

Wingborg, Olle (1996): Vem läser Tegnér? [Wer liest Tegnér?] In: Marian Ullén (Hrsg.) (1996): Under det höga valvet. En Tegnérbok sammanställd av Smålands Akademi [Unter dem hohen Gewölbe. Ein Tegnér-Buch zusammengestellt durch die Småländische Akademie]. Stockholm, S. 231-241. 


\section{Identitätskonstruktionen in der tschechischen Literatur des 19. Jahrhunderts. Der Entwurf einer nationalen Identität durch Sprache und Literatur}

Vergeblich sucht man in der tschechischen Literatur nach einem Nationalepos. Seit dem 14. Jahrhundert existieren zwar lyrische Gedichte, Satiren, Chroniken, Heiligenviten und lehrhafte Dichtungen, nicht aber ein eigenes Epos. Sein Fehlen wurde besonders dann als schwerer Mangel empfunden, als die „einheitsstiftende Funktion“ (Spörl 2006: 289) des Epos im Rahmen des tschechischen Nationsbildungsprozesses zum Entwurf einer nationalen Identität gebraucht wurde. Das Vakuum erzeugte eine Situation, die Josef Bysveen als die Notwendigkeit eines Epos (,the need for an epic“ Bysveen 1982: 51) bezeichnet hat. Den Versuch, ein (fragmentarisches) Epos nachträglich entstehen zu lassen, stellen in der tschechischen Kultur die gefälschten Manuskripte RK (Rukopis Královédvorský / Königinhofer Handschrift) und RZ (Rukopis Zelenohorský / Grünberger Handschrift) aus den Jahren 1817 und 1818 dar. Nebst lyrischen Dichtungen enthalten sie Fragmente von Heldenliedern. Hinsichtlich ihrer Echtheit werden sie in Fachkreisen vereinzelt bereits kurz nach ihrem Auftauchen angezweifelt, wirken aber in der tschechischen Kunst, Literatur, Musik und Architektur teilweise bis ins 20. Jahrhundert fort. Vor allem die im Manuskript RZ enthaltene Darstellung der legendären Stammesfürstin Libuše als einer Recht sprechenden Herrscherin wird in grundlegenden Texten der tschechischen Literatur, die in der Mitte des 19. Jahrhunderts folgen, übernommen und in Variationen ausgebaut. Zwei Texte, die als „Basistexte“ der tschechischen Literatur gelten, übernehmen die für das Epos typische Funktion, an die gemeinsame Vergangenheit sowie die eigenen Werte einer Gemeinschaft sprachlich wohlgestaltet zu erinnern. Sie füllen jene Leerstelle aus, die durch das Fehlen eines eigenen Nationalepos entstanden ist. Diese zwei in Vers und Prosa verfassten „Ersatzepen“ bauen den Ursprungsmythos einer weisen „Urmutter“ aus, unterlegen ihn mit dem biblischen Schöpfungsmythos und rei- 
chern ihn mit einem „tschechischen“ Wertekatalog an. Beide Texte wirken identitätskonstitutiv und epossubstituierend. Heute gehören sie zu den Grundfesten des tschechischen literarischen Kanons. Der Sprechakt der Urahnin wird in ihnen zum Schöpfungsakt der tschechischen Kulturgemeinschaft mit eigenen Werten und einer eigenen, schriftlich festgehaltenen Identität. Sprache und Literatur werden in ihnen identitäts- und kulturstiftend eingesetzt und dienen der Konstruktion einer Wunschwirklichkeit, gemäß der die ihr folgende Realität geformt werden soll.

Den Wertekatalog der tschechischen Sprachgemeinschaft soll im Folgenden die Analyse des bisher kaum beachteten Gedichtes "Slovo české“ von František Šír zeigen. Anschließend werden der Prosatext „Babička“ (1855) von Božena Němcová und das Gedicht „Kytice“ (1853) aus der gleichnamigen lyrischen Sammlung von Karel Jaromír Erben in ihrer Funktion als epossubstituierende Basistexte untersucht.

\section{„Slovo české“ (Das tschechische Wort)}

Die tschechische Kultur ist eng mit der tschechischen Sprache verbunden. Am deutlichsten manifestiert sich dieser Zusammenhang im 19. Jahrhundert - dem Jahrhundert, das die Grundlagen der modernen tschechischen Kultur geschaffen hat. Das 19. Jahrhundert wird in der tschechischen Literaturgeschichte, aber auch in der tschechischen Geschichtsschreibung, mit der so genannten Nationalen Wiedergeburt, dem „Obrození“ eingeläutet. ${ }^{1}$ Die Hauptphase der Wiedergeburt wird mehrheitlich in der ersten Hälfte des 19. Jahrhunderts angenommen. Der tschechische Literaturwissenschaftler Vladimír Macura hat in seinen kultursemiotischen Studien das historische Phänomen der Wiedergeburt als einen Kulturtyp mit einer eigenen Ästhetik definiert (vgl. Macura 1995 und 1998). Insbesondere

\footnotetext{
1 Tomáš Garrigue Masaryk, Historiker, Philosoph und erster Präsident der Tschechoslowakei, führte diesen Begriff in seiner Schrift „Česká otázka“ ein. (Vgl. Masaryk 1895) Er diskutiert in seinem Buch die historisch-kulturellen Gründe, die die tschechische Sprachgemeinschaft dazu geführt haben, sich als eine eigenständige Nation wahrzunehmen. Danach wurde die Bezeichnung „Obrození“ von den Literaturhistorikern J. Vlček und A. Novák übernommen (vgl. Stich 1998: 175).
} 
hebt er den metasprachlichen Charakter der tschechischen Kultur der Wiedergeburt hervor (vgl. Macura 1995: 57).

Von Feststellungen Macuras ausgehend wähle ich, um den Wertekatalog jener Zeit zu eruieren, einen literarischen Text, der die Sprache selbst zum Thema hat. Er müsste in besonderem Maße Aussagen zur Ästhetik enthalten. Kaum ein anderer literarischer Text der Wiedergeburt zählt die Eigenschaften der tschechischen Sprache prägnanter auf als das Gedicht „Slovo české“ („Tschechisches Wort“) von František Šír (1796-1867), das dem Band „Lyrika Českého obrození (17501850)“ vorangestellt ist (vgl. Jirát 1940). In höchsten Tönen wird darin das tschechische Wort gepriesen:

Krásně slovo české zní!

Slov líbeznost slovenčiných vezdy v závisti jest jiných; krásně slovo české zní! Sladce slovo české zní! $\mathrm{Z}$ úst dívky když se rozvine,

sladkostí jen co med plyne; sladce slovo české zní Mocně slovo české zní! Při zvučném harfy mé znění pohne srdcem čilým v pění; mocně slovo české zní! Slavně slovo české zní! Když se hlásá v shromáždění božské mravné naučení; slavně slovo české zní! Měkce slovo české zní! V sličném skladu, v blahoznění lehko splývá v řeči, v pění; měkce slovo české zní! Ten s námi neobcuj víc, kdo se snad být Čechem stydí; at' se znašich besed klidí ten s námi neobcuj víc!
Schön klingt das tschechische Wort!

Die Anmut der slavischen Worte Weckt seit jeher den Neid anderer; Schön klingt das tschechische Wort! Süß klingt das tschechische Wort! Entfaltet es sich von den Lippen eines Mädchens, fließt wie Honig so süß; Süß klingt das tschechische Wort! Mächtig klingt das tschechische Wort! Beim vollen Klang meiner Harfe bewegt es das schnelle Herz im Gesang; Mächtig klingt das tschechische Wort! Glorreich klingt das tschechische Wort! Wird in der Gemeinschaft Gottes Lehre und Moral verkündet; Glorreich klingt das tschechische Wort! Weich klingt das tschechische Wort! In einer vornehmen Gestalt, im Wohlklang fließt es leicht in der Rede, im Gesang; Weich klingt das tschechische Wort! Derjenige soll mit uns nicht mehr die Gemeinschaft teilen, der sich schämen wollte, ein Tscheche zu sein; er soll sich von unseren Gesprächen fern halten jener soll nicht mehr mit uns verkehren! 
Jede der fünf parallel strukturierten Strophen dieses Gedichtes beginnt und endet mit der Variation desselben Satzes, der einen Lobpreis auf die Qualitäten des tschechischen Wortes formuliert. Variiert wird nur das Adverb, das den Klang des thematisierten Wortes spezifiziert: „Krásně slovo české zní" („schön klingt das tschechische Wort"), "Sladce slovo české zni“ (,süß klingt das tschechische Wort“), „Mocně slovo české zní“ („mächtig klingt das tschechische Wort“), „Slavně slovo české zni“" (,glorreich klingt das tschechische Wort“), „Měkce slovo české zní“ (,weich klingt das tschechische Wort“). Die so aufgebaute Ästhetik des tschechischen Wortes besteht aus den Eigenschaften schön, süß, mächtig, glorreich und weich. Drei sind aus dem sinnlich-emotionalen, zwei aus dem politisch-sakralen Bereich. Alle tragen sie zur Errichtung eines Wertekatalogs der eigenen Sprache bei und definieren sie als einen ästhetischen (schön), sinnlich emotionalen (süß), historisch-politischen (mächtig), sakralen (glorreich) und kulturellen (weich, wohlklingend und deshalb zum Dichten geeignet) Wert, den es zu verteidigen gilt. Die letzte Strophe des Gedichtes enthält die „Moral“, in welche der Lobpreis auf das tschechische Wort mündet: Es gibt keinen Grund, sich der tschechischen Sprache zu schämen. Wer sich schämt, ein Tscheche zu sein, soll von der Gemeinschaft ausgeschlossen werden. Damit verbunden ist aber auch die Aufforderung an alle, die der tschechischen Sprache mächtig sind, diese in den aufgezählten Bereichen zu gebrauchen, in welchen sie all die positiven Eigenschaften entfaltet. Die Argumentation des Gedichtes lässt keine Zweifel darüber entstehen, dass sich die Zugehörigkeit zur tschechischen Gemeinschaft, die sich als eine eigenständige begreift (,s námi“, „mit uns“), auf Grund der tschechischen Sprache definiert. Tscheche ist nur, wer auch Tschechisch spricht. In welchen Bereichen des gesellschaftlichen Lebens dies zu erfolgen hat, wird einzeln aufgeführt: im privaten, familiären Bereich (durch „dívka“, „Mädchen“ repräsentiert), in der Gemeinschaft (,pění“, „Gesang“), im Gottesdienst („božské mravné naučení,, „Gottes Wort/Moral“), wie auch in der Dichtung und Lyrik („sklad“, „Dichtwerk“, „pění“, „Gesang“). Den Gegensatz zum positiven Katalog der tschechischen Sprachgemeinschaft bilden die negativen Verhaltensweisen der Outsider. Sie sind diejenigen, welche die Vorzüge der tschechischen Sprache ignorieren (letzte Strophe) oder sie erkennen, aber mit Neid reagieren (erste Strophe). Die erste und letzte Strophe des Gedichtes bilden somit eine Klammer 
negativer Reaktionen, die von außen an die tschechische Sprache herangetragen werden. Die Spannung aus dieser Antithese erzeugt beim Adressaten des Gedichtes eine Verteidigungshaltung in Bezug auf die tschechische Sprache, in Bezug auf ihre Benutzer, aber auch in Bezug auf die in ihr entstandenen Sprachzeugnisse. Aus der Verteidigungshaltung entsteht jene auffällig präsente ,sprachliche Verteidigungsaufgabe“ (Macura 1995: 57), die nicht nur ihre Sprecher auszeichnet, sondern insbesondere den literarischen Zeugnissen selbst zukommt. Sie wird im Zeitalter der Wiedergeburt auch dort relevant, wo Literatur und Sprache nicht explizit der Gegenstand eines Angriffs sind. Bereits der bloße Gebrauch der tschechischen Sprache in literarischen Texten wird zu einer Geste, die semantisch vielfältig aufgeladen ist und als solche genutzt und wahrgenommen wird (vgl. ebd.).

Jede der sprachimmanenten Eigenschaften in Šírs Gedicht ist aber noch vielschichtiger kodiert. Alle als „schön“ eingestuften Eigenschaften, die mit dem Neid anderer kontrastiert werden, konnotieren auch die bereits im kollektiven Bewusstsein existenten Verteidigungsschriften, die zuvor zur tschechischen Sprache verfasst worden sind. Der Hinweis auf die Eignung des tschechischen Wortes für den religiösen und kulturellen Kontext, den die vierte und fünfte Gedichtstrophe formulieren, stellt im Grunde die Wiederaufnahme jener Argumente dar, die seit dem Mittelalter im tschechischen Schrifttum auftauchen. Die Antithese des Eigenen und des Fremden erinnert z.B. an die Argumentationslinie der „Dalimil Chronik“ zugunsten der eigenen Sprache (vgl. die Ausgabe von Daňhelka 1988). Der Ausschluss der Neider und Feinde aus der sich definierenden Gemeinschaft lässt an die Verteidigungsschrift „Boemici praeconium idiomatis, Chvála českého jazyka“ von Ondřej František de Waldt aus der Barockzeit denken (vgl. Waldt 1938). Einen zentralen kulturellen Wert stellen die tschechische Sprache und Literatur bereits viel früher dar. In der Zeit der Wiedergeburt werden sie jedoch so geschickt funktionalisiert, dass sie kulturstiftend wirken. Im Gedicht können die genannten Vorzüge, wie oben gezeigt, in Hinblick auf die Sprache und die Sprachgemeinschaft gedeutet werden. Sie können aber ebenfalls auf die Sprachzeugnisse selbst bezogen werden. Die im Gedicht hervorgehobenen Qualitäten des tschechischen Wortes sind alle auf der Grundlage eines akustischen Eindruckes formuliert. Das Wort wird aufgrund des ästhetischen Eindrucks wahrge- 
nommen, den es als Lautfolge hinterlässt - es klingt schön. Die Fokussierung auf die klangliche Seite des Wortes in Šírs Gedicht ist einerseits erklärbar mit der vom Prager Strukturalisten Felix Vodička beschriebenen Tendenz, die Klangqualitäten eines dichterischen Textes der Wiedergeburt über sein Signifikat dominieren zu lassen. ${ }^{2}$ Andererseits ist sie mit der Tatsache zu erklären, dass in gebundener Sprache dem Klang des Wortes eine grundsätzlich andere Priorität zukommt als in der Prosa. Die vier inneren Strophen des sechsstrophigen „Slovo české“ könnten deshalb, in der Abfolge der Strophen 2 bis 4, bestimmte Formen der Dichtung darstellen, nach denen die tschechische Sprache und Dichtung jener Zeit besonders strebten: Liebeslyrik, versinnbildlicht mit der Süße der Mädchenlippen in der zweiten Strophe („z úst dívky, když se rozvine, sladkostí jen co med plyne“); Heldenepos, dargestellt durch den Wortgesang zur Harfe in der dritten Strophe („Při zvučném harfy mé znění“); geistliche Dichtung oder Predigt, verkörpert von der versammelten Gemeinde in der vierten Strophe, die der Lehre in der religiösen Verkündigung lauscht („Když se hlásá v shromáždění božské mravné naučení“) und weltliche Dichtung, wie sie in der fünften Strophe durch Wohlklang und harmonische Komposition charakterisiert wird („V sličném skladu, v blahoznění lehko splývá v řeči, v pění“). Alle erwähnten Gattungen sind Literaturformen der gehobenen Stillage, zu welcher sich die tschechische Sprache jener Epoche hinentwickeln sollte, wenn sie sich mit Sprachen und Literaturen der europäischen Nachbarn messen wollte. Der gehobene gesellschaftliche Kontext, in dem sich die in den einzelnen Strophen geschilderten Sprechszenen abspielen, stellt deshalb eher eine Wunschrealität denn eine real existierende Wirklichkeit der tschechischen Sprecher jener Zeit dar.

In der ersten Hälfte des 19. Jahrhunderts wurde Tschechisch nur in den ersten Grundschulklassen unterrichtet. Deutsch war bereits in den Schulen als Sprache der höheren Bildung etabliert und wurde als Sprache der gebildeten Schichten verwendet (vgl. Marek 1998: 121). Auch als Amtssprache sowie in allen offiziellen Kontexten war Deutsch geläu-

\footnotetext{
2 „Oslabená sdělovací funkce jazykového znaku nutně zaostřovala pozornost $\mathrm{k}$ znaku samému a k jeho zvukové realizaci.“ („Die Reduktion der Mitteilungsfunktion des Sprachzeichens lenkte auf unumgängliche Weise die Aufmerksamkeit auf das Zeichen und seine klangliche Gestalt selbst.") (Vodička 1994: 321) Wenn nicht anders vermerkt, stammen alle Übersetzungen in diesem Beitrag von der Verfasserin.
} 
fig. ${ }^{3}$ Die Verwendung der deutschen oder der tschechischen Sprache verriet deshalb die soziale Stellung des Sprechers und erlaubte Rückschlüsse auf seine Bildung oder seine Gesinnung (vgl. Bělina 1992: 61). Tschechisch wurde kaum noch geschrieben und für anspruchsvolle literarische Texte erst recht nicht mehr verwendet. Sollte das Tschechische nicht zur Sprache der ungebildeten Schicht verkommen, musste ein Sprachbewusstsein und eine Wertschätzung der eigenen Sprache entwickelt werden, die der tschechischen Sprache den Vorzug vor anderen traditionell verwendeten Sprachen einräumte.

\section{Handschriftenfunde RZ und RK}

In diesem Kontext sind auch die so genannten Handschriftenfunde RZ und RK in der Zeit der Wiedergeburt zu sehen. Sie stellen den bekanntesten Versuch dar, ein Epos in tschechischer Sprache entstehen zu lassen: Im Jahre 1817 gab es den ersten sensationellen Fund von Manuskripten in alttschechischer Sprache durch einen Schüler des Slavisten Josef Dobrovský. Václav Hanka fand im Turm der Kirche von Dvůr Králové die Handschrift RK (Rukopis královédvorský / Königinhofer Handschrift). Sie enthält die Fragmente eines Kodexes, der eine Anthologie unterschiedlicher literarischer Zeugnisse bildete: sechs Heldenlieder und acht lyrische Dichtungen, davon sechs mit Liebesthematik. Die Heldenlieder bezogen sich auf historische Begebenheiten, die ins 13.-14. Jahrhundert datiert werden, enthielten aber auch Personennamen (wie den des Čestmír aus der Lucká válka), die aus alten vorchristlichen tschechischen Mythen bekannt waren. Ein Jahr später folgte der Fund der Handschrift RZ im Schloss Zelená Hora (Rukopis zelenohorský / Grünberger Handschrift); die Handschrift war dem Tschechischen Nationalmuseum anonym zugeschickt worden. ${ }^{4} \mathrm{RZ}$ enthält zwei Fragmente von Dichtungen, die aufs 9. Jahrhundert datiert

\footnotetext{
${ }^{3}$ Im zweiten Dialog über die tschechische Sprache fordert Jungmann die Einführung des Tschechischen in höheren Schulen, offiziellen Ämtern und bei Rechtssprechungen (vgl. Jungmann 1841: 145, 157).

$4 \mathrm{Zu}$ diesen Handschriften sind aber auch andere „gefundene“ und gefälschte Handschriften hinzuzurechnen: das Manuskript der Liebeslieder König Wenzels, gefunden 1819, das Manuskript der tschechischen Glossen in Mater verborum, gefunden 1827, und die Weissagung Libušas aus dem 14. Jahrhundert, gefunden 1849. Es scheint, als ob alle diese Manuskripte Teil einer Idee gewesen wären.
} 
werden: „Sněm“ („Ratsversammlung“) und „Libušin soud“5 („Libušes Rechtsprechung“").

Die tschechische Öffentlichkeit war von den vermeintlich echten Funden begeistert. Der Philologe Josef Jungmann nahm die Handschriften wenige Jahre nach ihrem Fund in seine Geschichte der tschechischen Literatur auf. Im zweiten Teil des Buches widmet er der Königinhofer Handschrift einen ausführlichen wertenden Kommentar und erwähnt ihre bereits erfolgten Übersetzungen in die deutsche und russische Sprache (vgl. Jungmann 1825: 25f.). Als besondere Qualität der Handschrift unterstreicht er, dass sie einerseits ein Zeugnis der patriotischen Heldentaten, Ansichten und Bräuche der Tschechen sei, andererseits auch einen Schlüssel zur tschechischen Geschichte darstelle (ebd., 26). ${ }^{6}$ Als Bedenken und erste Zweifel an der Echtheit des zweiten Fundes (Rukopis zelenohorský) aufkamen, ${ }^{7}$ verteidigte die Jungmanngeneration den kulturstiftenden Zweck der Manuskripte und gewichtete diesen höher als die Frage der Echtheit. Spätestens seit Ende des 19. Jahrhunderts gilt aber als erwiesen, dass die Manuskripte RK und RZ Fälschungen sind. Dennoch werden die Diskussionen um die Handschriften bis zum heutigen Tag in Internetforen geführt. ${ }^{8}$

\footnotetext{
${ }^{5}$ Der Text handelt vom Urteil Libušes im Streit zweier Brüder (Chrudoš und Št’ahlav), die das väterliche Erbe aufgeteilt bekommen wollen. Nach deutschem Recht verlangt Chrudoš, als der ältere, das ganze Erbe. Libuše entscheidet nach tschechischem Recht, das Erbe in zwei Hälften zu teilen. Chrudoš ist wütend und beleidigt Libuše. Diese ruft die Tagsatzung zusammen und fordert sie auf, einen neuen Fürsten zu wählen. Das Motiv ist bereits aus der Chronik des Kosmas und aus der Dalimil-Chronik bekannt.

${ }^{6}$ Die Rekonstruktion und dichterische Evokation vergangener heldenhafter Zeiten entsprach den Hauptbedürfnissen der Jungmanngeneration. Ebenso war ihr die Schilderung einer gelungenen Verteidigung vor dem Feind wichtig. Beide Themenbereiche kommen in den Handschriften mehrmals zur Darstellung.

${ }^{7}$ Der Slavist Josef Dobrovský hielt die Handschrift RK für echt, lehnte jedoch die Handschrift RZ bereits in einem Artikel von 1824 als Fälschung und Betrug ab, da verschiedene Ungereimtheiten wie der Stil, das Beimischen russischer Wörter und die Orthographie in der Handschrift darauf hinwiesen. In seinem Artikel schrieb er die Tat einem Philologen zu, den er im Kreis seiner Schüler vermutete. Besonders verurteilte er das Erfinden von falschen Tatsachen, wie der Rechtsprechung Libušes auf der Burg Vyšegrad, die vor der Heirat der Fürstin noch gar nicht gestanden habe, sondern wie es in der lateinischen Chronik des Kosmas heißt, erst nach dem Tod ihres Gemahls Přemysl erbaut worden sei (vgl. Josef Dobrovský: O Libušině soudu (Original auf Deutsch), in Lehár/Stich 2000: 426).

${ }^{8}$ Die Fälschungen werden einer Gruppe von Tätern zugesprochen: Man nimmt als
} 
Unabhängig von der Frage der Echtheit haben die Handschriften eine große künstlerische Wirkung erzielt: Sie wurden zur Inspirationsquelle der tschechischen Maler, Bildhauer, Schriftsteller und Komponisten des 19. Jahrhunderts. ${ }^{9}$ In ihren Werken wirkten die Handschriften auf die breite Öffentlichkeit. Gegen Ende des 19. Jahrhunderts (1894) ist der Handschriftenstreit vom späteren Präsidenten der Tschechoslowakei, Tomáš Garrigue Masaryk, zu einem nationalen Thema erklärt worden. Seine Richtigstellung formulierte er als eine Aufgabe für die bestehenden sowie künftigen Generationen (vgl. Masaryk 1895: 162f.).

Eine nachhaltige Wirkung erzielte vor allem die Handschrift RZ. Sie stilisiert Libuše zur idealen, gerechten und eigenständigen Herrscherin und impliziert ein selbständiges, gebildetes, mit Macht und Rechtsprechung ausgestattetes Volk. Diese entworfene verbale Wirklichkeit wurde durch ihre wiederholte Aufnahme und Weiterverwendung in Literatur, Musik und Malerei zu einem festen Bestandteil des tschechischen Nationalbewusstseins des 19. und 20. Jahrhunderts. Libuše als weise Herrscherin, die in tschechischer Sprache Recht spricht, steht fortan im kollektiven Bewusstsein für die Eigenständigkeit und Wehrhaftigkeit der tschechischen Nation und wird zur Personifikation der nationalen Identität.

Libušes Sprechakt spiegelt aber auch die den Manuskripten zugedachte Aufgabe wieder. Die tschechische Sprache im Munde der Herrscherin übernimmt die Funktion eines Instrumentes zur Schaffung und zur Verteidigung nationaler Werte. Gleichzeitig ist die tschechische Sprache selbst der Wert, den es zu pflegen und zu verteidigen gilt. Sie steht für die eigene sprachliche Identität, für Heimat, Kultur und Geschichte. Im Mund der Urahnin erhält sie darüber hinaus einen sakralen Charakter. Die Sakralisierung der tschechischen Sprache, die bereits in den Epochen davor in den so genannten „Verteidigungsschriften“ beobachtet werden kann, wo die Sprache durch die Berührung mit einem Nationalheiligen einen heiligen Charakter erhält (vgl. Waldt

sicher die Beteiligung des Philologen und Dichters Václav Hanka an, als wahrscheinlich auch diejenige seiner Kollegen Josef Linda und Alois Svoboda.

${ }^{9}$ Unter anderem für die Maler Josef Mánes, Mikuláš Aleš, den Bildhauer Václav Myslbek (Statuen im Nationaltheater in Prag), für die Schriftsteller Jan Neruda, Jaroslav Vrchlický, Julius Zeyer sowie für die Komponisten Bedřich Smetana und Antonín Dvořák. 
1938: 37), erreicht in der Gestalt Libušes ihren Höhepunkt und ist ein wichtiger Bestandteil des tschechischen Identitätsentwurfs. Die in den folgenden literarischen Texten auftauchenden tschechischen Urmütter werden nach dem Modell der Recht sprechenden Fürstin Libuše entworfen und mit göttlichen Eigenschaften ausgestattet. Der Sakralisierungsvorgang erfasst ebenso die tschechische Sprache wie die tschechische Literatur. In Kombination mit dem christlichen Schöpfungsmythos des die Welt erschaffenden göttlichen Wortes macht das Ausgangsmodell der Fürstin Libuše die Urmütter zu Kulturmüttern, deren tschechisches mündliches Erbe von den Nachfahren als heilig erkannt, gepflegt und im Erzählvorgang materialisiert werden soll. Genauer soll diese These an den folgenden zwei Beispielen demonstriert werden.

\section{„Babička“" (Die Großmutter)}

Božena Němcovás (1820-1862) Prosa „Babička, obrazy venkovského života“ (1855, Die Großmutter, Bilder aus dem Landleben), der wohl bekannteste und bis heute attraktivste ${ }^{10}$ tschechische Roman des 19. Jahrhunderts, bietet bereits mit der Titelwahl den Hinweis auf einen mythischen Subtext. Hier wird nicht von einer lebenden Person aus Fleisch und Blut erzählt, sondern aus der Erinnerung an eine bereits vor langer Zeit gestorbene „gute Greisin“ („dobrá stařena“), das Ideal einer tschechischen Urahnin, der „Babička“ aller Tschechen (,každý ji jmenoval „babičko“, ,jeder nannte sie Babička“) entworfen. Ganz nach der Vorlage der eingeführten Gestalt, der mythischen Stammesführerin Libuše, verkörpert hier eine Frau Grundwerte, die für die tschechischsprachige Gesellschaft des 19. Jahrhunderts maßgebend waren. Babičkas Antlitz wird als sanft, lieblich, blass und faltig geschildert, ihre Augen als blau, voller Güte und Liebe. Die im Prolog aufgezählten äußeren Eigenschaften Babičkas sind allegorisch zu lesen als Eigenschaften, die im Wertekatalog der Wiedergeburt positiv belegt sind und dem eigenen Volk und seinen Vorfahren zugesprochen werden. In diesem Zusammenhang sind auch der Tisch aus Lindenholz (nicht etwa Eichenholz) zu sehen, den sich die Protagonistin ins Zimmer hat stellen lassen, wie auch die von der Stubendecke hängende und auf Babičkas

\footnotetext{
${ }^{10}$ S. dazu die Umfrage von Susanna Roth aus den Jahren 1987-1991 (vgl. Roth 1991: 260-320).
} 
Kopfhauben als Ornament angebrachte Taube. Die Taube steht in der Ideologie der Wiedergeburt für den friedliebenden Charakter der Slawen, die Linde wird als ihr heiliger Baum deklariert. ${ }^{11}$ Allerdings ist die Taube als Symbol im Text doppelt kodiert, sie steht hier auch als ein christliches Symbol für den Heiligen Geist (vgl. Němcová 1999: 18). Später erfahren wir, dass sich Babička ebenso wie die legendäre Fürstin Libuše in Kräutern auskennt, Streit schlichtet, für alle einen Rat weiß (auch die Stammesfürsten kamen zu Libuše, um sich bei ihr Rat zu holen) und alles im Haus sich nur noch nach ihrem Wort richtet (ebd., 20). ${ }^{12}$ Babičkas Wort ist aber nicht nur das weise Wort der mythischen Stammesfürstin, sondern gar das Welt erschaffende Wort der Genesis. Im Text wird explizit hervorgehoben, dass alles, was Babička sagt und tut, gut ist: „[C]o babička řekla a udělala, bylo dobře.“ (Ebd.) (,[W]as Babička sagte und tat, war gut"). Letztere Aussage beschließt das erste Kapitel des Romans und leitet durch den zweimaligen Hinweis auf das maßgebende gesprochene Wort Babičkas („slovo“, „řekla“) ein biblisches Zitat ein. Über das Ende des sechsten Schöpfungstages heißt es in der Bibel, dass alles gut war, nachdem Gott durch sein Wort die Welt und die Lebewesen erschaffen hatte (vgl. Genesis 1.25). Die Aufnahme dieses Bibelzitats in den Romantext und seine „Umschreibung" auf die Protagonistin hin bewirken, dass aus Babička parallel zu "Gott Vater" eine „Gott Mutter" wird. So ist es folgerichtig, dass Babičkas Gesten, ${ }^{13}$ Taten und Worte eine Autorität aufweisen, die sie nur mit dem biblischen Gott teilt. Da Letzterer nach christlicher Auffassung nicht nur Gott Vater, sondern auch Gottes Sohn zugleich ist, wird im Text aus Babička einerseits die „Mutter“, andererseits die „Schwester“ aller Dorfbewohner: „[V]šickni obyvatelé vesničtí byli bratřími jí a sestrami, ona jim byla matkou“ (Němcová 1999: 11) („,[A]lle Dorfbewohner waren ihre Brüder und Schwestern, und sie war ihnen Mutter"). Das biblische Modell verbindet Němcová mit einem

\footnotetext{
${ }^{11}$ So zum Beispiel in der Dichtung Jan Kollárs "Slávy dcera“ von 1824, wo diese Symbole zentral verwendet und gleichzeitig erklärt werden. Siehe zu diesen und weiteren Symbolen der Tschechischen „Wiedergeburt“ auch das maßgebende Buch von Vladimír Macura (Macura 1995), darin besonders das Kapitel „Mytologičnost“, 79-101, 91 .

12 „Brzy se v domě řídilo všecko dle babiččina slova.“ („Bald richtete sich alles im Haus nach Babičkas Wort.")

${ }^{13}$ Von Babičkas Händen wird zum Beispiel gesagt, dass sie zu segnen pflegten.
} 
heidnisch-mythischen. Dabei werden die heidnisch-mythischen Elemente so umgedeutet, dass sie in einen christlichen gesellschaftlichen Wertekontext passen. Aus der Stammesfürstin Libuše wird die Rat gebende Mutter aller Dorfbewohner: „ona jim byla [...] rádkyní“ (Němcová 1999: 11) („sie war ihnen eine Ratgeberin“). Kein religiöser und gleichzeitig gesellschaftlich relevanter Akt wird ohne Babička vorgenommen: „bez ní se neskončil ani křest, ani svatba, ani pohřeb“ (ebd.) („ohne sie wurde weder eine Taufe noch eine Hochzeit oder eine Beerdigung vollzogen / beendet“).

Diese ideale Ordnung, nach der bereits in Babičkas kleinem Ursprungsdorf in den Bergen alles funktionierte, wird mit ihrer Ankunft bei der Tochter in deren deutsch-tschechischen Haushalt bzw. in die deutsch-tschechische Realität Böhmens importiert. Auch hier soll nun alles blühen und gedeihen. Babička lässt ihr altes Häuschen zurück. Ihr Gepäck, mit dem sie bei der Tochter eintrifft, besteht zur Hauptsache aus einer Truhe. Dass diese Truhe als Bild für etwas steht, das nicht verloren gehen soll, offenbaren die in ihr aufbewahrten Inhalte. Es sind vorwiegend Gedächtnisinhalte. ${ }^{14}$ Die Truheninhalte sollen, wie im Text betont wird, nach Babičkas Tod die Enkelkinder erhalten. Das Erbe besteht demnach aus vielen religiösen und weltlichen Schriften, wenig Geld und Schmuck, religiösen Gegenständen und traditionellen Kleidungsstücken. Diese können als Schrift und Bildkultur (Schrifttum in Form von religiösen und nichtreligiösen Texten und Briefen; bildende Kunst in Form von Heiligenbildern, Ornamenten, Malereien auf der Truhe), Werte (böhmische Geschichte repräsentiert durch Könige und

\footnotetext{
${ }^{14}$ Die Truhe enthält (teilweise in kleineren Schachteln verschlossen) Mitbringsel von Pilgerfahrten (Heiligenbilder, Gebetstexte), zwei Rosenkranzketten, Familienschriften, Briefe, Geldmünzen, ein Halskettchen mit (böhmischen) Granatsteinen, Schmuckmünzen mit Porträts von Kaiser Josef (Habsburger Kaiser Josef II., der von1780-1790 regierte) und seiner Mutter Maria Theresia (Königin Böhmens von 1740-1780). Als einziger Habsburger Herrscher lernte Josef II. die tschechische Sprache sprechen und hielt sich wiederholt inkognito in Böhmen auf. Wegen seiner Agrarreformen und der Aufhebung der Leibeigenschaft im Jahre 1781 war er beim bäuerlichen Stand beliebt. Weiter befindet sich in der Truhe ein Stapel Wäsche. Letztere besteht aus sorgfältig aufbewahrten, ererbten Trachtenteilen, die teilweise noch Babičkas Mutter getragen hatte. Zu den Gedächtnisinhalten vgl. die folgende Feststellung: „Kästchen und Juwel haben einen emblematischen Bezug zu Gedächtnis und Erinnerung. Das Kästchen assoziiert das Gedächtnis als Hort, Schutz und Behälter, das Juwel bezeichnet den kostbaren und versicherungsbedürftigen Inhalt der Erinnerung.“ (Assmann 1999: 121)
} 
Kaiser auf Münzen, eigener Besitz in Form von Geldstücken und böhmischem Schmuck, religiöse Gegenstände) und Tradition (Erlebtes, Vergangenes, Bräuche, Trachten) verstanden werden.

Das kulturelle Gedächtnis, das Babička als Erbe ihren Enkeln mitbringt, generiert einen dreifachen Mythos: eine tschechische Idealwelt, in der alles in Harmonie und christlicher Ordnung lebt, mit Babička als ihrer Schöpferin und ihrem Ursprung; eine Kultur, die sich an eigenen heidnischen und christlichen Mythen orientiert und die tschechische Sprache als Kultursprache festschreibt; und nicht zuletzt ein eigenes Werteverständnis, das vorgestellt und für die nachfolgenden Generationen als Orientierung dienen soll.

Dass es sich um einen völlig neuen, vom bis dahin Bekannten differierenden Vorgang handelt, zeigt nicht zuletzt auch die Betonung der Andersartigkeit Babičkas. ${ }^{15}$ Sie unterscheidet sich ganz und gar von allen Großmüttern, die den Enkeln bekannt sind. In ihrer Andersartigkeit ist sie einmalig, schön und so interessant, dass die Kinder die Augen nicht von ihr abwenden können. Darüber hinaus ist sie unsterblich. Denn wie es in der Einleitung heißt, lebt Babička immer weiter, obwohl sie bereits gestorben ist - zumindest in der Seele der Schreibenden.

Das Modellieren der Protagonistin nach dem biblischen Schöpfungsmythos ist auch in anderer Hinsicht kein Zufall. Einerseits entsteht hier der Mythos einer eigenen tschechischen vergangenen Welt mit ihren Bräuchen und Riten, andererseits wird der neue Mythos durch Němcovás erzählerischen Vorgang (Weitergabe an die Nachwelt) erst geschaffen. Die mythenbildende Absicht hinter dem literarischen Akt unterstreicht die Tatsache, dass die Schaffung des Mythos von einer weiblichen Erzählerin vorgenommen wird, die häufig als Sprachrohr die Worte der Greisin zitiert. Dies entspricht der Mythenauffassung (Mythos als diskursive Praxis), wie sie Platon beschrieben hat: Eine Person hohen Alters und weiblichen Geschlechts erzählt mündlich (häufig Kindern) „eine Botschaft, vermittels deren eine Gemeinschaft von Ge-

\footnotetext{
15 „Jakpak, to byla babička zcela jinaká než všechny ty, co kdy viděly; takovou babičku ony ještě jaktěživy neviděly! Div na ní oči nenechaly!“ („Wie auch, das war eine Großmutter, ganz anders als alle diejenigen, welche sie jemals gesehen hatten; so eine Großmutter haben sie zeitlebens noch nie gesehen! Die Augen konnten sie nicht von ihr lassen!“) (Němcová 1999: 12f.)
} 
neration zu Generation weitergibt, was sie von dem, was sie als ihre Vergangenheit erachtet, in Erinnerung behält, wobei der Ausgangspunkt der Vergangenheit mit dem Ursprung der Götter zusammenfällt [...]" (zit. n. Brisson 1996: 20f.). Implizit steht hinter einer solchen Modellierung der Vergangenheit der tschechischsprachigen Gesellschaft die Aussage, dass es sich wie in der Antike um eine orale Kultur gehandelt habe, die nun von der Schriftstellerin in eine Schriftkultur transponiert wird. Die inzwischen bloß noch mündlich überlieferten Werte, Traditionen und Erzählungen sollen in der eigenen Sprache schriftlich festgehalten werden. ${ }^{16}$ Erst wenn wir berücksichtigen, dass der Mythos als Botschaft auch eine didaktische Seite aufweist, die den Adressaten dazu bringen soll, sein moralisches Verhalten dem gelieferten Modell anzupassen (vgl. ebd.), verstehen wir, warum die Schilderungen der Gewohnheiten, Bräuche und Redensarten Babičkas im Text so zahlreich und detailliert vorgenommen werden. Die genauen Beschreibungen der Bräuche und Redensarten in Němcovás Text dienen der Definition und zugleich der Etablierung einer tschechischen Identität, ${ }^{17}$ welche die Leserschicht als die eigene erkennen und weitergeben soll. Da die eigene Identität eine Differenz voraussetzt, muss die ankommende „Urmutter“ ganz anders sein als alle anderen Großmütter, die den Kindern bekannt sind. Die kulturelle Festschreibung der als anders und deshalb als eigen (,tschechisch“) dargestellten Werte und Kulturformen in Form eines literarischen Textes ${ }^{18}$ stellt gleichzeitig den Anspruch an den Leser dar, diese Werte zu erkennen, zu schätzen und weiter zu geben. Alles was Babička tut, bringt sie deshalb auch den

\footnotetext{
${ }^{16}$ Die Deutung des Textes als Überführung der traditionellen weiblichen Mündlichkeit in einen individuellen Akt der Schriftlichkeit, die Irina Wutsdorff (2006: 43) vornimmt, müsste insofern umformuliert werden, als es hier im Kontext der Wiedergeburtsideologie nicht um einen individuellen Schreibakt geht, sondern um die Überführung der tschechischen Kultur aus der Mündlichkeit in die Schriftlichkeit.

${ }^{17}$ Zur „Redseligkeit“ der Protagonisten in Babička als identitätsstiftendem Akt siehe die Monographie von Kathrin Berwanger (Berwanger 2001).

18 Auf das Individuationsprinzip, das sich niederschlägt in der „Betonung des Eigenständigen aus der Geschichte, der Sprache und schließlich der Literatur" im Prozess der nationalen Erneuerungsbewegung der „Wiedergeburt“ („obrození“), weist Walter Schamschula hin. Die Kultur, von der es sich abzugrenzen galt, war die deutsche Kultur (vgl. Schamschula 1990: 332f.).
} 
Kindern bei. ${ }^{19}$ Am meisten Raum erhalten dabei christliche Gebote, Riten und volkstümliche Bräuche, die sie alle vorlebt.

Gleich im ersten Kapitel erfahren wir, dass Babička dem kleinsten Enkelkind bei der ersten Begegnung ein Kreuzzeichen auf die Stirn zeichnet und von den anstehenden Hausarbeiten zuerst das Brotbacken selbst übernimmt. Letzteres ist mit etlichen Segnungen des Brotes beim Knet- und Backvorgang verbunden, die Babička sorgfältig einhält, damit das Brot seinen Charakter einer Gottesgabe behält. Das Kreuzzeichen soll dem kleinsten Kind Schutz geben, die Segnung des Brotes die Dankbarkeit für die von Gott erhaltene Nahrung zum Ausdruck bringen. Beides kann als Teil der Brotallegorie verstanden werden, in der Brot als tägliches Grundnahrungsmittel für die eigene Kultur stehen kann. Diese Lesart erhält im Text Unterstützung durch die Verwendung von Volksweisheiten, die eine übertragene Bedeutung des Nahrungsmittels Brot im Text selbst einführen. Im folgenden Bezug des Brotschneidens auf das zwischenmenschliche Verhalten „Kdo se nesrovnává s chlebem, nesrovnává se s lidmi“ (Němcová 1999: 16) („Wer das Brot nicht gerade schneidet, ist gegenüber Menschen nicht gerade / kommt mit Menschen nicht aus“) wird die „kulturelle“ Lesart vorgeführt. Dieses Brot soll in der richtigen Zubereitung durch die Großmutter regelmäßig genossen und an die künftigen Generationen weitergegeben werden.

Andererseits können das Kreuzzeichen und das Brot als Gabe Gottes in Němcovás Text theologisch verstanden werden. Sie stehen für Werte der christlichen Heilsbotschaft im Text. Berücksichtigt man, dass die christliche Religion in der Eucharistie den Kreuzestod Christi und seine Auferstehung durch die Wiederholung des letzten Abendmahls nachzeichnet und in der Wandlung (der beim Abendmahl ausgeteilten Hostie) aus dem Brotlaib der Leib Gottes wird, der den Gläubigen sättigen soll, so dient die im Text eingeführte Bildlichkeit der Installierung einer christlichen Ordnung, die als Referenzwert für alle anderen Werte in Němcovás Text steht. Brot wird darin als Seele, als menschlicher Leib und schließlich als Gottes Leib aufgefasst. Bemerkenswert ist die Tatsache, dass die christliche Brot-Bildlichkeit stellenweise mit heidni-

\footnotetext{
19 „Tomu všemu babička i děti učila.“ (Němcová 1999:16) („Das alles brachte Babička auch den Kindern bei.“)
} 
schen Reminiszenzen durchsetzt ist. ${ }^{20}$ Die Dominaz der christlichen Elemente, welche die heidnischen mythischen Elemente im Text überlagern, führt dazu, dass das eigene bzw. andersartige (nationale) dem verbindenden (übernationalen) christlichen Prinzip untergeordnet wird. Die heidnischen Relikte (Libuše, Götterwelt, Aberglaube) aus dem eigenen Mythenschatz werden so umgeformt, dass aus ihnen ein christlicher, genuin tschechischer Kosmos aufersteht.

Eine dritte metatextuelle Leseart der Brot-Bildlichkeit könnte die Deutung des Brotes auf Němcovás Text selbst beziehen: Dieser soll das Brot sein, das zubereitet, gegessen und weitergereicht wird. Parallel zur christlich-jüdischen Tradition, in der Gott als Wort in die Welt gekommen ist, das sich materialisiert hat, wird hier das Wort als eine Welt erschaffende Instanz verstanden, die neue tschechischsprachige Textwelten entstehen lässt.

\section{,Kytice“6 (Der Blumenstrauß)}

Die im untersuchten Anfangskapitel von Babička auftretenden Elemente finden wir im Wesentlichen in einem anderen Text aus der Mitte des 19. Jahrhunderts wieder: in Karel Jaromír Erbens (1811-1870) Balladensammlung „Kytice z pověstí národních“ („Ein Blumenstrauß aus Volkssagen“), die 1853 erschien. Das die Sammlung einführende gleichnamige Gedicht „Kytice“ („Der Blumenstrauß“) wählt zu seinem Anfangspunkt eine Mutterfigur (vgl. Erben 2003: 11). Wie im Vorspann zu Babička lebt diese mythische Urmutter nicht mehr und hinterlässt Kinder. Diesen gibt die verstorbene Mutter kulturelle Schätze,

\footnotetext{
${ }^{20}$ So weist die Großmutter darauf hin, dass die Brosamen dem Feuer gehören und deshalb nicht weggeworfen werden dürfen. Dennoch wird die christliche Bildlichkeit dadurch kaum gestört. Diese heidnisch konnotierte Auffassung, dass dem Feuer eine Opfergabe dargebracht werden solle, erfährt nämlich sogleich eine Umdeutung durch die unmittelbar darauf folgende Aussage, dass die Seelen im Fegefeuer weinen, wenn Brosamen mit Füßen getreten werden. So wird aus dem heidnischen Feuer das christliche Fegefeuer der Seelen. Ebenso verfährt Němcová mit einem anderen heidnischen Element, der Verhexung eines Gegenstandes durch einen bösen Blick oder ein Wort des im Backprozess stehenden Brotes. Die Gültigkeit dieses Aberglaubens wird nicht grundsätzlich bestritten. Vielmehr werden der böse Blick oder das unbedarfte Wort umgewandelt in den vom Eintretenden laut auszusprechenden christlichen Segenswunsch „Gott segne es“.
} 
die als solche erkannt und weitergegeben werden sollen. Mit dieser Aufforderung leitet das erste Gedicht alle folgenden Dichtungen der Sammlung ein.

Wie in „Babička“ soll in „Kytice“ altes und eigenes Kulturgut an die Nachwelt weitergegeben und der Wert der eigenen Kultur erkannt werden. So wie die Kinder täglich ans Grab gehen und die hier wachsenden duftenden Blumen (Quendel) als „Mutters Atem“ erkennen, sollen alle „Kinder“ ans Grab der tschechischen „Kulturmutter“ kommen und den Duft der eigenen Kultur einatmen und ihre Schönheit erkennen. Damit jeder Irrtum bei der Deutung der Mutter-KinderAllegorie ausgeschlossen ist, überträgt der Dichter das gewählte Bild von der spezifischen auf eine allgemeinere Ebene. Das lyrische Ich beteuert, seinen „Blumenstrauß“ an einfachen Volkserzählungen und Sagen („prosté pověsti“) an einem sehr alten Grabhügel („na dávné mohyle“) gepflückt zu haben, um „Mutters Atem“ an ihre Kinder (Töchter und Söhne) in ästhetisch ansprechender Form, d.h. mit einem Schmuckband versehen („ozdobně stužkou ovinu“), weiterzureichen. In der zweiten Hälfte des Gedichts wird aus der „Mutter“ metonymisch „unsere liebe Heimat“, aus den Pflanzen metaphorisch „unsere einfachen Sagen / Erzählungen“. Die Rolle des lyrischen Subjektes, das unschwer als das Alter Ego des Dichters erkannt wird, ist diejenige eines Vermittlers. Er sammelt die Sagen an einem alten Gedenkort („mohyla“, „vorgeschichtlicher Grabhügel“), formt und schmückt sie, um sie den potentiellen Adressaten zu bringen. Die Autorschaft selbst überlässt der Dichter der im Grab liegenden Urmutter. Diese inkarniert sich im Erzählvorgang, bleibt aber auch in der körperlosen Form als Hauch oder Duft bestehen. Karel Jaromír Erben scheint sich hier an der christlichen Auffassung des göttlichen „Wortes“ zu orientieren, das einerseits Körper, stets aber auch Geist / Atem bleibt, und er tauscht lediglich Gott-Vater durch eine Mutter-Heimat aus. Das religiöse Ausgangsmodell der Körperwerdung einerseits und der Auferstehung von den Toten andererseits unterlegen den Zieltext derart, dass die Eigenschaften des Körper gewordenen göttlichen Wortes ebenso wie die Eigenschaften des von den Toten auferstandenen Messias auf den heimatlichen (tschechischen) literarischen „Wortkörper“ übertragen werden. Ausgestattet mit einer sakralen Autorität wird das Erbe der Kulturmutter in materialisierter (schriftlicher) Form an die Nachwelt 
übergeben. Das Grab, ein Ort des Todes, wird somit zum Ort des Lebens und der kulturellen Wiedergeburt. Der wiedergeborenen Sprachgemeinschaft und ihrer Literatur fällt dabei die Rolle des Messias zu. ${ }^{21}$

\section{Fazit}

Beide untersuchten Texte weisen die Gemeinsamkeit auf, dass sie einen weiblichen Ursprungsmythos konstruieren, der eine gemeinsame „Urmutter" an den Anfang der tschechischen Identität stellt. Die Urmutter ist die Verkörperung der Nation und wird nach der mythischen Gestalt der Stammesfürstin Libuše modelliert. Als „Basistexte“ übernehmen „Babička“ und „Kytice“ die für das Epos typische Funktion, an die gemeinsame Vergangenheit sowie die eigenen Werte einer Gemeinschaft sprachlich wohlgestaltet zu erinnern. Sie füllen jene Leerstelle aus, die durch das Fehlen eines eigenen Nationalepos entstanden ist. Die erinnerte gemeinsame Vergangenheit zeugt von einer sprachlich-kulturell definierten Gemeinschaft und suggeriert eine tschechische Eigenstaatlichkeit. Beide Texte entwerfen ein spezifisches Werteverständnis, das

21 Im Kapitel zum Thema des Häuschens oder der Hütte (,chaloupka“) in der tschechischen Literatur hält Vladimír Macura fest, dass in der Konstruktion eines Kultes der nationalen Wiedergeburt die christliche Heilsgeschichte als Grundstruktur verwendet worden sei. Geburt, Kreuzigung und Auferstehung Christi bildeten die drei metaphorischen Ebenen, auf welchen Überlegungen zur Rolle der tschechischen Nation in der Weltgeschichte stattgefunden hätten. Der Sprachgemeinschaft, dem tschechischen Volk, oder ihrem herausragenden Vertreter, dem Dichter, sei die Rolle des Messias zugesprochen worden. Der Schriftsteller („,spisovatel“) werde zum Erlöser (,spasitel“) stilisiert. Das Thema der ärmlichen Hütte, in die der tschechische Dichter gestellt wird, ungeachtet dessen, ob er tatsächlich aus einfachen Verhältnissen gekommen ist oder nicht, folge dem Stall zu Bethlehem in der biblischen Vorlage. Der Dichter stehe stellvertretend für das Volk, das in einem Stall bzw. in einer einfachen Hütte geboren worden sei. Das Thema der Kreuzigung werde zum Analogon des mythisierten tschechischen Leidens in der Vergangenheit und die Auferstehung zur Metapher der tschechischen Wiedergeburt. Das tschechische Volk stehe in diesem Verständnis wie Christus von den Toten auf und steige aus dem Grab, in welches es nach der Schlacht auf dem Weißen Berg 1620 gelegt worden sei. (Hodrová/ Hrbata/Kubínová/Macura 1997: 52f.). Macuras Feststellungen bleibt nur hinzuzufügen, dass die Rollen in der heilsgeschichtlichen Grundstruktur variieren können. Im untersuchten Beispiel ist es die Literatur, die aufersteht. Der Dichter seinerseits erhält die Rolle des Priesters zugewiesen. 
als „tschechisch“ vorgestellt wird und den nachfolgenden Generationen als Identifikator ${ }^{22}$ dienen soll. Sie orientieren sich an eigenen heidnischen und christlichen Mythen und schreiben die tschechische Sprache als Kultur- und Gemeinschaftssprache fest. Mit Hilfe der Texte wird die zu jener Zeit vorwiegend orale tschechische Kultur in eine schriftliche Kultur übergeführt. Das christliche Verständnis des Wortes als einer Welt erschaffenden Instanz lässt nicht nur neue tschechischsprachige Textwelten entstehen, sondern soll für die tschechische Gemeinschaft eine neue Realität schaffen. Insofern sind diese „Epen“ nicht nur vergangenheits-, sondern auch zukunftsgerichtet. Die Eigenschaften des Körper gewordenen göttlichen Wortes ebenso wie die Eigenschaften des von den Toten auferstandenen Messias verleihen ihrem literarischen „Wortkörper“ eine sakrale Autorität. Bis heute gehören „Babička“ und „Kytice“ zu den Grundfesten des Literaturkanons und sind Teil der tschechischen kulturellen Identität.

\section{Literaturverzeichnis}

\section{Primärliteratur}

DAŇHElKa, Jiří/Karel HádeK/Bohuslav HaVRáNEK/Naděžda KvítKová (Hrsg.) (1988): Staročeská kronika tak řěceného Dalimila [Die alttschechische Chronik des sogenannten Dalimil]. Bd. 1-2. Praha.

ERBEN, Karel J. (2003): Kytice. České pohádky [Der Blumenstrauß. Tschechische Märchen]. Praha.

JiRÁT, Vojtěch (Hrsg.) (1940): Lyrika Českého obrození (1750-1850) [Lyrik der tschechischen Wiedergeburt 1750-1850]. Praha.

Jungmann, Josef (1841): Sebrané spisy weršem i prosau [Gesammelte Schriften in Vers und Prosa]. Praha.

Jungmann, Josef (1825): Historie literatury české aneb saustawný prehled spisů českých, s krátkau historij národu, oswicenj a gazyka [Geschichte der tschechischen Literatur oder ein chronologischer Überblick über das tschechische

\footnotetext{
${ }^{22}$ Zum Begriff „Identifikator“ und seiner Funktion s. die Studie von Jaroslav Stř́itecký (Střítecký 1994). Als Identifikatoren werden hier einzelne Komponenten bezeichnet, die zu einem identitätsbildenden Gesamtbild gewebt werden, das der Identifikation einer gesellschaftlichen Gruppe dient. Die Rolle eines Identifikators können beliebige Gegenstände, Personen, Heilige, Tiere, Naturgebilde, aber auch Kriterien wie Ethnikum, Sprache, Staat, Schrift oder Religion annehmen. Jeder Identifikator kann seine Funktionsfähigkeit auch wieder einbüßen (Stř́ítecký 1994: 55).
} 
Schrifttum, mit einer kurzen Geschichte der Nation, Religion und Sprache]. Praha.

LEHÁr, Jan/Alexandr STICH (2000): Česká literatura od počátků k dnešku. Kniha texti̊ [Tschechische Literatur von den Anfängen bis heute. Textbuch]. Bd. 1. Praha.

NĚMCOvÁ, Božena (1999): Babička. Obrazy venkovského života [Die Großmutter. Bilder aus dem Landleben]. Praha.

WALDT, Ondřej František de (1938): Boemici praeconium idiomatis, Chvála českého jazyka [Lob der tschechischen Sprache]. Lat.-tsch. Ausgabe. Hrsg. v. Josef Vašica. Praha.

\section{Sekundärliteratur}

Assmann, Aleida (1999): Erinnerungsräume. Formen und Wandlungen des kulturellen Gedächtnisses. München.

BĚlina, Pavel/Tomáš Grulich u.a. (Hrsg.) (1992): Dějiny zemi koruny české [Geschichte der Länder der böhmischen Krone]. Bd. 2. Praha.

Berwanger, Kathrin (2001): Die szenische Poetik Božena Němcovás. Theatralische Medialität in ihren Briefen, Reiseskizzen und Erzählwerken. München.

Brisson, Luc (1996): Einführung in die Philosophie des Mythos. Darmstadt.

Bysveen, Josef (1982): Epic Tradition and Innovation in James Macpherson's ,Fingal: Uppsala.

Hodrová, Daniela/Zdeněk Hrbata/Marie KubínOvÁ/Vladimír MacurA (1997): Poetika míst. Kapitoly z literárni tematologie [Poetik der Orte. Kapitel aus der literarischen Thematologie]. Praha.

Hroch, Miroslav (1994): Nationales Bewusstsein zwischen Nationalismustheorie und der Realität der nationalen Bewegungen. In: SchmidtHartmann, Eva (Hrsg.) (1994): Formen des nationalen Bewußtseins im Lichte zeitgenössischer Nationalismustheorien. München, S. 39-52.

MACURA, Vladimír (1995): Znamení zrodu. České národni obrození jako kulturni typ [Zeichen der Wiedergeburt. Die tschechische Wiedergeburt als Kulturtyp]. Praha.

MACURA, Vladimír (1998): Český sen [Der tschechische Traum]. Praha.

MAREK, Jaroslav (1998): Česká moderní kultura [Tschechische moderne Kultur]. Praha.

MASARYK, Tomáš G. (1895): Česká otázka. Snahy a tužby národního obrození [Die Tschechische Frage. Ziele und Hoffnungen der nationalen Wiedergeburt]. Praha.

RoTH, Susanna (1991): Babička im Urteil tschechischer Gegenwartsautoren. Eine Umfrage. In: Andreas Guski (Hrsg.) (1991): Zur Poetik und Rezeption von Božena Němcovás „Babička“. Wiesbaden, S. 260-320. 
Schamschula, Walter (1990): Geschichte der tschechischen Literatur. Von den Anfängen bis zur Aufklärungszeit. Bd. 1. Köln/Wien.

SPÖRL, Uwe (2006): Basislexikon Literaturwissenschaft. 2. Auflage. Paderborn/München/Wien/Zürich.

STICH, Alexander/Jaroslava JANÁČKOVÁ/Jan LEHÁr/Jiří HolÝ (1998): Česká literatura od počátků $k$ dnešku [Tschechische Literatur von den Anfängen bis heute]. Praha.

STř́́teCKÝ, Jaroslav (1994): Identitäten, Identifikationen, Identifikatoren. In: Schmidt-Hartmann, Eva (Hrsg.) (1994): Formen des nationalen Bewußtseins im Lichte zeitgenössischer Nationalismustheorien. München, S. 53-66.

VODIČKA, Felix (1994): Počátky krásné prózy novočeské [Die Anfänge der neutschechischen Prosa]. Praha.

WuTSDORFF, Irina (2006): Místo Babičky ve vývoji české literatury v pohledu genderu [Die Stellung von Babička in der Entwicklung der tschechischen Literatur aus der Gender-Perspektive]. In: Piorecký, Karel (Hrsg.) (2006): Božena Němcová a jeji Babička, Sborník př́spěvků z III. Kongresu světové literárněvědné bohemistiky [Božena Němcová und ihre Babička, Sammelband vom III. Kongress der internationalen literaturwissenschaftlichen Bohemistik]. Praha, S. 37-46. 


\section{Helden wie wir? Die Rezeption von ,Kalevala ${ }^{66}$ und „Nibelungenlied" als Nationalepen im 19. Jahrhundert}

Der vorliegende Beitrag beschäftigt sich mit der Bedeutung von Nationalepen, indem er die Rezeption von „Kalevala“ und „Nibelungenlied“ im 19. Jahrhundert vergleicht. Während die Entstehungsbedingungen völlig unterschiedlich sind, weisen ihre Funktionen als Nationalepen im 19. Jahrhundert neben ihrer jeweiligen Besonderheit auch Gemeinsamkeiten auf: Dabei entsteht das eine Epos, um der Nation den Beweis ihrer Eigenständigkeit und ihrer Existenzberechtigung zu erbringen, während das andere Werk nach Jahrhunderten der Vergessenheit die Größe der Vorväter demonstrieren und einen Katalog nationaler Tugenden liefern soll. Im Konzept des Nationalepos verdeutlicht sich das Bedürfnis nach einer identitätsstiftenden literarischen Grundlage, auf die sich die gesamte Nation - oft genug in politischer Bedrängnis - berufen kann. Der Schwerpunkt dieses Artikels liegt auf dem langwierigen Entstehungsprozess des „Kalevala“, der stellenweise mit der Rezeption verflochten ist. Dem wird die Rezeption des "Nibelungenliedes“ gegenübergestellt, das am Beginn des 19. Jahrhunderts im Kontext der Befreiungskriege zum Nationalepos avancierte.

\section{Der Entstehungsprozess des ,Kalevala“6}

Das 19. Jahrhundert begann für die Finnen mit einer dramatischen Veränderung, die sich im Laufe weiterer hundert Jahre allerdings als Glücksfall herausstellen sollte, was den alles bestimmenden Wunsch nach Eigenständigkeit, d.h. insbesondere nach Unabhängigkeit anbelangt. Im Russisch-Schwedischen Krieg unterlag Schweden und musste Finnland 1809 an das Zarenreich abtreten. Für das Königreich war die Niederlage schmerzhaft: Es verlor ein Drittel seines Reichsgebietes und ein Viertel der Bevölkerung. Viel weitgehender jedoch waren die Folgen für die Finnen, die nach mehr als fünfhundertjähriger Zugehörig- 
keit zu Schweden nun in eine schwere Identitätskrise gerieten. Auf der Reichstagsversammlung von 1809 in Porvoo wurde das autonome Großfürstentum Finnland von Zar Alexander I. in den Stand eines Nationalstaates erhoben, der durch ein eigenes Parlament in inneren Angelegenheiten praktisch frei walten konnte. Doch die neue Situation stellte auch eine Herausforderung dar.

Das Gefühl der finnischen Oberschicht jener Zeit lässt sich treffend mit jenen geflügelten Worten wiedergeben, die Adolf Ivar Arwidsson ${ }^{1}$ in den Mund gelegt wurden: „Schweden sind wir nicht mehr, Russen wollen wir nicht werden, lasst uns also Finnen sein!“ (Zit. n. Karhu 1979: 202) ${ }^{2}$ Die angesprochene Identitätskrise rührte daher, dass die Frage, wer bzw. was die Finnen und ob sie einer eigenen Nation würdig seien, keineswegs beantwortet war. Durch den politischen Wandel begab man sich deshalb auf die Suche nach dem Eigenen, das man sehr bald in der finnischen Volksdichtung fand. Das Feld dafür wurde im Übergang vom 18. zum 19. Jahrhundert bestellt, ${ }^{3}$ als verschiedene Strömungen und Schriften aus Deutschland ihre Wirkung in Finnland entfalteten. An der einzigen Universität des Landes, in Turku, ${ }^{4}$ fanden Aufklärung, Romantik und die Schriften Johann Gottfried Herders (1744-1803), Friedrich August Wolfs (1759-1824) und anderer deutscher Gelehrter fruchtbaren Nährboden. Der Universalgelehrte Henrik

1 Arwidsson emigrierte als polemischster Vertreter der so genannten Turkuer Romantik (s. u.) 1823 nach Schweden, nachdem er zunächst auf politischen Druck die Zeitschrift „Åbo Morgonblad“ einstellen musste und im Rahmen einer Säuberungsaktion 1822 seine Dozentur für Geschichte in Turku verlor.

${ }^{2}$ Die Übersetzungen in diesem Artikel stammen, sofern nicht anders ausgewiesen, von mir.

${ }^{3}$ Eine erwähnenswerte frühe Form der Beschäftigung mit finnischer Identiät ist die sogenannte Fennophilie im Umkreis des Turkuer Philologen Daniel Juslenius (16561752). Juslenius' bekanntestes Werk ist in dieser Hinsicht „Aboa Vetus et Nova“ (1700). Die Fennophilie wirkte jedoch über den kleinen Kreis der Turkuer Gelehrten nicht hinaus.

${ }^{4}$ Turku (schwed. Åbo) war bis 1812 geistiges Zentrum und Hauptstadt Finnlands. Nach Ausrufung des Großfürstentums Finnlands wurde - nicht zuletzt, um die nach wie vor bestehenden geistigen und kulturellen Beziehungen zu Schweden abzubrechen - das bis dahin vollkommen unbedeutende Helsinki zur neuen Hauptstadt erklärt und durch Carl Ludwig Engel zu einem „kleinen St. Petersburg“ ausgebaut. Nach einem verheerenden Stadtbrand in Turku wurde 1828 auch die Universität in die neue Hauptstadt verlegt. 
Gabriel Porthan (1739-1804) wirkte vor diesem Hintergrund als geistiger Wegbereiter für die kommenden Entwicklungen in Finnland. In sein Werk flossen Ideen Herders ein, insbesondere zur Bedeutung von Sprache, Literatur und Geschichte für den Charakter und das Selbstbewusstsein eines Volkes. ${ }^{5}$

Dabei kamen vier Hauptgedanken Herders besondere Bedeutung zu (vgl. Wilson 1976: 28ff.), die für das Verständnis der Verbindung von Volksdichtung und nationalen Bemühungen wichtig sind und daher kurz umrissen werden sollen. Nach Herders Ansicht, so die erste These, bestehen zwischen Völkern z.B. aufgrund der jeweiligen natürlichen Umgebung notwendig Unterschiede, die durch ihre individuelle Geschichte verstärkt werden (vgl. Herder 1990: 59f.). So komme es zu einer allmählichen Entwicklung nationaler Einheiten, deren organische Strukturen sich im jeweiligen Nationalcharakter oder „Volksgeist“ widerspiegeln.

Die zweite These besagt, dass eine Nation nur dann als solche überdauern kann, wenn sie dem eigenen Volksgeist treu bleibt und die eigene Kultur pflegt (vgl. Herder 1990: 21f.). Dies geschieht durch die Anknüpfung an ihre eigene Vergangenheit. Der natürlichste Staat sei jener mit einem Volk und einem „Volksgeist“. Vielvölkerstaaten wie Russland entbehren demnach der einheitlichen Identität: Nichts sei unnatürlicher als verschiedene Völker unter einem Zepter. Versuche eine Nation, auf eine andere als die zu ihm gehörende kulturelle Grundlage aufzubauen, so werde ihre organische Entwicklung gestört.

Drittens geht Herder davon aus, dass die „nationale Seele“ eines Volkes sich am deutlichsten in der Sprache und namentlich in der Volksdichtung des jeweiligen Volkes ausdrückt (vgl. Herder 1990: 60, 1993: 33 und 1994: 154f.). Dichtung enthält ihren Wert zwar bereits als künstlerisches Werk in sich, doch ist die ihr innewohnende Geschichte von größerer Bedeutung. Die Volksdichtung - dieser Gedanke lässt sich an vielen Stellen im Werk Herders finden - fungiert somit als Spiegel der Nation, als Archiv und Stimme des Volkes.

Die vierte Hauptaussage Herders betrifft Finnland aus der Sicht der Rezipienten des 19. Jahrhunderts in besonderer Weise. Sollte die Kon-

\footnotetext{
${ }^{5}$ Vgl. dazu und zum Folgenden auch den Beitrag von Hans Graubner in diesem Band.
} 
tinuität in der Entwicklung eines Volkes unterbrochen werden, so sei die einzige Rettung das Sammeln von Volksdichtung aus der Zeit vor der Unterbrechung. Daher

bliebe nur noch eins, und dem Anschein nach das Geringschätzigste übrig, sich etwa nach den Resten der Volkslieder, wie sie jetzt leben, oder wie sie vor weniger Zeit, uns noch verständlich, lebten umtue und zusehe und sammle. Vielleicht daß da noch ein Fünklein Deutschen Vaterlandes wenn gleich unter Asch und Moder - (Herder 1990: 17) ${ }^{6}$

In Finnland war dieser Aspekt besonders wichtig, weil bereits erste Sammlungen von Volksdichtungen vorgenommen worden waren. Ohne diese Vorarbeiten wären die Ideen Herders nicht auf einen solch fruchtbaren Boden gefallen. Man war sich des Vorhandenseins der finnischen Volksdichtung bewusst, ausgeprägt v. a. in den Sängergebieten Kareliens, wohingegen man - abgesehen von der Übersetzung des Neuen Testaments durch Mikael Agricola - auf keine Literatur in finnischer Sprache verweisen konnte.

Neben Christfried Gananders (eines Schülers Porthans) „Mythologia Fennica“7 von 1789 war es vor allem Porthans „De Poësi Fennica“ (1766-99), die sich mit der Volksdichtung beschäftigt hatte. Porthan sah in der Dichtung nicht nur eine Reflexion der Vergangenheit, sondern ebenso die Reflexion eines reinen und unverdorbenen Ursprungs, der durch das Volk ohne den Einfluss fremder Künste bewahrt werde (vgl. Wilson 1976: 21). Damit bildete sich am Ende des 18. Jahrhunderts das Konzept der Finnen als eigenes Volk mit eigener Sprache und eigener Geschichte, eigenen Bräuchen und einem Nationalgeist allmählich heraus. ${ }^{8}$

\footnotetext{
${ }^{6}$ Über Nordeuropa schrieb Herder: „Alle nordischen Völker [...] hatten Gesänge: Gesänge, in denen das Leben ihrer Väter, die Taten derselben, ihr Mut und ihr Herz lebte.“ (Herder 1994: 184) An späterer Stelle fügt er hinzu: „Unter Nordländern [...] hatte, und erhielt sie [ihre Dichtung] den Charakter der Nation im Guten und Bösen.“ (Ebd., 214)

7 Gananders Werk war auch Jacob Grimm bekannt, so dass er am Beginn der „Deutschen Mythologie“ (1835: XV) schreiben konnte: „von finnischer und lettischer mythologie sind wir ziemlich unterrichtet“.

${ }^{8}$ Das Wirken Porthans reichte über den akademischen Kreis hinaus. Er war u. a. auch in der Aurora-Gesellschaft (1770-1779) tätig, die das Ziel verfolgte, die finnische Kultur zu erforschen und zu pflegen.
} 


\section{Elias Lönnrot als Schöpfer des „Kalevala““}

Elias Lönnrots (1802-1884) Muttersprache war - im Gegensatz zu den meisten Angehörigen der finnischen Oberschicht - das Finnische. Er war Arzt, Botaniker, Professor der finnischen Sprache, Sammler von Volksdichtung, Volksaufklärer und Verfasser von Wörterbüchern. Seine bedeutendste Leistung liegt jedoch in der Kompilation finnischer Gesänge zum „Kalevala“. Lönnrot immatrikulierte sich 1822 - dem brisanten Jahr der politisch motivierten Entfernung Arwidssons ebenso wie der spätere finnische Nationaldichter Johan Ludvig Runeberg (1804-1877) und der spätere Nationalphilosoph Johan Vilhelm Snellman (1806-1881) an der Universität Turku. Dort hatte sich die Strömung der so genannten Turkuer Romantik etabliert - unter diesem Begriff wird ein erstes nationales Bewusstsein unter den Angehörigen der Generation nach Porthan verstanden. Ziele der Turkuer Romantiker waren es, einen Sinn für nationalen Stolz, d.h. die eigene Vergangenheit zu entfachen, die finnische Sprache zu fördern ${ }^{9}$ und zur Sprache aller Finnen werden zu lassen sowie eine finnischsprachige Literatur zu schaffen.

$\mathrm{Zu}$ den Lehrern Lönnrots zählte Reinhold von Becker (1788-1858). Er gab ab 1820 die „Turun Wiikko-Sanomat“ (Turkuer Wochenzeitung) heraus, in der zahlreiche gelehrte Aufsätze erschienen. Zu den bedeutendsten zählte die dreiteilige Abhandlung „Väinämöisestä“ (dt. „Über Väinämöinen“), die für das Entstehen des „Kalevala“ maßgeblich wurde. Becker hatte Passagen aus verschiedenen Dichtungen um den Helden zusammengefügt. Im Vorfeld des Entstehungsprozesses des „Kalevala“ wurde hier erstmals ein Text erstellt, der aus mehr als einem Gesang besteht und dessen Inhalt die Fortführung einer Handlung durch Aneinanderreihung von Liedern darstellt. Dieses Musters bediente sich später auch Lönnrot. Von Bedeutung ist zudem, dass - bereits vor dem „Kalevala“ - in dem Aufsatz v. Beckers Väinämöinen eng mit dem finnischen Volk verbunden und als historische Gestalt interpretiert wird:

Wann Väinämöinen lebte, ist unbekannt. Er verließ die Welt vor langer Zeit. Vergeblich haben hundert Helden, vergeblich tausend andere bedeutende Männer versucht, so wie er zu werden. Ihre Namen ver-

\footnotetext{
${ }^{9}$ Aufgrund dieser Bemühungen entstanden erste Zeitungen in finnischer Sprache.
} 
schwanden wie der Morgentau, [...] aber der Name Väinämöinens wird nicht verschwinden, solange das finnische Volk auf der Erde erwähnt wird. (Turun Wiikko-Sanomat v. 20. Mai 1820: 3, Zit. n. Wilson 1976: 50)

Die Vorgehensweise v. Beckers und später Lönnrots lässt eindeutig den Einfluss Friedrich August Wolfs (1759-1824) erkennen. In seiner Schrift „Prolegomena ad Homerum“ von 1795 kam der Hallesche Professor zu dem Schluss, dass die griechischen Heldenlieder auf einer langen mündlichen Tradition basierten und erst nach der Erfindung der Schrift von einem „Halbphilologen“ zu einem epischen Ganzen zusammengefügt wurden (vgl. Wolf 1985: 116, 121). Diese „Liedertheorie“ wurde von Karl Lachmann auch auf das „Nibelungenlied“ übertragen (vgl. Lachmann 1816). Carl Axel Gottlund (1796-1876) war der erste, der die Zusammenfügung der finnischen Gesänge zu einem Volksepos nach dem Vorbild der Ilias oder des „Nibelungenliedes“ als Möglichkeit in Betracht zog:

Wenn daher die Jugend Finnlands [...] versuchen würde, sich um die einheimische Literatur zu kümmern und an ihr zu arbeiten - welches Tätigkeitsfeld würde sich ihrem Unterfangen öffnen! Sie fände Stellen, die sie vergebens in ausländischer Literatur suchen würde - ja, der Kritiker [d. i. Gottlund] geht so weit zu behaupten, dass, wenn man die alten Volkslieder sammeln wollte und aus diesen ein geordnetes Ganzes bildete, so entstünde daraus ein Epos, ein Drama oder etwas anderes, dann könnte daraus ein neuer Homeros, Ossian oder Niebelungenlied [sic] erwachsen; und die finnische Literatur erwachte in ihrer Besonderheit zu Glanz und Ehre, sich ihrer selbst bewusst, dem Strahlenkranz ihres Fortschritts, zur Bewunderung der Zeitgenossen und der Nachwelt. ${ }^{10}$ (Zit. n. Heikinheimo 1933: 307)

Vor diesem Hintergrund entstand 1827 Elias Lönnrots Magisterarbeit mit dem Titel „De Väinämöine priscorum Fennorum numine“ (dt. „Über Väinämöinen, eine Gottheit der alten Finnen“), worin er die gesamte bis dahin zu Väinämöinen verfügbare Dichtung beschrieb und begann, Verse aus verschiedenen Liedern ähnlichen Inhalts miteinander zu kombinieren.

Diese Arbeit wurde von ihm in der mittelfinnischen Stadt Kajaani fortgeführt, in der er nach seiner Promotion 1832 als Distriktarzt arbeitete.

${ }^{10}$ Dass das „Kalevala“ häufig neben Homer und das „Nibelungenlied“ gestellt wird, lag an der frühen neuzeitlichen Nibelungenrezeption, auf die ich unten näher eingehe. 
Ein Jahr zuvor war die Finnische Literaturgesellschaft mit dem Ziel gegründet worden, die Dichtung im so genannten „Kalevala“-Metrum systematisch zu sammeln. Lönnrot wurde ihr erster Sekretär und trat von Kajaani aus die meisten der insgesamt elf Reisen - ca. 20.000 Kilometer legte er zu Fuß zurück - zum Sammeln der alten Volksdichtung an. ${ }^{11} 1833$ reifte in Lönnrot nach einem Gespräch mit dem karelischen Liedersänger Vaassila Kieleväinen, der mehrere Helden der Gesänge im „Kalevala“-Metrum in einem Heldenzeitalter verbunden hatte und durch die Wolfsche Homer-Theorie beeinflusst war, der Gedanke einer antiken Heldenepoche der Finnen. Die Entstehung des „Kalevala“ geschah über fünf Stufen, von denen das so genannte Alte „Kalevala“ (1835) und das so genannte Neue „Kalevala“ (1849) von besonderer Bedeutung waren. ${ }^{12}$

\section{Die „Kalevala“-Rezeption}

Nach Beendigung des (Alten) „Kalevala“ „wagte sich Lönnrot an die Öffentlichkeit, die sogleich in einer Art kongenialer Rezeption die Bedeutung des Unternehmens begriff“ (Fromm 1974: 13). Im Herbst 1835, kurz vor Erscheinen des Epos, dessen erster Teil zu Weihnachten des Jahres veröffentlicht wurde, äußerte sich Runeberg in seiner Zeitschrift äußerst wohlwollend über den ihm bekannten Teil des Werkes:

Die Redaktion hat nicht die Gelegenheit bekommen, die weiteren Gesänge des „Kalevala“ einzusehen, glaubt aber in der Lage zu sein, aufgrund des vorliegenden [9. Gesanges] sicher zu bestimmen, dass die finnische Literatur aus dieser Gedichtsammlung einen Schatz bekommen hat, der sowohl durch seinen Ton und die Haltung, als auch durch seine Größe und seinen Wert durchaus vergleichbar ist mit den schönsten epischen

\footnotetext{
${ }^{11}$ J. G. Linsén, Vorsitzender der Literaturgesellschaft, fertigte 1847 eine Karikatur des sich auf Sammelreise befindenden Lönnrot an. Ihre Umschrift lautet „Unus homo nobis cursando restituit rem“ (dt. etwa: „Ein Mann hat uns wandernd den Staat gerettet“). Damit verweist Linsén auf den Dienst, den Lönnrot der Nation geleistet hat, aber auch auf Ennius, dessen Spruch er abgewandelt hatte. Ennius (239-169 v. Chr.) gilt als Vater der römischen Poesie.

${ }^{12}$ Die anderen Stufen sind die 1833 entstandenen unveröffentlichten Passagen um die Helden Vänämöinen und Lemminkäinen nebst Heiratsliedern sowie das so genannte Ur- oder Proto-,,Kalevala“ und eine für Schulzwecke gekürzte Fassung von 1862 (vgl. Honko 2000).
} 
Meisterwerken der griechischen Kunst. Alle diese Verdienste, die großartige und ruhige Führung der Erzählung und die Vollständigkeit der Bilder und die Bedeutung besitzt auch die finnische Gedichtsammlung, und vielleicht ist sie ihnen auch überlegen, falls man das Perfekte überbieten kann in der Pracht der Naturschreibungen und der schnörkellosen Schönheit. (Zit. n. Haavio 1949: 241)

Die Einschätzung des angesehenen Dichters war für die spätere ausschließlich positive Aufnahme des „Kalevala“ eine wichtige Voraussetzung. Der Vergleich mit den griechischen Epen wurde fortgeführt und blieb in der Folgezeit - auch um andere Epenstoffe erweitert - aktuell. Im selben Jahr äußerte Matias Aleksanteri Castrén (1813-1852), später erster Professor für finnische Sprache in Helsinki, in einer Jubiläumsansprache der „Pohjalaiset“ (dt. „Nordgesellschaft“), dass die Jugend ihr zukünftiges Glück in eben diesem Werk finden werde. Das „Kalevala“ repräsentiere den Text,

in dem wir die ursprüngliche Eigenart des finnischen Nationalcharakters treffen neben dessen ältesten religiösen Glauben [...]. In jeder Hinsicht muss man dies als bemerkenswertes Phänomen ansehen. Könnte es denkbar sein, dass man einen festeren, schöneren und wertvolleren Grund[pfeiler] für die zukünftige finnische Literatur hätte als diesen? (Zit. n. Haavio 1949: 241)

Im „Kalevala“ möchte man also bereits am Beginn der Rezeption die in der Volksdichtung überlieferte Identität und Besonderheit der Finnen erkennen. Ganz selbstverständlich wird es als Grundstein der kommenden finnischen Literatur betrachtet, die zu jener Zeit höchstens in Ansätzen zu erkennen ist.

Der erste Vorsitzende der Finnischen Literaturgesellschaft, Johan Gabriel Linsén (1785-1848), sprach in seiner Grußadresse für die Gesellschaft anlässlich der Fertigstellung des „Kalevala“ 1836 davon, dass Porthan, würde er noch leben, seinen Segen für diesen unerwarteten Sieg des Vaterlandes gegeben hätte. Linsén betonte, dass die finnische Literatur im „Kalevala“ nun europäische Bedeutung erreicht habe. Berühmt wurde sein Ausspruch:

Im Besitz dieser epischen Gedichte kann Finnland mutig und selbstbewusst seine Urgeschichte richtig verstehen und dadurch auch seine künftigen Geistesentwicklungen. Es kann zu sich selbst sagen: „Auch ich habe eine Geschichte!" (J. G. Linsén, am 16.3.1836 während der Jahresversammlung 
der Finnischen Literaturgesellschaft; zit. n. Nivanka 1961: 11. Der zweite Teil des so genannten Alten „Kalevala“ war erst wenige Tage zuvor erschienen)

Linsén sah im Erscheinen dieser Gesänge die Bestätigung der kulturellen Eigenständigkeit. Der verbreiteten Ansicht, die Finnen seien nichts weiter als der mindere Teil Schwedens, konnte man sich nun entgegenstellen. Spürbar war auch ein bis dahin selten zum Ausdruck gebrachtes Gefühl der Selbstachtung, das in der Folgezeit des 19. Jahrhunderts bestimmend wurde. Das „Kalevala“ erfüllte die Ziele der Turkuer Romantiker und in der angesprochenen Rede erhob Linsén auch die Forderung, das „Kalevala“ an den Volksschulen einzusetzen. Aufgrund seiner Wirkmächtigkeit sehen einige Forscher im finnischen Epos „,ihr [= der Finnen] Buch der Unabhängigkeit, ihre Eintrittskarte in die Familie der zivilisierten Nationen" (Wilson 1976: X). Das Erscheinen des „Kalevala“ bewirkte auch eine anschließende intensive Sammeltätigkeit finnischen Brauchtums nach dem Vorbild Lönnrots, der sich über Jahrzehnte Finnen aller Gesellschaftsschichten anschlossen. Der so gesammelte und dokumentierte Bestand der finnischen Volksdichtung im „Kalevala“-Versmaß (,Suomen Kansan Vanhat Runot“) umfasst ca. 100.000 Texte.

Das Erscheinen des „Kalevala“ sorgte auch international für großes Interesse. Bekanntestes Beispiel für die frühe Beschäftigung mit dem „Kalevala“ außerhalb Finnlands ist Jacob Grimms am 13. März 1845 an der Akademie der Wissenschaften gehaltene Rede „Über das finnische Epos“. Erst durch die 1841 von Castrén besorgte schwedische Übersetzung konnte er sich dem Epos nähern, von dessen Existenz er längst wusste. $^{13}$

Der geschilderten Begeisterung ist jedoch eine wichtige Einschränkung hinzuzufügen: Obwohl das „Kalevala“ nach seinem Erscheinen euphorisch begrüßt wurde, war das Interesse an seiner Lektüre erstaunlich gering. Es dauerte ganze zwölf Jahre, bis sich die 500 Exemplare der

\footnotetext{
${ }^{13}$ Die in der Rede J. Grimms wiedergegebenen, auf der schwedischen Übertragung M. A. Castréns beruhenden Passagen des Alten „Kalevala“ sind die ersten in deutscher Sprache (vgl. Grimm 1865: 106f.). Aufgrund der anschließenden Korrespondenz flossen eindeutig auch Grimm'sche Ansichten in die Neugestaltung des „Kalevala“ von 1949 ein (vgl. Kaukonen 1963: 235), das mit 22.795 Versen fast doppelt so umfangreich wie das von Grimm besprochene Alte „Kalevala“ wurde.
} 
Erstauflage verkauften (vgl. Haavio 1949: 245). Weder die schwedischsprachige Oberschicht noch die finnischsprachige Presse verfügten über genauere Kenntnisse des Epos (vgl. ebd., 246). Linsén gestand ein, das „Kalevala“ nicht verstehen zu können. Nur durch diese - keineswegs bewusst geförderte - Unkenntnis lässt sich die sehr flexible Interpretierbarkeit erklären. ${ }^{14}$

Die Stellung der finnischen Sprache sollte nach Erscheinen des „Kalevala" zügig verbessert werden. Schwedisch war noch in der Mitte des 19. Jahrhunderts „alleinige Sprache der Rechtsprechung, der Verwaltung, der Beamten, des höheren Unterrichts und der gesamten Bildung" (Laurila 1944: 95), doch waren $90 \%$ der Bevölkerung finnischsprachig. Unter dem Begriff der Fennomanie, deren energischster Vertreter Snellman war, wurden kulturvereinheitlichende Aktivitäten vorangetrieben, die eine Gleichstellung der finnischen mit der schwedischen Sprache sowie eine Verhinderung des Russischen als Amtssprache zum Ziel hatten. Es ist bemerkenswert, in welchem Ausmaß Vertreter der schwedischsprachigen Oberschicht das Finnische förderten (das sie selbst oft kaum beherrschten) und damit auch eigene Vorteile hintanstellten. ${ }^{15}$ Der spätere Helsinkier Universitätsrektor Zachris Topelius (1818-1898) dichtete 1844 anlässlich einer Promotionsfeier:

Ein Volk! Ein Land! Eine Sprache! Ein Gesang und eine Weisheit! Von See zu See, von Brust zu Brust fliegen die Wörter. Aus eigenen Quellen fließen die Flüsse Finnlands, aus eigener Quelle sollte auch seine Zukunft entspringen! (Zit. n. Haavio 1949: 250)

Ähnlich ließ sich auch Snellman im selben Jahr vernehmen:

Ihr jungen Männer, jedes schwedische Wort, das Ihr ab jetzt sagen werdet, ist der [finnischen] Literatur, dem Namen Finnlands und der eigenen Ehre verhältnismäßig verloren gegangen. Nur die Muttersprache kann Euren

\footnotetext{
${ }^{14}$ Laut Honko (1987: 282) wurden z. B. in Zeiten äußeren politischen Drucks die Helden des „Kalevala“ als heldische Vorväter betrachtet, während sonst die mythische Betrachtungsweise des Epos überwog.

${ }^{15}$ Gegen die Fennomanie bildete sich jedoch auch die Strömung der so genannten Svecomanie (finn. Svekomania) heraus, die die Identität der Finnlandschweden erhalten wollte. Aus der Svecomanie entwickelte sich die heutige Schwedische Volkspartei RKP.
} 
Werken und Euren Namen einen Platz in der Welt geben. (Zit. n. Haavio 1949: 250$)^{16}$

Den Bemühungen der Fennomanen war Erfolg beschieden: Nach der Regierung Zar Nikolaus I., die besonders am Ende der Amtszeit ein repressives System zur Unterdrückung möglicher Unruhen einführte, was sich in Finnland durch temporäre Zensur bemerkbar machte, wurde Alexander I. als Wohltäter empfunden: Durch ein von Snellman angeregtes Dekret wurde 1863 die vollständige Gleichstellung der finnischen und schwedischen Sprache binnen 20 Jahren veranlasst. Die Autonomie der finnischen Großfürstentums wurde durch Einführung einer eigenen Währung, der markka, unterstrichen und zum 50. Jubiläum der Veröffentlichung des „Kalevala“ 1885 konnte man das Epos in den nunmehr 31 existierenden finnischen Zeitungen feiern (1835 gab es nur eine finnischsprachige Zeitung, zum 75-jährigen Jubiläum bereits 86). Am 28. Februar, dem „Kalevala“-Feiertag, erschien in der Turkuer Zeitung „Turun Lehti“ der Artikel „Viisikymmentä vuotta“ (dt. „Fünfzig Jahre“), in dem die Bedeutung des „Kalevala“ hervorgehoben wurde:

Dieser Fortschritt ist so groß, dass jeder Bürger, egal wie klein und unbedeutend er auch sein mag, stolz sein kann, zu einem Volk zu gehören, das eine Zukunft hat. Denn ein Volk, das das „Kalevala“ schuf und großartige Schritte auf dem Weg des Fortschritts unternommen hat - dieses Volk kann nicht ohne Zukunft bleiben. (Turun Lehti vom 28. Februar 1885, ohne Seitenzählung)

Die Zeitung von Rauma schrieb zum selben Anlass im Artikel „Kalevalan juhlat“ (dt. „Kalevala-Feier“):

Die Veröffentlichung des „Kalevala“ markiert den Wendepunkt im Leben unseres Volkes, oder genauer: Unsere nationale Existenz beginnt erst mit diesem Ereignis. Im „Kalevala“ lernte sich das finnische Volk selbst kennen und sich selbst zu vertrauen; in diesem erwachten Verständnis wurden nationale Bemühungen auf einer soliden Grundlage errichtet [...]. (Rauman Lehti vom 13. Juni 1885, ohne Seitenzählung)

Die zur Schau gestellte Zukunftserwartung und der Hinweis auf die „solide Grundlage“ der Existenz sind allerdings bereits Reaktionen auf

${ }^{16}$ Snellmans griffige Formel war: „Yksi kieli, yksi mieli“ (dt. „Eine Sprache, eine Gesinnung“). 
die Russifizierungspolitik unter Alexander III. und Nikolaus II., die u.a. vorsah, die Rechte des Reichstages einzuschränken, Russisch als Verwaltungssprache einzuführen und finnische Männer in die Armee des Zaren einzuberufen. Der Protest gegen die verfassungsmäßig garantierten Rechte artikulierte sich in der Bevölkerung z.B. 1889 in einer Unterschriftenaktion, an der sich 523.000 Finnen beteiligten - dies entsprach der Hälfte der erwachsenen Bevölkerung. Die Finnen betrachteten sich längst als unabhängige Nation. Auf künstlerischer Seite bildete sich in dieser Zeit der Karelianismus heraus, der in verschiedenen Ausdrucksformen dadurch an das Nationalgefühl appellierte, dass er sich an „Kalevala“-Motiven orientierte.

Abschließend ein kurzer Ausblick auf weitere historische Interpretationen und Instrumentalisierungen des „Kalevala“. In einer Schrift über Castrén fasste Snellman 1870 - in einer politisch eher ruhigen Zeit - die Bedeutung des „Kalevala“ folgendermaßen zusammen:

Deswegen war es kein geringer Gewinn für die finnische Literatur, als sich zeigte, dass nämlich schon im Volkslied ein Werk war, das auf dem gesamten Gebiet der europäischen Literatur kaum ebenbürtiges [fände], ein Werk, das immer neben den unsterblichen Gesängen Homers, dem „Niebelungenlied“ [sic!] und den skandinavischen Götter- und Heldengeschichten genannt würde. Es wird schwer fallen zu zeigen, dass irgendeine mit dem Schwert ausgeführte Heldentat beständiger sein sollte als die Großtat solch eines friedvollen Liedes, das das Nationalbewusstsein des Volkes erweckt. (Snellman 1930: 64)

Zwei Jahrzehnte später wird die Betonung des friedvollen Charakters zugunsten einer nun wieder historisch geprägten Auslegung zurückgestellt. Kaarle Krohn (1863-1933), Mitbegründer der geographisch-historischen Methode, weltweit erster Professor für Erzählforschung und späterer Vorsitzender der Finnischen Literaturgesellschaft, sah in den Haupthelden des „Kalevala“ historische Krieger, das Nordland Pohjola wurde mit Gotland in Verbindung gebracht, das als reiche Insel die finnischen Helden anlockte (vgl. Krohn 1924: 114-131). Diese Kehrtwende gegenüber seinen eigenen bisherigen Forschungsergebnissen und denen seines Vaters ist vielleicht auch als Erwiderung auf Domenico Comparretti (1835-1927) zu verstehen, der sich über die finnischen Helden wunderte: 
Der Held ist Zauberer, nicht Krieger, wie er es in allen andern grossen Heldengedichten zu sein pflegt; die heroische Handlung ist von bloss individuellem, nicht allgemeinem, nicht nationalem Interesse [...]. In anderen nationalen Epopöen wird die Handlung [...] im historischen Leben der Nation erblickt [...]. (Comparetti 1892: 301)

Diese Betrachtungsweise mochte Krohn nicht gelten lassen:

Die in den ursprünglichen fassungen der heldenlieder gelegentlich vorkommenden zauberkünste und wunder sind keineswegs derart, dass sie zu der annahme einer abnormität des finnischen heldentypus berechtigen könnten. (Krohn 1924: 129; zum Heldentypus im „Kalevala“ vgl. auch Fromm 1974: 18)

Am Ende des 19. Jahrhunderts war das finnische Epos zum Symbol einer kulturell und politisch eigenständigen Nation geworden - das ist es bis heute geblieben.

\section{Die Rezeption des ,Nibelungenliedes ${ }^{66}$}

Auch für die Deutschen begann das 19. Jahrhundert mit politischen Veränderungen: Durch den Reichsdeputationshauptschluss gestaltete sich 1803 die Karte des Heiligen Römischen Reiches völlig neu. Als Reaktion auf die Bildung des Rheinbunds fand die Tradition des Reichs durch Abdankung Kaiser Franz II. 1806 nach fast tausendjähriger Geschichte ein von vielen als betrüblich empfundenes Ende; Napoleon zog in das besiegte Berlin ein.

Die Niederlagen gegen Frankreich wurden insbesondere von der mehrheitlich antinapoleonisch ausgerichteten - bürgerlichen Bildungsschicht als Demütigung bewertet. Um ihren Zielen eine breite Basis zu verschaffen, griff sie auf das Konzept der Nationalbildung zurück. Schmerzlich vermisst wurde dabei die verbindende Kraft eines nationalen Gründungsmythos (vgl. von See 1991). Als verbindende kulturelle Bezugspunkte dienten stattdessen die Schriften Herders, die Ossian-Begeisterung, die zum Beispiel in Klopstocks Bardendichtung Widerhall fand, und die frühe Romantik.

Der Züricher Literaturkritiker, Schriftsteller und Übersetzer Johann Jakob Bodmer (1698-1783) besorgte 1757 den ersten neuzeitlichen 
Teildruck des späteren „Nibelungenliedes“ ${ }^{17}$ Er sah in dem Werk eine „Art Ilias, von Norwegischen Sagen entsprungen und mit einheimischen Romanzen verwebt“ (zit. n. Ehrismann 1975: 247). Zehn Jahre später erschien eine Bearbeitung von Bodmers Fassung in Hexametern, womit zugleich eine formale Nähe zu den klassischen griechischen Epen suggeriert und der zeitgenössische Geschmack bedient werden sollte (vgl. Kolk 1990: 4).

Die Verknüpfung mit dem griechischen Epos (vgl. Bodmer 1757: VIIf.) erwies sich als beständiger Faktor der Rezeptionsgeschichte, so 1781/82 in der eng aufeinanderfolgenden Veröffentlichung von Johann Heinrich Voß' Übertragung der „Odyssee“ und der ersten vollständigen Ausgabe des „Nibelungenliedes“, besorgt von Christoph Heinrich Myller. Myller wollte die Ausgabe Friedrich dem Großen widmen, der sie allerdings in einem Brief keinesfalls als Bereicherung der „Teutschen Sprache“ betrachtete; sie war ihm „nicht einen Schuß Pulver, werth“ (zit. n. Ehrismann 1975: 39). Um die Verbreitung der Myllerschen Ausgabe kümmerte sich insbesondere Johannes von Müller (1752-1809), dessen Deutung des „Nibelungenliedes“ als deutsche „Ilias“ sich weniger auf einen vergleichbaren Inhalt als vielmehr auf die erhoffte Wirkung stützte.

Im Zuge einer am Anfang des 19. Jahrhunderts um sich greifenden Mittelalterbegeisterung waren dann die Brüder Schlegel und bald darauf Friedrich Heinrich von der Hagen (1780-1856) die engagiertesten Verfechter des „Nibelungenliedes“.

August Wilhelm Schlegel (1764-1845) hielt seit 1801 in Berlin literaturhistorische Vorlesungen, in denen er sich auch dem „Nibelungenlied“ widmete. Sein Zugang zur Literatur des Mittelalters war romantisch geprägt:

Diese Heldensagen [des Mittelalters] beweisen uns, dass das damalige Menschengeschlecht nicht nur an Riesenkraft der Leiber, sondern an Größe und Reinheit der Gesinnungen den nachfolgenden weit überlegen war [...]. (Schlegel 1965: 109)

${ }^{17}$ Der erste Teil des „Nibelungenliedes“ bildete in der Auffassung Bodmers keine Einheit mit dem zweiten Teil, sondern lieferte v. a. biographische Angaben (vgl. Bodmer 1757: V). 
Der begeisterte Patriot v. d. Hagen stellte das „Nibelungenlied“ und dessen Verbreitung in das Zentrum seines Lebenswerkes. Hagens „Erneuung“ (so der von ihm verwendete Begriff) des "Nibelungenliedes“ aus dem Jahr 1807 brachte ihm 1810 die Berufung an den ersten Lehrstuhl für Deutsche Sprache und Literatur ein, der im Zuge der patriotischen Erhebung in Berlin geschaffen wurde und „unter den gegebenen Umständen eine Professur für mittelhochdeutsche Epen bedeutete“ (vgl. Hermand 1994: 31). Der Berliner Lehrstuhl bot - wie die vermehrte Einrichtung entsprechender Professuren im Lande - eine Möglichkeit der Opposition gegen Napoleon. V. d. Hagen verfolgte das Ziel einer „nationalpädagogischen Aufbereitung altdeutscher Texte“ (Kolk 1990: 49); dabei war ihm weniger an philologischer Genauigkeit als an der erwünschten Breitenwirkung gelegen. Die Nibelungen galten ihm als „lebendige Urkunde des unvertilgbaren deutschen Karakters, [...] der jede fremde Fessel über kurz oder lang immer wieder zerbricht“ (Der Nibelungen Lied 1824: I). Das „Nibelungenlied“ wurde als Erbauungstext betrachtet, der

die herrlichsten männlichen Tugenden offenbart, als da sind: Gastlichkeit, Biederkeit, Redlichkeit, Treue und Freundschaft bis in den Tod, Menschlichkeit, Milde und Großmuth in des Kampfes Noth, Heldensinn, unerschütterlicher Standmuth, übermenschliche Tapferkeit, Kühnheit und willige Opferung für Ehre, Pflicht und Recht; Tugenden die [...] uns [...] zugleich Muth zu Wort und That, mit Stolz und Vertrauen auf Vaterland und Volk, mit Hoffnung auf eine dereinstige Wiederkehr Deutscher Glorie und Weltherrlichkeit erfüllen. (Der Nibelungen Lied 1824: III)

Hier ist der Bezug zur politischen Situation unverkennbar, wenngleich die in Anschlag gebrachten Tugenden auch später immer wieder aufgegriffen wurden. Belegstellen für seinen recht heterogenen Tugendkatalog liefert v. d. Hagen nicht - ein eindeutiger Zusammenhang mit der Handlung des „Nibelungenliedes“ dürfte auch schwerlich herzustellen sein.

Die Bedeutung v. d. Hagens darf allerdings auch nicht überschätzt werden. Eine weite Verbreitung des Buches erfolgte nicht. Die erste und längere Zeit einzige neuhochdeutsche Übertragung des „Nibelungenliedes" erwies sich ebenso wenig als Verkaufserfolg wie die Ausgabe des mittelhochdeutschen Textes v.d. Hagens von 1810. Auch seine 
Vorlesungen fanden wenig Beachtung. Die Verlegerin Friderike Helene Unger schrieb 1811 an A. W. Schlegel:

Die Nibelungen liegen wie Blei; und außer denen, die ich verschenkt habe, und HE. v. d. Hagen verschenkte, kommen nur die verhaßten Remitenda; von 30 verschriebenen, remittiert 29. Dieß ist buchstäblich wahr; trotz dem, dass Profeßor Luden in Jena darüber ließt und andre ein großes Holzhacken drüber anstellen. Trotz dem, dass He. v. d. Hagen, bei hiesiger Universität einen Lehrstuhl eröffnete, Kollegia ankündigte, was mit Jubel erwiedert wurde, und zu welchem sich dennoch nur ein sage 1. Zuhörer fand; die privaten Vorlesungen hatten nicht besseren Fortgang; und somit ist dem altdeutschen Wesen der Stab gebrochen. (Zit. n. Schulte-Wülwer 1974: 12)

Im Jahr 1811 wechselte v. d. Hagen nach Breslau, wo er bis 1822 jedes Jahr seine Vorlesungen über das „Nibelungenlied“ wiederholte (vgl. Hermand 1994: 31). Auch an den Universitäten in Königsberg, Gießen, Greifswald und Heidelberg wurde mit entsprechenden Vorlesungen begonnen.

Nach der Niederlage Napoleons in Russland 1812 und der einsetzenden patriotischen Begeisterung in den Freiheitskriegen lässt sich eine signifikante Veränderung feststellen: Ein Jahr nach Ungers Brief hörten im Winter 1812-1813 in Berlin 300 der 600 eingeschriebenen Studenten die Vorlesungen zum „Nibelungenlied“ von August Zeune, der 1815 eine „Feld- und Zeltausgabe“ des Epos für die Soldaten herausgab und 1816 gutbesuchte Vorträge zum „Nibelungenlied“ in Heidelberg, Frankfurt am Main und Worms hielt.

Wie stark die Rezeption des „Nibelungenliedes“ mit dem politischen Geschehen verbunden war, lässt sich erneut an Zahlen ablesen: In der Phase der Restauration ging das Interesse an Vorlesungen über die altdeutsche Literatur geradezu dramatisch zurück, wenngleich die Zahl der Professoren zunahm (vgl. Schulte-Wülwer 1974: 73). Mit dem Einzug des Biedermeier erfolgte an den Universitäten eine zunehmend wissenschaftliche Beschäftigung mit dem „Nibelungenlied“, die von der gesellschaftlichen Entwicklung weitgehend abgekoppelt war. Die Auffassung vom Nationalepos blieb weiterhin bestehen, auch wenn an die Stelle der kurzzeitigen Nibelungenbegeisterung nun die Mode der Stauferromane trat: „[D]iese Barbarossas, Friedriche und Konradins nahmen für ein paar Jahrzehnte in sich auf, was vor ihnen Siegfried, 
Kriemhild und Hagen durchs Volk getragen hatten“ (Mackensen 1984: 230).

Unter dem Eindruck der gescheiterten Revolution von 1848 wurde (Fürsten-) Treue als vorrangige Nibelungentugend hervorgehoben. Symptomatisch heißt es in der viel gelesenen Literaturgeschichte A. F. C. Vilmars:

Für den lieben König und Herrn wird alles gethan, wird treulich gekämpft, wird willig geblutet, wird freudig in den Tod gegangen, für ihn wird mehr gethan als gestorben: für ihn werden starken Herzens auch die Kinder geopfert [...]. Diese Züge [...] sind das eigentliche Lebenselement des deutschen Volkes, das eigentlich schlagende Herz des deutschen Epos. (Zit. n. Der Schatz des Drachentödters 1977: 59)

Die Gründung des Deutschen Kaiserreiches 1871 führte zum wirtschaftlichen Erstarken des Bürgertums, dem nun auch politische Einflussnahme und Aufstiegschancen möglich waren. Dem „Nibelungenlied“" wurden abermals neue Seiten abgewonnen. Bismarck etwa wurde zu einem strahlenden Siegfried stilisiert und Kaiser Wilhelm II. hielt anlässlich eines Manövers in Koblenz im September 1893 einen Vortrag zum Thema „Die deutsche Einheit der Nibelungenhort“ (vgl. Büxenstein 1898: 81).

\section{Fazit}

Die Rezeption von „Kalevala“ und „Nibelungenlied“ verfügte im 19. Jahrhundert über eine eminente gesellschaftspolitische Dimension. Auf keine anderen Texte sind in Finnland und Deutschland so große politische Hoffnungen gesetzt worden. Während das „Kalevala“ von Beginn an als Nationalepos konzipiert war, wurde das „Nibelungenlied“ zunehmend als ein solches instrumentalisiert. In dieser Funktion erfuhren beide Werke eine wechselhafte Rezeption und begleiteten die Nation auf dem Weg zur Reichsgründung bzw. zur Unabhängigkeit. Dabei nahm das „Kalevala“ eine wesentlich stärker integrierende Rolle ein als das „Nibelungenlied“. Dass beide Texte häufiger rhetorisch genutzt als wirklich gelesen wurden, haben die geringen Verkaufszahlen gezeigt. Der politischen Instrumentalisierung kommt die weitgehende Textunkenntnis durchaus entgegen: Je flexibler die 
Texte dadurch eingesetzt werden können, desto besser eignen sie sich in unteschiedlichen historischen Kontexten als kulturelles Rückgrat der Nation.

\section{Literaturverzeichnis}

\section{Primärliteratur}

BoDmer, Johann Jacob (1757): Chriemhilden Rache, und die Klage; Zwey Heldengedichte aus dem schvvabischen Zeitpuncte. Zyrich.

Comparetti, Domenico (1892): Der Kalewala oder die traditionelle Poesie der Finnen, Historisch-kritische Studie über den Ursprung der großen nationalen Epopöen. Halle.

GRIMM, Jacob (1835):Deutsche Mythologie. Göttingen.

Grimm, Jacob (1865): Über das finnische Epos. In: ders. (1865): Kleinere Schriften. Zweiter Band. Berlin, S. 75-112.

HERDER, Johann Gottfried (1990): Volkslieder, Übertragungen, Dichtungen. In: ders. (1990): Werke in 10 Bänden. Hrsg. v. Ulrich Gaier. Werkausgabe Bd. 3. Frankfurt a. M.

Herder, Johann Gottfried (1994):, Schriften zu Philosophie, Literatur, Kunst und Altertum 1774-1787. In: ders. (1994): Werke in 10 Bänden. Hrsg. von Jürgen Brummak. Werkausgabe Bd. 4. Frankfurt a. M.

HERDER, Johann Gottfried (1993): Schriften zum Alten Testament. In: ders. (1993): Werke in 10 Bänden. Hrsg. v. Rudolf Smend. Werkausgabe Bd. 5. Frankfurt a. M.

JUSLENIUS, Daniel (1988 [1700]): Vanha ja uusi Turku, ins Finnische übertragen von Tuomo Pekkanen und Virpi Seppälä-Pekkanen. Jyväskylä.

Krohn, Kaarle (1924): Kalevalastudien. Bd. 1: Einleitung. Helsinki.

DER NIBELUNGEN LIED (1824). Erneuet und erklärt durch Friedrich Heinrich von der Hagen, zweite umgearbeitete Ausgabe. Frankfurt a. M.

RAUMAN LEHTI v. 13.06.1885.

SCHLEGEL, August Wilhelm ([1802-1803] 1965): Kritische Schriften und Briefe IV: Geschichte der romantischen Literatur. Hrsg. v. Edgar Lohner. Stuttgart.

Snellman, Johan Vilhelm (1930): Kootut teokset. 12 Bde, Porvoo 1928-1932, Bd. 10. Porvoo.

TURUN LEHTI v. 28.02.1885.

Wolf, Friedrich August (1795): Prolegomena ad Homerum. Halle [Englische Übersetzung (1985): Prolegomena to Homer. Translated with introduction and notes by Anthony Grafton/Glenn W. Most/James E. G. Zetzel. Princeton]. 


\section{Sekundärliteratur}

BÜXensteIn, Georg (1898): Unser Kaiser - Zehn Jahre der Regierung Wilhelm II. 1888-1898. Berlin/Stuttgart/Leipzig.

Ehrismann, Otfried (1975): Das Nibelungenlied in Deutschland. Studien zur Rezeption des Nibelungenlieds von der Mitte des 18. Jahrhunderts bis zum ersten Weltkrieg. Münchner Germanistische Beiträge. Bd. 14. München.

Fromm, Hans (1974): Zwischen Parodie und Mythos. Kalevalische Betrachtungen. In: Schriften aus dem Finnland-Institut in Köln 11. Hamburg, S. 7-35.

HAAvio, Martti (1949): Kalevalakultti. In: Frans Akseli Heporauta/Martti Haavio: Kalevala. Kansallinen aarre. Kirjoitelmia kansalliseepoksen vaiheilta. Porvoo/Helsinki, S. 240-275.

Heikinheimo, Ilmari (1933): Kaarle Aksel Gottlund: Elämä ja toiminta. Porvoo.

HERMAND, Jost (1994): Geschichte der Germanistik. Reinbek bei Hamburg.

Honko, Lauri (1987): The Kalevala: Myth or History? In: Bo Almqvist/ Séamas Ó Catháin/Pádraig Ó Héalaí (Hrsg.) (1987): The Heroic Process. Form, Function and Fantasy in Folk Epic. Dublin, S. 279-292.

Honko, Lauri (2000): Kalevalan viisi esitystä. In: Niina Roininen (Hrsg.) (2000): Viimeinen Väinämöinen. Näkökulmia. Turku, S. 10-36.

KARHU, Eino (1979): Suomen kirjallisuus runonlaulajista 1800-luvun loppuun, I osa. Helsinki.

Kaukonen, Väinö (1963): Jacob Grimm und das Kalevala-Epos. In: Deutsches Jahrbuch für Volkskunde. Bd. 9. Berlin, S. 229-239.

KoLK, Rainer (1990): Berlin oder Leipzig? Eine Studie zur sozialen Organisation der Germanistik im „Nibelungenstreit“. Tübingen.

LAURILA, Kaarle Sandfried (1944): Der deutsche Einfluß in der finnischen Literatur. In: Eino Sormunen (Hrsg.) (1944): Finnland und Deutschland: der Einflu $\beta$ Deutschlands auf die finnische Kultur. Schriften der Luther-Agricola Gesellschaft in Finnland 7. Turku, S. 66-104.

Mackensen, Lutz (1984): Die Nibelungen. Sage, Geschichte, ihr Lied und sein Dichter. Stuttgart.

Niedling, Christian (2007): Zur Bedeutung von Nationalepen im 19. Jahrhundert. Das Beispiel von Kalevala und Nibelungenlied. Köln.

NivankA, Eino (Hrsg.) (1961): Pysy Suomessa pyhänä: Suomalaisen Kirjallisuuden Seuran esimiesten puheita vuosina 1834-1946. Suomalaisen Kirjallisuuden Seuran toimituksia 268. Helsinki.

SCHulte-WülWER, Ulrich (1974): Das Nibelungenlied in der deutschen Kunst und Kunstliteratur zwischen 1806 und 1871. Diss. Kiel.

SEE, Klaus v. (1991): Das Nibelungenlied - ein Nationalepos? In: Joachim Heinzle/Anneliese Waldschmidt (Hrsg.) (1991): Die Nibelungen. Ein deutscher 
Wahn, ein deutscher Alptraum. Studien und Dokumente zur Rezeption des Nibelungenstoffs im 19. und 20. Jahrhundert. Frankfurt a. M., S. 43-110.

Wunderlich, Werner (Hrsg.) (1977): Der Schatz des Drachentödters. Materialien zur Wirkungsgeschichte des Nibelungenliedes. Stuttgart.

Wilson, William (1976): Folklore and Nationalism in Modern Finland. Indiana University Press (Bloomington). 


\section{Letzte Tage der Männlichkeit. Die Nibelungen in Heiner Müllers „GERMANIA“-Dramen}

Eine der düstersten Szenen aus den düsteren Stücken Heiner Müllers findet sich in seinem letzten Theatertext „GERMANIA 3 GESPENSTER AM TOTEN MANN“. Der Titel der Szene, die in Stalingrad lokalisiert ist, formuliert eine Spielanweisung und lautet: „Drei deutsche Soldaten nagen an einem Knochen" (G3 24). Als einer der nagenden Soldaten darüber spekuliert, ob der Knochen von einem Pferd oder einem deutschen Soldaten stammt, übergibt sich ein anderer. Der erste kommentiert: „Kotz dich aus / Bald sind wir alle drei nur noch Gefrierfleisch“ (ebd.). In diesem perspektivlosen Moment betreten Kriemhild und Hagen die Bühne - doch auch der Auftritt der beiden Nibelungen bringt für die Soldaten keine Wendung zum Erträglicheren. Vielmehr setzen die Nibelungen zu einer verbalen Selbstzerfleischung an, in der sie sich gegenseitig jenen Tod wünschen, dem auch die Soldaten nicht entkommen werden.

Das „Nibelungenlied“ wird bei Müller - das deutet schon dieser Ausschnitt an - im Kontext eines zivilisatorischen und nationalen Tiefpunkts aufgerufen. Wenn es erstens stimmt, dass das „Nibelungenlied“ seit dem späten 18. Jahrhundert ,als deutsches Nationalepos aufgefasst“ (Müller 2009: 180) wird, ja dass es bis heute „das Nationalepos“ (Anonym 2010) der Deutschen darstellt, wie man sowohl in der germanistischen Fachliteratur als auch bei Wikipedia nachlesen kann, ${ }^{1}$ und wenn man zweitens mit vielen Beiträgen dieses Bandes davon ausgeht, dass Nationalepen eine zentrale Funktion beim nation building zukommt - dann fungieren Heiner Müllers Texte als Abrissbirnen von positiven Nationalgefühlen. Müller verortet das „Nibelungenlied“ nicht im Kontext des Aufbaus, sondern der (Selbst-)Zerstörung des Nationalen.

\footnotetext{
${ }^{1}$ Auch der Artikel „Nationalepos“ in der Neuauflage des Metzler Lexikon Literatur nennt das „Nibelungenlied“ als einzigen Text „für Deutschland“ (Grimm 2007: 531).
} 
Erledigt hat sich das Nationalepos damit für ihn allerdings nicht. Anders als der renommierte Historiker Herfried Münkler, der seit den 1980er Jahren die These vertritt, dass die Nibelungen 1945 die Wirkungsmacht „über die Köpfe der Deutschen“ (Münkler/Storch 1988: 132) verloren hätten, ${ }^{2}$ gibt Müller 1983 in einem Interview mit dem „Spiegel“ zu Protokoll: „Deutschland spielt immer noch die Nibelungen“ (Müller 1983). ${ }^{3}$ Neben der griechischen Mythologie und Shakespeares Tragödien stellen die Nibelungen die dritte bedeutsame literarisch-mythologische Anlaufstelle im Werk des Zitationskünstlers Müller dar, und zwar - wie Müller gleich am Anfang eines 1987 mit dem Religionswissenschaftler und Nibelungenexperten Klaus Heinrich geführten langen Gesprächs über die Nibelungen klarstellt - im vollen Bewusstsein der im 19. Jahrhundert einsetzenden „Inthronisierung des ,Nibelungenliedes' als Nationalepos" (Heinrich/Müller 2007: 19). ${ }^{4}$

Das Ziel der folgenden Ausführungen besteht darin, die Spielweise der Nibelungen vor allem in Müllers beiden „GERMANIA“-Dramen von 1971 und 1995 differenzierter und mit einem anderen Ergebnis zu analysieren, als es in der bisherigen Forschung der Fall ist. Meine These lautet, dass die Nibelungen in beiden Texten ein nationales Endspiel austragen, das in „GERMANIA 3“ allerdings dadurch die Richtung ändert, dass es als Geschlechterkampf inszeniert wird: Während die Nibelungen im ersten Drama auf chauvinistische Weise ihre Männlichkeit feiern, markiert der Wechsel zu Kriemhild als wichtigster Protagonistin im zweiten Drama eine folgenreiche Geschlechtsumpolung des Nationalepos. Damit gewinnt das Drama eine vorsichtig positive Zukunfts-perspektive, welche die Überwindung der von Müller oft beschworenen „deutschen Misere“ (Müller 2008a: 75) denkbar werden lässt.

\footnotetext{
${ }^{2}$ Vgl. dazu auch das Kapitel zur Nibelungenrezeption, das 1945 abbricht. Münkler 2009: 69-107.

${ }^{3}$ Günther Heeg, Stefan Schnabel und KD Wolff vertreten 2007 die Ansicht, dass die 1980er Jahre ,zumindest im linken, aufgeklärten Bewusstsein, im Schatten des Nibelungen-Mythos“" stehen; allerdings nicht im Sinne einer affirmativen Rezeption, sondern im Kontext apokalyptischer Szenarien: „Die Nibelungen sind immer die anderen“ (Heeg 2007: 7f.).

${ }^{4}$ Im gleichen Gespräch stellt Heinrich die Frage, welche Version des Stoffes „eigentlich das Nationalepos“ sei; er bringt Wagners „Der Ring des Nibelungen“ ins Spiel, Storch plädiert für Hebbels „Die Nibelungen“ und Müller schweigt (Heinrich/Müller 2007: 26).
} 


\section{Der Kampf der Nibelungen als das deutsche ABC: „GERMANIA TOD IN BERLIN““}

Der zentrale Bezugstext des Spätwerks „GERMANIA 3“ ist Müllers 1971 fertig gestelltes Stück „GERMANIA TOD IN BERLIN“. Schon hier sind die Nibelungen in eine Szene integriert, die drei deutsche Soldaten in Stalingrad zeigt. An den Soldaten ziehen zunächst (mit grünem Gesicht) Cäsar und - „bleich und dick“ (G 341) - Napoleon vorbei, die sich als Untote von den Leichen ihrer Soldaten ernähren. „Dann treten überlebensgro $\beta$ in verrosteten Harnischen die Nibelungen Gunther, Hagen, Volker und Gernot auf" (ebd.). Während als Repräsentanten anderer europäischer Nationen politische beziehungsweise militärische Führer aufgerufen werden (dazu passt auch der Hinweis auf Stalin im Szenentitel „HOMMAGE A STALIN 1“), übernehmen im deutschen Fall bezeichnenderweise literarische Gestalten diese Position. Nationale Identifikationsfiguren entnimmt Müller nicht der Geschichte, sondern dem Epos, also einem fiktionalen Text. Gleichzeitig stellt die Assoziation von Stalingrad und Nibelungen ein historisch vorgegebenes, insofern faktuales Interpretationsmuster dar, als Hermann Göring (vermutlich angeregt von Joseph Goebbels $)^{5}$ in seiner Ansprache vom 30. Januar 1943 zum zehnten Jahrestag der nationalsozialistischen Machtübernahme den zu dieser Zeit bereits völlig aussichtlosen Kampf um Stalingrad als Wiederholung des Nibelungenstoffes gedeutet hat. Für Müller ist das nach eigenen Angaben die wichtigste Anregung zu seiner produktiven Beschäftigung mit dem Nibelungenstoff gewesen. ${ }^{6}$ Über den „Kampf der Nibelungen“ heißt es in Görings Rede, die kurz darauf auch im „Völkischen Beobachter“ nachzulesen war:

Auch sie standen in einer Halle von Feuer und Brand und löschten den Durst mit dem eigenen Blut - aber kämpften und kämpften bis zum letzten. Ein solcher Kampf tobt heute dort, und jeder Deutsche noch in tausend Jahren muß mit heiligen Schauern das Wort Stalingrad aussprechen und sich erinnern, daß dort Deutschland letzten Endes doch den Stempel zum Endsieg gesetzt hat! (Zit. n. Heinzle 2003: 395f.)

\footnotetext{
${ }^{5}$ Am 27. Januar 1943 hatte Goebbels in der Ministerkonferenz die Parole ausgegeben, man müsse „aus dem Heldentum von Stalingrad einen Mythos entstehen lassen, der einen kostbaren Besitze der deutschen Geschichte“ (zit. n. Bohse 1981: 91) bilden solle. ${ }^{6}$ Vgl. Heinrich/Müller 2007: 19f. Rezipiert hat er den Nibelungenstoff schon früh: Hebbels „Nibelungen“ habe er „so mit elf, zwölf“ (ebd., 42) gelesen.
} 
Bemerkenswerterweise wird der Kannibalismus der Nibelungen (und damit eines von Müllers Lieblingsmotiven $)^{7}$ selbst von Göring angesprochen (,und löschten den Durst mit dem eigenen Blut“). Vor allem aber versucht Göring - so lässt sich in Bezug auf das Thema dieses Bandes sagen - die bald eintausend Jahre alte Fiktion des "Nibelungenlieds“ mit dem zeitgenössischen Faktum Stalingrad zu einem neuen, jetzt faktisch-fiktionalen Nationalmythos zu verschmelzen, der für die nächsten tausend Jahre als nationaler Bezugspunkt fungieren soll. Heiner Müller arbeitet sich an dieser Konstellation in zahlreichen Texten und Interviews ab. ${ }^{8}$ Dabei überbietet er die von Göring bemühte Langzeitperspektive noch dadurch, dass er zusätzlich zur Assoziation von „Nibelungenlied“ und Stalingrad einen Zusammenhang zwischen Stalingrad und dem Scheitern der DDR herstellt - so in einem Interview von 1993:

Der Kessel, sagt Bernd Böhmel, von dem diese seltsame, aber einleuchtende These stammt, ist die Strategie der Konterrevolution. In Stalingrad haben die Sowjets sie übernommen. [...] Das Ergebnis der Übernahme der konterrevolutionären Strategie war die Bildung der Ostblockstaaten als gefrorene Kessel: Abgrenzung nach außen, Zerstörung der Binnenstruktur. Das war das gleiche Prinzip. Das Ende der DDR war eigentlich Stalingrad. ${ }^{9}$ (Müller 2008c: 389)

Dieser feste Bestandteil von Müllers Geschichtskonstruktion muss beim Blick auf die Stalingradszenen (zumindest in „GERMANIA 3“) mit bedacht werden. Stalingrad ist für Müller der Kristallisationspunkt deutscher Geschichte. Durchaus im Einklang mit Göring versteht er die

\footnotetext{
${ }^{7}$ Vgl. dazu u. a. die an „Germania Tod in Berlin“ anschließende Szene „Ich hatt einen Kameraden“ in dem 1974 geschriebenen Stück „Die Schlacht. Szenen aus Deutschland“, in dem drei Soldaten einen vierten verspeisen (vgl. Müller 2001b: 473f.). Auch in poetologischen Äußerungen arbeitet Müller gerne mit einer kannibalistischen Metaphorik: „Mein Hauptinteresse beim Schreiben ist es, Dinge zu zerstören. [...] Ich glaube, mein Impuls ist der, Dinge bis auf ihr Skelett zu reduzieren, ihr Fleisch und ihre Oberfläche herunterzureißen. Dann ist man mit ihnen fertig“ (Müller 2008a: 217f.).

${ }^{8}$ Interviews stellen bei diesem Autor nicht nur kommentierende Paratexte, sondern einen integralen Bestandteil des Werks dar; vgl. dazu Humble 2000, insb. 173, sowie Hoffmann 2011.

9 Ähnlich Müller 1994: 362 sowie Heinrich/Müller 2007: 59. Klaus Heinrich widerspricht dort dieser Gleichsetzung mit dem Argument, allein im „Nibelungenlied“ finde sich eine „Lust, bis zum Ende in diesem Kessel zu bleiben“ (ebd., 60).
} 
Kesselschlacht als treffendste historische Einlösung des nationalmythischen Modells, des existenziellen Kampfes gegen die Hunnen. Während Göring in einem stillschweigenden Bruch mit der literarischen Vorlage allerdings den Kurzschluss von Nibelungen und Endsieg sucht, parallelisiert Müller die Auslöschung der Nibelungen in Etzels Saal mit der Niederlage der Deutschen in Stalingrad und zudem mit dem Verschwinden der DDR. „Der Kessel von Stalingrad zitiert Etzels Saal“ (Müller 1978: 72), schreibt Müller schon in einem Kommentar zu seinem 1958/64 geschriebenen Stück „Philoktet“; die DDR als „Staat im Kessel“ (Heinrich/Müller 2007: 61) verweist in Müllers Logik somit zugleich auf Stalingrad und auf die Nibelungen. Unabhängig von der Plausibilität dieser Überblendungsstrategie klammert er epische Fiktion und historische Fakten noch enger aneinander als Göring - statt Göring zu destruieren, schraubt er dessen Vergleich eine historische Umdrehung weiter. Die Rhetorik des „Endsiegs“ verwandelt sich dabei in die Bildlichkeit eines Endspiels, in "GERMANIA TOD IN BERLIN“ zunächst in Form eines ewig währenden Kampfes der Nibelungen mit sich selbst, der in der Selbstauslöschung mündet.

„Immer dasselbe“, beschwert sich Gernot, der zugleich naiv-kindlichste und reflektierteste unter Müllers Nibelungen, nachdem sie Leichen und Leichenteile „brüllend auf imaginäre Hunnen“ geworfen haben:

GERNOT Ich sage nicht, daß ich nicht mehr mitmachen will. Aber worum geht es eigentlich.

VOLKER Hast Du Siegfried schon vergessen, den die Hunnen im Odenwald -

HAGEN hebt seine Hirnschale: Rache für Siegfried. [...]

GERNOT zu Hagen: Aber ich habe doch selbst gesehen. Ich meine, das weiß doch jeder, daß du ihn. [...] Ich habe gesehen, wer den Speer geworfen hat.

GUNTHER Er war ein Verräter.

GERNOT Wer.

GUNTHER Siegfried. Ich wollte es dir eigentlich nicht sagen. Man soll der Jugend ihre Illusionen lassen, solange es irgend geht. Jetzt weißt du es.

GERNOT Ich weiß immer noch nicht, warum wir uns hier mit den Hunnen herumschlagen.

VOLKER Bist Du ein Hunne, daß du zum Kämpfen einen Grund brauchst. 
HAGEN Weil wir aus dem Kessel nicht herauskommen, darum schlagen wir uns mit den Hunnen herum.

GERNOT Aber wir brauchen doch nur aufzuhören, und es gibt keinen Kessel mehr. [...] Ich will nicht jede Nacht sterben. Ich finde das langweilig. Es macht mir keinen Spaß. (G 342f.)

Die von Göring in Anschlag gebrachte Instrumentalisierung und politische Umdeutung des „Nibelungenliedes“ legt Müller hier kurzerhand (und in derber Komik) ${ }^{10}$ dessen Personal in den Mund. Der von Hagen verübte Mord an Siegfried wird den Hunnen angelastet - damit geht das Stück über die bloße Mythenadaptation hinaus und schlägt den Bogen vom Mythos zum Prozess der Mythenbildung. Dass dieser Schritt in der Rezeptionsgeschichte des „Nibelungenliedes“ oft ein kleiner gewesen ist, hat die Forschung insbesondere im Blick auf das 19. Jahrhundert gezeigt: Der großen Präsenz von Versatzstücken aus dem „Nibelungenlied“ (etwa in der patriotischen Lyrik sowie in politischen Traktaten bis zu Friedrich Engels) steht eine umgekehrt proportionale Textkenntnis gegenüber: Da kaum jemand das umfangreiche Epos gelesen hatte, kann eine beachtliche „Unsicherheit der Ikonographie“ (von See 1991: 95) in Texten und Bildern zum „Nibelungenlied“ konstatiert werden. ${ }^{11}$ Auch das „Nibelungenlied“ ist - um eine Formulierung aus dem in diesem Band enthaltenen Aufsatz von Thomas Taterka aufzugreifen - da, um da zu sein (und muss dafür nicht gelesen werden). Die damit einhergehende flexible Verwendungsmöglichkeit dieses so populären wie im eigentlichen Sinn niemals volkstümlich gewordenen Epos trug entscheidend dazu bei, dass die Rezeption des „Nibelungenlieds“ in Deutschland einen „heißen Abschnitt der Arbeit am Mythos“ (Münkler 2009: 72) darstellt, ${ }^{12}$ ja dass dieses Epos, das „weder aus einem patriotischen Impetus entstanden noch von irgendeiner

\footnotetext{
${ }^{10} \mathrm{Zu}$ den Komikstrategien in diesem Stück vgl. Schmitt-Sasse 1991: 373-375.

${ }^{11}$ Von See führt weiter aus, dass es „in der deutschen Nibelungenrezeption zu einem verwirrenden Nebeneinander von Altgermanischem, Wikingerzeitlichem und Hochmittelalterlichem" (von See 1991: 94) kam.

12 Etwas später heißt es dazu weiter: „Die Vorstellung, man könne durch kleine Eingriffe in die narrative Struktur den Mythos politisch handhabbar machen, scheint weit verbreitet gewesen zu sein. So wurde Deutschland, zunächst als Siegfried identifiziert, bei anderer Gelegenheit mit Hagen gleichgesetzt, und auch Bismarck [...] konnte beide Rollen übernehmen“ (Münkler 2009: 85).
} 
nationalen Geschichtsideologie getragen war“ (von See 1991: 94), überhaupt zu einem „deutschen Mythos“ taugte.

Dass das Epos für Heiner Müller nicht nur den Prototyp der Schlacht um Stalingrad enthält, sondern tatsächlich so etwas wie das „deutsche Wesen“ modelliert, legt sein Prolog zu Jürgen Flimms Inszenierung von Friedrich Hebbels „Die Nibelungen“ am Thalia Theater 1988 nahe. Die „goldne Brücke in den Untergang“, auf diese Kernthese läuft der Prolog zu, werde von den Nibelungen immer gerne begangen: „Gierig auf den Tod sie schreiben in den Schnee / Mit Schwert und Blut das deutsche ABC“ (Müller 2002a: 252). Die Nibelungen, so wird bereits in der oben zitierten Passage aus „GERMANIA TOD IN BERLIN“ deutlich, imaginieren sich lieber einen Gegner, als auf das Kämpfen ganz zu verzichten. „Feinderklärung ist Feinderfindung“ (Heeg 2003: 90), kommentiert Günther Heeg im Heiner Müller-Handbuch die Szene, in der sich die Sinnlosigkeit des Krieges so weit potenziert, dass die Sinnfrage schließlich prinzipiell zurückgewiesen wird: „Bist Du ein Hunne, daß du zum Kämpfen einen Grund brauchst.“ In diesem anti-aufklärerischen Gestus, der den Kampf zum Selbstzweck erklärt, verortet Müller den psychologischen Kern des Nibelungentypus. Der Wille zum Kampf ist bei Müller nicht erst im Hebbel-Prolog auch ein Wille zum Untergang: In „GERMANIA TOD IN BERLIN“ schlagen Hagen, Gunther und Volker zunächst den resistenten Gernot „in einem längeren Kampf [...] in Stücke“ (G 343), bevor der Geige spielende Volker von den anderen beiden umgebracht wird.$^{13}$ Über Gunther und Hagen, die letzten beiden Nibelungen, heißt es dann in einem Nebentext, der den Übergang vom in einer Theaterinszenierung Umsetzbaren zu einem epischen Lesestück markiert:

Schlagen einer den andern in Stücke. Einen Augenblick Stille. Auch der Schlachtlärm hat aufgehört. Dann kriechen die Leichenteile aufeinander zu und formieren sich mit Lärm aus Metall, Schreien, Gesangsfetzen zu einem Monster aus Schrott und Menschenmaterial. (G 344)

Die Geburt des Monsters aus dem Geist der Nibelungen, will sagen: aus deutschem Geist - das ist die Quintessenz der Nibelungenszene in

13 Bernhard Greiner hat darauf hingewiesen, dass diese Figurenkonstellation an Brechts „Die Maßnahme“ anschließt (vgl. Greiner 2003: 536f.). Müller verweist auf Parallelen zum „Fatzer“-Fragment (vgl. Heinrich/Müller 2007: 53f.). 
„GERMANIA TOD IN BERLIN“, der Heiner Müller in Interviews bis in die 1980er Jahre treu bleibt. In Müllers Augen - so seine Reaktion auf die ihm 1982 gestellte Frage, ob die Deutschen „die Versuchung der Gewalt, des Krieges überwunden“ hätten - ist „die Bestie noch auf dem Sprung“: „Ich bin ganz sicher. Sie wartet nur auf eine neue Gelegenheit“ (Müller 2008a: 200f.). In diesem Sinn ist dann auch seine ein Jahr später im „Spiegel“-Interview geäußerte Ansicht zu verstehen, die Deutschen spielten noch immer die Nibelungen. Das Nibelungenmodell, so kann aus den unterschiedlichen Zitaten geschlossen werden, repräsentiert für Müller eine nationale mentale Disposition. So wie er davon ausgeht, dass sich die „condition humaine [...] in den letzten Jahrhunderten ganz wenig verändert hat“, dass die „Entwicklung des Menschen als Gegenstand der Anthropologie [...] absolut minimal“ (ebd., 357) sei, hält er auch den Nationalcharakter für eine stabile psychologische Konstante. Hinter den spektakulären Effekten seines Theaters der Grausamkeit schreibt er damit eine Traditionslinie fort, die in der Aufklärung in Mode kam (nachzulesen etwa beim vorkritischen Kant $)^{14}$ und der sich im Blick auf das „Nibelungenlied“ Friedrich von der Hagen schon 1807 im Vorwort zu seiner Edition des „Nibelungenlieds“ angeschlossen hatte, in dem dieses als „lebendige Urkunde des unvertilgbaren Deutschen Karakters“ (zit. n. von See 1991: 61) gefeiert wird - freilich eher in Bezug auf Eigenschaften wie Treue oder Menschlichkeit als auf den von Müller unterstellten „katastrophaldestruktive[n] Volkscharakter der Deutschen“ (Bohn 2003: 213). ${ }^{15}$ „Unvertilgbar“ ist in der Logik des ersten „GERMANIA“ -Stückes nur die deutsche Tendenz zur Selbstvertilgung.

Damit trägt Müllers Text jenen Glauben an einen nationalen ,,ahistorischen Idealtypus“ (Grimm 2007: 531) weiter, der auch für Nationalepen charakteristisch ist - und zeigt sich unbeeindruckt von einer soziologischen Nationentheorie, die schon Jahrzehnte früher genau das für

\footnotetext{
14 Vgl. dazu etwa neben vielem anderen das lange Kapitel „Von den Nationalcharakteren“" in Kants vorkritischer Schrift über Schönheit und Erhabenheit von 1764 (Kant 1977: 868-884).

${ }^{15}$ Diese Strategie prägt nach Klaus von See auch die weitere Beschäftigung mit dem „Nibelungenlied“ im 19. Jahrhundert: „Da nationale Ideologie im Nibelungenlied [...] nicht von der Handlung her zu begründen war, suchte man sie auch weiterhin $[\ldots]$ in den Charakteren“ (von See 1991: 65).
} 
eine „zur Falschheit tendierende Ideologie“ hält, da die „Geschichte nationaler Bewusstseinsinhalte brüchig und kontingent" (Hárs 2010: 2f.) gewesen sei. Während Nationalmythen jedoch in der Regel „kollektives Bewußtsein und nationale Identität" (Berding 1996: 9) auf affirmative Weise produzieren sollen, führt Müllers Stück vor, dass dem aus dem „Nibelungenlied“ herausgelesenen Gründungsmythos der deutschen Nation deren Scheitern bereits eingeschrieben ist. Insofern trägt auch diese Szene zu jener „Totalabrechnung mit der gesamten deutschen Geschichte" (Hermand 1999: 62) bei, die Jost Hermand dem Stück bescheinigt hat. Wenn Stalingrad für Müller zum einen die verdrängte „Tragödie des deutschen Volkes und das Ende der deutschen Nation“ (Müller 2008b: 443) darstellt, zum anderen aber nur realisiert, was in der Fiktion des „Nibelungenlieds“ bereits durchgespielt wird, sind Anfang und Ende der Nation untrennbar miteinander verbunden. Das Nationalepos erzeugt und zerstört das Nationale in einem fortwährenden Kreislauf, es ist letztlich ein anti-nationales Nationalepos - das ist die bemerkenswerte Pointe von Müllers Umgang mit den Nibelungen in „GERMANIA TOD IN BERLIN“.

\section{Kriemhild und die Entnationalisierung des Nationalmythos: ,GERMANIA 3“6}

Die Nibelungenszene in dem 1995 abgeschlossenen Stück „GERMANIA 3 GESPENSTER AM TOTEN MANN“ setzt gleich mit ihrem Titel, den Müller bereits 1987 im Gespräch mit Klaus Heinrich einwirft, ${ }^{16}$ einen anderen Akzent als der erste „GERMANIA“ -Text: „SIEGFRIED EINE JÜDIN AUS POLEN“ (G3 15) rückt zum einen Siegfried in den Fokus des Textes und assoziiert zum anderen einen Nibelungen mit einer Jüdin, also mit der größten Opfergruppe der Nazis. Gleichzeitig wird

\footnotetext{
${ }^{16}$ Dort nutzt Müller die Formulierung noch in einem Kontext, der sich nur partiell mit dem späteren „GERMANIA 3“-Projekt überschneidet: „Ich will ein Stück schreiben über den Russland-Feldzug. Der Ausgangspunkt war ganz primitiv: Ich fuhr einigermaßen betrunken vom Bahnhof Friedrichstraße zum Bahnhof Zoo und habe aus irgendeinem Grund zum ersten Mal wirklich aus dem Fenster gesehen, die Wachtürme gesehen. Ich war betrunken genug, um mir vorzustellen, die Soldaten in diesen Türmen sind die Wächter Attilas. Sie sind da, weil Kriemhild als der kommunistischen Partei der Siegfried umgebracht worden ist. Siegfried eine Jüdin aus Polen. Die Rache der Kriemhild wurde manifest in Stalingrad“ (Heinrich/Müller 2007: 58).
} 
der an Müllers Anspielungsreichtum gewöhnte Leser auf eine zusätzliche Fährte gelockt: Bei „EINE JÜDIN AUS POLEN“ handelt es sich um ein Zitat aus Bertolt Brechts "Grabschrift für Rosa Luxemburg“. ${ }^{17}$ An Rosa Luxemburg mag man auch deshalb denken, weil der sterbende Hilse am Ende von „GERMANIA TOD IN BERLIN“ ihre Wiederkehr als Erlösungsfigur imaginiert hatte (vgl. G 376f.) und weil sie gleich in der ersten Szene von „GERMANIA 3“ wortlos über die Bühne geht (vgl. G3 8). Im Anhang der Werkausgabe findet sich dazu ein recht kryptischer Kommentar des Herausgebers: „Darüber hinaus identifizierte Müller Kriemhild mit Rosa Luxemburg, der ,Jüdin aus Polen' (Archiv). Beide symbolisieren für ihn die Kämpferinnen für das Proletariat, das er unter dem Namen "Siegfried" faßt" (Hörnigk 2002: 348). ${ }^{18}$ Die nicht näher belegte Selbstdeutung Müllers lässt sich auf den ersten Blick schwer am Dramentext bestätigen, da weder Siegfried noch Rosa Luxemburg in der Nibelungenszene auftreten. ${ }^{19}$ Vielleicht deshalb ist weder in Frank Hörnigks Kommentar noch in der Forschung die im Archivmaterial anklingende erstaunliche Neuakzentuierung des Nibelungenstoffes weiter verfolgt worden - obwohl sie, wie im Folgenden gezeigt werden soll, von entscheidender Bedeutung für Müllers späten Umgang mit den Nibelungen ist.

Zwei Veränderungen fallen sofort ins Auge: Erstens tritt in „GERMANIA 3“ aus dem Nibelungen-Personal des ersten „GERMANIA“-Dramas nur Hagen wieder auf, der nun in einen Dialog mit Kriemhild, der Frau seines Opfers, verwickelt ist. Zweitens weist die fast durchgängige Kursivierung des Kriemhild-Hagen-Dialogs darauf hin, dass es sich beim längsten Teil der Szene um Zitate aus Friedrich Hebbels „Die Nibelungen“ handelt. Die DDR zitiert Stalingrad und Stalingrad zitiert Etzels Saal; Müller zitiert Göring, den Nibelungenstoff und jetzt auch noch Hebbels Nibelungenvariante. Wenn er im Interview fordert, dass man in einem zeitgemäßen Geschichtsdrama „die Epoche zusammen-

\footnotetext{
${ }^{17}$ Brechts Text lautet: „Hier liegt begraben / Rosa Luxemburg / Eine Jüdin aus Polen / Vorkämpferin deutscher Arbeiter / Getötet im Auftrag / Deutscher Unterdrücker. Unterdrückte / Begrabt eure Zwietracht!“ (Brecht 1967: 958).

${ }^{18}$ Auf Müllers oben zitierte Assoziation von Kriemhild und der kommunistischen Partei verweist der Kommentar nicht.

${ }^{19}$ Allerdings hat bereits Friedrich Engels die Siegfried-Figur im Kontext der sozialen Emanzipation gedeutet und sie „zum Repräsentanten der rebellischen Jugend“ (von See 1991: 70) gemacht. Ob Müller davon wusste, ist ungewiss.
} 
schiebt, daß man jetzt in einer Art Zeitraffer auf die Geschichte [...] blickt" (Müller 2008a: 23) und mit Anachronismen arbeite, gilt das zunehmend auch für seine Intertextualitätsmanie, in der sich zahlreiche Zitat- und Anspielungsschichten überlagern. Müller hat die HebbelZitate allesamt dem in Etzels Saal spielenden 4. und 5. Akt von „Kriemhilds Rache" (dem abschließenden Teil der Trilogie) entnommen und neu arrangiert, etwa Kriemhild auch Worte in den Mund gelegt, die sie in Hebbels Version nicht an Hagen, sondern an Rüdeger richtet.

Der Dialog zwischen Kriemhild und Hagen enthält eine Vielzahl der Gewaltexzesse, die auch das erste Drama kennzeichnen, die nun allerdings nicht mehr ausagiert, sondern allein verbal präsentiert werden: Hagen, der sich jetzt emphatisch zu seinem Mord an Siegfried bekennt („Ich leugne nicht, daß ich den Todesspeer / Mit Freuden warf“, G3 25), will noch im Bewusstsein seiner ausweglosen Lage (gefangen auf Etzels Burg) Kriemhild mit in seinen Tod ziehen. Kriemhild steht Hagens Brutalität in nichts nach, sie übernimmt das bei Müller omnipräsente, hier gleich doppelt eingefügte Kannibalismusmotiv: „Ihr habt mein Fleisch gegessen und mein Blut / Getrunken [...] / Seid meine Gäste jetzt zur letzten Mahlzeit / Esst eure Toten und löscht euren Durst / Mit ihrem Blut.“ (G3 27) ${ }^{20}$ Trotz dieser Anklänge an „GERMANIA TOD IN BERLIN“ wird man dem Text nicht gerecht, wenn man wie Daniela Colombo (und viele Kommentatoren vor ihr) in ihm nur eine „Konstante in Müllers Denken“ ausfindig macht, „wonach Stalinismus und Faschismus sich aufeinander beziehen und die Mentalität des absoluten Durchhaltens (Nibelungentreue) eine weit in die Vergangenheit reichende und in der Gegenwart nachwirkende Tradition hat" (Colombo 2009: 133). Zwar kann Colombo zunächst insofern zugestimmt werden, als Müller die Nibelungen in „GERMANIA 3“ internationalisiert: Hagen wirft am Ende der Szene „seinen Mantel ab, darunter eine deutsche Generalsuniform“, während Kriemhild unter ihrem Mantel die

\footnotetext{
${ }^{20}$ Gleich in der nächsten Szene, die Hitler im Bunker der Reichskanzlei zeigt, wird der Kannibalismus erneut ins Spiel gebracht, wenn Hitler in seiner Verblendung den Krieg und die zahlreichen Kriegstoten als ein von ihm und Stalin verfolgtes Programm zur Verhinderung des Kannibalismus präsentiert: „Sie werden wissen was sie an uns hatten / Wenn überall der Mensch den Menschen frisst / Weil ihm der Platz nicht langt und nicht das Futter / Volk ohne Raum“ (G3 29); „Ich habe das Meinige getan, die Menschheit auszurotten, die den Planeten überschwemmt“ (G3 31).
} 
„Uniform der Roten Armee“ trägt, allerdings „ohne Rangabzeichen“ (G3 27). Der „alte deutsche Bruderkonflikt“, der in Müllers Augen ein „Hauptthema der deutschen Literatur" (Müller 2008a: 186) darstellt und in "GERMANIA TOD IN BERLIN" außerhalb der Nibelungenszene vor allem in einem längeren Tacitus-Zitat evoziert worden war (vgl. G 364f.), ${ }^{21}$ erscheint nun als deutsch-russischer Geschwisterkampf. Der Nationalmythos avanciert zum Europamythos.

Schon der an den Uniformen ablesbare Rangunterschied - hier ein General der Wehrmacht, dort eine einfache Soldatin der russischen Armee - muss aber als eine Sympathielenkung in Richtung von Kriemhild verstanden werden. Diese implizit-figurale Personencharakterisierung wird in Kriemhilds Abschlussrede, der einzigen von Müller selbst verfassten Passage in dieser Szene, noch stärker akzentuiert. Unbemerkt von der Forschung findet hier eine entscheidende Differenzierung zwischen den beiden Nibelungenfiguren statt:

Ihr habt mein Fleisch gegessen und mein Blut

Getrunken durch zehn Länder mich gejagt

In diese Hochzeit meinen andern Tod

Und meine Haut gespannt auf eure Trommel (G3 27)

Die auf die Trommel gespannte Haut erinnert an die Verarbeitung der Haut von jüdischen KZ-Opfern zu Lampenschirmen, sodass sich Kriemhild tatsächlich mit der im Szenentitel genannten „Jüdin aus Polen“ in Zusammenhang bringen lässt. ${ }^{22}$ Anders als in der Nibelungenszene aus dem ersten „GERMANIA“-Stück wird damit der Holocaust (dem ansonsten in Müllers literarischer Beschäftigung mit Nationalsozialismus und Zweitem Weltkrieg nur eine periphere Bedeutung zu-

\footnotetext{
${ }^{21}$ Auch im Interview, in dem es um aktuelle Konflikte zwischen BRD und DDR geht, beruft Müller sich auf Tacitus' Bericht über den Streit zwischen Arminius und Flavius an der Weser: „So fing das alles an - eine altdeutsche Situation.“ (Müller 2008a: 186) Wiederum deutet Müller somit einen zeitgenössischen politischen Konflikt im Rahmen eines vormodernen Textes und argumentiert dabei mit einem zeitlosen Nationalcharakter der Deutschen.

${ }^{22}$ Zumindest mit bedacht werden muss, dass es sich dabei auch um eine rhetorische Strategie, eine Selbstinszenierung handelt, die an die durchaus fragwürdige frühe Selbstlegitimierung der DDR als antifaschistischen Staat der Nazigegner erinnert. Dass hinter Kriemhild während ihrer Rede „der Schatten Stalins“ (G3 27) zu sehen ist, verleiht ihr eine schillernde Ambivalenz, auf die es Müller durchgängig ankommt.
} 
kommt) mit dem „deutschen ABC“ assoziiert. Und: Mit Kriemhild verortet sich eine Figur des „Nibelungenlieds“ auf der Seite der Opfer.

Es ist kein Zufall, dass es bei Müller dafür eine Frau braucht. In „GERMANIA TOD IN BERLIN" sind die Nibelungen noch als eine reine Männergemeinschaft präsentiert worden: „Der Krieg ist Männerarbeit" (G 343), lautet dazu das von Gunther formulierte Credo. Allein der ohnehin ausscherende Gernot hatte in seinem kindlichen Tonfall (auf den in „GERMANIA 3“ zugunsten eines von Hebbel vorgegebenen und von Müller fortgeführten erhabenen Stils völlig verzichtet wird) auf komische Weise an die Existenz eines anderen Geschlechts erinnert: „Ich möchte auch mal etwas anderes machen. Das mit den Frauen zum Beispiel. Ich habe vergessen, wie es heißt" (ebd.). Dass die anderen drei ihn daraufhin in Stücke schlagen und gemeinsam auf seine Leiche masturbieren, fasst die männliche Selbstgenügsamkeit in ein so eindrückliches wie schauderhaftes Bild. ${ }^{23}$ Und auch Gernot evoziert die Frau allein als ein Sexualobjekt. Allerdings lässt sich aus dem daran anschließenden Wortspiel mehr herauslesen, als den lachend onanierenden Nibelungen bewusst ist. Wenn Hagen von der Vagina als einem „Loch“ spricht und Gunther dazu assoziiert: „Das Loch im Kessel werden wir schon finden" (ebd.), wird bereits hier Weiblichkeit mit einem Ausweg aus dem ewigen Kämpfen assoziiert - mit einer Flucht vor jener mythisch-nationalen Disposition also, an der die Nibelungen mit Ausnahme Gernots noch bedingungslos festhalten.

Allein der Umstand, dass in „GERMANIA 3“ mit Kriemhild eine Frauenfigur in Erscheinung tritt, die zudem mehr als doppelt so viele Redeanteile wie Hagen zugewiesen bekommt, ist somit vor dem Hintergrund der früheren Nibelungenszene bemerkenswert. Zwar versucht Hagen in Müllers Montage aus Hebbel-Zitaten wiederum, die Frau auf ihre Rolle als Sexualobjekt festzulegen, kann sich mit dieser im ersten

\footnotetext{
${ }^{23}$ Ein Foto dieser Szene aus der Uraufführung an den Münchner Kammerspielen enthält Schmitt-Sasse 1991: 379. Im Interview bewertet Müller die im Krieg gegebene Möglichkeit, ,aus den sozialen Zwängen und auch von den Frauen wegzukommen“, als eine Kernerfahrung des Kriegs, als „das Gefährliche und auch das Faszinierende am Faschismus. Es ist eine Perversion: die ganze erotische, sexuelle Energie auf den Tod“ (Müller 2008b: 938). Ursula Schulze missdeutet die Onanie-Szene, wenn sie darin bloß den Wunsch nach „Liebe und Sex, eigentlich ein Bedürfnis aller“ (Schulze 2007: 348), zum Ausdruck kommen sieht.
} 
„GERMANIA“ -Stück allgemein akzeptierten Strategie aber nicht mehr durchsetzen:

HAGEN

Zu Bett, zu Bett!

Du hast jetzt andre Pflichten.

KRIEMHILD

Deinen Hohn

Erstick ich gleich in deinem schwarzen Blut:

Auf, Etzels Würger, auf, und zeigt es ihm

Warum ich in das zweite Ehbett stieg.

Und sei gewiß, du wirst mir nicht entkommen

Wenn du auch noch die nächste Sonne siehst.

Ich will zurück in meines Siegfrieds Gruft.

Doch muß ich mir das Totenhemd erst färben

Und das kann nur mit deinem Blut geschehn. (G3 25)

Kriemhild weist Hagens sexuelle Anspielungen mit einer verbalen Brutalität zurück, die zwar an die Gewaltorgien aus „GERMANIA TOD IN BERLIN" erinnert, aber auf entscheidende Weise anders kontextualisiert ist. Denn Kriemhild will ausdrücklich nicht in die unendliche Gewaltspirale der männlichen Nibelungen eintreten, die sich als ewige Wiedergänger jede Nacht aufs Neue lustvoll zerstückeln. Ihr kommt es vielmehr auf die gezielte Ermordung Hagens an, der ihren Mann umgebracht und damit ihr gemeinsames Lebenskonzept zerstört hat. Für Hagens weiteres Schicksal macht das keinen Unterschied, für das in Müllers Text entworfene Nibelungen-Modell dagegen unbedingt - weil die angekündigte Gewalt nun in einen Sinnhorizont eingebettet wird. Im Gegensatz zur sinnfreien Zerstörungswut der männlichen Nibelungen stellt Gewalt hier keinen Selbstzweck mehr da, sondern hat instrumentellen Charakter, mithin ein Ziel. Das machen die letzten von Hebbel übernommenen Kriemhild-Zitate unmissverständlich klar:

Die guten Mittel sind erschöpft, es kommen

Die Bösen an die Reihe, wie das Gift

Wenn keine Arznei mehr helfen will

Und erst, wenn Siegfrieds Tod gerochen ist

Gibt's wieder Missetaten auf der Erde.

So lange aber ist das Recht verhüllt

Und die Natur in tiefen Schlaf versenkt. (G3 26) 
Der Gewalteinsatz wird von Kriemhild abgewogen und erst nach der Wirkungslosigkeit der "guten Mittel“ beschlossen - eine rationale Haltung, die sich in Gernots naivem Widersprechen in der ersten Nibelungenszene nur vorsichtig andeutet und dort sofort zu seiner Liquidation führt. Nun haben sich die Machtverhältnisse umgekehrt, und mehr noch: Kriemhilds Gewaltkonzept weist über den Rand ihrer privaten Rachepläne hinaus, es öffnet tatsächlich ein „Loch im Kessel“, will sagen: eine Zukunftsperspektive jenseits des ewigen Mordens. „Rache für Siegfried“ (G 342) schwören Hagen, Gunther und Volker wiederholt in "GERMANIA TOD IN BERLIN“, formulieren damit aber nur einen austauschbaren Vorwand für ihr so grundloses wie perspektivloses Kämpfen. Kriemhild will den Slogan in „GERMANIA 3“ ernsthaft in die Tat umsetzen und verbindet damit eine klare Heilserwartung: Ist Siegfrieds Tod gerächt, können Gut und Böse, kann also eine moralische Ordnung re-installiert werden. Wer (wie Klaus Welzel) behauptet, dass Müllers Stück „den Verlust historischer Perspektive“ anzeige und dass darin auch der "Grund seiner schriftstellerischen Lähmung“ (Welzel 1998: 148) zu finden sei, überliest Kriemhilds Zukunftskonzept, durch das ein optimistischerer Blick auf die „deutsche Misere“ (Müller 2008a: 75) geworfen wird.

Ein entscheidender Faktor in Müllers nationalepischem Geschlechterkampf ist der unterschiedliche Umgang der männlichen und der weiblichen Nibelungen mit dem Tod. In „GERMANIA TOD IN BERLIN“ agieren die Männer als Untote, die selbst kein Ende finden und sich über die sterbenden Soldaten lustig machen, die „glauben, sie haben es hinter sich" (G 342). Die Ausschaltung des eigenen Todes geht hier einher mit einem ziellosen Tötungswunsch: Wer den anderen umbringt, erlebt sich selbst als Überlebenden, als zumindest für den Moment unsterblich. Ein definitiver Abschluss liegt außerhalb des mythischen Zeithorizonts der männlichen Nibelungen und ist nicht zu vereinbaren mit dem „permanenten Wiedergängertum der toten Heroen“ (Schulze 2007: 350). In Müllers Weltbild, in dem unter anderem „Europas Wille zur Macht in der Technik [...] doch letztlich auf der Verdrängung von Todesangst als einer Lebensrealität" (Müller 2008b: 410) beruht, fungiert die Todesverdrängung auch als der leistungsstärkste Motor des Nationalismus: „Die gesamte Geschichte und Politik reduziert sich auf die Verdrängung der Sterblichkeit“, immer wieder bilde 
man „ein nationales Kollektiv gegen die Todesangst“ (Müller 2008b: 605f.). ${ }^{24}$ Ganz anders Kriemhild, deren Handeln aus der Akzeptanz des eigenen Sterbens seine Kraft bezieht: „Ich will zurück in meines Siegfrieds Gruft" (G3 25) - mit dieser Begrenzung ihrer eigenen Lebensperspektive gelingt es Kriemhild, ein Gegenmodell zum Wiedergängertum ihrer männlichen Kollegen zu formulieren und damit aus den Grenzen des nationalmythischen Wiederholungszwangs in Richtung eines linearen, historischen Zeitkonzepts auszubrechen. ${ }^{25}$ Die notorische Abschlussschwäche der männlichen Nibelungen ist Kriemhild fremd, sie tritt an, um der Dauerwiederholung des männlichen Endspiels ein unwiderrufliches Ende zu bereiten, mithin ein finales Endspiel der Geschlechter einzuberufen: Nibelungin vs. Nibelungen. In Müllers „Philoktet“-Kommentar „Drei Punkte“ heißt es: „Die deutschen Soldaten haben im Kessel die Lektion der Nibelungen nicht gelernt. [...] Erst wenn das Modell geändert wird, kann aus der Geschichte gelernt werden.“ (Müller 1978: 73) Dieser Modellwechsel wird in „GERMANIA 3“ in Form eines Geschlechterwechsels vollzogen, genauer: in einer Umkehrung der Geschlechterhierarchie. Anstatt die destruktive Wirkungsmacht der Nibelungen „von außen“ zu durchbrechen, greift das Stück mit Kriemhild also auf die interne Lösung zurück.

\footnotetext{
${ }^{24}$ Wenn Müller hier von „Geschichte“ spricht, liegt dem allerdings ein ahistorisches Zeitmodell zugrunde - wo es „keinen Tod“ gibt, „da gibt es nur Gegenwart“ (Müller 2008b: 606), also mythische Zeitlosigkeit. Mit Blick auf andere Zitate hebt auch Günther Heeg im Heiner Müller-Handbuch die Bedeutung der Todesverdrängung für die „Konstitution der nationalen Gemeinschaft“ hervor: „Die affektive Energie dieser paranoiden [nationalsozialistischen und stalinistischen] ,Säuberungs-Prozesse s speist sich aus der Verdrängung der Todesfurcht: Die Utopie einer reinen, immanenten Gemeinschaft ist die ewige Dauer, des Überlebens des eigenen Todes, an den das ,Unreine" und der ,Abfall" unausweichlich erinnern“" (Heeg 2003: 90).

${ }^{25}$ Angeboten hat sich Kriemhild für diese Rolle nicht zuletzt deshalb, weil sie - anders als etwa Kudrun - bereits im „Nibelungenlied“ „gegen die Männerwelt“ in Stellung gebracht wird, indem sie zunächst auf die „minne“ verzichten will und sich auch sonst „von der Typenhaftigkeit des nibelungischen Personals“ (Jan-Dirk Müller 2009: 131 und 133) unterscheidet. Ferner mag Müllers Entscheidung für die Sonderrolle von Kriemhild auch damit zusammenhängen, dass Klaus Heinrich im Nibelungengespräch mit Müller mehrfach auf die Frauenfiguren $\mathrm{zu}$ sprechen kommt und dabei insbesondere Kriemhild - zumindest in Hebbels Stück - für zentral, „sympathisch“ und „modern“ (Heinrich/Müller 2007: 29 und 31) erklärt.
} 
Wenn sich Frank M. Raddatz in Bezug auf Müllers Geschlechterkonzept seit „Zement“ (1972) fragt, „ob für den Mann Geschichte nicht auch weiterhin konstruktives Planfeld bleibt und bleiben muß, während es der Frau zufällt, Geschichte als Bezugs- und Planungsfeld zu zerstören“ (Raddatz 1991: 163), lautet mein „GERMANIA 3“-Befund genau entgegengesetzt: Mit der weitgehend aus Hebbels Text collagierten Kriemhild installiert Müller eine literarisch-mythische Figur, die mit der Akzeptanz des eigenen Todes den Übergang vom (männlichen) Mythos zur (weiblichen) Geschichte einläutet - und damit eine über die Wiederkehr des Immergleichen hinausgehende Zukunft, einen historischen Fortschritt überhaupt erst vorstellbar macht. ${ }^{26}$ Die „Statik der dramatischen Konstellation" (Greiner 2003: 542), ${ }^{27}$ die Bernhard Greiner dem Stück vorgeworfen hat, geht also einher mit einer intertextuellen Dynamik, die in der Forschung regelmäßig übersehen wird. Während Germania als mythische Verkörperung der deutschen Nation bereits in „GERMANIA TOD IN BERLIN" von Hitler unter den Augen der Alliierten gefoltert, vor eine Kanone gebunden und zerbombt wird (vgl. G 359), mithin „der Kreislauf des ewig Deutschen an einer Stelle durchbrochen und damit Platz für Neues geschaffen worden" (Hermand 1999: 68) ist, gilt das Gleiche in „GERMANIA 3“ nun auch für die deutsche Mentalität. Die irritierende Pointe des Blickwechsels von den Männern zu Kriemhild besteht darin, die Macht des Nationalepos durch das Nationalepos zu brechen, es also gleichzeitig zu verabschieden und zu verteidigen.

Dass sich die Geschlechterkonfiguration im zweiten „GERMANIA“Stück massiv verändert hat, kann auch aus der unmittelbar folgenden Szene abgelesen werden. Während die Führerbunker-Szene in „GER-

\footnotetext{
${ }^{26}$ Wenn „Germania Tod in Berlin“, wie Joachim Schmitt-Sasse (1991: 371) schreibt, „einen Ausweg aus der Verstrickung historischer Erfahrung in eine mythische Dramaturgie“ postuliert, sucht „GERMANIA 3“ den Weg zurück aus dem Mythos in die Geschichte.

${ }^{27}$ Greiner bemängelt, dass „Siegfried eine Jüdin aus Polen“ das „ausgeschlossene und ausgelöschte Andere im Szenentitel zwar benennt, sich ihm in seinem dramatischen Diskurs aber nirgends zu öffnen vermag“" (Greiner 2003: 543) - und übersieht dabei die enorme Bedeutung Kriemhilds. Nicht Müller, sondern Greiner verschließt sich dem anderen, hier: weiblichen Nibelungendiskurs. Aus Kriemhilds Text zitiert Greiner kein Wort. Auch Ursula Schulze geht auf Kriemhilds Reden nicht ein, sondern kommentiert nur pauschal, dass die „Zitatkollagen [...] weniger deutlich als das frühere Stück Bedeutung konstituieren“" (Schulze 2007: 350).
} 
MANIA TOD IN BERLIN“ (abgesehen von der mythischen Germania) noch ohne weibliche Figuren auskommt, ja sogar mit Goebbels einen Mann ein Kind gebären lässt, zeigt die Parallelszene aus „GERMANIA 3“ ein überwiegend weibliches Personal: Kurz vor seinem Tod hält Hitler eine Dankesrede an nicht näher bezeichnete „Damen“ (G3 31ff.) und erwähnt darin auch die von ihm kurz zuvor geheiratete Eva Braun. Wie in den beiden Nibelungenszenen ist auch hier also die männliche Selbstgenügsamkeit einer Integration des Weiblichen gewichen. Vor allem aber endet die Szene nun mit einem „Tanz der Frauen vor dem Hintergrund der brennenden Hauptstadt zu Wagners GÖTTERDÄMMERUNG“" (G3 33). Während Hitler sich zuvor gleich zweimal in die Tradition der Nibelungen einreihen wollte, ${ }^{28}$ sind es am Ende tanzende Frauen, die die Nibelungentradition für sich reklamieren.

Als Abschluss und Anschluss zugleich lässt sich Müllers Neuakzentuierung des Nibelungenstoffes noch auf einer weiteren intertextuellen Ebene charakterisieren. Denn indem Kriemhild den Wiederholungszwang des Nationalmythos für beendet erklärt, ordnet sie sich implizit auch in eine europäische Literaturgeschichte der Frauenmythen ein, die in Müllers Werk ab Mitte der 1970er Jahre an Bedeutung gewinnt. Die Nibelungenszene in „GERMANIA 3“ wechselt von der männlichnationalen Traditionslinie des Müller'schen Schreibens (Stichwort: „das deutsche $\mathrm{ABC}^{\prime}$ ) auf den international-weiblichen Strang - und verortet die Nibelungen damit auch in jenem Spannungsfeld zwischen Nationalem und Universellem, zwischen „Volkspoesie“ und Weltliteratur, die für die Rezeptionsgeschichte vieler Nationalepen charakteristisch ist (von den in diesem Band analysierten unter anderem beim „Kalevipoeg“, bei Ossian oder Schillers „Wilhelm Tell“). Das zentrale Schlagwort für die internationale Ausrichtung der Müller'schen Frauenfiguren liefert das 1977 geschriebene Stück „Die Hamletmaschine“, dessen zweite Szene den programmatischen Titel „DAS EUROPA DER FRAU“ (Müller 2001a: 547) trägt. Auch dieser Text führt einen Geschlechterkonflikt vor, aus dem Hamlet sich schließlich ebenso wie aus seinem Stück zurückzieht: „Ich bin nicht Hamlet. Ich spiele keine Rolle

\footnotetext{
${ }^{28}$ Hitler gibt „Walhall“, also den auch im „Nibelungenlied“ genannten mythischen Ruheort toter Kämpfer, als sein letztes Ziel an und beruft sich am Ende auf die Edda, in der Teile des Nibelungenstoffes verarbeitet sind, als „das Heilige Buch, die Bibel des Nordens" (G3 30 und 33).
} 
mehr. [...] Mein Drama findet nicht mehr statt.“ (Müller 2001a: 549) Im Anklang an das „Monster aus Schrott und Menschenmaterial“ (G 344), in das sich die letzten Nibelungen in "GERMANIA TOD IN BERLIN“ verwandeln, lautet Hamlets letzter Wunsch: „Ich will eine Maschine sein“, bevor er bezeichnenderweise in eine mittelalterliche „Rüstung“ tritt und „mit dem Beil die Köpfe von Marx Lenin Mao“ (ebd., 553) spaltet. Hamlet zitiert noch einmal das männliche Zerstörungsmodell, das über keine Zukunftsperspektive mehr verfügt, sondern direkt in die historische Erstarrung führt. „Schnee. Eiszeit.“ (Ebd.) - das ist die Bilanz vor dem letzten Auftritt von Ophelia.

Während Hamlet somit an das „alte“ Nibelungenkonzept anschließt, im Unterschied zu den männlichen Nibelungen sich selbst und sein zeitloses Stück aber bereits als ein Auslaufmodell begreift („Ich will nicht mehr sterben. Ich will nicht mehr töten“; ebd., 552), weist Ophelia auf die „neue“ Nibelungin voraus. Schon sie formuliert jenes - keineswegs gewaltfreie - Rachekonzept Kriemhilds, das im Unterschied zur männlichen Gewalt auf ein Ende der Gewaltspirale zielt und damit über eine Befreiungskomponente verfügt:

Ich zertrümmre die Werkzeuge meiner Gefangenschaft den Stuhl den Tisch das Bett. Ich zerstöre das Schlachtfeld das mein Heim war. Ich reiße die Türen auf, damit der Wind herein kann und der Schrei der Welt. Ich zerschlage das Fenster. Mit meinen blutenden Händen zerreiße ich die Fotografien der Männer die ich geliebt habe und die mich gebraucht haben. (Ebd., 547f.)

Einen Siegfried als männliche Alternative zum Chauvinismus, als einen auf der Seite der Opfer stehenden Mann hat Ophelia in ihrem radikalen Männerhass noch nicht in der Hinterhand. Die im Szenentitel „Siegfried eine Jüdin aus Polen“ zum Ausdruck kommende Geschlechterambivalenz ist hier noch Zukunftsmusik, die im „SCHERZO“ (so der Titel der dritten Szene) nur spielerisch in Form einer Transvestitenshow angedeutet wird, wenn Hamlet als einzigen Ausweg aus seiner prekären Lage den Geschlechterwechsel ins Auge fasst: „Ich will eine Frau sein“, lautet seine verzweifelte Bitte, woraufhin er Ophelias Kleider anzieht und von ihr eine „Hurenmaske“ (ebd., 548) geschminkt bekommt. Ein überzeugendes Gegenmodell zur männlich-destruktiven Tradition sieht zweifellos anders aus als dieser "Hamlet in Hurenpose“ (ebd., 553). 
Dagegen steht Kriemhild in der Tradition der Müller'schen Ophelia, die sich in ihrem Abschlussmonolog explizit auf der Seite der von der (männlichen) Gewaltgeschichte Benachteiligten verortet. „Im Namen der Opfer" formuliert sie einen furiosen und wiederum intertextuell aufgeladenen Rachefeldzug, der sich problemlos mit Kriemhilds Schlussworten fusionieren ließe:

Ich verwandle die Milch meiner Brüste in tödliches Gift. [...] Nieder mit dem Glück der Unterwerfung. Es lebe der Haß, die Verachtung der Tod. Wenn sie mit Fleischermessern durch eure Schlafzimmer geht, werdet ihr die Wahrheit wissen. (Müller 2001a: 554)

Diese Allianz der rächenden Frauen in Müllers Werk wird noch um Elektra, deren Stimme sich Ophelia leiht („Hier spricht Elektra“), sowie um Medea erweitert, die Müller in „VERKOMMENES UFER MEDEAMATERIAL LANDSCHAFT MIT ARGONAUTEN“ in einem langen Monolog und mit ähnlich drastischer Bildlichkeit die Morde an der neuen Frau ihres Mannes („Pflanzt einen Wald von Messern ihr ins Fleisch“; Müller 2002b: 78) sowie an den eigenen Kindern feiern lässt. Müllers Ophelia, Elektra, Medea und Kriemhild - gemeinsam ist diesen Frauen als Perspektivfiguren, dass sie die Männerdominanz mit zum Teil exzessiver Gewalt beenden wollen und dabei dem eigenen Tod bewusst ins Auge sehen. Letzteres gilt für die Selbstmörderin Ophelia ohnehin („Die Frau am Strick Die Frau mit den aufgeschnittenen Pulsadern Die Frau mit der Überdosis AUF DEN LIPPEN SCHNEE Die Frau mit dem Kopf im Gasherd“; Müller 2001a: 547), aber auch Medea wünscht sich in Müllers Text: „Daß ein Tod mich wegnähm“ (Müller 2002b: 75). Nur wer sein Sterben akzeptiert, und das scheint bei Müller eine genuin weibliche Fähigkeit zu sein, kann sich aus den Zwängen des anderen Geschlechts ebenso wie aus der Macht der nationalen Disposition befreien. Verglichen etwa mit Ophelias Befreiungsrhetorik, die dadurch konterkariert wird, dass „,zwei Männer in Arztkitteln“ sie während ihrer Rede „in Mullbinden schnüren“ (ebd., 553), verfügt Kriemhilds Gewaltvision dabei noch über eine relative Ungebrochenheit. ${ }^{29}$

\footnotetext{
${ }^{29}$ Freilich bleibt es auch hier bei der verbalen Ankündigung von Gewalt; zudem gibt (wenn auch bei Müller nicht erwähnt) der Nibelungenstoff die auf Hagens Hinrichtung folgende Ermordung Kriemhilds vor. Durchweg optimistische oder unproblematische Identifikationsfiguren stellt kein Müller-Stück zur Verfügung.
} 
Festgehalten werden kann, dass die Nibelungen in „GERMANIA 3“ durch den Auftritt Kriemhilds von Müller in eine mythisch-literarische Traditionslinie der weiblichen Rache eingeschrieben werden, die bei ihm dezidiert europäisch angelegt ist. Im Unterschied zu den männlichen Nibelungen, die im ersten „GERMANIA“-Drama gleichsam die letzten Tage der Männlichkeit feiern, tritt Kriemhild als ein literarischer global player in Erscheinung, dessen Wege sich mit denen Elektras, Medeas und Ophelias kreuzen. Die Nibelungen werden damit internationalisiert und literaturgeschichtlich zukunftsfähig gemacht. Von einer substantialistisch-objektivistischen Nationentheorie, die in der Soziologie seit Anfang des 20. Jahrhunderts in Frage gestellt wird (vgl. Hárs 2010: 1f.), verabschiedet sich am Ende des Jahrhunderts nun auch Heiner Müller. Mit Kriemhild ist er seinem Ziel näher gekommen, die „deutsche Geschichte“ als seine eigene „Obsession zu zerstören“ (Müller 2008a: 218), also tatsächlich die selbst gestellte „Aufgabe“ einzulösen, „diese Nation [anständig] zu beerdigen“ (Müller 2008b: 70). Wenn Müller die Ansicht vertritt, dass man „zuerst die Existenz der Geschichte anerkennen“ müsse, um „den Alptraum der Geschichte“ loswerden zu können, um zu verhindern, dass Geschichte auf „die altmodische Weise wiederkehren“ (Müller 2008a: 187) könnte, beschreibt das nicht zuletzt seinen Umgang mit dem Nibelungenmodell: Während in „GERMANIA TOD IN BERLIN“ sowie in zahlreichen Interviews die Macht des „deutschen ABCs“ propagiert wird, eröffnet die Nibelungenszene in „GERMANIA 3“ eine Perspektive ins Jenseits des Nationalen; während der erste Text die sich durch das 19. Jahrhundert bis zu Göring ziehende Rezeptionsgeschichte des „Nibelungenlieds“ radikalisiert und travestiert, stellt der zweite Text eine optimistischere Form der Nibelungenrezeption vor, indem er versucht, eine Gegenlektüre zu etablieren, die das "Nibelungenlied“" von seiner nationalistischen Lesart wieder befreit. Kurz gesagt: Das Epos soll im Spiel bleiben, auf das Absingen der Nationalhymne aber verzichtet werden. ${ }^{30}$

\footnotetext{
${ }^{30}$ Für Anregungen danke ich Arndt Lümers.
} 


\section{Literatur}

\section{Siglen}

G MÜller, Heiner (2002): GERMANIA TOD IN BERLIN. In: ders. (2001): Werke 4: Die Stücke 2. Hrsg. v. Frank Hörnigk. Frankfurt a. M., S. 325-377.

G3 MÜlLER, Heiner (2002): GERMANIA 3 GESPENSTER AM TOTEN MANN. In: ders. (2002): Werke 5: Die Stücke 3. Hrsg. v. Frank Hörnigk. Frankfurt a. M., S. 253-309.

\section{Primärliteratur}

BRECHT, Bertolt (1967): Gesammelte Werke in 20 Bänden. Bd. 10: Gedichte 3. Hrsg. v. Suhrkamp Verlag in Zusammenarbeit mit Elisabeth Hauptmann. Frankfurt a. M.

HeINRICH, Klaus/ Heiner MülLER (2007): Die Faszination der Nibelungen. In: Günther Heeg/Stefan Schnabel/KD Wolff (Hrsg.) (2007): Kinder der Nibelungen. Heiner Müller und Klaus Heinrich im Gespräch mit Peter Kammerer und Wolfgang Storch. Frankfurt a. M., S. 19-68.

KANT, Immanuel (1977): Beobachtungen über das Gefühl des Schönen und Erhabenen. In: ders. (1977): Vorkritische Schriften bis 1768. Hrsg. v. Wilhelm Weischedel. Bd. 2. Frankfurt a. M., S. 820-884.

MülleR, Heiner (1978): Material zu Philoktet, Der Horatier und Mauser. In: ders. (1978): Mauser. Berlin, S. 71-85.

MülLER, Heiner (1983): Deutschland spielt immer noch die Nibelungen. Interview mit Hellmuth Karasek und Urs Jenny. In: Der Spiegel v. 9.5.1983, S. 196-207.

MülleR, Heiner (1994): Krieg ohne Schlacht. Leben in zwei Diktaturen. Eine Autobiographie. Erweiterte Neuausgabe. Köln.

Müller, Heiner (2001a): Die Hamletmaschine. In: ders.: Werke 4: Die Stücke 2. Hrsg. v. Frank Hörnigk. Frankfurt a. M., S. 543-554.

Müller, Heiner (2001b): Die Schlacht. In: ders.: Werke 4: Die Stücke 2. Hrsg. v. Frank Hörnigk. Frankfurt a. M.,S. 469-482.

MülleR, Heiner (2002a): [Aus rotem Nebel in das Rampenlicht ...]. In: ders.: Werke 5: Die Stücke 3. Hrsg. v. Frank Hörnigk. Frankfurt a. M.,S. 249-252.

MÜLLER, Heiner (2002b): Verkommenes Ufer Medeamaterial Landschaft mit Argonauten. In: ders.: Werke 5: Die Stücke 3. Hrsg. v. Frank Hörnigk. Frankfurt a. M., S. 71-84.

MülleR, Heiner (2008a): Werke 10: Gespräche 1. 1965-1987. Hrsg. v. Frank Hörnigk. Frankfurt a. M.

MülleR, Heiner (2008b): Werke 11: Gespräche 2. 1987-1991. Hrsg. v. Frank Hörnigk. Frankfurt a. M. 
MülleR, Heiner (2008c): Werke 12: Gespräche 3. 1991-1995. Hrsg. v. Frank Hörnigk. Frankfurt a. M.

\section{Sekundärliteratur}

ANONYM (2010): Nibelungenlied. Verfügbar unter:

http://de.wikipedia.org/wiki/Nibelungenlied (16.4.2010).

Colombo, Daniela (2009): Das Drama der Geschichte bei Heiner Müller und Christa Wolf. Würzburg.

BERding, Helmut (1996): Vorwort. In: ders. (Hrsg.) (1996): Mythos und Nation. Studien zur Entwicklung des kollektiven Bewußtseins in der Neuzeit 3. Frankfurt a. M.,S. 7-9.

BoHn, Volker (2003): Germania Tod in Berlin. In: Hans-Thies Lehmann/ Patrick Primavesi (Hrsg.) (2003): Heiner Müller Handbuch. Leben - Werk Wirkung. Stuttgart/Weimar, S. 207-214.

BOHSE, Jörg (1981): Inszenierte Kriegsbegeisterung und ohnmächtiger Friedenswille. Stuttgart.

Greiner, Bernhard (2003): Siegfried eine Jüdin aus Polen. Heiner Müllers Umgang mit dem Nibelungenstoff. In: Joachim Heinzle/Klaus Klein/Ute Obhof (Hrsg.) (2003): Die Nibelungen. Sage - Epos - Mythos. Wiesbaden, S. 531-546.

GRIMM, Gunter E. (2007): Nationalepos. In: Dieter Burdorf/Christoph Fasbender/Burkhard Moennighoff (Hrsg.) (2007): Metzler Lexikon Literatur. 3. Aufl. Stuttgart/Weimar, S. 530-531.

HÁRS, Endre: Herder und die Erfindung des Nationalen. Verfügbar unter: www.kakanien.ac.at/beitr/fallstudie/EHars3.pdf (20.3.2010).

HEEG, Günther (2003): Deutschland - Krieg. In: Hans-Thies Lehmann/Patrick Primavesi (Hrsg.) (2003): Heiner Müller Handbuch. Leben - Werk - Wirkung. Stuttgart/Weimar, S. 88-93.

HeEG, Günther/Stefan Schnabel/KD WOLFF (2007): Kinder der Nibelungen. In: dies. (2007): Kinder der Nibelungen. Heiner Müller und Klaus Heinrich im Gespräch mit Peter Kammerer und Wolfgang Storch. Frankfurt a. M., S. 7-18.

HeInzle, Joachim/Klaus KleIN/Ute Oberhof (Hrsg.) (2003): Die Nibelungen. Sage - Epos - Mythos. Wiesbaden.

Hermand, Jost (1999): Braut, Mutter oder Hure? Heiner Müllers Germania und ihre Vorgeschichte. In: Jost Hermand/Helen Fehervary (Hrsg.) (1999): Mit den Toten reden. Fragen an Heiner Müller. Köln u.a., S. 52-69.

Hoffmann, Torsten (2011): Die Ausschaltung der Einschaltung des Autors. Autorkritische Selbstinszenierungen in Interviews von Heiner Müller und W. G. Sebald. In: Christoph Jürgensen/Gerhard Kaiser (Hrsg.) (2011): Schriftstellerische Inszenierungspraktiken - Typologie und Geschichte. Heidelberg, S. 313-340. 
HÖRNIGK, Frank: Bibliographische Notizen. In: Heiner Müller: Werke 5: Die Stücke 3. Hrsg. v. Frank Hörnigk. Frankfurt a. M., S. 315-355.

Humble, Malcom (2000): Heiner Müllers gesammelte Irrtümer. Bekenntnisse und Provokationen. In: Ian Wallace/Dennis Tate/Gerd Labroisse (Hrsg.) (2000): Heiner Müller. Probleme und Perspektiven. Bath-Symposium 1998. Amsterdam/Atlanta, S. 171-186.

MüLler, Jan-Dirk (2009): Das Nibelungenlied. 3. Aufl. Berlin.

Münkler, Herfried/Wolfgang Storch (1988): Siegfrieden. Politik mit einem deutschen Mythos. Berlin, S. 132.

MüNKLER, Herfried (2009): Die Deutschen und ihre Mythen. Berlin, S. 69-107.

RADDATZ, Frank-Michael (1991): Dämonen unterm Roten Stern. Zu Geschichtsphilosophie und Ästhetik Heiner Müllers. Stuttgart.

SCHMitT-SASSE, Joachim (1991): Die Kunst aufzuhören. Der Nibelungen-Stoff in Heiner Müllers Germania Tod in Berlin. In: Joachim Heinzle/Anneleise Waldschmidt (Hrsg.) (1991): Die Nibelungen. Ein deutscher Wahn, ein deutscher Albtraum. Studien und Dokumente zur Rezeption des Nibelungenstoffs im 19. und 20. Jahrhundert. Frankfurt a. M., S. 370-396.

SCHUlzE, Ursula (2007): Aber wir brauchen doch nur aufzuhören und es gibt keinen Kessel mehr. Die Rezeption der Rezeption des Nibelungenliedes am Beispiel von Heiner Müllers Germania-Stücken. In: Ingrid Bennewitz (Hrsg.) (2007): wort unde wîse, singen und sagen. Festschrift für Ulrich Müller zum 65. Geburtstag. Göppingen, S. 341-355.

VON SEE, Klaus: Das Nibelungenlied - ein Nationalepos? In: Joachim Heinzle/Anneliese Waldschmidt (Hrsg.) (1991): Die Nibelungen. Ein deutscher Wahn, ein deutscher Alptraum. Studien und Dokumente zur Rezeption des Nibelungenstoffs im 19. und 20. Jahrhundert. Frankfurt a. M., S. 43-110.

Welzel, Klaus (1998): Utopieverlust. Die deutsche Einheit im Spiegel ostdeutscher Autoren. Würzburg. 


\section{Das estnische Epos ,Kalevipoeg“6 in der Spannung zwischen Nationalepos und Menschheitsepos. Eine Interpretation der Höllenfahrtszenen}

Keine Ilias hat Dr. Kreutzwald geschaffen, wohl aber der estnischen Literatur ein Kapitalwerk geschenkt, das für alle Zeiten sein wird, was den Griechen ihre Ilias war. Es ist ein volkstümliches Werk voll des köstlichen Reichtums der estnischen Lebensweisheit und voll sinniger Betrachtung der ganzen estnischen Welt.

(Franz Anton Schiefner und Ferdinand Johann Wiedemann) ${ }^{1}$

Narrative Texte, die auf die Nationsbildung sowie auf die Entwicklung und die Bewahrung des kulturellen Gedächtnisses eines „Volkes“ bzw. einer „Nation“ gerichtet sind, werden meist - bedingt durch die historischen Umstände und / oder die Rezeptionsgeschichte - auf das Nationale hin untersucht und rezipiert. Die Gattungsbezeichnung eines Nationalepos hat zudem durch das Bestimmungswort „national“ auf seine konstitutive Funktion im nationalen Bildungsprozess hinzuweisen, selbst auf die Gefahr hin, nationalistisch konnotiert und missbraucht zu werden. Von diesem Wissen ausgehend sollte ursprünglich auch das estnische Nationalepos „Kalevipoeg“ mit einer Einführung in die Textgenese und mit einer Interpretation der Höllenfahrtszenen einfach allgemein vorgestellt werden. Doch bei der Auseinandersetzung mit anderen Lesarten bzw. Rezeptionsmöglichkeiten entwickelte sich im Laufe des Schreibens zunächst unbewusst, dann immer bewusster und mit stetig wachsender Begeisterung für dieses Epos eine neue Sicht auf dessen Aussage. Schließlich ging aus dem ursprünglichen Vorhaben etwas Unerwartetes hervor; der Schwerpunkt des Aufsatzes verlagerte sich unwillkürlich vom Nationalen zum Universellen, zur überzeitlichen Gültigkeit. Dieser nicht ausformulierten These, die letztendlich unweigerlich einige Ergänzungen und Veränderungen nach sich zog, soll

\footnotetext{
${ }^{1}$ Zit. n. Kross 2004: 7. Jaan Kross zitiert J. F. Wiedemann und U. Schiefner. Er meint hier wohl Ferdinand Johann Wiedemann und Franz Anton Schiefner.
} 
auch die Interpretation der Höllenfahrtszenen dienen, die erheblich womöglich am stärksten - dazu beitragen, die allgemeinmenschliche Botschaft des Epos über die Landesgrenzen der nationalen Gemeinschaft der Esten hinauszutragen und seine universelle Eingebundenheit aufzuzeigen.

\section{Zur Textgenese und zur Gattungsbestimmung}

Wer bin ich? Woher komme ich? Wohin gehe ich? Wo stehe ich im Kosmos? Das sind Fragen, die wir uns von Generation zu Generation als Einzelwesen oder als Gemeinwesen, das heißt als Mitglied einer größeren oder kleineren Gemeinschaft oder einer Nation, stellen. Denn auch Nationen sind Gemeinschaften, und zwar „vorgestellte Gemeinschaften“, die als solche „eine neue kulturelle Formation“ (Brinker-Gabler 1998: 91) hervorbringen. Das sind offensichtlich Fragen gewesen, mit denen sich auch die kleine ethnische Gruppe der Esten in der einen oder anderen Form vor allem seit der Abschaffung der Leibeigenschaft 1816 in Estland und 1819 in Livland im Zuge eines erwachenden und wachsenden Zusammengehörigkeitsgefühls, auf der Suche nach ihrer nationalen Wir-Identität und ihrer Kosmogonie immer mehr zu beschäftigen begann. Ermunterung zur Bewältigung dieser Fragen und zur Selbstwahrnehmung bekamen die Esten paradoxerweise ausgerechnet von den ortsansässigen Deutschbalten, in deren Abhängigkeit sie seit über 700 Jahren $^{2}$ gelebt hatten. Genauer gesagt kam diese Unterstützung von den deutschbaltischen estophilen Bildungsschichten.

Bei der Sicherung des kollektiven Gedächtnisses in seiner Einheit und Eigenart brauchen die Nationen bzw. Gesellschaften etwas, worauf sie zurückgreifen können; etwas, was als sinnstiftend für ein gemeinsames Selbstbild empfunden wird und eine historische Kontinuität aufweist. Sie brauchen also die Vergangenheit, einen identitätssichernden und wirkungsmächtigen historisch-kulturellen (bzw. historisch-geistigen) Gemeinbesitz. Je reicher der Gemeinbesitz, je heldenhafter die Ereignisse der Vergangenheit sind, desto stärker werden die Gemeinschaft und ihr Selbstbewusstsein sein. „Gesellschaften brauchen die Vergan-

\footnotetext{
${ }^{2}$ Bis 1917 galt der größte Teil des Landes als Besitz der estnischen und livländischen Ritterschaft.
} 
genheit in erster Linie zum Zwecke ihrer Selbstdefinition. ,Eine Nation lebt nur, indem sie ihre Vergangenheit wiederaufleben läßt““ (Assmann 2007: 133) ${ }^{3}$ - erklärt der Ägyptologe Jan Assmann.

Die unmündige und wenig selbstbewusste Bevölkerung der Esten verfügte in der Mitte des 19. Jahrhunderts hingegen weder über eine heldenhafte Vergangenheit, ${ }^{4}$ über wesentliche verbindliche Traditionen noch über eine inhaltsreiche Erzählung, eine selbstständige Geschichte und ein beredtes kulturelles Gedächtnis. Eine solche Geschichte, eine solche Vergangenheit kann allerdings erfunden, um nicht zu sagen, einem Volk angedichtet werden. Um die Wunschvorstellungen, Erwartungen und Visionen gesellschaftlich zu legitimieren und zu festigen, projiziert man sie in eine bestimmte Vergangenheit bzw. in die nationalmythologische Geschichte zurück und schafft einen formativen Text, ein großes (literarisches) „Narrativ“, wie beispielsweise ein (National-)Epos. Dieses soll für die Selbstbestimmung einer Nation und für ihre Kulturgeschichte als konstitutiv oder zumindest exemplarisch gelten, es soll konsensuale und kollektive Identität schaffen oder symbolisieren. So gesehen kann man auch bei den Epen - darunter auch beim „Kalevipoeg“ - in gewisser Hinsicht im Sinne Eric Hobsbawms und Terence Rangers von invented traditions sprechen, oder, um den Ausdruck zu paraphrasieren, von invented myths. „Die Legitimierung der Gegenwart mit Hilfe der Vergangenheit war im Est- und Livland des 19. Jahrhunderts eine absolut verständliche psychologische Notwendigkeit“ (Järvelaid 2004: 312), bekräftigt der Rechtswissenschaftler Peeter Järvelaid. In einem so genannten Notzustand, in kulturellen, geistigen Umbruchszeiten ist man, wie wir wissen, sogar bereit, neue Mythen oder Sagen zu erfinden oder alte zu korrigieren, wie dies z.B. bei Kalevipoeg der Fall ist, der zum König, ja zum Nationalhelden stilisiert wird. Und nicht nur das. Da das kulturelle Gedächtnis nicht nur in den Körper eingeschrieben ist, sondern ebenso in die Topographie des Landes, gilt es, auch das weggenommene Land wiederzugewinnen. Dies bedeutet zugleich die Wiedergewinnung der Geschichten, die in die Landschaft des Landes eingeschrieben sind, oder, falls sie fehlen, deren Neuerschaffung. Denn das „Land lebt in Tieren, Sinneswahr-

\footnotetext{
${ }^{3}$ Jan Assmann bezieht sich auf den ägyptischen Autor Muhammad Husayn Haykal (1888-1965).

${ }^{4}$ S. dazu auch Järvelaid 2004: 309.
} 
nehmungen und insbesondere in Geschichten" (A. Assmann 1997: 292f.). Das heißt, das Land ist überzogen mit einem Narrativ, mit Geschichten bzw. seiner Folklore, welche die Landschaft semantisieren: seinen Mythen, Märchen, Volksliedern, Sprichwörtern, Redensarten, religiösen Mitteilungen, Gebeten. Wie zu zeigen sein wird, räumt der Verfasser des „Kalevipoeg“ der ganzen Natur, darunter den Tieren, einen außerordentlichen Platz in seinem Epos ein und lässt dessen Helden über das ganze Land, vor allem auf der östlich liegenden nordsüdlichen Achse, seine Spuren verstreuen, die sogar kartiert werden. „Das Land ist mehr als nur eine Grundlage materieller Versorgung; es ist selbst das kulturelle Gedächtnis." (Ebd., 293)

Ähnliche Gedankengänge mögen auch Friedrich Robert Faehlmann (1798-1850) und der deutschbaltische Estophile Georg Schultz-Bertram (1808-1875) entwickelt haben, als sie über die Schaffung eines Nationalepos nachzusinnen begannen und ihre Gedanken 1839 - der eine früher, der andere später - in der Gelehrten Esthnischen Gesellschaft ${ }^{5}$ vortrugen. Schultz-Bertram, der vom 1835 erschienenen finnischen Nationalepos „Kalevala“ beflügelt wurde, das er von seiner Reise nach Helsinki 1839 mit nach Hause brachte, beendete sein begeistertes Plädoyer für die Schaffung eines Epos mit folgenden Worten: „Geben wir dem Volke ein Epos und eine Geschichte und alles ist gewonnen!“ (Zit. n. Hasselblatt 2004: 299).

Beide Männer scheinen ein gutes Gespür für den passenden Zeitpunkt zur Entstehung eines Nationalepos gehabt zu haben, denn die gesellschaftlichen und psychischen Umstände waren äußerst günstig und das Bedürfnis nach einer sozial-geistigen nationalen Selbstdefinition und Selbstbehauptung und einem identitätsstiftenden bzw. -sichernden Wissen nicht nur in Estland groß, wovon auch die erstaunlich große Zahl der im 19. Jahrhundert entstandenen Nationalepen zeugt. Vor und in der Zeit der Französischen Revolution, der Revolutionen von 1848/49 sowie der nationalen Einigungsbewegungen im 19. Jahrhundert besann man sich in Europa auf die mythische Vorzeit und die Vergangenheit,

\footnotetext{
${ }^{5}$ Als Mitbegründer der 1838 gegründeten Gelehrten Esthnischen Gesellschaft gilt neben den Universitätsprofessoren Friedrich Georg von Bunge (Jura), Alexander Friedrich von Hueck (Anatomie), Friedrich Karl Hermann Kruse (Geschichte) und dem Lektor für estnische Sprache, Dietrich Heinrich Jürgenson, auch der Arzt und Schriftsteller Friedrich Robert Faehlmann.
} 
auf die Volksdichtung und deren Bedeutung für eine Nation. Zu denken ist vor allem an die literarischen Strömungen des Sturm und Drang $^{6}$ und die Romantik sowie die Werke ihrer Vertreter wie James Macpherson (1736-1796) mit seinen Ossian-Gesängen (1760), JeanJacques Rousseau (1712-1778) mit seinem „Zurück zur Natur“-Gedanken, Johann Georg Hamann ${ }^{7}$ (1730-1788) mit seinem Gedanken über die kulturbestimmende Rolle des Volkes sowie Jacob (1785-1863) und Wilhelm Grimm (1786-1859) mit ihren Märchensammlungen; vor allem aber Johann Gottfried Herder (1744-1803), ${ }^{8}$ der zum ersten Mal Sprache und Literatur als historisches Phänomen auffasste und im Individuum den Träger der Geschichte sah.

Dass der Vorbereiter des estnischen (National-)Epos, Robert Faehlmann, und der Verfasser desselben, Friedrich Reinhold Kreutzwald (1803-1882) - beide studierte Ärzte und Literaten -, mit den erwähnten geistigen und national-politischen Bewegungen mehr oder weniger vertraut waren und durch diese gar angeregt und angespornt wurden, unterliegt keinem Zweifel. Außer Zweifel steht ebenso, zumindest im Nachhinein, die funktionale Bedeutung des „Kalevipoeg“: Er wirkt als Ausdruck der sich im Gestaltungsprozess befindenden Nation, als Katalysator des Nationalisierungsprozesses. Eine Untermauerung findet diese Überlegung u.a. durch den estnischen Literaturwissenschaftler, Lyriker und Folkloristen August Annist, der das „Kalevala“ als erste und mächtigste Waffe bezeichnet, „welche den jahrhundertealten Minderwertigkeitskomplex des finnischen Geschlechtes,

\footnotetext{
${ }^{6}$ Folgende Elemente des Sturm und Drang lassen sich im „Kalevipoeg“ nachweisen: Abgrenzung gegen Autorität und Tradition (vgl. hierbei Kalevipoegs Verzicht auf „Kalevs Buch der Weisheit“ und den Abbruch jeglichen geistigen Kontakts zu seinem Vater im Grab); Behauptung des Rechts auf Individualität und überschwenglicher Geniekult; Streben nach einem Bündnis mit den bäuerlich-plebejischen Schichten (s. den Hirtenknaben im 12. Gesang; Kalevipoeg als König verkörpert andererseits auch etwas Bäuerliches: z. B. pflügt er als Ackerbauer das Land); Veränderung der verdorbenen Welt durch den Menschen als Selbsthelfer; Zentrierung auf emotio; pantheistische Weltsicht; aktives Empfinden der Natur.

${ }^{7}$ Unter anderem hat Johann Georg Hamann auch im Zuge seiner Londoner Sinnkrise von 1758 das Wort von der „Höllenfahrt der Selbsterkenntnis“ (zit. n. Rocholl 1869) geprägt. Vgl. dazu den zweiten Teil des vorliegenden Aufsatzes.

${ }^{8}$ Siehe zum Epos-Konzept bei Herder den Beitrag von Hans Graubner im vorliegenden Band.
} 
wie in Finnland so auch in Estland, gebrochen hat" (zit. n. Veidemann 2004: 264).

Also begab sich Friedrich Robert Faehlmann, der sich bereits vor dem Erscheinen des finnischen „Alten Kalevala“ (1835) der Volksdichtung und den Sagen um Kalevipoeg zugewandt hatte, nach dem Plädoyer von Georg Schultz-Bertram an die Arbeit. Sein früher Tod setzte aber allen Plänen ein Ende. Ausgeführt wurde sein Vorhaben durch Friedrich Reinhold Kreutzwald, der sich gleichfalls mit der Volksdichtung und dem folkloristischen Kalevipoeg-Stoff beschäftigt hatte. Nach seiner langjährigen folkloristischen und literarischen Tätigkeit ${ }^{9}$ erschien von 1857 bis 1861 in Dorpat sein wohl bedeutendstes Werk, das Epos „Kalevipoeg“, als wissenschaftliche estnisch-deutsche Parallelausgabe in Heften (19 087 Versen). ${ }^{10}$ Leider war ihm kein großer Erfolg beschieden, auch nicht mit einer 1862 in Finnland gedruckten erschwinglicheren Volksausgabe. Der Erfolg, wenn er sich später auch einstellte, musste, wie Cornelius Hasselblatt bemerkt, teilweise künstlich produziert werden, sowohl durch Kreutzwald selbst als auch durch die Rezeption und Interpretation vornehmlich im Ausland (vgl. Hasselblatt 2004: 302).

Kreutzwald war mit dem Werk gar nicht zufrieden, vor allem mit dem Ausgang der Geschichte, so dass er sich verpflichtet fühlte, in seinem späteren Kunstepos „Lembitu“ in vier Versen dazu Stellung zu nehmen (vgl. Laugaste 1953: 355). Insgesamt sei sein „Kalevipoeg“ kein poetisches Kunstwerk, sondern, wie er 1857 meint, „,nur eine Sammlung von

\footnotetext{
${ }^{9}$ S. auch Laugaste 1953: $343 \mathrm{f}$.

Rein Veidemann (2004: 264) vergleicht die Entstehung des estnischen Epos von der Idee bis zur endgültigen Fassung mit der Weitergabe eines Staffelstabes. An diesem Staffellauf beteiligten sich u. a. Christfrid Granander, Kristian Jaak Peterson, Friedrich Robert Faehlmann und Friedrich Reinhold Kreutzwald.

${ }^{10}$ Die ursprüngliche Fassung des „Kalevipoeg“ (13 817 Verse) wird im Oktober 1853 fertiggestellt. Deren erster Teil („Esiandeks“ - 3379 Verse), der Faehlmanns Mythen in gebundener Rede und an Macphersons „Ossians Gesänge“ erinnernde Anrufungen an die Himmelskörper enthält, ist in der darauffolgenden Ausgabe eliminiert worden. In der ursprünglichen Fassung nahmen sowohl die literarischen Entlehnungen als auch der Anteil von Kreutzwalds eigener Dichtung einen größeren Raum ein. Die Endfassung des Epos hingegen sei August Annist zufolge folkloristischer (estn. „rahva(luule)pärasem“ - eingeklammert wird das Wort „Dichtung“ -: „volks(dichter)ischer“, d.h. sie entspricht mehr der Dichtung des Volkes). Auch sprachlich sei sie besser bewältigt. Überdies werde das Ende im Lichte des estländischen Bauerngesetzes von 1856 optimistischer gestaltet (vgl. Kesküla 2005).
} 
wirklich im Munde des Volkes lebenden Sagen, die ich versucht habe in einer gewissen Ordnung an einander anzureihen“ (zit. n. Hasselblatt 2006: 242). Mit Hilfe seiner Phantasie hatte Kreutzwald es umzudenken und in Versform zu übertragen gehabt, wobei er sich auf den vierfüßigen Trochäus, das Versmaß des altestnischen alliterierenden Volksliedes, stützte. Als Vertreter des Volkes, als geborener Este, habe er, Kreutzwald, sogar das Recht gehabt, die uralte estnische Geschichte von Kalevipoeg, die einem verfallenen Gebäude glich, neu herzurichten, „von der Erdgrenze bis zum Dachfirst, so dass, wer hineintreten will, dort Schutz vor Wind und Regen findet" (Laugaste 1953: 345f.). Von einem ähnlichen Recht sprach auch Elias Lönnrot (1802-1884), der Verfasser des finnischen Epos „Kalevala“, der einen großen Teil des Versmaterials änderte, völlig neue Abschnitte hinzufügte und sich somit von der Volksdichtung entfernte. Er schrieb:

[I]ch meinte dasselbe Recht zu haben, das meiner Überzeugung nach die meisten Sänger sich nahmen, nämlich die Lieder danach zu ordnen, wie sie am besten zusammenpassen, d.h. in der Sprache der Dichtung: Itse loime loitsijaksi, laikahtime laulajaksi (Selbst sprach ich die Zauberworte, war als Liedersänger tätig), d.h. ich halte mich für einen ebenso guten Sänger, wie sie es waren. (Zit. n. KALEVALA 2010)

In den Umgestaltungsprozess bezog Kreutzwald auch fingierte Märchen ${ }^{12}$ und literarische Quellen wie beispielsweise die Epen der Antike, die „Gesänge Ossians“ und das finnische Epos „Kalevala“13 ein. Wie der estnische Schriftsteller und Literaturwissenschaftler Jaan Undusk (1994: $163)^{14}$ ausführt, sei es gar nicht denkbar, auch nur einen einzigen Text

\footnotetext{
${ }^{11}$ Übersetzt von der Verfasserin.

${ }^{12}$ Faehlmanns Verdienst bestehe Felix J. Oinas (1994: 30f.) zufolge darin, dass er als Erster die Legende um Kalevipoeg als den sagenhaften estnischen König schuf. Die Hauptkoordinaten der ins Epos eingegangenen Ereignisse stammen jedoch von Schultz-Bertram: die Tötung des Sohnes des finnischen Schmiedes, der Bannspruch des Schwerts. Er schuf auch die Legenden anderer Volksliedsammler und, wie wir wissen, das Vorbild des „Kalevala“.

13 Kreutzwald hatte sich zwar nicht unmittelbar an diesem „Epos des magischen Wortes“ (Rein Veidemann), namentlich „Altes Kalevala“ (1835) orientiert, doch am Versmaß und am Stilmittel des Parallelismus habe er sich ein Vorbild genommen (vgl. Veidemann 2004: 266).

${ }^{14}$ Jaan Undusk macht darauf aufmerksam, dass auch in der Folkloristik selbst die Intertextualität betont werde, und dies bereits längst vor der Prägung dieses Begriffs durch die bulgarisch-französische Psychoanalytikerin und Kultur- und Literatur-
} 
sozusagen von selbst zu produzieren; in jedem Text fänden sich Spuren fremder Texte. Dass im Grunde jeder „Text ein Gewebe von Zitaten aus unzähligen Stätten der Kultur“ (Barthes 2000: 190) ist, bestätigen schließlich Lese- und Kulturerfahrungen der bisherigen Menschheitsgeschichte. Der Folklore aber wohnten intertextuelle Bezüge ohnehin inne. Demnach ist auch ein Epos nicht zwingend einzig und allein an eine bestimmte Nation zu binden. Die historisch-kulturelle sowie intertexuelle Vernetzung, die wechselseitige Beeinflussung von Texten, auch von (National-)Epen, soll das für eine Nationsgemeinschaft Eigentümliche und Eigene, die zeitbezogene und konstitutive Funktion des Geschriebenen für das soziokulturelle und geistige Leben einer (sich herausbildenden) nationalen Gemeinschaft indes nicht aufheben. Dies gilt auch für Kalevs Sohn im Epos „Kalevipoeg“, der in seiner Gesamtheit durch und durch estnisch sei (vgl. Hasselblatt 2004: 303-306).

Unzufrieden zeigte sich Kreutzwald auch mit der Gattungszuordnung: Auf solch einen erhabenen Titel wie Volksepos (Nationalepos) habe sein „Kalevipoeg“ gar keinen Anspruch (vgl. Laugaste 1953: 346), weshalb er es für notwendig hielt, es zusätzlich mit dem Untertitel „Ein estnisches Märchen“ (estn. „Üks Eesti Ennemuistne Jutt“) zu versehen. Somit erhob er weder Anspruch auf den Begriff ,national“ noch auf den Begriff „Epos“.

Auch die späteren Forscher sind nicht umhingekommen, sich über die Zuordnung des Textes zur Gattung Epos zu äußern. Einer der bedeutendsten, der estnisch-amerikanische Volkskundler Felix J. Oinas, macht darauf aufmerksam, dass im Volksmunde nie ein Epos über Kalevipoeg kursiert habe, sondern nur manche Legenden und Sagen, die von der Form her Prosa waren (vgl. Oinas 1994: 32). Tatsächlich beinhaltet Kreutzwalds Werk nur einen recht geringen Teil an authentischer Volkdichtung - lediglich 13,07 \% von 19033 Versen (vgl. Hasselblatt 2004: 299). ${ }^{15}$ In Anbetracht dieses Sachverhalts, aber auch der oben dargestellten Verschiebung des Schwerpunktes, ist selbst die durch den estnischen Literaturwissenschaftler und Volkskundler

wissenschaftlerin Julia Kristeva in ihrem Aufsatz „Bakhtine, le mot, le dialogue et le roman“ (1967). Man kenne dort die intertextuelle Betrachtungsweise unter dem Namen der finnischen oder geographisch-historischen folkloristischen Methode.

${ }^{15}$ S. dazu auch Valk 2004: $316 f$. 
August Annist erfolgte gattungsmäßige Verortung des „Kalevipoeg“ als „ein auf der Volksdichtung basierendes Nationalepos" ${ }^{16}$ (Oinas 1994: 32) nicht ganz zutreffend, in ihrem ersten Bestandteil indes aber wohl eine dem Text am nächsten kommende Klassifikation. Cornelius Hasselblatt zufolge sollte hier zudem von einer Kunstdichtung ${ }^{17}$ (vgl. Hasselblatt 2004: 297) gesprochen werden:

Kreutzwald hat nicht unbedingt aus diesem Material, sondern vor allem auf Basis dieses Materials sein Epos geschaffen, denn wenn man genauer hinsieht, erweist sich der Kalevipoeg aus den verschiedenen Sagenvarianten als Unhold und Wüstling, was man von Kreutzwalds Figur, die immerhin offiziell König wird, wahrhaftig nicht behaupten kann. Kreutzwald hat sich also nur verschiedener uralter Elemente bedient und sich aus ihnen seine eigene, neue Welt zusammengestellt. (Ebd., 299)

Der estnische Literaturwissenschaftler Rein Veidemann erhebt gegen Kreutzwald gar den Vorwurf einer „literarische[n] Kompilation“ (Veidemann 2004: 266). Felix J. Oinas sieht im „Kalevipoeg“ obendrein nicht nur ein Epos, sondern zwei Epen: ein Makroepos, in dem die Taten des Protagonisten von der Geburt bis zum Tod und der Aufstieg seines Geistes in den Himmel geschildert werden, und ein Epos en miniature ${ }^{18}$, das mit dem Makroepos zwar verbunden, aber dennoch selbstständig sei. In diesem wird Kalevipoeg unter dem Vorwand, er müsse den Gehörnten bewachen, von der himmlischen Idylle entfernt und im Felsen an das Höllentor gefesselt. Wenn der Epilog des Buches im 20. Gesang - die Bestrafung Kalevipoegs - als Mikroepos fungieren sollte, ist über dessen kompositorische, inhaltliche und formelle Unzulänglichkeiten, über seinen Fragmentcharakter nicht hinwegzusehen. Selbst wenn man die Fesselung als Strafe für Kalevipoegs zwei schwere Sünden - die sexuelle Belästigung

\footnotetext{
${ }^{16}$ Hervorhebung E. P. Felix Oinas zufolge kennzeichne diese Bestimmung Kreutzwalds „Kalevipoeg“ am treffendsten (vgl. Oinas 1994: 32).

${ }^{17}$ Hervorhebung durch die Verfasserin.

${ }^{18}$ Wie Felix J. Oinas in seinem Buch „Surematu Kalevipoeg“ (dt. „Der unsterbliche Kalevipoeg“, 1994) nachweist, stammt die Schlussepisode hauptsächlich aus den estnischen Volksliedern, sie sei aber stark verdichtet worden. Alle zentralen Motive stammten allerdings aus der Weltliteratur. Dessen Vorbilder gehen in den Kaukasus zurück: In Georgien wird Amiran, der volkstümliche Verwandte des iranischen Ahriman bzw. des persischen Königs der Finsternis, wegen Übermut gegen Gott an den Felsen gefesselt. Denselben Mythos habe man auch auf den Teufel, Prometheus, Loki, Dukljan (Diocletianus) u. a. angewendet.
} 
der Frauen und das titanische Protzen mit seiner körperlichen Kraft versteht, wie dies Friedebert Tuglas und Felix J. Oinas tun, bleiben die Widersprüchlichkeiten ${ }^{19}$ dennoch unaufgelöst nebeneinander bestehen. Behält man jedoch die zeitgenössischen Zielsetzungen des „Kalevipoeg“ im Auge, die Legitimierung der Bildung einer Nation und die Verheißungen der Zukunft für diese Nation, kann man in der Schlussepisode des Epos durchaus auch, wie Rein Veidemann dies tut, Positives und zudem eine sakrale Dimension erblicken:

Aber gerade dieses Mikroepos enthält in vollem Umfang die ideologische, emotionale, ja sogar sakrale Kraft des Werkes. Der Mythos der ewigen Wiedergeburt wird als Bild für das ewige Fortdauern der Esten und des Estentums gesehen. Durch diese Ewigkeitshoffnung erhält „Kalevipoeg“ mit Hilfe der von beiden Seiten entfachten Spanflamme, die „nicht Vernichtung sät, sondern eine ewige Existenz symbolisiert“, seine sakrale Bedeutung. (Veidemann 2004: 267)

Und dennoch: Welche Bewandtnis hat es nun mit diesen Spänen, da ja gerade die Höllensöhne diejenigen sind, die versuchen, Kalevipoeg zu befreien?

Aber einmal naht die Zeit sich, Wo die Späne von zwei Enden

Angezündet loh'n und lodern,

Gleicher Zeit die Flammengluten

Machen frei die Hand des Helden:

Dann kehrt heim der Kalevide

Seinen Kindern Glück zu bringen,

Estenlande neu zu schaffen. ${ }^{20}$

\footnotetext{
${ }^{19}$ Darauf weist Felix Oinas selbst hin: Der estnische Gott Taara schickt Kalevipoeg zur Hölle, um ihn wieder anzustellen. Doch wie kann man an der Felsenwand gefesselt arbeiten? Aufschluss über die eigentlichen Ursachen der Bestrafung Kalevipoegs kann nur unsere Volksdichtung geben. In den Volkstraditionen führt sich der Recke gar nicht so auf, wie es einem König gebührt, da erscheint er auch als Unhold und Wüstling. In der Schlussepisode bleibt seine Bestrafung allerdings unaufgeklärt, denn für die in Finnland begangenen Untaten hat er ja bereits gebüßt. Des Weiteren fragt man sich, ob ein Gefesselter einen anderen Gefesselten bewachen kann und ob es überhaupt nötig ist, den gefesselten Gehörnten zu bewachen. Mehr als fragwürdig ist die Unfähigkeit der himmlischen Mächte. Im Himmel geben sie Kalevipoeg zwar seinen Körper zurück, sind aber nicht imstande, ihm seine Beine am Körper anzubringen (vgl. Oinas 1994: 53-57).

${ }^{20}$ Kalevipoeg 2004: 245. Alle weiteren Zitate und Vergleiche aus der deutsch-
} 
Vergegenwärtigt man sich zusätzlich zu dem oben Ausgeführten nochmals den Satz von Schultz-Bertram, dann wird immerhin ganz plausibel, welche Funktion diesem Text an der Schwelle des nationalen und geistigen Erwachens und der Selbsterkenntnis des estnischen Volkes in Wirklichkeit zugedacht worden war. Man zielte ja gar nicht auf den ästhetischen Genuss (vgl. Undusk 1994: 147) sowie auf gedankliche Folgerichtigkeit und logische Beziehungen, sondern zum einen darauf, den Nachweis zu erbringen, „dass man auf estnisch überhaupt so etwas wie Wortkunst veranstalten konnte; gleichzeitig sollte er zeigen, dass man dies schon sehr lange getan hat, dass es nun aber endlich auch einmal niedergeschrieben worden ist" (Hasselblatt 2004: 302). Zum anderen ging es um einen, wie Schulz-Bertram bekräftigte, eine Geschichte schaffenden Text und um einen, wie Jaan Undusk 1994 resümierte, eine Nation schaffenden Text, also um eine historisch-kulturell und zeitlich bedingte konstitutive Funktion und Notwendigkeit, um die Bewusstseins- und Nationsbildung, um die Selbstdefinition. Ob Kreutzwald seine Unzufriedenheit über die Bezeichnung „Volksepos“ bzw. „Nationalepos“ geäußert hatte, ob jemals ein Epos über Kalevipoeg kursiert hatte oder ob der Anteil an authentischer Volksdichtung recht gering ist, dies fiel - und fällt wohl auch heute - nicht ins Gewicht. „Kalevipoeg“ wurde tatsächlich zu einem nationalen Kerntext, „zur ideologischen Achse des estnischen Nationalgefühls, zum Erwecker der nationalen Geschichtsmythologie, der Grundvorstellungen und Denkmuster, zu einem auf seine Weise unwiderstehlichen Werk, das unter dem flachen Alltag die alten unterirdischen Kammern öffnete" (Undusk 1994: $148)^{21}$. Nun scheinen gerade diese „alten unterirdischen Kammern“ neben den intertextuellen Bezügen und Ansätzen die LeserInnen dazu anzuregen, über das Eingebundensein in die jeweilige Landschaft, das Zeitgebundene, die nationale oder ideologische Verengung und die (oft durch die Rezeptionsgeschichte aufgezwungene) eindimensionale historische Lesart hinaus sich auch anderen möglichen Rezeptionsweisen zu öffnen, ihnen nachzuspüren und sich die Frage zu stellen, ob in das „Kalevipoeg“ lediglich das Nationale eingeschrieben ist oder ob sich aus heutiger Warte und nach jetzigem Kenntnisstand hinter dem Text wesentlich mehr verbirgt. Ganz prägnant und anschaulich zu illustrieren und zu verdeutlichen vermögen diese Überlegungen, die Spannung zwischen dem

sprachigen Fassung werden nur mit der Seitenzahl nachgewiesen.

${ }^{21}$ Übersetzt von der Verfasserin. 
Nationalen und dem die Landesgrenzen Übergreifenden, die Höllenfahrten Kalevipoegs.

\section{Die Höllenfahrten Kalevipoegs}

Nicht nur die unterirdischen Kammern der grauen Vorzeit werden geöffnet, sondern auch die Kammern der mit uns verwobenen Mythologie und die unterbewussten Kammern. Es ist augenfällig, mit welcher „Eindringlichkeit und Ausführlichkeit“ (Petersen 2004: 287) Kreutzwald die beiden freiwilligen Höllenfahrten Kalevipoegs darstellt. Fünf der zwanzig Gesänge $(13,14,17,18,19)$ befassen sich mit seinen Höllenfahrten und seinem Gegenpart, dem Gehörnten. Zählt man noch den 10., den 15. und den 20. Gesang hinzu, dann sind es insgesamt sieben. Im Ersteren wird der Wassergeist mit dem Teufel gleichgesetzt: „Blieb dem blöden Wassergeiste, / Satans vielgeliebtem Sohne, [...]“ (120). Am Anfang des fünfzehnten Gesangs werden Kalevipoeg und die Höllenmaiden vom Gehörnten und seinen siebzig Hilfsgesellen verfolgt und im letzten Gesang, nach der zweiten Höllenfahrt, findet die Fesselung Kalevipoegs an das Höllentor und somit im gewissen Sinne seine Wiederbegegnung mit dem Gehörnten, einem seinerseits Gefesselten, statt. Das Wort „Hölle“ taucht bereits im WassergeistGesang auf, das Wort „Höllenfahrt“ wird am Anfang des achtzehnten Gesangs erwähnt - „Mag die Höllenfahrt des Helden, / Sein Durchwandern wüster Wege“ (208) - und dann noch einmal im neunzehnten Gesang:

Kalevs köstlicher Erzeugter,

Der nach seiner Höllenheerfahrt,

Viel des Guten unsern Gauen

Schuf zu aller Heil und Hulden,

Lebte selbst in Lindanisa

Froh mit seinen werten Freunden. (224)

Was mag Kreutzwald zu einer intensiven Hinwendung zum Motiv des Teufels, der Hölle und der Unterwelt bzw. einer Form des Jenseits bewegt haben? Bestimmt war es nicht vornehmlich der Umstand, dass der Teufel die populärste mythologische Figur in der estnischen Volkstra- 
dition ist, ${ }^{22}$ mit Sicherheit auch nicht allein das Wissen um die Produktivität dieser Motive in vielen literarischen und mythologischen Überlieferungen, z.B. in Vergils „Aeneis“, in Dantes „Divina Commedia“, im Orpheus-Mythos, im Faust-Stoff (Marlowe, Goethe) oder in der so genannten Teufelsliteratur der Romantik. Vielmehr ist anzunehmen, dass für Kreutzwald vor allem die inhaltliche und symbolisch-gleichnishafte Aussagekraft der Teufelsfigur und die mit ihr verbundene äußere und innere Topographie ausschlaggebend waren. Zu übersehen sind in Anbetracht der anfänglichen funktionalen Aufgabe des „Kalevipoeg“ auch nicht die historisch-zeitlichen Umstände der Esten und die semantischen Möglichkeiten, die sich aus der symbolischen Verwendung der Figur des Teufels in diesem Kontext ergeben. Überdies ist anzunehmen, dass Kreutzwald, dem eine christliche Erziehung zuteil geworden war und der eine sehr starke Beziehung zur Offenbarung des Göttlichen hatte, in seinem Epos auch auf die Offenbarung des Johannes anspielte $^{23}$ und ebenso auf die Höllenfahrt Christi und dessen Befreiungsmission. Eine ähnliche Mission lässt Kreutzwald Kalevipoeg vollziehen, der die Höllenmaiden aus dem Joch des Gehörnten befreit. Nicht ganz abwegig scheint der Gedanke zu sein, dass der romantisch gesinnte Kreutzwald sich auch in seinem Epos von den Empfindungen, Stimmungen und ästhetischen Anschauungen der Romantiker lenken lie $\beta^{24}$ und dass sein Rückgriff auf die graue Vorzeit und die gleichnishaften Höllenfahrten sowie die Teufelsfigur, ebenso wie der Rückgriff der Romantiker auf das Mittelalter und das Innere, in der „eigene[n] [...] Identitätssuche oder Identitätsfindung aus einem überwiegend gegenwartsbezogenen Anliegen heraus“ (Bärbel Rompeltien, zit. n. Vogt 2002: 33) begründet ist.

Kreutzwald selbst vermeidet die Bezeichnung „Teufel“ (kurat); stets ist er versucht, sie durch andere Bezeichnungen oder Euphemismen zu ersetzen und die Gestalt zumeist als „Gehörnten“ (Sarvik, Sarve-taat,

\footnotetext{
${ }^{22}$ S. zu den Erscheinungsformen des Teufels im estnischen Volksglauben Valk 1998, hier 9. Eduard Laugaste (1953: 350) zufolge werden besonders im achtzehnten und neunzehnten Gesang viele märchenhafte Stoffe verwendet. Als Vorbild für das Ringen des Kalevipoeg und des Gehörnten (Sarvik) dienen Geschichten über das Ringen Kalevipoegs und des Teufels (Vanapagan), zum Teil das Ringen des „starken Burschen“ und des Teufels (kurat). Volkstümlich ist auch das Fesseln des Gehörnten.

${ }^{23}$ S. dazu auch Kesküla 2005.

${ }^{24}$ S. dazu Aspel 1937.
} 
Sarvik-taat) anzusprechen. Lediglich in der deutschen Fassung von 2004 wird in den Höllenszenen einmal auch das Wort „Teufel“ verwendet Löwes deutsches Äquivalent für das estnische Wort taat („,der Alte“) ${ }^{25} \mathrm{im}$ neunzehnten Gesang lautet nämlich „Teufel“26 -, was durchaus für einen Stilbruch gehalten werden kann. Mit ca. 26 Entsprechungen sekundiert Löwe den ca. 18 Teufelsbezeichnungen Kreutzwalds bei den Höllenfahrten. ${ }^{27}$

Einer Benennung der höllischen Wesen bedarf Kreutzwald allerdings bereits im zehnten Gesang, wo der Wassergeist mit dem Teufel gleichgesetzt und dem Fersenknaben des Kalevsohnes befohlen wird, dem Wassergeist in die Tiefen des Erdkörpers zu folgen und somit eine Art Erkundungsfahrt in die Hölle (vgl. 121f.) zu unternehmen. Aber auch hier ist der Verfasser stets bemüht, der direkten Bezeichnung aus dem Wege zu gehen und sich stattdessen euphemistischer Ausdrücke zu bedienen, wie paharet (Satan, der garst'ge Geist), põrguline (der Höllentropf), purask (der Teufel), kuri (Böse), vana kaval võrgutaja (der alte tück'sche Teufel). Der Übersetzer dagegen spricht schon in diesem Gesang ein Höllenwesen mit seiner direkten, geläufigen Bezeichnung an, indem er gelegentlich anstelle des Wortes „Wassergeist“ (wortwörtliche Übersetzung des Kreutzwald'schen vetevaim $)^{28}$ „Wasserteufel“ (119 -

\footnotetext{
${ }^{25}$ In Klammern steht Löwes Übersetzung.

${ }^{26}$ „Kalevite kallis poega / Laskis sammud lustilisti / Taadi taalderi-tubaje, [...]“ (Kreutzwald 1953: 295). - „Kalevs köstlicher Erzeugter / Lenkte lustig seine Schritte / Nach des Teufels Talerstube, [...]“ (221). Hervorhebungen E. P.

27 Kalevipoegs Bezeichnungen in der deutschen Fassung und dem estnischen Originaltext: der Alte (Sarvik, taat), der Gehörnte (Sarve-taat, Sarvik-taat, Sarvik), der Widersacher (Sarvik), der Leere (Tühi), der alte Nichtsnutz (Vana Tühi, Tühi, Tühi-Taati), der Hörnerträger (Sarvik-taat), der gehörnte Alte (Sarvik-taat), der Höllenherrscher (põrgulane), der Höllenkönig (põrgulane), der Höllenfürst (kuri), der Höllenherr (põrgulane, põrgu peremees), der Böse (kuri, põrgulane, sarvik), der Wirt der Hölle (Sarviktaat), der Feind (Sarvik), der Wüterich (taadike), der Geschlagene (vaenumees), der Flegel (Sarvik), der Fürst der Hölle (Sarvik-taat), der Teufel (taat), der Herr des Hauses (peretaat), Hähnchen (kukekene), der Haushahn (perekukk), der Vater (taadikene), Leidesvogel (leinalind), am Fuß gefesselt Hühnchen (kammitsjalgel kukekene), der Vielgenannte (kuulus Sarve-taat).

28 In Löwes Übersetzung stehen für das estnische Wort vetevaim auch noch „Wasserkobold“, „Wasserdämon“, „Dämon“ und „Kobold“. In gewisser Hinsicht wären die folgenden Übertragungen mit „Teufel“ berechtigt, da in der estnischen Fassung das Wort põrguline (põrgu = „Hölle“) benutzt wird; doch wie gezeigt, gilt schon põrguline selbst als ein Euphemismus für „Teufel“: „Mit dem tück'schen Wasserteufel / Eine
} 
dreimal, 125, 126) und „Teufel“ („der led'ge Teufel“, 119; „der alte tück'sche Teufel“, 120) verwendet.

Die verschiedenen Namensgebungen bzw. Verbrämungen sollen uns jedoch keineswegs in die Irre leiten, als wollte Kreutzwald damit den dem Leser vertrauten, tradierten Charakter des Teufels verharmlosen. Im Gegenteil: Obgleich sie zum einen als literarisches Mittel für die Abgrenzung gegen dessen bekannte christliche Bedeutung als Inbegriff des Bösen zu wirken scheinen, vermögen sie zum anderen zugleich das Wesen und die Stellung des Teufels ausdrücklicher und differenzierter $\mathrm{zu}$ vermitteln. So wird dieser auch als ein einfältiges und / oder dummes und feiges Wesen dargestellt, als das er mitunter in der estnischen Volkstradition auftritt. Zugleich verweisen diese Benennungen, namentlich Tühi, Vana Tühi und Tühi-Taati - in Löwes Übersetzung steht für Tühi „der Leere“ und für Vana Tühi, Tühi, Tühi-Taati „der alte Nichtsnutz“ - , wie Sirje Purga bemerkt, auf „eine Kraft, die eigentlich von der Seelenleere lebt" (Purga 2004: 135) ${ }^{29}$. Auch seine Physis scheint etwas abgeschwächt, seine zauberischen Kräfte ermattet zu sein. Nur mit Hilfsmitteln aus der Märchenwelt, einer kleinen Weidenrute, eines Schnitzelhutes bzw. eines alten Filzhutes, eines Glöckchens und des Zauberwassers kann er beliebige Gestalt annehmen und zwischen Hölle, Schattenreich und Erde umherreisen.

Die von dem gewohnten Wort „Teufel“ und den mit ihm verknüpften Konnotationen abweichenden Bezeichnungen scheinen noch eine andere Funktion zu haben: die Ermutigung der sich herausbildenden Nation, jegliche Ängste abzubauen und damit mehr Vertrauen in sich selbst, in die eigene Kreativität und in die eigenen Entwicklungsmöglichkeiten zu gewinnen. Dabei ist man sich wohl gut dessen bewusst, dass das Böse bzw. die Destruktivität - ein Wort, das „[i]n der modernen Therapeutensprache [...] für den theologischen Begriff des Bösen (des Teufels in seinen verschiedenen Formen)" (Petersen 2003:

Wette nur zu wagen?“ (125, V. 830f. ) - „Vetevaimul' vägikorra / Pórgulise vastu püsiks?“ (Kreutzwald 1953: 164) „Mit dem tück'schen Wasserteufel / Einen Wettkampf nicht zu weigern, [...]“ (126, V. 835f.) - „Vetevaimul' vägikorral, / Pórgulisel' vastu paneks [...]“ (Kreutzwald 1953: 164). Auch das deutsche Äquivalent „Teufel“ für das estnische purask wäre insofern verständlich, als das Letztere folgende Bedeutungen hat: paharet, kurat.

${ }^{29}$ Übersetzt von der Verfasserin. 
11) steht - nie vollkommen aus der Welt ausgerottet werden kann. Aber: Der Teufel als Gegenpart und als Vertreter einer materialistischen Einstellung zu den Dingen und als in den Schöpfungsplan Gottes Eingebundener kann, wie Kalevipoeg dies demonstriert, gebändigt werden - auch wenn es ein langwieriges Unterfangen ist.

Denn ein Teufel, genauso auch Kreutzwalds Teufel, regiert mit „gewalt'ger Hand“ (165) und hortet große Reichtümer: „Große Güter hat der Alte / Ausgedehnte Herrschgebiete“ (164); sieben stattliche Zimmer hat er: Zimmer aus Eisen, Kupfer, Silber und Gold, ein Seidenstübchen, ein Sammetstübchen, ein „Kämmerlein aus schönen Spitzen“ (163); auf dem Hofe stehen sieben „[w]underbar gebaute Speicher“ (164) voll mit Getreide, Gemüse und Schweinefett; hinterm Hofe stehen Ställe. Zugleich ist er ein etwas mystischer Herrscher der Hölle, der Unterwelt und des Schattenreiches, dessen eigentliche Herkunft verhüllt bleibt:

Und kein sterblich Auge konnte

Jemals sehen seine Gänge,

Auch kein menschlich Ohr vermochte

Nachzuspüren seinen Wegen.

$[\ldots]$

Seine Wege sind uns dunkel.

In der Tiefe soll ein Kern,

Soll ein Hohlraum sich befinden,

In demselben sieben Welten,

Sieben sehr versteckte Inseln.

[...]

Über der Verstorb'nen Scharen

Herrscht der Alte, der Gehörnte,

Wie in seiner Weisheit Taara

Schon im Anbeginn der Schöpfung

Selber das Gesetz gegeben. (164f.)

In der Hölle und im Reich der Schatten sieht Kalevipoeg kein Tageslicht,$^{30}$ der Sinn für die Zeit als dynamische vierte Dimension geht ihm verloren, alles scheint in Erstarrung zu verharren:

\footnotetext{
${ }^{30}$ Diese erste Darstellung der Hölle findet sich, wie gesagt, im zehnten Gesang: „Der Gesell des Kalevsohnes / Folgte nach ihm auf dem Fuße, / Wandelnd unbekannte Wege, / [...] Als sie auf dem weiten Wege / Auf des Bösen Aue kamen, / An des Dunkelreiches Anger, / Wo ein Morgenlicht nicht leuchtet, / Wo kein Glanz des Abends glühet. /
} 
Maß der Zeit ließ sich nicht messen,

Tagesgrenze nicht ergründen:

In den Schoß der Tiefe scheinet

Nie das Licht der lieben Sonne,

Kann sich Mondes Glanz nicht melden,

Noch der Stern die Stunde deuten -

[...] (212)

$-$

Dort stehn weder Zahlenweiser,

Noch enthüllt der Himmel Zeichen,

Um der Tage Maß zu messen,

Länge der Nächte zu erlernen. (223)

Für die Rezeption und die Interpretation des zweifachen freiwilligen Ganges des Kalevipoeg in die Hölle bieten sich mindestens drei Zugänge an: eine historische, eine psychoanalytische bzw. psychotherapeutische und eine anthroposophische Sicht. Für die Volkskundler erweist sich mit Sicherheit auch die geographisch-historische folkloristische Methode (die Finnische Schule der Erzählforschung) als ergiebig.

Nähert man sich den Gesängen über die Höllenfahrten Kalevipoegs aus historischer Sicht, konkretisiert man einzelne Aussagen und Bilder lediglich historisch-zeitlich bzw. räumlich-landschaftlich und entreißt sie, wie Peter Petersen meines Erachtens zu Recht bemerkt, dem mythologischen und archetypischen Bild- und Sinnzusammenhang (vgl. Petersen 2004: 273). Ein Beispiel für diese dem analytischen und begrifflichen Denken entspringende Sichtweise wäre der Versuch, Kalevipoegs Höllenfahrten mit den Gängen in den Herrenhof, die Gestalt des Gehörnten mit dem Feudalherren, die Hölle mit dem Gutshof und die in gradueller Abstufung vorgeführten Höllenkammern mit dessen Zimmern zu vergleichen, wie dies Eduard Laugaste im Jahre 1953 unternommen hat. Seine Gedankengänge untermauert er mit dem Hinweis darauf, dass auch in den lyrischen estnischen Volkliedern die Hölle mit dem Gutshof verglichen werde. Indes kann Eduard Laugaste doch nicht umhin, sich des synthetischen Denkens - hier auch noch des archetypischen Denkens - zu bedienen, wenn er in Kalevipoegs Kampf mit den

Scheint doch tags nicht schöne Sonne, / Nachts der Mond kein mildes Licht gibt, / Weisen Sterne auch den Weg nicht / Auf des bangen Dunkels Bahnen. / Nur allmählich schoss ein Schimmer / Auf den Pfad, ihn halb erhellend, / Da von naher Pforte Pfosten / Fackeln Feuerschein ergossen." (120) 
Söhnen des Peipuszauberers (sortsid) dessen furchtlosen Kampf gegen alle dunklen Mächte sieht, die die schöpferischen Kräfte immer gehindert haben und die den Fortschritt stören (vgl. Laugaste 1953: 359).

Das Epos - ebenso wie Mythen, Märchen und Träume - ist vor allem ein Produkt bildhaften, synthetischen und imaginativen Denkens. Archetypische Erfahrungen und Bilder, Mythen, Märchen und Träume geschlafen wird im „Kalevipoeg“ viel - hat Kreutzwald nicht nur in die Höllenfahrtszenen und in den Epilog eingewoben. Was dabei meines Erachtens jedoch von bestimmender Bedeutung für ein Epos ist und eine psychoanalytische bzw. -therapeutische sowie anthroposophische Deutungsweise nahelegt, ja was ein Nationalepos obendrein zum weltliterarischen bzw. universellen Epos erhebt, ist der Umstand, dass die (symbolischen) Bilder als darin erfahrbare Archetypen oder als „transsubjektiv vorgeprägte Bilder“ (Charles Lamb, zit. n. A. Assmann 1999: 228) interpretiert werden können. Diese Urbilder menschlicher Vorstellungsmuster, die sich Aleida Assmann zufolge im kollektiven Bewusstsein befinden, stünden der Einprägungskraft des Gedächtnisses näher und der Interpretationskraft des Verstandes ferner und entwickelten eine ganz andere Übertragungsdynamik als Texte (vgl. A. Assmann 1999: 227). Hierbei sei zu erwägen, ob das Epos „Kalevipoeg“ sich trotz seines teilweise fragmentarischen Charakters bzw. der von Felix J. Oinas vorgeschlagenen Zweiteilung zumindest aus psychologischer und anthroposophischer Sicht nicht als ein Ganzes auffassen ließe.

Aus psychotherapeutischer Sicht können die Höllenfahrten Kalevipoegs als ein Teil seines Selbstwerdungsprozesses und seiner Bewusstseinsbildung durch Grenzerfahrung, als „der Dreischritt von erkunden, erkennen und bändigen der Destruktivität“ (Petersen 2004: 287), verstanden werden: Beim ersten Mal erkundet ${ }^{31}$ Kalevipoeg die Hölle, sammelt dort und hinterher weitere Erkenntnisse sowie Erfahrungen und bändigt schließlich bei der zweiten Höllenfahrt das Böse. Hat er schon beim ersten Gang in die Hölle verschiedene Hindernisse zu überwinden:

\section{Kalevs kühner Heldensprössling}

\footnotetext{
${ }^{31}$ Wie oben vermerkt, findet die allererste Begegnung mit den höllischen Bereichen durch den Fersenknaben des Kalevsohnes im zehnten Gesang statt.
} 
Strich die Strecke unermüdlich,

Wenn auch das gebückte Wandeln

Wie das Kriechen schwer ihm wurde;

Dichtes Dunkel in der Höhle

Machte misslicher den Gang noch [...] (154, 13. Gesang),

so werden diese bei seiner zweiten Höllenfahrt sowohl an Gestalt als auch an Anzahl konkreter: 1. „[d]ichte Wolken dunklen Rauches“ (209); 2. „sackdunkles Finster“ (210); 3. „die feinen Spinnenfäden“ (210); 4. ein scheinbar leicht zu überquerender Bach (vgl. 211); 5. „die schwarzen Schwärme“ (212) von Mücken, die Kalevipoegs Augen und Nase verstopfen; 6. „die schwere Eisenbrücke“ (213), der Fluss aus Feuerglut und der Kampf gegen Höllenschergen; 7. „[e]ine feste Felsenmauer“ (216), mit der der Gehörnte die Tür zu seinem Hof blockiert, und der Kampf Kalevipoegs mit den aus der verborgenen Tür hervorbrechenden Heergesellen. Erst dann tritt er dem Gehörnten gegenüber. Durch all diese Barrieren werden, wie der Psychotherapeut Peter Petersen erklärt, „im symbolischen Bild fast klassische psychologische Abwehrformen geschildert“ (vgl. Petersen 2004: 288f.).

Bei der Beschreibung der Überwindung der Hindernisse bzw. der psychologischen Abwehrformen auf der zweiten Höllenfahrt ist eine wichtige Rolle den Tieren, wie Rabe, Mäuschen, Kröte, Krebs, Grille und schon vorher Igel, zugeschrieben worden. Im ganzen Epos, das reich an Naturschilderungen ist, wird die enge Verbundenheit mit der Natur zum Ausdruck gebracht, sowohl durch die Naturbezogenheit der handelnden Figuren als auch des Sängers, der im Sinne Herders seine Dichtung aus dem Leben bezieht - und zwar aus dem mythologischen Leben - und diese wieder auf das Leben - und zwar auf das reale Leben - zurückwirken lässt und auf diese Weise die (Volks-)Poesie als naturnotwendige Muttersprache des menschlichen Geistes zelebriert.

Aber nicht nur den Tieren als Teil der Natur wird eine unterweisende und lebensrettende Aufgabe zugeordnet, sondern auch den Frauengestalten. Es ist erstaunlich, was für eine Rolle Kreutzwald im Unterschied zu den gewöhnlich männlich orientierten nationsbildenden Epen bzw. anderen Texten mit konstitutiver Funktion für das nation building ${ }^{32}$ den

\footnotetext{
${ }^{32}$ Eine Ausnahme unter den Ausnahmen bilden wohl die identitätsbildenden Texte bei der nationalen Wiedergeburt der Tschechen im 19. Jahrhundert, in denen sich
} 
Frauen zukommen lässt, ohne diese zu idealisieren oder zu verherrlichen. Dabei setzt das „Kalevipoeg“ andererseits ebenso auf männliche Heldentypen. Nicht im Sinne des unterdrückenden Status von Natur und Frau, nicht im Sinne der Stellung der Frau als Anderes, dem das männliche Subjekt sich entgegensetzt, erfolgt hier die Gleichsetzung von Natur und Frau. Kreutzwalds Mutterbild scheint vielmehr einem archetypischen Mutterbild der Mythologie, der matriarchalen Vorwelt zu entspringen, in der die Mutter bzw. die Frau als Leben spendende, hütende und rettende Kraft der Natur, als Symbol des Ewig-Weiblichen figuriert. Immer wenn die Not am größten und der Rat am nötigsten ist, leisten die Frauen - hier bezogen auf die Höllenszenen - Kalevipoeg Hilfe: ${ }^{33}$ Da sind Rasenmutters Töchter, die ihm vor dem Einstieg in die Hölle raten, diese unverwüstet zu lassen. Da ist die runzelwanzige Alte, die Hüterin der Hölle und die Mutter des Gehörnten, die in der Tiefe der Erde Kalevipoeg zu verführen sowie zu entkräften versucht und die ihm dennoch das Glöckchen in die Hand spielt, das ihm mehrmals das Leben retten und den Weg ins Zentrum der Hölle ermöglichen wird. ${ }^{34}$ Damit nimmt die Alte zugleich die Gefangennahme ihres Sohnes vorweg. Da sind die Höllenmaiden, ${ }^{35}$ die ihm von der Gewaltanwendung abraten und ihm mit Poesie, mit Rat und List bei der Besiegung des Gehörnten helfen. Von konstitutiver Bedeutung für dieses Epos ist nicht zuletzt die Mutter Linda, die wichtigste Frau für Kalevipoeg. Stark ist seine Bindung zur Mutter, deren Verlust er kaum verwinden kann und derentwegen er, denn so groß war die Trauer um sie, nach Finnland geht und dort teils unbewusst - aus Unwissenheit und Übermut - ähnlich wie Odysseus Schuld auf sich lädt. Ohne Weisung seiner

\footnotetext{
Frauenfiguren mächtig hervortun. Siehe dazu im vorliegenden Band den Beitrag von Zuzana Stolz-Hladká.

33 Kreutzwald zeigt aber auch, dass Frauen bedrohlich (Töchter des Wassergeistes) auftreten können.

34 „Allerdings ist der wache Blick (der Rationalität) des Kalevipoeg notwendig, um die lebenswichtige Bedeutung des Glöckleins zu erfassen und es sich zu verschaffen." (Petersen 2004: 275)

35 Und schließlich ist die jüngste Höllenmaid diejenige, die die Wünschelrute mitnimmt, die sie alle vor den verfolgenden Hilfsgesellen des Gehörnten retten.
} 
Schattenmutter ${ }^{36}$ hätte er beim letzten Kampf den Gehörnten nicht überwinden und bändigen können:

In der Halle haust' ein Mütterchen,

Eines toten Weibes Schemen,

Linda gleich in tiefem Harme.

Ja, der Mutter mattes Abbild

Schien des Sohnes Aug' zu schauen.

$\mathrm{Sa} \beta$ am Spinnrad seine Mutter,

Trat das Rad mit Windeseile,

Dass im Schwung die Scheibe schwirrte;

[...]

Schattenmutter milden Blickes

Winkt dem Sohne sichere Deutung

Nach dem Napfe, der zur Rechten. (216f., 18. Gesang)

Wachsam schaut der Mutter Schatten,

Wie der Sohn ermattet mählig;

Kurz gefasst nimmt sie die Kunkel,

Schwenkt sie zehenmal geschwinde

Übers Haupt in heft'ger Drehung,

Wirft sie heftig dann zu Boden,

Wink und Weisung ihrem Sohne. (220, 19. Gesang)

„Kalevs Sohn ist somit vor allem auch Lindas Sohn“37 - schreibt zu Recht Cornelius Hasselblatt (2004: 306). Vor allem Linda scheint die weibliche Figur zu sein, durch die sich das estnische Epos von einem eindeutig männlich geprägten Text absetzt. ${ }^{38}$

Einen etwas andersartigen Zugang zu unserem Epos als die psychoanalytische und psychotherapeutische Deutung, eine von den herkömmlichen Vorstellungen abweichende Herangehensweise an diesen Text bietet die anthroposophische Sichtweise, deren Ausgangspunkt die Annahme ist, alle Völker hätten einst - vor der logischen Form des Be-

36 „Psychologisch aufgefasst erscheint hier der produktive Aspekt des archetypischen Mutterbildes in der Seele des Helden. Indem er sich mit dieser Kraft verbindet, kann er die Destruktivität bändigen.“ (Petersen 2004: 286)

${ }^{37}$ Hervorhebung E. P.

${ }^{38} \mathrm{Zu}$ erwähnen sei, dass das ältere estnische Volkslied vor allem die lyrische Schöpfung der Frauen ist, in der das Maskulin-Epische nur eine untergeordnete Rolle spielt (vgl. Valk 2004: 317). 
griffs, vor der Entwicklung des eigenen Denkvermögens und der abstrakten Begrifflichkeit - über das hellsichtige Bewusstsein verfügt, ihre Sinnenwelt sei den geistigen Wesenheiten gegenüber offen und das Verstehen der Welt in Bilder gekleidet gewesen. Seinen Niederschlag habe das auch in diversen Mythen, Epen, Sagen, Legenden und Märchen gefunden. Die Erinnerung an die einstige Zeit der Weisheit sei den Menschen allerdings nicht völlig abhanden gekommen, sie sei in ihrem kollektiven Unbewussten, das die Traditionen nährt, noch aufbewahrt (vgl. Purga 2004: 7-9, 36).

In dieser Deutungsperspektive verkörpert Kalevipoeg, wie Sirje Purga in ihrem Buch zur Bildersprache des estnischen Nationalepos ausführt, das Bild vom Ich des Menschen (vgl. ebd., 26). Kalevipoeg gilt dank der Weisheitsmilch, mit der er von seiner Mutter Linda gestillt wurde, als der Geweihte, der noch den Kontakt mit der geistigen Welt herstellen und diese Weisheit ${ }^{39}$ fortbestehen lassen könne. Die Fahrten in die Hölle versinnbildlichen dabei Gänge in das Unbewusste, in das Innere der eigenen Seele, in eine geistige Welt, die zeit- und endlos ist und ein eigenes Licht hat (vgl. ebd., 114, 171). Als Erwecker des Ichbewusstseins, als Fragenproduzierer agiert sein Gegenpart, der Gehörnte, der als „Verfinsterer des Bewusstseins“ mithin zugleich eine positive Mission übernimmt, indem er den Menschen zum Nachdenken animiert (vgl. ebd., 122f., 128, 136, 138, 183).

Also: Wer sind wir? Woher kommen wir? Wohin gehen wir? Wo stehen wir im Kosmos? Als Schlüsselstellen für die Beantwortung dieser Fragen erweisen sich auch Kalevipoegs Fahrten in die Hölle als die wichtigsten Etappen auf seinem Entwicklungs-, Erkenntnis- und Initiationsweg zum Verständnis unserer Ursprünge in der Ureinheit und unserer Entstehung im Kosmos, zum Verständnis des Gleichgewichts der materiellen und geistigen Kräfte und zum eigentlichen Selbst. Gerade der psychotherapeutische und psychoanalytische sowie anthroposophische Zugang zum estnischen Epos „Kalevipoeg“, aber auch die darin versammelten archetypischen und mythologischen Erfahrungen sowie die intertextuellen Bezüge und Anspielungen auf die Folklore anderer Völker erheben es zu einer Länder übergreifenden literarischen Schöpfung und

\footnotetext{
${ }^{39}$ Kalevipoegs Vater Kalev ist ein Kind von Göttern und Menschen, seine verwitwete Mutter Linda die Trägerin dieser einstigen Weisheit.
} 
zu einem Sinnbild des menschlichen Werdens, Reifens, Wirkens und Seins. In diesem, aber auch im Herder'schen Sinne (vor allem aus anthropologischer Sicht),${ }^{40}$ ist „Kalevipoeg“ zumindest heute nicht mehr als ein Epos zu lesen, das lediglich für eine Nation in Anspruch genommen werden sollte, sondern zugleich als ein Menschheitsepos.

\section{Literaturverzeichnis}

\section{Primärliteratur}

Kalevipoeg. Das estnische Nationalepos (2004). In der Übersetzung von Ferdinand Löwe. Hrsg. v. Peter Petersen. Stuttgart/Berlin.

Kreutzwald, Friedrich Reinhold (1953): Kalevipoeg. Tallinn.

\section{Sekundärliteratur}

ASPEL, Aleksander (1937): Lähtekohti Kreutzwaldi stiili iseloomustmiseks [Grundlagen für die Charakterisierung von Kreutzwalds Stil]. Verfügbar unter: http://www.kirjandusarhiiv.net/?p=36 (05.04.2010).

AssmanN, Aleida (1999): Erinnerungsräume. Formen und Wandlungen des kulturellen Gedächtnisses. München.

Assmann, Jan (2007): Das kulturelle Gedächtnis. Schrift, Erinnerung und politische Identität in frühen Hochkulturen. München.

BARTHES, Roland (1968): Der Tod des Autors. In: Fotis Jannidis/Gerhard Lauer/Matias Martinez/Simone Winko (Hrsg.) (2000): Texte zur Theorie der Autorschaft. Stuttgart, S. 185-193.

BRINKER-GABLER, Gabriele (1998): Vom nationalen Kanon zur postnationalen Konstellation. In: Renate von Heydebrand (Hrsg.) (1998): Kanon Macht Kultur. Theoretische, historische und soziale Aspekte ästhetischer Kanonbildungen. Stuttgart/Weimar, S. 78-96.

Hasselblatt, Cornelius (2006): Geschichte der estnischen Literatur: von den Abhängen bis zur Gegenwart. Berlin/New York.

Hasselblatt, Cornelius (2004): Kalevs Sohn im estnischen und europäischen Kontext. Zur Entstehungsgeschichte des Kalevipoeg. In: Kalevipoeg. Das estnische Nationalepos (2004). Hrsg. v. Peter Petersen. Stuttgart/Berlin, S. 297306.

JÄRVELAID, Peter (2004): Kalevipoeg - seine staatstragende Gestaltung für Estland. Versuch, Kalevipoeg durch Kreutzwalds Leben zu rekonstruieren.

\footnotetext{
${ }^{40}$ Siehe zum Menschheitsepos-Konzept bei Herder den Beitrag von Hans Graubner im vorliegenden Band.
} 
In: Kalevipoeg. Das estnische Nationalepos (2004). Hrsg. v. Peter Petersen. Stuttgart/Berlin, S. 307-314.

Kalevala. Die Veröffentlichung des Kalevala 1835 und 1849 (2010). Verfügbar unter:

http://www.finlit.fi/kalevala/index.php?m=218\&s=221\&l=9 (04.04.2010).

KesKüLA, Kalev (2005): Lauluisa prohvetina [Vater des Gesangs als Prophet].

In: Eesti Ekspress. Areen v. 14.11.2005. Verfügbar unter:

http://paber.ekspress.ee/viewdoc/039372FCDEC3B5BFC22570B90056E496 (10.04.2010).

Kross, Jaan (2004): Geleitwort. In: Kalevipoeg. Das estnische Nationalepos (2004).

Hrsg. v. Peter Petersen. Stuttgart/Berlin, S. 7-8.

LAUGASTE, Eduard (1953): Järelsõna [Nachwort]. In: Friedrich Reinhold Kreutzwald (1953): Kalevipoeg. Tallinn, S. 327-383.

Oinas, Felix (1994): Surematu Kalevipoeg [Der unsterbliche Kalevioeg]. Tallinn.

Petersen, Peter (2003): Estland: Meine Begegnung mit einem widerständigen

Volk und seinem Nationalepos Kalevipoeg - Eine Liebeserklärung. 20.03.2003.

Petersen, Peter (2004): Kalevipoeg heute. Document humain einer künftigen

Kultur Europas. Psychologisch-anthropologische Aspekte. In: Kalevipoeg.

Das estnische Nationalepos (2004). Hrsg. v. Peter Petersen. Stuttgart/Berlin, S. 269-296.

PURGA, Sirje (2004): Mõtteid eepose „Kalevipoeg“ pildikeelest [Gedanken über die Bildersprache des Epos „Kalevipoeg“]. Tallinn.

Rocholl, Rudolf (1869): Johann Georg Hamann. In: Reiner Wild (Hrsg.) (1978): Johann Georg Hamann. Darmstadt, S. 91-118.

UNDUSK, Jaan (1994): Rahvaluuleteksti lõppematus. Felix Oinas, soome meetod ja intertekstuaalne „Kalevipoeg“ [Die Unabgeschlossenheit des folkloristischen Textes. Felix Oinas, die finnische Methode und das intertextuelle „Kalevipoeg“]. In: Felix Oinas (1994): Surematu Kalevipoeg. Tallinn, S. 147-174.

VALK, Ülo (1998): Allilma isand: kuradi ilmumiskujud eesti rahvausus [Der Herr der Unterwelt: Erscheinungsformen des Teufels im estnischen Volksglauben]. Tartu.

VALK (2004): Tendenzen und Anhaltspunkte in der Forschungsgeschichte des „Kalevipoeg“. In: Kalevipoeg. Das estnische Nationalepos (2004). Hrsg. v. Peter Petersen. Stuttgart/Berlin, S. 315-321.

VeIDEmann, Rein (2004): Fr. R. Kreutzwalds „Kalevipoeg“ als ein heiliger

Text der estnischen literarischen Kultur. Eine literarische Studie. In: Kalevipoeg. Das estnische Nationalepos (2004). Hrsg. v. Peter Petersen. Stuttgart/Berlin, S. 263-268.

VOGT, Jochen (2002): Einladung zur Literaturwissenschaft. München. 


\section{Fr. R. Kreutzwald als zeitkritischer Beobachter (anhand seiner Beiträge in der Wochenschrift ,Das Inland ${ }^{66}$ )}

Friedrich Reinhold Kreutzwald (1803-1882) ist in erster Linie als Verfasser des estnischen Nationalepos „Kalevipoeg“ bekannt, aber neben seiner täglichen Arbeit als Arzt und seiner literarischen und folkloristischen Tätigkeit war er zudem publizistisch tätig. Von seiner deutschsprachigen Publizistik sind besonders die Beiträge in der Wochenschrift „Das Inland“ hervorzuheben (vgl. Kruus 1995: 224; Kruus/Puhvel 2000: 222). Was hat Kreutzwalds publizistische Tätigkeit mit dem Epos „Kalevipoeg“ zu tun? Diese Periode in seinem Leben kann gewissermaBen als eine Vorstufe, als die Vorbereitungszeit für die Arbeit an dem Nationalepos, angesehen werden.

Wenn Kreutzwald im vorliegenden Beitrag als zeitkritischer Beobachter bezeichnet wird, so ist das Wort „kritisch“ im zusammengesetzten Adjektiv „zeitkritisch“ nicht unbedingt nur in der Bedeutung „negativ beurteilend“ zu verstehen. Der Begriff „kritisch“ wird hier so aufgefasst, dass Kreutzwald kein unbeteiligter Zuschauer ist, dass er an den Ereignissen, Erscheinungen und Zuständen, über die er in seinen Beiträgen berichtet, Anteil nimmt, dass seine persönliche Meinung, seine Stellungnahme zum Dargestellten zum Ausdruck kommt.

Die Wochenschrift „Das Inland“ erschien von 1836 bis 1863 in Dorpat (estn. Tartu). ${ }^{1}$ Der Begründer und erster Herausgeber der Zeitschrift war Friedrich Georg von Bunge (1802-1897), ein deutschbaltischer Rechtswissenschaftler und Historiker, der an der Universität Dorpat studiert hatte und anschließend an derselben Universität als Lehrkraft tätig war, seit 1831 als Professor. Bunge hat „Das Inland“ bis 1843 herausgegeben, als er wegen Auseinandersetzungen mit hohen russischen Beamten, vor allem mit dem Kurator der Universität, diese verlassen musste und nach Reval übersiedelte. Danach hatte die Zeitschrift mehrere Herausgeber, von denen Carl Reinthal, Pastor, Schulbuchautor

\footnotetext{
${ }^{1}$ Für eine ausführliche Behandlung der Wochenschrift „Das Inland“ vgl. Palm 2002.
} 
und Mitbegründer der Gelehrten Estnischen Gesellschaft, sowie Theodor Beise, der Syndikus von Dorpat und Funktionär der Gelehrten Estnischen Gesellschaft, zu erwähnen wären (vgl. Jansen 1994: 284).

Ein Wendepunkt aus estnischer kulturhistorischer Sicht war das Jahr 1843, als Heinrich Laakmann, der bedeutendste estnische Buchdrucker, Verleger und Buchhändler, den Druck und im nächsten Jahr auch den Verlag des „Inlands“ übernahm und diese Funktionen bis zur Einstellung der Zeitschrift Ende des Jahres 1863 ausübte (vgl. Kruus 1995: 263). „Das Inland“ wurde zwar in Dorpat herausgegeben, aber seine Zielgruppe waren Leser in allen drei Ostseeprovinzen des Russischen Imperiums, was auch im Untertitel der Zeitschrift zum Ausdruck kommt: „Eine Wochenschrift für Liv-, Esth- und Curland's Geschichte, Geographie, Statistik und Litteratur".

In der ersten Nummer des „Inlands“ legte Bunge sein ausführliches Programm dar, das den Beiträgern als Anleitung dienen sollte. Er rief seine Mitbürger auf, „den heimathlichen Boden in allen seinen Beziehungen, in der Vergangenheit wie in der Gegenwart" (Inland 1/1836, Sp. 1$)^{2}$ kennen zu lernen. Bunge und seine nächsten Mitarbeiter hatten sich die Aufgabe gestellt, Beiträge zur genaueren Kenntnis der Vorzeit und Gegenwart der deutschen Ostseeprovinzen Russlands, ebenso wie Beiträge über das öffentliche, gesellschaftliche und kulturelle Leben zu liefern. So wurden in der Zeitschrift alle wesentlichen Lebensbereiche betrachtet: die Geschichte Est-, Liv- und Kurlands, die wirtschaftliche Lage in den genannten Provinzen, Naturerscheinungen und Witterungsverhältnisse, die Lebensbedingungen der Bevölkerung, das kulturelle Leben und anderes mehr. Der Tatsache, dass Tartu eine Universitätsstadt ist, wurde durch die Rubrik „Universitäts- und Schulchronik“ Rechnung getragen, in der über aktuelle Ereignisse im Universitätsleben berichtet wurde, z.B. über Berufungen und Pensionierungen von Lehrkräften oder über die Verteidigung von Dissertationen. Zweimal jährlich wurden die Vorlesungspläne abgedruckt.

In seinem Programm nennt Bunge eine Reihe von Anforderungen, die an die Beiträge zu stellen sind. So sollten alle Korrespondenzartikel von

\footnotetext{
${ }^{2}$ Bei Verweisen auf die Wochenschrift „Das Inland“ bezeichnet die Zahl vor dem Schrägstrich die Nummer der Wochenschrift, die Zahl nach dem Schrägstrich das Erscheinungsjahr.
} 
neutraler Grundhaltung sein. Kommentare zur zeitgenössischen politischen Situation waren nicht gefragt:

Alle Correspondenzartikel sollen mehr referirend, als räsonnirend sein. Alle Fragen über die Politik der Gegenwart bleiben ohnehin durchaus ausgeschlossen. Thatsachen zu sammeln zu einer Chronik der Provinzen ist ein Hauptziel dieser Rubrik; deren schleunige und möglichst vollständige Mittheilung an die Redaction von Allen, denen sich dazu Gelegenheit bietet, ist dabei eine Hauptbedingnis. (Inland, 1/1836, Sp. 9)

Wissenschaftliche Seriösität ohne pedantische Gelehrsamkeit wird als Hauptmerkmal der Artikel betont. Die Darstellungsweise soll allgemein verständlich und möglichst anregend sein, ohne deshalb trivial zu werden. Der sprachliche Ausdruck soll knapp sein und Weitschweifigkeit vermieden werden. Von polemischen Artikeln sollte die Zeitschrift Abstand nehmen (vgl. Inland 1/1836, Sp. 9).

Aus dem Gesagten könnte man nicht schließen, dass Bunge ausgesprochen konservativ oder reaktionär gewesen sein muss. Die erwähnten Anforderungen wurden jedoch wegen der Zensur gestellt, hätte man doch sonst keine Erlaubnis bekommen, die Zeitschrift herauszugeben.

Viele Beiträge des „Inlands“ über Geschichte, Recht, Wirtschaft, Bildungswesen, das kulturelle Leben, Völkerkunde, volkstümliche Sitten und Traditionen sind von bleibendem Wert und für Kulturhistoriker und Philologen, die sich mit der estnischen und lettischen Kulturgeschichte sowie den Ostseeprovinzen insgesamt beschäftigen, eine wahre Fundgrube (vgl. Jansen 1994: 287). Trotz der genannten Vorzüge sind die Beiträge der Wochenschrift „Das Inland“ bis heute nicht gebührend behandelt und erforscht worden (vgl. Salupere 2006: 77f.). Man kann an dieser Stelle nur die Diplomarbeit von Ann-Aet Joon (vgl. Joon 1990) sowie einen Artikel und die Magisterarbeit von Andres Kärssin nennen (vgl. Kärssin 1998a; Kärssin 1998b). Joons Diplomarbeit gibt einen Überblick über die Thematik und den Entwicklungsweg der Wochenschrift; der Schwerpunkt liegt auf den Artikeln und Kurznachrichten, die das kulturelle Leben im weitesten Sinne behandeln. Kärssins Magisterarbeit beschäftigt sich hauptsächlich mit den Artikeln über das Leben der Landbevölkerung.

Wenn man über Bunge und die Wochenschrift „Das Inland“ sowie schließlich über Kreutzwalds Mitarbeit an dieser Zeitschrift spricht, darf 
die Beziehung zwischen Bunge (respektive dem „Inland“) und der Gelehrten Estnischen Gesellschaft, zu deren Mitgliedern sowohl Bunge als auch Kreutzwald gehörten, nicht außer Acht gelassen werden. Bunge hat bei der Gründung der Gelehrten Estnischen Gesellschaft eine wichtige Rolle gespielt; so hat kein anderer als Bunge das Statut der Gesellschaft verfasst, in dem denn auch viele programmatische Grundsätze des „Inlands“ wiederholt wurden (vgl. Salupere 2006: 76). Das estnischsprachige Schriftum, darunter auch Zeitungen und Zeitschriften, hatte sich lange an eine nur gering ausgebildete Bevölkerungsschicht gerichtet - die meisten verfügten nur über Grundschulbildung -, während das Weltbild der bildungstragenden Schicht hauptsächlich durch die deutschsprachige Literatur und Presse geprägt wurde. Die Aufsätze über die estnische Geschichte, Überlieferungen, Sitten und Bräuche, aber auch über das Alltagsleben, die von Kreutzwald und anderen Mitarbeitern der Wochenschrift veröffentlicht wurden, haben die nationale Frage stärker ins allgemeine Bewusstsein gebracht, sowohl bei den Deutschbalten als auch bei den Esten. Die deutsche Sprache, die unter den damaligen Verhältnissen im Baltikum Sprache der Gebildeten war, hat zu einem größeren Leserkreis und zur Verbreitung der Ideen der nationalen Bewegung beigetragen. Somit hat „Das Inland“ zusammen mit der Gelehrten Estnischen Gesellschaft bei der Entstehung der estnischen nationalen Bewegung eine wesentliche Rolle gespielt (vgl. Salupere 2006: 77).

Was die wissenschaftliche Erforschung von Kreutzwalds deutschsprachiger Publizistik betrifft, so liegt hier ein ähnlicher Befund vor wie beim „Inland“ insgesamt: Bisher stehen systematische und umfassende Untersuchungen zu Kreutzwalds deutschsprachiger Publizistik noch immer aus. Aus diesem Bereich könnte man auf einige meiner Aufsätze hinweisen (vgl. Palm 2002, Palm 2005, Palm 2009), von denen sich die beiden letzteren mit dem Sprachgebrauch Kreutzwalds beschäftigen. Es sei noch hinzugefügt, dass vor einigen Jahren am Lehrstuhl der Germanistik der Universität Tartu eine Bakkalaureusarbeit über Kreutzwalds Kurznachrichten aus Werro (estn. Vóru) und dem Werro'schen Kreis im „Inland“ verfasst wurde (vgl. Kuha 2004).

F. R. Kreutzwald gehörte zu den aktivsten Mitarbeitern der Wochenschrift „Das Inland“ (vgl. Jansen 1994: 286). Im Jahr 1837 gibt es im „Inland“ insgesamt acht kürzere und längere Beiträge von Kreutzwald, 
von denen sich sieben explizit mit estnischen Themen beschäftigen. Für das Jahr 1838 sind nur vier längere Artikel zu verzeichnen, aber mit diesem Jahr beginnt die Tätigkeit Kreutzwalds als Korrespondent - aus Werro und dem Werro'schen Kreis wurden 28 Berichte und Kurznachrichten an das „Inland“ geliefert. Von 1839 und 1840 gibt es je einen längeren Beitrag; die Zahl der Lokalnachrichten aus Werro und dem Werro'schen Kreis beträgt 27 im ersten und 19 im zweiten Jahr. Für das Jahr 1841 finden sich vier längere Beiträge und 14 Korrespondenznachrichten. Für den Jahrgang 1842 des „Inlands“ können drei längere Beiträge und elf Lokalnachrichten ermittelt werden. 1843 gibt es keinen längeren Artikel über ein bestimmtes estnisches Thema, wohl aber 13 Lokalnachrichten. 1844 finden sich zwei Artikel und zwölf Lokalnachrichten; die entsprechenden Zahlen im Jahr 1845 sind eins und sieben. Von 1846 bis 1859 (mit Unterbrechungen in den Jahren $1850,1854-1856,1858)$ hat Kreutzwald nur Korrespondenznachrichten geliefert, deren Anzahl bedeutend geringer als in früheren Jahren ist - höchstens vier Nachrichten in einem Jahr, in den Jahren 1848, 1851-1853 und 1859 sogar nur jeweils eine.

Im Folgenden sollen Kreutzwalds Schriften, die er für „Das Inland“ verfasst hat, näher betrachtet werden. Analysiert habe ich die Jahrgänge von 1837 bis 1845 , weil eben diese Jahre die aktivste Periode der publizistischen Tätigkeit Kreutzwalds darstellen (vgl. Kruus 1995: 224; Laidvee 1978: 142-156). Was die Thematik der Artikel von Kreutzwald im „Inland“ betrifft, so liegt der Schwerpunkt natürlich auf den Beiträgen, die mit Estland und den Esten verbunden sind (volkstümliche Sitten und Bräuche, alte Sagen, Aberglaube usw.). Ich konzentriere mich eben auf diese Beiträge - von denen hier nur die bedeutendsten vorgestellt werden können -, da in ihnen Kreutzwalds Ansichten, persönliche Meinungen und Einstellungen zum Ausdruck kommen.

In drei Nummern des Jahres 1837 berichtet Kreutzwald über einige festliche Gebräuche bei den Esten. Am umfangreichsten ist der Artikel „Das Hochzeitsfest“ (Nr. 12), was sich vielleicht dadurch erklären lässt, dass die Hochzeiten der Esten, die nach der Ernte begangen wurden, die Hauptfeierlichkeiten des Volkes gewesen sind. Der Aufsatz beginnt damit, wie der junge Mann auf Brautschau geht, und endet mit dem Hochzeitsfest, das mitunter bis zu einer Woche dauern konnte. Alles wird sehr ausführlich, in allen Einzelheiten dargestellt. 
Noch interessanter als die Beschreibungen einzelner Sitten und Bräuche sind die Überlegungen, die Kreutzwald über den Charakter seiner Landsleute anstellt, ebenso die Beobachtungen über die materielle Lage des Volkes und die zunehmende Armut auf dem Lande.

Der Este sei eigennützig. Die Liebe gehöre zwar noch nicht zu den Bedürfnissen, wenn man heiraten will, aber einen triftigen Heiratsgrund, den Eigennutz, wisse der Este zu würdigen. Deshalb erkundigt sich der Freier, ob das Mädchen arbeitsam ist, oder er stellt sich selbst auf die Lauer und beobachtet, wie die üblichen Frauenarbeiten (Spinnen, Stricken, Flachshecheln usw.) der potentiellen Heiratskandidatin von der Hand gehen.

Der Este sei begabt und schöpferisch. Diese Behauptung Kreutzwalds stützt sich auf die sogenannten Wettgesänge auf dem Hochzeitsfest. Zwei Weiberchöre ${ }^{3}$ - Frauen aus der Verwandtschaft des Bräutigams und aus der Verwandtschaft der Braut - singen um die Wette. Dabei versuchen die Verwandten des Bräutigams die Braut herabzusetzen, während die Verwandten der Braut darauf bedacht sind, ihre Vorzüge zu preisen. Es wird ohne Vorbereitung, aus dem Stegreif gesungen; die Lieder enthielten viel beißenden Witz und mitunter einen poetischen Wert.

Nach einem alten Brauch pflegte die Neuvermählte, ihre Gaben unter den Hochzeitsgästen zu verteilen: selbstgestrickte Strümpfe, Socken, Handschuhe und Ähnliches. Aber wie Kreutzwald bemerkt, sei diese Sitte durch die zunehmende Armut des Volkes in Verfall geraten, und die Mehrzahl der Bräute teile keine Geschenke mehr aus (vgl. Inland 12/1837, Sp. 193-200).

Im Grunde genommen sei der Este still, in sich verschlossen, was aber die Lust zum Feiern nicht ausschließt:

Der mehr stille, in sich verschlossene Charakter der Esthen ist dem Frohsinn keineswegs abhold; er sieht es vielmehr gern, wenn Andere bei ihm die Fröhlichkeit erwecken, weshalb man zu jeder Hochzeit aufge-

\footnotetext{
${ }^{3}$ Hier wird Kreutzwalds Sprachgebrauch beibehalten, weil das Wort „Weib“ damals hierzulande eine ganz neutrale Bezeichnung für eine erwachsene weibliche Person war, wie heute „Frau“. Es ist in diesem Kontext weder veraltet/veraltend noch abwertend, wie es heute der Fall ist. „Weib“ ist auch in anderen Texten von Kreutzwald das übliche Wort.
} 
räumte, mit Mutterwitz begabte Jünglinge zieht, die das Amt der Spaßmacher verwalten. Solche Fröhlichkeitsstimulanten nennt der Esthe „Nalja-, irwi- oder koera-hammas“, d.h. Spaß-, Spöttel- oder Hundszahn. Die Zusammensetzung des Scherzes mit einem Zahn ist im höchsten Grade charakteristisch: der Esthnische Witz fällt meist sehr beißend aus. (Inland, 12/1837, Sp. 200)

Im „Beitrag zur Mythologie der Esthen“ (Nr. 9/1838) wird über viele Sitten und Bräuche berichtet, die mit dem Mond verbunden sind. Der reichhaltige folkloristische Stoff gibt Kreutzwald Anlass zur Folgerung, dass der Mond im estnischen Altertum eine wichtige Gottheit verkörpert haben muss. Die alten Esten müssen im Monde Kraft, Stärke, Gesundheit, Gedeihen und Wachstum verehrt haben.

Besonders signifikant sind Kreutzwalds Gedanken über die Bedeutung der religiösen Denkmäler eines Volkes, die Kreutzwald in den einleitenden Sätzen des genannten Beitrags äußert:

Die religiösen Denkmäler eines Volkes [...] sind dem Geschichtsforscher insofern von Wichtigkeit, als sie ihn beim Mangel irgend eines schriftlichen Nachlasses aus der Vorzeit zu interessanten Untersuchungen führen können. [...] Eine bekannte Erfahrungssache, die sich überall bestätigt, ist die, daß ein überwundenes Volk mit eiserner Festigkeit an den Sitten und Gebräuchen seiner glücklichen Vorzeit hängt; die Erinnerung der Freiheit und Selbständigkeit knüpft sich [...] oft an die unbedeutendsten Dinge, die gerade dadurch den Werth erhalten und auf spätere Generationen, die keine Ahnung von der großen Vergangenheit haben, forterben; [...] Man unterwirft sich zwar öffentlich den neuen Formen, aber im Verborgenen [...] werden den chimärischen Götzenbildern manche stille Opfer gebracht: weil das Herz der alten Lehre treu blieb. (Inland, 9/1838, Sp. 129f.)

Aus diesen Worten Kreutzwalds kann man schließen, dass die Esten, die schon seit Jahrhunderten Christen waren, im Inneren doch am alten heidnischen Glauben gehangen haben. Ob und in welchem Maße das Mitte des 19. Jahrhunderts noch zutraf, sei hier dahingestellt, doch das aufgeführte Zitat lässt keinen Grund, an Kreutzwalds Überzeugung zu zweifeln.

Außer den Schriften über estnische Folklore und Mythologie, die wohl den Hauptteil von Kreutzwalds Publikationen im „Inland“ bilden, stammen aus seiner Feder Beiträge über weitere Themen, von denen einige hier kurz vorgestellt werden sollen: Der erste Artikel über die 
„Marien-Casse für Witwen und Waisen der Ärzte in Russland“ erscheint in der Nr. 50 des Jahres 1837, und es folgen noch drei weitere (Nr. 4/1839, Nr. 16/1840 und Nr. 19/1841). Es handelt sich dabei um eine wohltätige Organisation, die 1835 von einigen St. Petersburger Ärzten gegründet wurde. Es ist kein Wunder, dass ausgerechnet Kreutzwald als Arzt sich mit diesem Thema beschäftigt. Im ersten Artikel werden die Leser über die erst gegründete und von der Kaiserlichen Majestät bestätigte wohltätige Einrichtung informiert, in den folgenden Beiträgen wird schon über die Tätigkeit der „Marien-Casse“ berichtet; zu diesem Zweck wird immer auch der Bericht des vorangehenden Jahres veröffentlicht. In Nr. 4/1839 drückt der Verfasser seine Unzufriedenheit über die geringe Anzahl der Mitglieder der „Marien-Casse“ aus und fordert seine Kollegen auf, sich dieser gemeinnützigen Einrichtung anzuschließen (vgl. Inland, 4/1839, Sp. 53).

In zwei längeren Aufsätzen mit dem Titel „Aphorismen zur Wassercur“ (Nr. 1 und 2/1841) wird über die Anwendung kalten Wassers bei verschiedenen Krankheiten und Gebrechen berichtet, die damals insbesondere in Deutschland große Mode geworden war. Kreutzwald teilt die allgemeine Begeisterung nicht vorbehaltlos und versucht sie eher zu dämpfen. Er setzt sich mit der genannten Thematik auseinander, gibt einen Überblick über die Geschichte der Wasserheilkunde und erwägt das Für und Wider der Wasserbehandlung (vgl. Inland, 1/1841, Sp. 310; 2/1841, Sp. 17-24).

In dem Beitrag „Ein Wort über die weiblichen Erziehungsanstalten in Werro" vergleicht Kreutzwald zwei weibliche Erziehungsanstalten der Stadt miteinander und gibt ein Urteil über sie ab. Ebenso äußert er seine Meinung über die weibliche Erziehung im Allgemeinen. Kurz gesagt gehe es der weiblichen Privatschul- und Erziehungsanstalt der Demoiselle Jeanneret in jeder Hinsicht gut. Die Anstalt kenne keine finanziellen Probleme, sie erfreue sich eines renommierten Rufes und könne sich ausgezeichnete Lehrer leisten. Die Mehrzahl der Zöglinge gehöre höheren Ständen an. Der einzige Nachteil der Anstalt bestehe darin, dass keine öffentlichen Schulprüfungen stattfänden. Der weiblichen Privatschul- und Erziehungsanstalt der Madame König gehe es bei weitem nicht so gut. Die Anstalt hatte und habe mit finanziellen Schwierigkeiten zu kämpfen, weil ihrer ortsfremden Vorsteherin wohltuende Freunde und Gönner fehlten. Daraus ergäben sich weitere 
Probleme. Trotzdem dürfe sich die Anstalt der guten Leistungen ihrer Schülerinnen rühmen, was auch durch wiederholt veranstaltete öffentliche Prüfungen bestätigt werden könne. Zum Schluss bringt Kreutzwald seine Ansichten über die Mädchenerziehung zum Ausdruck. Die Erziehung in Pensionsanstalten sei seiner Meinung nach eine verfehlte Sache, denn ein junges Mädchen, das seiner natürlichen Bestimmung gemäß für den engen häuslichen Kreis erzogen wird, dürfe nur so wenig wie möglich dieser seiner künftigen Sphäre und der mütterlichen Aufsicht entrückt werden. Die Erziehung selbst in den vorzüglichsten Anstalten könne diesem Zwecke nie vollkommen genügen. Mit der Schule verhalte es sich anders, denn dort blieben die Kinder der mütterlichen Obhut bloß einige Stunden täglich entzogen (vgl. Inland, 46/1841, Sp. 734f.).

Wie oben erwähnt wurde, hat Kreutzwald außer längeren Beiträgen, die gewöhnlich einem bestimmten Thema gewidmet sind, auch Berichte und Kurznachrichten an das „Inland“ geliefert. Die Tätigkeit des Korrespondenten Kreutzwald dauerte von 1838 bis 1859 (mit Unterbrechungen in den Jahren 1850, 1854-1856 und 1858). Die Anzahl der Korrespondenznachrichten aus Werro und dem Werro'schen Kreis war in den Jahren 1838-1844 recht groß (von zwölf bis 28 pro Jahr), nahm aber ab 1845 wieder stark ab. Die Nachrichten sind thematisch von großer Vielfalt, Kreutzwald berichtet über aktuelle Tagesereignisse, über das alltägliche Leben, über das Wetter und die wirtschaftliche Lage der Bauern, über den Gesundheitszustand der Bevölkerung, über den sich ausbreitenden Alkoholismus, über kulturelle Ereignisse und das gesellschaftliche Leben usw. Im Folgenden werden aus dieser Palette vier Themenbereiche herausgegriffen: die Lage der Bauern, die Gesundheit der Bevölkerung, Alkoholismus und Abstinenz sowie das Bildungswesen.

Ein zentrales Thema in den Korrespondenznachrichten aus dem Werro'schen Kreis ist die Lage der Bauern. Kreutzwald berichtet über die wirtschaftliche Situation auf dem Lande, über gute Ernten und Missernten, über Wechselwirkungen zwischen Wetter und Ernte, über verschiedene landwirtschaftliche Probleme. Das Bild, das dem Leser dargeboten wird, ist ziemlich trostlos. Von Nummer zu Nummer, von Jahr zu Jahr wird über die große Not unter der Landbevölkerung, über den Mangel an Getreide und Viehfutter geschrieben. Weil das Futter 
knapp ist, sterben die Haustiere (vgl. 6/1839, 13/1839, 15/1839, 50/1840, 22/1841, 12/1844, 8/1846). Nur selten kann man lesen, dass es keinen Hunger, keinen Mangel an Getreide und Viehfutter gibt (vgl. 18/1843, 10/1848):

Die fortdauernd strenge Regierung des Winters läßt der Hoffnung auf einen baldigen Frühling wenig Raum, und doch ist die Sehnsucht des Landmanns auf schneebefreite Flächen nicht minder groß, als die der Carawane in Afrikanischer Sandwüste auf eine Oase. Der Futtermangel wird mit jeder Woche ausgebreiteter und dringender, die fernere Erhaltung des Viehs immer schwieriger. (Inland, 13/1839, Sp. 202)

Kreutzwald macht sich Sorgen um die Folgen der allgemeinen Armut, wie die wachsende Anzahl der Bettler, die umherziehen, betteln und stehlen (vgl. 8/1838). Eine andere Folge sei nach Kreutzwalds Worten "die Völkerwanderung, die auf Unvernunft und Leichtigkeit beruht" (vgl. 19/1847). Es hatte sich nämlich ein Gerücht von einem Eldorado im südlichen Russland verbreitet, doch die Reise endete für die meisten schon in Pleskau (russ. Pskow, estn. Pihkva).

Kreutzwald begnügt sich nicht nur damit, das Leben des Bauernvolkes zu schildern, sondern er macht Vorschläge für die Verbesserung der Lebensverhältnisse. So meint er, dass es zweckmäßig wäre, den Kartoffelanbau zu erweitern und zu fördern, da der Boden dafür geeignet sei (vgl. 45/1838, 22/1841). Auch verbreitet er Rezepte für Futter- und Brotsurrogate, um Menschen in Not Abhilfe zu schaffen (vgl. 17/1839, 27/1841). „Eine Schutzmethode gegen Hunger“ (vgl. 20/1842) könnte der Gartenbau sein. Neben den praktischen Ratschlägen und Maßnahmen hält Kreutzwald die Entwicklung der Selbstständigkeit des Landvolkes für wichtig, das sich nicht mehr bevormunden lassen solle (vgl. 37/1840):

[...], aber bei weitem wichtiger wäre es im Allgemeinen, wenn man mit vereinten Kräften dahin wirkte, daß eine größere und freiere Selbstständigkeit des Landvolkes entwickelt würde, damit dieses die Einsicht erlangte, um als vernünftiges Wesen seinen wahren Nutzen aus eigenem Antriebe zu befördern. Durch eine ewige Bevormundung werden die eigenen geistigen Kräfte des Bauern zuletzt gänzlich erschlaffen [...] (Inland, 37/1840, Sp. 586).

Es ist kein Wunder, dass Kreutzwald als Arzt viel Zeit und Raum dem Thema Gesundheit widmet. Er informiert die Leser des „Inlands“ über 
den allgemeinen Gesundheitszustand der Bevölkerung sowie über verbreitete Krankheiten. Es gibt Zeiten, in denen man über den Gesundheitszustand nichts Schlechtes hört (vgl. 5/1838), der Gesundheitszustand gut und die Sterblichkeit gering (vgl. 31/1840) oder von Epidemien nichts zu hören sei (vgl. 38/1844). Viel häufiger gibt es jedoch Nachrichten über verschiedene Krankheiten, die oft mit dem Tod enden. Von den Krankheiten werden wiederholt verschiedene katarrhische und rheumatische Krankheiten, Ruhr, Masern, Blattern, Scharlach, Typhus, und Grippe erwähnt (vgl. 8/1838, 11/1838, 44/1838, 5/1839, 30/1839, 45/1839, 50/1839, 6/1840, 51/1840, 20/1842, 20/1843, 16/1845, 40/1846). Als Krankheitsursachen werden außer dem kalten und feuchten Wetter ungünstige lokale Verhältnisse und Unwissenheit, anders gesagt das niedrige Bildungsniveau der Menschen genannt (vgl. 6/1839).

Kreutzwald war auch als Tierarzt tätig, deshalb kann man in seinen Korrespondenznachrichten vieles über Tierkrankheiten und deren Behandlung finden, z.B. in den Nummern 29, 33, 38 und 45 vom Jahr 1838.

Ein weiterer für Kreutzwald sehr wichtiger Themenbereich war Alkoholismus und Abstinenz. Kreutzwald weist auf die verheerenden Folgen der Alkoholsucht hin. ${ }^{4}$ Er berichtet über Sterbefälle und Verbrechen, deren Ursache der übermäßige Genuss von Branntwein sei (vgl. 31/1839, 14/1840, 12/1842, 20/1842). Er versucht den Menschen ins Gewissen zu reden, nicht mehr so viel zu trinken. Einen Ausweg sieht Kreutzwald in der Gründung der Mäßigkeitsvereine, aber er muss leider feststellen, dass die Mäßigkeitsbewegung nicht besonders viele Anhänger findet (vgl. 51/1838, 49/1839, 12/1841). Er macht den Vorschlag, alle Mitteilungen von den Opfern der Trunksucht zu veröffentlichen - die Todesangst oder die Angst vor völliger Verkommenheit könnten vielleicht wirksam sein (vgl. 47/1841, 12/1842).

Unter den Korrespondenznachrichten über das Bildungswesen bilden den größten Teil die Mitteilungen über die Krümmer'sche Anstalt in Werro, aber man bekommt auch Informationen über andere Bildungs-

\footnotetext{
4 In diesem Zusammenhang sei bemerkt, dass die von Kreutzwald ins Estnische übersetzte und bearbeitete „Branntweinpest“ des Schweizers Zschocke (estn. Viinakatk) im Jahr 1840 von der Gelehrten Estnischen Gesellschaft verlegt wurde.
} 
einrichtungen der Stadt und Kreutzwalds Ansichten über die Bildung. In der Nummer 20 vom Jahr 1839 gibt Kreutzwald einen Überblick über die Bildungsanstalten der Stadt Werro. Es gibt vier [öffentliche] Bildungsanstalten: eine deutsche Kreisschule, eine deutsche Elementarschule für Jungen, eine deutsche Elementarschule für Mädchen und eine estnische Elementarschule für Jungen und Mädchen. Dazu kommen noch vier Privatlehranstalten: eine Lehr- und Erziehungsanstalt des Herrn Krümmer für Jungen, eine Töchterschule der Demoiselle Unverdorben, eine weibliche Schul- und Erziehungsanstalt der Madame König und eine weibliche Erziehungsanstalt der Madame Genge. Wie Kreutzwald bemerkt, gibt es in Werro eine große Zahl von Erziehungsanstalten und es besteht die Möglichkeit der Auswahl (vgl. 20/ 1839).

In Nummer 51 des Jahres 1839 wird bekannt gegeben, dass das 25-jährige Lehrerjubiläum des Direktors Krümmer gefeiert wurde. Aus diesem Anlass gibt Kreutzwald einen kurzen Überblick über den Dienstgang Herrn Krümmers.

Weitere Nachrichten beschränken sich hauptsächlich auf die öffentlichen Prüfungen und andere Ereignisse in der Krümmer'schen Anstalt (vgl. 22/1839, 261839, 23/1844, 1/1847).

Von Interesse ist die Nachricht darüber, dass Pastor Schwartz in Pölwe (estn. Põlva) eine Parochialschule für estnische Jungen gegründet hat, in der außer Lesen, Schreiben, Rechnen, Denk- und Gedächtnisübungen auch deutsche Sprache gelehrt wurde (vgl. 13/1838).

Kreutzwald meint, dass einige Musterwirtschaften gegründet werden sollten, die für andere Haushalte ein Vorbild sein könnten (vgl. 37/1841).

Zum Abschluss möchte ich noch auf eine Korrespondenznachricht Kreutzwalds näher eingehen, die der geforderten neutralen Grundhaltung der Beiträge - wie Bunge in seinem Programm proklamiert hatte - keineswegs entspricht und die infolgedessen Staub aufgewirbelt hat und sowohl Bunge als auch Kreutzwald zum Verhängnis wurde. Es handelt sich um einen ganz kurzen Bericht in Nummer 18 aus dem Jahr 1843, in dem Kreutzwald über einen außerordentlich langen und harten Winter in Estland schreibt. Diesem Bericht fügte Kreutzwald eine Nachricht über die Hungersnot hinzu, die ihm als einem Mitarbeiter des „Inlands“ zugeschickt worden war. 
Aus Strandwierland, vom 17. April

Wir leben noch immer im tiefen Winter, der jetzt erst seinen Eigensinn bei uns zeigen will und einem hartnäckigen Feinde gleich um jeden Schritt kämpfend sich zurückzieht. Unsere Felder liegen Fuß tief unter dem Schnee, und in der Nacht friert es regelmäßig bei 8 bis 10 Grad Kälte. Nur auf der Südseite unserer Wohnungen und hie und da auf den Wegen ist es der Mittagssonne gelungen einen schwarzen Fleck auf die weiße Fläche zu zaubern.

Die Noth ist auf dem Lande überall groß! Der hungrigen Menschen giebt es viele, und die Hausthiere sind an manchen Orten dem Verhungern nahe, weil die Futtervorräthe fast allenthalben erschöpft sind. - Reisende, welche aus dem District Jerwen kamen, fuhren auf Schlitten und fanden namentlich in den Wäldern großen Schneevorrath, so daß die Wege kaum fahrbar waren. (Inland, 18/1843, Sp. 157)

Eine solche Information hat natürlich Aufregung und Empörung hervorgerufen. Dazu kam noch, dass Kreutzwald den Namen seines Informanten nicht preisgegeben hat, weil er ihm keine Unannehmlichkeiten bereiten wollte. $\mathrm{Zu}$ guter Letzt sah sich die Redaktion gezwungen, die folgende Berichtigung zu veröffentlichen.

Auf höhere Veranlassung erklärt die Redaction des Inlandes die in Nr. 18 Sp. 157 dieser Zeitschrift unter der Überschrift: „Aus Strandwierland, vom 17. April“ enthaltenen Worte: „Die Noth ist auf dem Lande überall groß! Der hungrigen Menschen giebt es viele“ u.s.w. für unrichtig, weil in Estland zu jener Zeit keine Hungersnoth stattgefunden. (Inland, 27/1843, Sp. 232)

Die Veröffentlichung der genannten Korrespondenznachricht und die sich daraus ergebenden Folgen mögen ein Grund gewesen sein, warum die Zahl von Kreutzwalds Beiträgen ab 1843 stark abnahm. Es gab noch andere Erklärungen. Nach Gründung der Gelehrten Estnischen Gesellschaft im Jahr 1838 begann Kreutzwalds aktive schriftstellerische und aufklärerische Tätigkeit - seine Schriften dienten zum großen Teil aufklärerischen Zielen. Nach dem Tod seines Freundes und Mitstreiters Faehlmann im Jahr 1850 war Kreutzwald mit der Zusammenstellung des Epos „Kalevipoeg“ beschäftigt. Die Mitarbeit an der Wochenzeitung „Das Inland“, die Beschäftigung mit alten Überlieferungen, mit estnischer Folklore und Mythologie, mit Sitten und Bräuchen haben ihm aber Kenntnisse und Erfahrungen vermittelt, die er bei der Abfassung des estnischen Nationalepos verwenden konnte. 


\section{Literaturverzeichnis}

\section{Primärliteratur}

Das Inland. Eine Wochenschrift für Liv-, Esth- und Curland's Geschichte, Geographie, Statistik und Litteratur. Jahrgänge 1837-1859.

\section{Sekundärliteratur}

JANSEN, Ea (1994): Baltisaksa ajakirjanduse areng XVII-XIX sajandil [Entwicklung der deutschbaltischen Journalistik vom 17. bis zum 19. Jahrhundert]. In: Juhan Peegel u.a. (Hrsg.) (1994): Eesti ajakirjanduse teed ja ristteed [Wege und Kreuzwege der estnischen Journalistik]. Tartu/Tallinn, S. 267-300.

JoOn, Ann-Aet (1990): Die kulturgeschichtlichen Artikel im „Inland“ 1836-1850. Diplomarbeit. Lehrstuhl für Germanistik, Universität Tartu.

KÄRSSIN, Andres (1998a): Baltisaksa nädalakiri „Das Inland“ - loomine ja kadumine [Die deutschbaltische Wochenschrift „Das Inland“ - Anfang und Ende]. In: Teaduste Akadeemia Aastaraamat 4, S. 54-61.

KÄRSSIN, Andres (1998b): Maarahva käsitlus baltisaksa nädalakirjas „Das Inland“ (1836-1863) [Behandlung der Problematik der Landbevölkerung in der deutschbaltischen Wochenschrift „Das Inland“ (1836-1863)]. Magisterarbeit. Lehrstuhl für estnische Geschichte, Universität Tartu.

KRuUS, Oskar (1995): Eesti kirjarahva leksikon [Estnisches Literatenlexikon]. Tallinn.

KruUs, Oskar/Heino PuHvel (2000): Eesti kirjanike leksikon. [Estnisches Schriftstellerlexikon]. Tallinn.

KuHA, Kaia (2004): Kreutzwalds Kurznachrichten aus Werro und dem Werroschen Kreis in der deutschbaltischen Zeitschrift „Das Inland“. Bakkalaureusarbeit. Lehrstuhl für Germanistik, Universität Tartu.

LAIDVEe, Herbert (1978): Fr. R. Kreutzwaldi bibliograafia 1833-1969. [Bibliographie von Fr. R. Kreutzwald 1833-1969]. Tallinn.

PALM, Mari-Ann (2002): Friedrich Reinhold Kreutzwald als Mitarbeiter der Dorpater Wochenschrift „Das Inland“. In: Triangulum. Germanistisches Jahrbuch für Estland, Lettland und Litauen 9, S. 124-138.

PALM, Mari-Ann (2005): Friedrich Reinhold Kreutzwald als Mitarbeiter der Wochenschrift „Das Inland“. In: Jörg Riecke/Britt-Marie Schuster (Hrsg.) (2005): Deutschsprachige Zeitungen in Mittel- und Osteuropa. Berlin, S. 63-78.

PALM, Mari-Ann (2009): Zum Sprachgebrauch Friedrich Reinhold Kreutzwalds anhand seiner Beiträge in der Wochenschrift „Das Inland“. In: Thomas Taterka/Dzintra Lele-Rozentāle/Silvija Pavīdis (Hrsg.) (2009): Am Rande im 
Zentrum. Beiträge des VII. Nordischen Germanistentreffens Riga, 7.-11. Juni 2006. Berlin, S. 382-389.

SAlupere, Malle (2006): F. G. von Bunge ja Tartu kultuuriajakirjad [F. G. von Bunge und Dorpater Kulturzeitschriften]. In: Tiit Rosenberg/Marju Luts (Hrsg.) (2006): Tundmatu Friedrich Georg von Bunge. Materjale ÕESi konverentsilt „200 aastat Friedrich Georg von Bunge sünnist“ Tartu Ülikooli ajaloo muuseumis 27. aprillil 2002. Õpetatud Eesti Seltsi Toimetised XXXV [Der unbekannte Friedrich Georg von Bunge. Veröffentlichungen der Konferenz der Gelehrten Estnischen Gesellschaft „200 Jahre von der Geburt Fr. G. von Bunges“ im Museum für Geschichte der Universität Tartu am 27. April 2002. Verhandlungen der Gelehrten Estnischen Gesellschaft XXXV]. Tartu, S. 76-100. 


\section{Das estnische Epos „Kalevipoeg“6 und seine Rezeption in Kultur und Literatur ${ }^{1}$}

\section{Einführung}

Das durch das „Kalevala“ (1835) Elias Lönnrots inspirierte estnische Nationalepos „Kalevipoeg“ (1861) ist im breiteren Bewusstsein der estnischen Kultur eine monologische Erscheinung geblieben, die eher kulturgeschichtlichen als künstlerischen Wert hat. Die Ereignisse des Epos entrollen sich in 20 Gesängen und 19033 Versen als Erzählung des Sängergottes Laulik, der seine Kräfte wiederum von Vanemuine, dem alten Gott des Gesangs, erhält. Inhalt des Epos ist der estnische König und Held Kalevipoeg (Sohn des Kalev) mit seinen Taten, Kämpfen, Wanderungen und schließlich, nach Einfall des Feindes, seinem traurigen Schicksal und dem Versprechen einer Wiederkehr. Entstanden in den Strömungen der Nachromantik, entwickelte sich das Epos in der zweiten Hälfte des 19. Jahrhunderts rasch zum Symboltext des estnischen Erwachens. Bis heute ist der Gesamttext des Epos in 19 Auflagen erschienen und hat sich durch Übersetzungen in mehrere Dutzend Sprachen zu einer Visitenkarte estnischer Kultur entwickelt.

In rezeptionsgeschichtlicher Hinsicht ist das Epos ein klassisches, kanonisches Werk, in der Begriffswelt Hans Robert Jauss' ein kulturelles „Monument", dem stets große Aufmerksamkeit zugewandt und dessen Interpretation von den herrschenden Ideologien immer stark kontrolliert wurde (vgl. Jauss 1970). Verfolgt man das Schicksal des Textes durch mehrere kulturgeschichtliche Perioden des 19. und 20. Jahrhunderts, so finden sich reichlich Belege für Jauss' theoretische Behauptung: Jede neue Macht versuchte sowohl das „Kalevipoeg“ als auch dessen einzelne, besonders bedeutsame Bilder und Motive dem eigenen Willen zu unterwerfen. Das Epos als soziokulturelle Waffe nutzte aber auch der einfache Leser, das Volk: Aus der Geschichte von Kampf und Schicksal des Helden im „Kalevipoeg“ ist im Laufe der Jahrzehnte für das estnische Volk eine wahre „eigene Geschichte“ geworden.

${ }^{1}$ Die Abfassung des Artikels wurde durch Fördergelder des Eesti Teadusfond (Estnischer Wissenschaftsfond; Projekte Nr. 7162, 8006 und 7679) unterstützt. 
Entsprechend wurde der Text mehrfach umgearbeitet, sowohl in Erinnerungen als auch in Liederbüchern oder Lebensgeschichten (vgl. Laak 2003).

Das „Kalevipoeg“ ist heute, so lässt sich behaupten, zu einem wichtigen Kerntext der Nationenbildung geworden, was sich auf allen Ebenen der estnischen Kultur zeigen lässt, an Straßennamen bis hin zu neuen auf Grundlage des Epos geschaffenen Kunstwerken. Wir können in diesem Artikel nur einen groben Überblick über die Rezeption des Epos geben, indem wir uns auf die Analyse verschiedener Texte stützen. Der Schwerpunkt des vorliegenden Aufsatzes liegt auf der Rezeption des Epos in der estnischen Gegenwartsliteratur, insbesondere der neuesten, postmodernen Literatur.

\section{Das „Kalevipoeg“ in der wissenschaftlichen Bewertung}

Ungeachtet seiner soziokulturellen Bedeutung ist das „Kalevipoeg“ in Bezug auf folkloristische Authentizität scharf kritisiert worden. Heute wissen wir, dass wir es mit einem Kunstepos (artistic epos) zu tun haben, das der dichterisch begabte Stadtarzt von Võru, Dr. Friedrich Reinhold Kreutzwald (1803-1879), lediglich auf der Grundlage von Stoffen estnischer Folklore schuf. Die Erstausgabe erschien in den Veröffentlichungen der Gelehrten Estnischen Gesellschaft als wissenschaftlich kommentierte Ausgabe in estnischer und deutscher Sprache (vgl. Kreutzwald 1857-1861). Folkloristische Untersuchungen haben ergeben, dass der Text nur zu knapp einem Achtel, lediglich zu 12,5\%, authentisches Volksliedgut enthält (vgl. Pino 1961: 420). Das Talent des Autors für die Imitation von Volksliedern und das Umschmelzen von Volkslegenden in Prosaform zu Versen war beachtlich, stellte gleichzeitig jedoch ein Hindernis für die Bewertung des Werkes dar. In der wissenschaftlichen Auseinandersetzung mit dem Epos begann erst an der Wende vom 20. zum 21. Jahrhundert, sowohl in der Literaturwissenschaft als auch in der Folkloristik, das Eis ein wenig zu brechen: „Dank der Erneuerung des folkloristischen Denkens können wir das ,Kalevipoeg" und seinen Autor von pseudomythologischen Anschuldigungen freisprechen“2 (Valk 2003).

\footnotetext{
${ }^{2}$ Im estnischen Original: „Tänu folkloristliku mõtte uuenemisele võime vabastada
} 
Einen wichtigen Einfluss auf die Rezeption des „Kalevipoeg“ hatte Jaan Undusks kulturphilosophischer Artikel „Der Geist Hamanns und Herders als Förderer der estnischen Literatur: das Prinzip der Synekdoche" (Undusk 1995). In seinem Artikel zeigt der Autor die rhetorische Verbundenheit der deutschbaltischen Estophilen im Umkreis der Gelehrten Estnischen Gesellschaft mit der „synekdochischen Tradition“ der Herder'schen deutschen Kulturphilosophie. Undusk betont, dass die deutschbaltischen Estophilen durch das Sammeln estnischer Volksdichtung und den Aufruf zur Wiedererschaffung eines Epos Herders Idee der antiken Palingenese, der ewigen Wiedergeburt der Kulturseele, umsetzten: „Beim Lesen von Volksliedern ergreift ihn [Herder] die unwiderstehliche Ahnung, dass vor ihm nur die Reste von etwas Großem und Vollkommenem wie den homerischen Epen liegen“ (Undusk 1995: 677). Sowohl Herder als auch seine Nachfolger gebrauchten, wenn sie über Volkslieder sprachen, Wörter wie „Trümmer“, „Ruinen“, „Bruchstücke“, „Reste“, „Fragmente“. In Auseinandersetzung mit der Rhetorik der Einleitung zum Epos beantwortet Undusk die Frage nach der Authentizität des Epos, die in der folkloristischen Kritik seit über einem Jahrhundert virulent war, wie folgt:

All das war aber eben kein Lug und Trug, wie seinerzeit dem „Kalevipoeg“ vorgeworfen wurde. [...] Keiner von ihnen [F. R. Faehlmann und F. R. Kreutzwald] hielt sich für den Verfasser des Textes, sondern vielmehr für dessen Überträger: Ihrer Meinung nach sammelten sie nur die Reste alter Texte zusammen und schrieben die Texte auf dieser Grundlage sozusagen sauber, vollständig um, im Glauben, dass sie genauso einst im Volksmund ausgesehen haben könnten. Die Texte von Faehlmann, Kreutzwald u.a. stellen einen kulturell spannenden Fall dar: eine sogenannte Umschrift aus dem Nichts, also eine Abschrift, deren mündliche oder schriftliche Quelle offensichtlich nie vorhanden war [...] Der Umschreiber [Kreutzwald] bringt den Text einfach in Befolgung einer höheren Vorschrift zu Papier, ohne Autorenschaft zu beanspruchen, und schreibt den Text einem anderen, sakralen Autor, zum Beispiel dem Volk zu. (Ebd., 751)

Die Verschmelzung einzelner aus dem Volksmund stammender Lieder, Legenden und Kurzformen verlangte von Kreutzwald, wie bereits gesagt, eine beachtliche Begabung. Doch zusätzlich zu Quellen der Volks-

„Kalevipoja“ ja tema autori pseudomütoloogilisest süüdistusest“. Die Übersetzungen der Zitate stammen, wenn nicht anders vermerkt, von Axel Jagau. 
dichtung lassen sich bei einer Analyse des „Kalevipoeg“-Textes auch internationale Architexte erkennen, Motive anderer klassischer Epen und literarischer Werke. Nach dem vergleichend-philosophischen Standpunkt von Jüri Talvet gehört das „Kalevipoeg“ als Kunstepos in die Reihe der Spitzenwerke der europäischen Romantik. Als solches gehört es in den Kanon der großen bekannten Individual- und Kunstepen der Weltliteratur, der im Westen mit Vergils „Aeneis“ beginnt und mit den späteren Kunstepen wie dem „Rolandslied“, dem „Lied von meinem Cid“, dem „Nibelungenlied“, den „Lusiaden“, „Camões“, „Orlando Furioso“, dem „Lied von Hiawatha“ fortgeführt wird und seinen lebendigen Ausdruck auch in der Literatur der europäischen Romantik findet. Talvet betont die Wichtigkeit der Individualepen für das nation building gerade bei kleinen Völkern, die versucht hatten, sich durch die Schaffung eines Epos eine geistige Grundlage zu schaffen (vgl. Talvet 2003b und 2003a). Dass ein komparatistischer Blickwinkel bei der Erforschung der estnischen und lettischen Nationalepen ergiebig ist, hat auch Sergei Kruks mit seinem Artikel „Kalevipoeg and Lāčplēsis“ gezeigt, in dem er den mentalen Habitus der Heldenfiguren im estnischen und lettischen Epos miteinander vergleicht (vgl. Kruks 2003).

Unter Zugrundelegung von Jüri Talvets Argumentation interessierte uns neben der Erforschung des „Kalevipoeg“ als soziokulturellem Zeichen auch das Schicksal von Kreutzwalds Werk als literarischem Text und dessen Verbindungen zu späteren literarischen Texten. Ist derjenige Teil des Epos, der mit der internationalen Mythologie übereinstimmt, ausgiebig untersucht worden, ${ }^{3}$ so wären die späteren und gegenwärtigen Bedeutungen des Epos durch eine intertextuelle Analyse moderner und postmoderner Texte der estnischen Literatur zu erkunden (vgl. Laak/Viires 2004, Laak 2005 und 2008).

\section{Die Textstruktur des ,Kalevipoeg“}

Voraussetzung für unsere intertextuelle Analyse des „Kalevipoeg“ war eine aufmerksame Textlektüre (close reading). Danach ist der Text nicht das Narrativ eines vollständigen Epos, sondern gerade die Verwendung

\footnotetext{
${ }^{3}$ S. dazu Oinas 1994, Annist 2004.
} 
und/oder Verstärkung bestimmter kleinerer Motive. Solche Motive können von recht kleinen Texteinheiten getragen werden, die sich untereinander intratextuell, innerhalb eines Bezugspfades, verknüpfen lassen. Bei einer eingehenderen Analyse könnten wir zu dem Schluss kommen, dass das Herausfiltern derjenigen Motive, die den Text des „Kalevipoeg“ strukturieren, auch abhängig ist von den Bezügen des Epos zu früheren (literarischen) Grundtexten und (folkloristischen) Architexten.

Obwohl sich das „Kalevipoeg“, wie bereits erwähnt, als Kunstepos (artistic epic) einordnen lässt, schuf Kreutzwald eine für estnische Volkslieder charakteristische Poetik. Entsprechend ist auch der Text als Gesamtheit auf innere, thematische Wiederholungen gegründet und dies nicht nur bei den Parallelversen, sondern auch in einem weiteren Sinne. Ähnliche Motive und Themen lassen sich in verschiedenen Liedern bzw. Geschichten verfolgen; sie variieren und wiederholen sich zyklisch durch das gesamte Epos hindurch. So beginnen dann bestimmte Themen, insbesondere durch intratextuelle Bezüge, sich zu verstärken. Zwischen den verschiedenen Variationen desselben Themas entsteht eine lyrische Spannung; die bisherigen Bedeutungen werden dabei sozusagen verfeinert. Gerade Letzteres erklärt auch die Produktivität bestimmter Themen bzw. Motive in der Gegenwartskultur. Zum Beispiel tritt im Epos das Motiv des „Steins“ wiederholt als mehrdimensionales Zeichen auf. Je nach Kontext wird damit sowohl die Erinnerung an den Vater (das Grab des Vaters) als auch an die Mutter Linda bezeichnet. Denn Linda trägt ihrerseits Steine auf Kalevs Grab zusammen und wird ja ihrerseits in einen Stein verwandelt. In beiden Fällen tragen gerade diese „Stellen“ im Text die empfindsamsten und lyrischsten Bedeutungen, zum Beispiel die Trauer, die auch Jüri Talvet (2003b) als große Besonderheit des „Kalevipoeg“ betont. Andererseits bezeichnet der „Stein“ binär Sicherheit, eine Burg, die gegen den Feind errichtet wird - der „Stein“ steht für die Kraft und Macht des Helden, das Werfen des Steins legt Kalevipoegs Königtum fest.

Ähnliche (binäre) Konnotationen tragen auch einige andere Motive, zum Beispiel das des „Schwerts“, das einerseits Symbol für Königtum und Macht ist, andererseits aber als Vollstrecker von Kalevipoegs traurigem Schicksal figuriert. Ebenso bietet das Motiv der Inselmagd im 
Epos sehr schöne intratextuelle Bezüge - die Verführung der Jungfrau und die daraus resultierende verhängnisvolle Schuld.

Aus der intratextuellen Analyse des Epos wird deutlich, dass der Text motivische bzw. thematische „Komplexe“, d.h. Gruppen kleiner Texteinheiten aus verschiedenen Motiven, Themen und Metaphern, generiert. Solche motivischen Komplexe bildeten die Grundlage für unsere Untersuchung intertextueller Bezüge in der estnischen Gegenwartskultur. Man könnte sagen, dass sich die Bedeutung des „Kalevipoeg“ gerade darin zeigt, dass diese Motive (Themen, Bilder usw.) heutzutage neue, moderne Texte hervorgebracht haben. Inwieweit diese Texte mit Kreutzwalds Originaltext und mit dessen späteren Interpretationen, zum Beispiel durch ideologisch beeinflusste Artefakte, verbunden sind, wäre allerdings noch zu untersuchen.

Vergleicht man die Motivgruppen, die die innere Struktur des „Kalevipoeg“" ausmachen, mit den späteren Reproduktionen des Epos in verschiedenen Textsorten, darunter in der Literatur, so lassen sich drei wichtige Tendenzen ausmachen:

1. In den verschiedenen Künsten werden diese Motive und Motivgruppen jeweils unterschiedlich weitergeführt; die Verwendung ist dabei durch gattungs- und medienspezifische Faktoren bedingt: Ist in der bildenden Kunst die Darstellung statischer Zustände produktiv („das Erschrecken der Inselmagd“), so sind es in der Lyrik eher philosophische („Schicksal“, „Hoffnung“).

2. Die Aktualisierung der Motive in verschiedenen Perioden der Geschichte ist eng verbunden mit dem gesellschaftlichen Kontext sowie der herrschenden Ideologie. In der Zeit des nationalen Erwachens waren romantische Freiheitsideen beliebt, in Kriegszeiten (Revolution von 1905, Erster und Zweiter Weltkrieg) wurde Kalevipoegs Kampf mit dem Feind betont. Während des Aufbaus der Republik Estland in den 1920er und 1930er Jahren betonte man die Idee des Kalevipoeg als „Pflüger und Sämann“ (so waren für die bildende Kunst dieser Jahrzehnte beispielsweise Gemälde mit dem Titel „Kalevipoeg in der Ackerfurche“ beliebt).

3. Das Epos wurde schließlich immer auch beim Wechsel literarästhetischer Strömungen verwendet, von romantischer und modernisti- 
scher Dichtung bis hin zu den postmodernen Texten der 1990er Jahre, worauf wir im Weiteren näher eingehen werden.

\section{„Kalevipoeg, eine Estnische Sage“6 im 19. Jahrhundert}

Für eine rezeptionsästhetische Analyse ist es wichtig, wie der Text den jeweiligen kulturellen Kontext anspricht. Wie wir zuvor gesehen haben, war für die Entstehung des „Kalevipoeg“ die Herder'sche Kulturphilosophie von entscheidender Bedeutung, nach der nur die „Überbleibsel“, „Ruinen“ und „Fragmente“ eines einstigen vollständigen Epos zusammengesammelt wurden, um auf deren Grundlage einen vollständigen Text zu rekonstruieren. Aus dem historischen Blickwinkel der Rezeption ist auch Kreutzwalds Rhetorik verständlich, auf die wir mit Jaan Undusk bereits verwiesen haben. Kreutzwald präsentierte das Epos seinen Zeitgenossen, dem Publikum des ausgehenden 19. Jahrhunderts, nicht als eigene Schöpfung:

Mein Kalewipoeg wenigstens macht nicht den geringsten Anspruch an so hochtrabenden Titel und will kein poetisches Kunstwerk sein, sondern nur eine Sammlung von wirklich im Munde des Volkes lebenden Sagen, die ich versucht habe in einer gewissen Ordnung an einander anzureihen. (Kreutzwald 1963: 71, zit. n. Hasselblatt 2006: 242)

Gerade eine derartige Konzeption entsprach zu Zeiten des nationalen Erwachens den romantischen Erwartungen an eine einstige Zeit estnischen Glücks und einen großen König Kalev. Es ist noch einmal zu betonen, dass es ein vollständiges estnisches Nationalepos „Kalevipoeg“ nie gegeben hat, auch nicht in Form von Runenliedern, die sich von Generation zu Generation tradiert haben. Kreutzwald präsentierte die Geschichte des Kalevipoeg als zusammenhängendes Narrativ, flocht einige im Volk gesammelte Ortslegenden mit ein, außerdem einige Volkslieder und Märchen. Zudem verwendete er Kurzformen der Volksdichtung wie Wendungen, Sprichwörter und Rätsel. Obgleich die geringe Authentizität vom folkloristischen Standpunkt aus gesehen dem „Kalevipoeg“ als Schwäche angelastet wurde, zeigt sich gerade hier die schöpferische Begabung des Autors.

Im Estland zur Zeit des nationalen Erwachens war jedoch die Idee, das „Kalevipoeg“ als uraltes „Liedgut des Volkes“ zu präsentieren, ein 
rezeptionsgeschichtlich verständlicher Akt, der, wie gesagt, durch die zeitgenössischen Erwartungen denn auch eine entsprechende Resonanz erzeugte: Die estnische Kultur hatte sich davor jahrhundertelang in ihren reichhaltigen Formen hauptsächlich als mündliche Tradition erhalten. Die Herder'sche Lobpreisung der Kultur von Naturvölkern spornte diese Sichtweise nur an. Dass Kreutzwald das Epos als wirkliches „Liedgut“ des Volkes präsentierte, bedeutete für das Volk in dieser existenziellen Umbruchszeit geradezu eine Rückerstattung seines geistigen Reichtums und seines Selbstbewusstseins. Der Text entwickelte sich, wie gesagt, zu einem „Denkmal der goldenen Zeit der Freiheit“ - all dies führte zu einem ungeahnten Anstieg des nationalen Selbstvertrauens und einem Zuwachs an kulturellem Selbstbewusstsein, dessen Endpunkt in der Ausrufung der Republik Estland im Jahre 1918 gesehen werden kann. Die oben genannte „antike Palingenese“, die kulturelle Wiedergeburt des Volkes, die die Idee hinter der Schaffung des Epos gewesen war, hatte sich erfüllt.

Größtenteils wurde das Epos in der Rhetorik der Staatsgründung, der Freiheit, des Kampfes oder dann der Zukunftshoffnung rezipiert. Im Gegensatz dazu wurden die lyrischeren Unterströmungen des Epos gefühlvoll in der späteren estnischen Dichtung interpretiert, über deren Bezüge sich in großer Menge intertextuell verbundene neue Texte anführen lassen. Doch auch hier können verschiedene rezeptionsgeschichtliche Perioden unterschieden werden. So war zum Beispiel das Besingen der alten Götter eines der Lieblingsthemen der Lyrik zu Zeiten des nationalen Erwachens und der nachfolgenden Periode, wobei die Anspielungen auf das „Kalevipoeg“ recht deutlich waren, wie zum Beispiel in Lydia Koidulas Gedicht „Mõtted Toomemäel“ (dt. Gedanken auf dem Domberg). Das zentrale Bild des Gedichtes, die „Harfe des Vanemuine“" gehört auch zum Epos, doch liegen seine intertextuellen Wurzeln in der Sage von F. R. Faehlmann „Wannemunne's Sang“. ${ }^{4}$

\footnotetext{
${ }^{4}$ Das Bild beruht auf Ch. Ganaders „Mythologia Fennica“, die von dem begabten estnischen Dichter Kristian Jaak Peterson (1801-1822) aus dem Schwedischen ins Deutsche übertragen und dabei zugleich erweitert wurde. Die Übersetzung erschien in der deutschbaltischen Zeitschrift „Beiträge“ im Jahr 1822. Petersons Bearbeitung bildete die Grundlage für die estnische Kunstmythologie und die Erschaffung eines Pantheons, das auch im „Kalevipoeg“ verwendet wurde und bis heute besteht.
} 
Vanemuine, laulujumal, sinu laululehkav kannel

helises siin põhja peal!

Siin, kus, Kalev, sinu lapsed,

kanged eesti kännu võsud,

käisid, kostis tema hääl.

(Koidula 1989: 131)

(Vanemuine, Sangesgott, / deine sangesduftende Harfe / tönte hier im Norden! / Hier, wo, Kalev, deine Kinder, / starke Triebe estnischen Stammes, / gingen, erklang ihre Stimme.)

Man kann behaupten, dass in jeder neuen gesellschaftlichen Situation aus dem Epos genau jene Bedeutungsebenen herausgeholt werden, die im Einklang mit den Ideologien, Repräsentations- und Interpretationsumgebungen standen. Verfolgt man die Rezeption des „Kalevipoeg“, so sieht man, dass die Hinwendung zum Epos gerade an historischen Wendepunkten besonders aktiv ist, beispielsweise bei politischen Machtwechseln. Zentral wurden in solchen Fällen die Schlusszeilen des Epos, die Rückkehr des Helden zu seinem Volk.

Aga ükskord algab aega,

Kus kõik piirud kahelotsal

Lausa lähvad lõkendama;

Lausa tuleleeki lõikab

Kätte kaljukammitsasta:

Kül siis Kalev jõuab koeu

Oma lastel' õnne tooma,

Eestipõlve uueks looma.

(Kreutzwald 1861: 734f.)
Einmal wird die Zeit beginnen, Wo die Spähne von zwei Seiten In gewalt'gen Flammen brennen, Und die off'nen Gluthen schmelzen Dann die Hand auch von dem Jelsen. Dann kehrt Kalev auf die Erde, Seinem Volke Glück zu bringen, Eine neue Zeit der Esten.

\section{Die soziokulturelle Rezeption des „Kalevipoeg“}

Das Motiv der „Rückkehr des Kalevipoeg“ wurde auch in den 1950er Jahren, in der Periode des Stalinismus, aktuell. Nach der damals üblichen Deutung sollten die Schlusszeilen des Epos „Einmal wird die Zeit beginnen..." gerade jetzt Wirklichkeit werden. War doch die „Rückkehr Kalevs“ gerade eben zusammen mit den sowjetischen Streitkräften

Vanemuine war demnach der alte Sängergott, dessen Gesang von den magischen Klängen der Harfe begleitet wurde. 
erfolgt, und nach der damaligen offiziellen Ideologie wurde das estnische Volk unter Führung des Kalevipoeg zusammen mit der Errichtung des Kommunismus neu geschaffen. Typisch für die genannte Zeit sind zum Beispiel die Schlussverse des Gedichtes „Tõeks saanud muinasjutt" (dt. Wahr ist geworden das Märchen) (1952) von Paul Rummo:

Ja liigutatult muistne vägilane

käe kilpi hoides südamele paneb:

"Võrdkujuks rahvale mind hallil ajal lõite, mu vägevuse lõi te unistus.

Said unistustest teod. Nüüd näha võite

kuis rahvavõimust võrsund elu uus.

Tõeks saanud muinasjutt..."

(Rummo 1955: 16)

(Und bewegt legt der Held der alten Zeit / die Hand aufs Herz, den Schild in der Hand: / „Als Sinnbild des Volkes schuft ihr mich in grauer Zeit, / meine Kraft schuf euer Traum. / Träume wurden Taten. Nun seht ihr / wie aus Volksmacht neues Leben gewachsen. / Wahr ist geworden das Märchen...“

Das Gedicht enthält eine Anspielung auf die Schlusszeilen des „Kalevipoeg“, doch die Beschreibung des Helden erinnert an die Porträts altrussischer Recken. ${ }^{5}$ Das Bild des Kalevipoeg verwandelte sich in den 1950er Jahren in eine Ikone „selbstverleugnender Arbeit“ und des mit den „Unterdrückern und Versklavern des Volkes“ zu führenden Kampfes. Zeichen dafür lassen sich zuhauf in Dichtung, Kunst und Musik und natürlich in Schulbüchern ausmachen. Die ideologisch-patriotische Aufbauarbeit des „Kalevipoeg“ war eines der zentralen Themen in Eugen Kapps Ballett „Kalevipoeg“ (1948), dessen unterschiedliche Inszenierungen als Konzertfilm und in Dokumentarfilmen festgehalten wurden. 1961, als das Epos sein hundertjähriges Jubiläum feierte, wurde im Rahmen der Feierlichkeiten eine neue Bearbeitung des Balletts inszeniert. In diesem Zusammenhang ertönte in der Kinowochenschau „Sowjetestland“ die für die damalige Zeit typische Rhetorik:

\footnotetext{
${ }^{5}$ Eine solche Parallele ließ sich vom folkloristischen Standpunkt aus begründen, denn die Legenden um Kalevipoeg waren auch im estnisch-russischen Grenzgebiet bekannt (vgl. Hiiemäe 2003: 67-70).
} 
„Die in den Schlussversen des Epos ausgedrückten Gedanken sind mit der Realität übereingekommen. Die estnische Nationalkultur wurde von Kalevipoeg selbst, dessen Figur die Meister der Kunst immer anspornte, auf seinen gewaltigen Schultern in die Höhe getragen“. (Rundschau Sowjetestland 1961$)^{6}$

Charakteristisch für diese Periode war es, im Epos Umformulierungen und Streichungen vorzunehmen, bis hin zu einer radikalen Veränderung des Sujets. Ein weiteres Beispiel für eine ideologische Lesart kanonischer Texte ist das in Moskau während des Zweiten Weltkriegs herausgegebene Literaturlesebuch. Dieses Lesebuch aus Kriegszeiten enthält eine Auswahl russischer und estnischer Literatur, die das Thema von Tapferkeit und Kampf, Krieg und Schlachten, Blut, Tod und Gräbern zur Grundlage hat. Unter anderem wurden für das Lesebuch aus dem „Kalevipoeg“ gerade solche Lieder ausgewählt, die das Volk zum Kampf gegen den eingedrungenen Feind aufrufen.

Man kann sicher sein, dass die stalinistischen Verzerrungen sich auf eine ernsthafte (Re-)Lektüre des „Kalevipoeg“ und auch auf dessen Rezeption hemmend ausgewirkt haben. Die ideologischen Manipulationen (insbesondere bezogen auf die Rückkehr des Kalevipoeg) ließen den Nachkriegsleser gegenüber dem gesamten Text Abneigung empfinden.

Verfolgen wir die Aktualisierung des Nationalepos am Ende des 20. Jahrhunderts, so sehen wir, wie sich daraus ein immer aktiver funktionierender Kerntext der estnischen Kultur entwickelt (vgl. Veidemann 2003). Kalevipoeg-Zeichen sind wieder zu einem untrennbaren Bestandteil auch der politischen Medien geworden. Der Held Kalevipoeg war das Symbol der „Singenden Revolution“ im Sommer und Herbst des Jahres 1988. Die Lieder des Komponisten Alo Mattiisen, die zum Symbol der Singenden Revolution wurden, waren zu Worten des Nationalepos geschaffen worden, so zum Beispiel die Verse „Isamaa ilu hoieldes, vaenlase vastu võideldes!“ (dt. Bewahrend die Schönheit des Vaterlandes, kämpfend gegen den Feind). Man könnte sogar sagen, dass die gesamte patriotische Ideologie zu Anfang der 1990er Jahre mit Kalevipoegs Heimkehr verbunden war. Die an

\footnotetext{
6 Rundschau „Sowjetestland“ 1961, Nr. 39, 7. Bericht, Kalevipoeg 100. - Eesti Filmiarhiiv, f 203, 1342.
} 
zwei Enden aufflammenden „Späne“ gehörten zur Symbolik der estnischen politischen Parteien. Das Motiv der Heimkehr wurde auch in der Lyrik erneut virulent; indes ist das heutige Pathos dem sowjetischen vollkommen entgegengesetzt, worauf noch zurückzukommen sein wird.

Es wäre noch hinzuzufügen, dass Kalevipoeg als Figur heute einen ziemlich stabilen Charakter angenommen hat, indem er zum Archetypen des etwas behäbigen, doch ehrlichen und fleißigen Esten wurde. Genauso sehen wir ihn oft als täglichen Besucher in den politischen Karikaturen der zentralen estnischen Tageszeitung „Postimees“, wo er zum Beispiel über die estnisch-russischen Beziehungen oder die neuen Vorschriften der Europäischen Union nachsinnt.

\section{Die literarische Rezeption des ,Kalevipoeg“6}

Eine ganz andere Dimension des Epos eröffnet sich, wenn man die soziokulturellen Deutungen beiseitelässt und die Rezeption in literarischen Texten verfolgt. Hier geht es nicht mehr um allgemeine Deutungen auf der Makroebene, wie sie sich in der ideologischen und soziokulturellen Rezeption zeigten, sondern um wesentlich feinere intertextuelle Bezüge.

Ein bedeutender Durchbruch in den literarischen Interpretationen des „Kalevipoeg“ erfolgte in der estnischen Literatur im Jahr 1971, als in der zentralen Literaturzeitschrift „Looming“ der humoristische Roman „Kalevipoja mälestused“ (dt. Die Erinnerungen des Kalevipoeg) von Enn Vetemaa erschien, ein parodistischer Text, den der Autor selbst auch als Travestie bezeichnet hat. Wir haben es hier mit einem humorvollen re-writing zu tun, in dem, psychoanalytisch inspiriert, Aufbau und Motive von Kreutzwalds Text detailliert übernommen werden. Die 20 Gesänge des Epos und die sich in ihnen entwickelnden Ereignisse, die vom Helden mit den Augen des Ich-Erzählers dargeboten werden, verweisen auf viele Ebenen, die in der bisherigen folkloristischen oder historisch-vergleichenden Kritik unbeachtet geblieben sind.

Ein gutes Beispiel für die Differenz zwischen soziokultureller und literarischer Rezeption ist das Motiv der "Höllenfahrt“ des Kalevipoeg. Wie einige bereits erwähnte Motive („Stein“, „Schwert“ usw.) gehört 
auch die „Höllenfahrt“ zur Tiefenstruktur des Textes; denn auch dieses Motiv durchzieht das gesamte Epos. ${ }^{7}$ Kalevipoeg begibt sich in Kreutzwalds Epos dreimal in die Unterwelt, in die Hölle. Der Schwierigkeitsgrad dieser Fahrten entwickelt sich stufenweise, jedes Mal muss der Held mit den „Kräften der Hölle“ und zum Schluss mit dem Leibhaftigen selbst kämpfen, doch selbstverständlich setzt er sich letztendlich durch und kommt als Sieger auf die Erde zurück. In allen früheren, ideologischen Deutungen wurden diese Szenen zu Ikonen des Kampfes gegen den Feind stilisiert.

Kreutzwald zeigte die Ankunft des Kalevipoeg in der Unterwelt jedoch von Anfang an relativ humorvoll. Zum Beispiel trifft Kalevipoeg gleich bei seiner ersten Höllenfahrt drei verzauberte Höllenmägde und tanzt, singt und vergnügt sich mit ihnen die ganze Nacht. Es scheint paradox, dass die Höllenfahrt in Hinblick auf die Begegnung mit den Höllenmägden eine der strahlendsten und fröhlichsten Stellen im gesamten Epos ist. Eine solche Deutung finden wir später in der als Sommertheater in Estland aufgeführten Komödie „Kalevipoeg“ (Kivirähk 2006), in der das Treffen mit den Höllenmägden sogar eine verrückte, kabarettistische Form annimmt. Die komödiantische Umsetzung stützte sich auf den schon erwähnten parodistischen Roman von Enn Vetemaa „Die Erinnerungen des Kalevipoeg“. Im Kontext der 1970er Jahre war ein derartiger Akzent im Vergleich zu der nach wie vor gültigen pathetischen und ideologischen Interpretation vollkommen neuartig.

Kalevipoegs zweite Höllenfahrt erfolgt gegen Ende des Epos, nach einer schweren Schlacht mit dem Feind. Beide Höllenfahrten verbindet die Rückkehr von Kalevipoeg auf die Erde mit Säcken von Gold, dem Schatz des Gehörnten. Vor dem letzten Kampf, zum Beispiel als Kalevipoeg den Gehörnten in Ketten legt, nennt dieser ihn „Dieb“ und „Plünderer“. Enn Vetemaa hat dieses Motiv in seinen „Erinnerungen des Kalevipoeg weiterentwickelt. Dabei hat er aufgezeigt, dass der ganze Reichtum des estnischen Königs und des auf ihm gründenden Staates, zum Beispiel auch der spätere Bau von Städten, auf Besitz basiert, der aus der Unterwelt geholt wurde. Das gleiche Motiv hat der Autor weiterentwickelt, indem er den Kampf mit dem Wassergeist und den Sieg über denselben darstellt: Für das vom Wassergeist gewonnene

\footnotetext{
${ }^{7}$ Vgl. zu den Höllenfahrtszenen auch den Beitrag von Eve Pormeister in diesem Band.
} 
Gold geht der Held nach Russland, um für den Städtebau Bretter zu kaufen, und zahlt seine Schulden bei dem finnischen Schmied für das Schwert ab.

Nach dem Erscheinen von Enn Vetemaas Travestie bzw. psychoanalytischer Parodie scheint der Held geradezu von seinen Fesseln befreit zu sein. Seither können sowohl etablierte als auch Laienautoren künstlerisch ungezwungener mit dem „Kalevipoeg“ umgehen bzw. dieses fiktional weiterschreiben; dieser neue Umgang mit dem klassischen Text schafft neue Bedeutungen und stellt sich in einen Gegensatz zur bisherigen, hauptsächlich ideologischen Interpretation.

\section{Das postmoderne ,Kalevipoeg“6}

In der Literatur vom Ende der 1990er und vom Anfang der 2000er Jahre finden sich überraschend häufig Rekurse auf das „Kalevipoeg“. Gleichzeitig sind an die Stelle des noch vor zehn Jahren vorherrschenden patriotischen Pathos postmoderne Parodie und Verspieltheit getreten. ${ }^{8}$

Da Postmodernismus ein weiter Begriff ist, sollen hier nur einige Kennzeichen der postmodernen Literatur, die am häufigsten hervorgehoben werden, Erwähnung finden: Intertextualität, Fragmentcharakter, Eklektik, Ironie, Skeptizismus, Verwischung der Genregrenzen, Schwund des Unterschieds zwischen Massenkultur und hoher Literatur, zunehmende Bedeutung des Autorenimages, Medienzentrierung der Autoren usw. (vgl. z.B. Viires 2008: 37f.). Laut Umberto Eco ist die postmoderne Literatur durch den „Verlust der Unschuld“ gekennzeichnet - the loss of innocence: Der postmoderne Schriftsteller schreibe nurmehr ironisch, denn jedes Wort und jeder Satz seien stets schon einmal von jemandem gesagt worden, und durch deren Verwendung verweise man auf alle früheren Bedeutungen. Laut Eco sei der postmoderne Autor der Auffassung, dass es kein Entrinnen aus der Vergangenheit gebe, man diese jedoch vorführen und in einer nicht nur unschuldigen, ironischen oder parodistischen Weise verwenden könne. Jede Geschichte erzähle

\footnotetext{
${ }^{8}$ S. dazu Laak/Viires 2004: 297-301, Laitila 2003: 125-126.
} 
eine Geschichte, die schon einmal erzählt worden sei (vgl. Eco 1985: 19f.).

Als eine der ersten postmodernen Interpretationen des „Kalevipoeg“ ließe sich „Lehekülg eesti kultuuri ajaloost“ (dt. Eine Seite aus der estnischen Kulturgeschichte) anführen, ein bereits aus dem Jahre 1974 stammendes kurzes Prosastück von Mati Unt, heute ein Klassiker der neueren estnischen Literatur. Der Autor stellt in seinem Text eine Unterhaltung zwischen Kreutzwald und seiner Zeitgenossin, der estnischen nationalromantischen Dichterin Lydia Koidula, dar und lässt in dessen Verlauf den Helden Kalevipoeg ins Zimmer stürmen. In dem Text wird eine mythologische Figur des „Kalevipoeg“"verwendet, die in der Volksüberlieferung als Riese bekannt und mit vielen estnischen Ortslegenden verknüpft ist. Der böse Kalevipoeg greift in Mati Unts Geschichte die Dichterin an:

Kalevipoeg machte einen Schritt auf die dichtende Jungfrau zu und umfasste mit seinen großen Patschen ihren Rücken. Sein Gesicht verriet deutlich, was für eine Szene nun folgen sollte. Doch zuvor griff Kreutzwald aus der Kommode hinter sich seinen kleinen Damenrevolver und jagte Kalevipoeg eine Kugel in den Kopf. Polternd brach der Riese im Zimmer zusammen. Es bedurfte der Anstrengungen der ganzen Familie, die Leiche noch in derselben Nacht im nahegelegenen Tamulasee zu versenken. Durch das Wasser soll der Leichnam noch heute zu sehen sein. Diese Stelle wird im Volksmund das Kalevloch genannt. (Unt 1985: 9)

Die Beschreibung ist absurd genug, man könnte sagen, anarchisch, die Struktur des Textes postmodern fragmentarisch. Mati Unts Kalevipoeg-Variation ist voll von intertextuellen Anspielungen auf andere spätere Werke zum Stoff des „Kalevipoeg“, darunter auch die bereits erwähnten „Erinnerungen des Kalevipoeg“ von Enn Vetemaa.

Als postmoderne Interpretation des „Kalevipoeg“ ließe sich auch das Schauspiel „Kalev und Linda“ (1994) von Maimu Berg bezeichnen, wo auf das Nationalepos jedoch nur über die Namen der Hauptpersonen verwiesen wird. Kalev und Linda sind in der estnischen Kultur bekannte Vornamen, aber es sind eben auch die Eltern Kalevipoegs, auf die der erste und der zweite Gesang des Epos konzentriert eingehen. Obwohl die Verbindung weit hergeholt $\mathrm{zu}$ sein scheint, ist das Epos als Hintergrund des Schauspiels deutlich erkennbar. Dabei ist es grotesk, dass Kalev und Linda diesmal Darsteller in einem Pornofilm 
sind, dessen Produzenten unter anderem meinen: ,[M]an könnte glatt einen Porno über das Nationalepos machen. Könnte man wirklich, da würde man ganz effektvolle Dinge hinkriegen mit allen möglichen Hexern und Zauberern und Igeln..." (Berg 1994: 11). Das ganze Stück selbst ist realistisch, postmodern wird es gerade durch den Verweis auf den Grundtext und die ironische Dissonanz, die dazu hergestellt wird.

Die brodelnde Literatur der 1990er Jahre brachte eine Verstärkung der postmodernen Tendenz und einen allgemeinen explosiven Anstieg von literarischen Experimenten und Spielarten mit sich. Die Thematik des „Kalevipoeg“ bot nun einigen estnischen Schriftstellern, vor allem Lyrikern, spielerische Interpretationsmöglichkeiten. Am bekanntesten ist wohl das Poem „Tarzani poeg“ (dt. Der Sohn des Tarzan) des Dichters Contra (Margus Konnula), das heute in der estnischen Literatur zu einem Beispiel postmoderner Dichtung voller Chrestomanie geworden ist. Hier geht es um ein zweifaches re-writing: Die Motive von Tarzan und Kalevipoeg sind verschmolzen, die intertextuellen Verweise vermischen sich mit Anspielungen auf das zeitgenössische estnische Milieu der 1990er Jahre. Contras Poem ist ein fragmentarischer, polymorpher, anarchischer und dennoch humorvoller Text.

Aga ükskord algab aega

Kokku kogutakse kautsjon

Tarzan tuleb tonnid taskus

Poja päästab priiusesse

Viisavabadus on varsti

Küll siis Tarzan tuleb koju

Džunglirahval õnne tooma

Õnne õuel õlut jooma

(Contra 1998: 32)

(Einmal wird die Zeit beginnen / Da man die Kaution zusammenbringt / Tarzan kommt mit den Tausendern in der Tasche / rettet den Sohn in die Freiheit // Bald ist Visafreiheit / Dann wird Tarzan schon nach Hause kommen / dem Dschungelvolke Glück zu bringen / Auf dem Hof des Glückes Bier zu trinken)

$\mathrm{Zu}$ Contras Poem passt auch das Gedicht von Olavi Ruitlane, einem gleichfalls jungen Lyriker. Sein Gedicht weist ebenfalls komische, groteske und postmoderne Züge auf: 
aga ükskord algab aega

mil ma tulen mootorsaega

läbi kadrioru pargi

lóikan kada tarvis hargi

(Ruitlane 1998: 16)

(Einmal wird die Zeit beginnen / da ich mit der Motorsäge komme / durch den Park von Kadriorg / schneide ich zum Schleudern von Steinen eine Gabel)

Eine Symbiose von Contras und Ruitlanes lyrischen Texten mit dem „Kalevipoeg“ kommt zustande in einem gemeinsamen Gedicht beider Lyriker, in dem sie die Schlusszeilen („Einmal wird die Zeit beginnen“) ihrer Gedichte parodieren. Neben dem Heimkehr-Motiv verweist auch der Rhythmus auf das Epos, denn die jungen estnischen Autoren greifen auf das Metrum des estnischen (Kunst-)Runenlieds zurück, das bekanntlich auch Kreutzwald in seinem Epos angewandt hatte (Särg 1999).

Zahlreiche Beispiele, wie das „Kalevipoeg“ in der estnischen Literatur gerade in Zeiten des Umbruchs aktualisiert worden ist, finden sich in Kalev Keskülas Gedichtband „Vabariigi laulud“ (dt. Gedichte der Republik) aus dem Jahr 1998. Der Autor versetzt die Figur des Kalevipoeg in den Kontext der amerikanisierten westlichen Gesellschaft, die auch im Estland des Umbruchs eine immer größere Rolle bei der Herausbildung von Lebensstilen und Wertvorstellungen zu spielen begann. Das Gedicht „Die Heimkehr des Kalevipoeg“ ist ebenfalls eine Aneinanderreihung intertextueller Assoziationen und ein ironischer postmoderner Text, in dem Kesküla auf zeitgenössische „Helden“ anspielt:

Kalevipoeg

vabariikliku tähtsusega Herakles

tahab koju tulla

tal on nüüd Ameerika pass ja kangelaspension

omanimelisest teadusfondist Indianas

(Kesküla 1998: 51)

(Kalevipoeg / ein Herakles von republikweiter Bedeutung / möchte nach Hause kommen / er hat jetzt einen amerikanischen Pass und eine Heldenpension / aus einer nach ihm benannten Wissenschaftsstiftung in Indiana“ 
Auch Amateure im Internet haben, und dies in beachtlicher Zahl, Texte nach Stoffen des „Kalevipoeg“ geschaffen: Kalevipoeg ist darin die zentrale Figur, es werden bekannte Szenen aus dem Epos paraphrasiert und mit Verweisen auf die Realität zum Zeitpunkt des Schreibens versehen. Interessant ist es dabei, einen Text, der zum Beispiel 1993 nach Stoffen des „Kalevipoeg“ geschrieben wurde, mit solchen der Jahrtausendwende zu vergleichen. 1993 waren in den Text Verweise auf Erscheinungen des frühkapitalistischen Estland eingeflochten worden Kooperatoren, Miss-Wahlen, sowjetische Rubel und estnische Kronen. Ende der 1990er und besonders zu Beginn des 21. Jahrhunderts wurde jedoch die Verbindung des „Kalevipoeg“ mit dem Thema Europa, der Europäischen Union aktuell, und es wird gezeigt, wie der estnische Recke versucht, sich an die europäische Bürokratie anzupassen und sich durchzuschlagen.

\section{Das „Kalevipoeg“ im 21. Jahrhundert}

Mit Unterstützung des „Kalevipoeg“ gelangte die estnische Literatur auch ins 21. Jahrhundert. Fiel in den 1990er Jahren gerade die große Zahl an postmoderner Lyrik zu Stoffen des „Kalevipoeg“ auf, so erschien 2000 der Roman „Kalevipoeg“ der bis dahin noch unbekannten jungen Schriftstellerin Kerttu Rakke, der einen direkten intertextuellen Verweis auf das estnische Nationalepos darstellt (vgl. Rakke 2000). Rakkes „Kalevipoeg“ ist ein Pastiche, in der sich die postmoderne Intertextualität in ihrer reinsten Form zeigt. Auf den Grundtext verweist schon der Titel, der auf die Doppelkodierung und Intertextualität anspielt. Mit Umberto Eco könnte man gerade hier die „verlorene Unschuld" sehen. Die Hauptfigur in Rakkes Roman ist eine junge Frau namens Ädu; anstelle von Kalevipoegs städtebauenden Freunden hat Ädu hingegen Freundinnen. Versteckte Anspielungen, aber auch direkte Zitate und Paraphrasen des Epos finden sich im Roman auf mehreren Ebenen, beginnend mit den Kapitelnummern, die auf die Gesänge des „Kalevipoeg“ verweisen. Manchmal sind die Parallelen offenkundig. Ist zum Beispiel eines der zentralen thematischen Motive des Epos, dass Kalevipoeg nach Finnland schwimmt und bei dem finnischen Schmied das machtvolle Schwert erwirbt, so fährt Rakkes Heldin Ädu nach Finnland, um sich von dort ein besonderes Auto zu 
holen, das sie Sexmobil nennt. Manchmal sind die intertextuellen Bezüge jedoch versteckter. Zum Beispiel verweist das 16. Kapitel des Romans „Kalevipoeg“ auf den 16. Gesang der Vorlage, deren Thema die abenteuerliche Fahrt des Helden ans Ende der Welt mit seinem Schiff „Lennuk“ ist. Kerttu Rakke lässt ihre Figuren ans Ende der Welt reisen und im Drogenrausch eine unbekannte Realität erleben (vgl. den englischen Slangausdruck trip). Der berühmte Schlussvers des Epos (die Befreiung des Kalevipoeg aus dem Felsen und die Wiedererstehung des estnischen Volkes) ist im Roman einfach zu einem jugendtypischen „Verdammt, käme man hier aus dem Krankenhaus raus, könnte man sich wie ein normaler Mensch die Kante geben!“ (Rakke 2000: 48) geworden.

Es ließen sich noch zahlreiche weitere literarische Texte anführen, deren Titel bereits direkt auf Kreutzwalds Epos anspielen. Doch zugleich können die Verbindungen zum Epos recht unterschiedlich sein. Ist zum Beispiel bei der Komödie „Kalevipoeg“ von Andrus Kivirähk (vgl. Kivirähk 2006), einem der gegenwärtig bekanntesten estnischen Schriftsteller, der intertextuelle Bezug zum Grundtext sofort gegeben, so liegt mit der Novellensammlung „Kalevipoeg“ desselben Autors ein komplizierterer Fall vor (vgl. Kivirähk 1997). Lässt sich in der Komödie ein groteskes und spielerisches re-writing des Epostextes erkennen, so könnte man die Novellensammlung sozusagen als einen Minustext bezeichnen: Der Titel lautet zwar „Kalevipoeg“, doch ist dieser ein leerer, ein Null-Zeichen-Titel - im Buch findet sich kein Wort über Kalevipoeg oder über irgendein anderes Motiv des Epos.

Als eine der gattungsreinsten postmodernen Interpretationen des „Kalevipoeg“ vom Anfang des 21. Jahrhunderts lässt sich hingegen das Buch „Rahvuseepos Kalevipoeg ehk Armastus“ (dt. Das Nationalepos Kalevipoeg oder Die Liebe) des Lyrikers Kivisildnik ansehen (vgl. Kivisildnik 2003). Es ist vielleicht nicht korrekt, diese Publikation als „Gedichtband“ zu bezeichnen, haben wir es doch eher mit einem postmodernen „Projekt“ zu tun. Denn die Gedichte wurden mit dem konkreten Vorsatz geschrieben, in der Gegenwartslyrik Interpretationen des „Kalevipoeg“ zusammenzutragen. Diese Interpretationen waren für unser eigenes Projekt wichtig, das nach Motiven des „Kalevipoeg“ in der estnischen Gegenwartsliteratur sucht. Kivisildnik begann neue Kalevipoeg-Texte zu schreiben, nachdem wir die bisher am meisten 
verwendeten Motive des Epostextes bereits benannt hatten: die Reise des Helden ans Ende der Welt, den Kauf des Schwerts beim finnischen Schmied, den tragischen Tod des Helden u.a. In zwei Monaten wurde ein ganzes Buch mit Gedichten zu „Kalevipoeg“-Themen fertig, in dem der Lyriker genau auf die von uns angeführten Motive rekurrierte. Unsere Untersuchung erhielt auf diese Weise unerwartet neues und originelles Material. Wie für Kivisildnik typisch, hat er eine fragmentarische, ironische Textsammlung vorgelegt. Die Absicht des Autors war es ja auch, ein Pastiche, eine leere Parodie ohne komische oder satirische Momente zu schaffen. Auf dem Titelblatt des Buches lesen wir, dass wir es hier mit dem „estnischen Nationalepos“ zu tun haben. Die postmoderne Intertextualität wird zudem durch die Gestaltung des Buches betont, bei der der Künstler Andres Rõhu Auszüge und direkte visuelle Zitate aus der Jubiläumsausgabe des Nationalepos von 1961 eingesetzt hat. Der Textstrategie nach erinnert „Kalevipoeg oder Die Liebe“ an Kivisildniks frühere, nach dem Maschinenprinzip geschaffene Werke, in denen Phrase an Phrase gereiht ist. Zugleich erwächst aus diesen Fragmenten jedoch ein größeres Ganzes, denn Kivisildnik spielt mit den Ortslegenden des Kalevipoeg. So entsteht eine gewisse Dimension von Kosmo- und Mythogonie. Fügt man noch hinzu, dass sich auf dem Einband zufällig gewählte Zitate über Kalevipoeg auf Polnisch, Französisch, Ungarisch, Chinesisch und in anderen Sprachen befinden und um den Einband ein Streifen mit dem Text „Die Inselmagd empfiehlt“ gelegt ist, dann zeugt all das von einem makellosen und vollendeten postmodernen Projekt mit den bereits erwähnten Kennzeichen Verspieltheit, Anarchie, Fragmentcharakter, Intertextualität und Schizophrenie.

Dass das „Kalevipoeg“ nach wie vor aktuell ist und postmoderne Umdichtungen inspiriert, beweist der im Herbst 2010 als Taschenbuch in Massenauflage erschienene Roman des unbekannten Schriftstellers Kristjan Krisfeld „Kalevipoeg 2.0“, dessen Handlung in die Gegenwart verlegt ist und der in traditionellem epischen Versmaß in ziemlich robuster, teils sogar pornographischer Form die Abenteuer des Angebers Kalevipoeg im Estland der Gegenwart beschreibt. Der „Held“ wird dabei in einer von Actionfilmen und Computerspielen bekannten Weise dargestellt: Kalevipoeg fährt hier mit einem gewaltigen Jeep durch die Gegend, benutzt im Kampf mit Feinden Laserwaffen usw. Hintergrund 
dieser neuen Version ist auch die Wirtschaftskrise und die unter Darlehen leidenden Esten. Dabei ist es interessant, sich wiederum die Schlussverse anzusehen und mit den vorherigen Interpretationen zu vergleichen. Denn hier wird nicht zur nationalen Freiheit aufgerufen (wie im „Original-Kalevipoeg“) und auch nicht zum fröhlichen Biertrinken (wie in der Version von Contra), sondern das Glück kommt durch die Befreiung vom Joch der Darlehen:

Aga ükskord algab aega,

Mil saab vabalt laenu võtta,

Lausa tagasimaksmata;

Küll siis Kalev jõuab koju

Oma lastel' õnne tooma,

Eesti asja edendama.

(Kirsfeldt 2010: 476)

(Einmal wird die Zeit beginnen, / In der man frei leihen kann, / Sogar ohne Rückzahlung; / Dann wird wohl Kalev heimkehren / Seinen Kindern das Glück zu bringen / die estnische Sache voranzuteiben.)

Damit wenden sich die Autoren auch heute noch dem „Kalevipoeg“ als einem Kerntext der estnischen Kultur zu, schaffen jedoch eigene literarische Deutungen, was wiederum die Aktualität des „Kalevipoeg“ zu allen Zeiten bis in die Gegenwart manifestiert.

\section{Zusammenfassung}

Die Rezeption von Kreutzwalds Epos „Kalevipoeg“ in der estnischen Literatur, so wie sie sich in vielen neuen Texten zeigt, ist mehrschichtig und nuancenreich. Kreutzwald kompilierte aus einzelnen in Volksliedern erhaltenen Zeichen ein vollständiges Epos, das wiederum in groBer Menge neue Texte generierte und damit zu einem der wichtigsten Kerntexte der estnischen Gegenwartskultur wurde. In der Rezeption des „Kalevipoeg“ lassen sich deutlich eine ideologische, eine wissenschaftlich-kritische und eine schöpferische Ebene unterscheiden, Letztere aktiviert das „Kalevipoeg“ als produktiven literarischen Grundtext.

Bei der Verwendung des „Kalevipoeg“ als literarischem Grundtext lassen sich formal zwei Modelle unterscheiden - das kontextuelle und das textuelle. Im ersten Fall ist die Interpretation des Epos an räumlich- 
zeitliche und soziokulturelle Kontexte gebunden. An einem Ende dieser Achse befindet sich die volkstümliche „unsere Geschichte“, am anderen Ende ein ideologisches Konstrukt - von der nationsbildenden Zeit des Erwachens im 19. Jahrhundert bis hin zu den Kerntexten der estnischen Singenden Revolution Ende des 20. Jahrhunderts. Im zweiten Fall müsste man vom „Kalevipoeg“ als einem in der Gegenwartskultur aktiv wirkenden Grundtext sprechen, der auf einer breiten Skala von der modernen Kunst bis hin zu den heutigen Texten der Popkultur wirkt. Im ersten Fall ist die Gesamtbedeutung des Nationalepos als großes Zeichen wichtig (oft ist aus einer ideologischen „Notwendigkeit“ heraus sozusagen das Inhaltsnarrativ redigiert worden), da in der Dichtung, der Kunst, der Musik usw. aus den „Kalevipoeg“-Stoffen kleine Textteilchen (einzelne Phrasen, Aussagen, Fragmente, Motive, Themen) verwendet wurden.

So lässt sich bestätigen, dass das estnische Nationalepos „Kalevipoeg“ seine Aktualität auch in der postmodernen oder der auf neuen Medien und dem Internet basierenden estnischen Literatur nicht verloren hat. Der Text des „Kalevipoeg“ enthält großartige Möglichkeiten zur Umsetzung postmoderner Spiele und Experimente, die durch elektronische Medien nur begünstigt werden. Die Geschichte des Helden Kalevipoeg wird immer wieder aufs Neue erzählt, wenn man an das Zitat von Umberto Eco erinnern darf. Oder, wie einer der populärsten estnischen Gegenwartsautoren Andrus Kivirähk sagte: Das Epos „Kalevipoeg“" sei wie eine Grube, aus der sich zu jeder Zeit Themen schürfen lassen. Die Bedeutungen des Textes konnten in den letzten 150 Jahren nicht vollständig erschöpft werden; das Epos ist ein sakraler Text des estnischen Volkes geblieben, dessen Rezeption auf allen Ebenen der Kultur zu erkennen ist, insbesondere aber in der Literatur.

Aus dem Estnischen übersetzt von Axel Jagau

\section{Literaturverzeichnis}

\section{Primärliteratur}

BERG, Maimu (1994): Kalev ja Linda. (Näitemäng kahes vaatuses ja kümnes pildis) [Kalev und Linda. (Schauspiel in zwei Akten und zehn Bildern)]. In: Vikerkaar 9, S. 2-23; 10, S. 21-41. 
CONTRA (1998): Tarczan [Tarzan]. Võru.

KeSKÜLA, Kalev (1998): Vabariigi laulud [Gedichte der Republik]. Tallinn.

KIRSFELDT, Kristian (2010): Kalevipoeg 2.0 [Kalevipoeg 2.0]. Tallinn.

KIVIRÄHK, Andrus (1997): Kalevipoeg [Kalevipoeg]. Tallinn.

KIVIRÄHK, Andrus (2006): Aabitsa kukk. Näidendid [Der Fibelhahn. Schauspiele]. Tallinn.

KIVISILDNIK (2003): Rahvuseepos Kalevipoeg ehk Armastus [Das Nationalepos Kalevipoeg oder Die Liebe]. Tallinn.

Koidula, Lydia (1989): Mõtted Toomemäel [Gedanken auf dem Domberg].

In: Sõnarine. Eesti luule antoloogia. 4 köites. 1. Köide, koostanud Karl Muru [Sõnarine: estnische Lyrikanthologie in 4 Bänden. Bd. 1, hrsg. v. Karl Muru]. Tallinn, S. 131.

KreutzWALD, Friedrich Reinhold (1857-1861: Kalewipoeg, eine Estnische

Sage. In: Verhandlungen der gelehrten Estnischen Gesellschaft zu Dorpat 4, H. 14; 5, H. 1-2/3. Verfügbar unter:

http://kreutzwald.kirmus.ee/et/kalevipoeg/tekstiversioon?book_id=16 (02.03.2011).

RAKKE, Kerttu (2000): Kalevipoeg [Kalevipoeg]. Tallinn.

Ruitlane, Olavi (1998): Inemise sisu [Der Inhalt des Menschen]. Tartu.

Rummo, Paul (1955): Tõeks saanud muinasjutt [Wahr ist geworden das Märchen]. In: ders. (1955): Veerev kivi: luuletusi 1951-1954. Tallinn, S. 16.

UnT, Mati (1985): Valitud teosed 2 [Ausgewählte Werke 2]. Tallinn.

VetemaA, Enn (1971): Kalevipoja mälestused [Die Erinnerungen des Kalevipoeg]. In: Looming 11, S. 1619-1671; 12, S. 1763-1820.

\section{Sekundärliteratur}

ANNIST, August (2005): Friedrich Reinhold Kreutzwaldi „Kalevipoeg““ [Friedrich Reinhold Kreutzwalds „Kalevipoeg“]. Tartu.

ECO, Umberto (1985): Reflections on "The Name of the Rose”. London.

Hasselblatt, Cornelius (2006): Geschichte der estnischen Literatur. Von den Anfängen bis zur Gegenwart. Berlin.

HııемÄE, Mall (2003): Vaateid vägilasmuistenditele: Kalevipoeg ja Dobrõnja

[Sichten auf Heldenlegenden: Kalevipoeg und Dobrynja]. In: Paar sammukest. Eesti Kirjandusmuuseumi aastaraamat 20, S. 61-75.

Jauss, Hans Robert (1970): Literaturgeschichte als Provokation. Frankfurt a. M.

KRUKS, Sergei (2003): Kalevipoeg and Lāčplēsis: The Ways We Imagine Our Communities. A Sociological Reading of Estonian and Latvian epics. In: Interlitteraria 8, S. 227-247.

LAAK, Marin (2003): Monument vs. alustekst: „Kalevipoja“ retseptsioonist ja intertekstuaalsusest [Monument vs. Grundtext. Zur Rezeption und 
Intertextualität des „Kalevipoeg“]. In: Paar sammukest. Eesti Kirjandusmuuseumi aastaraamat 20, S. 129-142.

LAAK, Marin/Piret VIIRES (2004): Intertextuality and Technology: The Models of "Kalevipoeg”. In: Marina Grishakova/Markku Lehtimäki (Hrsg.) (2004): Intertextuality and Intersemiosis. Tartu, S. 284-312.

LAAK, Marin (2005): Kalevipoja kohanemine: teksti ja konteksti probleeme ning võrgukeskkonna võimalusi [Die Anpassung des Kalevipoeg. Probleme von Text und Kontext und Möglichkeiten der Internetgesellschaft]. In: Virve Sarapik/Maie Kalda (Hrsg.) (2005): Kohanevad tekstid. Tartu, S. 169205.

LAAK, Marin (2008): Kalevipoeg as a Core Text: the Island Maiden's Thread. In: Interlitteraria 13, H. 1, S. 197-213.

Laitila, Anu (2003): Kangelase metamorfoos. Rahvuseeposte rahvuslikud paroodiad [Die Metamorphose des Helden. Nationale Parodien von Nationalepen]. In: Paar sammukest. Eesti Kirjandusmuuseumi aastaraamat 20, S. 121-128.

OINAS, Felix (1994): Surematu Kalevipoeg [Der unsterbliche Kalevipoeg]. Tallinn.

Pino, Veera (1961): Rahvalaulud „Kalevipojas“ [Volkslieder im „Kalevipoeg“]. In: Friedrich Reinhold Kreutzwald: Kalevipoeg. Tekstikriitiline väljaanne ühes kommentaaride ja muude lisadega. Tallinn, S. 413-420.

SÄRG, Taive (1999): Tänapäeva folkloor ja Tartu noorte kirjanike laulud [Heutige Folklore und Lieder junger Tartuer Schriftsteller]. Verfügbar unter: http://www.suri.ee/etnofutu/3/doc/taive.html (27.02.2011).

TALveT, Jüri (2003a): Kalevipoeg, A Great European Epic. In: Estonian Literary Magazine 17, S. 4-9.

TALvET, Jüri (2003b): „Kalevipoeg“ - suur Euroopa eepos [„Kalevipoeg“ - ein großes europäisches Epos]. In: Keel ja Kirjandus 12, S. 886-890.

UNDUSK, Jaan (1995): Hamanni ja Herderi vaim eesti kirjanduse edendajana: sünekdohhi printsiip [Der Geist Hamanns und Herders als Förderer der estnischen Literatur: das Prinzip der Synekdoche]. In: Keel ja Kirjandus 9, S. 577-578; 10, S. 669-679; 11, S. 746-756.

VALK, Ülo (2003): Kuidas vabastada „Kalevipoeg“? [Wie befreit man das „Kalevipoeg“?]. In: Sirp 14, H. 7, S. 4.

VEIDEMANN, Rein (2003): F. R. Kreutzwaldi „Kalevipoeg“ kui eesti kirjanduskultuuri sakraaltekst [F. R. Kreutzwalds „Kalevipoeg“ als Sakraltext der estnischen literarischen Kultur]. In: Keel ja Kirjandus 12, S. 891-896.

VIIRES, Piret (2008): Eesti kirjandus ja postmodernism [Estnische Literatur und Postmodernismus]. Tartu. 


\section{Angaben zur Person}

Heinrich Detering, Prof. Dr. Dr. h.c., geb. 1959, Professor für Neuere deutsche und Vergleichende Literaturwissenschaft an der GeorgAugust-Universität Göttingen. Mitbegründer der Germanistischen Institutspartnerschaft zwischen Tartu und Göttingen. Letzte Veröffentlichungen: Kindheitsspuren. Theodor Storm und das Ende der Romantik. Heide i. H. (2011); Der Antichrist und der Gekreuzigte: Friedrich Nietzsches letzte Texte (2010); Bertolt Brecht und Laotse (2008).

Hans Graubner, Dr., Akad. Direktor i. R. am Seminar für Deutsche Philologie der Georg-August-Universität Göttingen. Initiator der Germanistischen Institutspartnerschaft zwischen Tartu und Göttingen. Veröffentlichungen zum 18. Jahrhundert (J. G. Hamann, Immanuel Kant, J. G. Herder, J. R. M. Lenz, deutschbaltische Geschichte) und zum 20. Jahrhundert (R. M. Rilke, Paul Celan, Ingeborg Bachmann, Johannes Bobrowski).

Karin Hoff, Prof. Dr., Professorin für Skandinavistik an der GeorgAugust-Universität Göttingen. Forschungsschwerpunkte und Veröffentlichungen zu deutsch-skandinavischen Kulturkontakten, Aufklärung, Klassische Moderne und Gegenwartsliteratur, Drama und Theater sowie Text-Bild-Verhältnissen und Kinder- und Jugendliteratur.

Torsten Hoffmann, Jun.-Prof. Dr., geb. 1973, Juniorprofessor für Neuere deutsche Literaturwissenschaft an der Goethe-Universität Frankfurt a. M. Letzte Veröffentlichungen: Anthropologien der Endlichkeit. Stationen einer literarischen Denkfigur seit der Aufklärung (2011, Mithrsg.); Rilke: Schriften zur Literatur und Kunst (2009, Hrsg.); Lehrer ohne Lehre. Zur Rezeption Paul Cézannes (2008, Hrsg.).

Marin Laak, Dr., geb. 1964, wissenschaftliche Mitarbeiterin und Projektleiterin im Estnischen Literaturmuseum und Chefredakteurin der Fachzeitschrift Methis. Studia humaniora Estonica. Veröffentlichungen 
u.a. zur Rezeption kanonischer Texte im digitalen Zeitalter, insbesondere am Beispiel des „Kalevipoeg“.

Christian Niedling, FL [Lizentiat der Philosophie], geb. 1976, Universitätslektor für Deutsch als Fremdsprache an der Universität Helsinki. Veröffentlichungen u.a. zu den Bereichen Heldenepik, Rezeption von Kalevala und Nibelungenlied im 19. Jahrhundert, autonomes Lernen.

Esbjörn Nyström, Dr., geb. 1973, wissenschaftlicher Mitarbeiter für germanistische Literaturwissenschaft an der Universität Stockholm, 2008-2011 Lektor für schwedische Philologie an der Universität Tartu. Veröffentlichungen u.a. zum Opernlibretto, Bertolt Brecht, J. W. Goethe, Selma Lagerlöf.

Mari-Ann Palm, geb. 1942, Lektorin für deutsche Philologie an der Universität Tartu. Veröffentlichungen u.a. zu polysemen Verben und Funktionsverbgefügen im Deutschen und im Estnischen, Stilistik (didaktische Materialien), der deutschsprachigen Presse in den ehemaligen Ostseeprovinzen Russlands.

Silke Pasewalck, Dr., geb. 1969, DAAD-Langzeitdozentin für Germanistik an der Universität Tartu. Veröffentlichungen u.a. zum Verhältnis von Poetik und Wahrnehmung („Die fünffingrige Hand“. Die Bedeutung der sinnlichen Wahrnehmung beim späten Rilke. 2002), Diktatur und Schreiben (u.a. bei Herta Müller, Ilse Aichinger, Christoph Hein), poetischer Interkulturalität sowie der Rolle von Literatur im Unterricht Deutsch als Fremdsprache.

Eve Pormeister, Dr., geb. 1956, Assoz. Professorin für Neuere deutschsprachige Literatur an der Universität Tartu. Letzte Veröffentlichungen: Grenzgängerinnen. Gertrud Leutenegger und die schreibende Nonne Silja Walter aus der Schweiz (2010); Tradition und Moderne in der Literatur der Schweiz im 20. Jahrhundert (2008, Mithrsg.); Ingeborg Bachmann. „Die Wahrheit ist dem Menschen zumutbar“ (2007, Mithrsg.).

Barbara Schaff, Prof. Dr., geb. 1957, Professorin für Englische Literaturund Kulturwissenschaft an der Georg-August-Universität Göttingen. Veröffentlichungen u.a. zu Autorschaft und Gender, Intertextualität, literarischem Tourismus, historischen Reiseführern, Autormystifikationen und Fälschungen. 
Zuzana Stolz-Hladká, Dr., geb. 1960, Lehrbeauftragte für bohemistische Literaturwissenschaft an der Georg-August-Universität Göttingen und Lektorin für Tschechisch an der Universität Konstanz. Veröffentlichungen u.a. zu poetologischen Aspekten der Moderne und Postmoderne im Werk des russischen Schriftstellers Vladimir Makanin (Monographie), zur Wort- und Sprachthematik sowie zur Wortpoetik und ästhetisch-religiösen Fragestellungen in der tschechischen Literatur des 19. und 20. Jahrhunderts.

Thomas Taterka, Prof. Dr., geb. 1963, Professor für deutsche Literatur und Direktor des Baltischen Germanistischen Zentrums an der Universität Lettlands in Riga. Veröffentlichungen u.a. zur internationalen KZLiteratur, den europäischen Nationalepen, zur deutschen Literatur in baltischen Bezügen, zur deutsch-jüdischen Literatur, zur Literatur der DDR, zur frühen lettischen Literatur, zu Literatur, Memoria und Nationalität und zur historischen Lexikographie.

Piret Viires, Prof. Dr., geb. 1963, Professorin für estnische Literatur an der Universität Tallinn und wissenschaftliche Mitarbeiterin im Estnischen Literaturmuseum Tartu. Veröffentlichungen u.a. zur estnischen Literatur der Gegenwart, Literatur und Digitalisisierung, Intertextualität (am Beispiel der „Kalevipoeg“-Rezeption). 